\title{
Radiological Safety Analysis Computer (RSAC) Program Version 7.2 Users' Manual
}

\author{
Bradley J. Schrader
}

October 2010

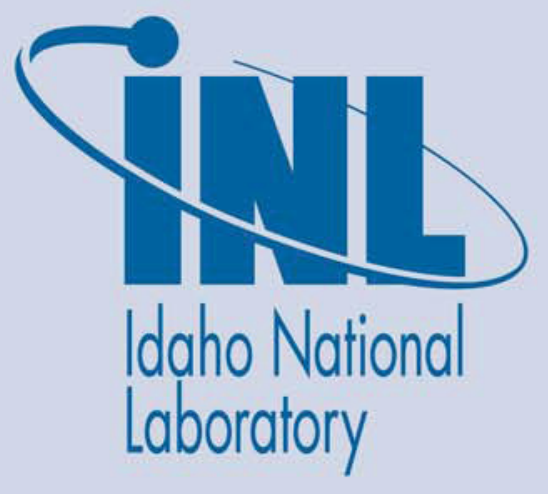

The INL is a U.S. Department of Energy National Laboratory operated by Battelle Energy Alliance 


\section{DISCLAIMER}

This information was prepared as an account of work sponsored by an agency of the U.S. Government. Neither the u.s. government nor any agency thereof, nor any of their employees, makes any warranty, expressed or implied, or assumes any legal liability or responsibility for the accuracy, completeness, or usefulness, of any information, apparatus, product, or process disclosed, or represents that its use would not infringe privately owned rights. References herein to any specific commercial product, process, or service by trade name, trade mark, manufacturer, or otherwise, does not necessarily constitute or imply its endorsement, recommendation, or favoring by the U.S. Government or any agency thereof. The views and opinions of authors expressed herein do not necessarily state or reflect those of the U.S. government or any agency thereof.

\section{DISCLAIMER}

NOTICE: This computer software was prepared by Battelle Energy Alliance, LLC, hereinafter the Contractor, under Contract No. DE-AC07-05ID14517 with the United States (U.S.) Department of Energy (DOE). NEITHER THE UNITED STATES GOVERNMENT, NOR DOE, NOR THE CONTRACTOR MAKE ANY WARRANTY, EXPRESSED OR IMPLIED, OR ASSUMES ANY LIABILITY OR RESPONSIBILITY FOR THE USE, ACCURACY, COMPLETENESS, OR USEFULNESS OR ANY INFORMATION, APPARATUS, PRODUCT, OR PROCESS DISOCLOSED, OR REPRESENTS THAT ITS USE WOULD NOT INFRINGE PRIVATELY OWNED RIGHTS.

EXPORT RESTRICTIONS. The provider of this computer software and its employees and its agents are subject to U.S. export control laws that prohibit or restrict (i) transactions with certain parties, and (ii) the type and level of technologies and services that may be exported. You agree to comply fully with all laws and regulations of the United States and other countries (Export Laws) to assure that neither this computer software, nor any direct products thereof are (1) exported, directly or indirectly, in violation of Export Laws, or (2) are used for any purpose prohibited by Export Laws, including, without limitation, nuclear, chemical, or biological weapons proliferation.

None of this computer software or underlying information or technology may be downloaded or otherwise exported or re-exported (i) into (or to a national or resident of) Cuba, North Korea, Iran, Sudan, Syria or any other country to which the U.S. has embargoed goods; or (ii) to anyone on the U.S. Treasury Department's List of Specially Designated Nationals or the U.S. Commerce Department's Denied Persons List, Unverified List, Entity List, Nonproliferation Sanctions or General Orders. By downloading or using this computer software, you are agreeing to the foregoing and you are representing and warranting that you are not located in, under the control of, or a national or resident of any such country or on any such list, and that you acknowledge you are responsible to obtain any necessary U.S. government authorization to ensure compliance with U.S. law. 

INL/EXT-09-15275

Revision 1

\title{
Radiological Safety Analysis Computer (RSAC) Program Version 7.2 Users' Manual
}

\author{
Bradley J. Schrader
}

October 2010

Idaho National Laboratory
Idaho Falls, Idaho 83415

Prepared for the

U.S. Department of Energy

National Nuclear Security Administration

Office of Field Support

Under DOE Idaho Operations Office

Contract DE-AC07-05ID14517 



\begin{abstract}
The Radiological Safety Analysis Computer (RSAC) Program Version 7.2 (RSAC-7) is the newest version of the RSAC legacy code. RSAC-7 calculates the consequences of a release of radionuclides to the atmosphere. Users generates a fission product inventory from either reactor operating history or a nuclear criticality event. RSAC-7 models the effects of high-efficiency particulate air filters or other cleanup systems and calculates the decay and ingrowth during transport through processes, facilities, and the environment. Doses are calculated for inhalation, air immersion, ground surface, ingestion, and cloud gamma pathways. RSAC-7 is used as a tool to evaluate accident conditions in emergency response scenarios, radiological sabotage events, and safety basis accident consequences.

This users' manual contains the mathematical models and operating instructions for RSAC-7. Instructions, screens, and examples are provided to guide the user through the functions provided by RSAC-7. This program is designed for users who are familiar with radiological dose assessment methods.
\end{abstract}


INTENTIONALLY BLANK 


\section{CONTENTS}

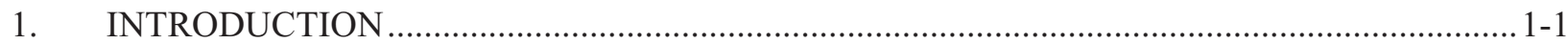

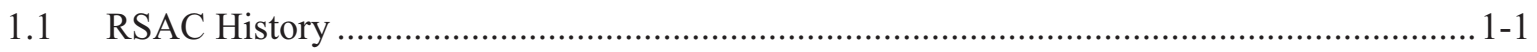

1.2 Summary of RSAC-7.2 Capabilities .......................................................................... 1-4

1.2.1 1000 Series - Fission Product Calculation and Inventory Decay ............................ 1-4

1.2.2 2000 Series - Direct Radionuclide Input .................................................................. 1-4

1.2.3 3000 Series - Dose Summary Option ................................................................. 1-5

1.2.4 5000 Series - Meteorological Data Input......................................................... 1-5

1.2.5 6000 Series - Radionuclide Inventory Decay for Printout .................................... 1-5

1.2.6 7000 Series - Internal/External Dose Calculations................................................ 1-6

1.2.7 9000 Series - Cloud Gamma Dose Calculation ..................................................... 1-6

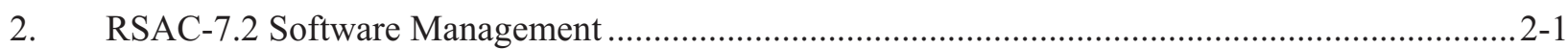

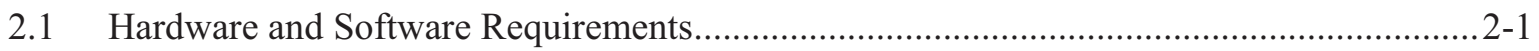

2.2 Loading Instructions and Validation of Installation......................................................... 2-2

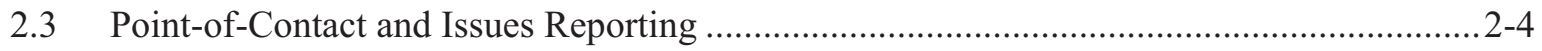

2.4 Software Management and Quality Assurance ................................................................2-4

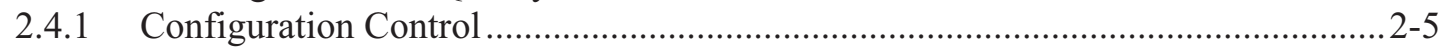

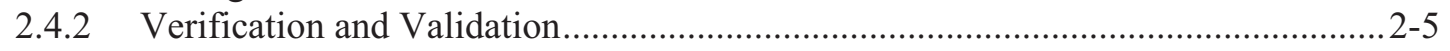

2.4.3 Restrictions or Limitations .............................................................................. 2-5

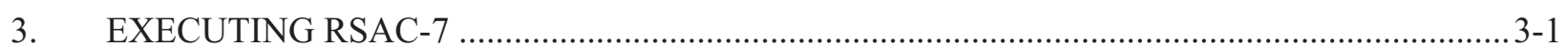

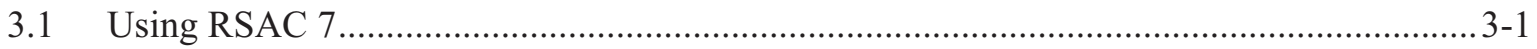

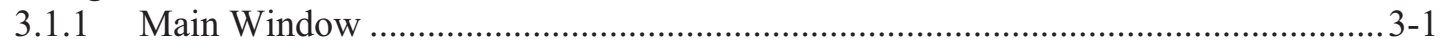

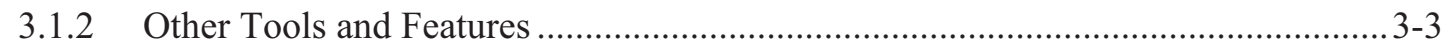

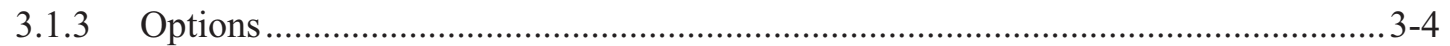

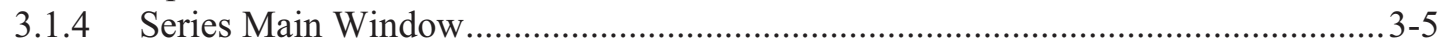

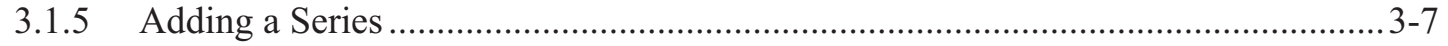

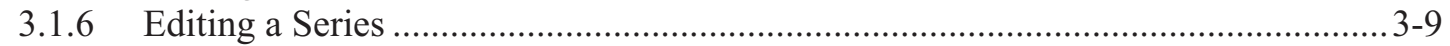

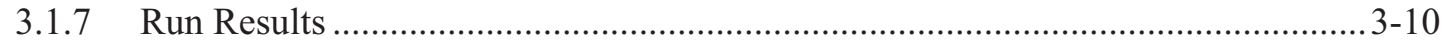

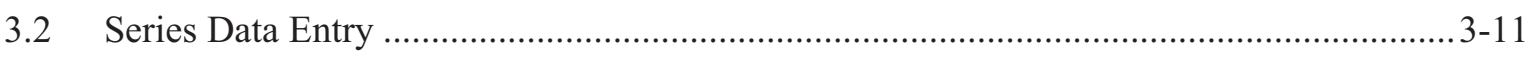

3.2.1 1000 Series - Fission Product Inventory Calculation .......................................... 3-11

3.2.2 2000 Series - Direct Radionuclide Input ..................................................... 3-18

3.2.3 3000 Series - Dose Summary Option ....................................................... 3-21

3.2.4 5000 Series - Dispersion Control Input ........................................................... 3-24

3.2.5 6000 Series - Radionuclide Inventory Decay and Printout ...................................3-34

3.2.6 7000 Series - Internal/External Dose Calculation .............................................. 3-42

3.2.7 9000 Series - Cloud Gamma Dose Calculation ...................................................... 3-60

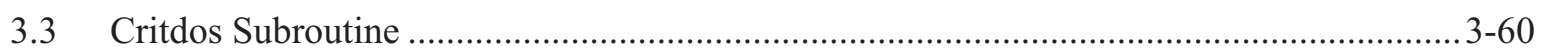

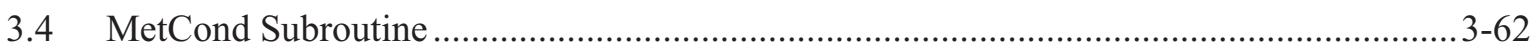

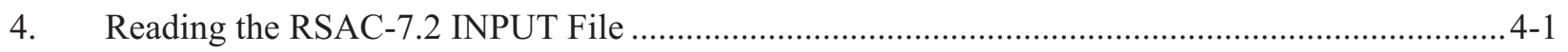

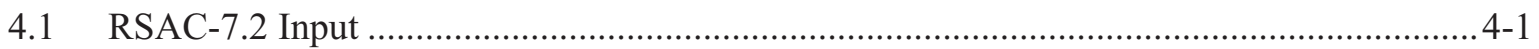

4.2 Calculation Title Line ............................................................................................. 4-2

4.2.1 1000 Series - Fission Product Inventory Calculation and Inventory Decay ............. 4-2

4.2.2 2000 Series - Direct Radionuclide Input ..........................................................

4.2.3 3000 Series - Dose Summary Option ............................................................ 4-8 
4.2.4 5000 Series - Dispersion Control Input ............................................................ 4-10

4.2.5 6000 Series - Radionuclide Inventory Decay for Printout ….............................. 4-18

4.2.6 7000 Series - Internal/External Dose Calculation ............................................ 4-22

4.2.7 9000 Series - Cloud Gamma Dose Calculation ................................................. 4-32

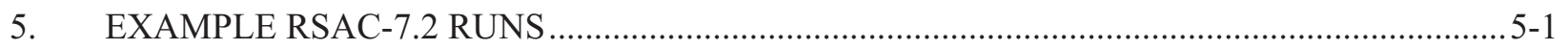

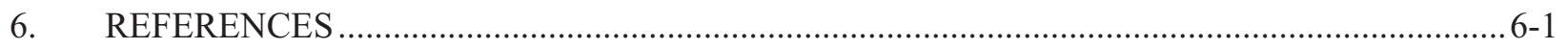

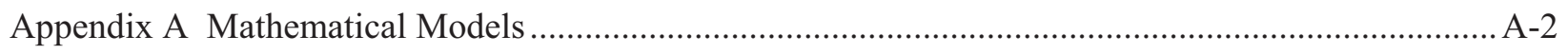

Appendix B RSAC-7.2 Nuclear Data Library …............................................................................. B-2

Appendix C Meteorological Diffusion Parameters.......................................................................... C-2

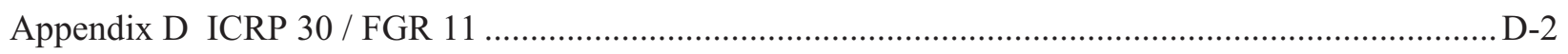

\section{FIGURES}

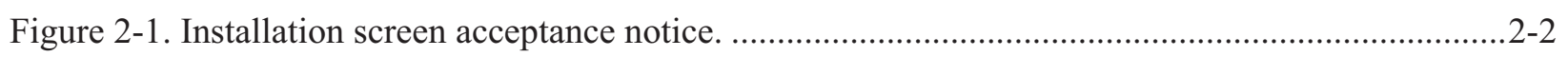

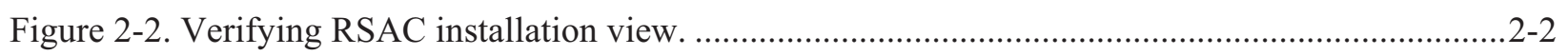

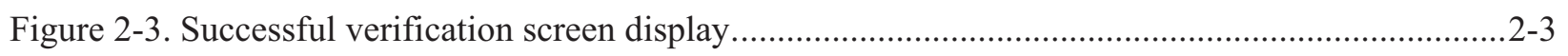

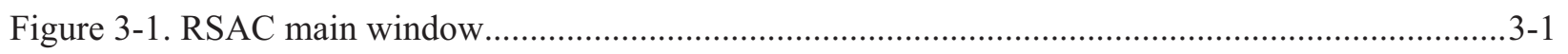

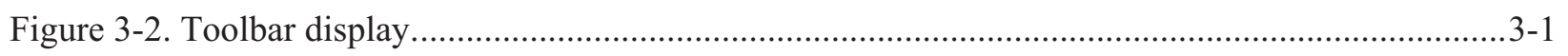

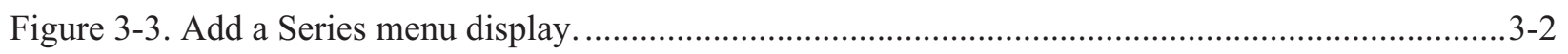

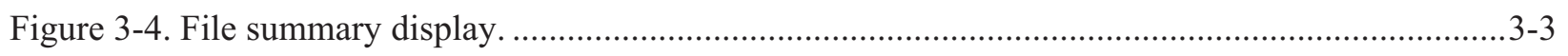

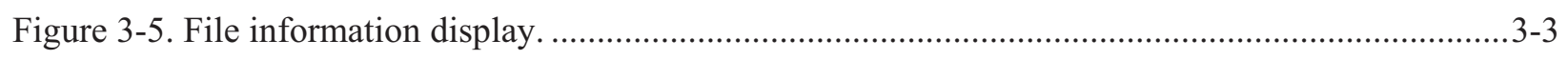

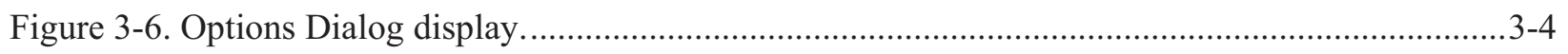

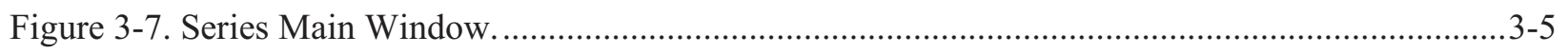

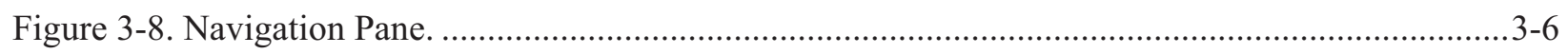

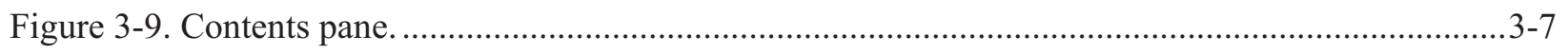

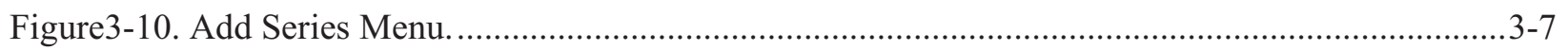

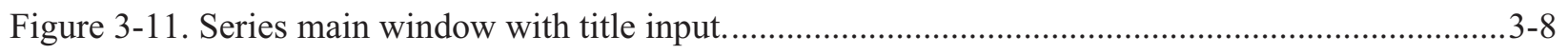

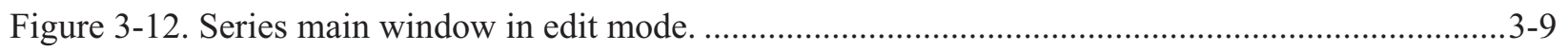

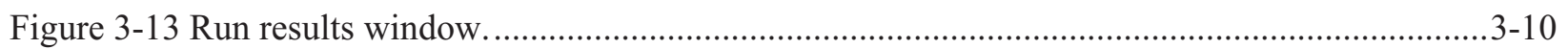

Figure 3-14. Comment entry screen......................................................................................... $3-11$

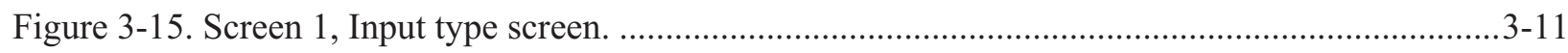

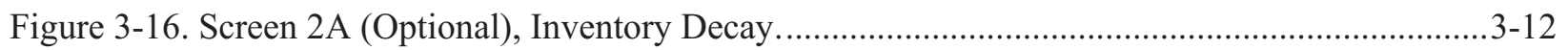

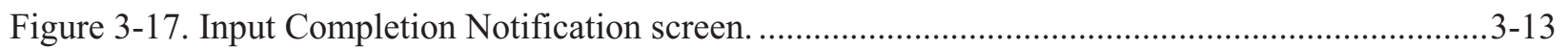

Figure 3-18. Screen 2B (Optional), Reactor Operation. .........................................................................13

Figure 3-19. Screen 3A, Release During Reactor Operation................................................................ 
Figure 3-20. Screen 4A, Release During Fission Product. ................................................................ 3-14

Figure 3-21. Screen 2C (Optional), Fractionate Inventory. ............................................................. 3-15

Figure 3-22. Screen 3B (Optional), Fractionation by Group. ......................................................... 3-15

Figure 3-23. Screen 3C (Optional), Fractionation by a Constant. .................................................... 3-16

Figure 3-24. Screen 3D (Optional), Fractionation by Element..........................................................

Figure 3-25. Screen 4B, Element Fractionation Specification............................................................. $3-17$

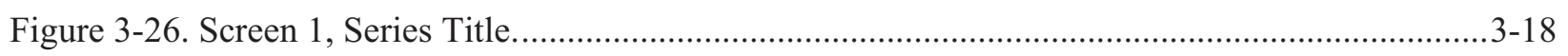

Figure 3-27. Screen 2, Radionuclide Input Options..........................................................................

Figure 3-28. Previous Inventory Deleted Warning.......................................................................... 3-19

Figure 3-29. Screen 3, Direct Radionuclide Input. ........................................................................

Figure 3-30. Screen 4A (Optional) Radionuclide Curie Input..........................................................3-20

Figure 3-31. Screen 4B (Optional), External File for Radionuclide Entry. ..........................................3-21

Figure 3-32. Screen 5, Series Complete Notification. .................................................................. $3-21$

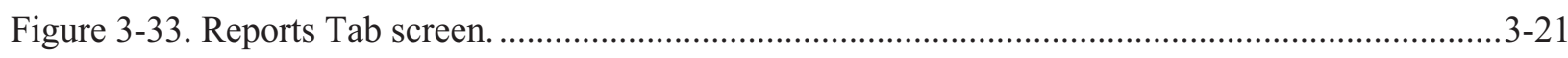

Figure 3-34. Screen 2, Dose Summary Options............................................................................ $3-22$

Figure 3-35. Screen 3 (Optional), Organ Selection.......................................................................... $3-23$

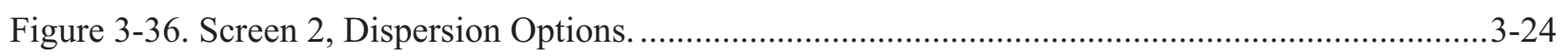

Figure 3-37. Screen 3 (Optional), General Meteorological Information. ............................................... $3-25$

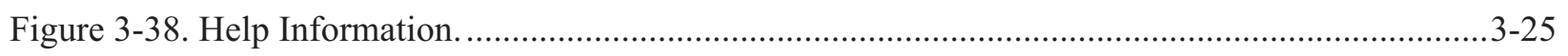

Figure 3-39. Screen 4 (Optional), Dry Deposition Variables. ................................................................ $3-26$

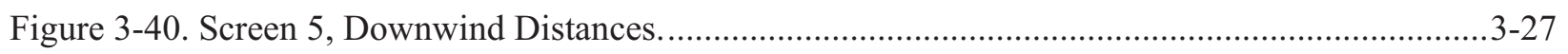

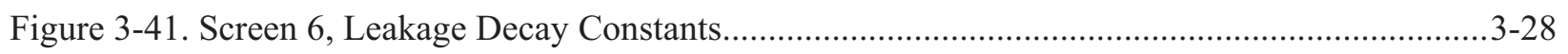

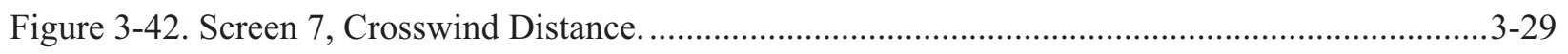

Figure 3-43. Screen 8, Diffusion Coefficient Control.......................................................................3-30

Figure 3-44. Screen 10A (Optional), Coefficient of Standard Deviation. .............................................3-31

Figure 3-45. Screen 10B (Optional), Plume Standard Deviation Control. ............................................3-32

Figure 3-46 Screen 10C (Optional), Direct Chi/Q Input....................................................................3-33

Figure 3-47. Screen 11A (Optional), Jet Plume Rise Parameters. ...........................................................3-33

Figure 3-48. Screen 11B (Optional), Buoyant Plume Rise Parameters. ...............................................3-34

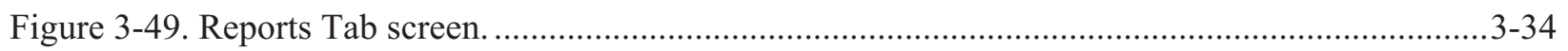

Figure 3-50. Screen 2, Radionuclide Decay Control. ........................................................................3

Figure 3-51. Screen 3 (Optional), Exponential Leakage Decay. .........................................................3-36

Figure 3-52. Leakage Decay Constants Prompt screen. ........................................................................3-36

Figure 3-53. Screen 4 (Optional), Leakage Decay Constants.............................................................3-37

Figure 3-54. Screen 5 (Optional), Radionuclide Selection. ....................................................................3-38 


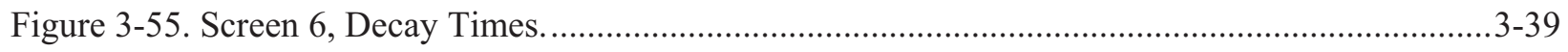

Figure 3-56. Screen 7 (Optional), Summation Control...................................................................... 3-40

Figure 3-57. Screen 8 (Optional), Element Summation......................................................................

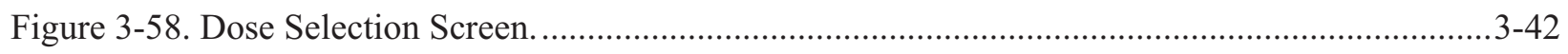

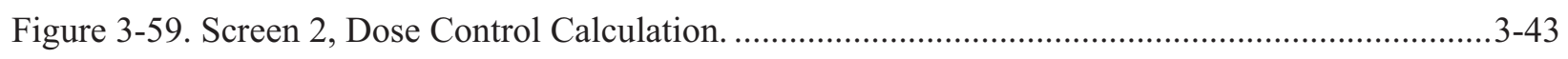

Figure 3-60. Screen 3A (Optional), Inhalation Dose Control............................................................ 3-44

Figure 3-61. Screen 4A (Optional), Inhalation Parameters Dose Calculation........................................3-45

Figure 3-62. Screen 5A (Optional), Clearance Class Entry............................................................... 3-46

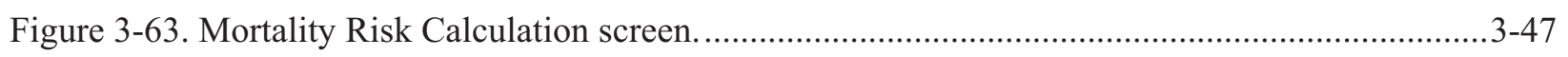

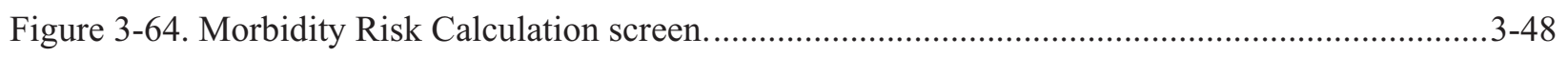

Figure 3-65. Screen 6 (Optional), Resuspension of Activity.............................................................3-49

Figure 3-66. Screen 3B (Optional) - Ingestion Dose Parameters.........................................................3-50

Figure 3-67. Screen 4B (Optional), Ingestion Dose Control. .............................................................. $3-51$

Figure 3-68. Screen 5B (Optional), Usage Constants Tab.............................................................. $3-52$

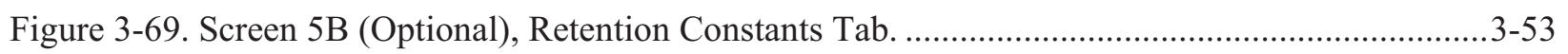

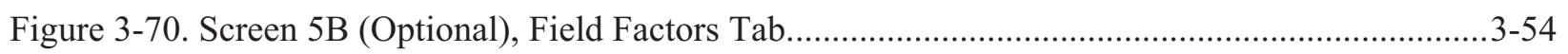

Figure 3-71. Screen 5B (Optional), Forage Constants Tab.............................................................. 3-55

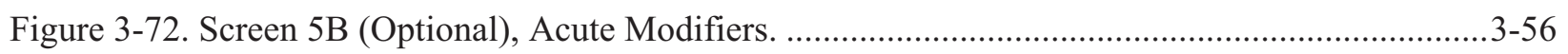

Figure 3-73. Screen 3C (Optional), Ground Surface Dose Parameters. .................................................. $3-57$

Figure 3-74. Screen 3D (Optional), Air Immersion Dose Parameters.........................................................57

Figure 3-75. Screen (Optional), Internal/External Organ Selection..........................................................5

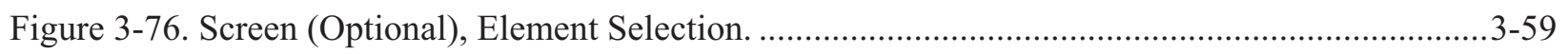

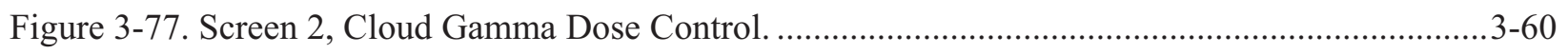

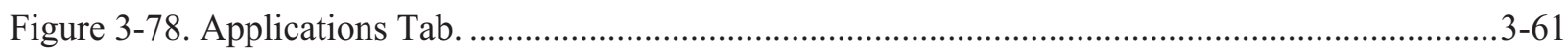

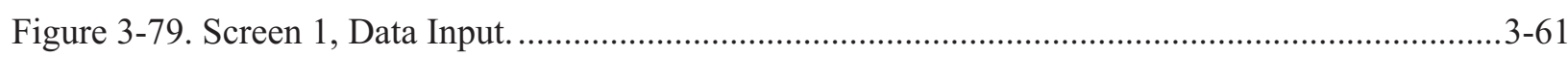

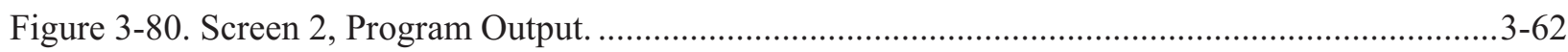

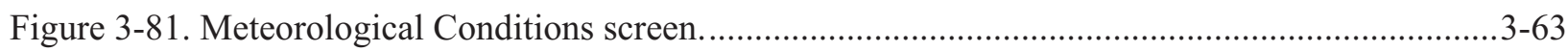

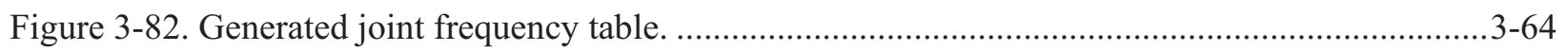

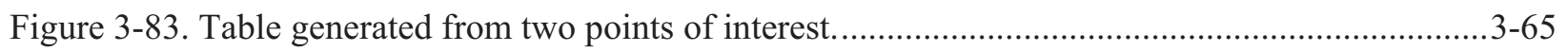

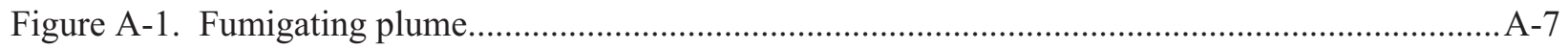

Figure A-2. Deposition of dust in the respiratory system ..............................................................A-18

Figure A-3. Clearance pathways for the ICRP-30 model ................................................................A-18

Figure C-1. $\sigma_{\mathrm{y}}$ versus distance downwind by stability class (Hilsmeier-Gifford). ................................ C-2

Figure $\mathrm{C}-2 . \sigma_{\mathrm{z}}$ versus distance downwind by stability class (Hilsmeier-Gifford). ................................. C-3 
Figure C-3. $\sigma_{\mathrm{y}}$ versus distance downwind by stability class (Markee) ....................................................

Figure C-4. $\sigma_{\mathrm{z}}$ versus distance downwind by stability class (Markee). ................................................ C-5

Figure C-5. $\sigma_{\mathrm{y}}$ versus distance downwind by stability class (Pasquill-Gifford).................................... -6

Figure C-6. $\sigma_{z}$ versus distance downwind by stability class (Pasquill-Gifford). .................................... C-7

\section{TABLES}

Table A-1. Estimated seasonal and annual mixing depths $(\mathrm{m})$ for mornings and afternoons at the

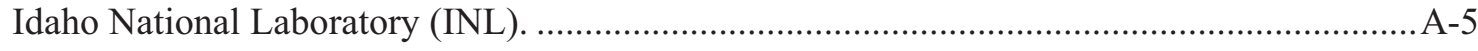

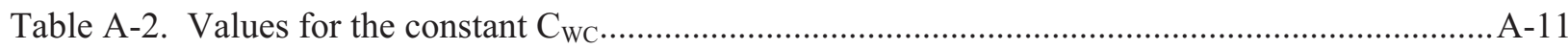

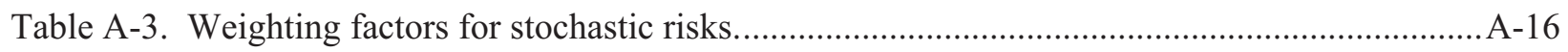

Table A-4. ICRP-30 mathematical model used to describe clearance from the respiratory system......A-17

Table A-5. Default annual dietary ingestion rates for adults. ............................................................ 19

Table A-6. RSAC-7.2 default radionuclide independent parameters used to calculate

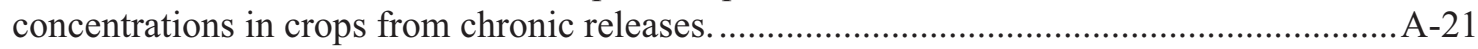

Table A-7. RSAC-7.2 element-dependent parameters used to calculate concentrations in crops.........A-22

Table A-8. Comparison of calculated buildup factors for air to Berger's buildup factors. ...................A-37

Table A-9. Photon energy groups and dose conversion factors........................................................ -38 


\section{INTRODUCTION}

Radioactive releases from nuclear facilities may contribute to radiation exposure through a number of pathways: external exposures by direct radiation from plumes or deposited radionuclides or internal exposures from inhalation or ingestion of radioactive material. The Radiological Safety Analysis Computer (RSAC) Program calculates the consequences of a release of radionuclides to the atmosphere. RSAC 7.2 is the current release and RSAC-7 is the version. Using a personal computer, RSAC 7 users generate a fission product inventory; calculate inventory decay and ingrowth; fractionate the inventory during transport through processes, facilities, and the environment; model the downwind dispersion of the activity; and calculate doses to downwind individuals.

A fission product inventory is calculated from reactor operating history and is used to simulate a nuclear criticality accident. Radionuclide inventories are also directly input into RSAC-7.2 if desired. Source term modeling allows for complete progeny ingrowth and decay during all accident phases. RSAC-7.2 release scenario modeling allows fractionation of the inventory by chemical group or element. RSAC-7.2 also models the effects of high-efficiency particulate air (HEPA) filters or other cleanup systems. RSAC-7's meteorological capabilities include Gaussian plume diffusion for Pasquill-Gifford, Hilsmeier-Gifford, and Markee models. RSAC-7.2 possesses the unique ability to model Class F fumigation conditions. Optionally, users supply plume standard deviations $(\sigma s)$ or atmospheric diffusion $(\chi / Q s)$ to the code as input data. See Appendix A

for mathematical models. RSAC-7.2 also includes corrections for deposition (wet and dry) plume rise (jet and buoyant), resuspension, and release in a room and building wake. Doses are calculated through inhalation, immersion, ground surface, and ingestion pathways, and cloud gamma dose from semi-infinite plume model and finite plume model.

RSAC-7 calculates internal dose using the dose conversion factors and methodology from both International Commission for Radiological Protection (ICRP) 26/30 and ICRP 60/68/72. In addition to the calculation of lifetime dose, RSAC-7 calculates the acute 24-hour dose from radiological sabotage events.

RSAC-7 is an excellent tool to evaluate accident conditions in emergency response scenarios and to evaluate safety basis accident conditions.

\subsection{RSAC History}

RSAC was originally developed and written in assembly language (MAP) for the IBM 7044/44 in 1966 by R. L. Coates and N. R. Horton ${ }^{11}$ for support of the Advanced Test Reactor dose consequence calculations. In 1968, a FORTRAN version of the program was prepared by L. C. Richardson ${ }^{29}$. Since 1968 , RSAC has undergone substantial revision.

In 1973, RSAC-2 was issued by D. R. Wenzel (Wenzel 1973) ${ }^{38}$ to:

- Add input and output options

- Change the inhalation dose calculations (lung and gastro-intestinal tract)

- Change the numerical integration methods for cloud gamma dose calculations

- Change the gamma-ray buildup factor model

- Revise radionuclide yields and half-lives in the standard library

- Refine output format for ease of reading

- reduce computer memory requirements. 
In 1982, RSAC-3 was issued (Wenzel 1982) ${ }^{39}$ to:

- Add a 50-mile population dose calculation

- Use the U.S. Nuclear Regulatory Commission (NRC) Regulatory Guide 1.109 for ingestion dose calculations

- Use the ICRP Lung Dynamics Model for inhalation dose calculations

- Use the Dolphin and Eve Gastro-intestinal Tract Model

- Improve error detection.

After undergoing an extensive verification and validation, RSAC-4 (Wenzel 1990) ${ }^{40}$ was enhanced and issued in 1990 to:

- $\quad$ Convert the program to FORTRAN 77

- Execute RSAC-4 on a personal computer

- Use internal dose conversion factors from DOE/EH-0071 and external dose-rate conversion factors from DOE/EH-0070

- Add dose summary tables

- Add an ingestion dose model for an acute release

- Increase the number of organs in the dose calculations

- Include water immersion dose calculations

- Program calculated plume rise for either jet or buoyant plume

- Revise fission yields and half-lives

- Add radionuclides to the standard library

- Update the photon data library

- Enhance error diagnostics

- Include verification and validation necessary to meet the additional requirements for software imposed by American Society of Mechanical Engineers (ASME)- Nuclear Quality Assurance (NQA)-1-2000, "Quality Assurance Requirements for Nuclear Facility Applications²."

In 1994, RSAC-5 (Wenzel 1994) ${ }^{41}$ was issued to:

- Add an option to calculate cloud-gamma doses expressed in external dose equivalent

- Add a variable particle size option for inhalation dose calculations

- Resolve the over depletion for ground level releases during stable meteorology that was observed in earlier versions of RSAC

- Add a reflective meteorological model to better model diffusion below the mixing depth

- Include additional radionuclides to more accurately model the U-235 fission chain

- Add a dose summing option

- Incorporate a simplified notation for radionuclide identification

- Include a capability to read radionuclide inventories from external files 
- Correct errors observed in earlier versions of RSAC for the finite-plume model integration for cloud-gamma dose calculations and large plumes

- Add meteorological diffusion using Pasquill-Gifford parameters

- Include an option to simulate the release of fission products from an operating reactor

- Update forage and vegetation yields

- Include an option to read ingestion transfer parameters from an external file

- Refine the model for ingestion dose calculations from an acute release.

After major modifications, RSAC-6 was released in 2001 to:

- Add radionuclides to the program library

- Use internal dose conversion factors from Federal Guidance Report (FGR)-11 and external dose-rate conversion factors from FGR-12

- Calculate doses at distances of less than 100 meters

- Correct minor errors identified in the program

- Printout radionuclides in a logical order

- Add default lung clearance classes to provide the maximum dose based on each element

- Allow entry of radionuclide input in either upper or lower case characters

- Eliminate a discontinuity in the leakage function

- Add an option to allow the user to enter a respirable fraction for inhalation dose calculations

- Add an option to allow the user to enter an occupancy factor for ground surface dose calculations

- Incorporate editorial changes in program output

- Enhance the method to estimate the building wake effect

- Evaluate the instantaneous release to a room

- Evaluate the resuspension of particulate activity

- Enhance the method for evaluation of dry deposition

- Perform calculation of an effective $\sigma_{\mathrm{y}}$ and $\sigma_{\mathrm{z}}$ when $\chi / \mathrm{Q}$ is directly input.

RSAC-7.2 is the current release of of RSAC-7 and was released in 2010. This revision of RSAC:

- Added internal dose conversion factors from ICRP 68 and 72

- Added acute dose conversion factors for a 24-hour exposure from a sabotage event

- Corrected minor errors in the printing and display features

- Added the capability to perform joint frequency meteorological conditions to calculate both $50 \%$ and 95\% metrological conditions for input into RSAC

- Established an internal validation process to assure proper verification of installation parameters

- Established 20 new examples for execution of the enhanced capabilities of RSAC-7

- Added input units of curies, grams, and Becquerel to the direct input model. 


\subsection{Summary of RSAC-7.2 Capabilities}

RSAC-7.2 consists of nine subroutines. Each subroutine performs a type of calculation and operates together with or independently of the others, depending on the analysis being performed. Historically, these subroutines have been referred to as a series. For consistency with earlier versions, this nomenclature has been retained. Both the series number and the subroutine function are indentified. These series are identified by input series lines in multiples of 1000. A summary of each of the program series follows.

\subsubsection{Series - Fission Product Calculation and Inventory Decay}

RSAC-7.2 allows the user to establish an inventory of fission products (and subsequent decay products) by simulating the operation of a thermal reactor. The user can simulate steady-state, transient, or cyclic reactor operation. A refueling option is also available. After establishing the reactor operating history, the user can then specify the fractional release of the radionuclide inventory by individual element, by groups of elements (solids, halogens, noble gases, cesium, or ruthenium), or by a single release fraction for the entire inventory.

RSAC-7.2 calculates inventories for fission products only. The nuclear data library (see Appendix B

) contains selected activation products, actinides, and the daughters of actinides in addition to the fission products. Inventories for activation products and actinides are not calculated by RSAC-7; however, they can be added to the inventory by using the radionuclide direct input section of the program. Subsequent sections of the program calculate the radioactive decay and doses from these additional radionuclides.

The model used by RSAC-7.2 to calculate fission product inventories is simple compared to the model used in the Oak Ridge isotope generation 2 (ORIGEN2) program (Croff $1980^{13}$, RSICC $1991^{31}$ ). RSAC-7.2 is simple to run and requires less computer time than ORIGEN2. In general, the RSAC-7.2 model calculates fission product inventories well. However, it does not calculate inventories for activation products or actinides. While the RSAC-7.2 model corrects for depletions of fission products by neutron activation, it does not calculate all of the subsequent radionuclides that are produced by the neutron activation of fission products. When irradiation times are long, the burnup is relatively high, or the enrichment of the fuel is low, inventories of radionuclides produced primarily by the activation of fission products (Cs-134, Pm-147, Sm-151, Eu-154, and Eu-155) can differ from ORIGEN2-calculated inventories by more than $20 \%$. When doses from these radionuclides are significant compared to the other fission products, users should use a more sophisticated computer program such as ORIGEN2 and import the final inventory using the 2000 Series direct radionuclide input option. RSAC-7.2 can then be used to calculate inventory decay and simulate additional reactor operation or fuel handling accidents such as a criticality.

The 1000 Series of RSAC-7.2 can be reentered as many times as desired to modify the radionuclide inventory. One of the options in this series is to fractionate the radionuclide inventory and to simulate removal of activity by cleanup systems such as HEPA filters. The inventory can be fractionated for a chemical group, element, or the entire inventory.

\subsubsection{Series - Direct Radionuclide Input}

This series allows users to input a radionuclide inventory from an external file or to directly input the amounts of radionuclides to be used in subsequent calculations. The direct radionuclide input option should be used to add activation products and other radionuclides not generated by the 1000 series source term generation function. 


\subsubsection{Series - Dose Summary Option}

This series allows doses from different exposure pathways and multiple RSAC-7.2 calculations within the same input run to be summarized, added, and reported in summary tables. This option has strict operating guidelines (see Section 4.1, Dose Summary Option Control Line [3000]).

\subsubsection{Series - Meteorological Data Input}

This series allows the user to specify meteorological conditions at the time of release and to calculate diffusion, dispersion, and depletion factors.

This input series of RSAC-7.2 must normally be entered before any dose calculations are requested. After establishing basic meteorological parameters (such as stack height, wind velocity, and mixing layer depth), the user specifies points of interest for dose calculations at downwind and/or crosswind positions.

RSAC-7.2 models the release of radioactivity from containment structures using exponential functions (see Appendix A

). Instantaneous and continuous releases are modeled using a single exponential function. Complex release scenarios can be modeled using a series of up to 10 exponential functions. These functions calculate the radionuclide inventory decay while it is held up by the containment structure before it is released.

Atmospheric diffusion parameters can be input directly by the user or calculated by RSAC-7. RSAC-7.2 calculates plume standard deviations $(\sigma \mathrm{s})$ developed for three different conditions. Hilsmeier-Gifford os (Clawson et al. $1989^{10}$ ) were developed for desert terrains and releases from a few to 15 minutes. Markee os (Clawson et al. $1989^{10}$ ) were also developed for a desert terrain; however, they were developed for releases from 15 to 60 minutes in duration. Pasquill-Gifford $\sigma \mathrm{s}$ are presented in Nuclear Regulatory Commission (NRC) Regulatory Guide 1.145 (NRC 1982) ${ }^{26}$ and by Slade (1968) from the Prairie Grass experiments for effluent releases with durations of 10 to 60 minutes.

Other meteorological options available in RSAC-7.2 are corrections for plume rise using models by Briggs (1969), ${ }^{7}$ building wake corrections (Ramsdell, 1997), ${ }^{28}$ and plume depletion using modeling of Markee $(1967)^{23}$ and Chamberlain (1953). ${ }^{8}$

\subsubsection{Series - Radionuclide Inventory Decay for Printout}

This series allows the user to calculate the radioactive decay of the entire radionuclide inventory or of selected radionuclides for printout. Decay of the radionuclide inventory for subsequent dose calculations is not done in this series, but in the 1000 Series. If downwind distances have been previously specified in the meteorological section of the program (5000 Series), decay times are calculated for each downwind position. Alternately, the user can directly specify decay times in this series. Radionuclide inventory printout options are then available. Inventories for activation products and actinides are printed only when 2000 Series input has been used to enter these radionuclides. 


\subsubsection{Series - Internal/External Dose Calculations}

This series allows the user to perform a variety of dose calculations. The radionuclide source term for these calculations is the radionuclide inventory created and operated on in the 1000 and 2000 Series. An internal dose can be calculated for up to 23 organs in addition to the committed effective dose equivalent (CEDE) for the inhalation or ingestion pathways. Internal doses are calculated using dose conversion factors from Federal Guidance Report No. 11 (Eckerman 1988) ${ }^{16}$. Ingestion doses from a chronic release are calculated using models described in NRC Regulatory Guide 1.109 (NRC 1977a) ${ }^{24}$. Because of the lack of a consensus model, equations for calculating ingestion doses from an acute release have been developed specifically for RSAC-7. Standard ingestion constants are provided in the program; however, the user can alter any of the constants. External dose can also be calculated for up to 23 organs in addition to the external effective dose equivalent (EDE) for the ground surface and for air immersion pathways. The air immersion model should be used with caution to ensure that the plume has diffused to the ground level and that the plume size is large compared to the mean free path of the gamma rays. Otherwise, using the air immersion model can result in significant error in the dose calculation. External doses are calculated using dose-rate conversion factors from Federal Guidance Report No. 12 (Eckerman 1993). ${ }^{15}$ External exposure from a release to a room and internal exposure from resuspension are also available.

\subsubsection{Series - Cloud Gamma Dose Calculation}

RSAC-7.2 calculates cloud gamma doses (in addition to the air immersion model provided in the 7000 Series input) using either a finite plume model or a semi-infinite cloud gamma model. The finite plume model is accurate for any plume size, location, or release point. However, compared to the air immersion or semi-infinite models, it requires longer computer time to perform calculations. When the plume has diffused to ground level and is large compared to the mean free path of the gamma rays, both the semi-infinite and the air immersion models give accurate results. However, as noted in the 7000 Series discussion in this section, significant errors can result when the proper conditions for these simplified models do not exist. Whenever in doubt, the user should use the finite plume cloud gamma model. By comparing the results of the finite plume model with the semi-infinite plume model, users can establish when the simplified models can be used. 


\section{RSAC-7.2 Software Management}

The purpose of RSAC 7 software management is to outline and explain the management of the RSAC-7.2 software project. RSAC-7.2 is the newest version of the RSAC legacy program. It was developed by modifying RSAC-7.1; however, as a result of major modifications to the program, RSAC-7.2 is considered a new software project and not a maintenance upgrade of RSAC-7.1. Therefore, the existing software management plan (SMP) for Version 6.2 was left unchanged, and a new SMP for Version 7 was developed.

The modifications that was made to RSAC-7.2, along with other added capabilities, is described in more detail in the technical and functional requirements document. The purpose was to create RSAC-7.2 with sufficient quality so that it could confidently be released on an international scale to NQA-1-2000, "Quality Assurance Requirements for Nuclear Facility Applications," Subpart 2.7, "Quality Assurance Requirements for Computer Software for Nuclear Facility Applications. ${ }^{2}$ " In addition to the requirements of NQA-1-2000, NQA-1-2008 "Quality Assurance Requirements for Nuclear Facility Applications," Subpart 2.7, "Quality Assurance Requirements for Computer Software for Nuclear Facility Applications, ${ }^{27}$ " was also used as a basis for establishing software requirements. Where a difference existed between the documents, the most conservative process or method was selected.

The SMP for version 7 applies to all point releases. As in 7.0.x, 7.2.x, 7.4.x, 7.6.x etc. The released versions are controlled as even point releases. During the testing phase the versions are controlled as odd point releases. All releases of RSAC-7 are required to follow this SMP and the other implementing documents of this plan.

This chapter provides the software management (SM) and software quality assurance (SQA) requirements of DOE O 414.1C, Quality Assurance, dated 6-17-05, for RSAC-7. This chapter supplements the quality assurance program (QAP) requirements of Title 10 Code of Federal Regulations (CFR) 830, Subpart A, Quality Assurance, for DOE nuclear facilities and activities. The SQA requirements for DOE, including the National Nuclear Security Administration (NNSA), and its contractors are necessary to implement effective quality assurance (QA) processes and achieve safe nuclear facility operations.

DOE promulgated the software requirements and this guidance to control or eliminate the hazards and associated vulnerability posed by security software. Software failures or unintended output can lead to unexpected program failures and undue risks to the DOE/NNSA mission, the environment, the public, and the workers. This standard includes software application practices covered by appropriate national and international consensus standards and various processes currently in use at DOE facilities. This guidance is considered to be of sufficient rigor and depth to ensure acceptable reliability of safety software at DOE/NNSA facilities.

This chapter should be used by organizations to help determine and support the steps necessary to address possible design or functional implementation deficiencies that might exist and to reduce operational hazards-related risks to an acceptable level. Attributes such as the facility life-cycle stage and the hazardous nature of each facility's operations should be considered when using this standard. Alternative methods to those described in this standard may be used provided they result in compliance with applicable requirements. Another objective of this guidance is to encourage robust software quality methods to enable the development of high quality applications. This section describes the installation procedures for loading RSAC-7.2 onto a personal computer. The minimum hardware and software requirements are listed.

This section also identifies the point-of-contact for questions about the program and a summary of quality assurance activities conducted to ensure the integrity of RSAC.

\subsection{Hardware and Software Requirements}

RSAC-7.2 runs on an personal computer or compatible computer running Windows XP, Vista, and Windows 7. Although the code does run on earlier versions of Windows operating systems, it has not 
been validated on those earlier versions of Windows. The computational program is written in FORTRAN, and the user interface is written in VisualBasic.

\subsection{Loading Instructions and Validation of Installation}

Place the RSAC-7.2 CD in the CD reader. Double click on "My Computer." Double click on the drive letter for your CD reader. Double click on "Setup" and answer the questions. You will be requested to have a key to install the software. A readme file is included with the software that can assist with installation if necessary. Once the program has been installed and opened, a screen will open that requires a response (see Figure 2-1).

\section{Notice}

This computer software was prepared by Battelle Energy Alliance, LLC, hereinafter the Contractor, under Contract No.

DE-AC07-05ID14517 with the United States (U.S.) Department of Energy (DOE). NEITHER THE UNITED STATES GOVERNMENT, NOR DOE, NOR THE CONTRACTOR MAKE ANY WARRANTY, EXPRESSED OR IMPLIED, OR ASSUMES ANY LIABILITY

OR RESPONSIBILITY FOR THE USE, ACCURACY, COMPLETENESS, OR USEFULNESS OR ANY INFORMATION, APPARATUS, PRODUCT, OR PROCESS DISOCLOSED, OR REPRESENTS THAT ITS USE WOULD NOT INFRINGE PRIVATELY OWNED RIGHTS.

EXPORT RESTRICTIONS. The provider of this computer software and its employees and its agents are subject to U.S. export control laws that prohbit or restrict (i) transactions with certain parties, and (ii) the type and level of technologies and services that may be exported. You agree to comply fully with all laws and regulations of the United States and other countries (Export Laws) to assure that neither this computer software, nor any direct products thereof are (1) exported, directly or indirectly, in violation of Export Laws, or (2) are used for any purpose prohbited by Export Laws, including, without limitation, nuclear, chemical, or biological weapons proliferation.

None of this computer software or underlying information or technology may be downloaded or otherwise exported or re-exported (i) into (or to a national or resident of) Cuba, North Korea, Iran, Sudan, Syria or any other country to which the U.S. has embargoed goods; or (ii) to anyone on the U.S. Treasury Department's List of Specially Designated Nationals or the U.S. Commerce Department's Denied Persons List, Unverified List, Entity List, Nonproliferation Sanctions or General Orders. By downloading or using this computer software, you are agreeing to the foregoing and you are representing and warranting that you are not located in, under the control of, or a national or resident of any such country or on any such list, and that you acknowledge you are responsible to obtain any necessary U.S. government authorization to ensure compliance with U.S. law.

Figure 2-1. Installation screen acceptance notice.

The terms of the license must be accepted each time the software is opened in order to continue with use of the software. The next step validates the installation by clicking on the RSAC QC selection under the help menu. Once the selection is made, acceptance of the verification is required (see Figure 2-2).

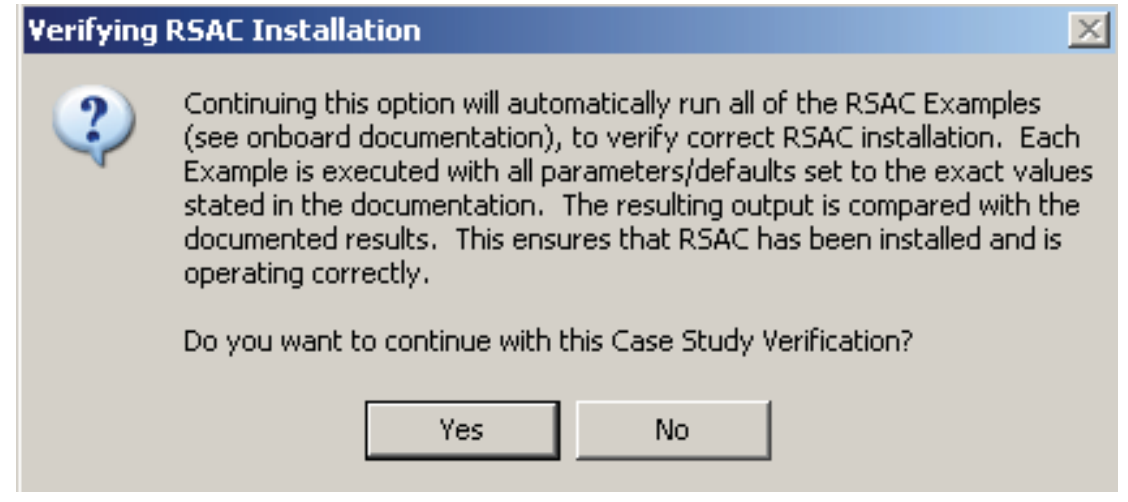

Figure 2-2. Verifying RSAC installation view. 
If yes is selected, the installation validation will continue, and all 20 examples are excuted and compared against the verified and validated results. If Figure 2-3appears, the installation was successfully verified. This QC check should be performed each time a change is made to the operating system. This assures that the change has not affected the RSAC execution capabilities.

If no is selected then the installation will abort and the user is returned to the main screen.

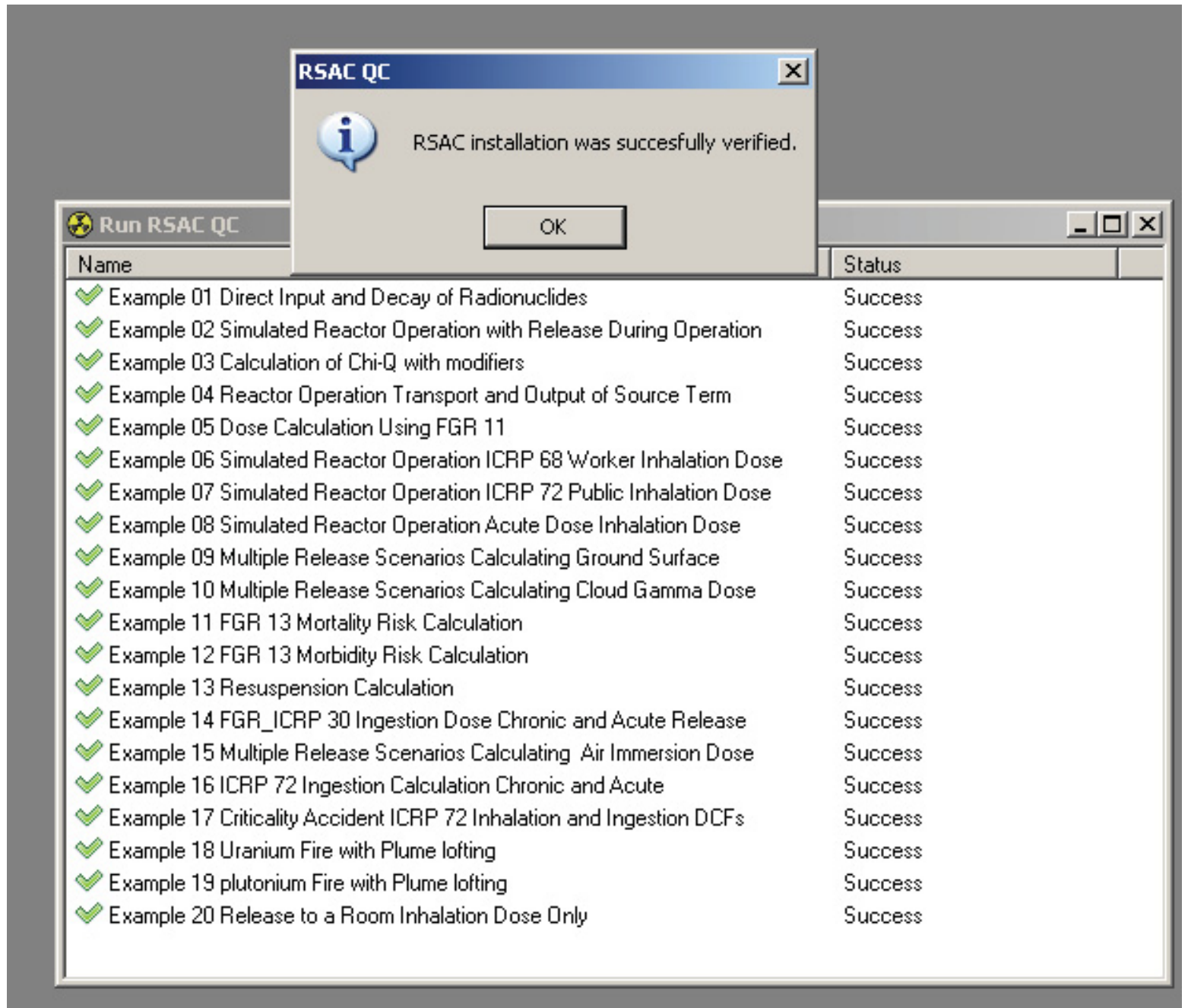

Figure 2-3. Successful verification screen display.

If the screen shown in Figure 2-3 does not display, an error screen will display with a request that the user no longer use the software and to notify the RSAC program point of contact of the problem through the bug reporting system. 


\subsection{Point-of-Contact and Issues Reporting}

A method to report bugs, provide suggestions, and look for program updates has been imbedded in the Help menu of RSAC-7.2. . Click on the Help menu and select website from the drop down menu to be directly linked to the Idaho National Laboratory RSAC website. The RSAC website has links to report bugs, provide suggestions, look up product information, and obtain downloads for program updates and manuals.

To obtain a copy of RSAC-7.2 or to resolve problems encountered when running RSAC-7.2, contact:

Dr. Bradley .J. Schrader P.E., CHP

Idaho National Laboratory

P.O. Box 1625

Idaho Falls, ID 83415-3214

(208) 526-0912

email: Bradley.Schrader@inl.gov

\subsection{Software Management and Quality Assurance}

The scope of the Department of Energy Quality Assurance (QA) Rule, 10 CFR 830 Subpart A, is stated as "This subpart establishes quality assurance requirements for contractors conducting activities, including providing items or services, that affect, or may affect, nuclear safety of DOE nuclear facilities." The scope of the QA Rule encompasses the contractor's conduct of activities as they relate to software (items or services). Therefore, the RSAC software application for nuclear safety, safeguards and security, and emergency preparedness are within its scope. DOE O 414.1C establishes the Software Quality Assurance (SQA) requirements to be implemented under the Rule for RSAC.

DOE O 414.1C requires that an appropriate level of quality infrastructure be established and a commitment made to maintain this infrastructure for the software. The RSAC SQA program establishes the appropriate software life-cycle practices, including design concepts, to ensure that the software functions reliably and performs correctly the intended work specified for that software. The RSAC SQA program is fully documented and available for review from the RSAC program point of contact. The software management program has 10 software quality work activities that ensure that the safety software performs its intended functions. The RSAC SQA plan documents the implementation strategies and appropriate standards for these 10 activities, which are:

1. Software project management and quality planning.

2. Software risk management.

3. Software configuration management (SCM).

4. Procurement and supplier management.

5. Software requirements identification and management.

6. Software design and implementation.

7. Software security.

8. Verification and validation $(\mathrm{V} \& \mathrm{~V})$.

9. Problem reporting and corrective action.

10. Training of personnel in the design, development, use, and evaluation of security software.

RSAC nuclear safety software is controlled in a traceable, planned, and orderly manner. The software quality work activities defined in this section provide the basis for planning, implementing, maintaining, and operating safety software. 


\subsubsection{Configuration Control}

Configuration control is maintained by issuing copies of RSAC-7.2 with a unique serial number. Only binary copies of RSAC-7.2 and its libraries are issued to users to prevent user changes to the program that would invalidate the extensive $\mathrm{V} \& \mathrm{~V}$.

\subsubsection{Verification and Validation}

RSAC-7.2 has been subjected to extensive independent V\&V for use in performing safety-related dose calculations to support safety analysis reports and emergency response conditions (INEEL 2001). ${ }^{21}$ RSAC V\&V files are contained in seven volumes in excess of 10,000 pages. The files are maintained by the Idaho National Laboratory (INL) and are available for review. The INL maintains a Software Management Plan and a Software Quality Assurance Plan per DOE recommendations.

\subsubsection{Restrictions or Limitations}

The RSAC is based on the Gaussian model of dispersion. As such, RSAC is best suited for specific types of conditions, which should be considered before applying RSAC. The conditions are:

- Plume Duration - RSAC is best suited for "short" duration plumes, ranging from approximately several minutes to several days. It should be understood that plume meander has a significant effect on releases longer than an hour. Meteorological conditions change and will cause plume variations from that approximated using the Gaussian model.

- Source Distance - RSAC does not model dispersion close to the source (less than 100 meters from the source), especially where the influence of structures or other obstacles is still significant. Although the selection of distances inside of 100 meters can be performed, the results should be understood as only a conservative approximation. Dispersion influenced by several, collocated facilities, within several hundred meters of each other should be modeled with care. Similarly, RSAC should be applied with caution at distances greater than 10 to 15 miles, especially if meteorological conditions are likely to be different from those at the source of the release. Long-range projections of dose conditions are better calculated with mesoscale, regional models that are able to account for multiple weather observations. Nevertheless, some applications may require 50-mile or greater radius analysis to meet requirements, e.g., Environmental Impact Statements (EISs) or Probabilistic Safety Assessments (PSAs).

- Terrain - Gaussian models are inherently flat-earth models, and perform best over regions of transport where there is minimal variation in terrain. Because of this, there is inherent conservatism (and simplicity) if the environs have significant nearby buildings, tall vegetation, or grade variations not taken into account in the dispersion parameterization.

- Momentum - RSAC does not account for momentum-driven releases from detonation type events.

- Briggs Algorithm - In plumes arising from fire-related source terms, the user should exercise caution with the models that use the Briggs algorithm, such as RSAC. The Briggs approach for accounting for sensible energy in a plume is valid for "open-field" releases (not impacted by buildings and other obstacles), or if used in combination with building wake effects.

- Dose Conversion- The user should ensure that the dose conversion factors used in RSAC are applicable to the radionuclides in the source term and the physicochemical characteristics. For example, plutonium nitrates and oxides have different time scales for dosimetric effects in the body. Thus, the appropriate lung absorption type should be used in the dose conversion factor file used in the RSAC run. In all cases RSAC will default to the lung absorption type that results in the highest dose. 
INTENTIONALLY BLANK 
The toolbar provides shortcuts for:

- Opening files

- Printing

- Using the cut, copy, paste, insert, and delete series

- Running the currently open file with RSAC.

The Add a Series menu (see Figure 3-3) allows selecting a series to add to the open file. It works similar to a tab control. Click on General to add a series or Reports to generate a report.

Note: Some series may be disabled until its prerequisites are met.

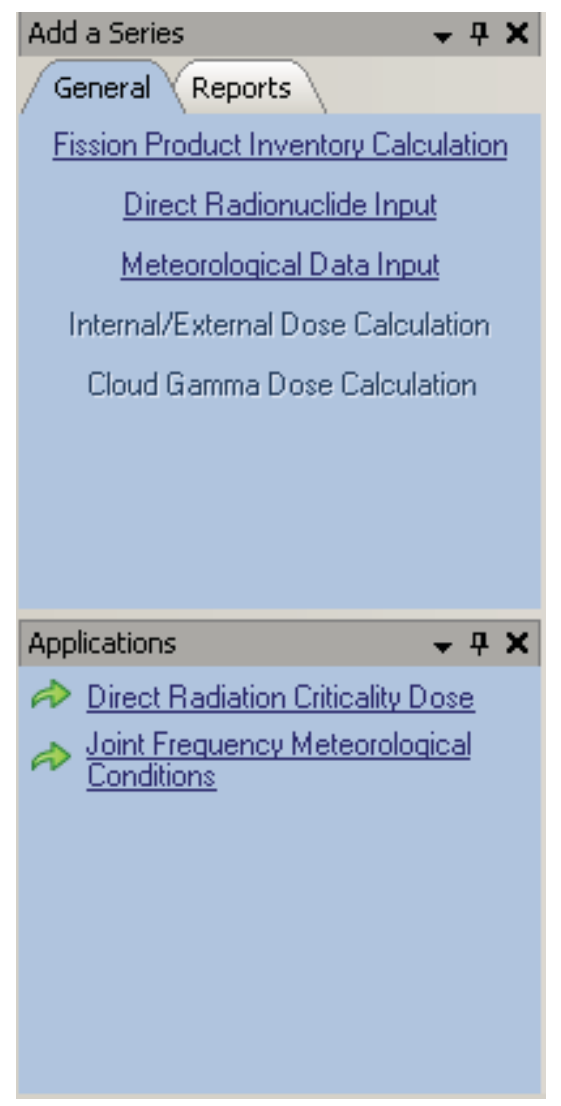

Figure 3-3. Add a Series menu display.

The file summary (see Figure 3-4) displays the following:

- Quick view of what series are in the file

- Cut, Copy, Paste, Insert, and Delete series

- The option to open a series in edit mode 


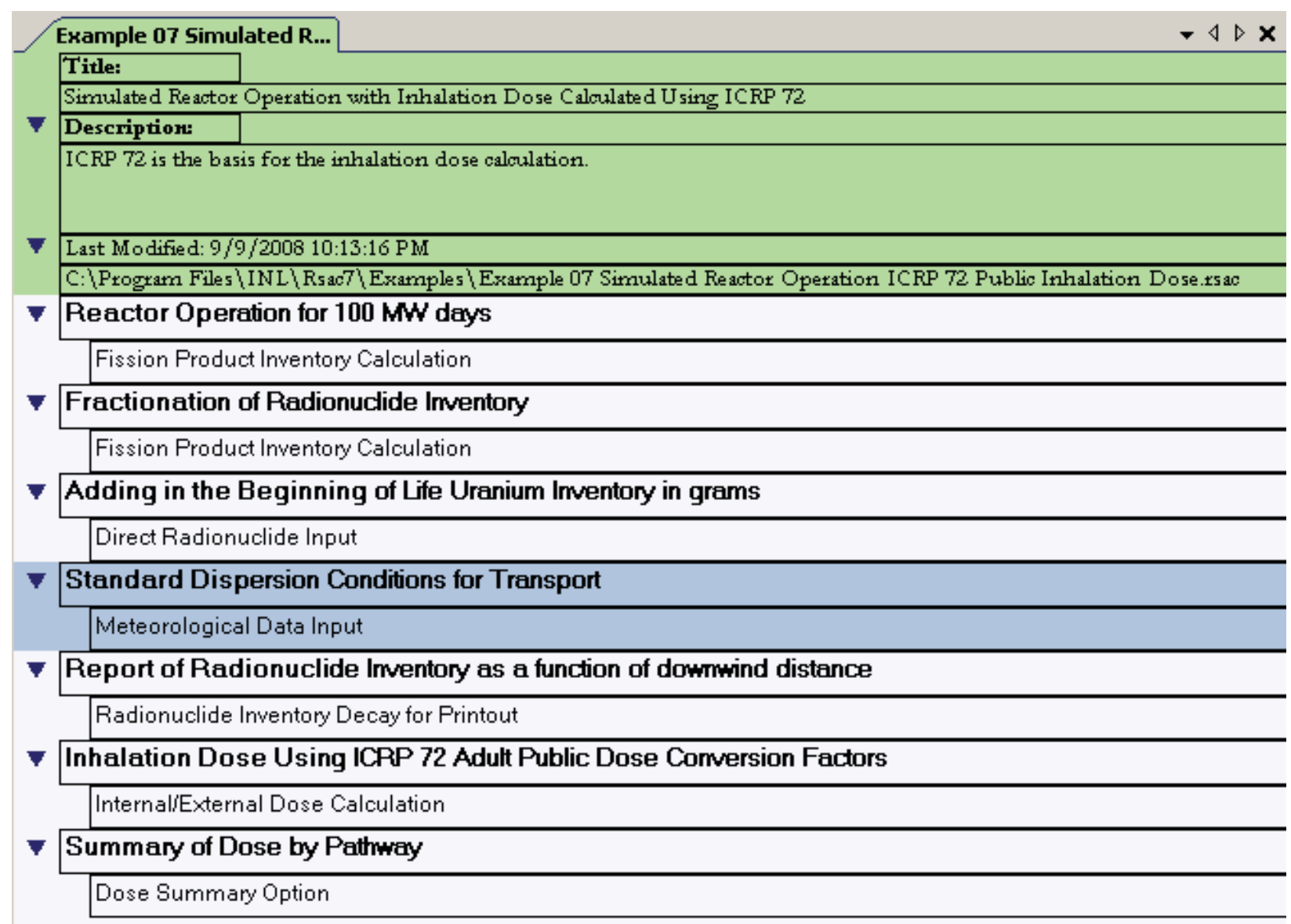

Figure 3-4. File summary display.

The file information (see Figure 3-5) located at the bottom of the screen shows the full path of the currently open file and the date and time it was last modified.

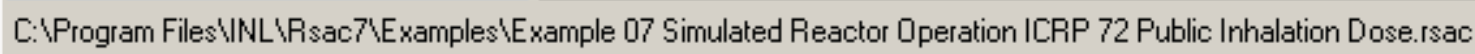

Figure 3-5. File information display.

\subsubsection{Other Tools and Features}

Other tools and features that are accessible under the drop-down menu at the top of the window are:

- Create Text File - Creates a text file from the currently open file

- Edit Text and ASCII Files - Opens the selected file in Notepad for editing

- Browse File - Browse the currently open file in text format

- Run Batch - Allows running a batch of mixed file types with RSAC

- Run History - Views history database of all files run with RSAC

- View Existing - Opens existing run output files for viewing 
- Options - Controls user settings for WinRp

- Website - Opens the RSAC website in Internet Explorer

- RSAC Manual - Opens the RSAC pdf manual, Adobe Acrobat Reader is required.

\subsubsection{Options}

Certain features of WinRp can be controlled in the options dialog (see Figure 3-6). To open the Options Dialog, click the Tools menu then click Options.

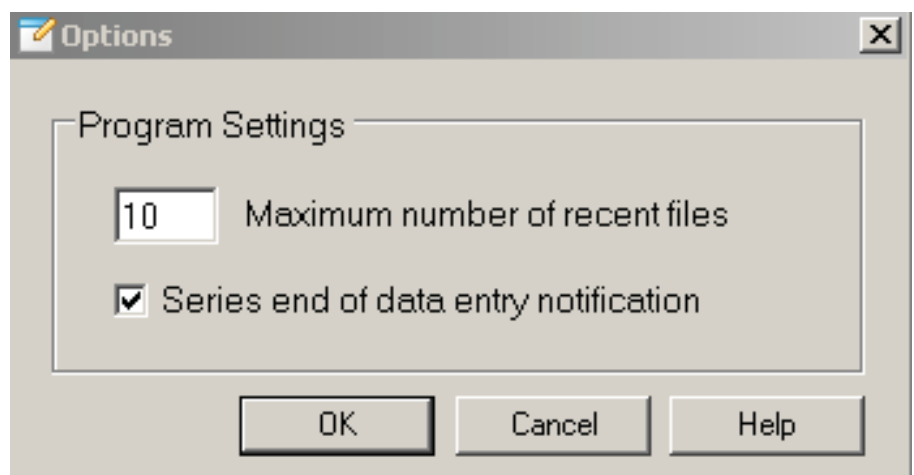

Figure 3-6. Options Dialog display. 


\subsubsection{Series Main Window}

The series main window (See Figure 3-7) provides a summary of all data that have been entered for the current series. Data can be reviewed then saved, edited, or discarded using the buttons on the lower right corner of the window.

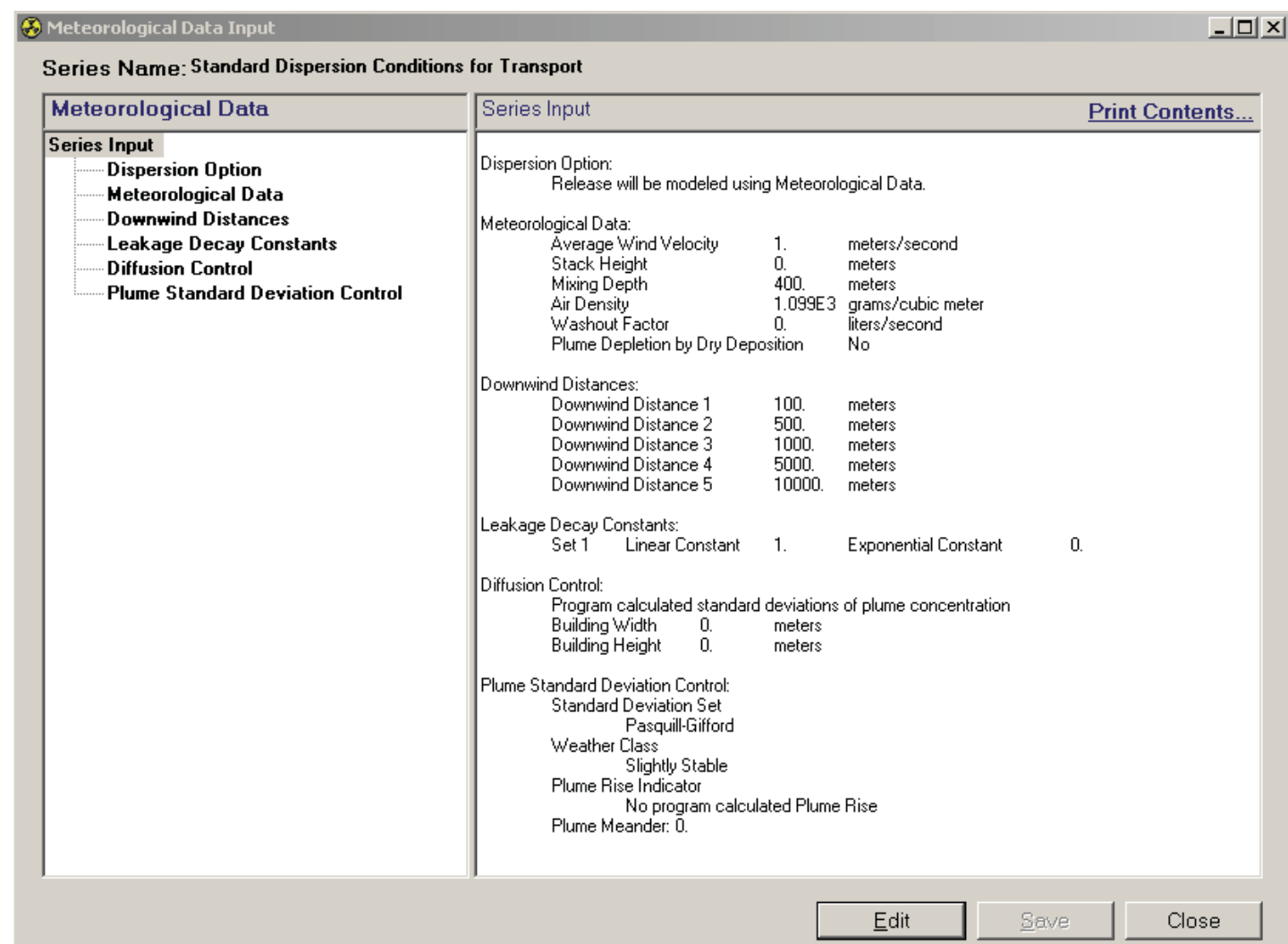

Figure 3-7. Series Main Window. 
The navigation pane (see Figure 3-8) on the left side of the series main window gives a brief outline of what data have been entered into the Series.

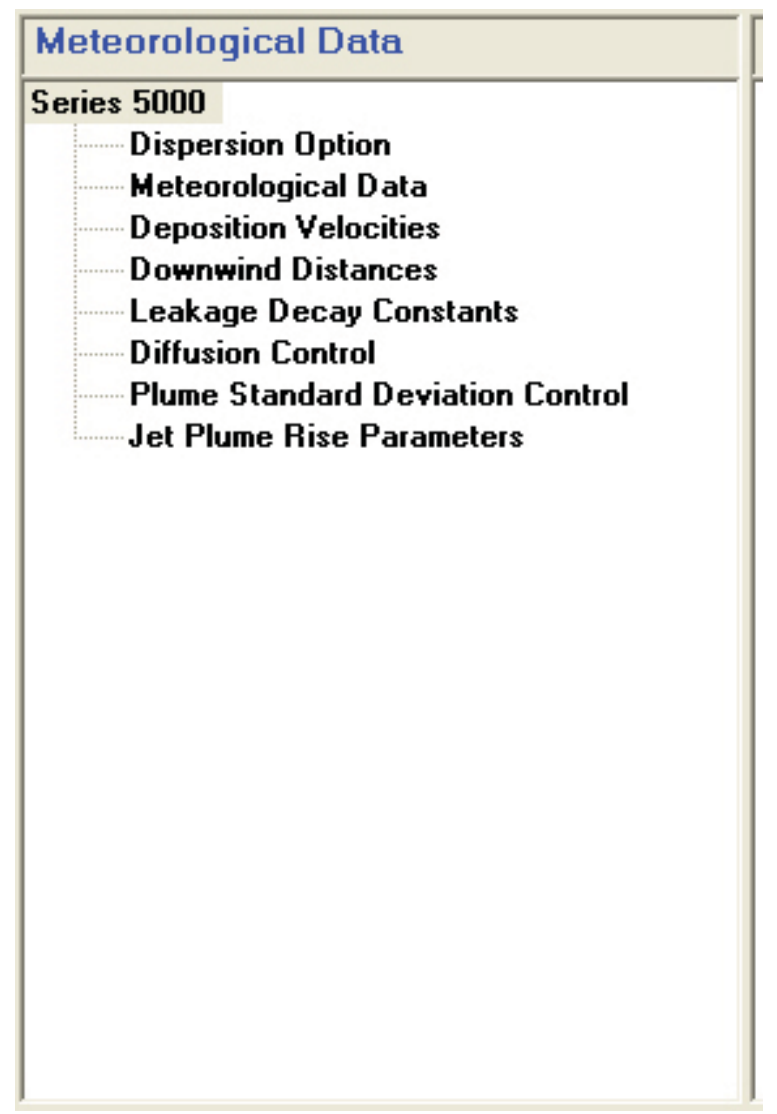

Figure 3-8. Navigation Pane. 
The contents pane (see Figure 3-9) will display the data for the selected item in the navigation pane. Thus, when a subitem is selected in the navigation pane the corresponding data for that item are displayed in the contents pane. This provides quick access to the specific data that are in question. The Print

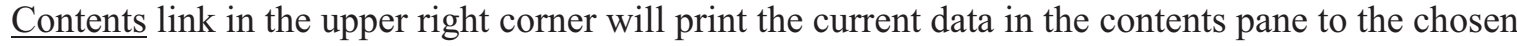
printer.

\begin{tabular}{|c|c|c|c|c|c|}
\hline \multicolumn{3}{|l|}{ Series 5000} & \multicolumn{3}{|c|}{ Print Contents... } \\
\hline \multicolumn{6}{|c|}{$\begin{array}{l}\text { Dispersion 0ption: } \\
\quad \text { Rielease will be modeled using Meteorological Data. }\end{array}$} \\
\hline $\begin{array}{l}\text { Meterological Data: } \\
\text { Average Wind Vel } \\
\text { Stack Height } \\
\text { Mixing Depth } \\
\text { Air Density } \\
\text { Washout Factor } \\
\text { Plume Depletion b }\end{array}$ & locity & $\begin{array}{l}2 \\
76 \\
380 \\
1.099 \mathrm{E} 3 \\
0 \\
\text { sition }\end{array}$ & $\begin{array}{l}\text { meters/second } \\
\text { meters } \\
\text { meters } \\
\text { grams/cubic meter } \\
\text { liters/second } \\
\text { Yes }\end{array}$ & & \\
\hline $\begin{array}{c}\text { Deposition Velocities: } \\
\text { Solids } \\
\text { Halogens } \\
\text { Noble Gases } \\
\text { Cesium } \\
\text { Ruthenium }\end{array}$ & $\begin{array}{l}0.001 \\
0.01 \\
0 \\
0.001 \\
0.001\end{array}$ & $\begin{array}{l}\text { meters/se } \\
\text { meters } / \text { se } \\
\text { meters } / \text { se } \\
\text { meters/se } \\
\text { meters/se }\end{array}$ & $\begin{array}{l}\text { econd } \\
\text { econd } \\
\text { econd } \\
\text { econd }\end{array}$ & & \\
\hline $\begin{array}{l}\text { Downwind Distances: } \\
\text { Downwind Distano }\end{array}$ & $=1$ & $3 . \mathrm{E} 3$ & meters & & \\
\hline $\begin{array}{l}\text { Leakage Decay Constants: } \\
\text { Set } 1 \text { Linear } 0\end{array}$ & onstant & 1 & Exponential Constant & 0 & \\
\hline $\begin{array}{l}\text { Diffusion Control: } \\
\text { Program calculate } \\
\text { Building Width } \\
\text { Building Height }\end{array}$ & $\begin{array}{l}\text { d standar } \\
0 \\
0\end{array}$ & $\begin{array}{l}\text { deviations } \\
\text { meters } \\
\text { meters }\end{array}$ & of plume concentration & & \\
\hline
\end{tabular}

Figure 3-9. Contents pane.

\subsubsection{Adding a Series}

To add or append a new series to the file, use the Add Series Menu (see Figure 3-10) on the main window and click the name of the desired series.

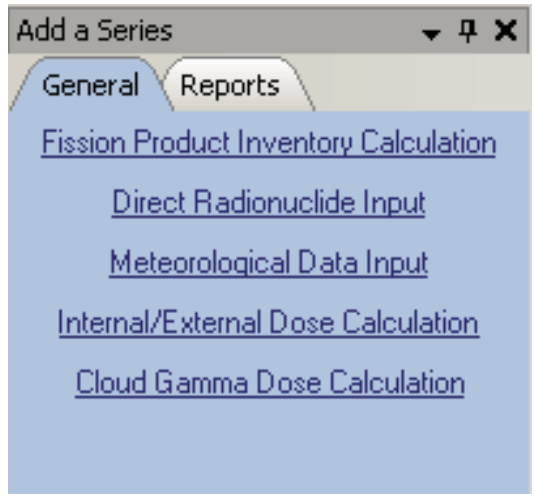

Figure 3-10. Add Series Menu. 
When the series name is clicked, the main series window will appear with the series title window on top of it (see Figure 3-11).

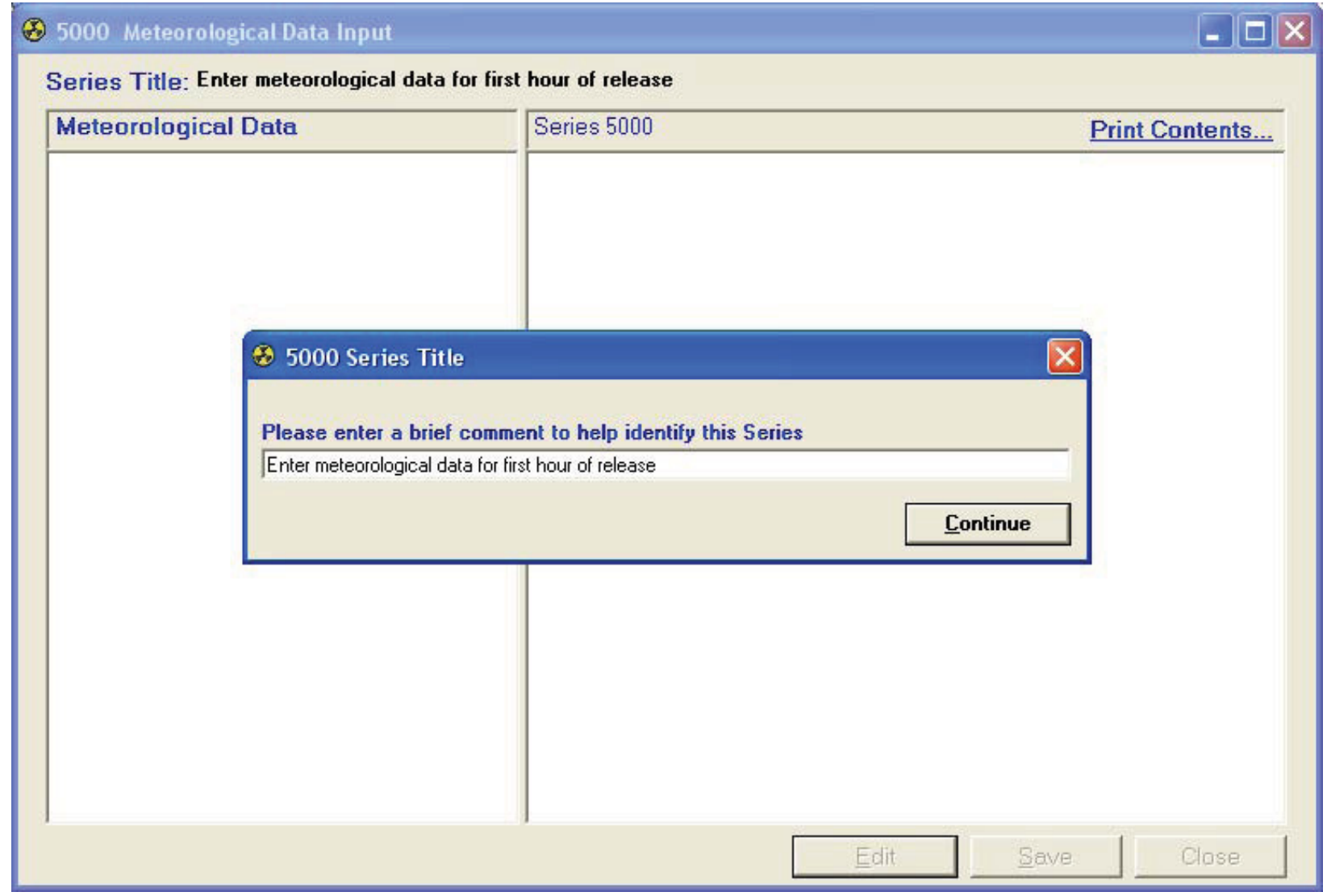

Figure 3-11. Series main window with title input.

The series title is used to identify the series in the file summary on the main window to make future editing sessions easier. Once the series title has been entered, the data entry screens are shown in sequence to allow input of the data for that series. When all the data have been entered for that series, the series main window becomes active again allowing review of the data and the option to save or discard the data.

To cancel data entry for a series, click the $\mathrm{X}$ in the upper right corner of the current data entry screen and click yes in response to the confirmation. The series main window becomes active again allowing the click of the cancel button. 


\subsubsection{Editing a Series}

To edit a series in the open file, use the file summary on the main window and double-click the series to edit. The series main window will appear similar to Figure 3-12.

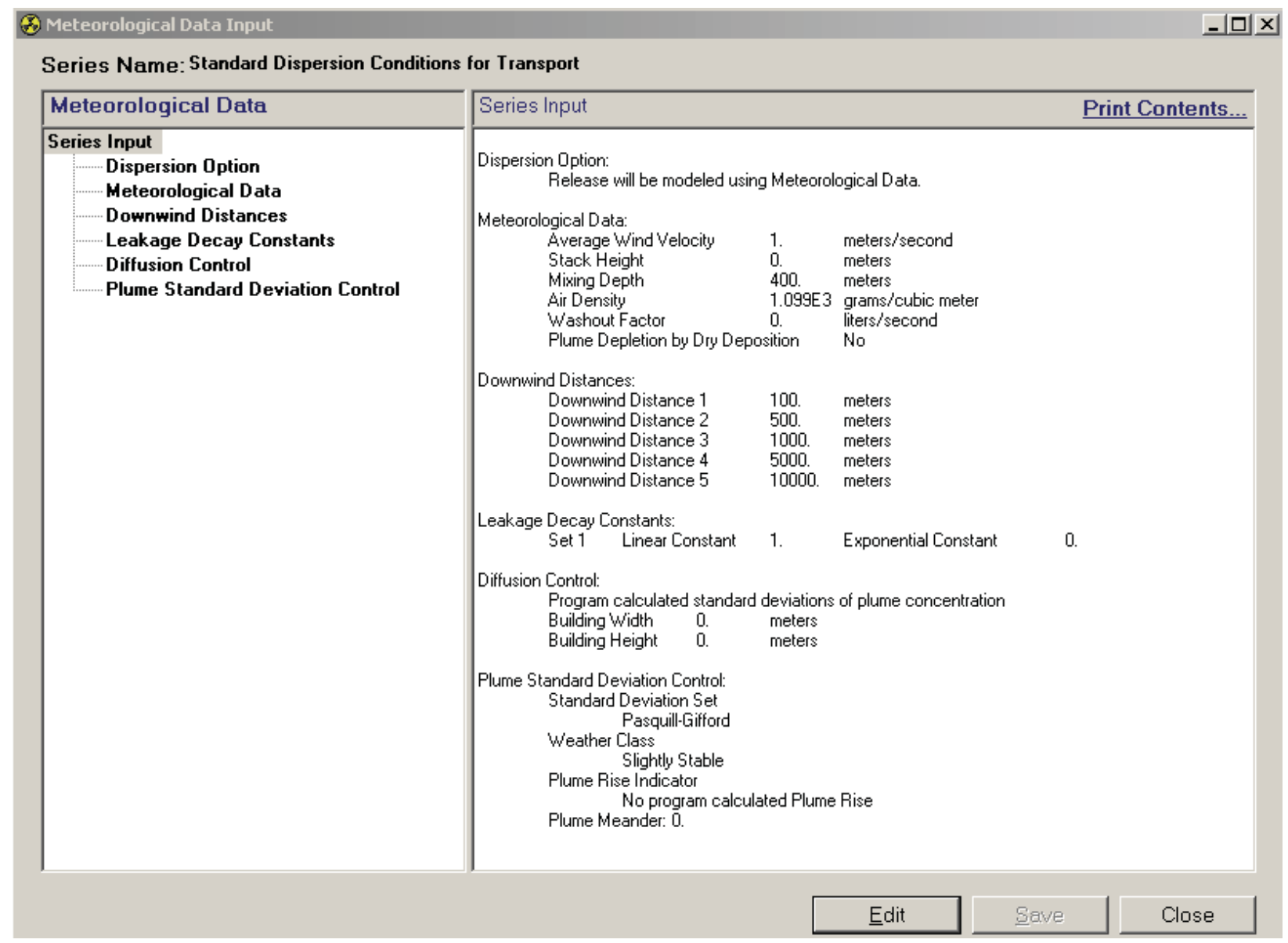

Figure 3-12. Series main window in edit mode.

The series main window shows the data that were entered in for the series. To edit the data, click the edit button and each data entry screen is shown in sequence for editing. Once through the whole series, the data can be reviewed and saved or discarded. If the data are discarded the original data will remain in the file.

To cancel the edit of a series, click the $\mathrm{X}$ in the upper right corner of the current data entry screen and click yes in response to the confirmation. The original data is then reloaded into the series main window. 


\subsubsection{Run Results}

The run results window (see Figure 3-13) gives an explorer-like view of the run output from RSAC allowing the user to explore the results of several files at a time.

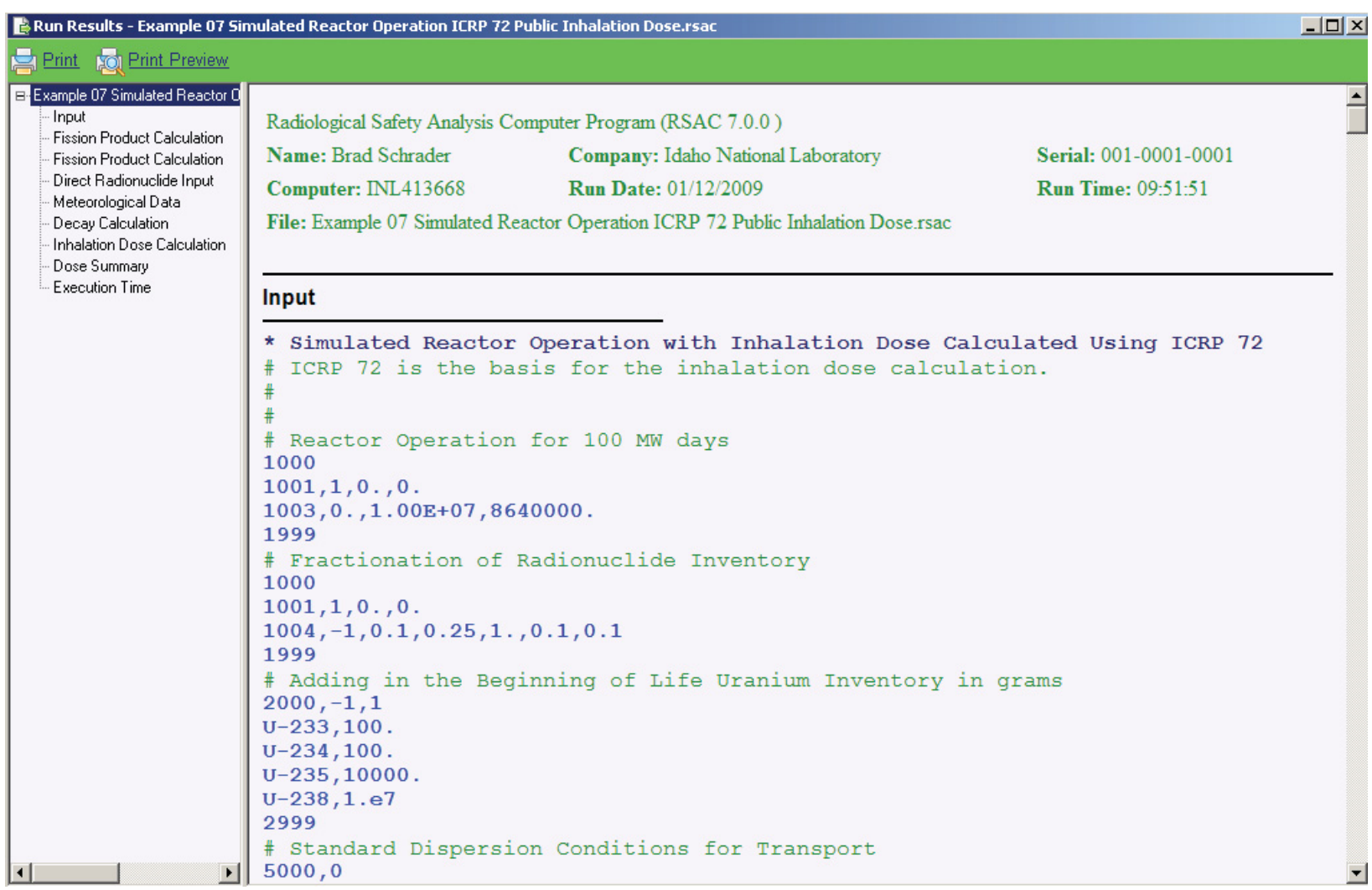

Figure 3-13. Run results window.

Each file that was run with RSAC appears as the top level item in the left navigation pane. The file is broken down into sections that are identified in the output, which will be the subitems under the file. The item that is currently selected in the navigation pane is displayed in the right pane.

- To view the contents of the whole file click the top level item that has the same name as the file. The whole contents of the file will then be displayed in the right pane. To view just one section of the file, click on the sections item in the navigation pane that is listed under the file. 


\subsection{Series Data Entry}

The following section steps through the data entry options are available in each series to build an input file for RSAC. If at any time a comment button is active during series input, a comment screen is available for use (see Figure 3-14). Information can be cut and paste into the comment screen from any windows based program or it can be directly typed into the form.

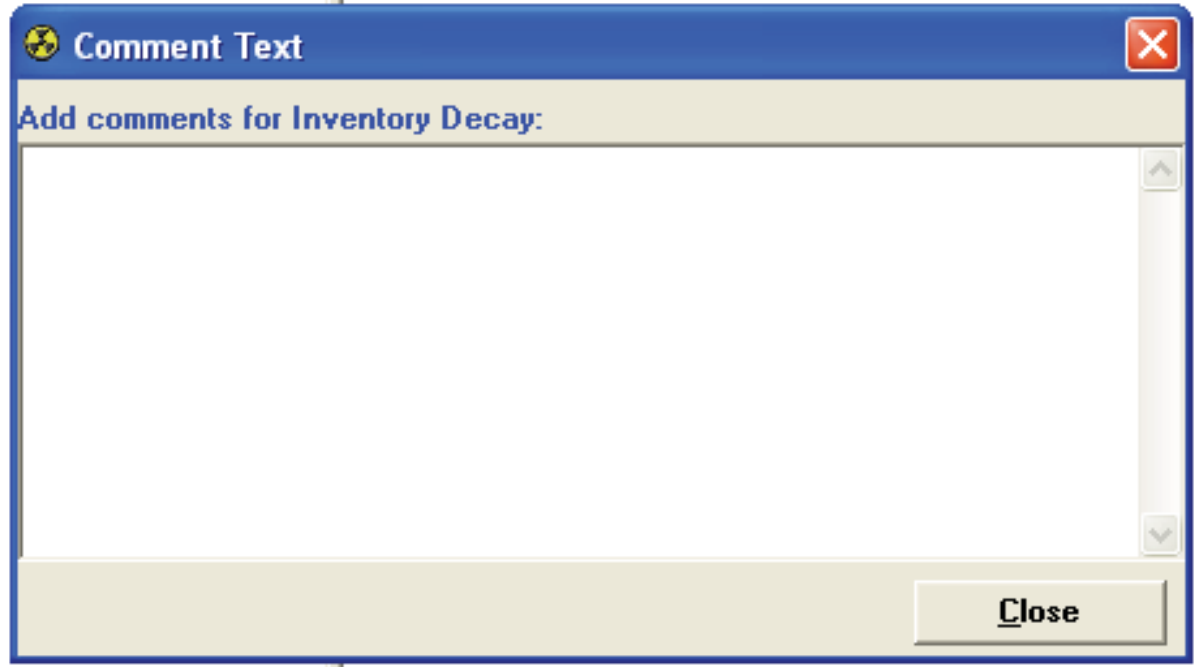

Figure 3-14. Comment entry screen.

\subsubsection{Series - Fission Product Inventory Calculation}

Screen 1 - Input Type: The first data entry screen for the 1000 series is the Input Type (see Figure 3-15). Select the type of input to be generated. Only one type can be selected at a time. The option chosen determines the sequence of screens that follow screen 1.

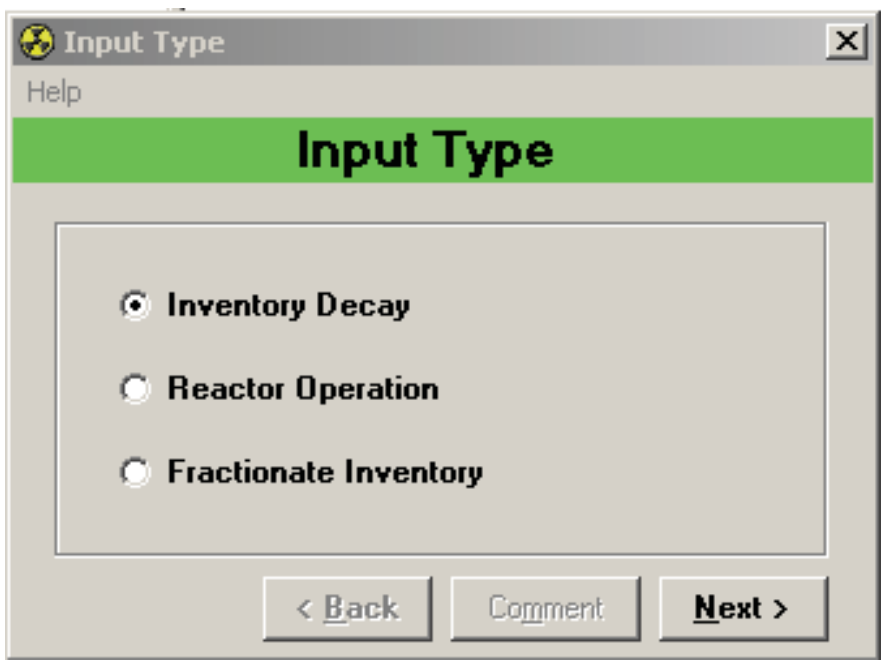

Figure 3-15. Screen 1, Input type screen.

Screen 2A (Optional) - Inventory Decay: This screen appears only if Inventory Decay is chosen on screen 1. Indicate the inventory decay time (see Figure 3-16). An inventory must have been input 
previously for this to function properly. A pull down menu is available to allow for a variety of input options.

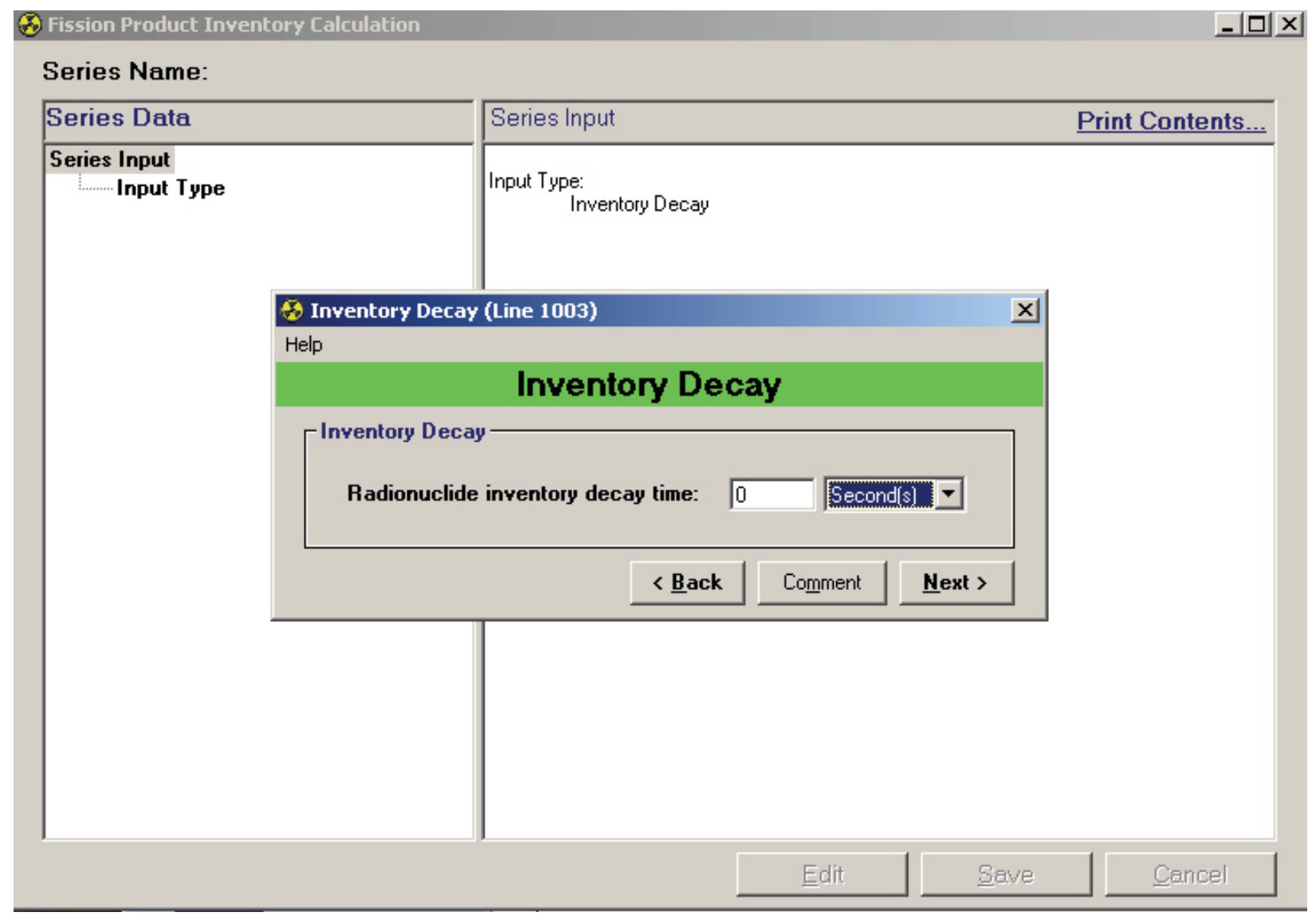

Figure 3-16. Screen 2A (Optional), Inventory Decay. 
Next, notification of input completion for the 1000 series is given (see Figure 3-17). Click the OK button to end data entry for the series and review the data input.

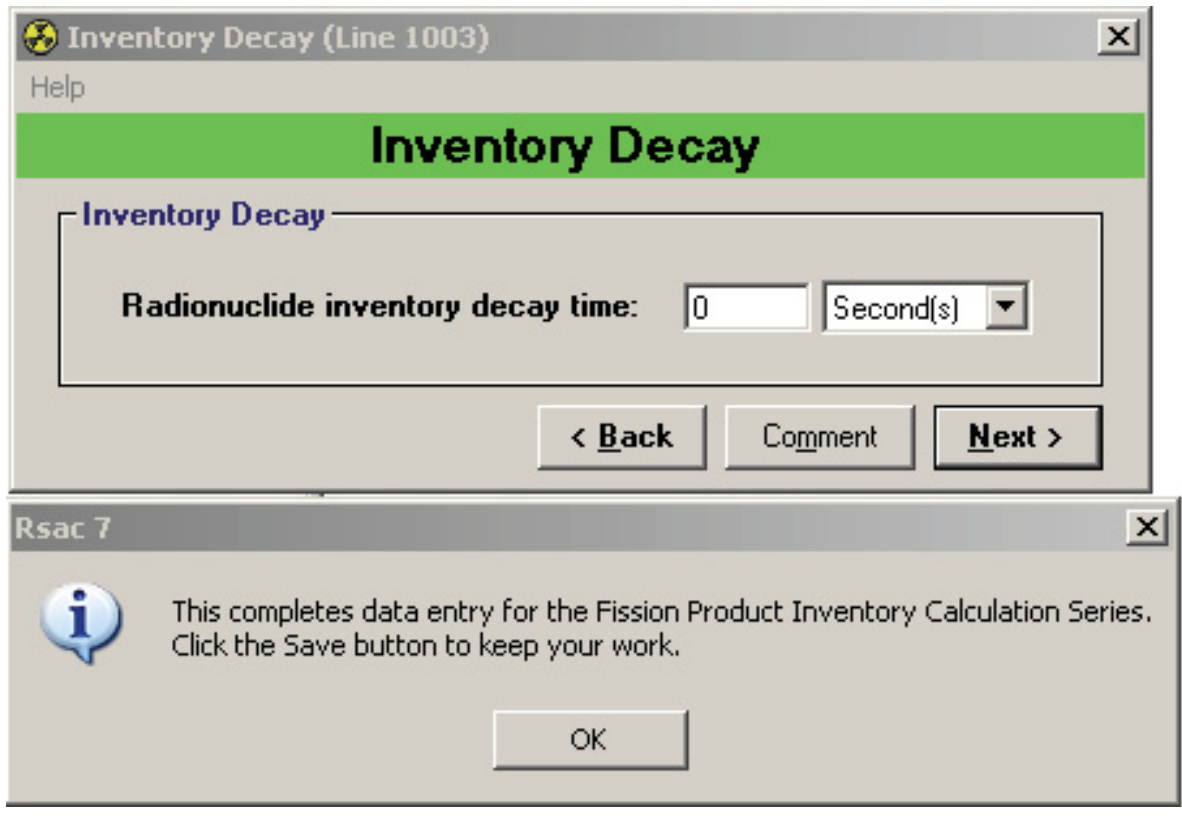

Figure 3-17. Input Completion Notification screen.

Screen 2B (Optional) - Reactor Operation: Shown only if Reactor Operation is selected on screen 1, see Figure 3-18.

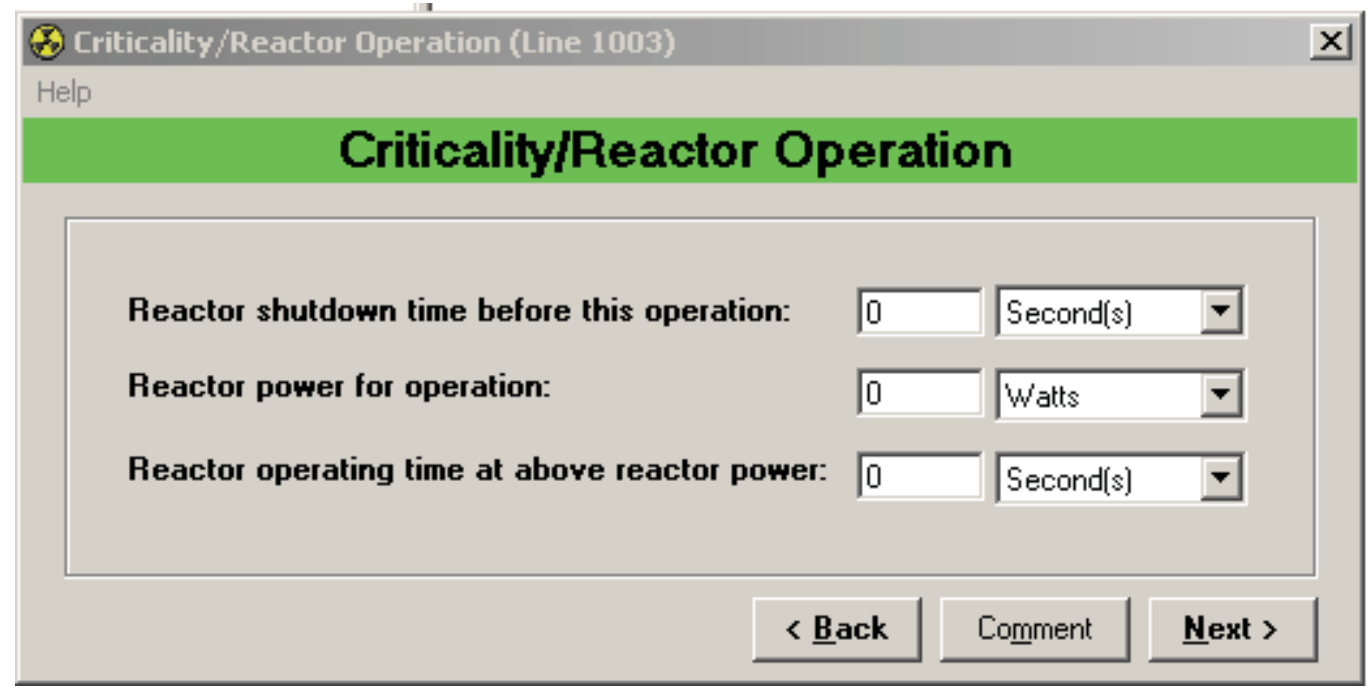

Figure 3-18. Screen 2B (Optional), Reactor Operation. 
Screen 3A - Release During Reactor Operation: This screen appears after optional screen 2B Reactor Operation (see Figure 3-19). If YES is clicked, the Release During Fission Product screen will appear next.

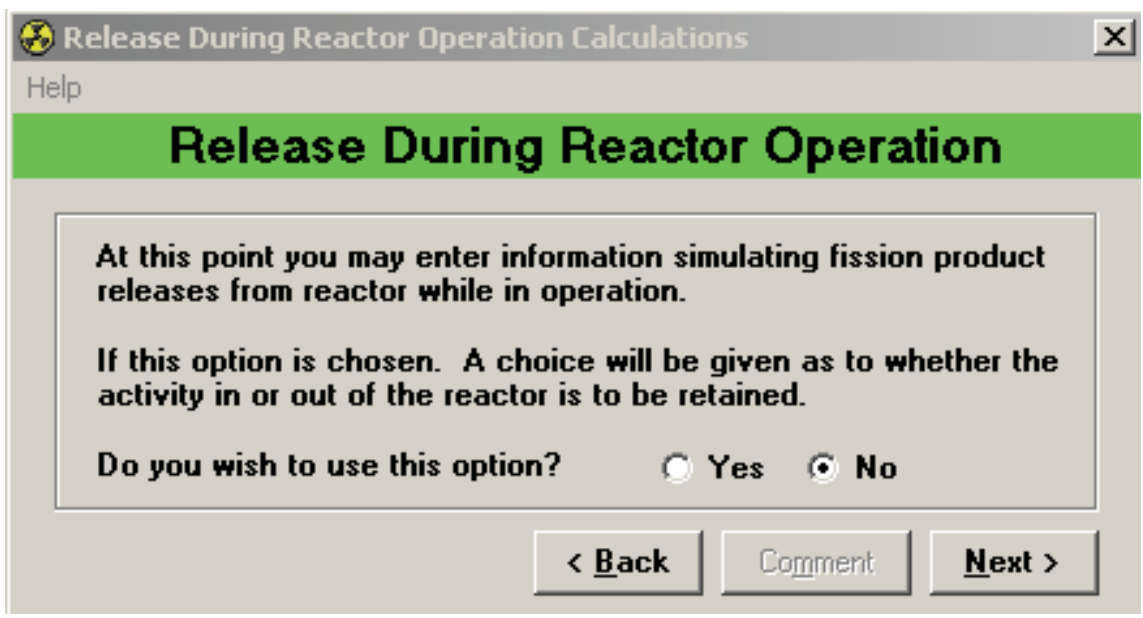

Figure 3-19. Screen 3A, Release During Reactor Operation.

Screen 4A - Release During Fission Product: On this screen (see Figure 3-20), enter the inventory to be retained for subsequent calculations. Specifically, supply the following:

- Number of reactor incremental release steps

- Radionuclide leak rate from the reactor for each of the following: solids, halogens, noble gases, cesium, and ruthenium.

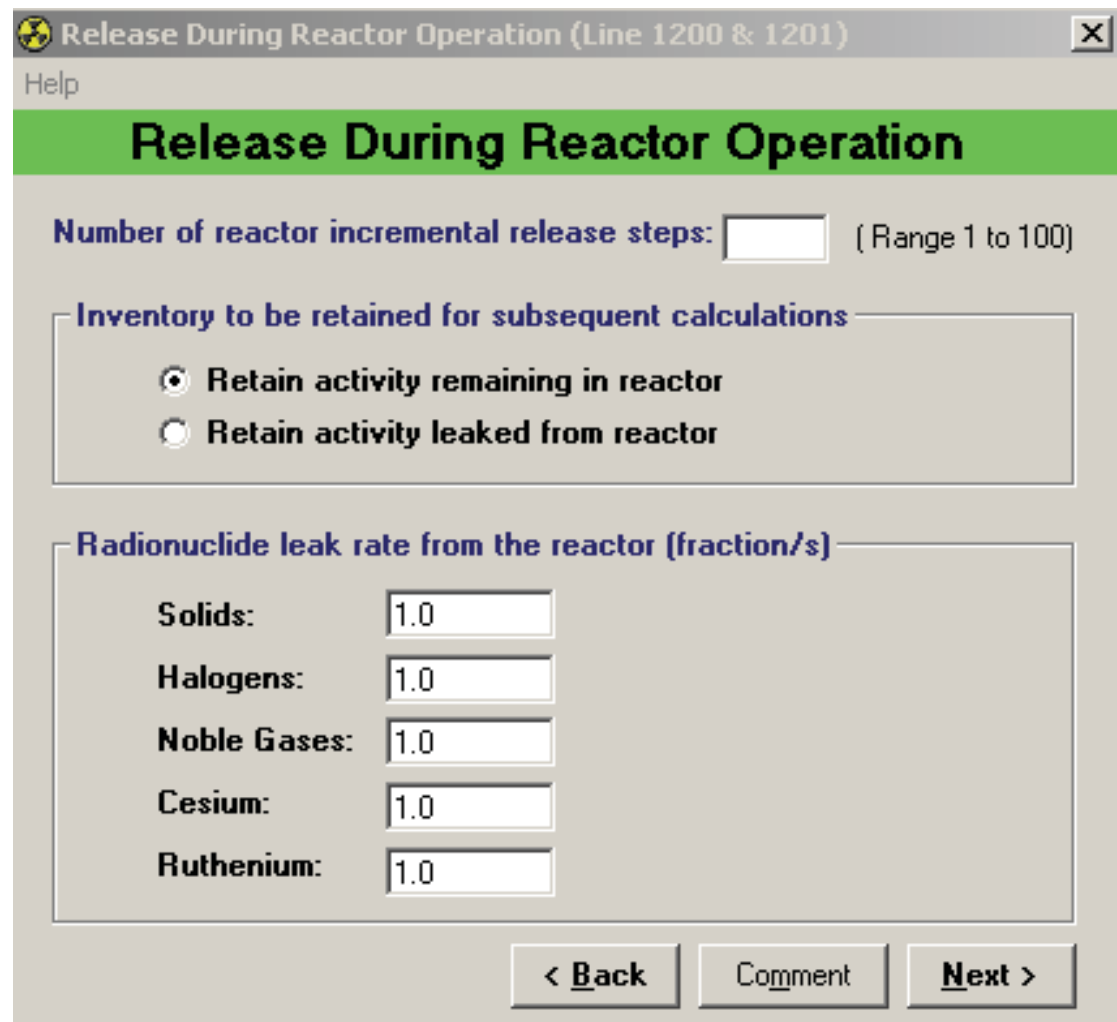

Figure 3-20. Screen 4A, Release During Fission Product. 
Screen 2C (Optional) - Fractionate Inventory: This screen appears only if Fractionate Inventory is selected on screen 1 (see Figure 3-21). Select the option of what type of fractionation should be performed.

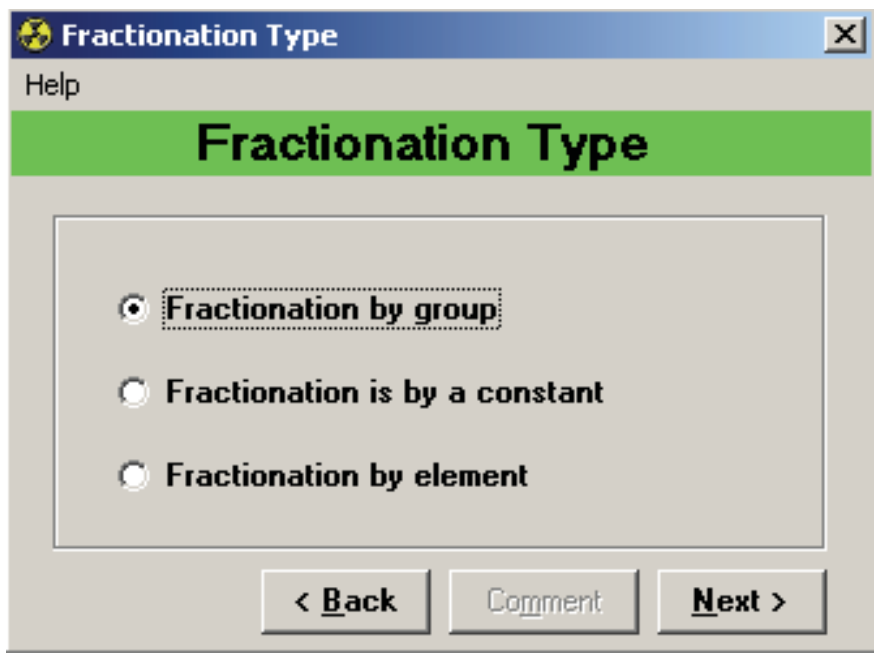

Figure 3-21. Screen 2C (Optional), Fractionate Inventory.

Screen 3B (Optional) - Fractionation by Group: This screen appears only if Fractionation by group is selected on the Fractionate Inventory screen 2C (see Figure 3-22).

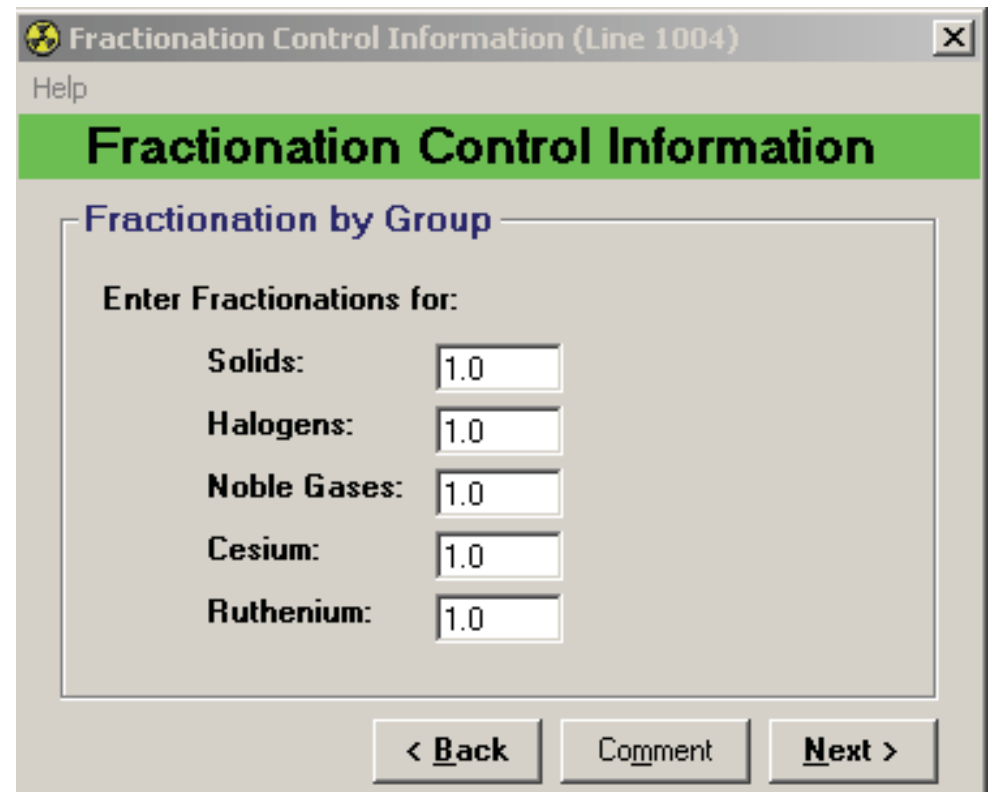

Figure 3-22. Screen 3B (Optional), Fractionation by Group. 
Screen 3C(Optional) - Fractionation by Constant: This screen appears only if Fractionation is by a constant is selected on the Fractionate Inventory screen 2 (see Figure 3-23).

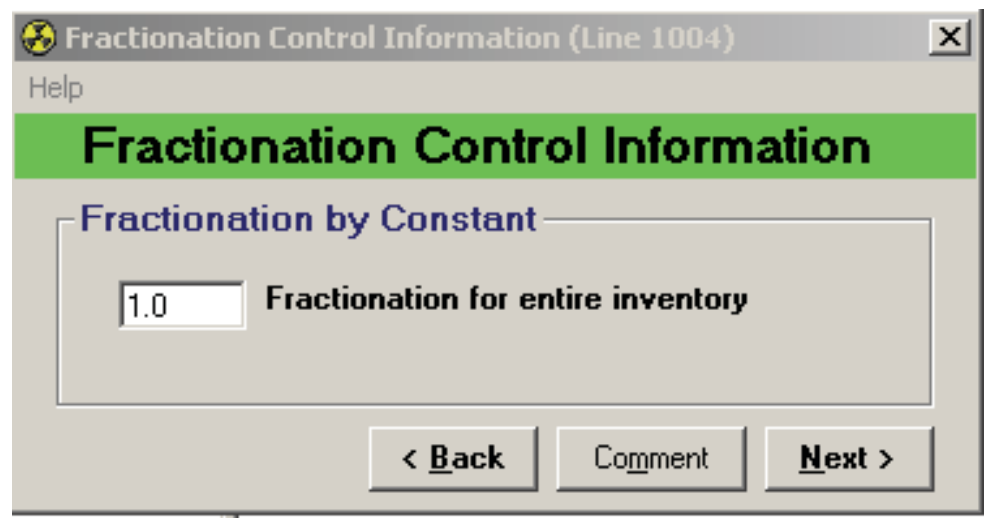

Figure 3-23. Screen 3C (Optional), Fractionation by a Constant.

Screen 3D (Optional) - Fractionation by Element: This screen appears only if Fractionation by element is selected on the Fractionate Inventory screen 2C (see Figure 3-24). Provide the fractionation for elements that are not individual fractionated on the next screen.

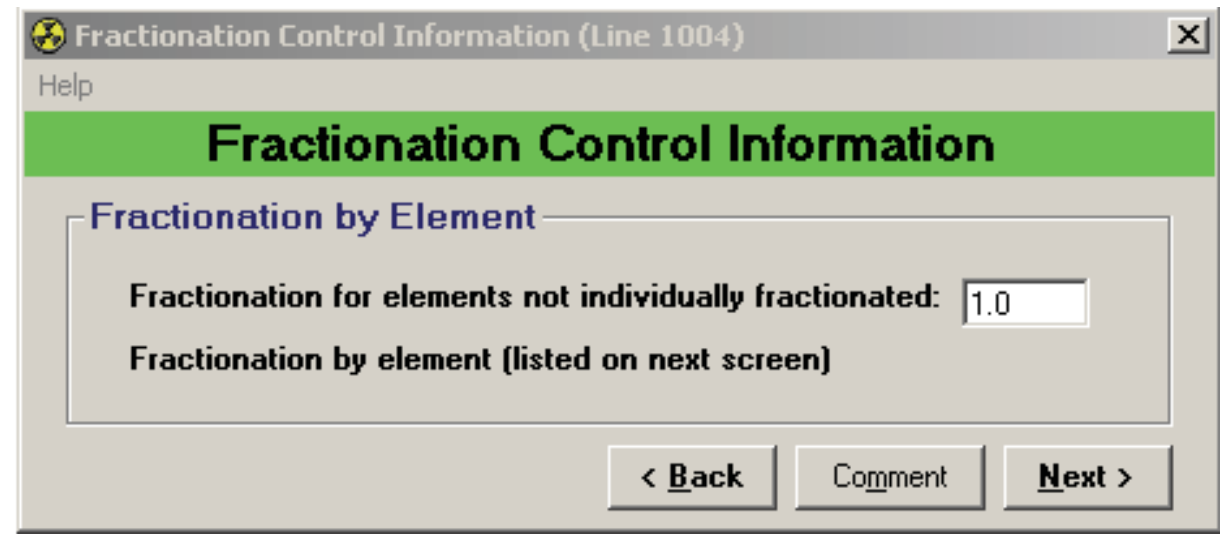

Figure 3-24. Screen 3D (Optional), Fractionation by Element. 
Screen 4B - Element Fractionation Specification: This screen specifies individual element fractionations (see Figure 3-25). To enter a fractionation for an element use one of the following methods. Use the $\langle\uparrow\rangle$ and $\langle\downarrow\rangle$ to select the desired element in the list; scroll through the list and select the desired element; type the symbol to quickly select the desired element. Then click the Enter Fractionation button below the list or double-click the element to supply a value. Once the value has been supplied click the OK button to accept the value or click the Cancel button to discard the supplied value.

NOTE To supply the same fractionation to multiple elements hold the $<$ shift $>$ or $<$ ctrl $>$ keys while selecting element then click the Enter Fractionation button. To discard a fractionation already entered, select the element from the list and click the Clear Selected button.

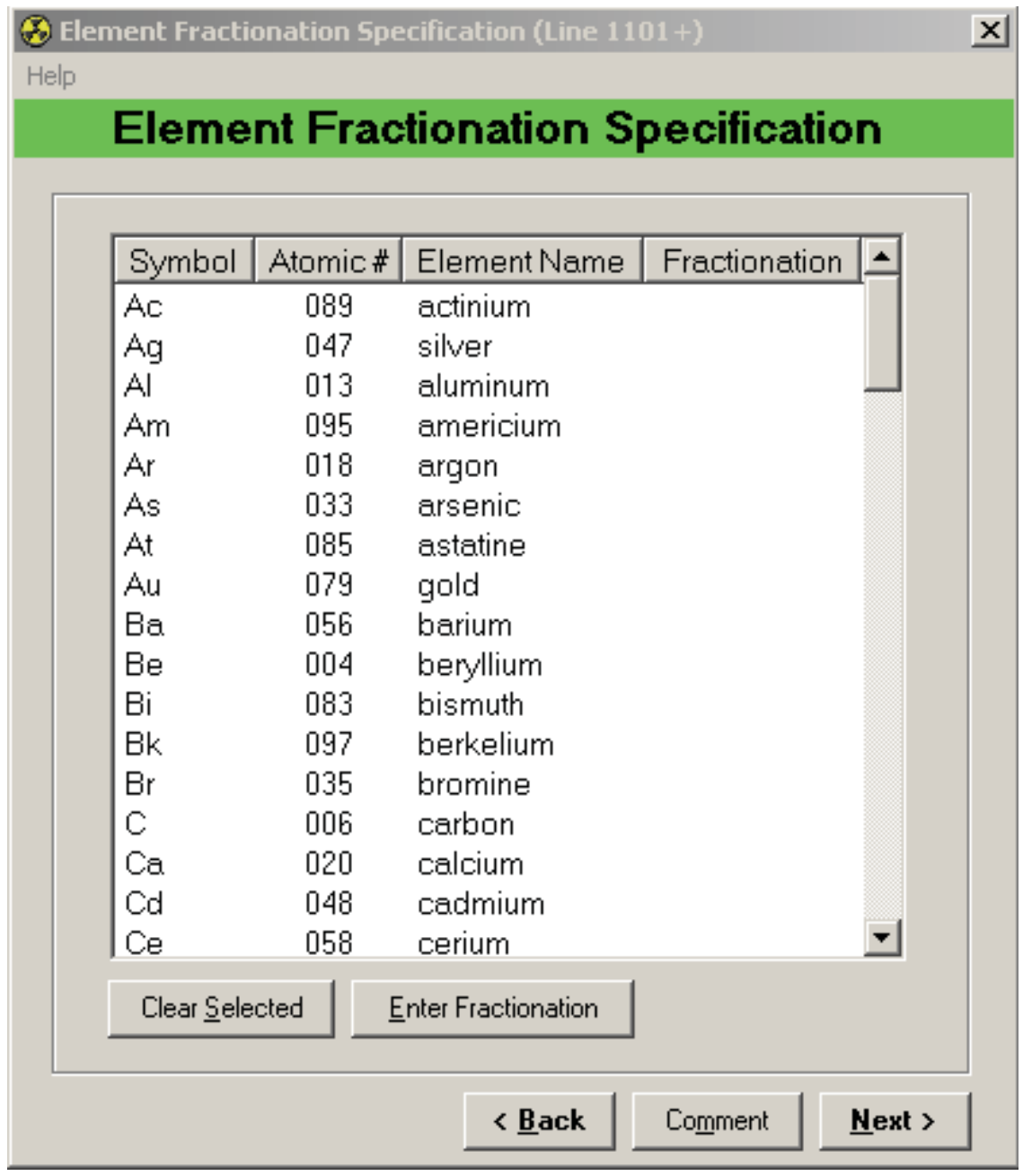

Figure 3-25. Screen 4B, Element Fractionation Specification. 


\subsubsection{Series - Direct Radionuclide Input}

Screen 1 - Series Title: Enter a brief comment about the 2000 Series that is being appended and click on Continue (see Figure 3-26). This comment is used to distinguish between series and can make future editing sessions easier. This comment will also appear in the generated RSAC-7.2 input file.

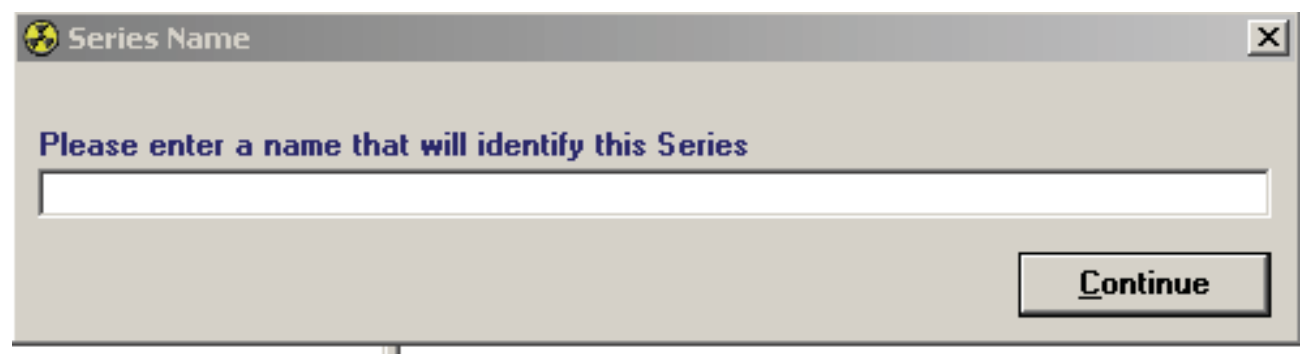

Figure 3-26. Screen 1, Series Title.

Screen 2 - Radionuclide Input Options: Use the mouse to select the appropriate option for your problem (see Figure 3-27).

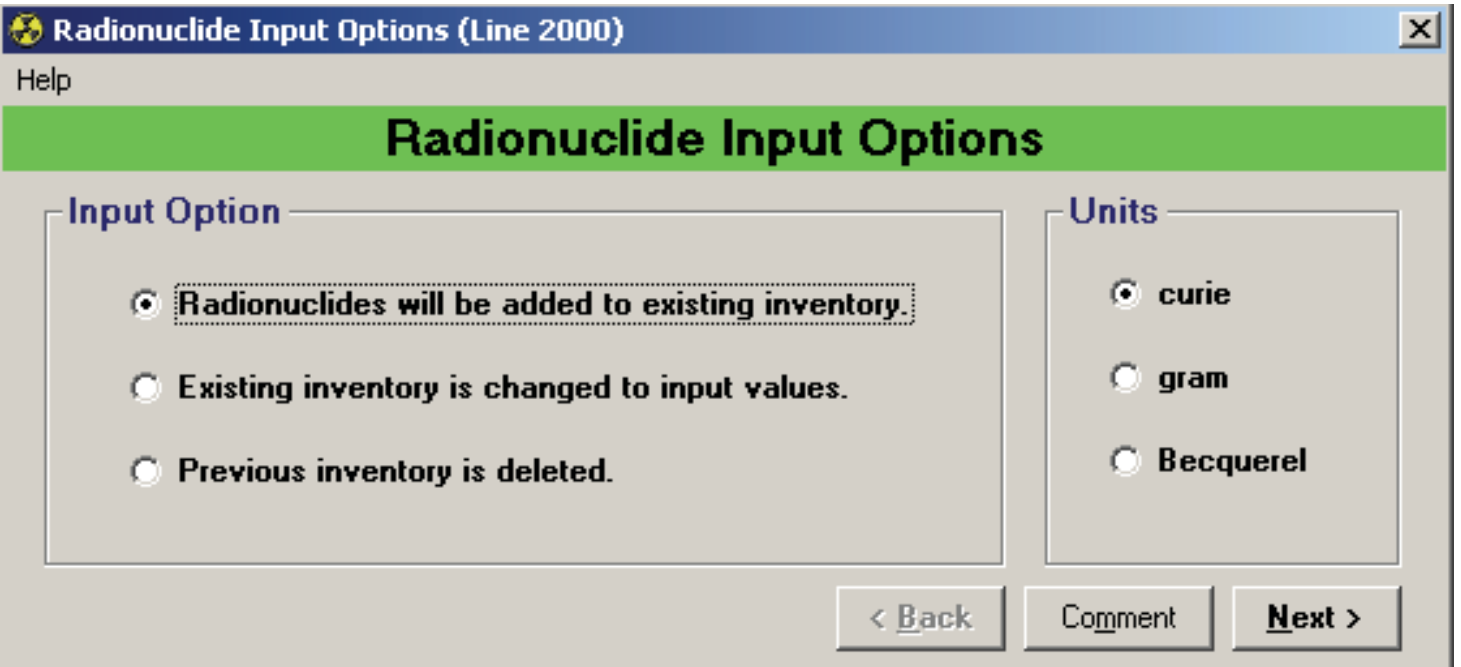

Figure 3-27. Screen 2, Radionuclide Input Options.

- First selection - Retain the previous radionuclide inventory and to add the inventory for the radionuclides selected on the subsequent screens to the previous values.

- Second selection - Retain the previous radionuclide inventory and to change the inventory for the radionuclides selected on the subsequent screens to the new values entered.

- Third selection - Initializes the inventory. You will be entering the radionuclide inventory and any previous radionuclide inventory is deleted. If this option is selected, the warning in Figure 3-28 is displayed. It is very important to understand that if a 1000 series was used to generate a fission product inventory previously, this option will delete the inventory from memory. Use this option with caution.

- A new option in RSAC 7.2 is to allow input in various units. Make sure the appropriate unit of input is selected. 


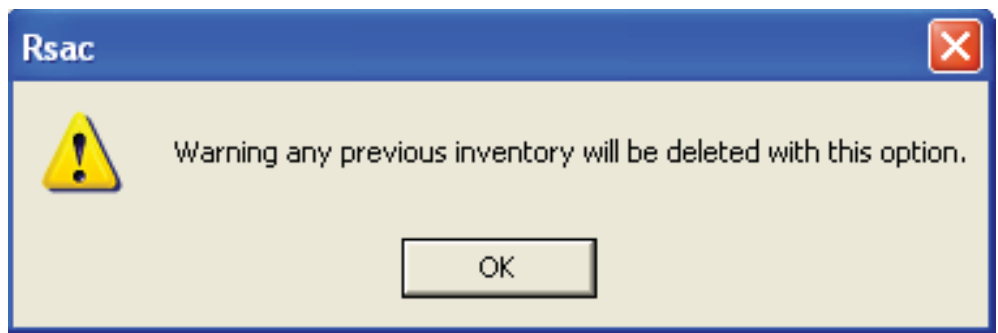

Figure 3-28. Previous Inventory Deleted Warning.

Screen 3 - Direct Radionuclide Input: This screen (see Figure 3-29) determines whether the radionuclides will be selected and values input directly or if an external file will be used as the source for radionuclide input.

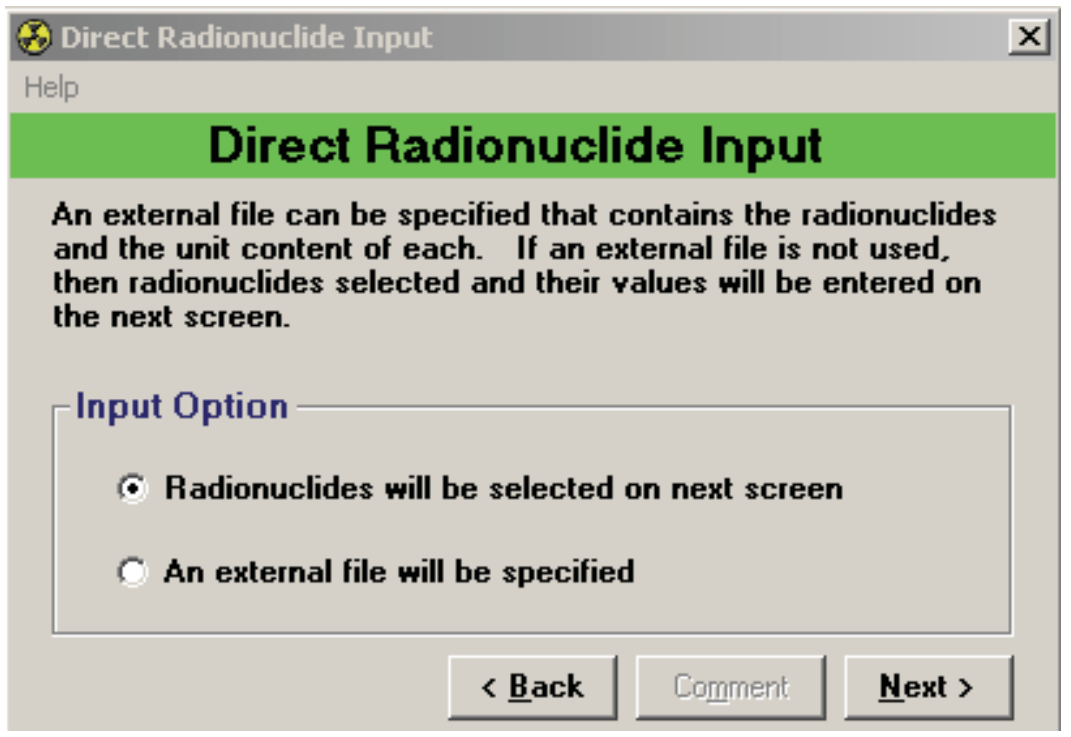

Figure 3-29. Screen 3, Direct Radionuclide Input. 
Screen 4A (Optional) - Radionuclide Curie Input: This screen appears only when Radionuclides will be selected on next screen is chosen on screen 3. On this screen (see Figure 3-30), select the radionuclide and input the activity desired by using one of the following methods. Use the $\langle\uparrow\rangle$ and $\langle\downarrow\rangle$ to select the desired radionuclide in the list; scroll through the list and select the desired radionuclide; type the symbol to quickly select the desired radionuclide. Then click the Enter Curie button below the list or double-click the radionuclide to supply a value. Once the value has been supplied, click the OK button to accept the value or click the Cancel button to discard the supplied value.

NOTE 1: To supply the same curie to multiple radionuclides hold the $<$ shift $>$ or $<$ ctrl $>$ keys while selecting radionuclide then click the Enter Curie button. To discard a Curie already entered, select the radionuclide from the list and click the Clear Selected button.

NOTE 2: If the selection mode changes from curies to grams or Becquerel's, the input screen is basically the same other than the name on the enter key.

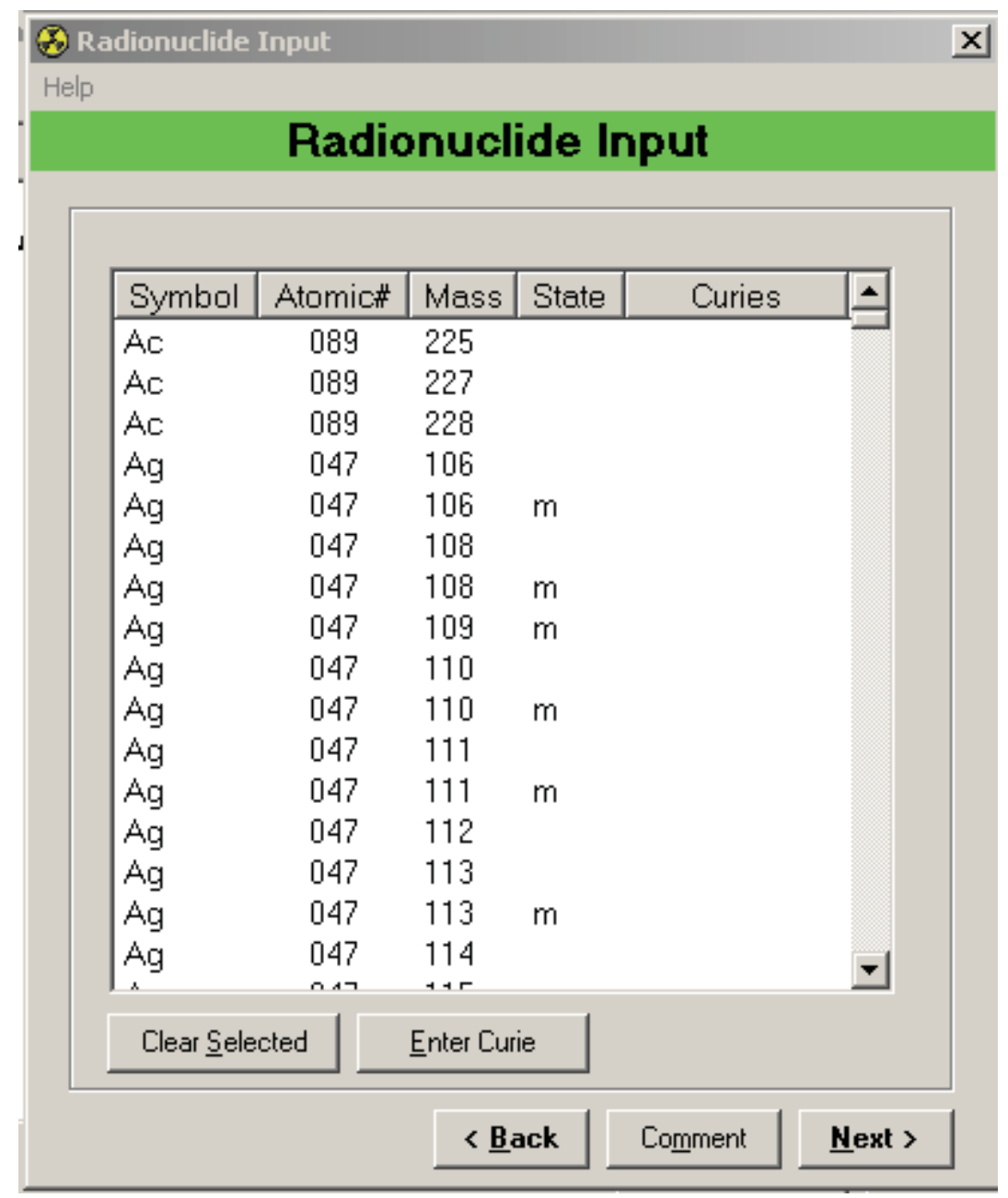

Figure 3-30. Screen 4A (Optional) Radionuclide Curie Input. 
Screen 4B (Optional) - External File for Radionuclide Entry: This screen appears only when $A n$ external file will be specified is chosen on screen 3 (see Figure 3-31). Enter the name of the file that contains the list of radionuclides and curie content. Use the Select File button to locate the file.

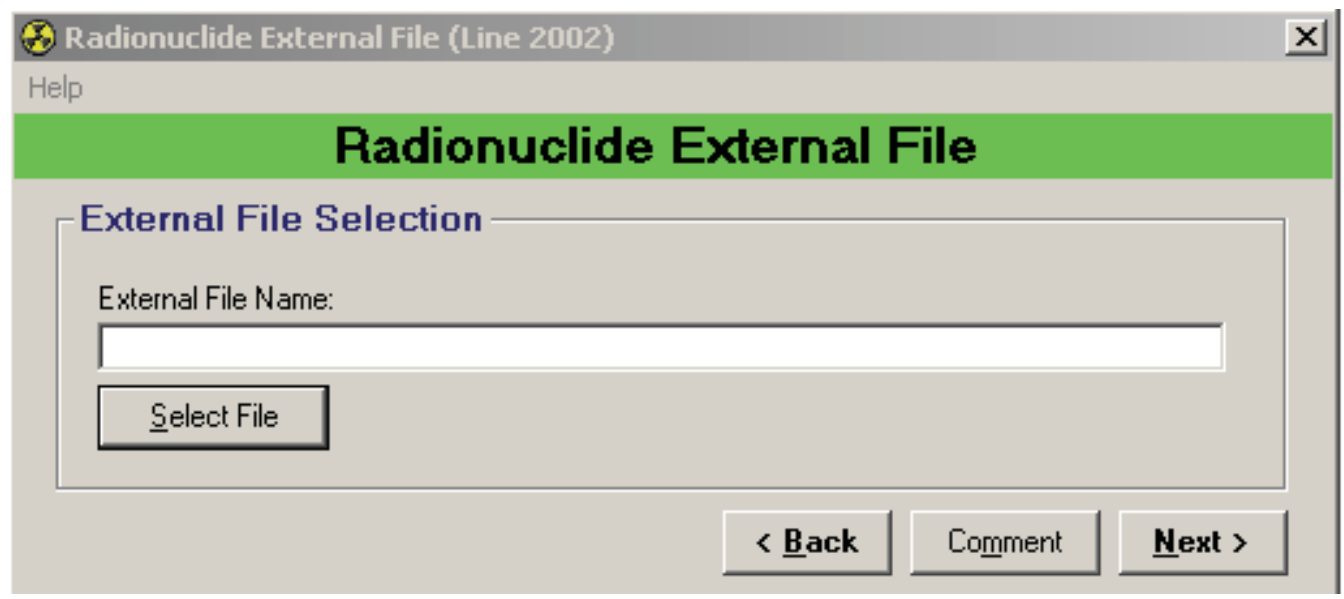

Figure 3-31. Screen 4B (Optional), External File for Radionuclide Entry.

Screen 5 - Series Complete Notification: When finished with the data entry screens, a completed notification appears (see Figure 3-32). Click OK to return to the series main window (see Figure 3-11) to review and save entered data.

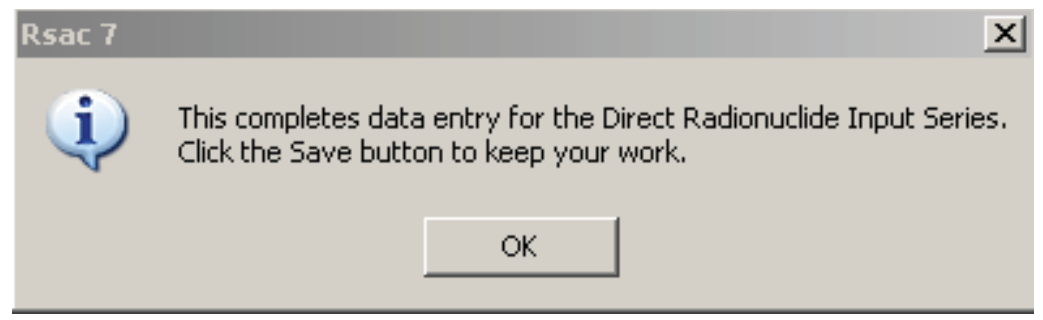

Figure 3-32. Screen 5, Series Complete Notification.

\subsubsection{Series - Dose Summary Option}

The dose summary option cannot be initialized until meteorological data (5000 Series) has been entered. The initiation of the dose summary option is automatically performed. In addition, downwind distances cannot be changed using subsequent 5000 Series input after the dose summary option has been initiated.

The 3000 series is accessed by clicking on the Reports Tab (see Figure 3-33).

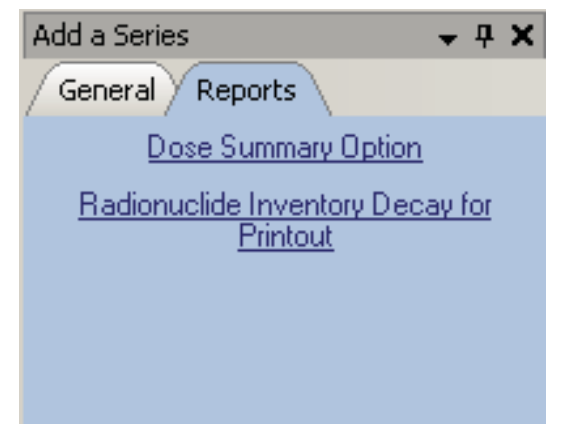

Figure 3-33. Reports Tab screen. 
Screen 2 - Dose Summary Options: After the series title screen is dismissed the following selections are available (see Figure 3-34).

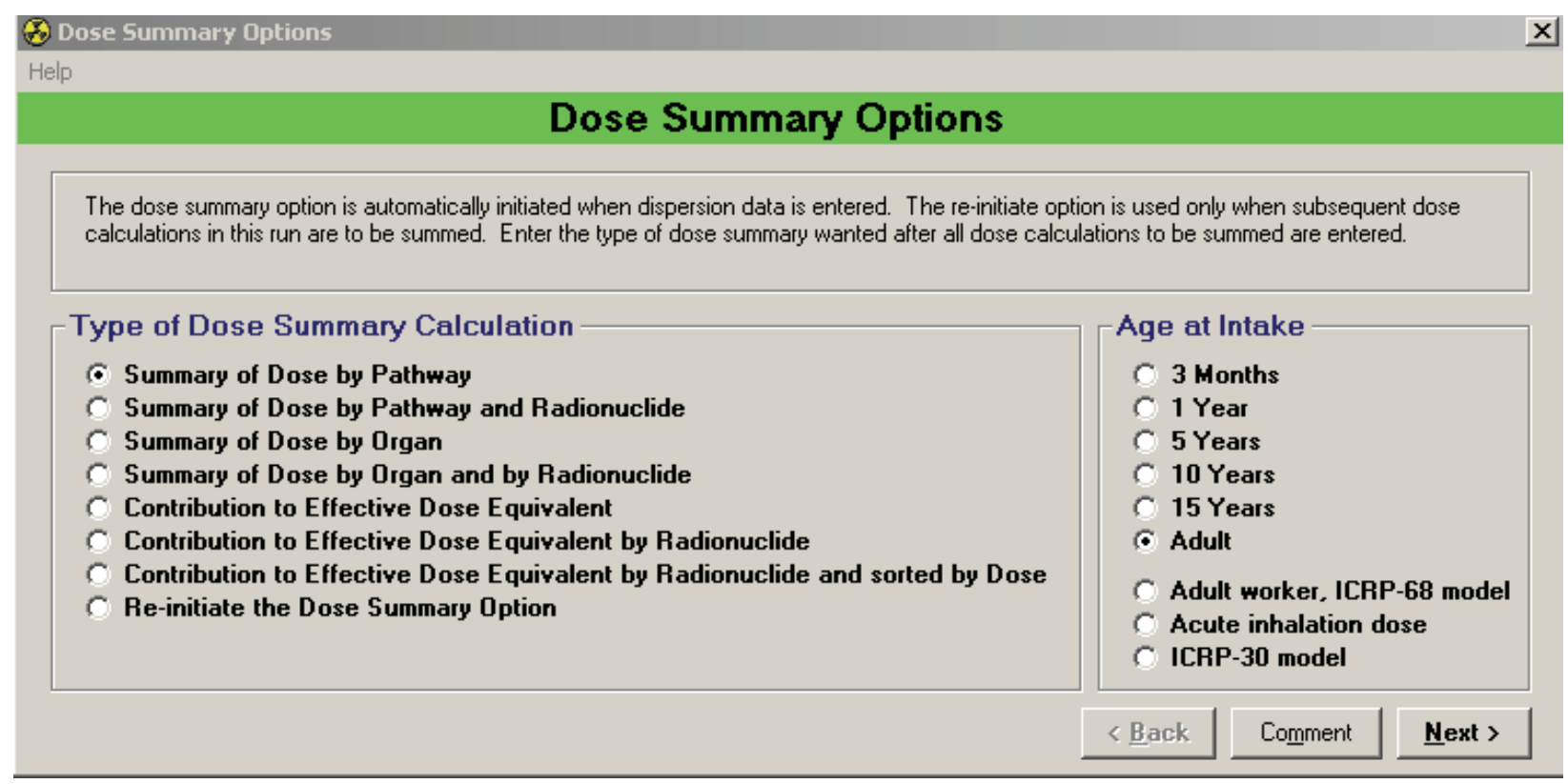

Figure 3-34. Screen 2, Dose Summary Options. 
One or all of the options may be selected and may be selected for a specific age group.

- Summary of Dose by Pathway - Summarizes the CEDE for each pathway and totals the dose.

- $\quad$ Summary of Dose by Pathway and Radionuclide - Summarizes the CEDE for each radionuclide and each pathway. It does not summarize for the plume gamma pathway.

- Summary of Dose by Organ - Requires the selection of organs on optional screen 3 (see Figure 3-35). Click the organ in the list to select it and click again to unselect the organ. An X will appear in the selected column to indicate the organ is selected. If the Clear Selected button is clicked, then all organs are unselected.

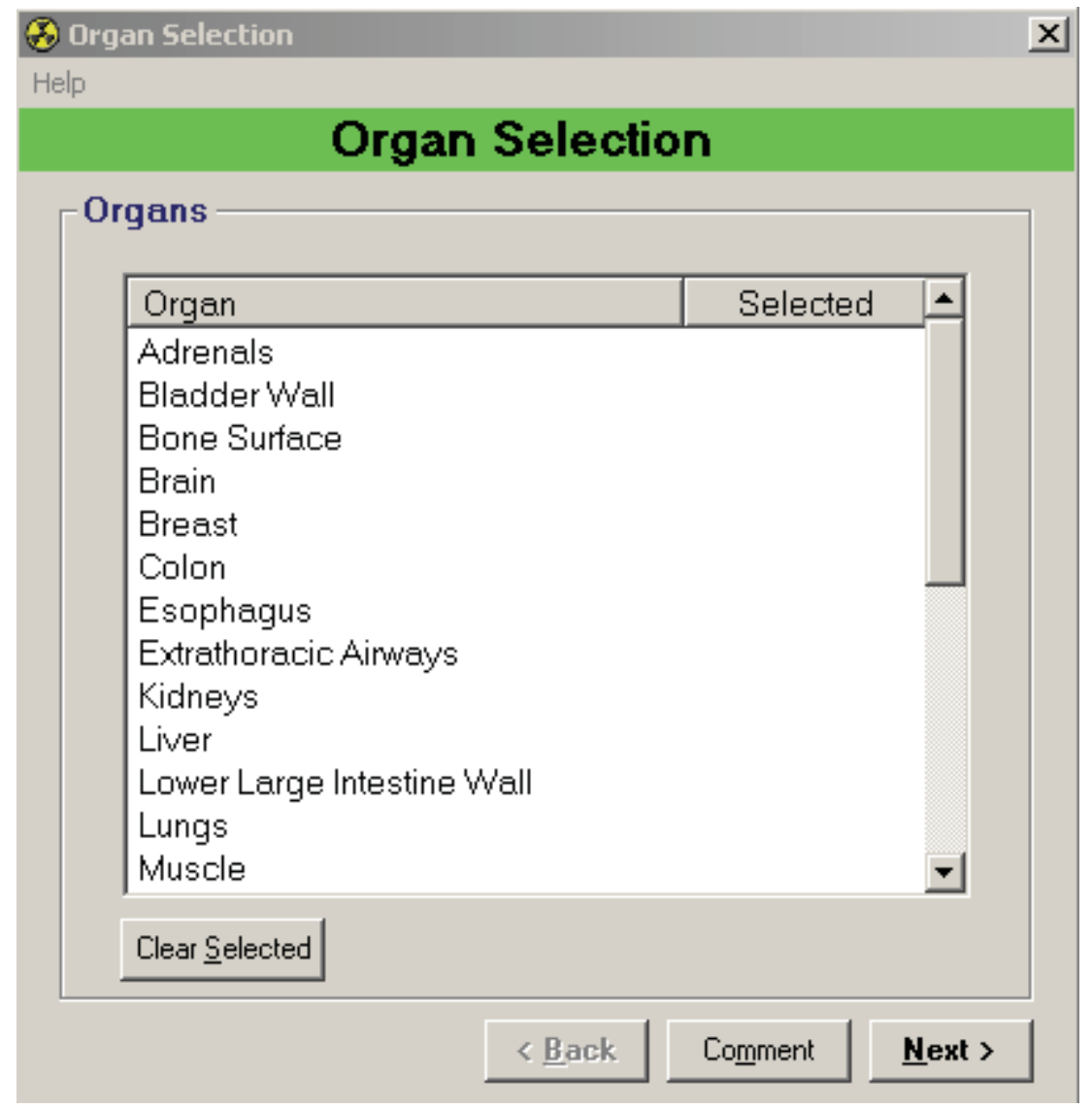

Figure 3-35. Screen 3 (Optional), Organ Selection.

- $\quad$ Summary of Dose by Organ and Radionuclide - Same as the previous option but radionuclides are added to the summary. The organ selection optional screen 3(see Figure 3-35) is shown with a note that it is summarized by organ and radionuclide.

- $\quad$ Summary of Dose from Contribution to Effective Dose Equivalent - This summary function shows in order of distance the pathway to EDE.

- $\quad$ Summary of Dose from Contribution to EDE and Radionuclide - Same as the previous report and sorted alphabetically by radionuclide.

- $\quad$ Summary of Dose from Contribution to EDE and Radionuclide Sorted by Dose - Same as the previous report except the order is from highest dose to lowest by radionuclide. 


\subsubsection{Series - Dispersion Control Input}

Screen 2 - Dispersion Options: After the series title screen the Dispersion options screen is displayed (see Figure 3-36). Select the type of dispersion control desired and click on the next button.

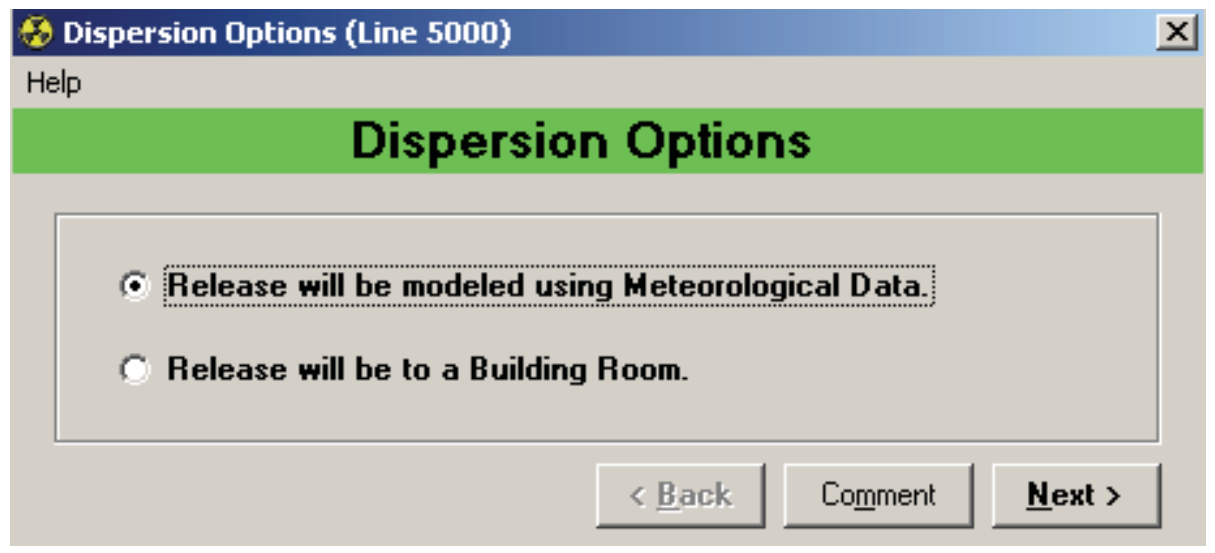

Figure 3-36. Screen 2, Dispersion Options.

- Option 1 - The release will be modeled using meteorological data.

- Option 2 - The release will be to a room. If this option is selected, only the inhalation pathway can be evaluated. 
Screen 3 (Optional) - General Meteorological Information: This screen appears only if option 1 was chosen on screen 2. Enter the Meteorological Conditions and click on next (see Figure 3-37). If questions arise on what the inputs are or how the default values were chosen, move the cursor over the item in question and right-click, then click on Display Help. Select Help and the information will be displayed (see Figure 3-38).

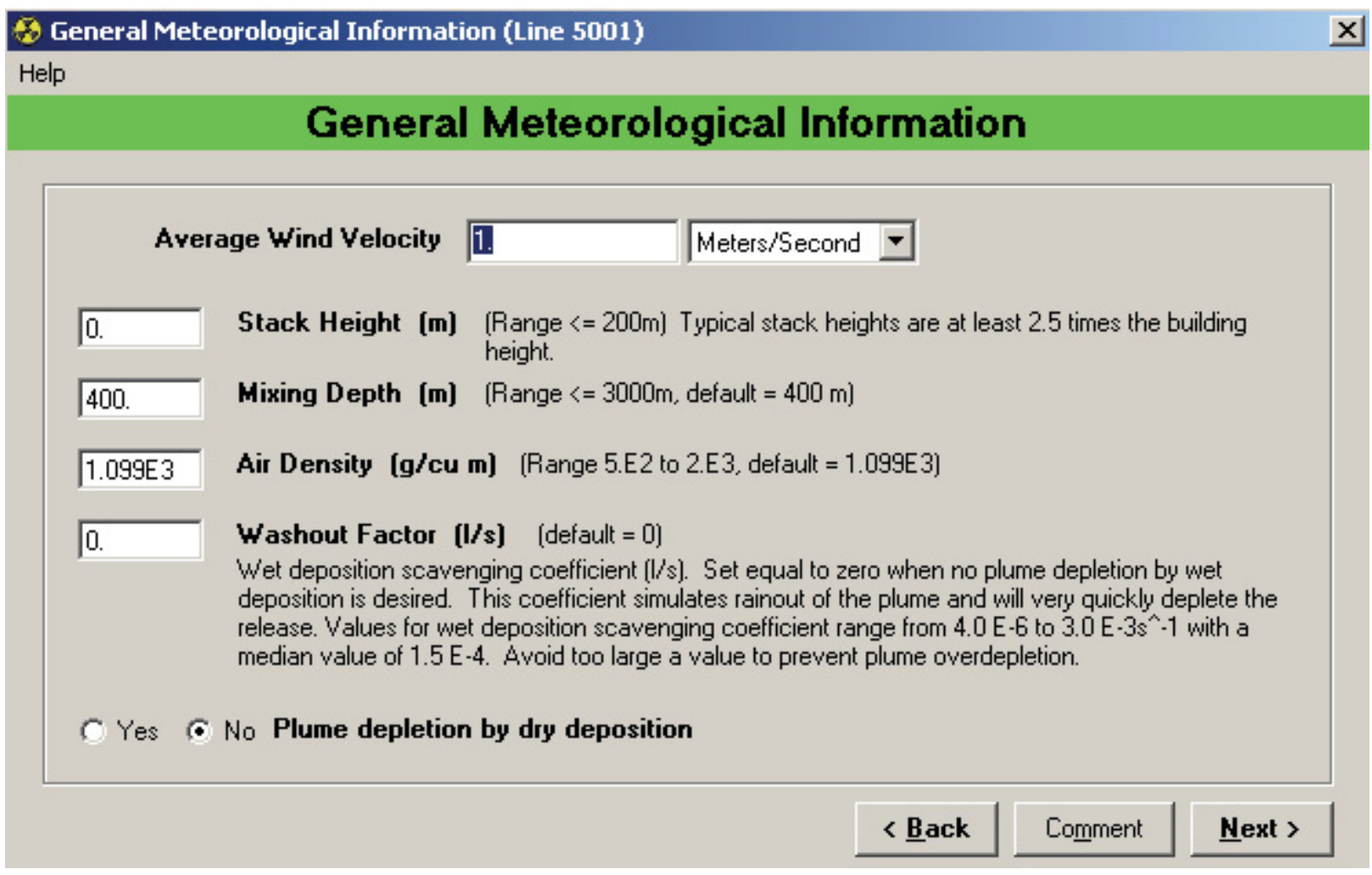

Figure 3-37. Screen 3 (Optional), General Meteorological Information.

\begin{tabular}{l} 
Mixing Depth: \\
The third selection is the mixing depth. This depth acts as an effective \\
ceiling to the release. Mixing depths are difficult to determine. The default \\
value is 400 meters. Other values are identified below. \\
\begin{tabular}{|l|c|c|}
\hline Season & Morning & Afternoon \\
\hline Spring & 480 & 2330 \\
\hline Summer & 260 & 2900 \\
\hline Autumn & 330 & 1550 \\
\hline Winter & 400 & 730 \\
\hline Annual & 370 & 2090 \\
\hline
\end{tabular} \\
\hline
\end{tabular}

Figure 3-38. Help Information. 
Screen 4 (Optional) - Dry Deposition Variables: This screen is only displayed when YES has been selected for Plume depletion by dry deposition on screen 3 (see Figure 3-39). It is important to understand that if plume depletion is not requested, the options for calculation of ingestion and ground surface dose will not be available. If the RSAC-7.2 default variables are chosen, then the Deposition Velocities will be those defined in Figure 3-39. Ensure that the deposition velocities are selected based on facility-specific recommendations.

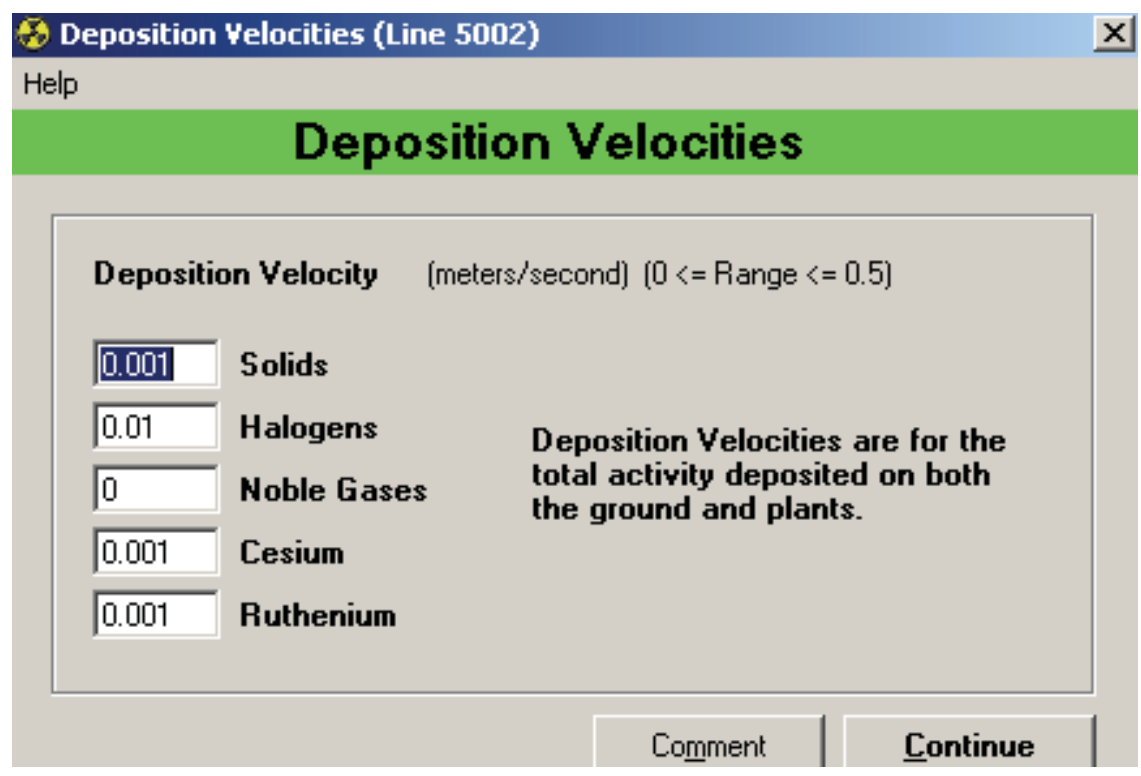

Figure 3-39. Screen 4 (Optional), Dry Deposition Variables. 
Screen 5 - Downwind Distances: Enter one or more unique downwind distances (see Figure 3-40). If a duplicate distance is entered, you will be alerted and the field in error will automatically be highlighted. Be careful when editing downwind distances because the direct input of $\chi / Q$ values and the direct input of standard deviations must correspond to downwind distances.

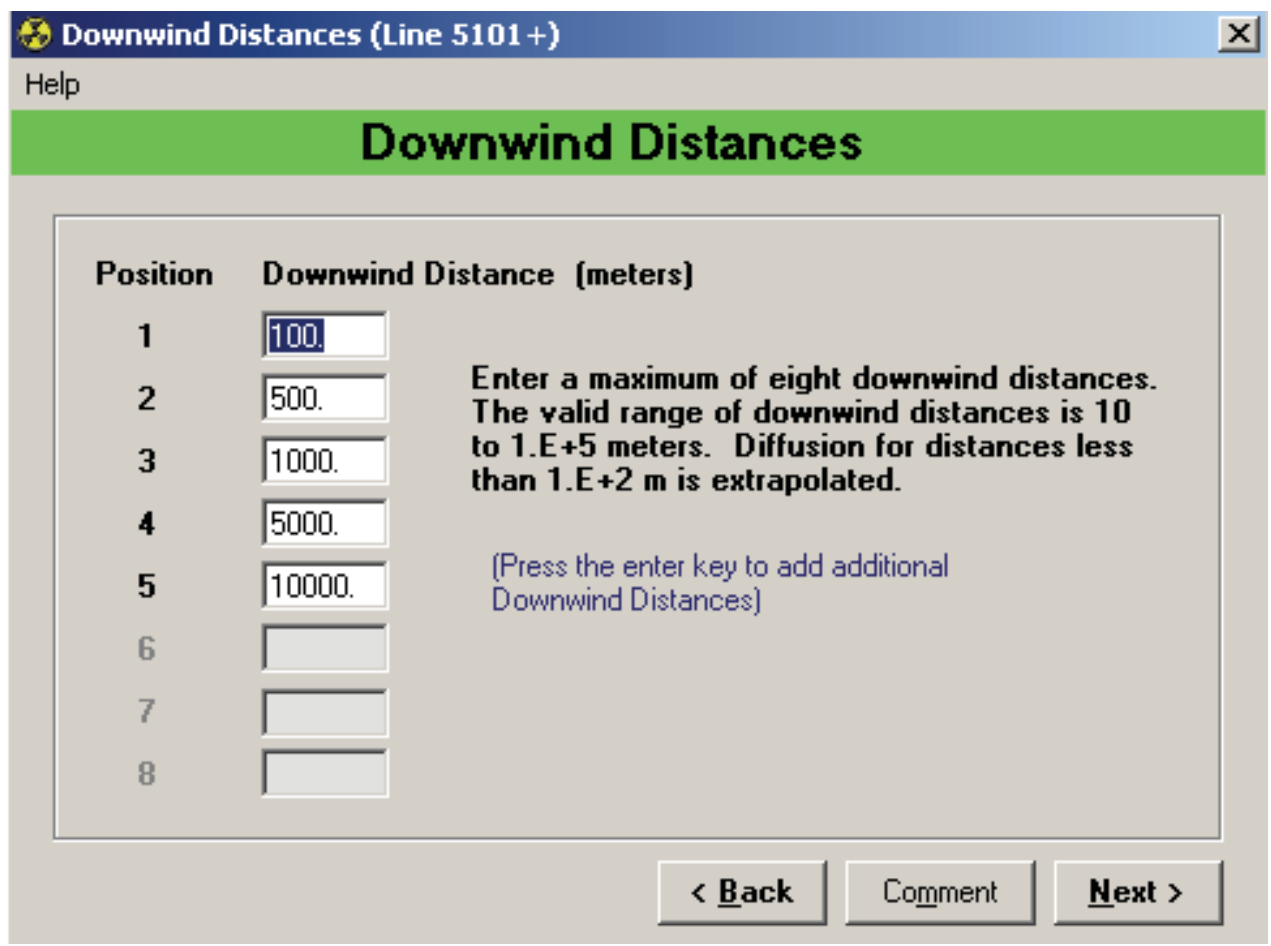

Figure 3-40. Screen 5, Downwind Distances. 
Screen 6 - Leakage Decay Constants: Enter linear or exponential constants (s) (see Figure 3-41). Up to 10 sets of constants can be entered. The leakage decay constants must be entered in sets of two.

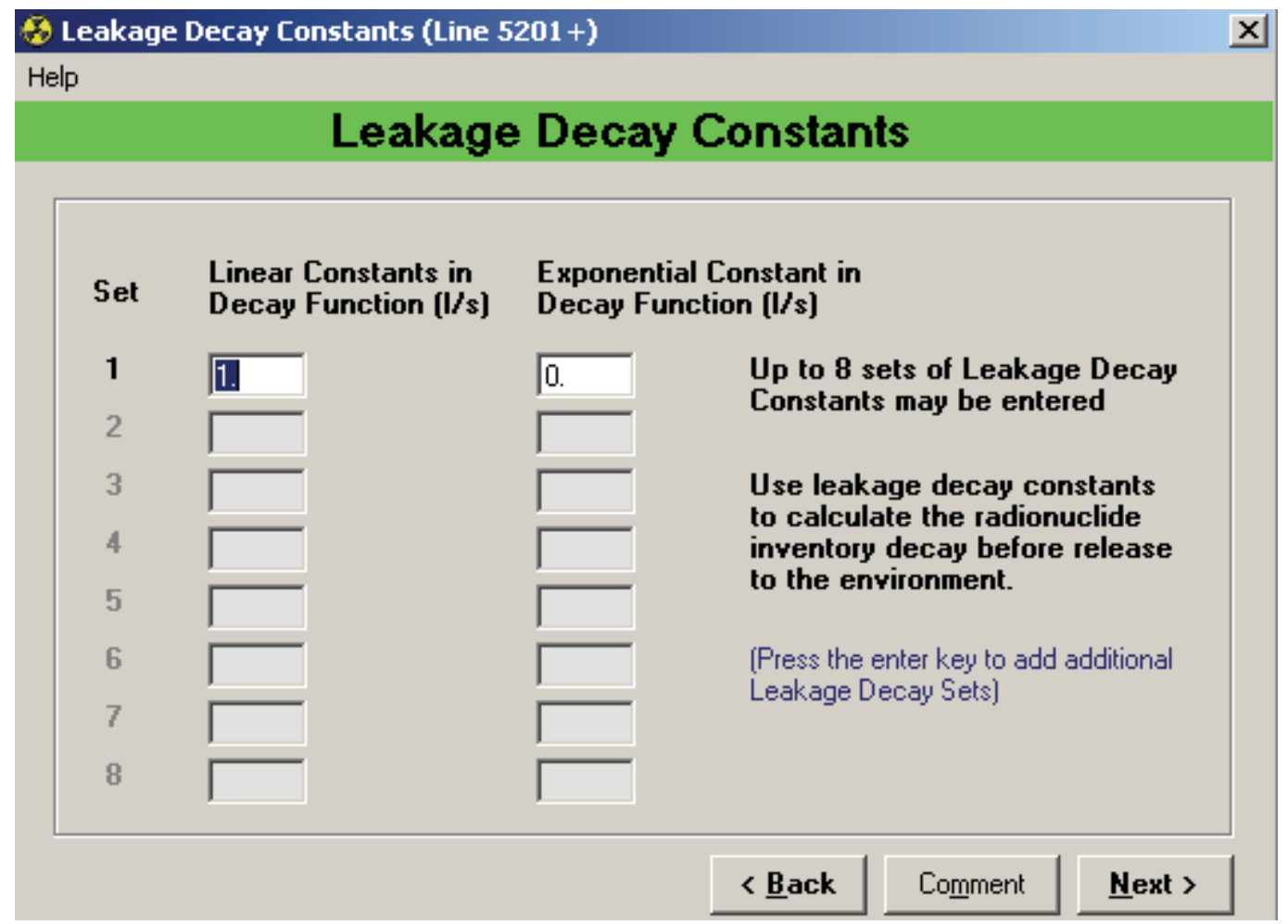

Figure 3-41. Screen 6, Leakage Decay Constants. 
Screen 7 - Crosswind Distance: Select Yes if you want to enter crosswind distances; otherwise, select No (see Figure 3-42). If yes is selected, the input fields will become active allowing up to 15 crosswind distances to be entered.

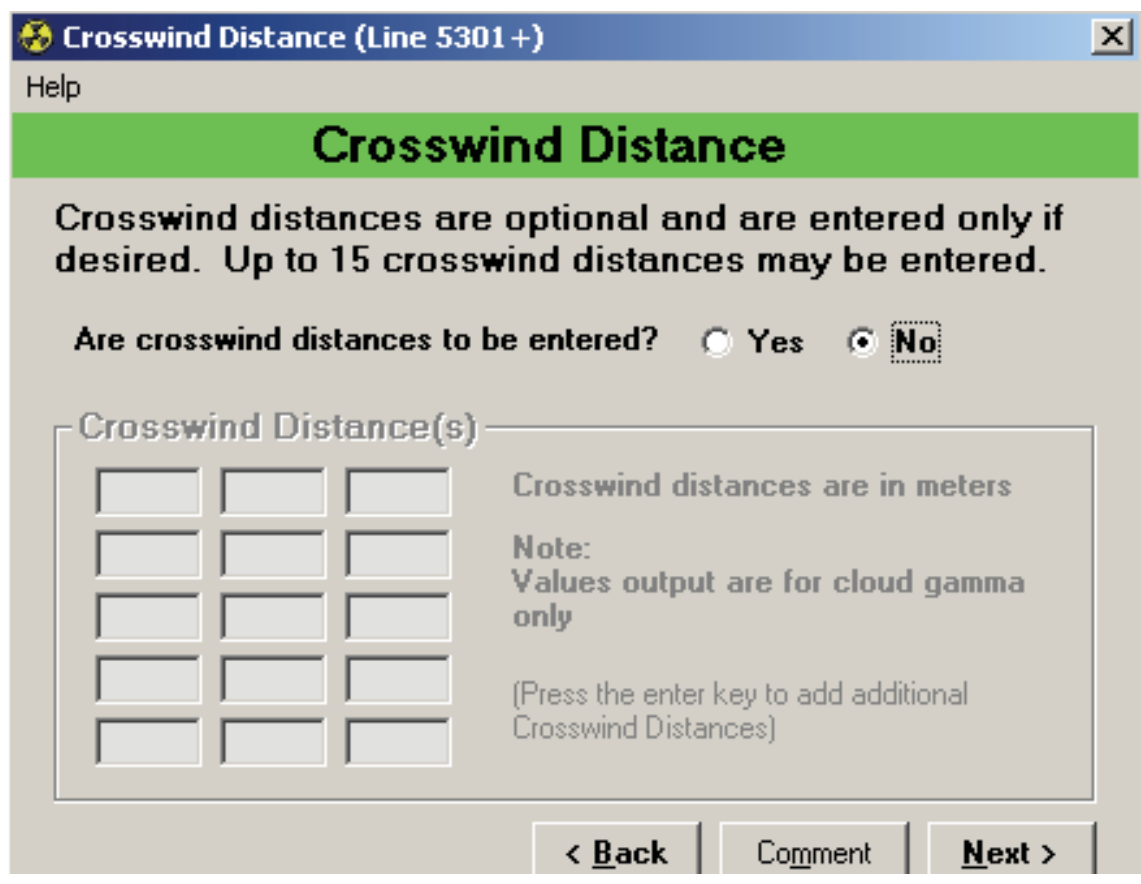

Figure 3-42. Screen 7, Crosswind Distance. 
Screen 7 - Diffusion Coefficient Control: The following options are available for diffusion coefficient control (see Figure 3-43):

- If option 1 is selected, then the Coefficient of Standard Deviation screen will appear next. Enter the values for $\sigma_{\mathrm{y}}$ and $\sigma_{\mathrm{z}}$. Standard deviations must be entered in sets of two.

- If option 2 is selected, then the Plume Standard Deviation Control screen will appear next. Enter the type of sigma weather class and plume rise indicator on a sequence of input screens.

- If option 3 is selected, then the Direct $\chi / Q$ Input screen will appear next. Enter the $\chi / Q$ associated with the downwind distance.

NOTE: Building wake control is only available if stack height was equal to zero on screen 3 (see Figure 3-43).

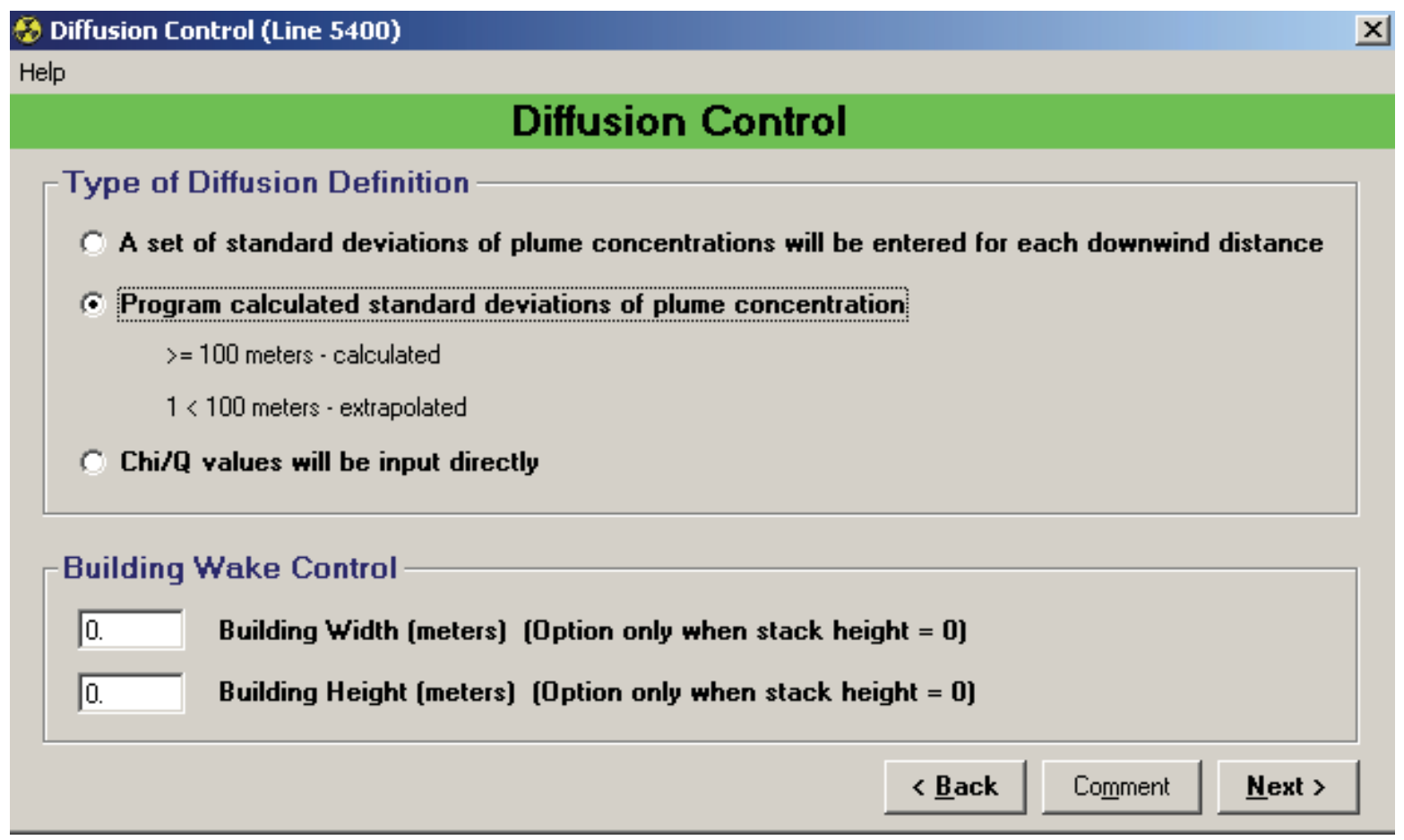

Figure 3-43. Screen 8, Diffusion Coefficient Control. 
Screen 10A (Optional) - Coefficient of Standard Deviation: This screen appears only if option 1 was chosen on screen 9 (see Figure 3-44).

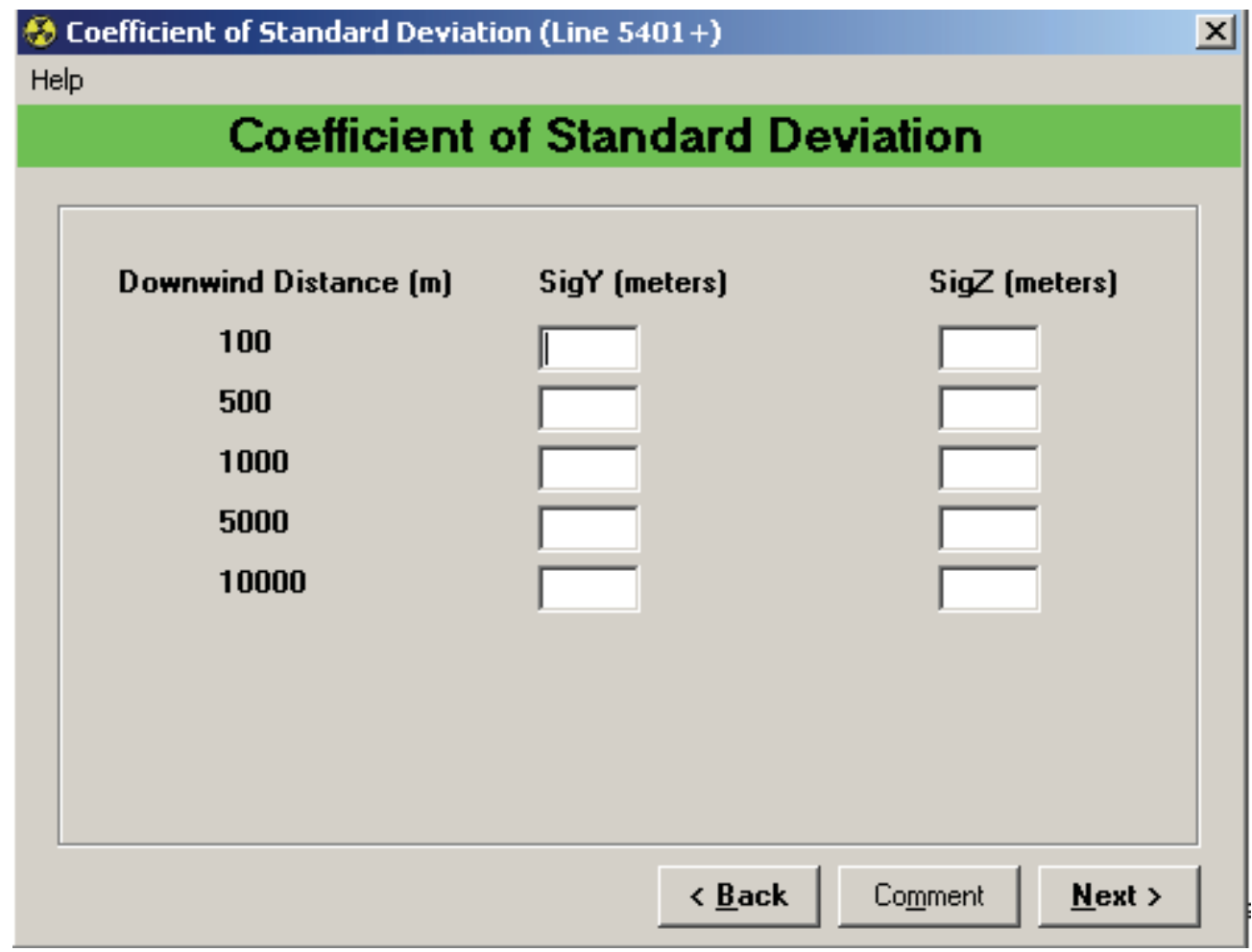

Figure 3-44. Screen 10A (Optional), Coefficient of Standard Deviation. 
Screen 10B (Optional) - Plume Standard Deviation Control: This screen appears only if option 2 was chosen on screen 9 (see Figure 3-45).

NOTE: Weather class F Extremely Stable (Fumigation) is only available if stack height was equal to zero on screen 3. Plume meander is a factor that allows for additional spreading of the plume. Also known as a spreading ratio it is a factor greater than 1 that adjusts the calculated Chi/Q values to account for very low wind speed spreading.

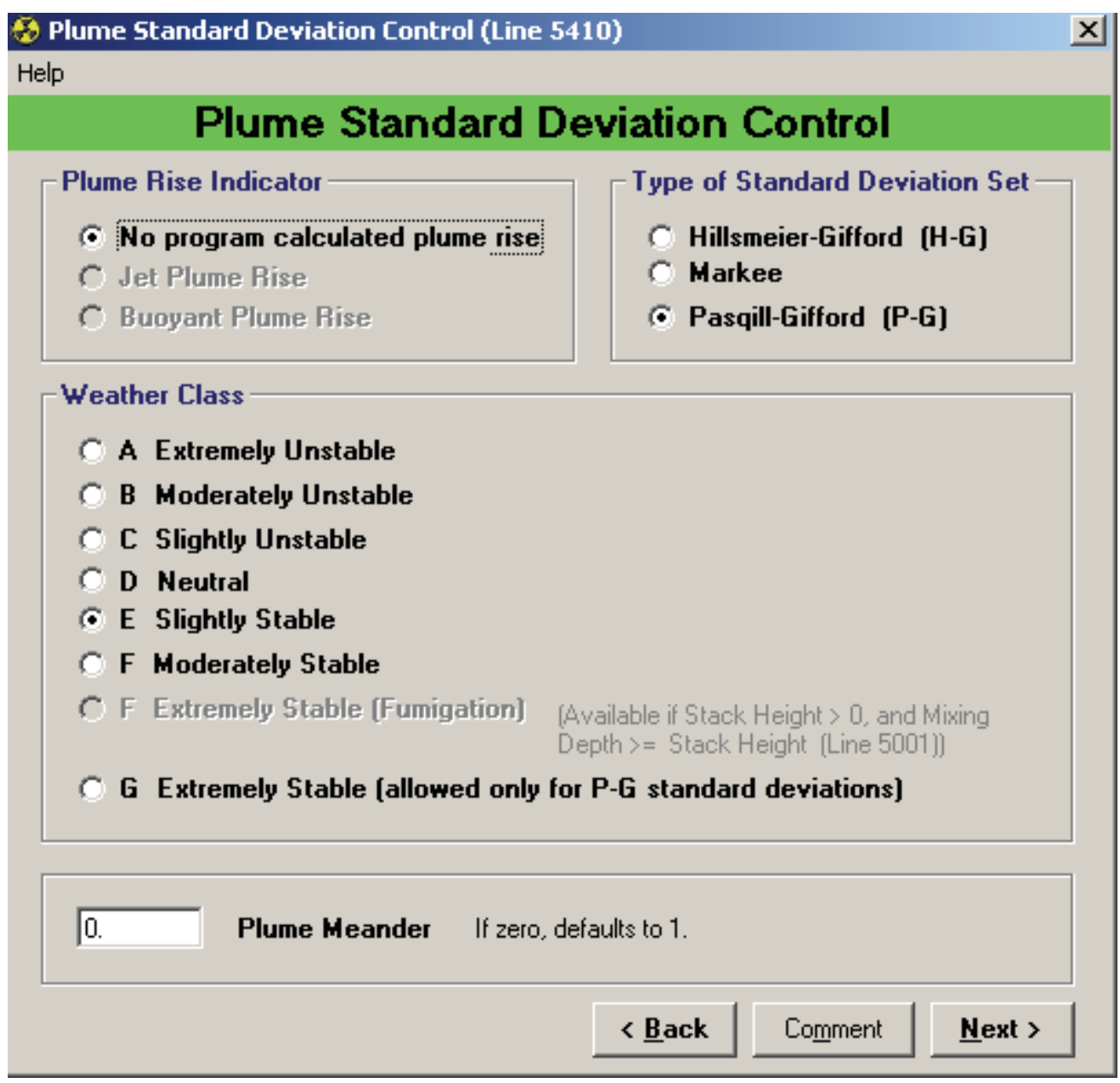

Figure 3-45. Screen 10B (Optional), Plume Standard Deviation Control. 
Screen 10C (Optional) - Direct Chi/Q Input: This screen appears only if option 3 was chosen on screen 9 (see Figure 3-46).

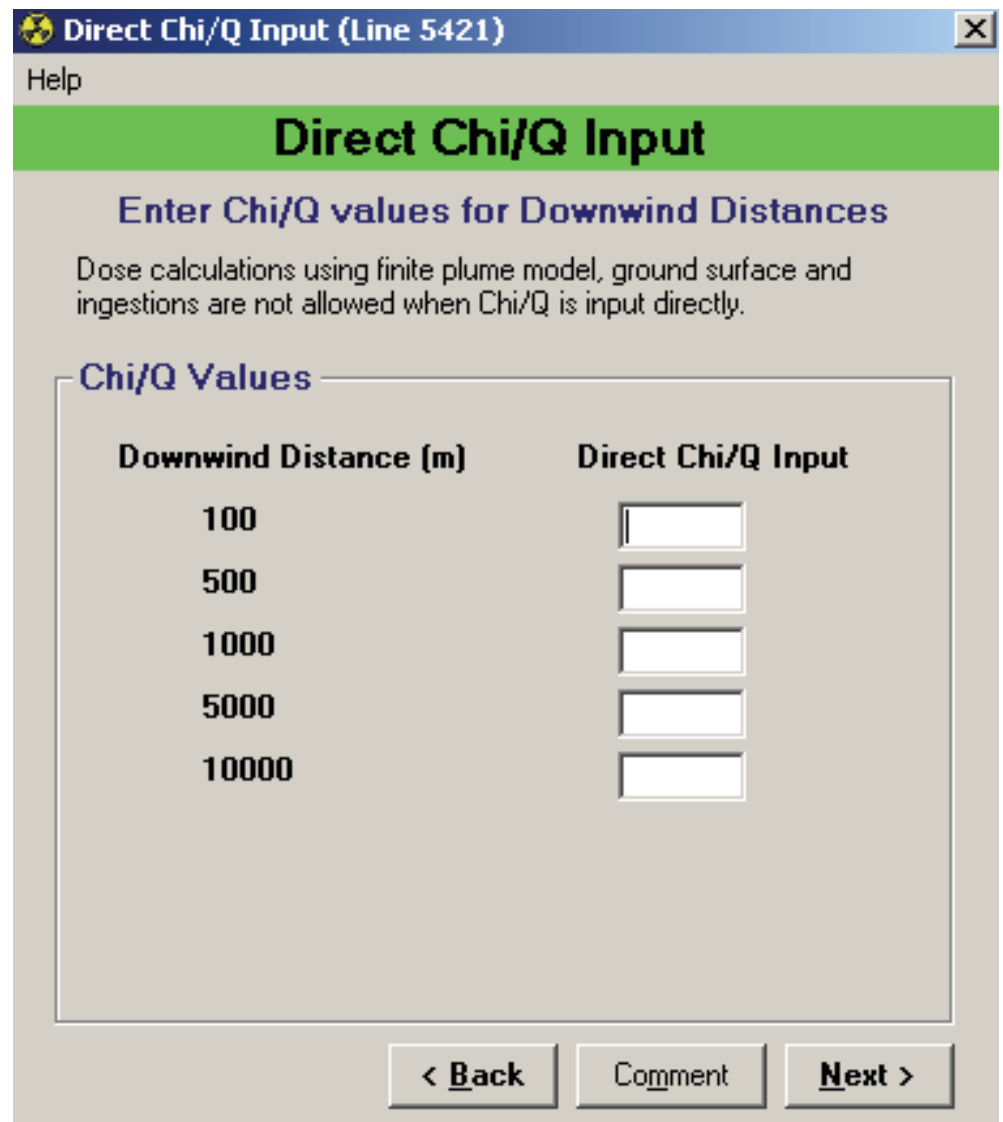

Figure 3-46. Screen 10C (Optional), Direct Chi/Q Input.

Screen 11A (Optional) - Jet Plume Rise Parameters: This screen appears only if Jet Plume Rise was chosen on Plume Standard Deviation Control screen 10B (see Figure 3-47).

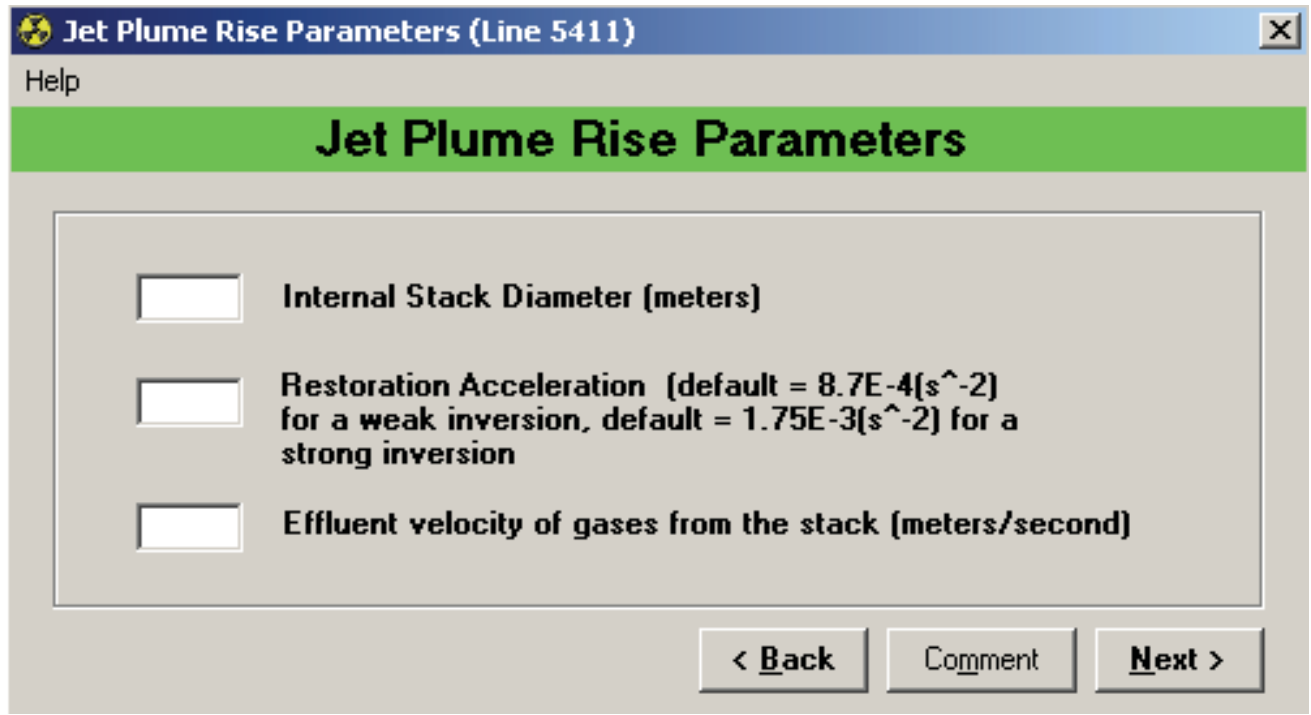

Figure 3-47. Screen 11A (Optional), Jet Plume Rise Parameters. 
Screen 11B (Optional) - Buoyant Plume Rise Parameters: This screen appears only if Buoyant Plume Rise was chosen on Plume Standard Deviation Control screen 10B (see Figure 3-48).

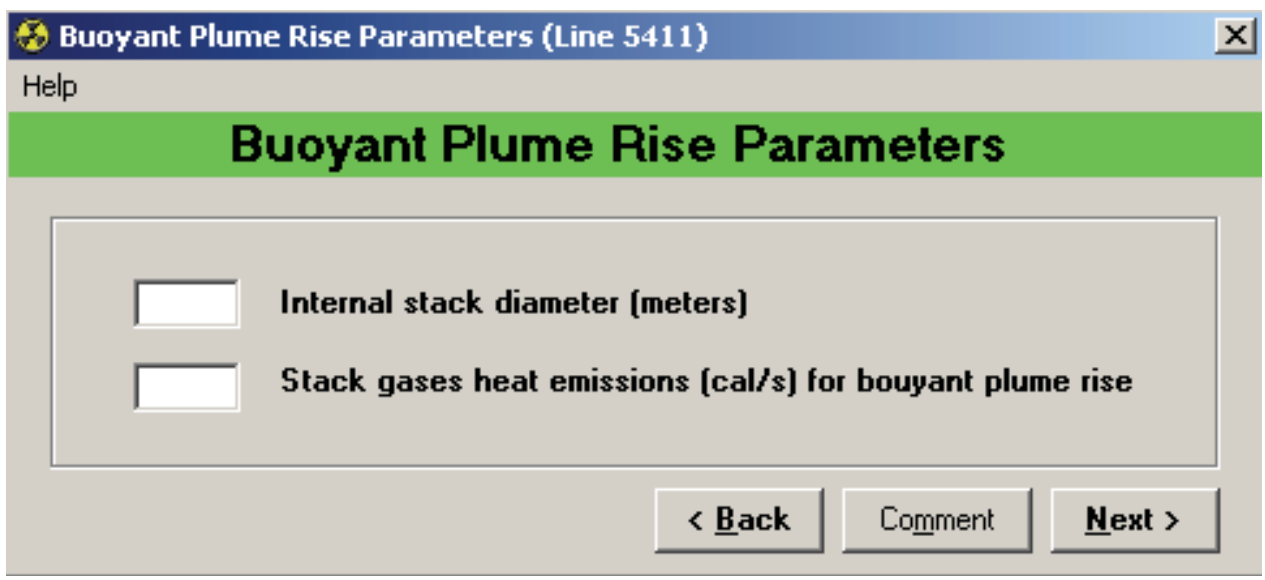

Figure 3-48. Screen 11B (Optional), Buoyant Plume Rise Parameters.

\subsubsection{Series - Radionuclide Inventory Decay and Printout}

To append a new 6000 series in the current file, click on the Reports tab (see Figure 3-49).

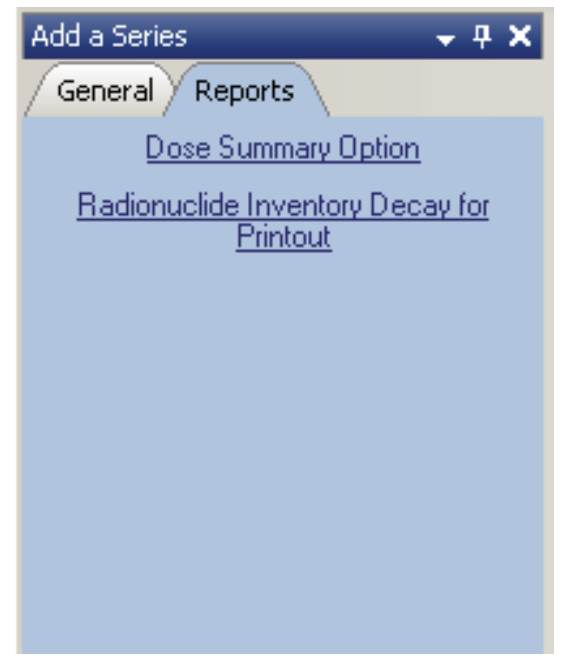

Figure 3-49. Reports Tab screen. 
Screen 2 - Radionuclide Decay Control: This screen is shown after the series title screen for the 6000 series (see Figure 3-50). In this data entry screen sequence, the following information must be provided:

- If all or selected radionuclide decay will be calculated

- If inventories are to be printed

- Which units of measure

- If the exponential leakage decay option is desired.

8 Radionuclide Decay Control (Line 6000)

Help

\section{Radionuclide Decay Control}

Radionuclides to be decayed

( All radionuclides in the library will be decayed

C Only radionuclides that are selected on an upcoming screen will be decayed

-Inventory Printout Options

c No individual radionuclide inventories are printed

$C$ Print all fission products; and any activation products, actinides and daughters of actinides with positive values

C. Same as above option except suppress short-lived fission products which have no available dose conversion factors

C Print inventory of radionuclides that have positive values at or following first decay time

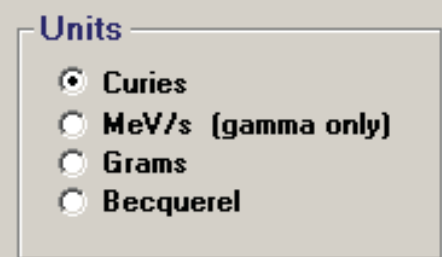

Exponential Leakage

C No exponential leakage corrections are included

$C$ Corrections for exponential leakage decay will be manually entered

Figure 3-50. Screen 2, Radionuclide Decay Control. 
Screen 3 (Optional) - Exponential Leakage Decay: This screen appears only if Corrections for exponential leakage decay will be manually entered was chosen on screen 2 (see Figure 3-51). Enter the decay time(s) for the exponential decay function. After clicking next, a prompt will appear asking if you want to change the Leakage Decay constants (see Figure 3-52). If the constants have been previously entered and do not need to be changed, click on No to proceed; otherwise click Yes to change the Leakage Decay constants.

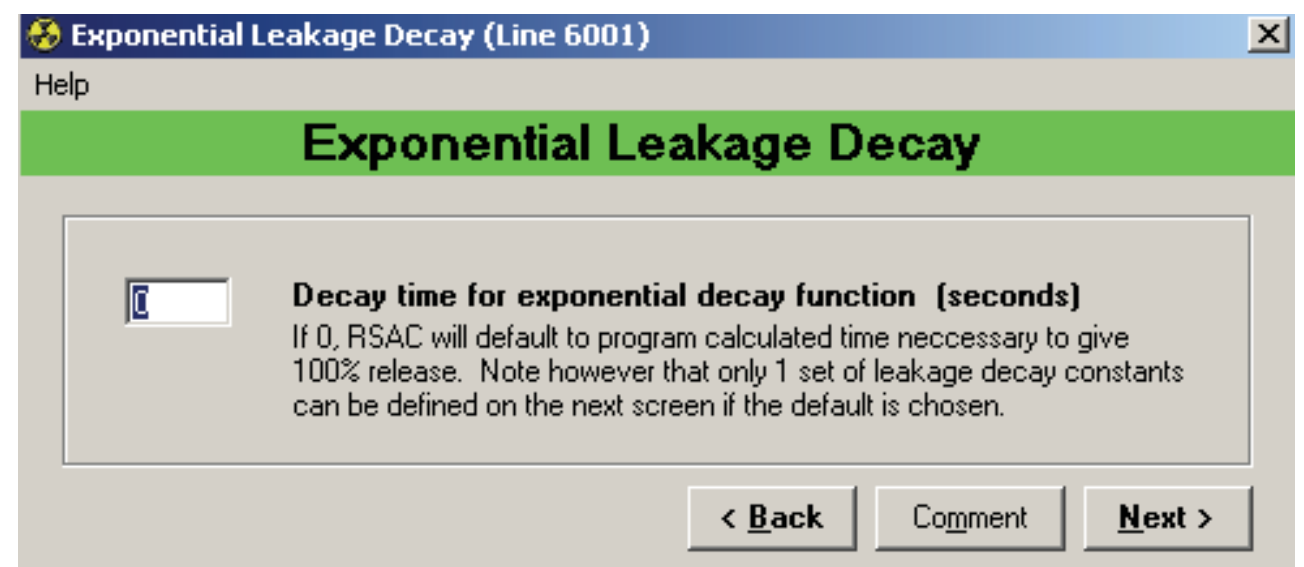

Figure 3-51. Screen 3 (Optional), Exponential Leakage Decay.

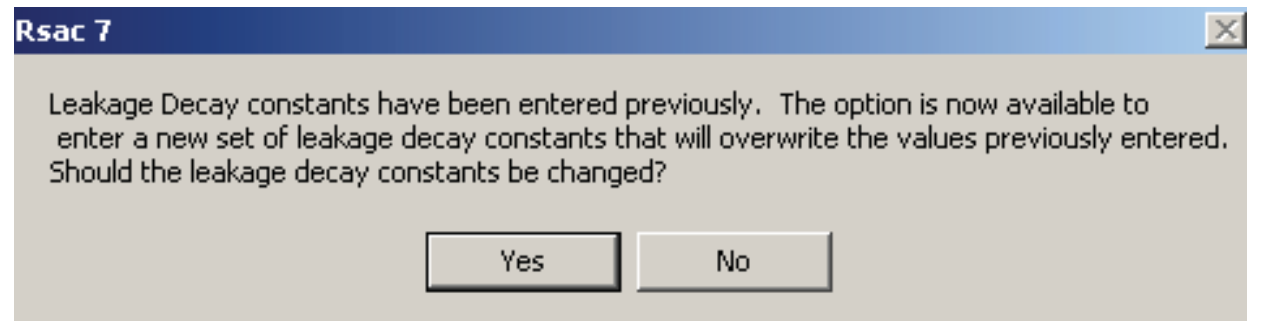

Figure 3-52. Leakage Decay Constants Prompt screen. 
Screen 4 (Optional) - Leakage Decay Constants: If Yes was chosen on the Leakage Decay Constants Prompt then the screen in Figure 3-53 appears to enter linear and exponential constants $\left(\mathrm{s}^{-1}\right)$. Up to eight sets of constants can be entered. After entering a set of constants, press the $<$ enter $>$ key to allow entry of another set.

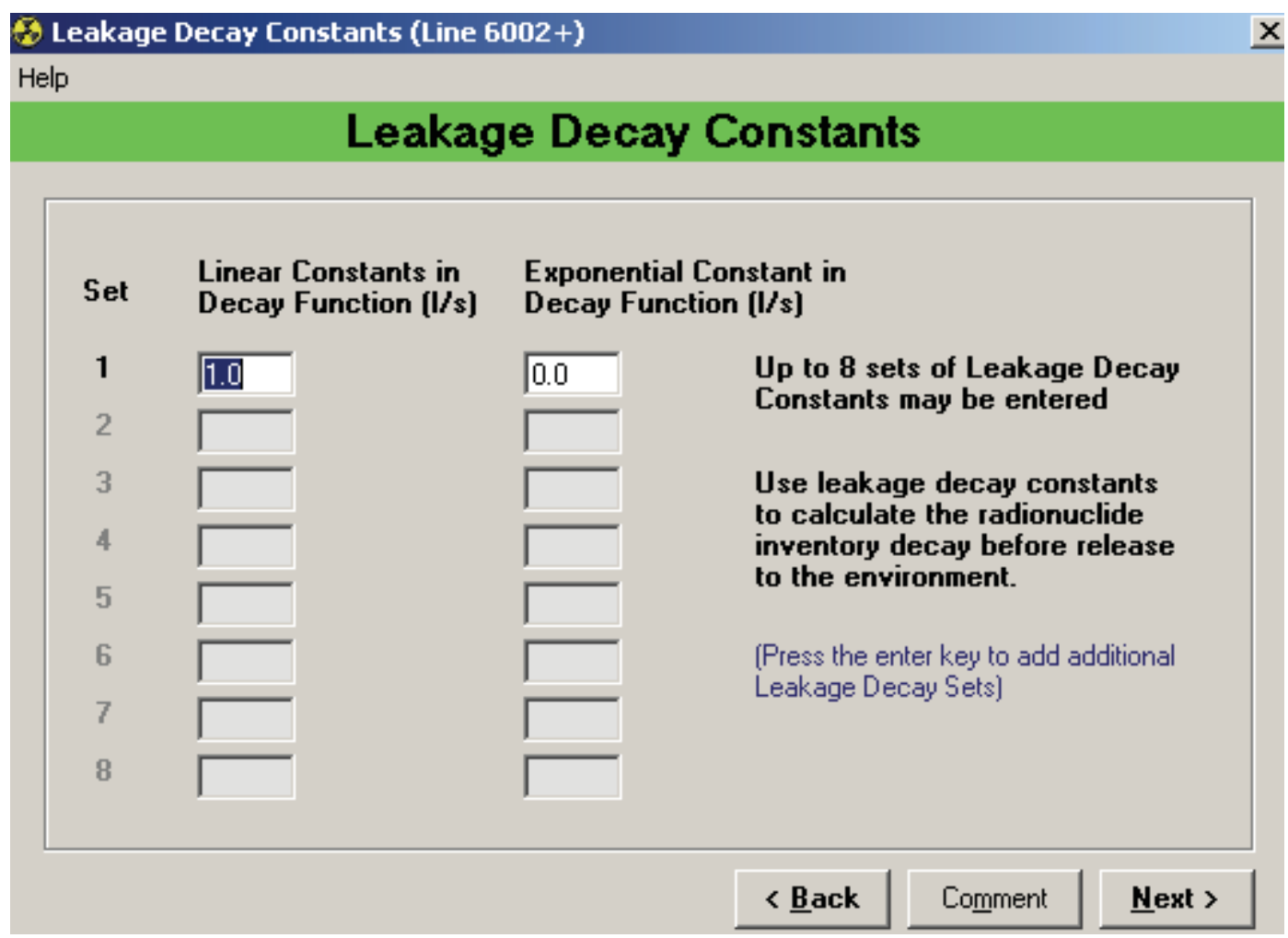

Figure 3-53. Screen 4 (Optional), Leakage Decay Constants. 
Screen 5 (Optional) - Radionuclide Selection: This screen appears only if Only radionuclides that are selected on an upcoming screen will be decayed was chosen on screen 2. On this screen (see Figure 3-54), select the radionuclide using one of the following methods. Scroll through the list and click on the desired radionuclide; type the symbol to quickly select the desired radionuclide. To unselect a radionuclide, click it in the list a second time. To clear all selected, click the Clear Selected button.

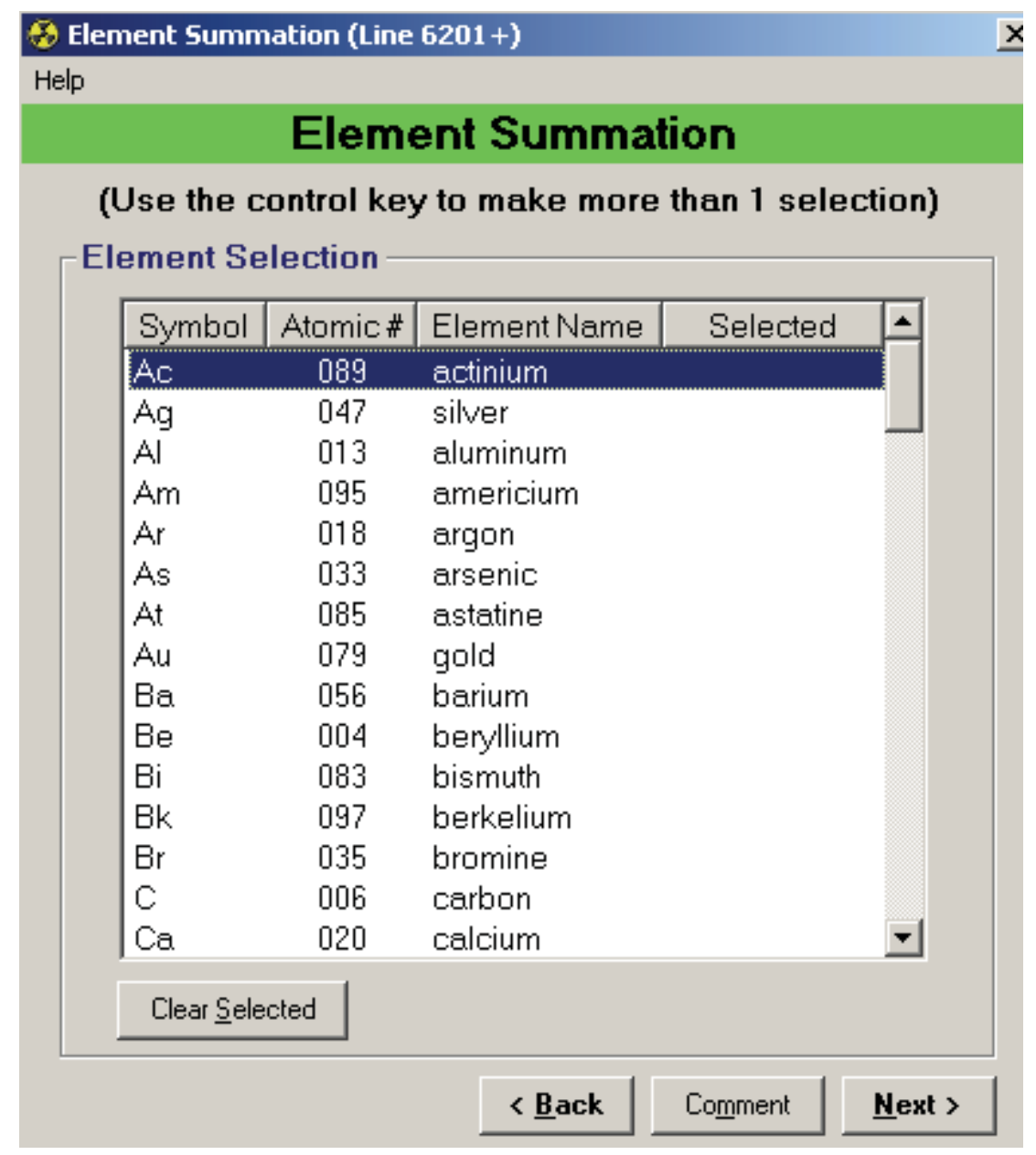

Figure 3-54. Screen 5 (Optional), Radionuclide Selection. 
Screen 6 - Decay Times: The screen asks if you want to enter decay times directly (see Figure 3-55). If Yes is selected, the decay times input section will be enabled allowing input of decay times. A maximum of eight decay times can be entered. However, when you want to see all of the output data on an unshifted screen or printed on a standard 80-column page, enter a maximum of three decay times.

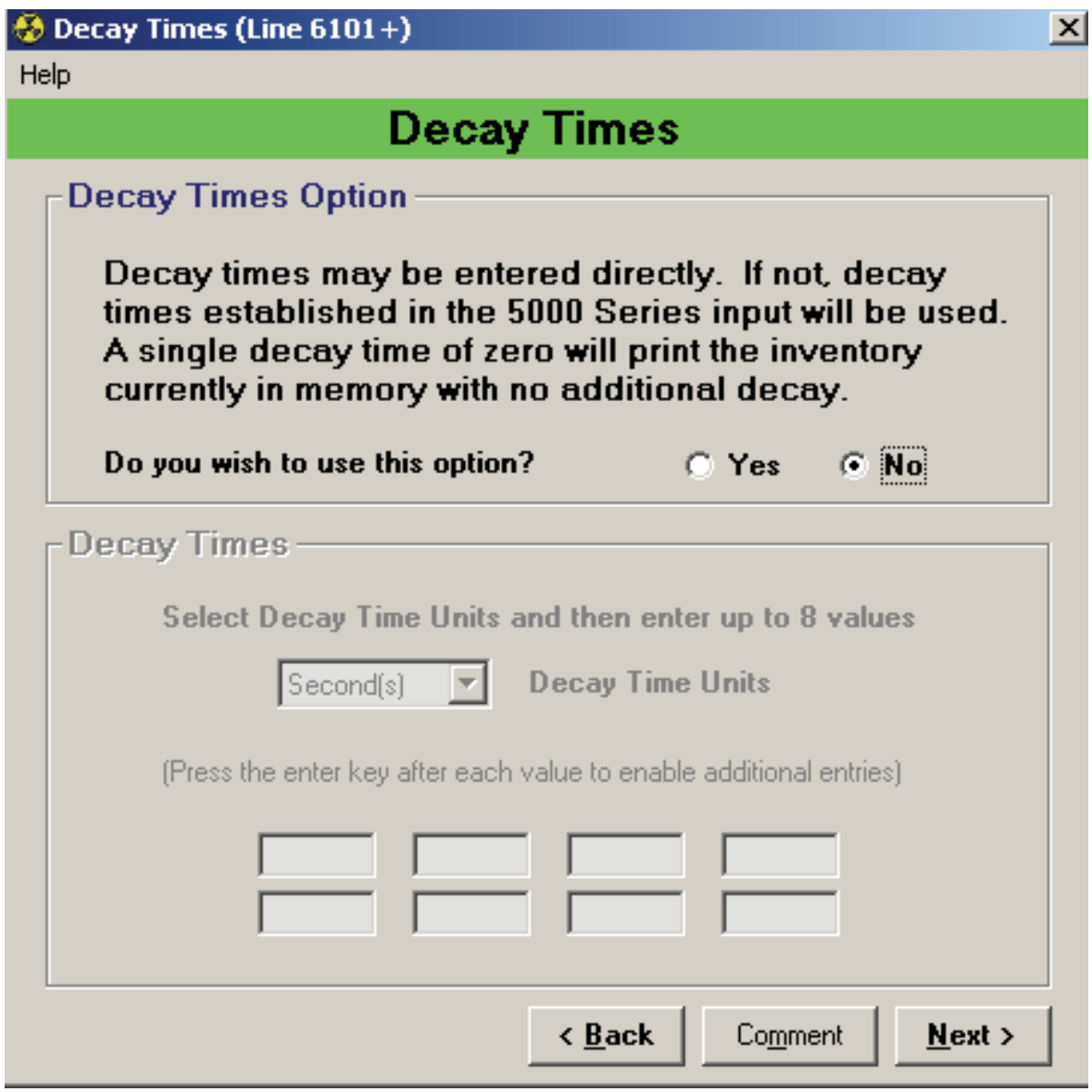

Figure 3-55. Screen 6, Decay Times. 
Screen 7 (Optional) - Summation Control: Shown only if All radionuclides in the library will be decayed was chosen on screen 2. This screen (see Figure 3-56) will determine if you would like a summation of the radionuclide inventory by group (solids, halogens, noble gases, cesium, and ruthenium) and if the radionuclide inventory should be summed by element.

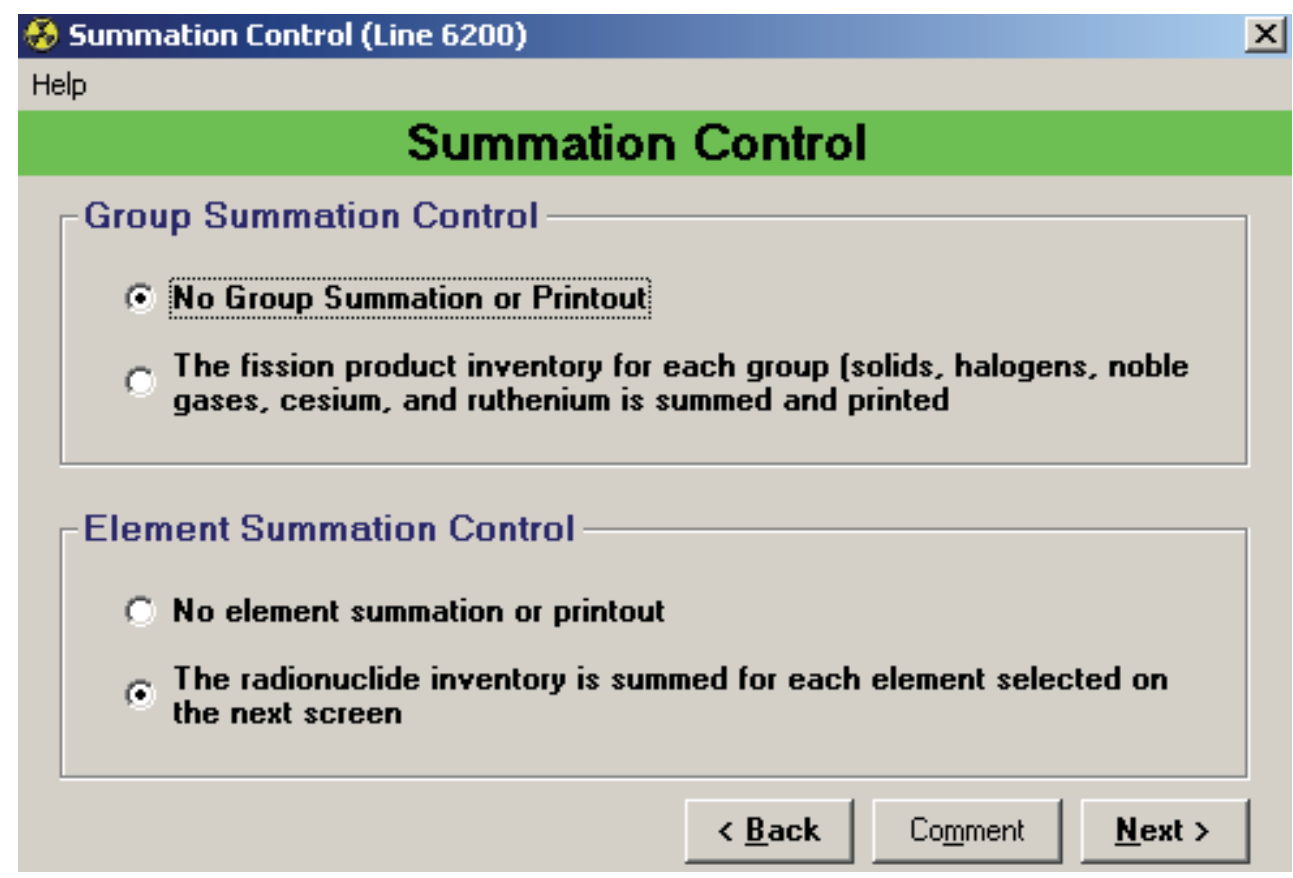

Figure 3-56. Screen 7 (Optional), Summation Control. 
Screen 8 (Optional) - Element Summation: This screen appears only if The radionuclide inventory is summed of each element selected on the next screen is chosen on screen 7. On this screen (see Figure 3-57), select the element using one of the following methods. Scroll through the list and click on the desired element; type the symbol to quickly select the desired element. To unselect an element click it in the list a second time. To clear all selected, click the Clear Selected button.

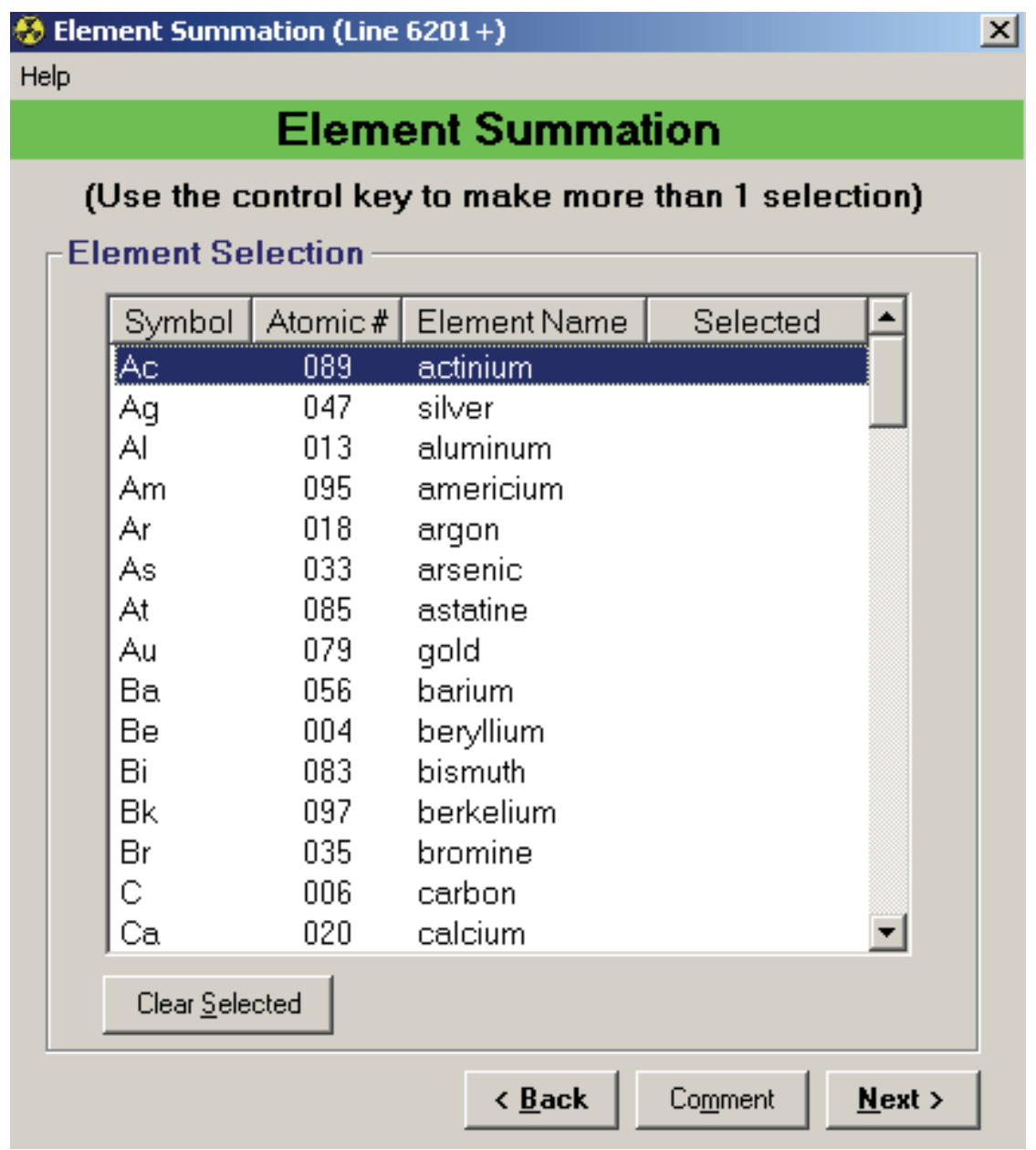

Figure 3-57. Screen 8 (Optional), Element Summation. 


\subsubsection{Series - Internal/External Dose Calculation}

Screen 2 - Dose Control Selection: After the series title screen the Dose Control Calculation screen is displayed (see Figure 3-58). In this data entry screen you will be asked to select the type of dose calculation or risk evaluation per Federal Guidance Report 13.

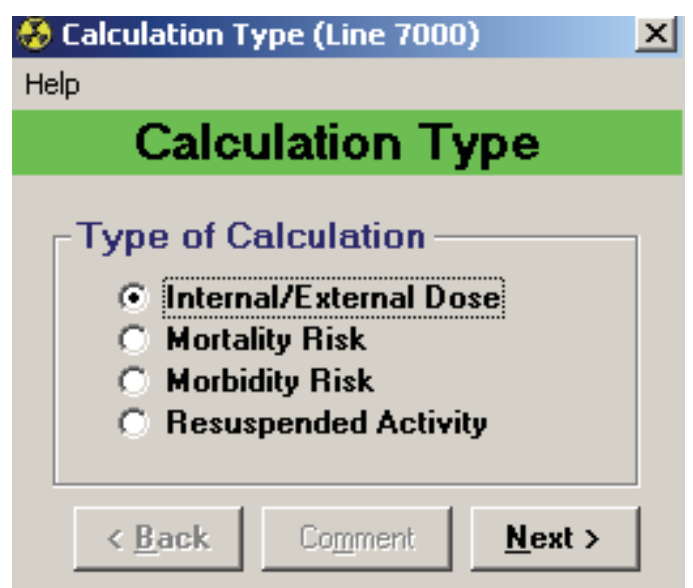

Figure 3-58. Dose Selection Screen. 
Based on the type of calculation chosen, a different screen sequence will be presented (see Figure 3-59).

- Type of dose calculation - Internal/External

- Amount of printed output

- Dose unit

- If all elements are to be used in the calculation

- If all organs are to be included in the dose calculation.

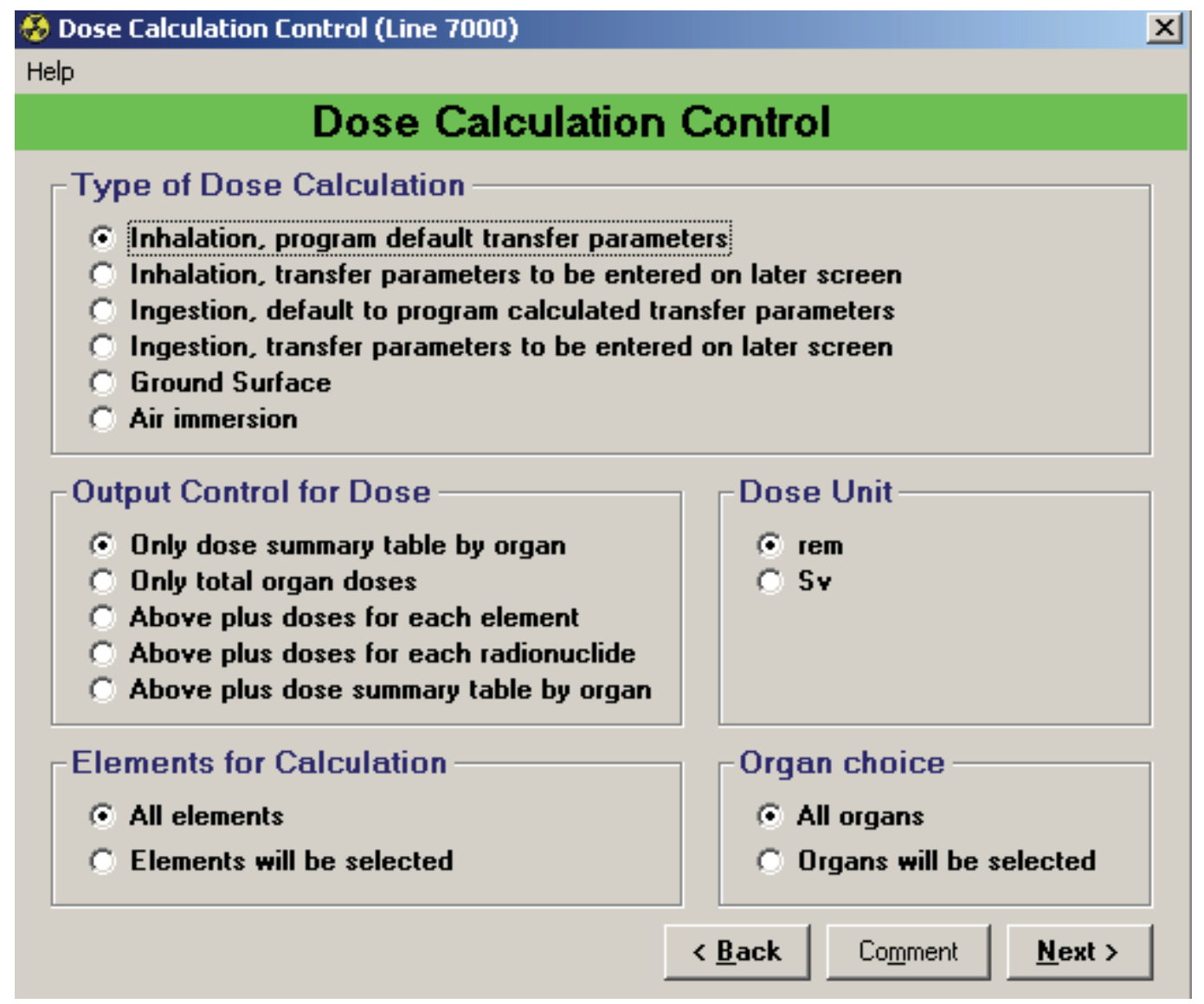

Figure 3-59. Screen 2, Dose Control Calculation. 
Screen 3A (Optional) - Inhalation Dose Control: This screen appears only when option 1, 2, 7, or 8 is chosen for the Type of Dose Calculation on screen 2. Enter the breathing rate $\left(\mathrm{m}^{3} / \mathrm{s}\right)$ and decay time (s) for exponential decay function (see Figure 3-60).

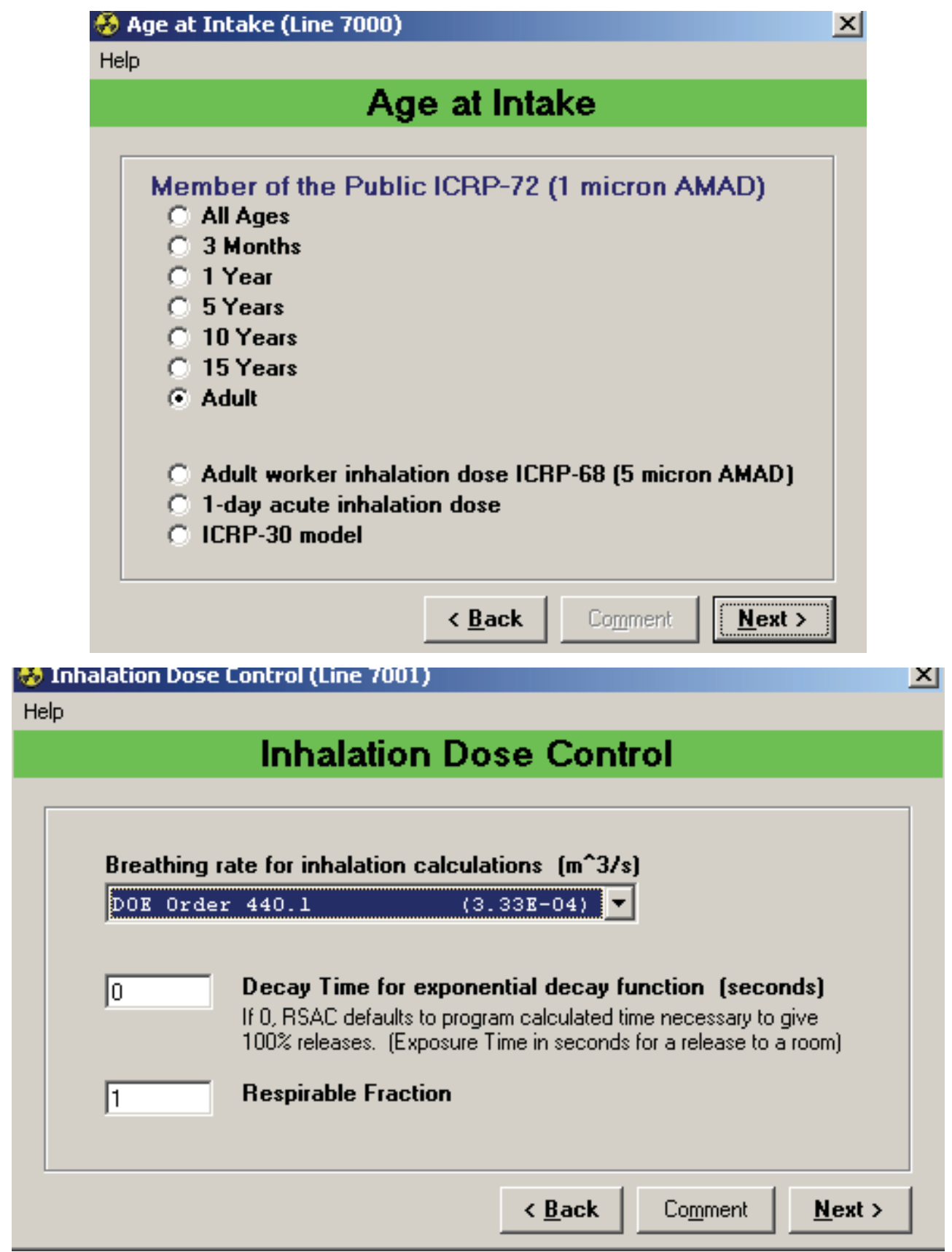

Figure 3-60. Screen 3A (Optional), Inhalation Dose Control. 
Screen 4A (Optional) - Inhalation Parameters Dose Calculation: This screen appears only if option 2 or 8 is chosen for the Type of Dose Calculation on screen 2. Enter activity median aerodynamic diameter (AMAD) $(\mu)$ and whether default lung clearance classes are to be used (see Figure 3-61). If user input of lung clearance classes is chosen, the Clearance Class Entry screen will appear next.

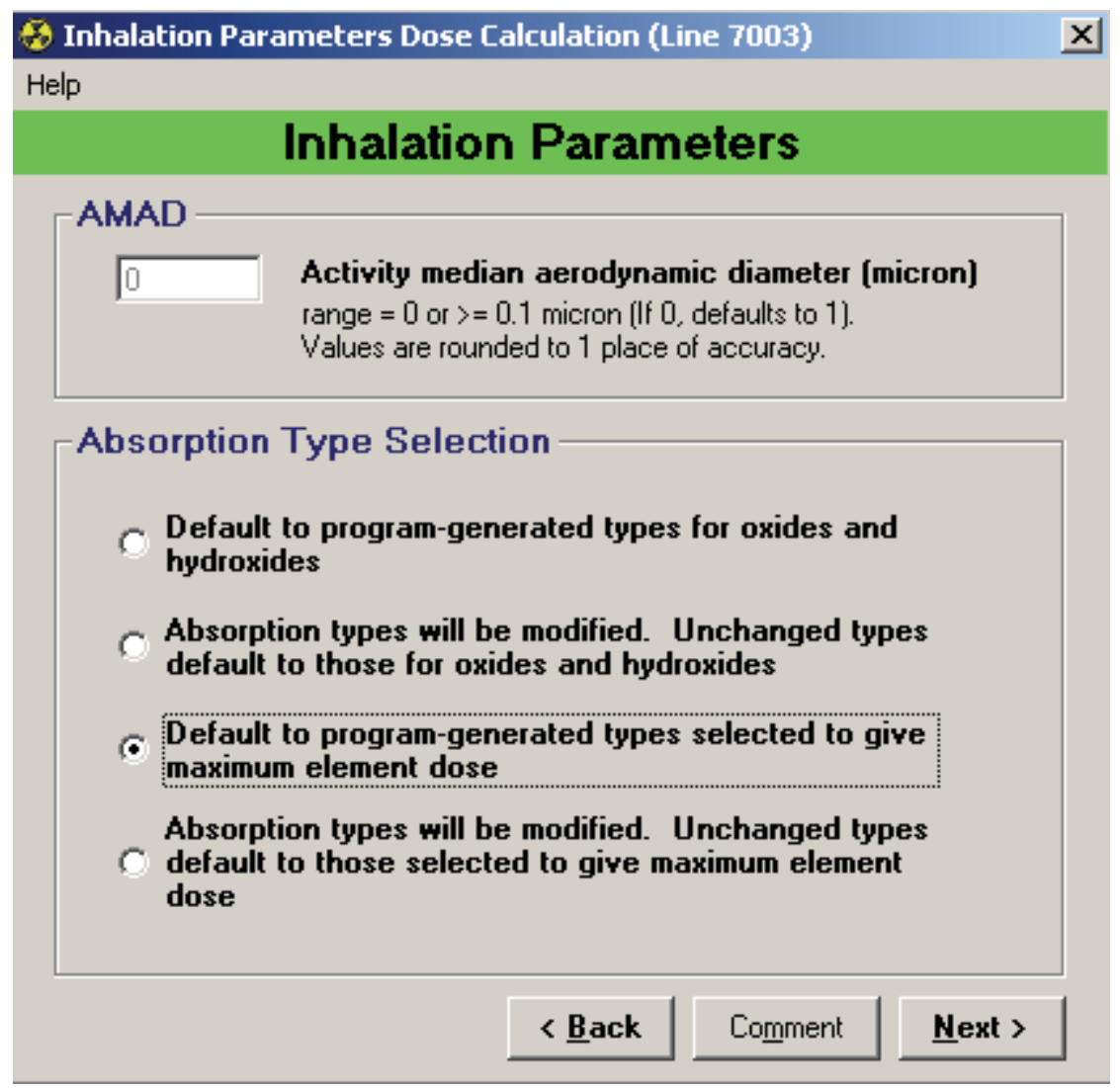

Figure 3-61. Screen 4A (Optional), Inhalation Parameters Dose Calculation. 
Screen 5A (Optional) - Absorption Type Entry: Shown only if option 2 or 4 is chosen for Absorption Type Entry on screen 4A (see Figure 3-62). Scroll through the list and click on the desired element. A pop-up screen will appear showing the valid lung clearance classes for the chosen element. Select the desired lung clearance class and click on Continue.

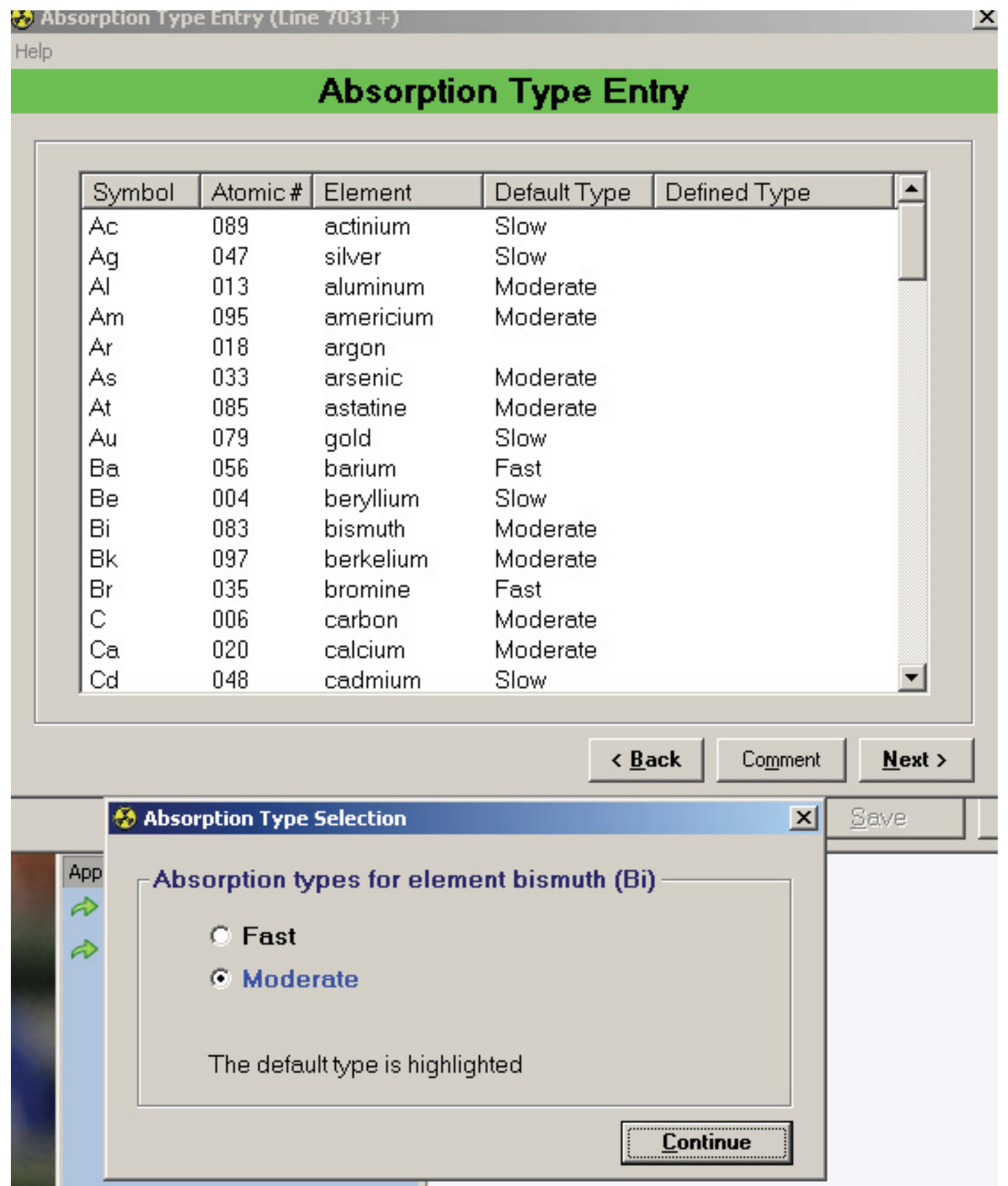

Figure 3-62. Screen 5A (Optional), Clearance Class Entry. 
Mortality Risk Calculation- This screen appears when mortality risk is selected on the opening screen (see Figure 3-63).

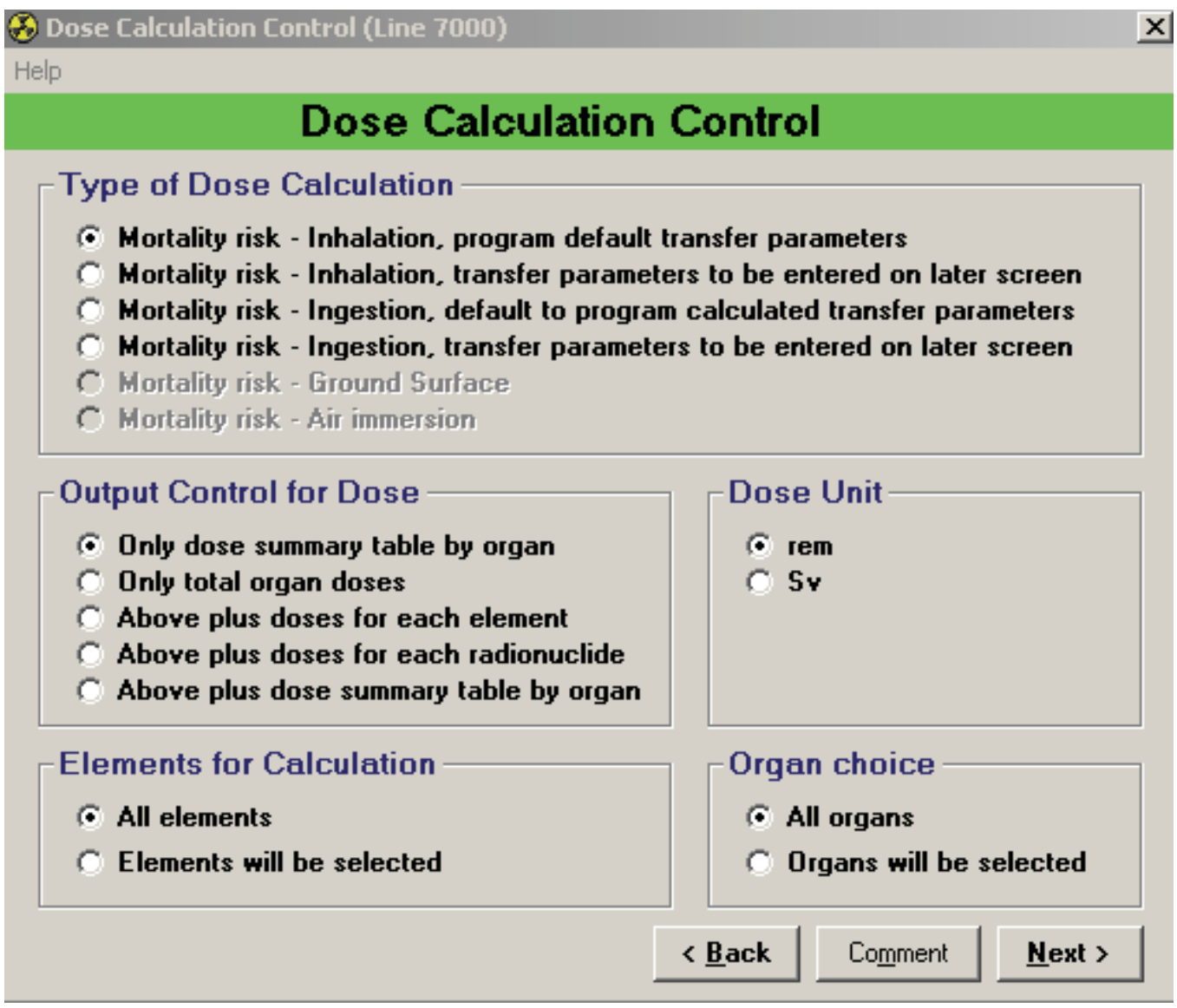

Figure 3-63. Mortality Risk Calculation screen.

All optional screens for inhalation/ingestion transfer parameters and output control are generated and controlled the same as for dose calculation. The primary difference is that summary output controls are specific to the risk calculation function and should be calculated separate from a dose calculation. 
Morbidity Risk Calculation- This screen appears when mortality risk is selected on the opening screen (see Figure 3-64).

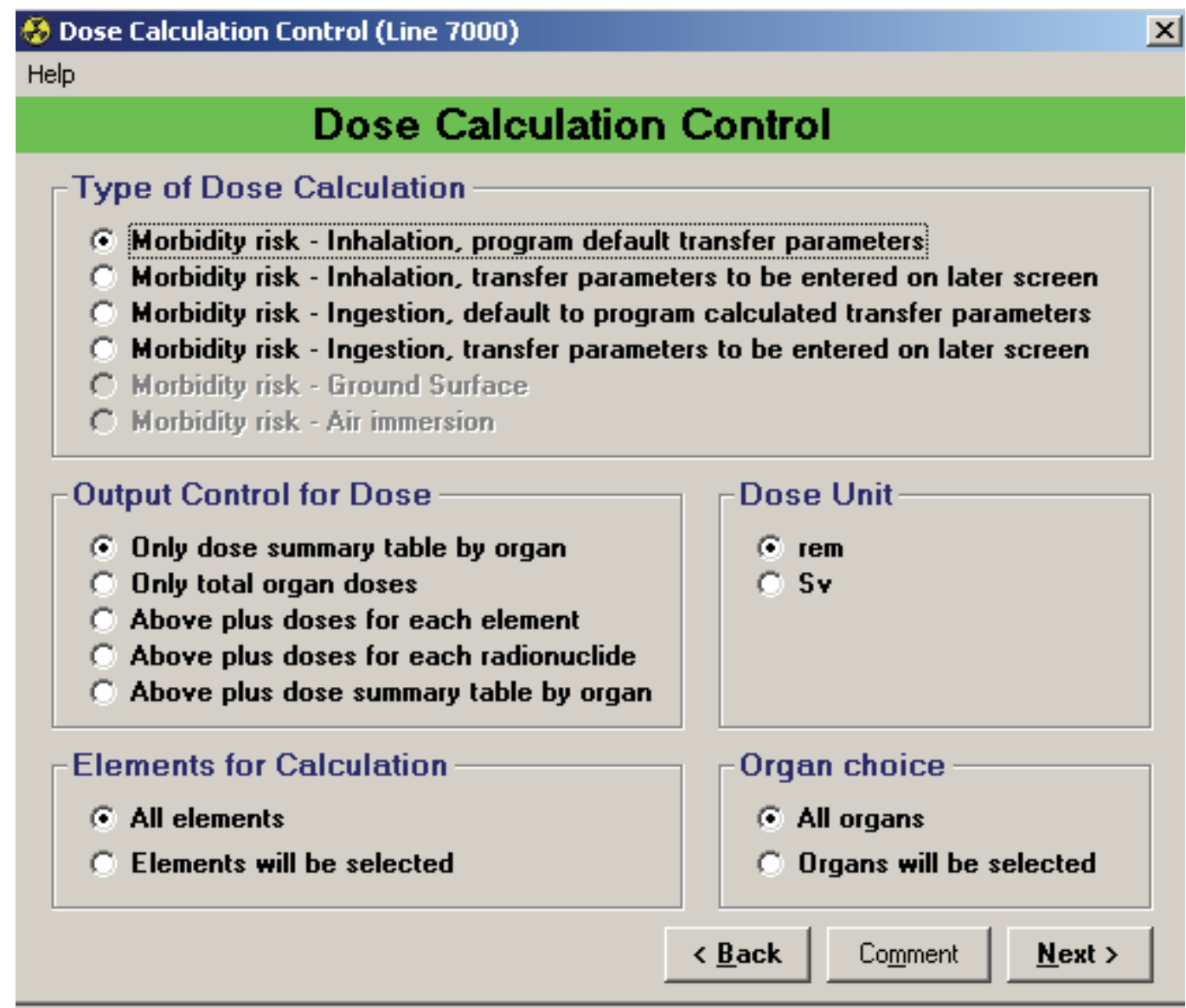

Figure 3-64. Morbidity Risk Calculation screen. 
Screen 6 (Optional) - Resuspension of Activity: This screen appears onlyif option 7 or 8 is chosen for Type of Dose Calculation on screen 2 (see Figure 3-65).

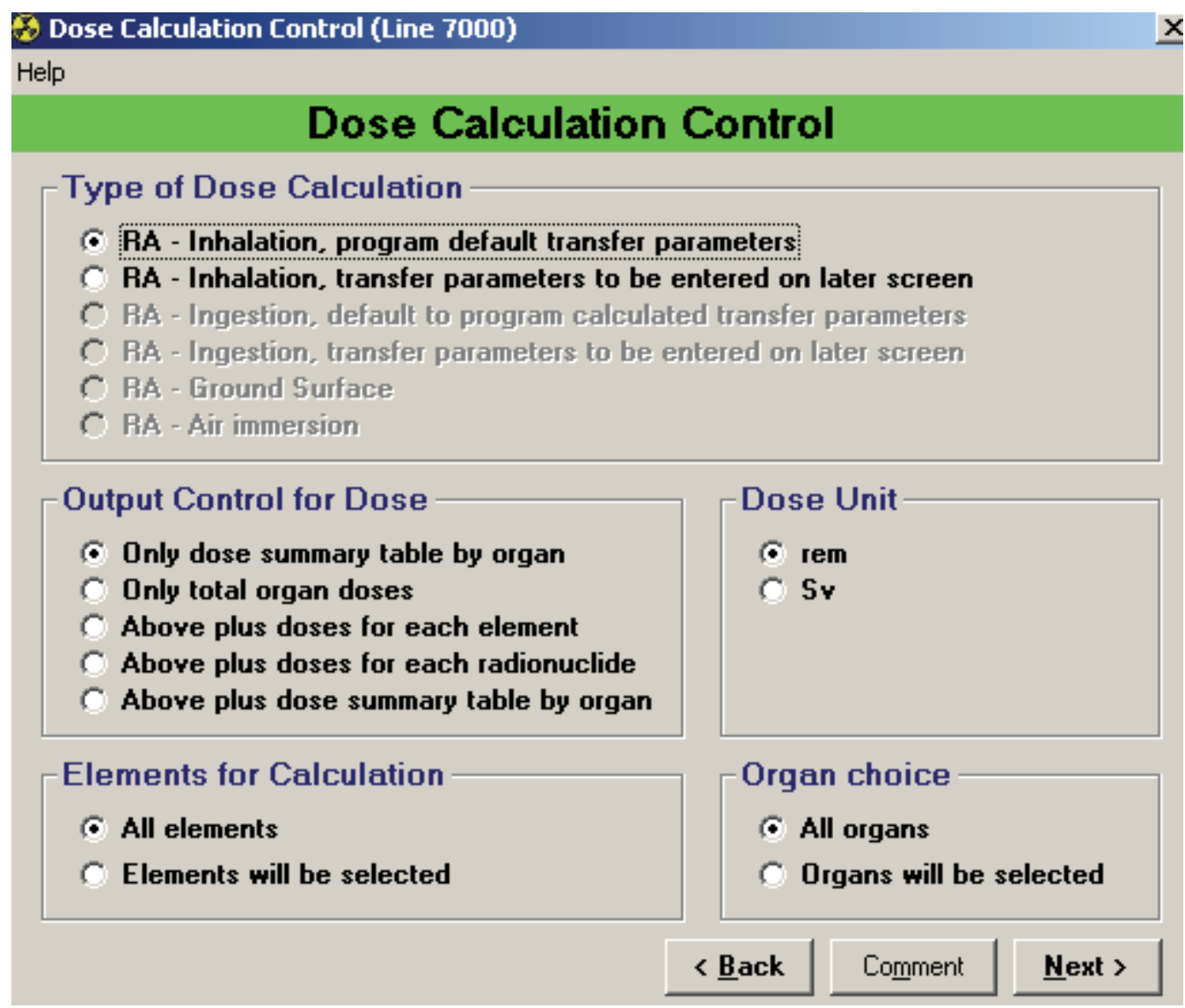

Figure 3-65. Screen 6 (Optional), Resuspension of Activity. 
Screen 3B (Optional) - Ingestion Dose Parameters: This screen appears only if option 3 or 4 is chosen for Type of Dose Calculation on screen 2 (see Figure 3-66). Enter decay time (s) for exponential decay function and the plant midpoint of operating life $(\mathrm{y})$.
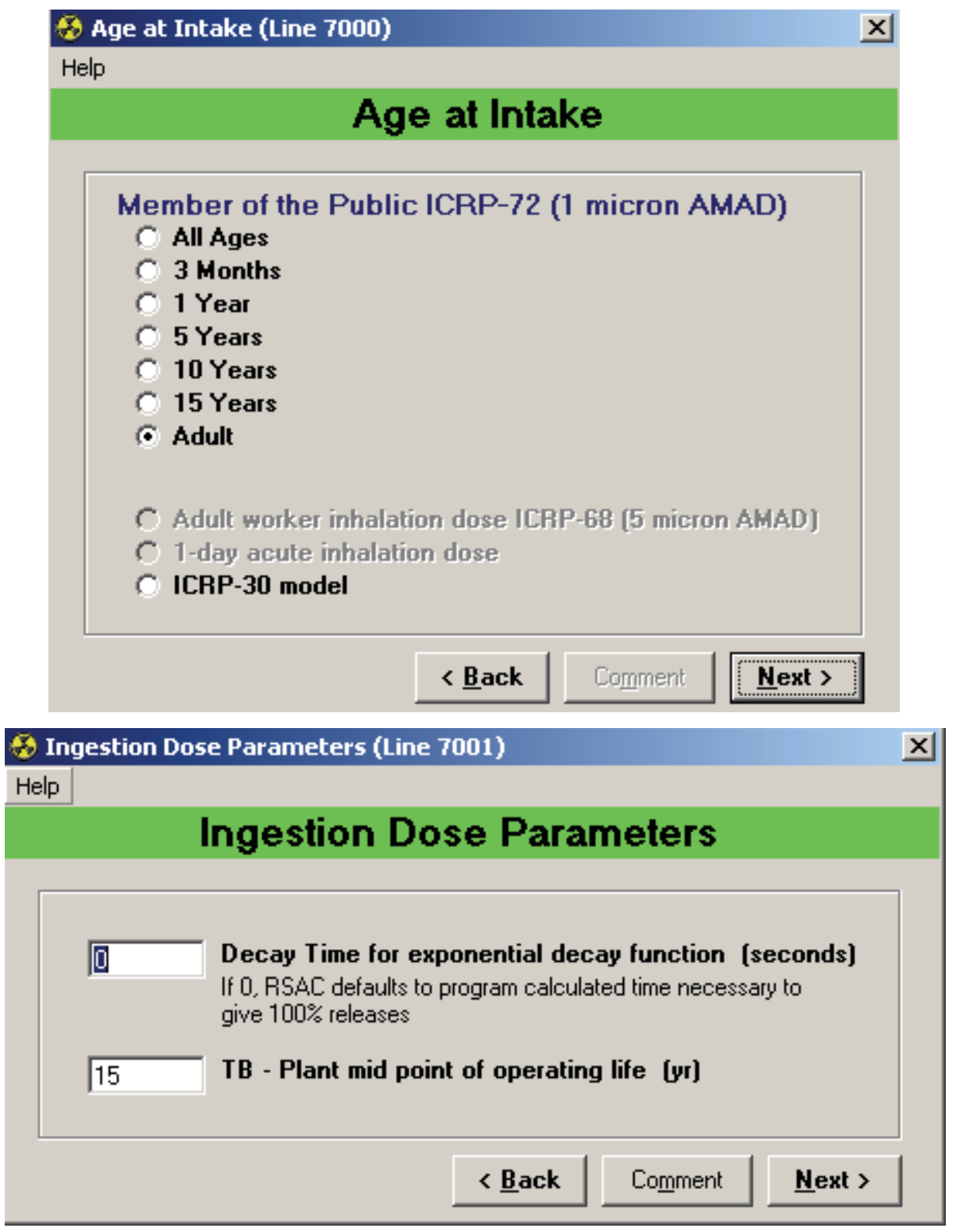

Figure 3-66. Screen 3B (Optional) - Ingestion Dose Parameters. 
Screen 4B (Optional) - Ingestion Dose Control: This screen appears only if option 4 is chosen for Type of Dose Calculation on screen 2 (see Figure 3-67). Use this sequence of screens to choose whether to use default ingestion transfer parameters; whether the release is chronic, acute, or if ingestion parameters are to be user entered; the time period crops are exposed to contamination during the growing season when the release is not chronic; and the harvest duration period following the end of an acute release period. When you select to enter ingestion parameters, a series of screens will appear that contain the RSAC-7.2 default ingestion parameters.

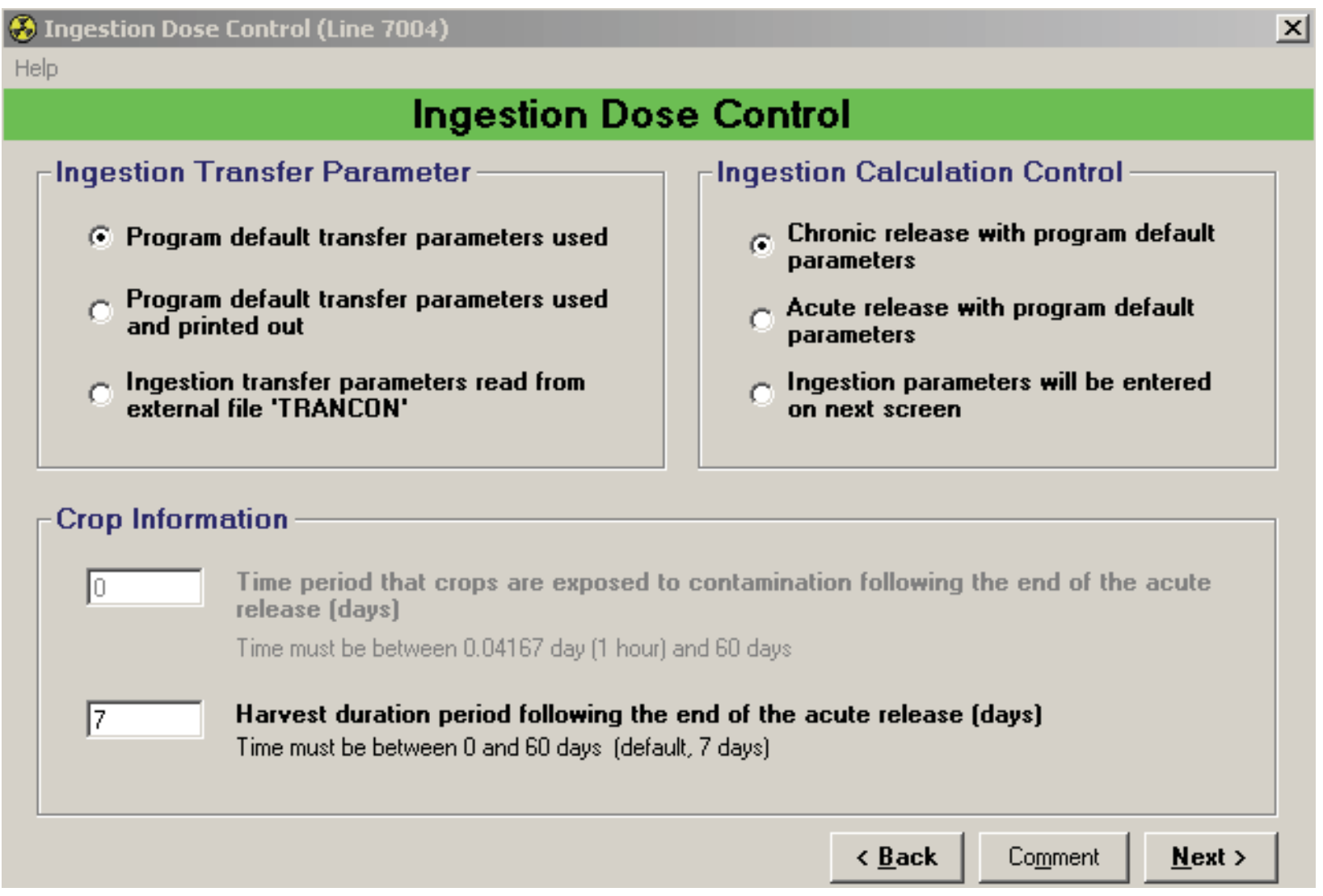

Figure 3-67. Screen 4B (Optional), Ingestion Dose Control. 
Screen 5B (Optional) - Ingestion Dose Constants: This screen appears only if Ingestion parameters will be entered on next screen is chosen on screen 4B (see Figures 3-68 through 3-72).

NOTE: All tabs will need to be reviewed before continuing.

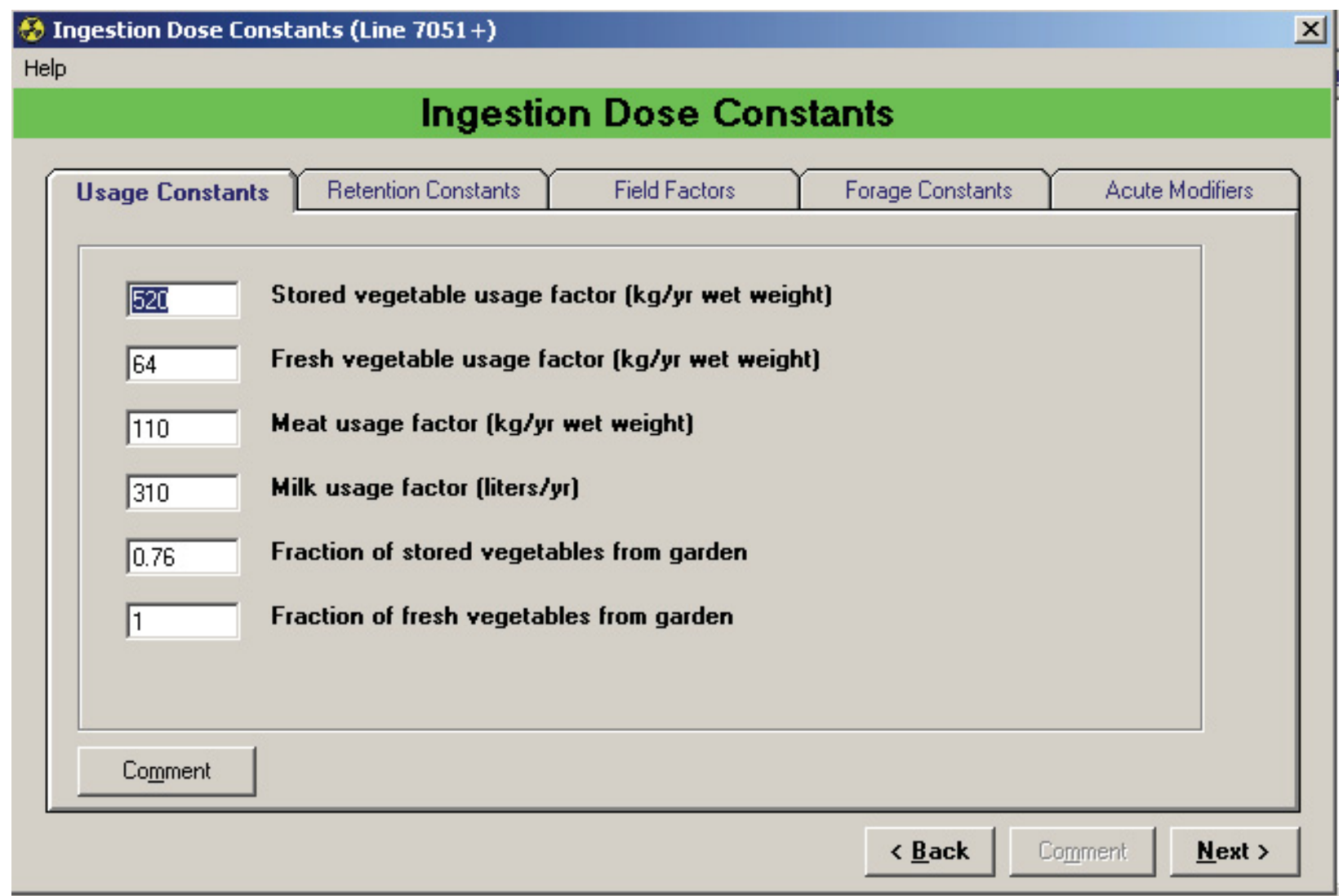

Figure 3-68. Screen 5B (Optional), Usage Constants Tab. 


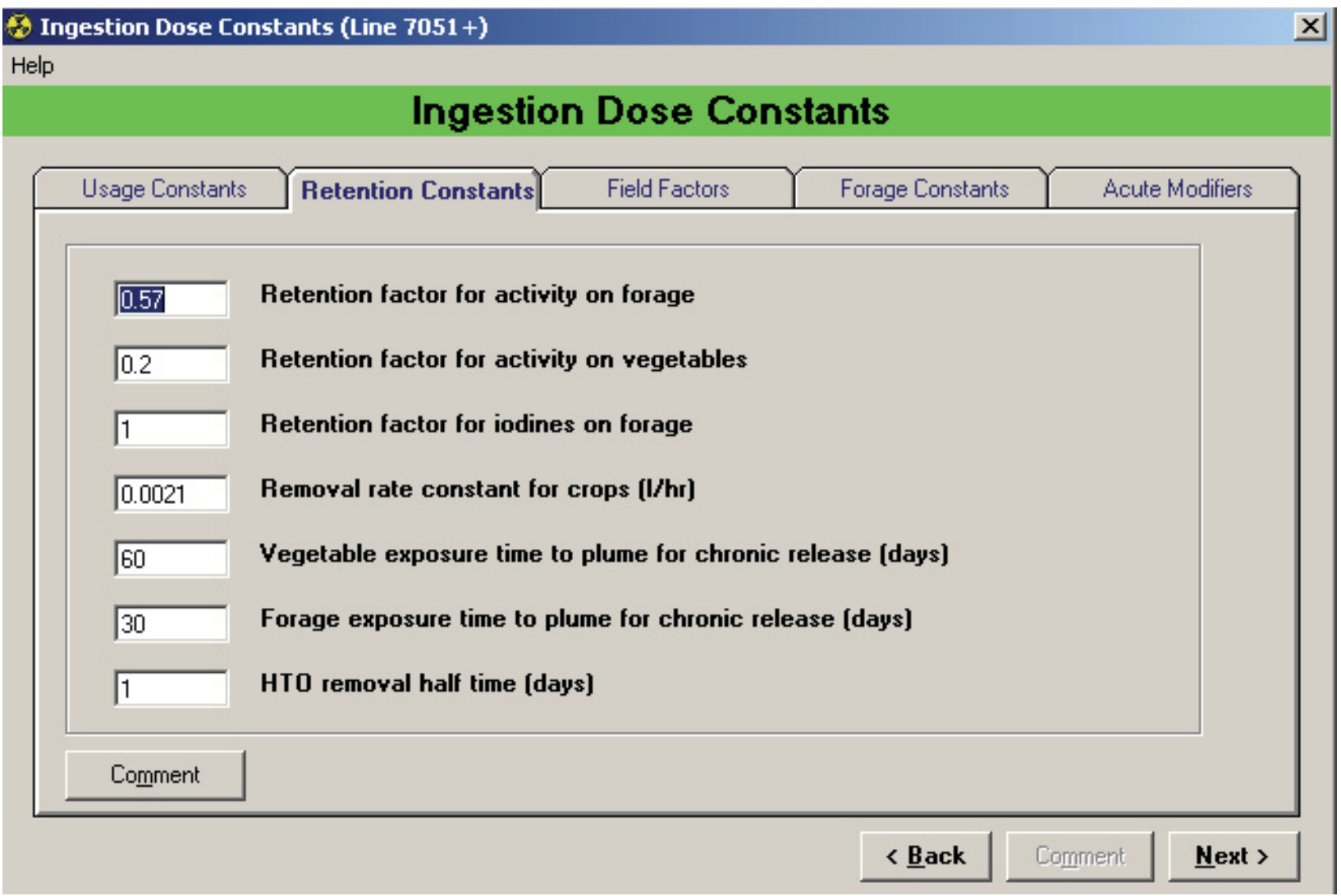

Figure 3-69. Screen 5B (Optional), Retention Constants Tab. 


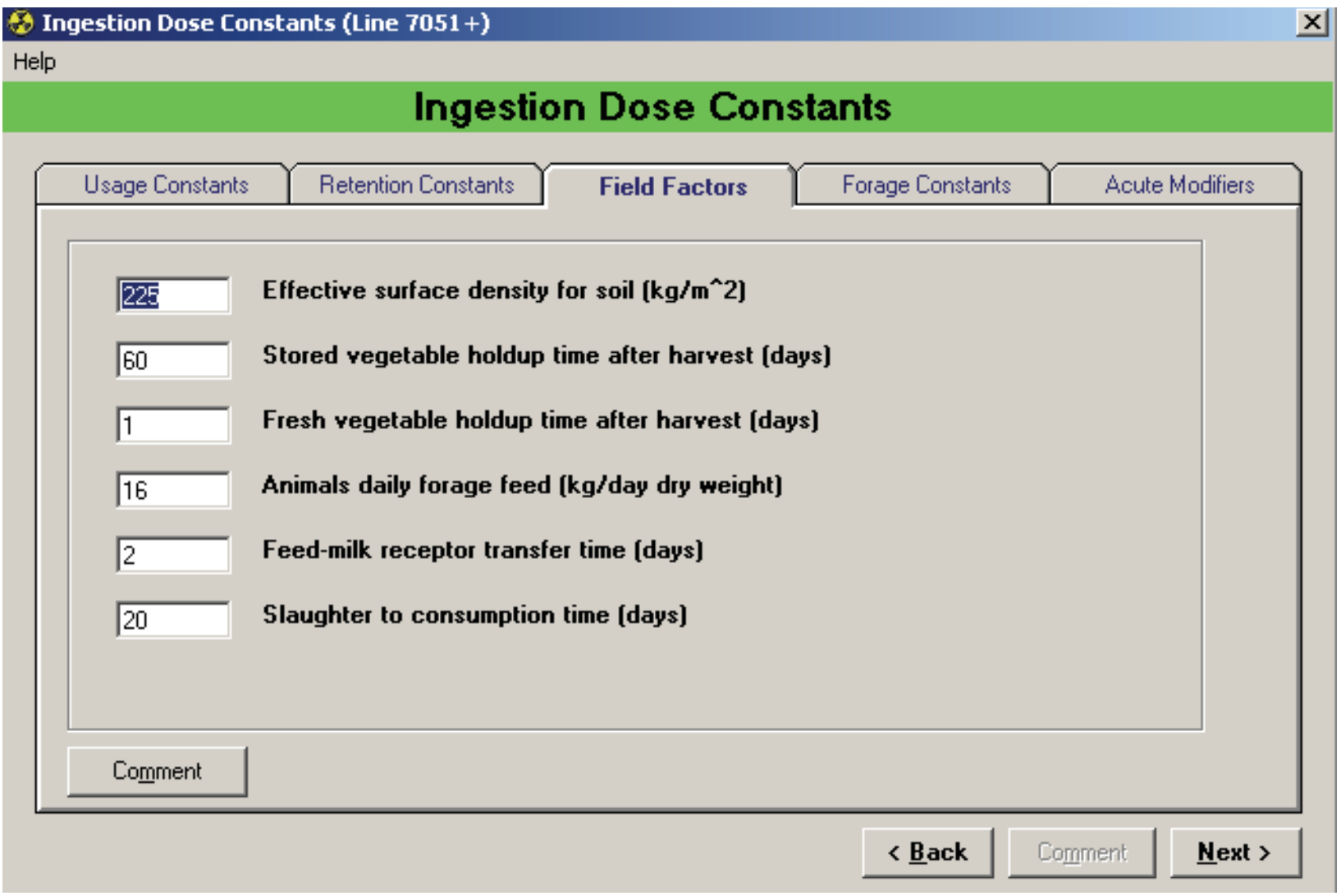

Figure 3-70. Screen 5B (Optional), Field Factors Tab. 


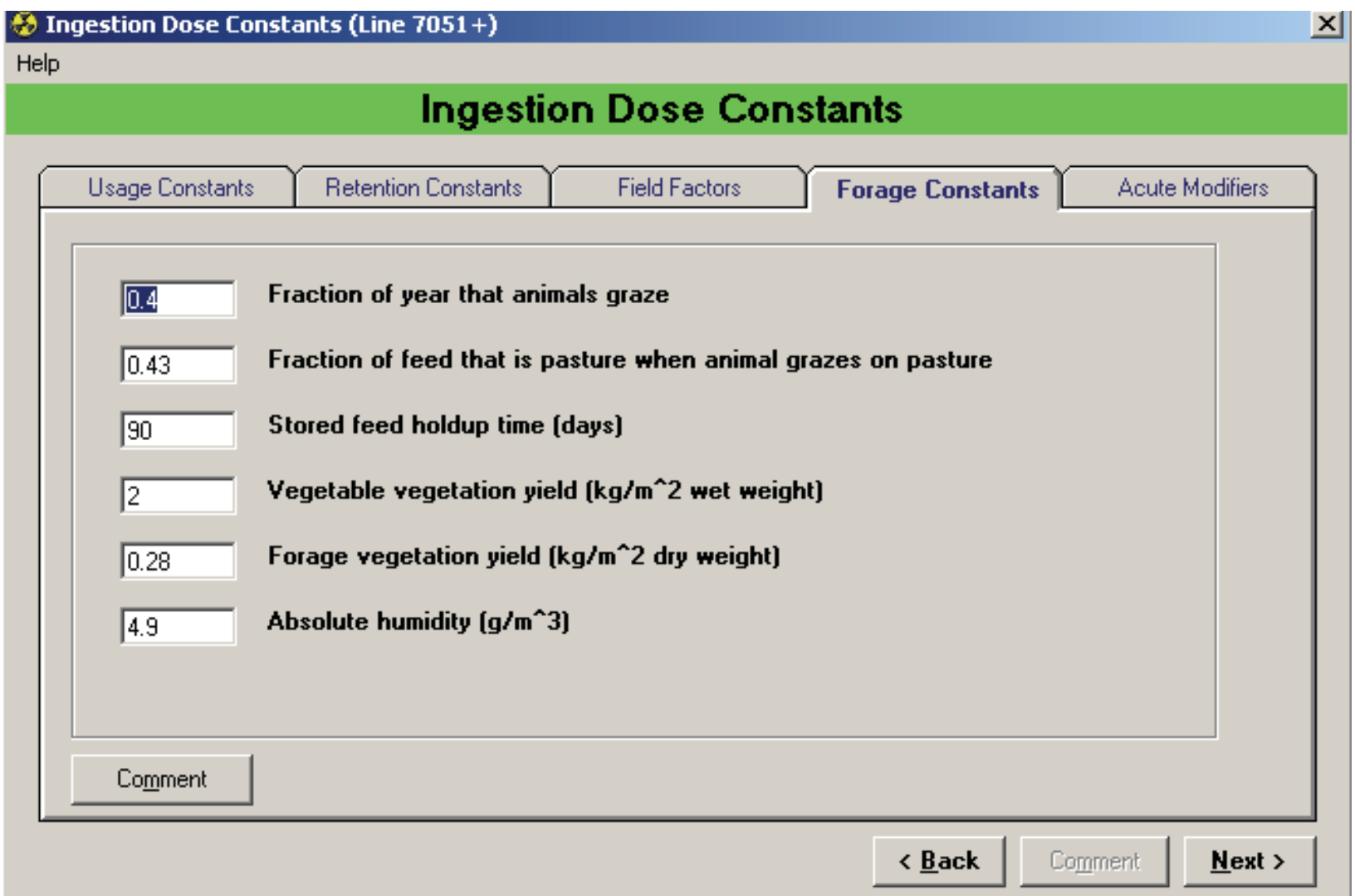

Figure 3-71. Screen 5B (Optional), Forage Constants Tab. 


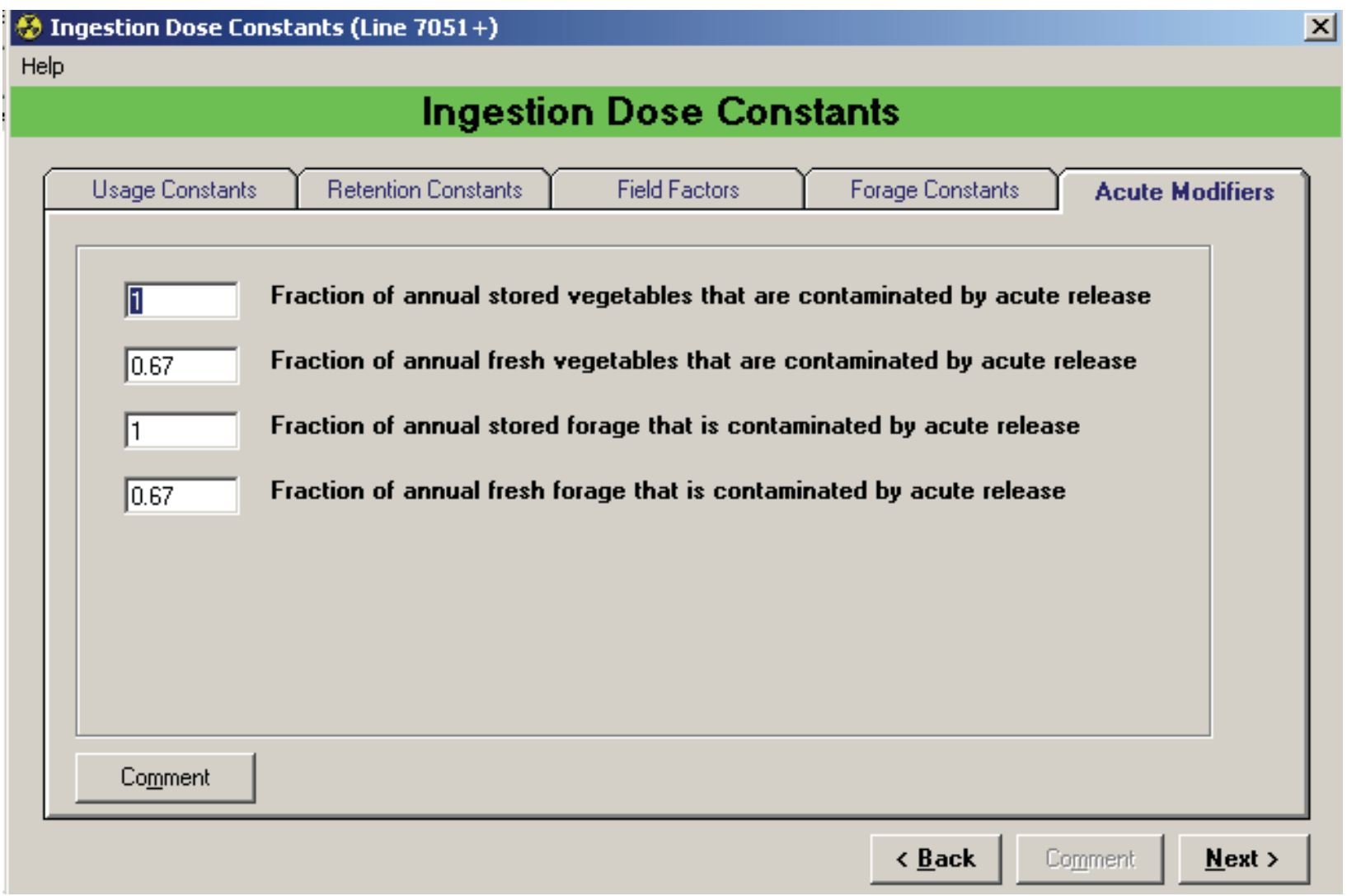

Figure 3-72. Screen 5B (Optional), Acute Modifiers. 
Screen 3C (Optional) - Ground Surface Dose Parameters: Shown only if option 5 is chosen for Type of Dose Calculation on screen 2. Enter the decay time (s) for exponential calculations, exposure time of the receptor to contaminated ground surface, and the building shielding factor (see Figure 3-73).

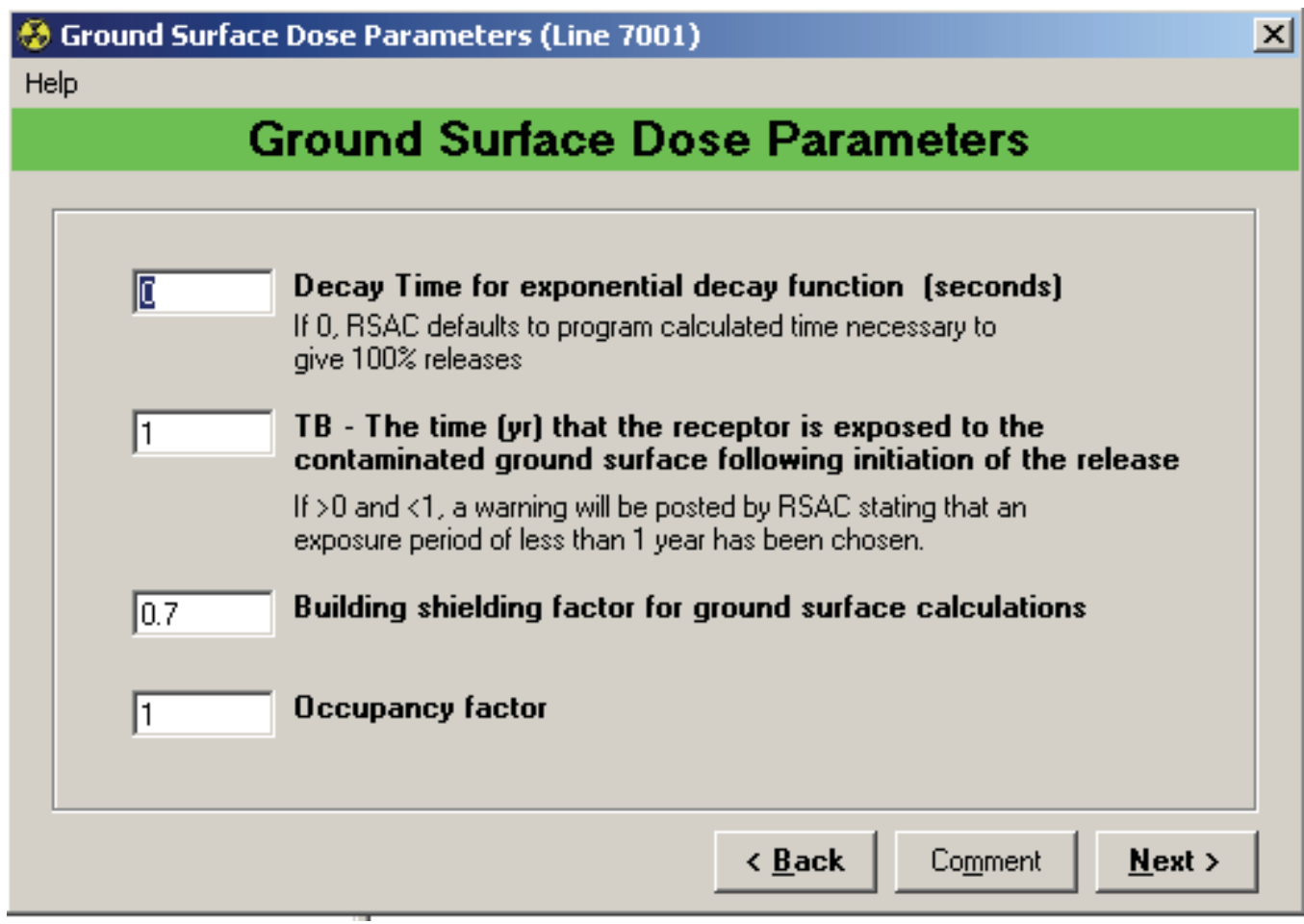

Figure 3-73. Screen 3C (Optional), Ground Surface Dose Parameters.

Screen 3D (Optional) - Air Immersion Dose Parameters: This screen appears only if option 6 is chosen for Type of Dose Calculation on screen 2. Enter decay time (s) for exponential decay functions (see Figure 3-74).

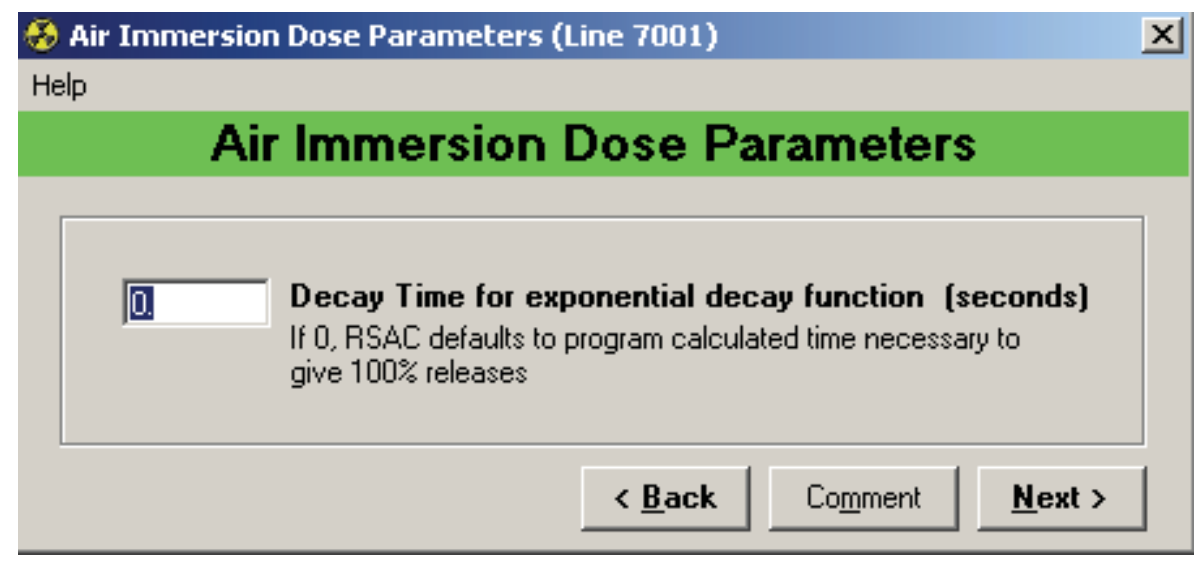

Figure 3-74. Screen 3D (Optional), Air Immersion Dose Parameters. 
Screen (Optional) - Internal/External Organ Selection: This screen appears only if Organs will be listed on a upcoming screen is chosen on screen 2. On this screen (see Figure 3-75), select the organ using one of the following methods. Scroll through the list and click on the desired organ; type the organ name to quickly select the desired organ. To unselect an organ click it in the list a second time. To clear all selected, click the Clear Selected button.

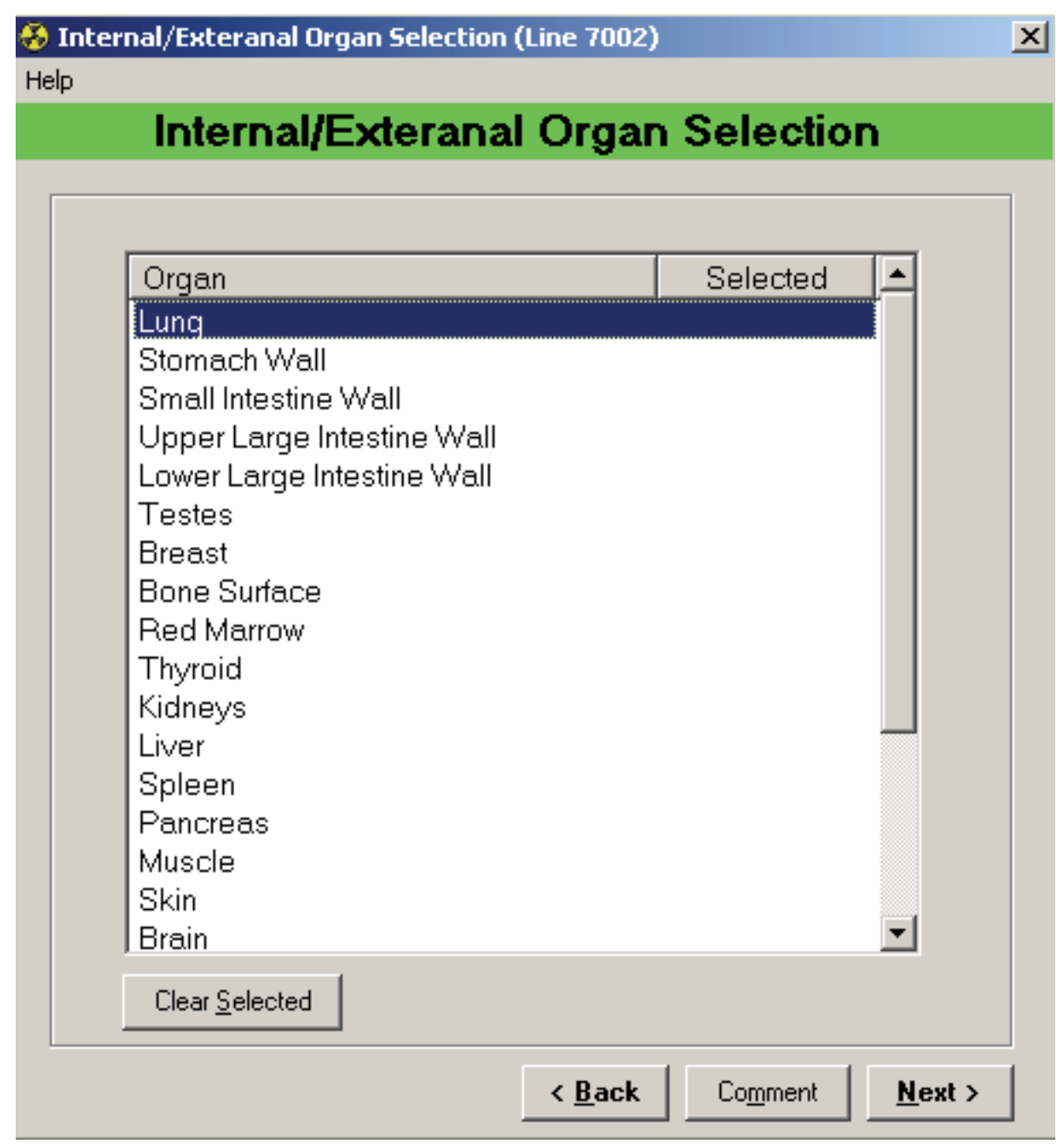

Figure 3-75. Screen (Optional), Internal/External Organ Selection. 
Screen (Optional) - Element Selection: This screen appears only if Elements will be listed on a upcoming screen is chosen on screen 2. On this screen (see Figure 3-76), select the element using one of the following methods. Scroll through the list and click on the desired element; type the symbol to quickly select the desired element. To unselect an element click it in the list a second time. To clear all selected, click the Clear Selected button.

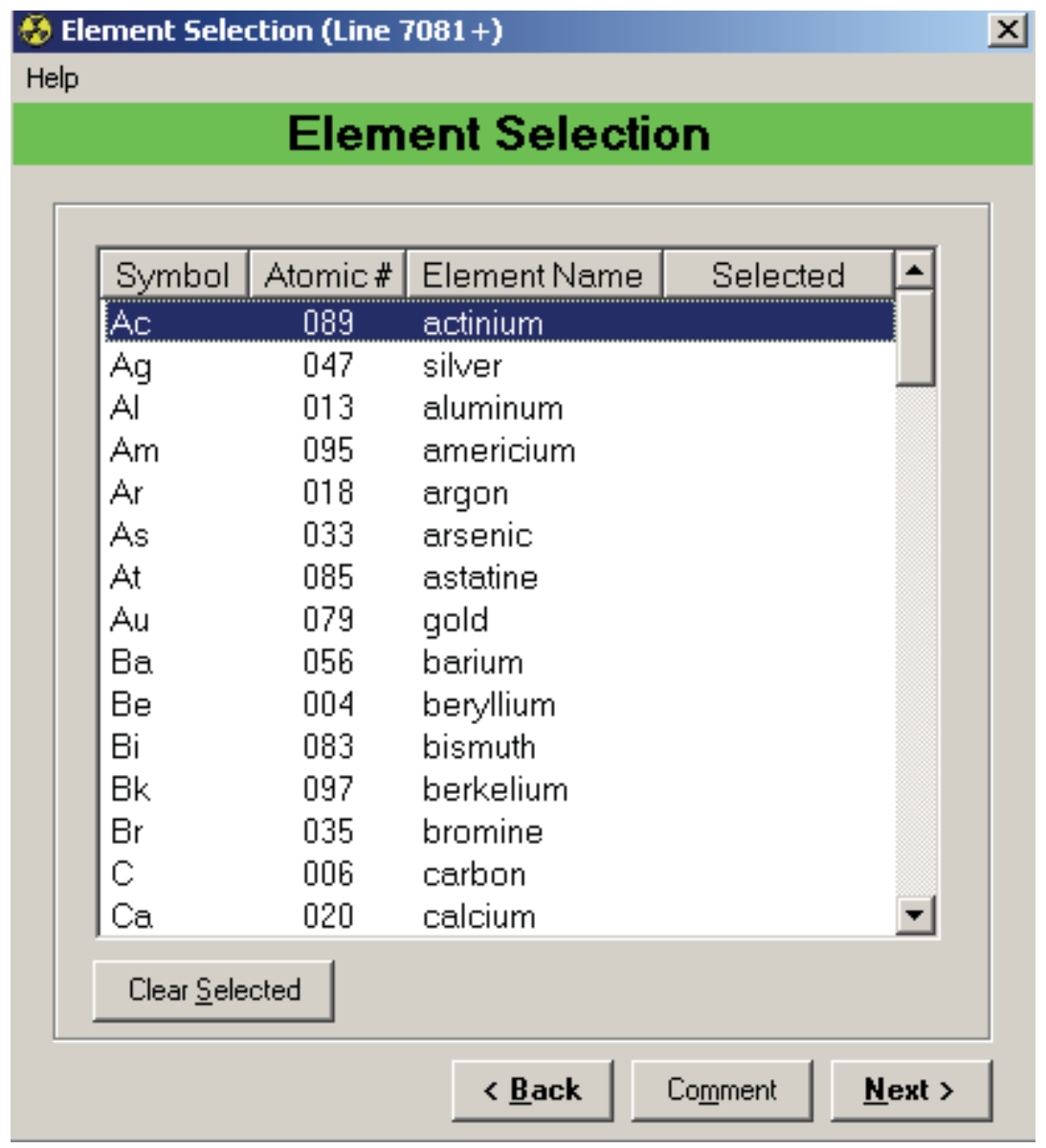

Figure 3-76. Screen (Optional), Element Selection. 


\subsubsection{Series - Cloud Gamma Dose Calculation}

Screen 2 - Cloud Gamma Dose Calculation: After the series title screen the cloud gamma does calculation screen appear asking whether calculations are to be made using the finite or semi-infinite plume model (see Figure 3-77). By checking which calculation should be used the inputs for the exponential decay function will be enabled.

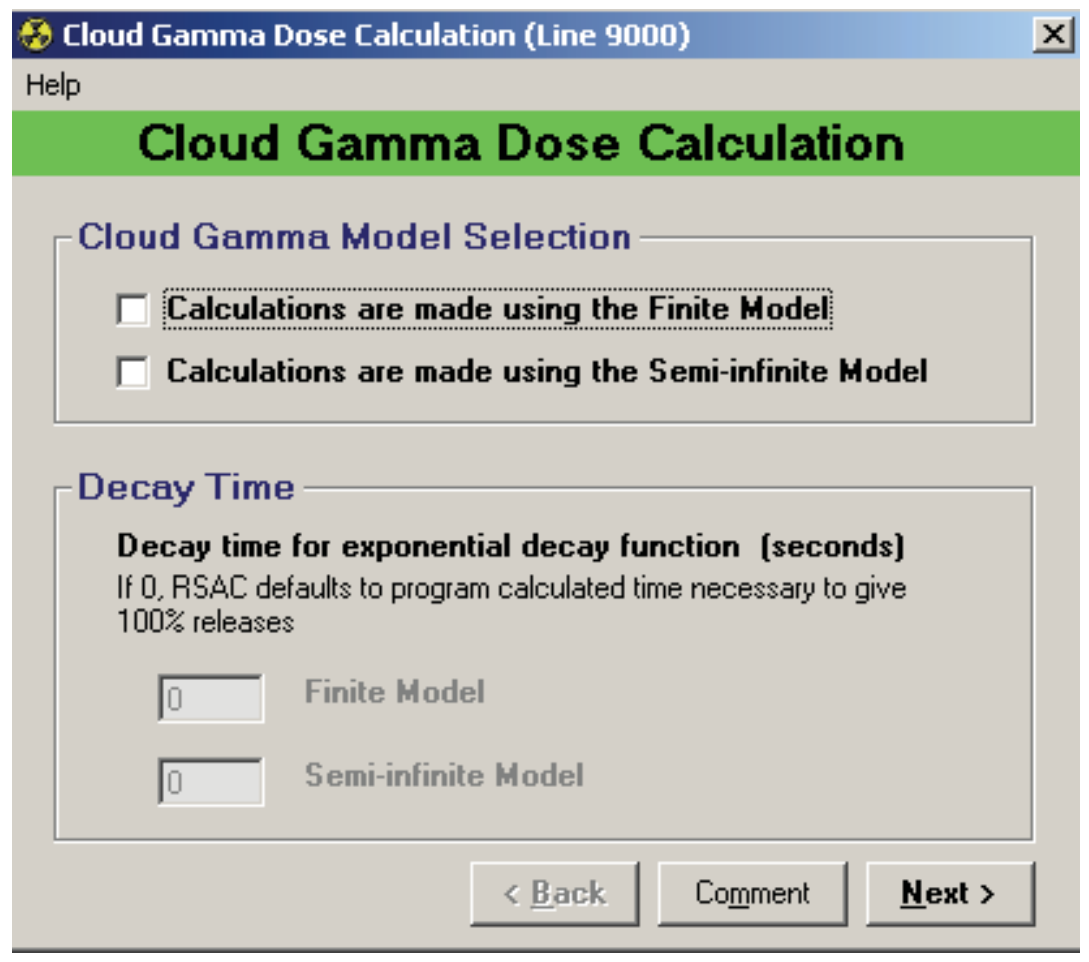

Figure 3-77. Screen 2, Cloud Gamma Dose Control.

\subsection{Critdos Subroutine}

CRITDOS calculates the prompt neutron doses using the NRC Regulatory Guide 3.33 (RG 3.33) equations. Both unshielded and shielded direct doses are calculated based on the total fission yield of the postulated criticality, the distance from the criticality to the receptor, equivalent concrete thickness of the shield, and the system being analyzed (i.e., neutron escape fraction based on the system size).

The gamma and neutron attenuation factors given in RG 3.33 vary according to the thickness of the concrete. That is, the first few inches of concrete are not as effective at attenuating radiation as the remaining thickness of concrete. Equations have been derived and put into CRITDOS that take this into account. In addition, the equations for concrete shielding that is less than $12 \mathrm{in.} \mathrm{thick} \mathrm{have} \mathrm{been} \mathrm{modified}$ to make them more realistic (i.e., best estimate rather than conservative).

The equations for calculating a dose, in rem, from RG 3.33 are based on $10 \%$ of the neutrons escaping from the system. The equations in CRITDOS have been modified to allow the user two additional options for neutron escaping from the system. In addition to the 0.10 escape fraction, which is representative of a large moderated system, the user can choose a moderated system with an escape fraction of 0.30 or a small unreflected metal system with an escape fraction of 0.70 .

To run the Critdos subroutine click on the Critdos tab and click the Launch Critdos link (see Figure 3-78). 


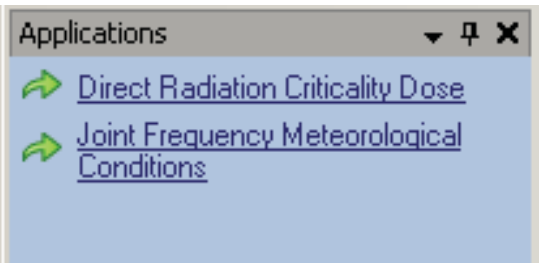

Figure 3-78. Applications Tab.

Screen 1 - Data Input: Use this screen to supply the following information (see Figure 3-79): The title that will appear on each page of output: The total fissions; Distance in feet; Concrete thickness in inches; and the System type.

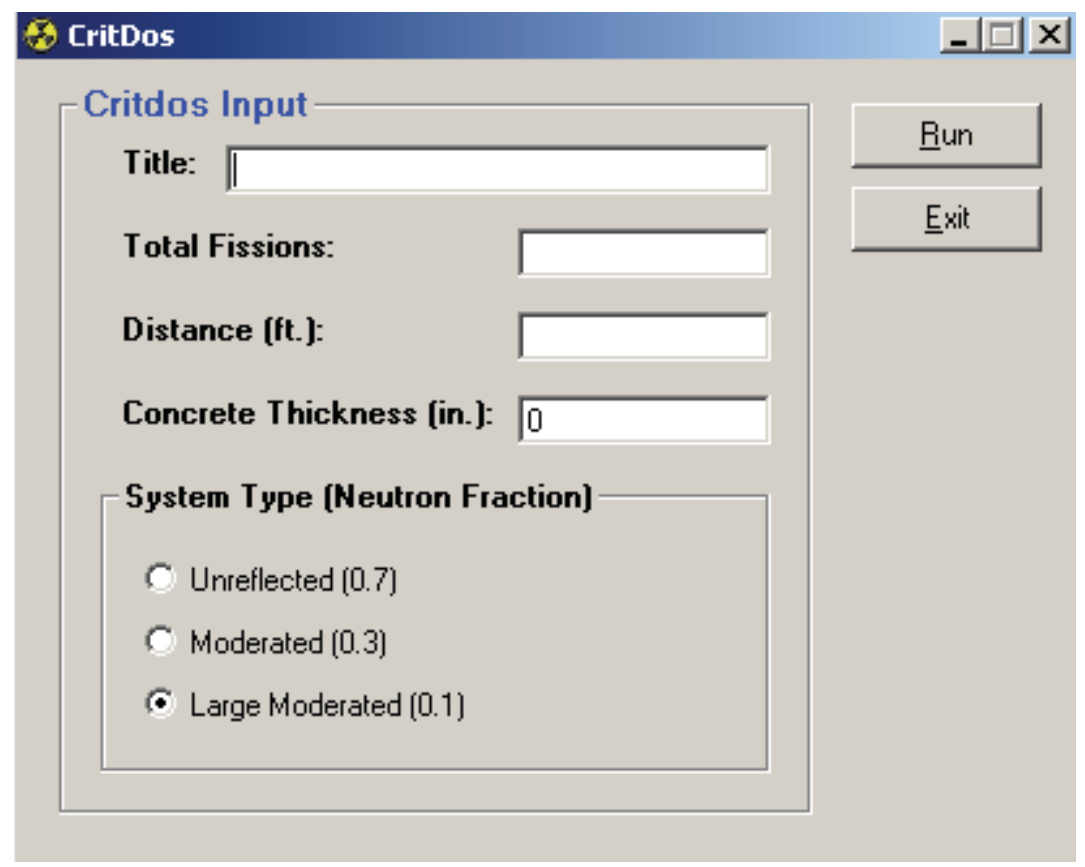

Figure 3-79. Screen 1, Data Input. 
Screen 2 - Program Output: Displays the output results from Critdos (see Figure 3-80).

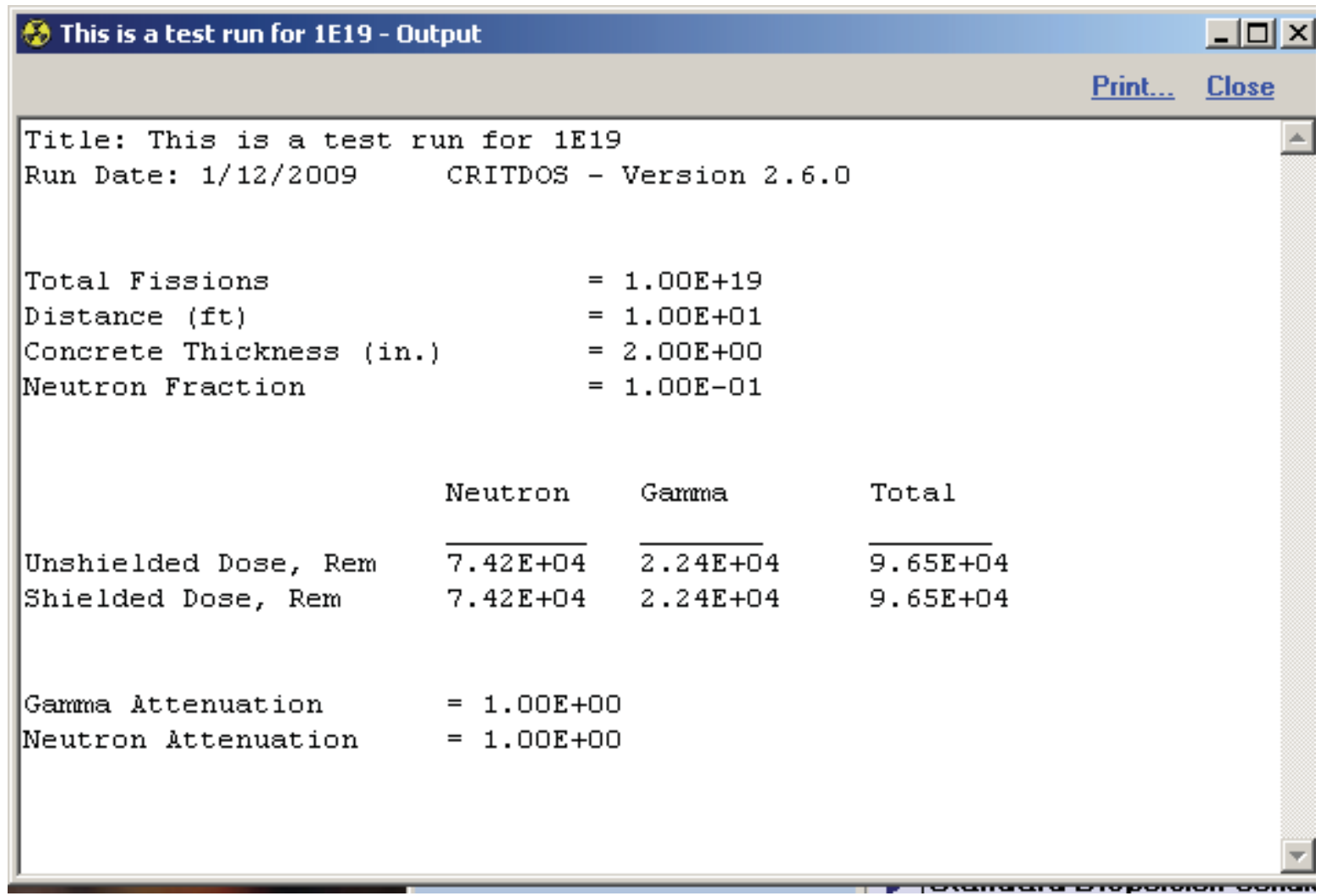

Figure 3-80. Screen 2, Program Output.

\subsection{MetCond Subroutine}

The metCond subroutine uses a joint frequency distribution to define the meteorological conditions where normalized concentrations $(\chi / \mathrm{Q})$ are exceeded no more than $5 \%$ and $50 \%$ of the time. The metCond subroutine defines this condition on data as summarized by the National Weather Service (NWS) meteorological data, CD-144 format. The input is a joint frequency distribution of 6 windspeeds, 16 wind directions, and 6 stability categories (Pasquill - Gifford: A through F) for the station and time period desired. The computational program is written in FORTRAN, and the user interface is written in VisualBasic for DOS. The joint frequency data for a significant number of locations have been provided integral to the software. If your specific location is not available, the data are available from the NWS and can be directly added to the library. 


\section{Joint Frequency Meteorological Conditions}

A description of the facility and its reason for selection is placed in the top frame (see Figure 3-81). This program reads standard STAR data obtainable from most airports and consists of a reduction of hourly readings to a form that can be evaluated in a joint frequency model. The output is a metrological stability class and wind speed that represents the conditions where $95 \%$ of the time will result in lower dose to a receptor.

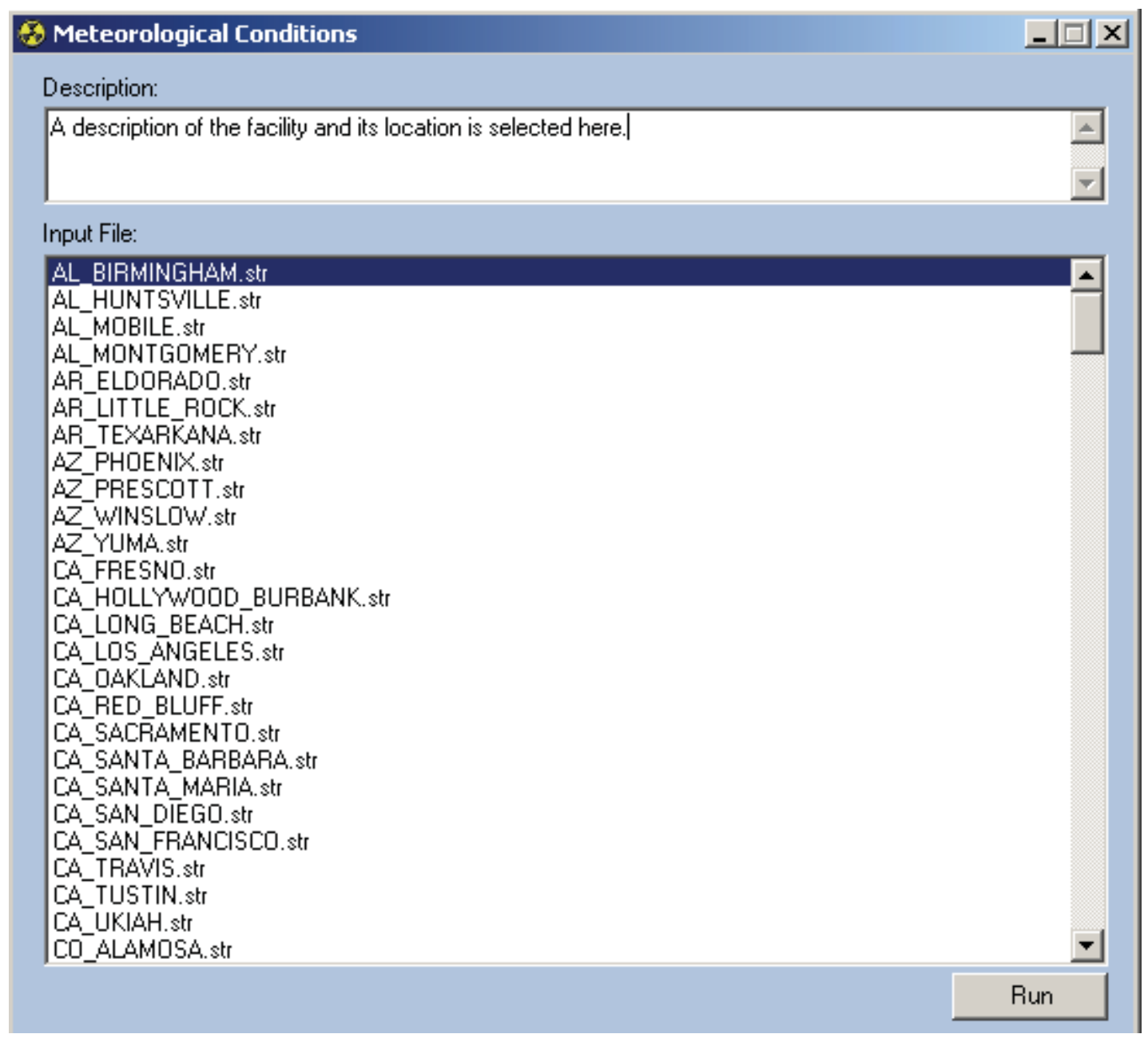

Figure 3-81. Meteorological Conditions screen.

A joint frequency table is generated as shown in Figure 3-82. 


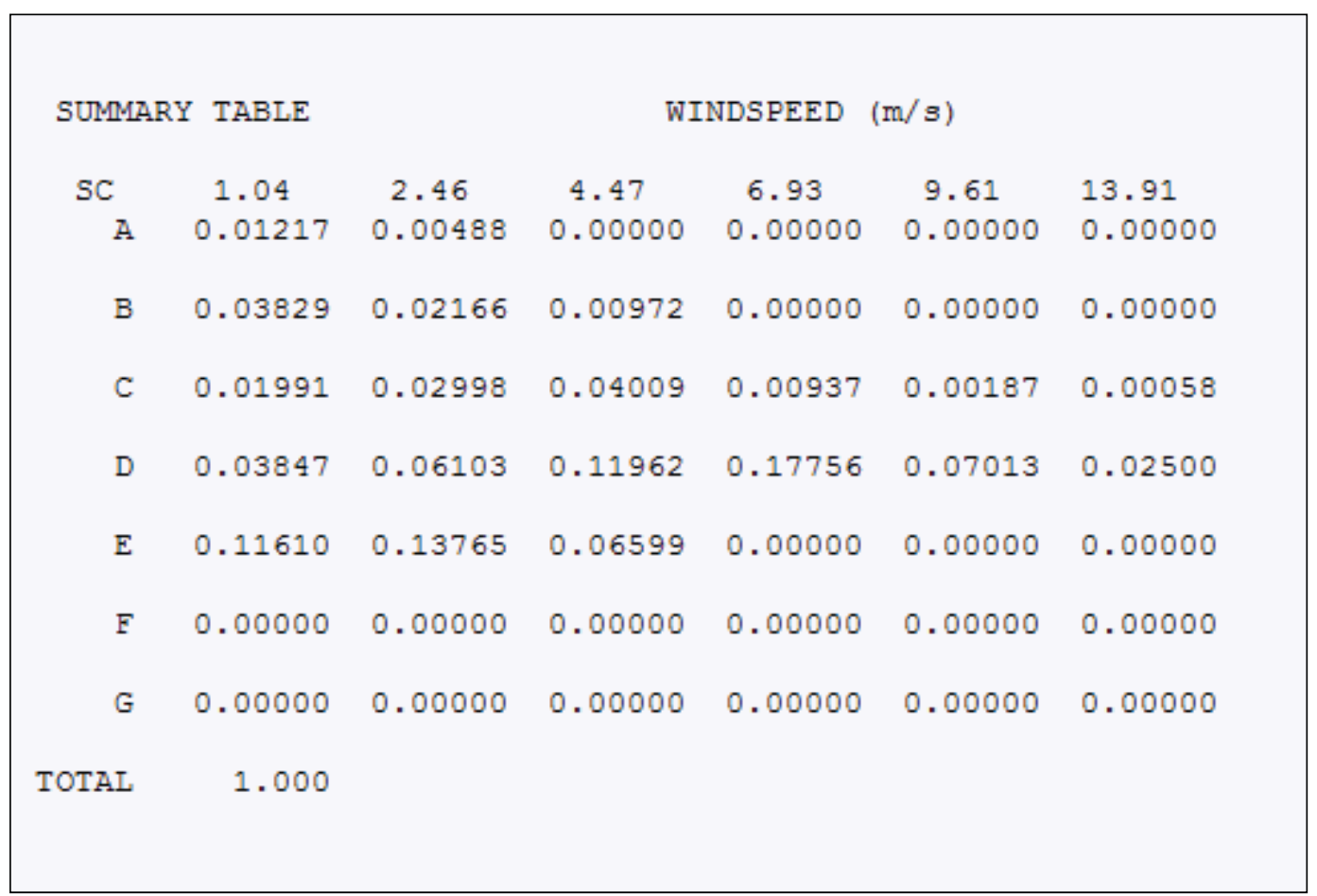

Figure 3-82. Generated joint frequency table.

From that data two points of interest are reported (see Figure 3-83). 


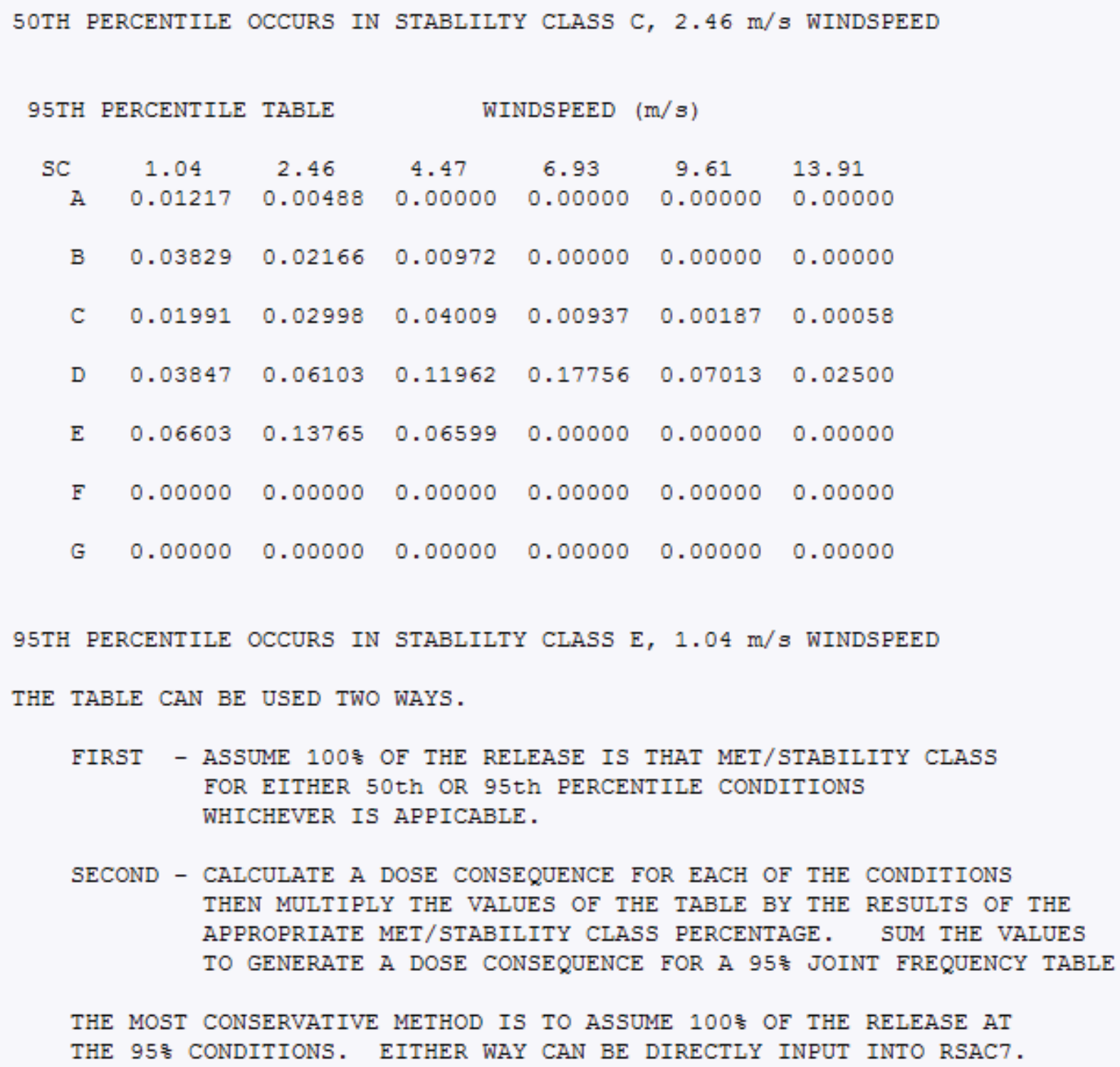

Figure 3-83. Table generated from two points of interest. 
INTENTIONALLY BLANK 


\section{Reading the RSAC-7.2 INPUT File \\ 4.1 RSAC-7.2 Input}

A typical RSAC-7.2 input line includes

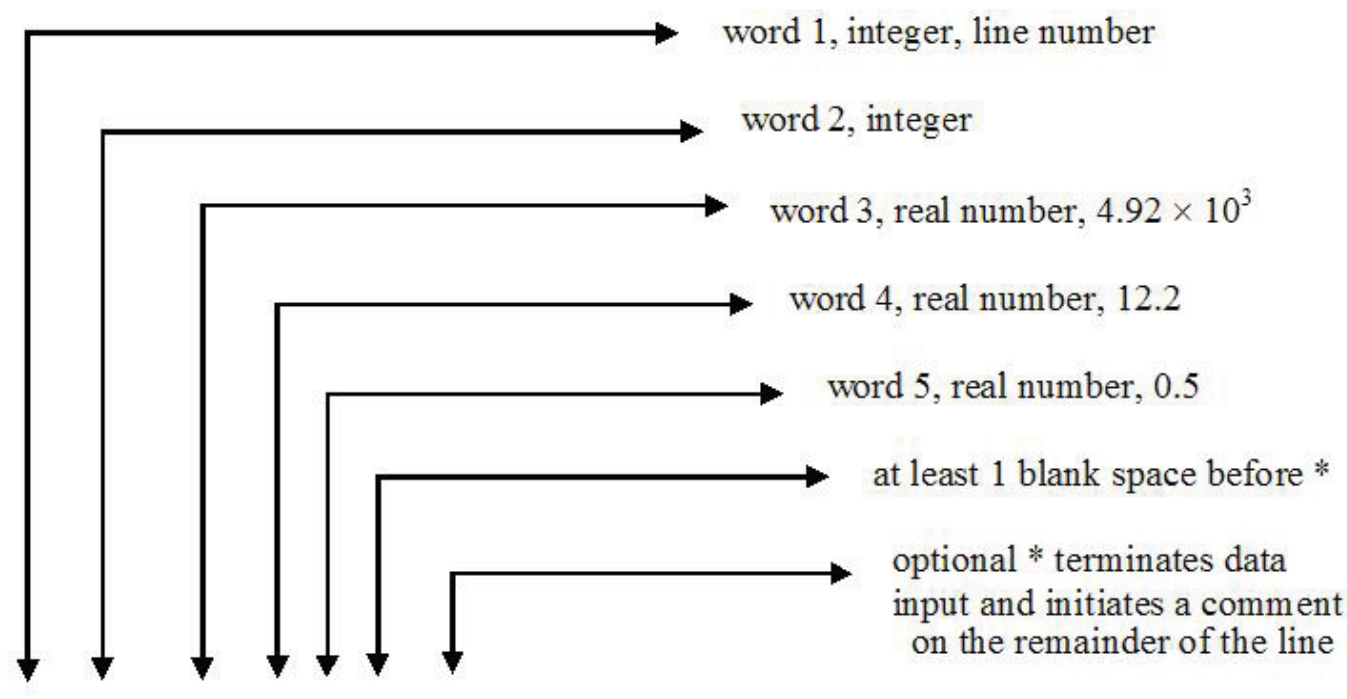

$5400,1,4.92+3,12.2, .5 \quad$ *YOUR COMMENT ON LINE

Other variations of this same line include

5400, 1, 4.92E3, 12.2, 5.E-1 *YOUR COMMENT ON LINE

\section{$54001492+4$ 1.22E+1 5.-1 *YOUR COMMENT ON LINE}

A comma or a blank space can be used as delimiters between entries. Each integer or real number entry is referred to as a "word." The first word of every line is referred to as the "line number," which is used to check input sequences.

As shown in the third word of the last variation above $(492+4)$, when a real number does not contain a decimal point, the decimal point is assumed to appear before the first digit. However, you are encouraged to place a decimal point in real numbers. The following RSAC-7.2 input descriptions assume that all words are real numbers unless otherwise noted. Changes from RSAC-6 to RSAC-7.2 are noted in red.

The input descriptions in this section include word, program name, entry, and description information. The word column presents the location of the entry. The program name column identifies the name given to the variable in the source program and is not input on a line. The entry and description columns provide the entry numbers or type of entry and their corresponding descriptions.

To insert a comment line, type a \# sign in the first column. There is no limit to the number of comment lines you can insert. Comment lines are printed in the RSAC-7.2 ASCII input file and appear in the list of input printed at the beginning of each output file.

The example runs in Section 5 will help you learn how to prepare ASCII input for the RSAC-7.2 program. 


\subsection{Calculation Title Line}

\section{ColumnEntry}

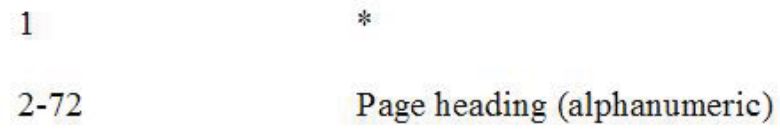

RSAC-7.2 ignores all lines of input until it reads a line that contains an asterisk in column 1. This allows the program to start the next problem if an error is found in the input. If output is not received from an RSAC-7.2 run, check to see if a line contains an asterisk in column 1.

\subsection{1 $\quad$ 1000 Series - Fission Product Inventory Calculation and Inventory Decay}

Use a Fission Product Calculation and Inventory Decay Control Line (1000) to initiate fission product inventory calculations or inventory decay calculations of a directly input radionuclide inventory. Input the following lines to describe the reactor operating history and the fractionation of the fission product inventory. This calculation generates a fission product inventory only. It does not calculate the actinides available for release. These should be directly input using a 2000 series and may be added to the calculated fission product inventory. If subsequent decay is required, an additional 1000 series should be used to calculate the decay of inventory. The 6000 series does not calculate a decayed inventory for subsequent release. It will only decay the inventory for printout purposes.

\subsubsection{Fission Product Inventory Calculation and Inventory Decay Control Line (1000)}

\begin{tabular}{cccc} 
Word & Variable Name & Entry & Description \\
\hline 1 & 1000 &
\end{tabular}

\subsubsection{Inventory Control/Initial Reactor Data Line (1001)}

The required Inventory Control/Initial Reactor Data Line (1001) must immediately follow the Fission Product Inventory Calculation and Inventory Decay Control Line (1000). Use the control word on this line to indicate whether you are

a) calculating a new fission product inventory (actinides are not calculated) or

b) modifying a previously calculated radionuclide inventory.

If you want to calculate a new fission product inventory, enter the reactor power, and operating time on this line. The next line may be a Refueling Line (1002), Decay/Cycle Line (1003), or Fractionation Line (1004) to modify the release calculation.

If you are modifying a directly input radionuclide inventory, the remaining words on this line are ignored (but must be present) and the next line must be a Refueling Line (1002), Decay/Cycle Line (1003), or Fractionation Line (1004).

\begin{tabular}{cll} 
Word Variable Name & Entry & \multicolumn{1}{c}{ Description } \\
\hline 1 & 1001 & \\
2 & Integer & Control word: \\
0 & Calculations start with no previous radionuclide inventory. \\
& & $\begin{array}{l}\text { Previous radionuclide inventory is retained and the next line } \\
\text { must be a Refueling Line (1002), Decay/Cycle Line (1003), or } \\
\text { Fractionation Line (1004). The values for the remaining } \\
\text { words on this line are ignored; however, values for each of } \\
\text { the following words must be present. }\end{array}$
\end{tabular}




\begin{tabular}{|c|c|c|c|}
\hline Word & Variable Name & Entry & Description \\
\hline \multirow[t]{6}{*}{3} & POWER & & Reactor power (W) or 0.0 if word $2=1$ \\
\hline & & & $\begin{array}{l}\text { If megawatt days }(\mathrm{MWd}) \text { of an operating cycle are known } \\
\text { use the following conversion to generate the inputs for words } \\
3 \text { and } 4 \text {. }\end{array}$ \\
\hline & & & If operating power and MWd are known: \\
\hline & & & $\begin{array}{l}8.64 \mathrm{E} 10 \mathrm{~W}-\mathrm{s} / \mathrm{MWd} \text {, then divide through by the average } \\
\text { power }(\mathrm{W}) \text { for the cycle, and the resultant will give the } \\
\text { reactor operating time in seconds. }\end{array}$ \\
\hline & & & If operating time and MWd are known: \\
\hline & & & $\begin{array}{l}8.64 \mathrm{E} 10 \mathrm{~W}-\mathrm{s} / \mathrm{MWd} \text {, then divide through by the } \\
\text { operating time (seconds) for the cycle, and the resultant } \\
\text { will give an average reactor power in watts. }\end{array}$ \\
\hline 4 & TROP & & $\begin{array}{l}\text { Reactor operating time at the above power (s) or } 0.0 \text { if word } \\
2=1 \text {. }\end{array}$ \\
\hline
\end{tabular}

\subsubsection{Refueling Line (1002)}

\begin{tabular}{|c|c|c|c|}
\hline Word & Variable Name & Entry & Description \\
\hline 1 & & 1002 & \\
\hline 2 & & & $\begin{array}{l}\text { The fraction of radionuclide inventory remaining after } \\
\text { refueling. This is the same total inventory fractionation as } \\
\text { performed when word } 2 \text { of Fractionation Control Line } \\
\text { (1004) is equal to } 2 \text {. }\end{array}$ \\
\hline
\end{tabular}

The Decay/Cycle Line (1003) is used to calculate the inventory decay as generated with an Inventory Control/Initial Reactor Data Line (1001) or a 2000 series directly input radionuclide inventory. This is the only location in the program where the radionuclide inventory decay can be calculated. A 6000 series decay does not calculate an inventory decay for subsequent release. If a subsequent reactor cycle is required then words 3 and 4 can be used to cycle the reactor.

\subsubsection{Decay/Cycle Line (1003)}

\begin{tabular}{cccl} 
Word & Variable Name & Entry & \multicolumn{1}{c}{ Description } \\
\hline 1 & & 1003 & \\
2 & TTROP & & $\begin{array}{l}\text { Decay time or reactor shutdown time before this cycle (s). } \\
\text { Reactor power for cycle (W). If zero, TROP below is set to } \\
\text { zero, and the next entry is ignored. }\end{array}$ \\
& POWER & TROP & $\begin{array}{l}\text { Reactor operating time at above reactor power for this } \\
\text { cycle (s). This quantity is set to zero if reactor power above is } \\
\text { zero. }\end{array}$
\end{tabular}

\subsubsection{Fractionation Control Line (1004)}

Use this line to release a fraction of the radionuclide inventory and simulate removal of activity by cleanup systems such as HEPA filters. Use the control word on this line to determine whether the type of fractionation is by group, by a constant value, or by element. Specify fractionation by the following 
groups: solids, halogens, noble gases, cesium, and ruthenium. Enter the fractionation value for each group on this line. If the constant fractionation option is used, the entire radionuclide inventory is fractionated by the next value entered on this line. If fractionation by element is chosen, enter a fractionation value for those elements not described by an Element Fractionation Lines $(1101+)$ on this line. Enter the Element Fractionation Lines (1101+), describing the fractionation of each desired element.

\begin{tabular}{ccl} 
Word & Entry & \\
\hline 1 & 1004 & Description \\
2 & -1 & Fractionation by group as specified by the next five words. \\
& & Fractionation for solids. \\
4 & & Fractionation for halogens. \\
5 & & Fractionation for noble gases. \\
6 & & Fractionation for cesium. \\
7 & & Fractionation for ruthenium. \\
2 & & Fractionation is by a constant specified by the next word. \\
3 & FRAC & Fractionation for entire radionuclide inventory. \\
2 & 1 & $\begin{array}{l}\text { Fractionation by element. Following lines will be Element Fractionation Lines } \\
\text { (1101+). }\end{array}$ \\
3 & FRAC & Fractionation for elements not described by Element Fractionation Lines (1101+).
\end{tabular}

\subsubsection{Element Fractionation Lines (1101+)}

Use these lines only if you want fractionation by element.

\begin{tabular}{lll}
\multicolumn{1}{c}{ Word } & \multicolumn{1}{c}{ Entry } & \multicolumn{1}{c}{ Description } \\
\hline 1 & Integer & $11 \mathrm{XX}(\mathrm{XX}=01,02, \ldots$, etc. $)$ \\
2 & Integer & Atomic number of element. \\
3 & & Fractionation for above element. \\
$\cdot$ & & $\cdot$ \\
$\cdot$ & & $\cdot$ \\
$2 \mathrm{~N}$ & Integer & $\mathrm{N}^{\text {th }}$ atomic number \\
$2 \mathrm{~N}+1$ & $\mathrm{X}$ & $\mathrm{N}^{\text {th }}$ fractionation
\end{tabular}

Enter additional sets of two values on this and following lines until all desired elements have been described. The number of sets per line is optional.

\subsubsection{Release During Simulated Reactor Operations Line (1200)}

Use this optional control line to simulate radionuclide releases from a reactor while it is operating. Insert a Release During Fission Product Calculation Line (1200) immediately following either the Initial Reactor Data Line (1001) or the Cycle Line (1003) to modify the reactor operations requested by the (1001) or (1003) lines. 
A Reactor Linear Leak Rates Line (1201) must immediately follow a (1200) line. Activity is removed from the reactor incrementally using the number of chosen steps (1 to 100) over the entire reactor operating cycle requested by a (1001) or (1003) line. The number of steps should reflect the need for resolution of the release. The more steps, the more exact the totals will be for the shorter lived radionuclides.

RSAC-7.2 has two memory buffers for storing radionuclide inventories: main and hold. The activity remaining in the reactor is stored in a main memory buffer, and the activity released from the reactor is stored in the hold memory buffer. You can choose whether the activity leaked from the reactor (hold buffer) or that remaining in the reactor following operations (main buffer) is used in further calculations. When you choose the option to retain the activity remaining in the reactor after encountering a (1999) line, the main memory buffer is retained for further calculations and the hold buffer is deleted. Normally the activity leaked from the reactor (hold buffer) is used for release calculations.

When you choose the option to retain the activities released from the reactor during each step increment are summed to give the total amount of each radionuclide released from the reactor during the total operating period. After activity is entered into the hold memory buffer, it cannot be decayed until after a Fission Product Calculation and Inventory Decay End Line (1999) is encountered When you choose the option to retain the activity released from the reactor, the hold memory buffer is copied to the main memory buffer for subsequent calculations, and the radionuclide inventory that was remaining in the reactor is deleted.

After a (1200) line is encountered, it remains in effect on all subsequent reactor cycle operations (Cycle Line [1003]) until either another (1200) line or a Fission Product Calculation and Inventory Decay End Line (1999) is encountered.

When the (1200) line option is used, all subsequent fractionations of the radionuclide inventory using (1004) lines (until a [1999] line is encountered) are made on the inventory chosen to be retained for subsequent calculations. If desired you can make even further decay (and fractionation) by exiting the 1000 Series with a (1999) line and reentering the 1000 Series with another (1000) line.

\begin{tabular}{cccl} 
Word & $\begin{array}{c}\text { Variable } \\
\text { Name }\end{array}$ & Entry & \multicolumn{1}{c}{ Description } \\
\hline 1 & & 1200 & \\
2 & NCS & Integer & Number of reactor release steps $(\leq 100)$ \\
3 & KEEPFLAG & Integer & Inventory to be retained for subsequent calculations: \\
& & 0 & Retain activity remaining in reactor \\
& & 1 & Retain activity remaining in reactor
\end{tabular}

\subsubsection{Reactor Linear Leak Rates Line (1201)}

You must insert the Reactor Linear Leak Rates Lines (1201) immediately following a (1200) line to establish the leak rates for the different groups of fission products. Calculation of the Linear Leak Rate is performed by dividing the fraction of the group to be released from the reactor by the total reactor operating time of the cycle in seconds.

\begin{tabular}{cccl} 
Word & $\begin{array}{c}\text { Variable } \\
\text { Name }\end{array}$ & Entry & \multicolumn{1}{c}{ Description } \\
\hline 1 & & 1201 & Radionuclide leak rate from the operating reactor (fraction/s) \\
2 & RR(1) & & Solids \\
3 & RR(2) & & Halogens
\end{tabular}




\begin{tabular}{cccc} 
Word & $\begin{array}{c}\text { Variable } \\
\text { Name }\end{array}$ & Entry & Description \\
\hline 4 & $\operatorname{RR}(3)$ & Noble gases & \\
5 & $\operatorname{RR}(4)$ & Cesium & \\
6 & $\operatorname{RR}(5)$ & Ruthenium &
\end{tabular}

\subsubsection{Fission Product Calculation and Inventory Decay End Line (1999)}

Use this line to end the fission product inventory calculation or inventory decay requested by the last Fission Product Calculation and Inventory Decay Line (1000).

\begin{tabular}{cc} 
Word & Entry \\
\hline 1 & 1999
\end{tabular}

\subsubsection{Series - Direct Radionuclide Input}

Use the Radionuclide Direct Input Control Line (2000) to initiate directly entering the radionuclide inventory in curies instead of using a fission product inventory. All radionuclides are identified by the radionuclide identification number (NUCL) or by entering the element symbol followed by the atomic number.

\subsubsection{Radionuclide Direct Input Control Line (2000)}

This control line has one data word that identifies whether an existing radionuclide inventory should be deleted, changed, or appended. If the option to change or append the file is chosen, the previous radionuclide inventory can be from another directly calculated (1000 series), input or another external file. It is important to understand that if an inventory decay is required, it must be done in a 1000 series decay (1003) line. A 6000 series decay calculation is for display and print purposes only and will not calculate the active inventory decay.

\begin{tabular}{|c|c|c|}
\hline Word & Entry & Description \\
\hline 1 & 2000 & \\
\hline \multirow[t]{3}{*}{2} & 0 & $\begin{array}{l}\text { Radionuclide inventory input option is chosen. Any previous radionuclide inventory } \\
\text { is deleted. Radionuclide entry lines or an external file (2002) may be identified. If } \\
\text { direct input of radionuclides and their respective activities is desired then the } \\
\text { requirements of Radionuclide Entry Lines must be followed. If an external file is } \\
\text { requested the requirements of line (2002) must be followed. }\end{array}$ \\
\hline & 1 & $\begin{array}{l}\text { Same as for entry } 0 \text { except the previous radionuclide inventory is retained and the } \\
\text { activity of the chosen radionuclide is changed to that indicated on either the } \\
\text { Radionuclide Entry Lines or an external file. }\end{array}$ \\
\hline & -1 & $\begin{array}{l}\text { Same as for entry } 0 \text { except the previous radionuclide inventory is retained and the } \\
\text { activity of the chosen radionuclide is added to that indicated on either the } \\
\text { Radionuclide Entry Lines or an external file. }\end{array}$ \\
\hline \multirow[t]{3}{*}{3} & 0 & curie \\
\hline & 1 & gram \\
\hline & 2 & $\mathrm{~Bq}$ \\
\hline
\end{tabular}




\subsubsection{Radionuclide Entry Lines}

Radionuclide Entry Lines are present only when an external file (2002) line option is not selected. Following the last entry of an inventory for a radionuclide, you must enter an Input End Line (2999).

\begin{tabular}{|c|c|c|c|}
\hline Word & $\begin{array}{c}\text { Variable } \\
\text { Name }\end{array}$ & Entry & Description \\
\hline \multirow[t]{2}{*}{1} & NUCL & Integer & $\begin{array}{l}\text { Radionuclide identification number (see } 4000 \text { Series, } \\
\text { Radionuclide Data Change Line). An alternate entry can be } \\
\text { made by replacing NUCL with the element symbol (in capital } \\
\text { letters) followed by the mass number and metastable state } \\
\text { indicator. Examples of allowable styles include }\end{array}$ \\
\hline & & & $\begin{array}{l}\text { Cs137, Cs-137, Cs } 137 \\
\text { Ba137m, Ba-137m, Ba } 137 \mathrm{~m} \\
\text { CS137, CS-137, CS } 137 \\
\text { BA137M, BA-137M, BA 137M }\end{array}$ \\
\hline 2 & & & $\begin{array}{l}\text { The amount in curies, grams, or } \mathrm{Bq} \text { as specified in the } 2000 \text { line } \\
\text { of this radionuclide. }\end{array}$ \\
\hline
\end{tabular}

Make additional line entries until all desired radionuclides have been entered into the radionuclide inventory. Only one radionuclide and associated curies per line is allowed. Line numbers are not required.

\subsubsection{External Radionuclide File Control Line (2002)}

This optional line allows you to specify an external file for inputting radionuclide inventories. This line may follow Line (2000). Data in the external file have the same format as that on the Radionuclide Entry Lines with one exception. The first line in the external file is used to identify the data set and is printed on the RSAC-7.2 output file. The program stops reading radionuclide inventories from an external file when it encounters either a blank line or the end of the file. An Input End Line (2999) must immediately follow a (2002) line.

\begin{tabular}{cccc} 
Word & $\begin{array}{c}\text { Variable } \\
\text { Name }\end{array}$ & Entry & Description \\
\hline 1 & & 2002 & \\
2 & EXTFILE & $\begin{array}{l}\text { Enter the name of the external file containing the radionuclide } \\
\text { inventory input. The name entered must be a valid DOS } \\
\text { filename with no extensions. }\end{array}$
\end{tabular}

\subsubsection{Radionuclide Direct Input End Line (2999)}

Use this line to end the direct input of radionuclide inventory input.

\begin{tabular}{cc} 
Word & Entry \\
\hline 1 & 2999
\end{tabular}




\subsubsection{Series - Dose Summary Option}

Use this option to summarize, add, and report in summary tables doses from different exposure pathways and multiple RSAC-7.2 calculations.

\subsubsection{Dose Summary Option Control Line (3000)}

RSAC-7.2 automatically initiates the dose summary. Following dose calculations for the pathways desired, enter additional (3000) lines to request dose summaries. Changes can be made in the 5000 Series (Dispersion Control Input) following initiation of the 3000 Series option; however, downwind distances cannot be changed.

\begin{tabular}{|c|c|c|c|c|}
\hline Word & Name & \multirow{2}{*}{\multicolumn{2}{|c|}{$\frac{\text { Entry }}{3000}$}} & Description \\
\hline 1 & \multicolumn{2}{|c|}{3000} & & \\
\hline \multirow[t]{9}{*}{2} & \multirow[t]{9}{*}{ ISUMTYPE } & & Integer & Type of calculation: \\
\hline & & & 1 & $\begin{array}{l}\text { Re-initiate the dose/cancer risk summary option } \\
\text { (used only to zero dose history for stacked cases in } \\
\text { the same run). }\end{array}$ \\
\hline & & & 2 & Summary of dose by pathway. \\
\hline & & & 3 & Summary of dose by pathway and radionuclide. \\
\hline & & & 4 & $\begin{array}{l}\text { Summary of dose/cancer risk by organ/cancer } \\
\text { (requires a [3001] Line to follow). }\end{array}$ \\
\hline & & & 5 & $\begin{array}{l}\text { Summary of dose/cancer risk by organ and } \\
\text { radionuclide (requires a [3001] Line to follow). }\end{array}$ \\
\hline & & & 6 & Contribution to the effective dose. \\
\hline & & & 7 & Contribution to E-50/cancer risk by radionuclide. \\
\hline & & & 8 & $\begin{array}{l}\text { Contribution to E- } 50 / \text { cancer risk by radionuclide } \\
\text { sorted by dose. }\end{array}$ \\
\hline \multirow[t]{11}{*}{3} & \multirow[t]{11}{*}{ INAGE } & \multicolumn{2}{|c|}{$\begin{array}{l}\text { Inhalation/Ingestion } \\
\text { intake age }\end{array}$} & $\begin{array}{l}\text { Mortality/Morbidity } \\
\text { age group }\end{array}$ \\
\hline & & \multicolumn{3}{|c|}{ ICRP-72 model } \\
\hline & & 1 & 3 months & $0-5$ years \\
\hline & & 2 & 1 year & $5-15$ years \\
\hline & & 3 & 5 years & $15-25$ years \\
\hline & & 4 & 10 years & $25-70$ years \\
\hline & & 5 & 15 years & $0-100$ years \\
\hline & & 6 & Adult & \\
\hline & & 7 & \multicolumn{2}{|c|}{ Adult Worker, ICRP-68 model } \\
\hline & & 8 & \multicolumn{2}{|c|}{ Acute inhalation dose } \\
\hline & & 9 & \multicolumn{2}{|l|}{ ICRP-30 model } \\
\hline
\end{tabular}




\subsubsection{Dose Summary Organ Selection (3001)}

This line is present only if word 2 on the (3000) line is 4 or 5. Dose summaries for up to four organs can be entered. When additional dose summaries for organs are desired, add additional (3000) and (3001) lines.

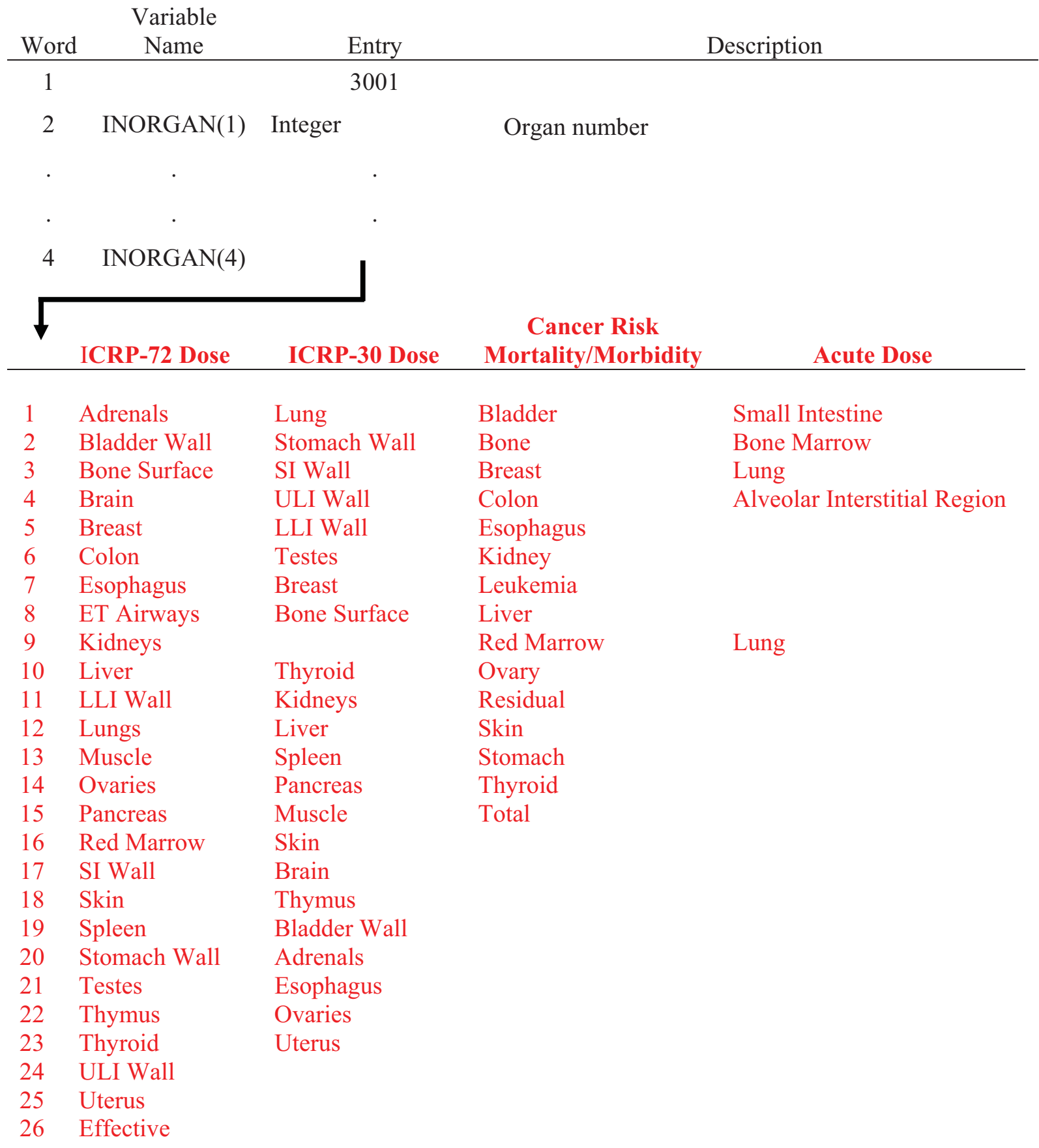




\subsubsection{Series - Dispersion Control Input}

The 5000 Series creates the conditions under which the release parameters will be evaluated.

\subsubsection{Dispersion Control Line (5000)}

Use a Dispersion Control Line (5000) to initiate input of meteorological or room release data.

\begin{tabular}{cll} 
Word & Entry & \\
\hline 1 & 5000 & \\
2 & 0 & $\begin{array}{l}\text { Release will be modeled using meteorological dispersion data. A } 5001 \text { line will } \\
\text { immediately follow the } 5000 \text { line. }\end{array}$ \\
& & $\begin{array}{l}\text { Release will be into a building/room. A } 5500 \text { line will immediately follow the } \\
5000 \text { line. }\end{array}$
\end{tabular}

\subsubsection{General Meteorological Information Line (5001)}

\begin{tabular}{|c|c|c|c|}
\hline Word & $\begin{array}{l}\text { Variable } \\
\text { Name }\end{array}$ & Entry & Description \\
\hline 1 & & 5001 & \\
\hline 2 & UBAR & & Average wind velocity $(\mathrm{m} / \mathrm{s})$ \\
\hline 3 & & & $\begin{array}{l}\text { Stack height }(\mathrm{m}) \text {. Typical stack heights are at least } 2.5 \\
\text { times the building height. }\end{array}$ \\
\hline 4 & $\mathrm{H}$ & & Mixing layer depth (m). If zero, defaults to $400 \mathrm{~m}$. \\
\hline 5 & ADEN & & $\begin{array}{l}\text { Air density }\left(\mathrm{g} / \mathrm{m}^{3}\right) \text {. If zero, defaults to } 1.099 \mathrm{E}+3 \text { (average density } \\
\text { for } 5000 \mathrm{ft} \text {. altitude). }\end{array}$ \\
\hline 6 & AMBDA & & $\begin{array}{l}\text { Wet deposition scavenging coefficient }(1 / \mathrm{s}) \text {. Set equal to zero when } \\
\text { no plume depletion by wet deposition is desired. This coefficient } \\
\text { simulates rainout of the plume and will very quickly deplete the } \\
\text { release. Values for wet deposition scavenging coefficient range } \\
\text { from } 4.0 \mathrm{E}-6 \text { to } 3.0 \mathrm{E}-3 \mathrm{~s}^{-1} \text { with a median value of } 1.5 \mathrm{E}-4 \text {. Avoid } \\
\text { too large a value to prevent plume overdepletion. }\end{array}$ \\
\hline \multirow[t]{3}{*}{7} & SW1 & Integer & Plume depletion by dry deposition: \\
\hline & & 0 & No \\
\hline & & 1 & Yes \\
\hline
\end{tabular}




\subsubsection{Deposition Velocities Line (5002)}

Entering this line is optional. However, the line must be present if you are making ingestion or ground surface dose calculations.

\begin{tabular}{|c|c|c|c|}
\hline Word & $\begin{array}{l}\text { Variable } \\
\text { Name }\end{array}$ & Entry & Description \\
\hline 1 & & 5002 & Deposition velocity $(\mathrm{m} / \mathrm{s})$ for: \\
\hline 2 & $\mathrm{DV}(1)$ & & Solids \\
\hline 3 & $\mathrm{DV}(2)$ & & Halogens \\
\hline 4 & $\mathrm{DV}(3)$ & & Noble gases \\
\hline 5 & $\mathrm{DV}(4)$ & & Cesium \\
\hline 6 & $\mathrm{DV}(5)$ & & Ruthenium \\
\hline
\end{tabular}

\subsubsection{Downwind Distance Lines (5101+)}

\begin{tabular}{lcll}
\multicolumn{1}{l}{ Word } & $\begin{array}{l}\text { Variable } \\
\text { Name }\end{array}$ & Entry & Description \\
1 & & Integer & $510 \mathrm{X}(\mathrm{X}=1,2, \ldots$, etc. $)$ \\
2 & DIE(1) & & \\
$\cdot$ & $\cdot$ & & \\
$\cdot$ & $\cdot$ & & \\
$\cdot$ & $\cdot$ & & \\
$\mathrm{N}$ & $\operatorname{DIE}(\mathrm{N})$ &
\end{tabular}

Enter a maximum of eight downwind distances. The valid range of downwind distances is 10 to 1.E $+5 \mathrm{~m}$. Diffusion for distances less than $1 . \mathrm{E}+2 \mathrm{~m}$ is extrapolated. 


\subsubsection{Leakage Decay Constants Lines (5201+)}

Use leakage decay constants to calculate the radionuclide inventory decay before release to the environment. When the radionuclide inventory decay has already been corrected to the actual amount to be released, treat the release as an instantaneous release as described below to avoid double decay.

\begin{tabular}{|c|c|c|c|}
\hline Word & $\begin{array}{c}\text { Variable } \\
\text { Name }\end{array}$ & Entry & Description \\
\hline 1 & & Integer & $52 \mathrm{XX}(\mathrm{XX}=01,02, \ldots$, etc. $)$ \\
\hline 2 & $\mathrm{~K} 1(1)$ & & Linear constant in the leakage rate function $\left(\mathrm{s}^{-1}\right)$ \\
\hline 3 & $\mathrm{~K} 2(1)$ & & Exponential constant in leakage rate function $\left(\mathrm{s}^{-1}\right)$ \\
\hline
\end{tabular}

Enter additional sets of two values on this and following lines up to a maximum of 10 sets.

Values of $\mathrm{K} 1$ and $\mathrm{K} 2$ can be either positive or negative. If a constant leakage is desired, set $\mathrm{K} 2=0$ and $\mathrm{K} 1=$ the reciprocal of the time that it takes for the activity to be released to the atmosphere. The use of one set of leakage constants is normally sufficient for most calculations.

When an instantaneous release is desired, enter only one set of leakage constants and set $\mathrm{K} 1=1$., $\mathrm{K} 2=0$, and the exposure time to the plume to 1 second.

When decay correction is desired for a constant release, set $\mathrm{K} 1=$ the reciprocal of the release time (s), $\mathrm{K} 2=0$, and the decay time for the leakage rate function $=$ the time (s) over which the release occurs [see Appendix A, Equation (A-28)].

When an exponential release as a function of time is desired, set $\mathrm{K} 2=1 / \mathrm{T}_{\mathrm{h}}$, where $\mathrm{T}_{\mathrm{h}}$ is the release half-time (s) for the exponential decay function. K1 can be calculated using the following equation:

$$
\mathrm{K} 1=\frac{\mathrm{L}_{\mathrm{f}} \mathrm{K} 2}{1 .-\mathrm{e}^{-\mathrm{K} 2 \mathrm{~T}}}
$$

where $L_{f}$ is the fraction of the total source volume to be released over the time $T(s)$.

Decay times for the leakage rate function used with these constants are entered on lines (6001), (7001), (8020), and (9000) lines. An option is provided for the program to automatically calculate the necessary decay times to give a $100 \%$ release if only one set of constants is entered (K1 $>0$ and $\mathrm{K} 1>\mathrm{K} 2$ ). When these conditions are not met, you must directly enter the decay time for the leakage rate function. It is important not to decay the radionuclide inventory twice before its release to the atmosphere. This can inadvertently occur when the total activity of each radionuclide to be released to the atmosphere over an extended period of time is entered directly into RSAC-7.2 rather than using RSAC-7.2 to calculate the radionuclide inventory. When this is the case, no additional decay of the activity before release is desired even though the total activity entered may represent a release over an extended period of time. 


\subsubsection{Crosswind Distance Lines (5301+)}

You can omit these lines if no crosswind calculations are desired.

$\begin{array}{llll}\underline{\text { Word }} & \begin{array}{l}\text { Variable } \\ \text { Name }\end{array} & \underline{\text { Entry }} & \underline{\text { Description }} \\ 1 & & \text { Integer } & 53 \mathrm{XX}(\mathrm{XX}=01,02, \ldots, \text { etc. }) \\ 2 & \text { ELB(1) } & & \\ \cdot & & \text { Crosswind distance (m) } \\ \cdot & & \\ \cdot & & \\ \mathrm{N} & \mathrm{ELB}(\mathrm{N}-1) & \end{array}$

Additional values on this and following lines are entered up to a maximum of 15 crosswind distances.

\subsubsection{Diffusion Control Line (5400)}

\begin{tabular}{|c|c|c|c|}
\hline$\underline{\text { Word }}$ & $\begin{array}{l}\text { Variable } \\
\text { Name } \\
\end{array}$ & Entry & $\underline{\text { Description }}$ \\
\hline 1 & & 5400 & \\
\hline 2 & NTRL & 1 & $\begin{array}{l}\text { A set of standard deviations of plume concentrations is entered } \\
\text { on the Standard Deviation Lines (5401+) for each downwind } \\
\text { distance. }\end{array}$ \\
\hline & & 2 & $\begin{array}{l}\text { Program-calculated standard deviations of plume } \\
\text { concentration. A (5410) line will immediately follow this line. }\end{array}$ \\
\hline & & 3 & $\begin{array}{l}\chi / \mathrm{Q} \text { values are input directly. The remainder of this line is } \\
\text { ignored, and } \chi / \mathrm{Q} \text { values are read from }(542 X) \text { lines. }\end{array}$ \\
\hline 3 & DUMMY & & Building width (m) (Smallest representative width). \\
\hline 4 & DUMMZ & & Building height (m) (Smallest representative height). \\
\hline
\end{tabular}




\subsubsection{Standard Deviation Lines (5401+)}

Enter these lines only if word 2 on the Diffusion Control Line (5400) is equal to 1.

$\begin{array}{lll}\underline{\text { Word }} \begin{array}{l}\text { Variable } \\ \text { Name }\end{array} & \text { Entry } & \underline{\text { Description }} \\ 1 & \text { Integer } & \begin{array}{l}540 \mathrm{X}(\mathrm{X}=1,2, \ldots, \text { etc. }) \\ \text { The horizontal dispersion standard deviation for the first } \\ \text { downwind distance }(\mathrm{m}) .\end{array} \\ 3 & \text { SIGZ(1) } & \begin{array}{l}\text { The vertical dispersion standard deviation for the first } \\ \text { downwind distance }(\mathrm{m}) .\end{array} \\ . & & \\ . & \end{array}$

Enter additional sets of standard deviations on this and following lines for the additional downwind distance until values have been entered corresponding to each downwind position entered on the (5100+) lines above. A set of standard deviations must be entered for each downwind distance. 


\subsubsection{Plume Standard Deviation Control Line (5410)}

Enter this line only if word 2 on the Diffusion Control Line (5400) is 2. See Appendix C for information on the different sets of $\sigma s$ that are available. Hilsmeier-Gifford $\sigma \mathrm{s}$ (Clawson et al. 1989 ${ }^{10}$ ) should be used for desert terrains (such as the INL) for effluent releases from a few minutes to 15 minute in duration. Markee os (Clawson et al. $1989^{10}$ ) should be used for desert terrains for effluent releases from 15 to 60 minute in duration. Pasquill-Gifford $\sigma \mathrm{s}$ were developed from the Prairie Grass experiments for effluent releases from 10 to 60 minutes in duration. The Pasquill-Gifford $\sigma s$ are presented in Regulatory Guide 1.145 (NRC $1982^{26}$ ) and by Slade $\left(1968^{34}\right)$. Carefully evaluate the appropriateness of using the program-generated $\sigma \mathrm{s}$ for effluent releases of different durations than noted above. When you consider the program-generated $\sigma \mathrm{s}$ inappropriate, word 2 on the Diffusion Control Line (5400) should be set to 1, and $\sigma$ s should be entered directly using the $(540 X)$ lines.

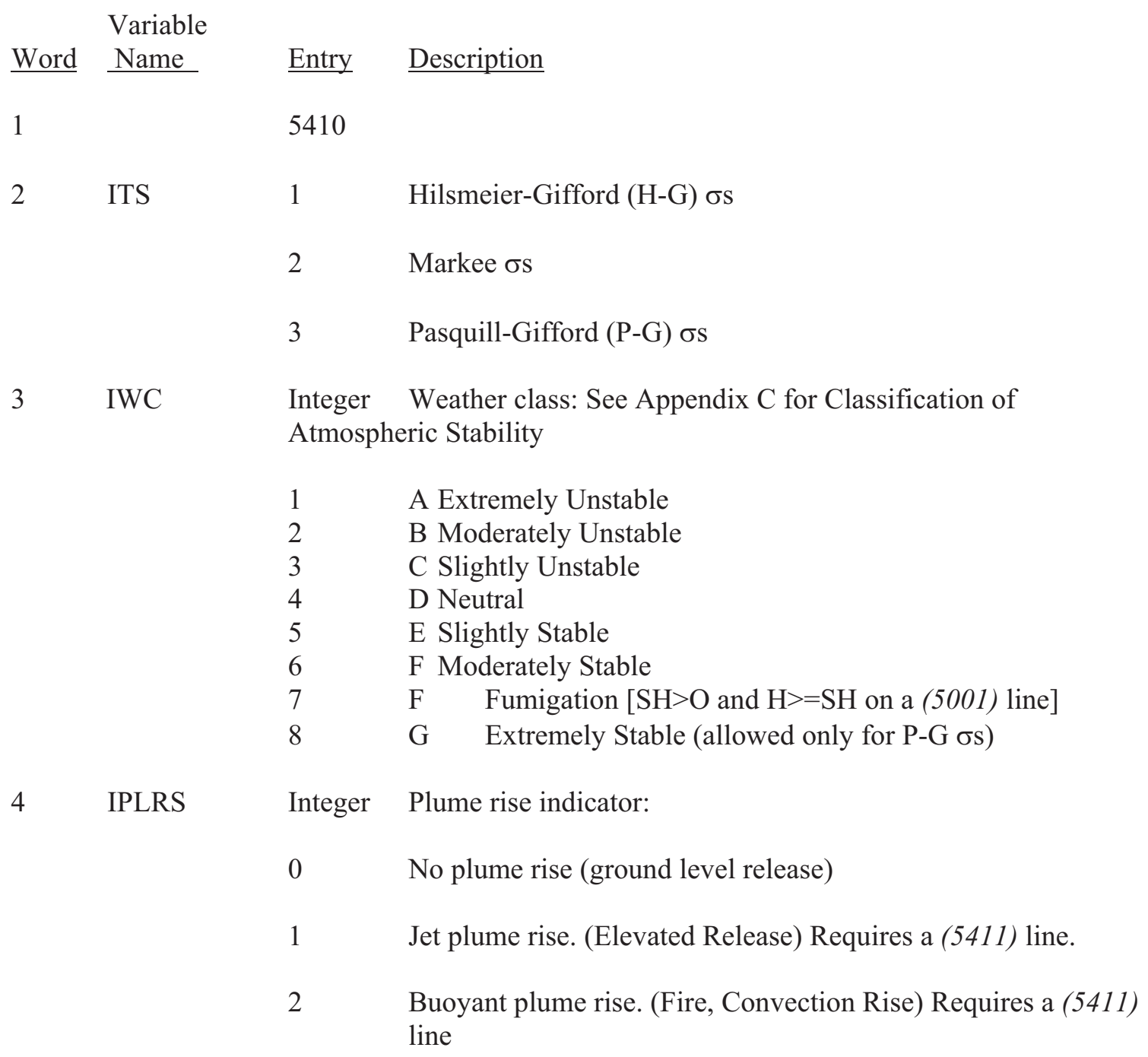

Add a 5th word to Line 5410

Word $\quad$ Description

$5 \quad$ Plume meander. If 0 , defaults to 1. 


\subsubsection{Plume Rise Control Line (5411)}

The (5411) line is present only when word 4 on the (5410) line is not equal to 0.

Variable

$\underline{\text { Word Name }} \underline{\text { Entry }}$ Description

1

$5411 \quad$ Plume rise parameters:

2 SDIA

Internal stack diameter (m).

3 RS

Restoring acceleration $\left(\mathrm{s}^{-2}\right)$. If zero, defaults to program calculated values of 8.7E-4 $\left(\mathrm{s}^{-2}\right)$ for a weak inversion and $1.75 \mathrm{E}-3\left(\mathrm{~s}^{-2}\right)$ for a strong inversion.

$4 \quad$ WO

Effluent velocity of gases from the stack $(\mathrm{m} / \mathrm{s})$.

$5 \quad \mathrm{QH}$

Stack gasses heat emission (cal/s) for buoyant plume rise. Enter zero for jet plume. 


\subsubsection{Direct $\chi / Q$ Input Lines (5421+)}

Enter these lines only if word 2 on the Diffusion Control Line (5400) is 3. Cloud gamma calculations using the finite plume model and plume depletion by ground deposition are not allowed when using this option.

\begin{tabular}{|c|c|c|c|}
\hline Word & $\begin{array}{l}\text { Variable } \\
\text { Name } \\
\end{array}$ & Entry & $\underline{\text { Description }}$ \\
\hline 1 & & Integer & $542 \mathrm{X}(\mathrm{X}=1,2, \ldots$, etc. $)$ \\
\hline 2 & & CQ & $\chi / \mathrm{Q}$ for the lst downwind distance \\
\hline · & & . & \\
\hline · & & . & \\
\hline$\cdot$ & & - & \\
\hline $\mathrm{N}$ & & CQ & $\chi / \mathrm{Q}$ for the $\mathrm{N}^{\text {th }}$ downwind distance \\
\hline
\end{tabular}

Enter additional values on this and following line for each downwind distance entered on the (5101) line. A (5999) line must immediately follow the input of the (542X)lines.

\subsubsection{Dispersion to Building/Room Line (5500)}

Enter the volume in cubic meters of the building/room in which the release will occur. Input the exposure time for an individual in the room on a 7001 line.

$\begin{array}{llll}\underline{\text { Word }} & \begin{array}{l}\text { Variable } \\ \text { Name }\end{array} & \underline{\text { Entry }} & \text { Description } \\ 1 & 5500 & \\ 2 & \text { ROOMVOL } & & \text { Volume }\left(\mathrm{m}^{3)}\right.\end{array}$

\subsubsection{Meteorological Data End Line (5999)}

Use this line to end the meteorological data input and calculations as requested by the Meteorological Control Line (5000).

Word $\quad \underline{\text { Entry }}$

125999




\subsection{5 $\quad 6000$ Series - Radionuclide Inventory Decay for Printout}

This series is used only to calculate the radionuclide inventory decay for printout. Radionuclide decay for subsequent dose calculations must be calculated in the 1000 Series. Use the Decay Control Line (6000) to initiate radionuclide inventory decay calculations. Decay of either the entire radionuclide inventory or selected radionuclides can be calculated. Decay times can be entered directly with Decay Times Lines (6101+) or they can be established from the 5000 Series meteorological downwind data lines. Individual radionuclides selected are printed. If desired, rather than printing the entire radionuclide inventory you can select other printout options.

\subsubsection{Decay Control Line (6000)}

\begin{tabular}{|c|c|c|c|}
\hline$\frac{\text { Word }}{1}$ & $\begin{array}{l}\text { Variable } \\
\text { Name } \\
\end{array}$ & $\frac{\text { Entry }}{6000}$ & $\underline{\text { Description }}$ \\
\hline \multirow[t]{3}{*}{2} & $\mathrm{NCH}$ & Integer & Printout control: \\
\hline & & 0 & $\begin{array}{l}\text { Decay of radionuclides in the RSAC- } 7.2 \text { library will be } \\
\text { calculated. }\end{array}$ \\
\hline & & 1 & $\begin{array}{l}\text { Only radionuclides selected following a (6021) line will be } \\
\text { printed. }\end{array}$ \\
\hline \multirow[t]{5}{*}{3} & ISW2 & Integer & Printout options: \\
\hline & & 0 & No individual radionuclide inventories are printed. \\
\hline & & -1 & $\begin{array}{l}\text { Print all fission products and any activation products, actinides, } \\
\text { and daughters of actinides with positive values. }\end{array}$ \\
\hline & & 1 & $\begin{array}{l}\text { Same as }-1 \text { option except suppress short-lived fission products } \\
\text { that have no available dose conversion factors. }\end{array}$ \\
\hline & & 2 & $\begin{array}{l}\text { Print inventory of radionuclides that have positive values at or } \\
\text { following the first requested decay time. }\end{array}$ \\
\hline \multirow[t]{4}{*}{4} & ISW & Integer & Units control word: \\
\hline & & 0 & Curies \\
\hline & & 1 & $\mathrm{MeV} / \mathrm{s}$ (gamma only) \\
\hline & & 2 & Grams \\
\hline \multirow[t]{3}{*}{5} & LEAK & Integer & Exponential leakage option \\
\hline & & 0 & No exponential leakage corrections are included. \\
\hline & & 1 & $\begin{array}{l}\text { Correction for exponential leakage decay included. A ( } 6001) \\
\text { line must immediately follow this line. This option provides an } \\
\text { inventory of the radionuclides reaching a downwind location }\end{array}$ \\
\hline
\end{tabular}


following a release that varies exponentially as a function of time.

\subsubsection{Decay Time for Leakage Rate Function (6001)}

Use this line only when LEAK on the (6000) line is equal to 1

Word $\begin{aligned} & \text { Variable } \\ & \text { Name }\end{aligned}$ Entry $\begin{aligned} & \text { Description } \\ & 1\end{aligned}$
2001

\subsubsection{Leakage Decay Constants (6002+)}

Use these lines only when the exponential leakage option is requested (i.e., LEAK $=1$ ). You can omit these lines if leak rate exponentials have been previously entered with $(5201+)$ lines.

$\begin{array}{llll}\underline{\text { Word }} & \begin{array}{l}\text { Variable } \\ \text { Name }\end{array} & \text { Entry } & \underline{\text { Description }} \\ 1 & & \text { Integer } & 60 \mathrm{XX}(\mathrm{XX}=02,03, \ldots, \text { etc. }) \\ 2 & \mathrm{~K} 1(1) & & \text { Linear constant in leak rate function }\left(\mathrm{s}^{-1}\right) \\ 3 & \mathrm{~K} 2(1) & & \text { Exponential constant in leak rate function }\left(\mathrm{s}^{-1}\right)\end{array}$

Enter additional sets of two values on this and following lines up to a maximum of 10 sets. 


\title{
4.2.5.4 Radionuclide Selection Option Line (6021)
}

This line is required only if NCH (word 2) entered on the Decay Control Line (6000) is equal to 1. This line is followed by additional lines described as following:

\author{
Variable \\ $\underline{\text { Word Name }} \quad \underline{\text { Entry }}$ Description \\ 1 NUCL Integer Radionuclide identification number (see Series 4000, \\ Radionuclide Data Change Line). An alternate entry can be \\ made by replacing NUCL with the element symbol followed by \\ the mass number and metastable state indicator. Examples of \\ allowable styles include: \\ Cs137, Cs-137, Cs 137 \\ Ba137m, Ba-137m, Ba $137 \mathrm{~m}$ \\ CS137, CS-137, CS 137 \\ BA137M, BA-137M, BA 137M
}

Make additional line entries until all desired radionuclides have been entered into the radionuclide inventory. A (6101) or (6999) line must follow last radionuclide identification entered.

\subsubsection{Decay Times Lines (6101+)}

You can omit these lines if decay times have been established using the $(5001+)$ lines.

\begin{tabular}{|c|c|c|c|}
\hline$\underline{\text { Word }}$ & $\begin{array}{l}\text { Variable } \\
\text { Name } \\
\end{array}$ & Entry & $\underline{\text { Description }}$ \\
\hline 1 & & Integer & $61 \mathrm{XX}(\mathrm{XX}=01,02, \ldots$, etc. $)$ \\
\hline 2 & IUNIT & Integer & Decay time unit: \\
\hline & & & $\begin{array}{l}1=\text { Second } \\
2=\text { Minute } \\
3=\text { Hour } \\
4=\text { Day } \\
5=\text { Year }\end{array}$ \\
\hline 3 & TIME(2) & & Decay time \\
\hline · & . & & \\
\hline$\cdot$ & $\cdot$ & & \\
\hline$\cdot$ & $\cdot$ & & \\
\hline $\mathrm{N}$ & TIME(N-1) & & \\
\hline
\end{tabular}

Enter additional values on this and following lines up to a maximum of eight values. When you want to see all of the output data on an unshifted screen or printed on a standard 80-column page, a maximum of three decay times should be entered on each 6000 Series input. 


\subsubsection{Summation Control Line (6200)}

This line is present only if the entire radionuclide inventory decay is calculated and it can be deleted if desired. A summation of the radionuclide inventory by group (solids, halogens, noble gases, cesium, and ruthenium) and/or by element can be printed. If summation by element is requested, enter the Element Summation Lines (6201+) next, selecting the elements to be summed.

\begin{tabular}{|c|c|c|}
\hline Word & Entry & Description \\
\hline 1 & 6200 & \\
\hline \multirow[t]{3}{*}{2} & & Group summation control word: \\
\hline & 0 & No summation or printout. \\
\hline & 1 & $\begin{array}{l}\text { The fission product inventory for each group (solids, halogens, } \\
\text { noble gases, cesium, and ruthenium) is summed and printed. }\end{array}$ \\
\hline \multirow[t]{3}{*}{3} & Integer & Element summation control word: \\
\hline & 0 & No summation or printout. \\
\hline & 1 & $\begin{array}{l}\text { The radionuclide inventory is summed for each element } \\
\text { selected by the Element Summation Lines }(6201+) \text { that follow. }\end{array}$ \\
\hline
\end{tabular}

\subsubsection{Element Summation Lines (6201+)}

These lines are required only if the entire radionuclide inventory decay is calculated and if the element summation option on the Summation Control Line (6200) is chosen. Enter any number of these lines.

$\begin{array}{lll}\text { Word } & \text { Entry } & \text { Description } \\ 1 & \text { Integer } & 62 \mathrm{XX}(\mathrm{XX}=01,02, \ldots, \text { etc. }) . \\ 2 & \text { Integer } & \text { Atomic number of element to be summed. }\end{array}$

Enter additional words on this and following lines until the desired elements have been selected for summation.

\subsubsection{Decay End Line (6999)}

Use this line to end the fission product inventory decay and printout as requested by the Decay Control Line (6000).

$\underline{\text { Word }} \quad \underline{\text { Entry }}$

116999




\subsubsection{Series - Internal/External Dose Calculation}

Use the initial line of this series to establish the type of dose calculation to be made and the amount of output data. Air-immersion doses are calculated using dose-rate conversion factors from Federal Guidance Report 12 (Eckerman 1993 ${ }^{15)}$ developed for a semi-infinite plume. Use caution to ensure that the plume size is large compared to the mean free path of the gamma rays. If there is any doubt, make cloud gamma calculations (see 9000 Series in this section) using both the finite plume model and the semi-infinite plume model and ensure that the doses are converged.

\subsubsection{Dose Calculation Control Line 1 (7000)}

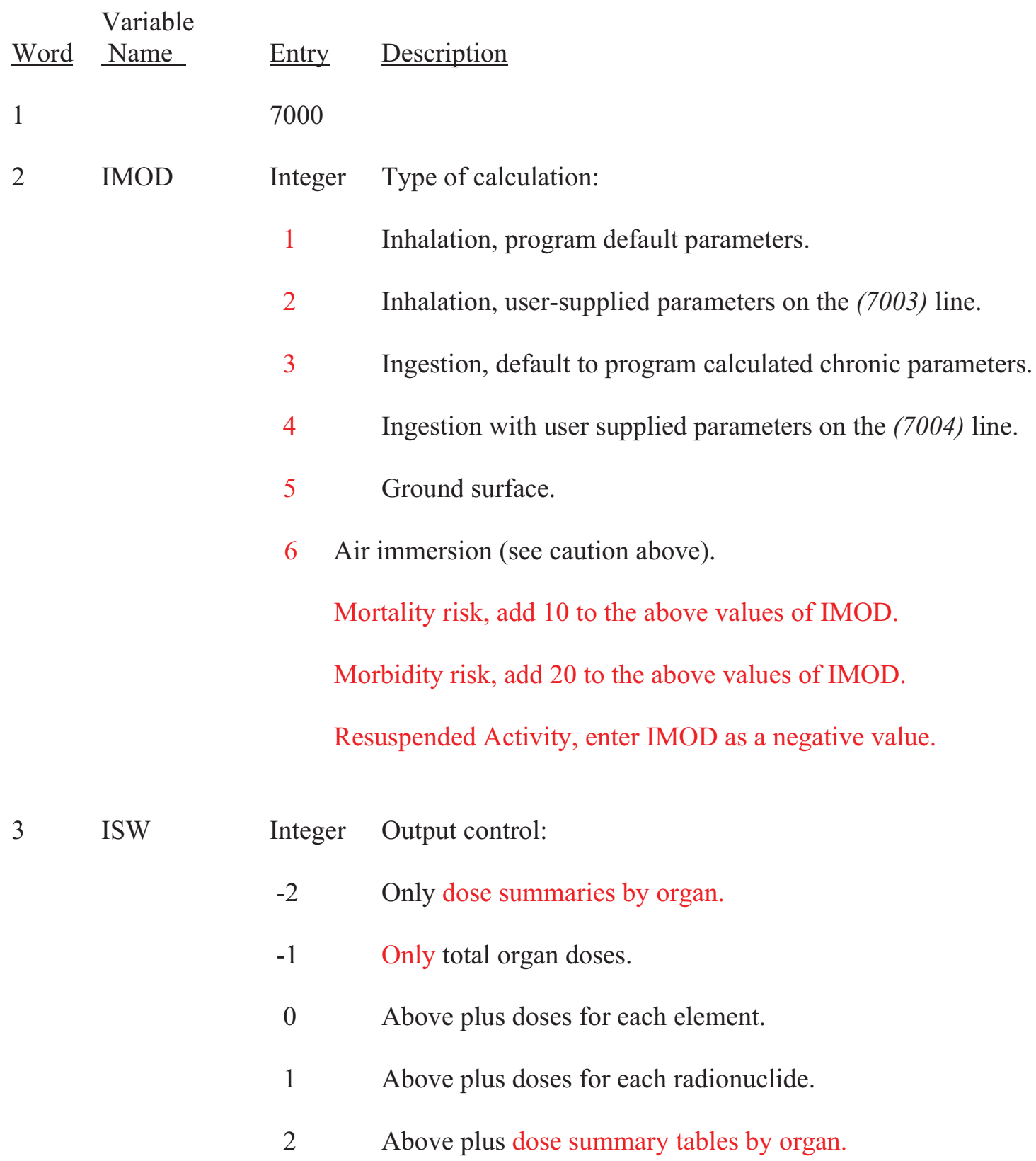




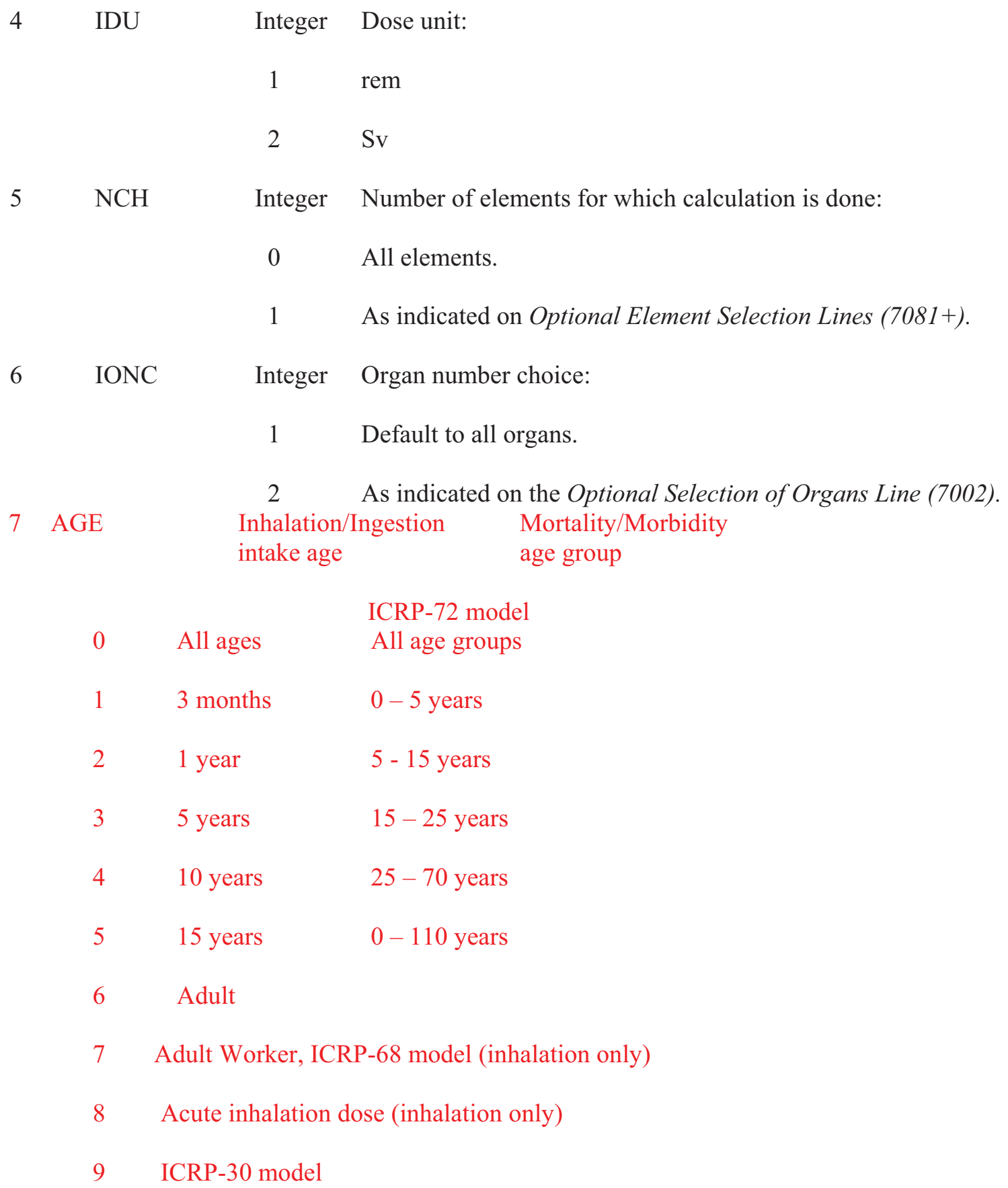

If word two, IMOD, was entered as 'ground surface' or 'air immersion' calculation, then the final word in this line, 'age,' is not used in any calculations. However, this word must be present. It is suggested that you use ' 0 ' for this value, though integers 1-9 would have the same results.

A special test option has been added to print out the actual dose conversion factors used in RSAC-7. This is initiated by putting -201 in word 4 of Line 7001 for the variable TB. This should be very useful for performing $V \& V$. The place to look closely is for the elements with special chemical forms. 


\subsubsection{Dose Calculation Control Line 2 (7001)}

Variable

$\underline{\text { Word Name }} \underline{\text { Entry }}$ Description

1

7001

2 BREATH

Breathing rate $\left(\mathrm{m}^{3} / \mathrm{s}\right)$ for inhalation calculations. If zero, defaults to $3.33 \mathrm{E}-4$. Use $2.66 \mathrm{E}-4$ for $24-\mathrm{h}$ average breathing rate.

3 TINHA

Release to atmosphere:

Decay time (s) for the exponential decay function (see Appendix A, Section A-2.4, "Leakage Rate Function"). If zero, defaults to the time necessary to give $100 \%$ release.

Release to building:

Time that receptor is exposed (s). If zero, defaults to $60 \mathrm{~s}$.

$4 \quad \mathrm{~TB}$

Values for the term "TB" depend the type of calculation being made:

For acute releases: TB is the number of years that crops are grown on the contaminated soil. TB should be 1. year for dose during the year of intake. Values greater than 1. year give the dose from growing crops on the contaminated soil for the specified number of years. If zero, defaults to 15 years.

Ingestion from chronic release: For chronic releases, TB is the years of long-term buildup of activity in the soil. TB should be equal to the plant mid-point of operating life (y). If zero, defaults to 15 years.

Ground surface: TB is the time in years that the receptor is exposed to the contaminated ground surface following initiation of the release. If $>0$ and $<1$, a warning will be given that an exposure period of $<1$ year has been chosen. If zero, defaults to 1 year.

$5 \quad$ BS

Building shielding factor for ground surface dose calculations. If zero, defaults to 0.7 .

$6 \quad$ OCFACT

Occupancy factor for ground surface dose calculations (entry of word is optional). If zero, defaults to 1.0. 


\subsubsection{Optional Selection of Organs Line (7002)}

\begin{tabular}{|c|c|c|c|c|c|}
\hline & Word & $\begin{array}{l}\text { Variable } \\
\text { Name }\end{array}$ & Entry & Description & \\
\hline & 1 & & 7002 & User selection of organs & \\
\hline & 2 & $\mathrm{IO}(1)$ & Integer & Organ number: & \\
\hline & . & . & & & \\
\hline & . & . & & & \\
\hline & $\dot{\mathrm{N}}+1$ & $\dot{\mathrm{IO}(\mathrm{N})}$ & & & \\
\hline & & & & $\begin{array}{l}\text { Mortality/ } \\
\text { Morbidity }\end{array}$ & \\
\hline & ICRP- & 72 Dose & ICRP-30 Dose & Cancer Risk & Acute Dose \\
\hline 1 & Adrena & & Lung & Bladder & Small Intestine \\
\hline 2 & Bladde & Wall & Stomach Wall & Bone & Bone Marrow \\
\hline 3 & Bone $\mathrm{S}$ & urface & SI Wall & Breast & Lung \\
\hline 4 & Brain & & ULI Wall & Colon & Alveolar Interstitial Region \\
\hline 5 & Breast & & LLI Wall & Esophagus & \\
\hline 6 & Colon & & Testes & Kidney & \\
\hline 7 & Esopha & gus & Breast & Leukemia & \\
\hline 8 & ET Air & ways & Bone Surface & Liver & \\
\hline 9 & Kidney & & Red Marrow & Lung & \\
\hline 10 & Liver & & Thyroid & Ovary & \\
\hline 11 & LLI W & & Kidneys & Residual & \\
\hline 12 & Lungs & & Liver & Skin & \\
\hline 13 & Muscle & & Spleen & Stomach & \\
\hline 14 & Ovaries & & Pancreas & Thyroid & \\
\hline 15 & Pancrea & & Muscle & Total & \\
\hline 16 & Red M & arrow & Skin & & \\
\hline 17 & SI Wal & & Brain & & \\
\hline 18 & Skin & & Thymus & & \\
\hline 19 & Spleen & & Bladder Wall & & \\
\hline 20 & Stomac & h Wall & Adrenals & & \\
\hline 21 & Testes & & Esophagus & & \\
\hline 22 & Thymu & & Ovaries & & \\
\hline 23 & Thyroi & & Uterus & & \\
\hline 24 & LLI W & & Effective & & \\
\hline 25 & Uterus & & & & \\
\hline 26 & Effecti & & & & \\
\hline
\end{tabular}

Line 7003

AMAD only is used with the ICRP-30 model. A value must be present, but it is ignored in other calculations. Default to 0 . 


\subsubsection{Optional Inhalation Dose Calculation Control Line (7003)}

This line is present only if IMOD (word 2) on the (7000) line is 1. It is important to understand that when the default recommended or maximum parameter is selected, it is for the element and all associated nuclides. For example, the maximum value for ICRP 72 adult with respect to plutonium is defined as Fast. This is true for the majority of the plutonium radionuclides. However, if $\mathrm{Pu}-234, \mathrm{Pu}-235$, and a few others are being evaluated, it is not the maximum clearance type. For those nuclides, Slow is the maximum type. Therefore, it is very important that you understand the nuclide and the appropriate clearance class/type for your specific application. A option has been added to output all of the clearance class values by changing the third word values to a negative number. See Appendix D

for the default values for all options.

\begin{tabular}{|c|c|c|c|}
\hline$\underline{\text { Word }}$ & $\begin{array}{l}\text { Variable } \\
\text { Name } \\
\end{array}$ & $\underline{\text { Entry }}$ & $\underline{\text { Description }}$ \\
\hline 1 & & 7003 & User-supplied inhalation parameters. \\
\hline 2 & AMAD & & $\begin{array}{l}\text { Activity median aerodynamic diameter }(\mu \mathrm{m}) \text {. If zero, defaults } \\
\text { to } 1 \text {. AMAD must be } \geq 0.1 \mu \mathrm{m} \text {. }\end{array}$ \\
\hline \multirow[t]{6}{*}{3} & ICCI & & Clearance class indicator: \\
\hline & & 1 & $\begin{array}{l}\text { Default to program-generated classes for ICRP } 72 \\
\text { recommended values and oxides and hydroxides where no } \\
\text { recommendations exist. }\end{array}$ \\
\hline & & 2 & $\begin{array}{l}\text { User input of classes on ( } 703 X) \text { lines. Unchanged classes } \\
\text { default to those for selection (1). }\end{array}$ \\
\hline & & 3 & $\begin{array}{l}\text { Default to program-generated classes selected to give } \\
\text { maximum element dose. }\end{array}$ \\
\hline & & 4 & $\begin{array}{l}\text { User input of classes on ( } 703 \mathrm{X}) \text { lines. Unchanged classes } \\
\text { default to those selected to give maximum element dose. }\end{array}$ \\
\hline & & & $\begin{array}{l}\text { Add a negative (-) sign in front of word } 3 \text { and the values used } \\
\text { for all selected clearance classes, including changes made on } \\
703 X \text { lines, will be output. }\end{array}$ \\
\hline
\end{tabular}

\subsubsection{Optional Ingestion Dose Calculation Control Line (7004)}

This line is present only if IMOD (word 2) on the (7000) line is 3.

$\underline{\text { Word Name }} \begin{aligned} & \text { Variable } \\ & 1\end{aligned}$


2

ITRAN Integer Ingestion transfer parameter control:

$0=$ Program default transfer parameters used.

$1=$ Program default transfer parameters are used and printed out.

$2=$ Read ingestion transfer parameters from external file TRANCON.

ITYPE

Integer

User control for ingestion calculations

$0=$ Chronic release with program default parameters.

$1=$ Acute release with program default parameters.

$2=$ User-supplied ingestion parameters on $(705 X)$ lines.

4 ATIME

Time period (d) that crops are exposed to contamination during the growing season. A time period of $\geq 60$ days signifies a chronic release with vegetable and forage exposure times to the plume as indicated in Series 7000, Ingestion Constants Line 3 (7052). A time period of $<60$ days signifies an acute release.

ITYPE $=0$. Variable not used.

ITYPE $=1$. Time must be between 0.04167 day (1. hour) and $<60$. day.

ITYPE $=2$. If zero or $>60$., defaults to 60 . days. Otherwise, must not be $<0.04167$.

5 THD

Harvest duration time period $(0 . \leq \mathrm{THD}<60$.) following an acute release (d). If zero, defaults to 7 days. When the sum of ATIME and THD exceeds ETV (see [7052] line), the program automatically decreases the value input for THD to give a sum of ETV days for produce calculations. The program also automatically calculates a value for THD for forage calculations so that the sum of ATIME and THD do not exceed the value of ETM (see [7052] line).

\subsubsection{Optional Clearance Class by Element Lines (7031+)}

These lines are present only if ICCI (word 3) on the (7003) line is equal to 2. Make entries in pairs of two: the element's atomic number followed by the clearance class code. Refer to Appendix D

for valid clearance classes. 


\begin{tabular}{|c|c|c|c|c|c|}
\hline Word & $\begin{array}{l}\text { Variable } \\
\text { Name } \\
\end{array}$ & Entry & \multicolumn{3}{|c|}{$\underline{\text { Description }}$} \\
\hline 1 & & Integer & \multicolumn{3}{|c|}{$703 X(X=1,2, \ldots$, etc. $)$. } \\
\hline 2 & $\mathrm{NN}$ & Integer & \multicolumn{3}{|c|}{ Atomic number for element. } \\
\hline \multirow[t]{4}{*}{3} & $\mathrm{ICI}(\mathrm{NN})$ & Integer & ICRP-72 & ICRP 68 & ICRP-30 \\
\hline & & 1 & Type F & Type F & Class D \\
\hline & & 2 & Type M & Туре M & Class W \\
\hline & & 3 & Type S & Type $\mathrm{S}$ & Class Y \\
\hline
\end{tabular}

Enter as many pairs of entries and up to eight pairs per line.

\subsubsection{Optional Ingestion Dose Constants Lines (7051+)}

These lines are present only if ITYPE (word 3) on the (7004) line is equal to 2.

Ingestion Constants Line 1 (7051)

\begin{tabular}{|c|c|c|c|c|}
\hline Word & $\begin{array}{l}\text { Variable } \\
\text { Name }\end{array}$ & Description & $\begin{array}{l}\text { Default } \\
\text { Value }\end{array}$ & $\begin{array}{l}\text { Variable } \\
\text { Name }\end{array}$ \\
\hline 1 & & 7051 & & \\
\hline 2 & UFSV & $\begin{array}{l}\text { Stored vegetable } \\
\text { usage factor } \\
\text { (kg/yr wet weight) }\end{array}$ & 520. & $\mathrm{U}^{\mathrm{v}}$ \\
\hline 3 & UFFV & $\begin{array}{l}\text { Fresh vegetable } \\
\text { usage factor } \\
\text { (kg/yr wet weight) }\end{array}$ & 64. & $\mathrm{U}^{\mathrm{L}}$ \\
\hline 4 & UFMP & $\begin{array}{l}\text { Meat usage factor } \\
\text { (kg/yr wet weight) }\end{array}$ & 110. & $\mathrm{U}^{\mathrm{F}}$ \\
\hline 5 & UFM & $\begin{array}{l}\text { Milk usage factor } \\
(\mathrm{L} / \mathrm{yr})\end{array}$ & 310. & $\mathrm{U}^{\mathrm{m}}$ \\
\hline 6 & $\mathrm{FG}$ & $\begin{array}{l}\text { Fraction of stored } \\
\text { vegetables from } \\
\text { garden }\end{array}$ & 0.76 & $f_{g}$ \\
\hline 7 & FY & $\begin{array}{l}\text { Fraction of fresh } \\
\text { vegetables from } \\
\text { garden }\end{array}$ & 1.0 & $\mathrm{f}_{1}$ \\
\hline
\end{tabular}


Ingestion Constants Line 2 (7052)

\begin{tabular}{|c|c|c|c|c|}
\hline Word & $\begin{array}{l}\text { Variable } \\
\text { Name } \\
\end{array}$ & Description & $\begin{array}{c}\text { Default } \\
\text { Value } \\
\end{array}$ & $\begin{array}{l}\text { Variable } \\
\text { Name } \\
\end{array}$ \\
\hline 1 & & 7052 & & \\
\hline 2 & RF1 & $\begin{array}{l}\text { Retention factor } \\
\text { for activity on } \\
\text { forage }\end{array}$ & 0.57 & $\mathrm{r}$ \\
\hline 3 & RF2 & $\begin{array}{l}\text { Retention factor } \\
\text { for activity on } \\
\text { vegetables }\end{array}$ & 0.2 & $\mathrm{r}$ \\
\hline 4 & RFI & $\begin{array}{l}\text { Retention factor } \\
\text { for iodines on } \\
\text { forage }\end{array}$ & 1.0 & $\mathrm{r}$ \\
\hline 5 & $\mathrm{RRC}$ & $\begin{array}{l}\text { Removal rate } \\
\text { constant for crops } \\
(1 / \mathrm{h})\end{array}$ & 0.0021 & $\lambda_{\mathrm{w}}$ \\
\hline 6 & ETV & $\begin{array}{l}\text { Vegetable exposure } \\
\text { time to plume for } \\
\text { chronic release (d) }\end{array}$ & 60. & $t_{e}$ \\
\hline 7 & ETM & $\begin{array}{l}\text { Forage exposure time } \\
\text { to plume for chronic } \\
\text { release }(\mathrm{d})\end{array}$ & 30. & $\mathrm{t}_{\mathrm{e}}$ \\
\hline 8 & HRHT & $\begin{array}{l}\text { HTO removal half } \\
\text { time (d) }\end{array}$ & 1. & $\lambda_{\mathrm{p}}$ \\
\hline
\end{tabular}

Ingestion Constants Line 3 (7053)

$\begin{array}{lllll}\underline{\text { Word }} \begin{array}{l}\text { Variable } \\ \text { Name }\end{array} & \text { Description } & \begin{array}{l}\text { Default } \\ \text { Value }\end{array} & \begin{array}{l}\text { Variable } \\ \text { Name }\end{array} \\ 2 & \text { SD } & \begin{array}{l}\text { Effective surface } \\ \text { density for soil } \\ \left(\mathrm{kg} / \mathrm{m}^{2}\right)\end{array} & 225 . & \mathrm{P} \\ 3 & \text { THS } & \begin{array}{l}\text { Stored vegetable } \\ \text { holdup time after } \\ \text { harvest (d) }\end{array} & \\ & & & \\ & & & \end{array}$




$\begin{array}{lllll}4 & \text { THF } & \begin{array}{l}\text { Fresh vegetable } \\ \text { holdup time after } \\ \text { harvest (d) }\end{array} & 1 . & \mathrm{t}_{\mathrm{h}} \\ 5 & \text { QF } & \begin{array}{l}\text { Animals daily forage } \\ \text { feed (kg/day dry } \\ \text { weight) }\end{array} & 16 . & \mathrm{Q}_{\mathrm{F}} \\ 6 & \text { TRAN } & \begin{array}{l}\text { Feed-milk receptor } \\ \text { transfer time (d) }\end{array} & 2 . & \mathrm{t}_{\mathrm{f}} \\ 7 & \text { TSLA } & \begin{array}{l}\text { Slaughter to } \\ \text { consumption time (d) }\end{array} & \end{array}$

Ingestion Constants Line 4 (7054)

\begin{tabular}{|c|c|c|c|c|}
\hline Word & $\begin{array}{l}\text { Variable } \\
\text { Name }\end{array}$ & Description & $\begin{array}{l}\text { Default } \\
\text { Value }\end{array}$ & $\begin{array}{l}\text { Variable } \\
\text { Name }\end{array}$ \\
\hline 1 & & 7054 & & \\
\hline 2 & FPAST & $\begin{array}{l}\text { Fraction of year } \\
\text { that animals graze }\end{array}$ & 0.4 & $f_{p}$ \\
\hline 3 & FS & $\begin{array}{l}\text { Fraction of feed that } \\
\text { is pasture when animal } \\
\text { grazes on pasture }\end{array}$ & .43 & $f_{s}$ \\
\hline 4 & THSF & $\begin{array}{l}\text { Stored feed holdup } \\
\text { time (d) }\end{array}$ & 90. & $t_{h}$ \\
\hline 5 & VYV & $\begin{array}{l}\text { Vegetable vegetation } \\
\text { yield }\left(\mathrm{kg} / \mathrm{m}^{2} \text { wet }\right. \\
\text { weight })\end{array}$ & 2. & $Y_{v}$ \\
\hline 6 & VYM & $\begin{array}{l}\text { Forage vegetation } \\
\text { yield }\left(\mathrm{kg} / \mathrm{m}^{2} \text { dry }\right. \\
\text { weight })\end{array}$ & 0.28 & $\mathrm{Y}_{\mathrm{v}}$ \\
\hline 7 & HUM & $\begin{array}{l}\text { Absolute humidity } \\
\left(\mathrm{g} / \mathrm{m}^{3}\right)\end{array}$ & 4.9 & $\mathrm{H}$ \\
\hline
\end{tabular}

\subsubsection{Optional Acute Ingestion Constants Line 4 (7055)}

This line can be omitted; however, when it is not entered, all acute ingestion constants are set equal to 1 . 


\begin{tabular}{|c|c|c|c|c|}
\hline Word & $\begin{array}{l}\text { Variable } \\
\text { Name } \\
\end{array}$ & Description & $\begin{array}{l}\text { Default } \\
\text { Value }\end{array}$ & $\begin{array}{l}\text { Variable } \\
\text { Name } \\
\end{array}$ \\
\hline 1 & & 7055 & & \\
\hline 2 & AFG & $\begin{array}{l}\text { Fraction of annual } \\
\text { stored vegetables } \\
\text { that are contaminated } \\
\text { by acute release }\end{array}$ & $\begin{array}{l}0.5^{\mathrm{a}} \\
1.0^{\mathrm{b}}\end{array}$ & $\mathrm{F}_{\mathrm{a}}$ \\
\hline 3 & AFY & $\begin{array}{l}\text { Fraction of annual } \\
\text { fresh vegetables } \\
\text { that are contaminated } \\
\text { by acute release }\end{array}$ & $\begin{array}{l}0.33^{\mathrm{a}} \\
0.67^{\mathrm{b}}\end{array}$ & $\mathrm{F}_{\mathrm{a}}$ \\
\hline 4 & AFFS & $\begin{array}{l}\text { Fraction of annual } \\
\text { stored forage that } \\
\text { is contaminated by } \\
\text { acute release }\end{array}$ & $\begin{array}{l}0.5^{\mathrm{a}} \\
1.0^{\mathrm{b}}\end{array}$ & $\mathrm{F}_{\mathrm{a}}$ \\
\hline 5 & AFFF & $\begin{array}{l}\text { Fraction of annual } \\
\text { fresh forage that is } \\
\text { contaminated by acute } \\
\text { release }\end{array}$ & $\begin{array}{l}0.33^{\mathrm{a}} \\
0.67^{\mathrm{b}}\end{array}$ & $\mathrm{F}_{\mathrm{a}}$ \\
\hline
\end{tabular}

a. Crops exposed to contamination between 1 hour and $<30$ days.

b. Crops exposed to contamination between 30 days and $<60$ days.

\subsubsection{Optional Element Selection Lines (7081+)}

These lines are present only if word $5(\mathrm{NCH})$ on the (7000) line is greater than zero.

$\begin{array}{llll}\text { Word } & \begin{array}{l}\text { Variable } \\ \text { Name }\end{array} & \text { Entry } & \text { Description } \\ 1 & & \text { Integer } & 708 \mathrm{X}(\mathrm{X}=1,2, \ldots, \text { etc. }) . \\ 2 & \text { NUMBER(1) } & \text { Integer } & \text { Atomic number of element. } \\ \cdot & \cdot & & \\ . & \cdot & & \\ \mathrm{N} & \text { NUMBER(N) } & \end{array}$

Enter additional values on this and following lines until the number of elements indicated on the (7000) line have been entered. 


\subsubsection{Resuspension Control Line (7090)}

Enter the parameters for evaluating inhalation dose from resuspended activity. Ingestion and External dose from resuspension of activity is not calculated due to its negligible contribution to CEDE.

$\begin{array}{llll}\text { Word } & \begin{array}{l}\text { Variable } \\ \text { Name }\end{array} & \text { Entry } & \text { Description } \\ 1 & & & \\ 2 & \text { TSD } & & \text { Time since deposition (days). } \\ 3 & \text { RET } & & \text { Exposure time to resuspended activity. } \\ 4 & \text { ARL } & \text { Linear constant in the resuspension rate function }\left(\mathrm{d}^{-1}\right) . \\ & & \text { Defaults to } 4.9 \mathrm{E}-8\left(\mathrm{~d}^{-1}\right) . \\ 5 & \text { BRE } & \text { Exponential constant in the resuspension rate function }\left(\mathrm{d}^{-1}\right) . \\ & & \text { Defaults to } 4.1 \mathrm{E}-3\left(\mathrm{~d}^{-1}\right) .\end{array}$

\subsubsection{Dose Calculation End Line (7999)}

Use this line to end the input for the calculations requested by a Dose Calculation Control Line 1 (7001).

$\begin{array}{lll}\text { Word } & & \text { Entry } \\ 1 & 7999 & \\ 2 & & \end{array}$

\subsubsection{Series - Cloud Gamma Dose Calculation}

Use a (9000) control line to initiate a cloud gamma dose calculation.

\begin{tabular}{|c|c|c|c|}
\hline Word & $\begin{array}{l}\text { Variable } \\
\text { Name } \\
\end{array}$ & Entry & Description \\
\hline 1 & & 9000 & \\
\hline 2 & IT & 0 & All calculations are made using the finite plume model \\
\hline & & 1 & All calculations are made using the semi-infinite model \\
\hline 3 & $\mathrm{~T}$ & & $\begin{array}{l}\text { Decay time for the leakage rate function (s). If zero defaults to } \\
\text { the time necessary to give } 100 \% \text { (see }[5201+] \text { lines). }\end{array}$ \\
\hline
\end{tabular}




\section{EXAMPLE RSAC-7.2 RUNS}

RSAC-7.2 has 20 examples that are useful in helping the user learn how to run RSAC-7. These examples are also used to validate the installation. The examples available are as follows:

1. Direct Input and Decay of Nuclides: This example shows the various ways nuclides can be input and decayed for output viewing.

2. Simulated Reactor Operation with Release During Operation: This example generates a fission product inventory from a simulated reactor operation of $50 \mathrm{MW}$ for 50 days. In addition the simulation of a fuel failure fractionates the calculated inventory. The decay and output of two scenarios is shown. The first scenario is for the activity retained in the reactor and the second is the activity released from the reactor.

3. Calculation of $\mathbf{C h i} / \mathbf{Q}$ with modifiers: This example is a demonstration of the various conditions that can be modeled to establish Chi/Q values.

4. Reactor Operation Transport and Output of Source Term: This example combines the techniques of Examples 1-3, then outputs the transported source term using the report function.

5. Dose Calculation Using FGR 11: This example evaluates all the pathways using the same dose conversion factors used in RSAC 6.

6. Simulated Reactor Operation ICRP 68 Worker Inhalation Dose: This example evaluates all the pathways with the exception of ingestion using the facility worker dose conversion factors from ICRP 68.

7. Simulated Reactor Operation ICRP 72 Public Inhalation Dose: This example evaluates all the pathways using the Adult dose conversion factor from ICRP 72 for inhalation and ingestion.

8. Simulated Reactor Operation Acute Dose Inhalation: This example evaluates the 24 hour acute dose from a release from an operating reactor.

9. Multiple Release Scenarios Calculating Ground Surface: This example demonstrates the capabilities of RSAC with respect to various release conditions while calculating ground surface dose.

10. Multiple Release Scenarios Calculating Cloud Gamma Dose: This example demonstrates the capabilities of RSAC with respect to various release conditions while calculating cloud gamma dose.

11. FGR 13 Mortality Risk Calculation: This example evaluates mortality risk from release of an operating reactor.

12. FGR 13 Morbidity Risk Calculation: This example evaluates morbidity risk from release of an operating reactor.

13. Resuspension Calculation: This example evaluates inhalation dose from resuspension.

14. FGR_ICRP 30 Ingestion Dose Chronic and Acute Release: This example demonstrates both models of ingestion (Chronic and Acute) using FGR 11 values.

15. Multiple Release Scenarios Calculating Air Immersion Dose: This example demonstrates the capabilities of RSAC with respect to various release conditions while calculating air immersion dose.

16. ICRP 72 Ingestion Dose Chronic and Acute Release: This example demonstrates both models of ingestion (Chronic and Acute) using ICRP 72 Adult values. 
17. Criticality Accident ICRP 72 Inhalation and Ingestion DCFs: This example demonstrates the complete evaluation of a 1.0 E18 fissions/sec for 10 seconds. All pathways are evaluated using the ICRP 72 Adult values for ingestion and inhalation.

18. Uranium Fire with Plume Lofting: This example evaluates the release of uranium from a fire with plume lofting to show how important it is to identify where the plume reaches the ground.

19. Plutonium Fire with Plume Lofting: This example evaluates the release of plutonium from a fire with plume lofting to show how important it is to identify where the plume reaches the ground. This example is similar to example 18.

20. Release to a Room Inhalation Dose Only: This example demonstrates how RSAC can calculate the inhalation dose from a release to a volume.

The examples are added to demonstrate the capabilities of RSAC-7.2 and validate the 127 executable commands within the software. The examples are write only, but can be saved as another name and edited. The output of example 1 is documented here for information purposes only. 


\section{Example 1 Direct Input and Decay of Radionuclides}

Radiological Safety Analysis Computer Program (RSAC 7.1.0 preview)

Name: INL

Company: Idaho National Laboratory

Seria1: 0001

Computer: INL413668 Run Date: 10/28/2010

Run Time: 09:58:24

File: Example 07 Simulated Reactor operation ICRP 72 Pub7ic Inhalation Dose.rsac

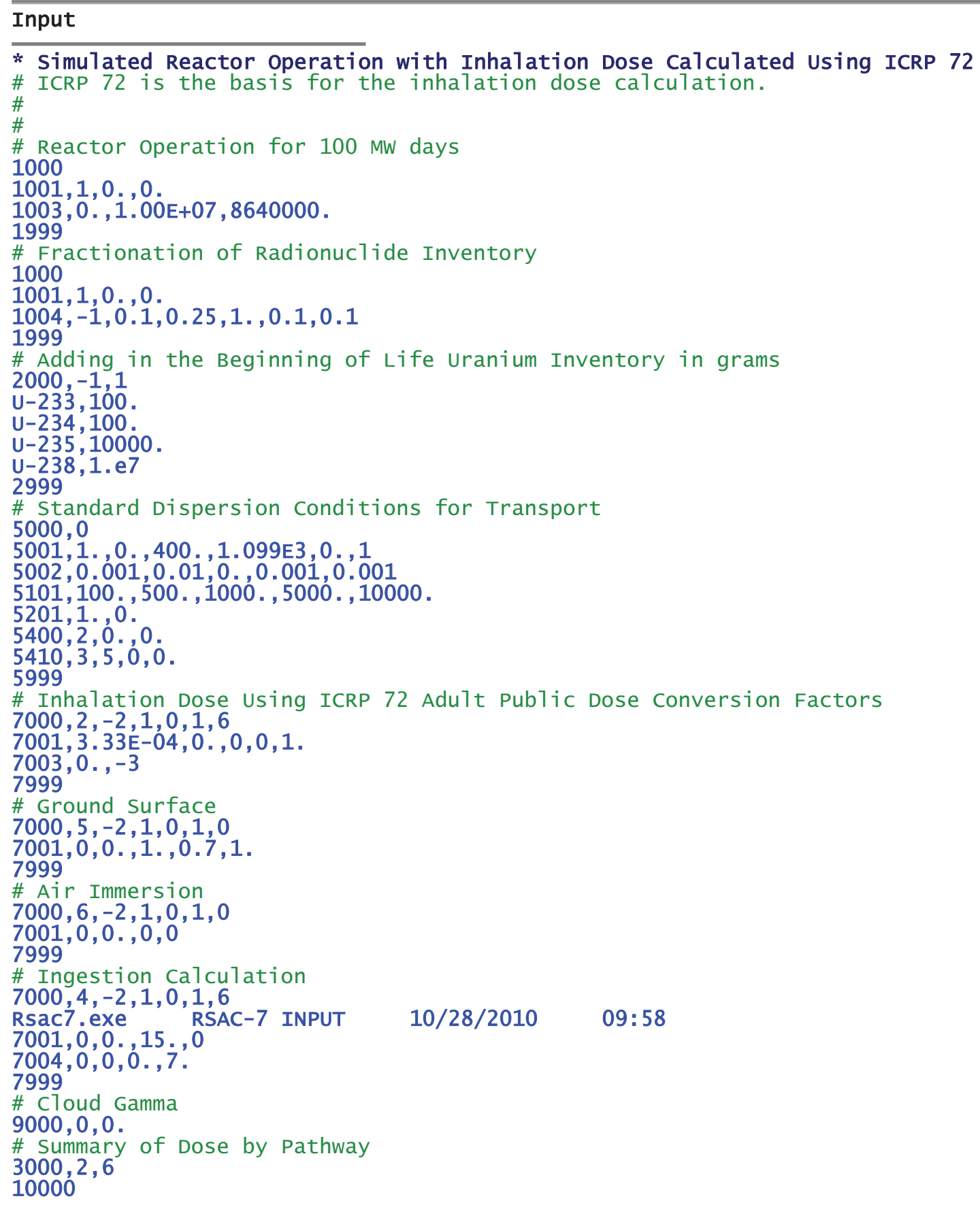




\title{
Fission Product calculation
}

RADIONUCLIDE INVENTORY HAS BEEN DECAYED FOR $0.000 \mathrm{E}+00$ SECONDS

THE REACTOR HAS OPERATED AT 1.000E+07 WATTS FOR 8.640E+06 SECONDS BURNUP $=1.000 E+03$ MWD

TOTAL RADIONUCLIDE REMAINING $=1.727 \mathrm{E}+18 \mathrm{D} / \mathrm{S}$ OR $4.668 \mathrm{E}+07 \mathrm{CI}$

\author{
Fission Product Calculation \\ FRACTIONATION BY ELEMENT GROUP \\ SOLIDS $=1.000 \mathrm{E}-01 \quad$ HALOGENS $=2.500 \mathrm{E}-01 \quad$ NOBLE GASES $=1.000 \mathrm{E}+00$ \\ CESIUM $=1.000 \mathrm{E}-01 \quad$ RUTHENIUM $=1.000 \mathrm{E}-01$ \\ TOTAL RADIONUCLIDE REMAINING $=3.785 \mathrm{E}+17 \mathrm{D} / \mathrm{S}$ OR $1.023 \mathrm{E}+07 \mathrm{CI}$
}

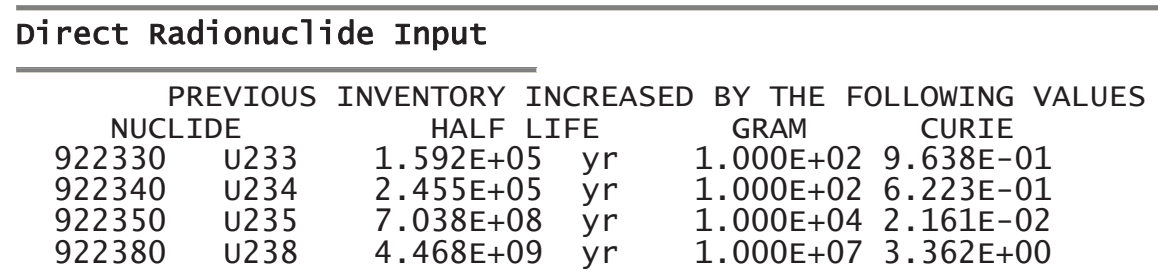

\section{Meteorological Data \\ MEAN WIND SPEED $=1.000 E+00(\mathrm{~m} / \mathrm{s}) \quad \operatorname{STACK}$ HEIGHT $=0.000 \mathrm{E}+00(\mathrm{~m})$ \\ MIXING LAYER HEIGHT $=4.000 \mathrm{E}+02(\mathrm{~m}) \quad$ AIR DENSITY $=1.099 \mathrm{E}+03(\mathrm{~g} / \mathrm{cu} \mathrm{m})$ \\ WET DEPOSITION SCAVENGING COEFFICIENT $=0.000 \mathrm{E}+00(1 / \mathrm{s})$ \\ DRY DEPOSITION VELOCITIES $(\mathrm{m} / \mathrm{s})$ \\ SOLIDS $=1.000 \mathrm{E}-03 \quad$ HALOGENS $=1.000 \mathrm{E}-02 \quad$ NOBLE GASES $=0.000 \mathrm{E}+00$ \\ CESIUM $=1.000 \mathrm{E}-03 \quad$ RUTHENIUM $=1.000 \mathrm{E}-03$ \\ THERE IS 1 SET OF LEAKAGE CONSTANTS (K1,K2) $1.000 \mathrm{E}+00 \quad 0.000 \mathrm{E}+00$ \\ PLUME MEANDER FACTOR $=1.00 \mathrm{E}+00$ \\ PASQUILL CLASS E METEOROLOGY, P-G SIGMA VALUES \\ NO BUILDING WAKE CORRECTION MADE \\ DOWNWIND DISTANCE STACK

$\begin{array}{lcccc} & \text { HEIGHT }(\mathrm{m}) & (\mathrm{m}) & (\mathrm{m}) & (\mathrm{s} / \mathrm{m} \wedge 3) \\ 1.000 \mathrm{E}+02 & 0.000 \mathrm{E}+00 & 6.695 \mathrm{E}+00 & 3.489 \mathrm{E}+00 & 1.363 \mathrm{E}-02 \\ 5.000 \mathrm{E}+02 & 0.000 \mathrm{E}+00 & 2.864 \mathrm{E}+01 & 1.296 \mathrm{E}+01 & 8.574 \mathrm{E}-04 \\ 1.000 \mathrm{E}+03 & 0.000 \mathrm{E}+00 & 5.356 \mathrm{E}+01 & 2.134 \mathrm{E}+01 & 2.785 \mathrm{E}-04 \\ 5.000 \mathrm{E}+03 & 0.000 \mathrm{E}+00 & 2.291 \mathrm{E}+02 & 5.641 \mathrm{E}+01 & 2.463 \mathrm{E}-05 \\ 1.000 \mathrm{E}+04 & 0.000 \mathrm{E}+00 & 4.285 \mathrm{E}+02 & 7.769 \mathrm{E}+01 & 9.562 \mathrm{E}-06\end{array}$ \\ PLUME DEPLETION BY FALLOUT IS INCLUDED \\ FRACTION OF PLUME REMAINING AIRBORNE FOLLOWING DEPLETION BY DEPOSITION

$\begin{array}{ccccc}\text { DOWNWIND DISTANCE } & \text { SOLIDS } & \text { HALOGENS } & \text { CESIUM } & \text { RUTHENIUM } \\ 1.000 \mathrm{E}+02 & 9.527 \mathrm{E}-01 & 6.161 \mathrm{E}-01 & 9.527 \mathrm{E}-01 & 9.527 \mathrm{E}-01 \\ 5.000 \mathrm{E}+02 & 9.402 \mathrm{E}-01 & 5.400 \mathrm{E}-01 & 9.402 \mathrm{E}-01 & 9.402 \mathrm{E}-01 \\ 1.000 \mathrm{E}+03 & 9.331 \mathrm{E}-01 & 5.004 \mathrm{E}-01 & 9.331 \mathrm{E}-01 & 9.331 \mathrm{E}-01 \\ 5.000 \mathrm{E}+03 & 9.129 \mathrm{E}-01 & 4.018 \mathrm{E}-01 & 9.129 \mathrm{E}-01 & 9.129 \mathrm{E}-01 \\ 1.000 \mathrm{E}+04 & 8.971 \mathrm{E}-01 & 3.377 \mathrm{E}-01 & 8.971 \mathrm{E}-01 & 8.971 \mathrm{E}-01\end{array}$

Inhalation Dose Calculation

USING DOSE CONVERSION FACTORS FROM ICRP-72 FOR MEMBERS OF THE PUBLIC

RESPIRABLE FRACTION $=1.000 \mathrm{E}+00$

BREATHING RATE $=3.330 \mathrm{E}-04(\mathrm{~m} \wedge 3 / \mathrm{s})$

RELEASE TIME FOR EXPONENTIAL DECAY FUNCTION $=1.000 \mathrm{E}+00(\mathrm{~s})$

INTERNAL EXPOSURE TIME PERIOD $=5.000 \mathrm{E}+01$ (yr)

LUNG ABSORPTION TYPES SELECTED TO GIVE MAXIMUM DOSE

LUNG CEARANCE TYPES USED IN CALCULATIONS

$\begin{array}{rrr}\text { ELEMENT } & \text { TYPE } \\ 1 & \mathrm{H} & \mathrm{F} \\ 4 & \mathrm{Be} & \mathrm{S} \\ 6 & \mathrm{C} & \mathrm{S} \\ 9 & \mathrm{~F} & \mathrm{~S} \\ 11 & \mathrm{Na} & \mathrm{F}\end{array}$




\begin{tabular}{|c|c|c|}
\hline 12 & $\mathrm{Mg}$ & M \\
\hline 13 & A 1 & M \\
\hline 14 & $\mathrm{Si}$ & $\mathrm{S}$ \\
\hline 15 & $P$ & $M$ \\
\hline 16 & $S$ & $S$ \\
\hline 17 & Cl & M \\
\hline 19 & $\mathrm{~K}$ & $\mathrm{~F}$ \\
\hline 20 & $\mathrm{Ca}$ & $S$ \\
\hline 21 & SC & $S$ \\
\hline 22 & Ti & $S$ \\
\hline 23 & V & $M$ \\
\hline 24 & $\mathrm{Cr}$ & $S$ \\
\hline 25 & $\mathrm{Mn}$ & $M$ \\
\hline 26 & $\mathrm{Fe}$ & $S$ \\
\hline 27 & Co & $S$ \\
\hline 28 & $\mathrm{Ni}$ & $\mathrm{S}$ \\
\hline 29 & $\mathrm{Cu}$ & $S$ \\
\hline 30 & $\mathrm{Zn}$ & $S$ \\
\hline 31 & $\mathrm{Ga}$ & $M$ \\
\hline 32 & $\mathrm{Ge}$ & $M$ \\
\hline 33 & As & $M$ \\
\hline 34 & $\mathrm{Se}$ & $S$ \\
\hline 35 & $\mathrm{Br}$ & $M$ \\
\hline 37 & $\mathrm{Rb}$ & $F$ \\
\hline 38 & $\mathrm{Sr}$ & $S$ \\
\hline 39 & Y & $S$ \\
\hline 40 & $\mathrm{Zr}$ & $S$ \\
\hline 41 & $\mathrm{Nb}$ & $\mathrm{S}$ \\
\hline 42 & Mo & S \\
\hline 43 & TC & $S$ \\
\hline 44 & $\mathrm{Ru}$ & $S$ \\
\hline 45 & $\mathrm{Rh}$ & $S$ \\
\hline 46 & $\mathrm{Pd}$ & S \\
\hline 47 & $\mathrm{Ag}$ & $\mathrm{S}$ \\
\hline 48 & $c \vec{d}$ & $\mathrm{~F}$ \\
\hline 49 & In & $M$ \\
\hline 50 & $\mathrm{Sn}$ & $M$ \\
\hline 51 & $\mathrm{sb}$ & $S$ \\
\hline 52 & $\mathrm{Te}$ & $S$ \\
\hline 53 & I & $\mathrm{F}$ \\
\hline 5 & CS & $S$ \\
\hline 56 & $\mathrm{Ba}$ & $S$ \\
\hline 57 & La & $M$ \\
\hline 58 & $\mathrm{Ce}$ & $S$ \\
\hline 59 & $\mathrm{Pr}$ & $\mathrm{S}$ \\
\hline 60 & $\mathrm{Nd}$ & $S$ \\
\hline 61 & $\mathrm{Pm}$ & $S$ \\
\hline 62 & Sm & $M$ \\
\hline 63 & $\mathrm{Eu}$ & $M$ \\
\hline 64 & $\mathrm{Gd}$ & $M$ \\
\hline 65 & $\mathrm{~Tb}$ & $M$ \\
\hline 66 & Dy & $M$ \\
\hline 67 & Ho & $M$ \\
\hline 68 & $\mathrm{Er}$ & $M$ \\
\hline 69 & $\mathrm{Tm}$ & $M$ \\
\hline 70 & $\mathrm{Yb}$ & $\mathrm{S}$ \\
\hline 71 & Lu & $S$ \\
\hline 72 & $\mathrm{Hf}$ & $M$ \\
\hline 73 & $\mathrm{Ta}$ & $S$ \\
\hline 74 & W & $F$ \\
\hline 75 & $\mathrm{Re}$ & $M$ \\
\hline 76 & os & $S$ \\
\hline 77 & Ir & $\mathrm{S}$ \\
\hline 78 & $\mathrm{Pt}$ & $\mathrm{F}$ \\
\hline 79 & $\mathrm{Au}$ & $S$ \\
\hline 80 & $\mathrm{Hg}$ & $M$ \\
\hline 81 & $\mathrm{~T}\rceil$ & $\mathrm{F}$ \\
\hline 8 & $\mathrm{~Pb}$ & $\mathrm{~S}$ \\
\hline & $\mathrm{Bi}$ & $M$ \\
\hline & Po & $\mathrm{S}$ \\
\hline & At & $M$ \\
\hline & $\mathrm{Fr}$ & $F$ \\
\hline
\end{tabular}




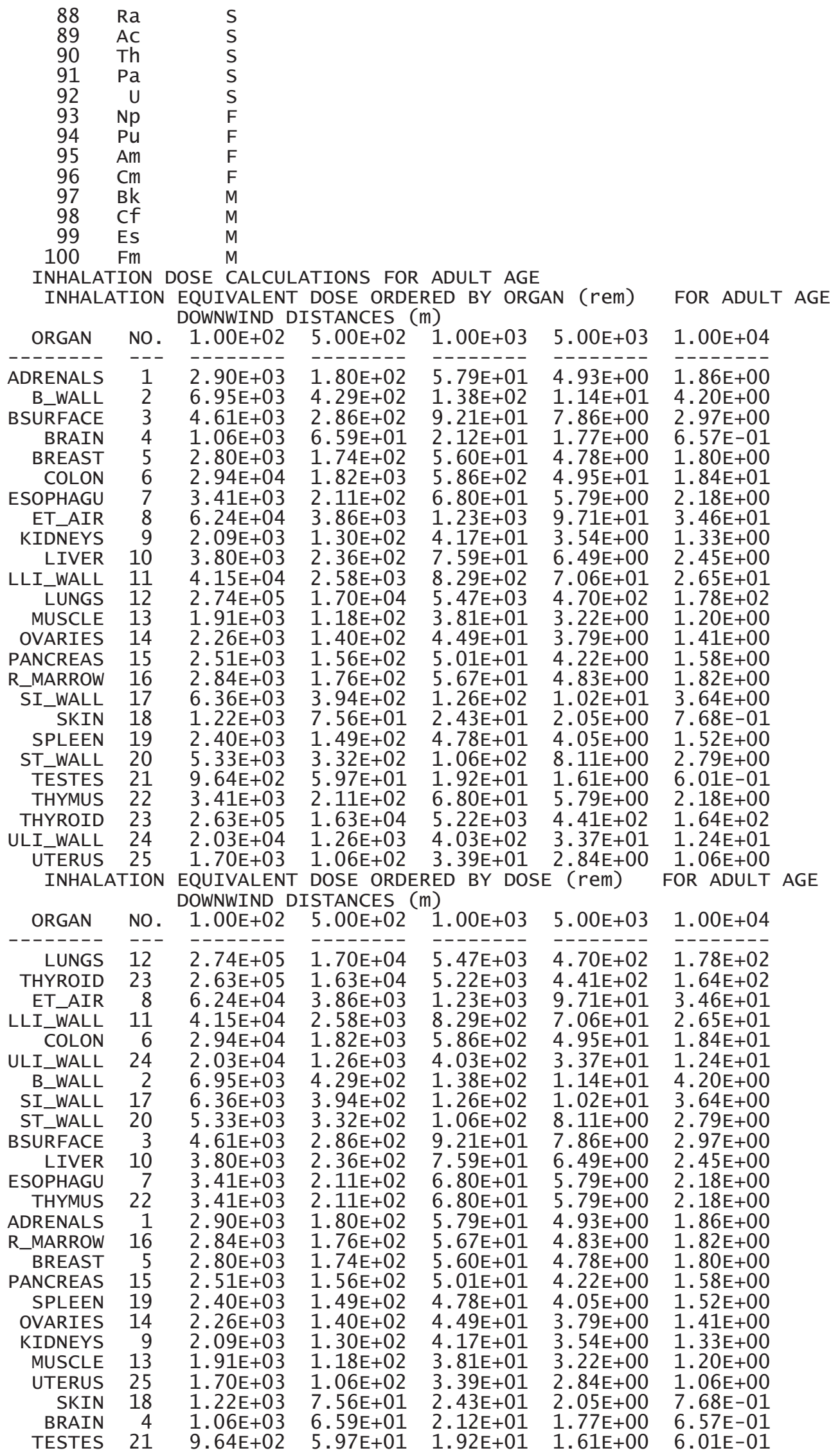




\begin{tabular}{|c|c|c|c|c|c|c|}
\hline \multicolumn{2}{|c|}{ INHALATION } & \multicolumn{3}{|c|}{ EFFECTIVE DOSE ORDERED BY DOSE } & \multicolumn{2}{|c|}{ FOR } \\
\hline ORGAN & NO. & 1. $00 \mathrm{E}+02$ & $5.00 \mathrm{E}+02$ & 1.00E+03 & $5.00 \mathrm{E}+03$ & $1.00 \mathrm{E}+04$ \\
\hline & 1 & $45 E+02$ & $01 E+00$ & $2.90 \mathrm{E}+00$ & & \\
\hline & $\frac{1}{2}$ & $\begin{array}{l}1.45 \mathrm{~s} \\
3.47 \mathrm{E}\end{array}$ & $5 \mathrm{E}+01$ & $6.88 \mathrm{E}$ & & \\
\hline SURFACE & 3 & $4.61 E+01$ & $6 \mathrm{E}+00$ & 2. & 02 & \\
\hline BRAIN & 4 & 5.32 & $0 \mathrm{E}+00$ & 1.06 & & \\
\hline BREAST & 5 & $1.40 \mathrm{E}+02$ & $0 \mathrm{E}+00$ & $2.80 \mathrm{E}+00$ & & \\
\hline COLON & 6 & 3.53 & $9 \mathrm{E}+02$ & $7.03 \mathrm{E}+01$ & 50 & 2 \\
\hline SOPHAGU & 7 & 1. $70 \mathrm{E}+02$ & $1.06 \mathrm{E}+01$ & $3.40 E+00$ & & 1 \\
\hline ET_ & 8 & 3.12 & 2 & & & \\
\hline KIDNEYSS & 9 & 1.0 & 6.49 & 2.0 & 1 & \\
\hline LIVER & 10 & 1.90 & 1. & 3. & & \\
\hline LI_WALL & 11 & 2. & 2 & 4. & & \\
\hline LUNGS & 12 & & $2.04 \mathrm{E}+03$ & 6.5 & & \\
\hline MUS & 13 & 9.5 & 5. & 1.9 & & \\
\hline OVAR & 14 & 1.1 & 6. & 2.2 & & \\
\hline PANCR & 15 & 1.2 & $7.7=9$ & 2.5 & & \\
\hline R_MARROW & 16 & & & & & \\
\hline SI_WALL & 17 & $3.7-7-3$ & 1. & 6 & & \\
\hline SKIN & 18 & 1.2 & & & & \\
\hline SPL & 19 & 1.2 & 7. & & & \\
\hline ST_W & 2( & 1.0 & & & & \\
\hline TESTES & 21 & $4 . \varepsilon$ & $2.99 \mathrm{E}+00$ & 9.5 & & \\
\hline THYMUS & 22 & 1.7 & & 3.4 & & \\
\hline THYROID & 23 & 1.3 & 8. & 2.6 & & \\
\hline ULI_WALL & & & & & & \\
\hline UTE & 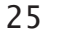 & $0.3+3$ & 5.2 & $1.6 \mathrm{~s}$ & & \\
\hline E_50 & 2 & +04 & 3 & 1 & & \\
\hline
\end{tabular}

Ground Surface Dose Calculation

OCCUPANCY FACTOR $=1.000 \mathrm{E}+00$

TIME RECEPTOR IS EXPOSED TO CONTAMINATED SOIL $=1.000 \mathrm{E}+00(\mathrm{y} r)$

BUILDING SHIELDING FACTOR $=7.000 \mathrm{E}-01$

RELEASE TIME FOR EXPONENTIAL DECAY FUNCTION $=1.000 \mathrm{E}+00 \mathrm{~S}$

GROUND SURFACE DOSE DOWNWIND DISTANCE $=1.00 \mathrm{E}+02(\mathrm{~m})$

GROUND SURFACE DOSE

DOWNWIND DISTANCE $=5.00 \mathrm{E}+02(\mathrm{~m})$

GROUND SURFACE DOSE

DOWNWIND DISTANCE $=1.00 \mathrm{E}+03(\mathrm{~m})$

GROUND SURFACE DOSE

DOWNWIND DISTANCE $=5.00 \mathrm{E}+03(\mathrm{~m})$

GROUND SURFACE DOSE

DOWNWIND DISTANCE $=1.00 \mathrm{E}+04(\mathrm{~m})$

GROUND SURFACE EFFECTIVE DOSE ORDERED

DOWNWIND DISTANCES (M)

\begin{tabular}{|c|c|c|c|c|c|c|}
\hline ORGAN & NO. & 1. $00 \mathrm{E}+02$ & $5.00 \mathrm{E}+02$ & $1.00 \mathrm{E}+03$ & $5.00 \mathrm{E}+03$ & $1.00 \mathrm{E}+04$ \\
\hline Lung & 1 & $5.41 E+04$ & $35 \mathrm{E}+03$ & $1.08 \mathrm{E}+03$ & $9.10 \mathrm{E}+0$ & $3.41 E$ \\
\hline s wa11 & 2 & 04 & & 1.0 & & \\
\hline SI Wail & 3 & $5.03 E+04$ & $3.12 \mathrm{E}+03$ & $1.00 \mathrm{E}+03$ & $8.47 \mathrm{E}+01$ & 3.1 \\
\hline LI Wa11 & 4 & $5.10 \mathrm{E}+04$ & $3.16 \mathrm{E}+03$ & $1.01 \mathrm{E}+03$ & $8.59 \mathrm{E}+01$ & 01 \\
\hline LI Wa11 & 5 & 04 & 3 & $1.04 \mathrm{E}+03$ & 8 & 3 \\
\hline Testes & 6 & 4 & 3. & 1.18 & 9 & 3. \\
\hline reast & 7 & +04 & & 1.13 & & \\
\hline BSurface & 8 & +04 & & $1.61 E+03$ & 22 & D \\
\hline $\mathrm{R}$ Marrow & 9 & 4 & & 1.09 & 01 & \\
\hline Thyroid & 10 & 4 & & 1.11 & & \\
\hline idney & 11 & 4 & & 1.03 & 8. & \\
\hline L7) & 12 & 04 & & 1.0 & & \\
\hline Spleen & 13 & 04 & & 1.0 & & \\
\hline Pancreas & 14 & & & & & \\
\hline Muscle & 15 & & & & & \\
\hline & 16 & 5 & & 7. & & \\
\hline Braj & 17 & 4 & & $E+03$ & & \\
\hline Thym & 18 & +04 & & $\mathrm{E}+03$ & 8 & \\
\hline U B1 & 1. & 7 & J & $1.04 \mathrm{E}+0$ & ILY & \\
\hline Adrena & 20 & $E+04$ & $E+03$ & $1.17 \mathrm{E}+03$ & $6 \mathrm{E}+01$ & \\
\hline
\end{tabular}

RSAC-7

$\mathrm{CHI} / \mathrm{Q}=1.363 \mathrm{E}-02(\mathrm{~s} / \mathrm{m} \wedge 3)$

$\mathrm{CHI} / \mathrm{Q}=8.574 \mathrm{E}-04(\mathrm{~s} / \mathrm{m} \wedge 3)$

$\mathrm{CHI} / \mathrm{Q}=2.785 \mathrm{E}-04(\mathrm{~s} / \mathrm{m} \wedge 3)$

$\mathrm{CHI} / \mathrm{Q}=2.463 \mathrm{E}-05(\mathrm{~s} / \mathrm{m} \wedge 3)$

$\mathrm{CHI} / \mathrm{Q}=9.562 \mathrm{E}-06(\mathrm{~s} / \mathrm{m} \wedge 3)$

PLUME TRAVEL TIME $=1.00 \mathrm{E}+02(\mathrm{~s})$

PLUME TRAVEL TIME $=5.00 \mathrm{E}+02(\mathrm{~s})$

PLUME TRAVEL TIME $=1.00 \mathrm{E}+03$ (s)

PLUME TRAVEL TIME $=5.00 \mathrm{E}+03(\mathrm{~s})$

PLUME TRAVEL TIME $=1.00 \mathrm{E}+04(\mathrm{~s})$ 


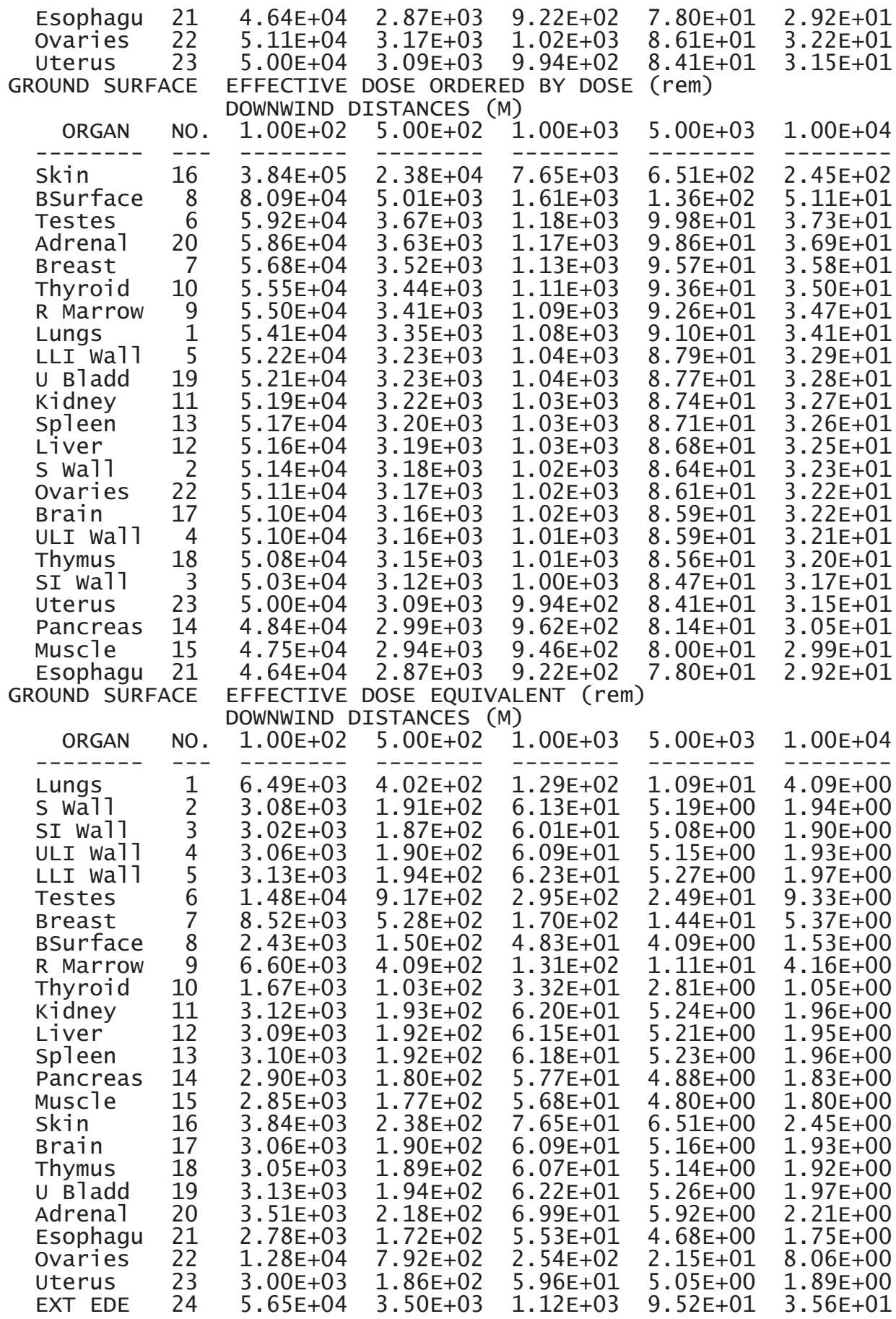

\section{Air Immersion Dose Equivalent Calculation'>}

RELEASE TIME FOR EXPONENTIAL DECAY FUNCTION $=1.000 \mathrm{E}+00 \mathrm{~s}$

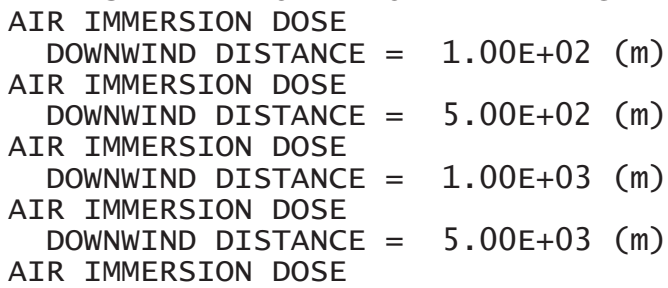
$\mathrm{CHI} / \mathrm{Q}=1.363 \mathrm{E}-02(\mathrm{~m} \wedge 3 \mathrm{~m})$ PLUME TRAVEL TIME $=1.00 \mathrm{E}+02(\mathrm{~s})$ $\mathrm{CHI} / \mathrm{Q}=8.574 \mathrm{E}-04(\mathrm{~m} \wedge 3 \mathrm{~m})$ PLUME TRAVEL TIME $=5.00 \mathrm{E}+02(\mathrm{~s})$ $\mathrm{CHI} / \mathrm{Q}=2.785 \mathrm{E}-04(\mathrm{~m} \wedge 3 \mathrm{~m})$ PLUME TRAVEL TIME $=1.00 \mathrm{E}+03(\mathrm{~s})$ $\mathrm{CHI} / \mathrm{Q}=2.463 \mathrm{E}-05(\mathrm{~m} \wedge 3 \mathrm{~m})$ PLUME TRAVEL TIME $=5.00 \mathrm{E}+03(\mathrm{~s})$ $\mathrm{CHI} / \mathrm{Q}=9.562 \mathrm{E}-06(\mathrm{~m} \wedge 3 \mathrm{~m})$ 


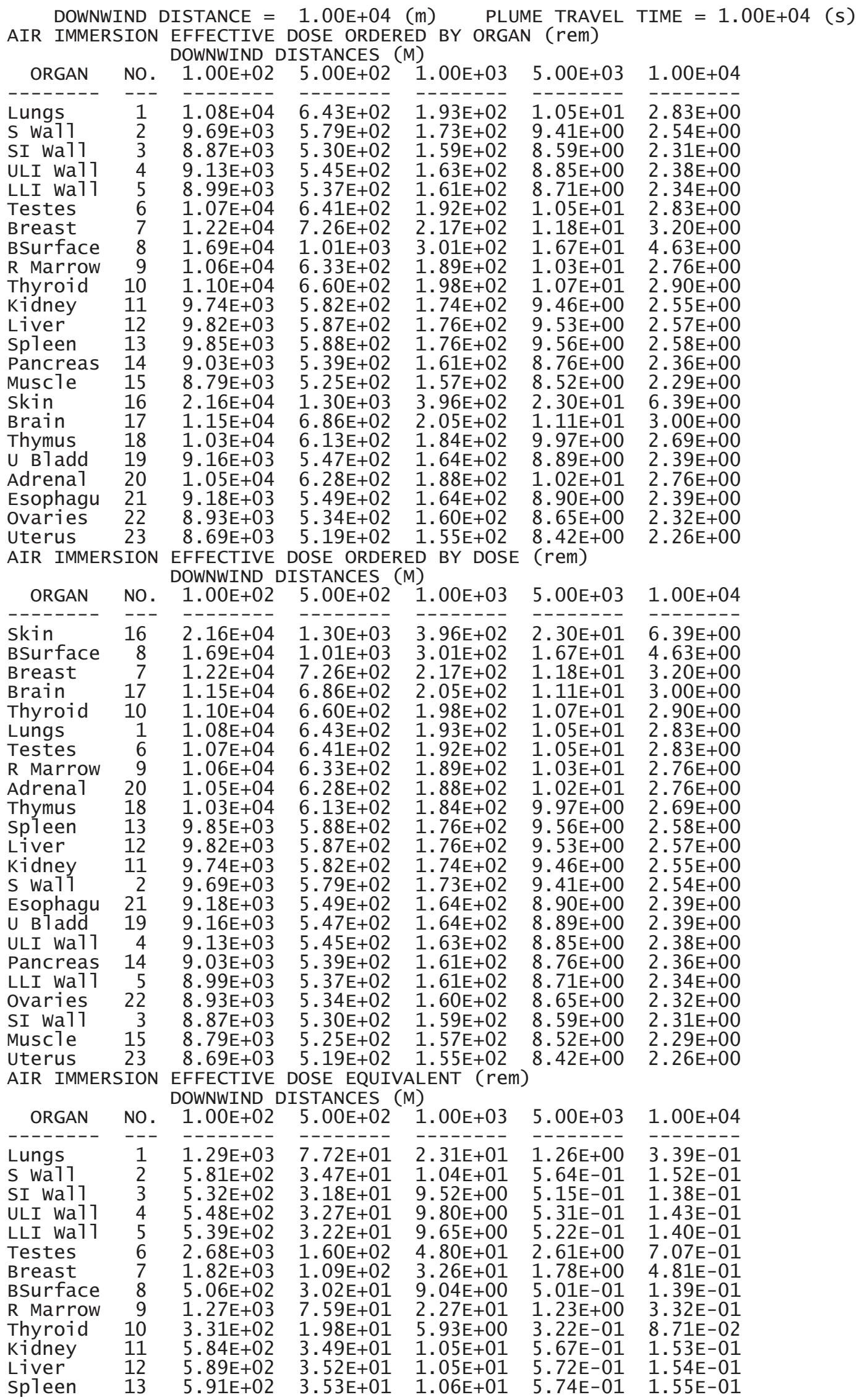




$\begin{array}{lllllll}\text { Pancreas } & 14 & 5.42 \mathrm{E}+02 & 3.23 \mathrm{E}+01 & 9.69 \mathrm{E}+00 & 5.25 \mathrm{E}-01 & 1.42 \mathrm{E}-01 \\ \text { Muscle } & 15 & 5.27 \mathrm{E}+02 & 3.15 \mathrm{E}+01 & 9.43 \mathrm{E}+00 & 5.11 \mathrm{E}-01 & 1.37 \mathrm{E}-01 \\ \text { Skin } & 16 & 2.16 \mathrm{E}+02 & 1.30 \mathrm{E}+01 & 3.96 \mathrm{E}+00 & 2.30 \mathrm{E}-01 & 6.39 \mathrm{E}-02 \\ \text { Brain } & 17 & 6.89 \mathrm{E}+02 & 4.12 \mathrm{E}+01 & 1.23 \mathrm{E}+01 & 6.69 \mathrm{E}-01 & 1.80 \mathrm{E}-01 \\ \text { Thymus } & 18 & 6.16 \mathrm{E}+02 & 3.68 \mathrm{E}+01 & 1.10 \mathrm{E}+01 & 5.98 \mathrm{E}-01 & 1.61 \mathrm{E}-01 \\ \text { U B1add } & 19 & 5.50 \mathrm{E}+02 & 3.28 \mathrm{E}+01 & 9.83 \mathrm{E}+00 & 5.33 \mathrm{E}-01 & 1.44 \mathrm{E}-01 \\ \text { Adrena1 } & 20 & 6.31 \mathrm{E}+02 & 3.77 \mathrm{E}+01 & 1.13 \mathrm{E}+01 & 6.14 \mathrm{E}-01 & 1.66 \mathrm{E}-01 \\ \text { Esophagu } & 21 & 5.51 \mathrm{E}+02 & 3.29 \mathrm{E}+01 & 9.86 \mathrm{E}+00 & 5.34 \mathrm{E}-01 & 1.43 \mathrm{E}-01 \\ \text { Ovaries } & 22 & 2.23 \mathrm{E}+03 & 1.34 \mathrm{E}+02 & 4.00 \mathrm{E}+01 & 2.16 \mathrm{E}+00 & 5.79 \mathrm{E}-01 \\ \text { Uterus } & 23 & 5.21 \mathrm{E}+02 & 3.11 \mathrm{E}+01 & 9.33 \mathrm{E}+00 & 5.05 \mathrm{E}-01 & 1.36 \mathrm{E}-01 \\ \text { EXT EDE } & 24 & 1.10 \mathrm{E}+04 & 6.58 \mathrm{E}+02 & 1.97 \mathrm{E}+02 & 1.07 \mathrm{E}+01 & 2.90 \mathrm{E}+00\end{array}$

\section{Ingestion Dose Calculation}

USING DOSE CONVERSION FACTORS FROM ICRP-72 FOR MEMBERS OF THE PUBLIC RELEASE TIME FOR EXPONENTIAL DECAY FUNCTION $=1.000 \mathrm{E}+00(\mathrm{~s})$ INTERNAL EXPOSURE TIME PERIOD $=5.000 E+01(\mathrm{yr})$

INGESTION CALCULATIONS MADE USING CODE CALCULATED CONSTANTS INGESTION CONSTANTS:
5.20E+02 STORED VEGETABLE USAGE FACTOR (KG/YR)
6.40E+01 FRESH VEGETABLE USAGE FACTOR (KG/YR)
1.10E+02 MEAT USAGE FACTOR (KG/YR)
3.10E+02 MILK USAGE FACTOR (L/YR)
7.60E-01 FRACTION OF STORED VEGETABLES FROM GARDEN
1.00E+00 FRACTION OF FRESH VEGETABLES FROM GARDEN
5.70E-01 RETENTION FACTOR FOR ACTIVITY ON FORAGE
2.00E-01 RETENTION FACTOR FOR ACTIVITY ON VEGETABLES
1.00E+00 RETENTION FACTOR FOR IODINES
2.10E-03 REMOVAL RATE CONSTANT FOR CROPS $(1 / \mathrm{H})$
6.00E+01 VEGETABLE EXPOSURE TIME TO PLUME FOR CHRONIC RELEASE (D)
3.00E+01 FORAGE EXPOSURE TIME TO PLUME FOR CHRONIC RELEASE (D)
1.00E+00 HTO REMOVAL HALF TIME (D)
2.25E+02 EFFECTIVE SURFACE SOIL DENSITY (KG/SQ M)
6.00E+01 STORED VEGETABLE HOLDUP TIME AFTER HARVEST (D)
1.00E+00 FRESH VEGETABLE HOLDUP TIME AFTER HARVEST (D)
1.60E+01 ANIMALS DAILY FORAGE FEED (KG/D)
2.00E+00 FEED-MILK-RECEPTOR TRANSFER TIME (D)
2.00E+01 SLAUGHTER TO CONSUMPTION TIME (D)
4.00E-01 FRACTION OF YEAR ON PASTURE
4.30E-01 PASTURE FEED FRACTION
9.00E+01 STORED FEED STORAGE TIME
2.00E+00 VEGETABLE VEGETATION YIELD (KG/SQ M)
2.80E-01 FORAGE VEGETATION YIELD (KG/SQ M)
4.90E+00 ABSOLUTE HUMIDITY (G/CU M)

CHRONIC RELEASE - ANNUAL DOSE

ACTIVITY BUILDUP IN SOIL OVER $1.500 E+01$ (YR) ICRP-72 INGESTION DOSE CALCULATIONS FOR ADULT AGE INGESTION EQUIVALENT DOSE ORDERED BY ORGAN (rem)

\begin{tabular}{|c|c|c|c|c|c|c|}
\hline ORGAN & NO. & $\begin{array}{l}\text { DOWNWIND } \\
1.00 \mathrm{E}+02\end{array}$ & $\begin{array}{l}\text { ISTANCES } \\
5.00 \mathrm{E}+02\end{array}$ & 1.00E+03 & $5.00 \mathrm{E}+03$ & 1. $.00 \mathrm{E}+04$ \\
\hline DRENALS & 1 & $5.21 E+03$ & $3 . \angle 3 E+U \angle$ & 1.04E+02 & $8.89 \mathrm{E}+0$ & כJ \\
\hline B_WALL & 2 & $3.46 \mathrm{E}+04$ & -03 & $6.90 \mathrm{E}+02$ & & \\
\hline BSURFACE & 3 & $5.24 \mathrm{E}+04$ & 3.25 & $1.05 \mathrm{E}+03$ & $E+01$ & \\
\hline BRAIN & 4 & $6.88 \mathrm{E}+03$ & $4.27 \mathrm{E}+02$ & 1. $38 \mathrm{E}+02$ & $18 \mathrm{E}+01$ & \\
\hline BREAST & 5 & $4.21 E+03$ & $2.61 \mathrm{E}+02$ & $8.42 \mathrm{E}+01$ & $21 E+00$ & 2 \\
\hline COLON & 6 & $1.59 \mathrm{E}+05$ & $9.90 \mathrm{E}+03$ & $3.19 E+03$ & $6 \mathrm{E}+02$ & \\
\hline SOPHAGU & 7 & $7.44 \mathrm{E}+03$ & 4.62 & 1.49 & 1 & \\
\hline ET_AIR & 8 & 7.36 & 4.5 & $1.47 \mathrm{E}+02$ & 1 & \\
\hline KIDNEYS & 9 & & 02 & 1.27E+02 & 1 & \\
\hline LIVER & 10 & 6. & 3 & 1.23 & $6 \mathrm{E}+01$ & \\
\hline LLI_WALL & 11 & +05 & 1. & 4.87 & 4 & \\
\hline LUNGS & 12 & 5.5 & 3.7 & 1. & 1 & \\
\hline MUSCLE & 13 & 7.5 & -02 & 02 & 1 & \\
\hline OVARIES & 14 & +04 & +02 & +02 & $2.22 \mathrm{E}+01$ & \\
\hline PANCREAS & 15 & 6.3 & +02 & +02 & $E+01$ & \\
\hline R_MARROW & 16 & 2.7 & & +02 & & \\
\hline SI_WALL & 17 & 2.4 & & 4 & & \\
\hline SKIN & 18 & & & 9 & 8 & \\
\hline SPLEEN & 19 & 3.3 & 3.3 & 1.07E+02 & $9.14 \mathrm{E}+00$ & \\
\hline ST_WALL & 20 & 2.7 & 03 & +02 & 01 & \\
\hline
\end{tabular}




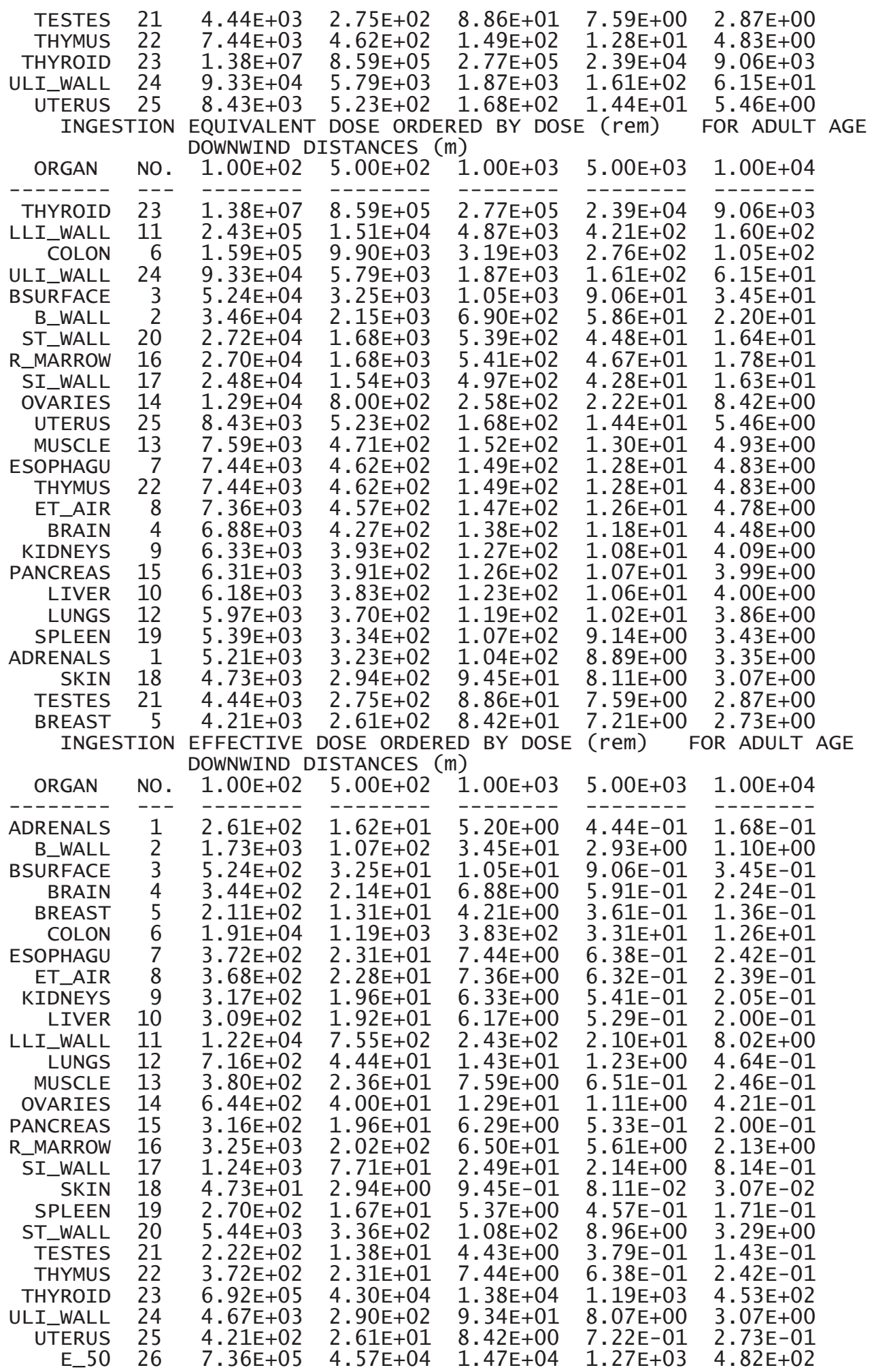

Gamma Dose Calculation

EXPOSURE TIME $=1.0000 \mathrm{E}+00(\mathrm{~S})$

CALCULATIONS MADE USING THE FINITE MODEL

DOWNWIND DISTANCE $=1.000 \mathrm{E}+02(\mathrm{M})$
EXTERNAL EDE

DOSE $=3.93 \mathrm{E}+02(\mathrm{REM})$ 


DOWNWIND DISTANCE $=5.000 \mathrm{E}+02(\mathrm{M})$
DOWNWIND DISTANCE $=1.000 \mathrm{E}+03(\mathrm{M})$
DOWNWIND DISTANCE $=5.000 \mathrm{E}+03(\mathrm{M})$
DOWNWIND DISTANCE $=1.000 \mathrm{E}+04(\mathrm{M})$

DOSE $=6.13 \mathrm{E}+01$ (REM)
DOSE $=2.91 \mathrm{E}+01$ (REM)
DOSE $=3.87 \mathrm{E}+00$ (REM)
DOSE $=1.32 \mathrm{E}+00$ (REM)

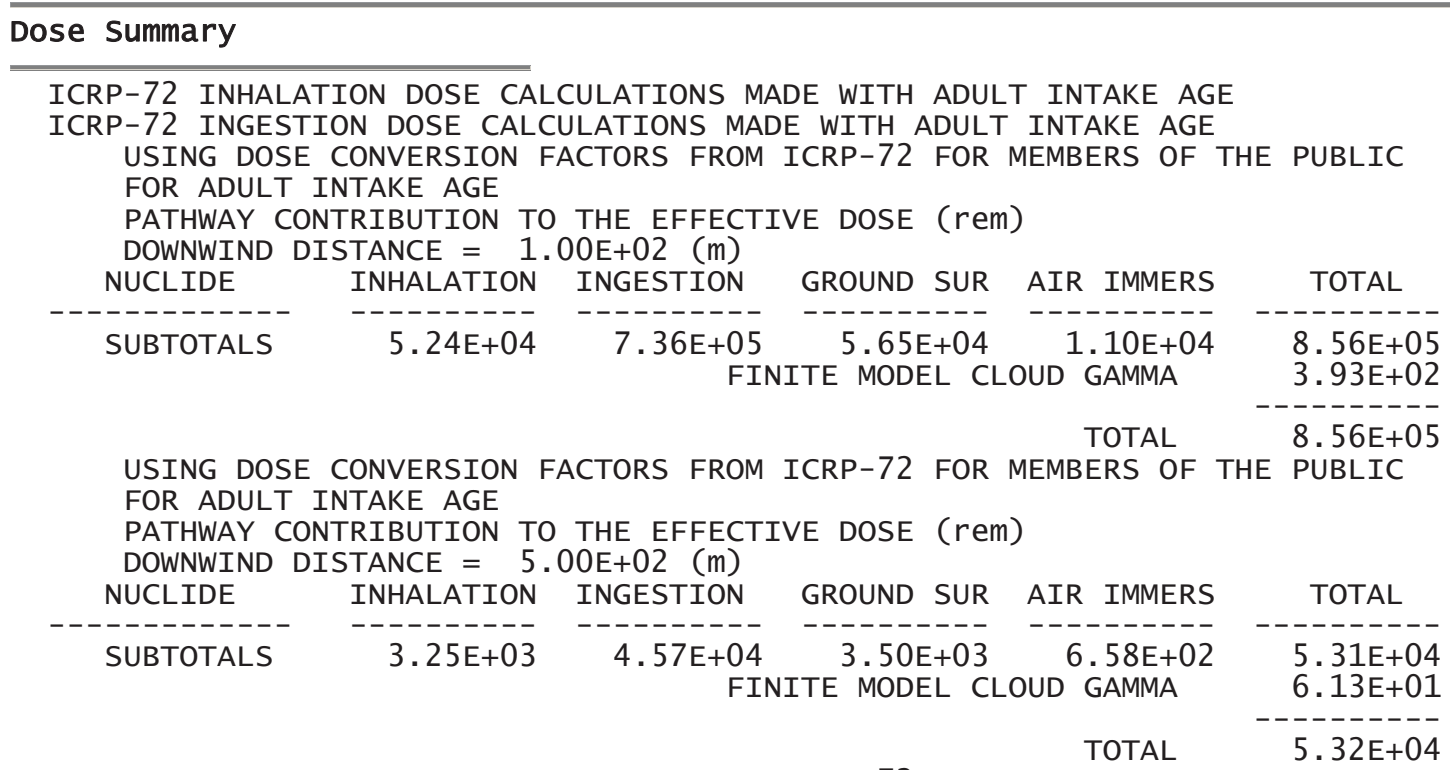

USING DOSE CONVERSION FACTORS FROM ICRP-72 FOR MEMBERS OF THE PUBLIC FOR ADULT INTAKE AGE PATHWAY CONTRIBUTION TO THE EFFECTIVE DOSE (rem) DOWNWIND DISTANCE $=1.00 \mathrm{E}+03(\mathrm{~m})$

TOTAL $\quad 5.55 \mathrm{E}+02$

Execution Time 


\section{REFERENCES}

1. American National Standards Institute, Inc./American Nuclear Society (ANSI/ANS), 1987, American National Standard Guidelines for the Verification and Validation of Scientific and Engineering Computer Programs for the Nuclear Industry, ANSI/ANS-10.4.

2. American Society of Mechanical Engineers (ASME), 2000, Quality Assurance Program Requirements for Nuclear Facility Applications, ASME-NQA-1-2000.

3. Abramowitz, M and I. A. Stegum (eds.), 1964: Handbook of Mathematical Functions with Formulas, Graphs, and Mathematical Tables, AMS 55, pp. 887-890.

4. Baes, C. F. III, R. D. Sharp, A. L. Sjoreen, R. W. Shor, 1984, A Review and Analysis of Parameters for Assessing Transport of Environmentally Released Radionuclides through Agriculture, ORNL-5786, Oak Ridge National Laboratory, Oak Ridge Tennessee.

5. Berger, M. J. and R. G. Jaeger, 1968, Engineering Compendium on Radiation Shielding, Vol. I, New York: Springer-Verlag Inc., p. 218.

6. Boone, F. W., Y. C. Ng, J. M. Palms, 1981, "Terrestrial Pathways of Radionuclide Particulates," Health Physics, 41, pp. 735-747.

7. Briggs, G. A., 1969, Plume Rise, TID-25075, U.S. Atomic Energy Commission, Oak Ridge, Tennessee.

8. Chamberlain, A. C., 1953, Aspects of Travel and Deposition of Aerosol and Vapour Clouds, AERE-HP/R-1261, Harwell, Great Britian.

9. Chu, S. Y. F., L. P. Ekstrom and R. B. Firestone, The Lund/LBNL Nuclear Data Search, Version 2.0, Ernst O. Lawrence Berkeley National Laboratory, Berkely, California, and LUND University, Sweden, February 1999.

10. Clawson, K. L., G. E. Start, N. R. Ricks, 1989, Climatography of the Idaho National Engineering Laboratory, 2nd Edition, DOE/ID-12118, U.S. Department of Commerce, National Oceanic and Atmospheric Administration, Environmental Research Laboratories, Air Resource Laboratory, Field Research Division, Idaho Falls, Idaho, December.

11. Coates, R. L. and N. R. Horton, 1966, RSAC_-A Radiological Safety Analysis Computer Program, IDO-17151, Idaho National Engineering Laboratory, Idaho Falls, Idaho.

12. Croff, A. G., R. L. Haese, N. B. Gove, 1979, Updated Decay and Photon Libraries for the Origen Code, ORNL/TM-6055, Oak Ridge National Laboratory, Oak Ridge Tennessee.

13. Croff, A. G., 1980, ORIGEN2-A Revised and Updated Version of the Oak Ridge Isotope Generation and Depletion Code, ORNL-5621, Oak Ridge National Laboratory, Oak Ridge, Tennessee.

14. DOE, 1994, Airborne Release Fractions/Rates and Respirable Fractions for NonReactor Nuclear Facilities,DOE-HDBK-3010-94, U.S. Department of Energy, Washington, D.C.

15. Eckerman, K.F., and Ryman, J.C. 1993, External Exposures to Radionuclides in Air; Water; and Soil, Federal Guidance Report No. 12, EPA-402/R-93-081U.S. Environmental Protection Agency Washington, D.C.

16. Eckerman, K.F., Wolbarst, A.B., and Richardson, A.C.B., 1988, Limiting Values of Radionuclide Intake and Air Concentration and Dose Conversion Factors for Inhalation, Submersion, and Ingestion. Federal Guidance Report No. 11, EPA-5201/1-88-020, U.S. Environmental Protection Agency, Washington, D.C. 
17. Hanna, S. R., G. A. Briggs, R. P. Hosker Jr., 1982, Handbook on Atmospheric Diffusion, DOE/TIC-11223, U.S. Department of Energy, Oak Ridge, Tennessee.

18. ICRP (International Commission on Radiological Protection), 1977, Report of the Task Group on Reference Man, ICRP Publication 23, Pergamon Press, Oxford, Great Britain.

19. ICRP, 1979, Limits for Intakes of Radionuclides by Workers, Part 1, ICRP Publication 30, Pergamon Press, Oxford, Great Britain.

20. ICRP, 1983, Radionuclide Transformations, Energy and Intensity of Emissions, ICRP Publication 38, Pergamon Press, Oxford, Great Britain.

21. INEEL, 2001, Verification and Validation of RSAC-7.2, Idaho National Engineering and Environmental Laboratory, Idaho Falls, Idaho

22. Islitzer, N. F., 1965, Aerodynamic Effects of Large Reactor Complexes Upon Atmospheric Turbulence and Diffusion, IDO-12041, Idaho National Engineering Laboratory, Idaho Falls, Idaho.

23. Markee, E. H. Jr., 1967, "A Parametric Study of Gaseous Plume Depletion by Ground Surface Adsorption," in Proceeding of USAEC Meteorological Information Meeting, C. A. Mawson, Editor, AECL-2787, pp. 602-613.

24. NRC (U.S. Nuclear Regulatory Commission), 1977a, Calculation of Annual Doses to Man from Routine Releases of Reactor Effluents for the Purpose of Evaluating Compliance with 10 CFR Part 50, Appendix I, Regulatory Guide 1.109 Revision 1, Washington, D.C.

25. NRC, 1977b, Methods for Estimating Atmospheric Transport and Dispersion of Gaseous Effluents in Routine Releases from Light-Water-Cooled Reactors, Regulatory Guide 1.111 Revision 1, Washington, D.C.

26. NRC, 1982, Atmospheric Dispersion Models for Potential Accident Consequence Assessments at Nuclear Power Plants, Regulatory Guide 1.145, Revision 1, Washington, D.C.

27. NQA-1-2008, "Quality Assurance Requirements for Nuclear Facility Applications", Subpart 2.7, "Quality Assurance Requirements for Computer Software for Nuclear Facility Applications."

28. Ramsdell, J.V., Jr., Simonen, C.A., 1997, Atmospheric Relative Concentrations in Building Wakes, Report NUREG/CR-6331. U.S. Nuclear Regulatory Commission, Washington, D.C.

29. Richardson, L. C., 1968, User's Manual for the FORTRAN Version of RSAC, IDO-17261, Idaho National Engineering Laboratory, Idaho Falls, Idaho.

30. RSIC (Radiation Shielding Information Center), 1981, RSIC Data Library Collection, "DRALIST, Radioactive Decay Data for Application to Radiation Dosimetry and Radiological Assessments", DLC-80, Oak Ridge, Tennessee.

31. RSIC, 1991, RSIC Computer Code Collection, "ORIGEN 2.1, Isotope Generation and Depletion Code Matrix Exponential Method", CCC-371, Oak Ridge, Tennessee.

32. Rubinson, W., 1949, "The Equations of Radioactive Transformation in a Neutron Flux," Journal Chemical Phys, 17, pp. 542-547.

33. Sehmel, G. A., 1980: "Particle and Gas Dry Deposition: A Review," Atmospheric Environment, 14, pp. 983-1011.

34. Slade, D. H. (ed), 1968: Meteorology and Atomic Energy, AEC/TID-24190, U.S. Atomic Energy Commission, Silver Spring, Maryland.

35. SRA (Shonka Research Associates, Inc.), 1993, Software Verification and Validation Report for the WINCO RSAC-5 Code, Marietta, Georgia. 
36. Till, J.E., and Meyer, H.R., eds., 1983, Radiological Assessment: A textbook on Environmental Dose Analysis, Report NUREG/CR-3332. U.S. Nuclear Regulatory Commission, Washington, D.C.

37. Turner, D. B., 1970, Workbook of Atmospheric Dispersion Estimates, Revised, U.S. Environmental Protection Agency, Research Triangle Park, North Carolina.

38. Wenzel, D. R., 1973, Preliminary User's Manual for the Revised Radiological Safety Analysis Computer Program-RSAC-2, ACI-139, Allied Chemical Corporation, Idaho National Engineering Laboratory, Idaho Falls, Idaho.

39. Wenzel, D. R., 1982, RSAC-3, Radiological Safety Analysis Computer Program, ENICO-1002, Idaho National Engineering Laboratory, Idaho Falls, Idaho.

40. Wenzel, D. R., 1990, Interim Users Manual for RSAC-4, Radiological Safety Analysis Computer Program, Version 4.03, Westinghouse Idaho Nuclear Company, Inc., Idaho National Engineering Laboratory, Idaho Falls, Idaho.

41. Wenzel, D. R. 1994, The Radiological Safety Analysis Computer Program (RSAC-5) User's Manual, WINCO-1123, Revision 1, Idaho national Engineering and Environmental Laboratory, Idaho Falls, Idaho.

42. Yanskey, G. R., E. H. Markee Jr., A. P. Richter, 1966, Climatography of the National Reactor Testing Station, IDO-12045, Idaho National Engineering Laboratory, Idaho Falls, Idaho. 
INTENTIONALLY BLANK 


\section{Appendix A}

\section{Mathematical Models}




\section{Appendix A}

\section{Mathematical Models}

\section{A-1. FISSION PRODUCT INVENTORY}

The calculation of a fission product inventory for a given operating history is divided into two parts: fission product buildup and radionuclide decay.

\section{A-1.1 Fission Product Buildup}

The rate of buildup or fission product generation of the various radionuclides of a decay chain is described by a set of simultaneous differential equations of the first order:

$$
\begin{aligned}
& \frac{\mathrm{dQ}_{1}}{\mathrm{dt}}=\mathrm{S}_{1}-\mu_{1} \mathrm{Q}_{1} \\
& \frac{\mathrm{dQ}_{2}}{\mathrm{dt}}=\mathrm{s}_{2}-\mu_{2} \mathrm{Q}_{2}+\lambda_{1} \mathrm{Q}_{1} \\
& \frac{\mathrm{dQ}}{\mathrm{dt}}=\mathrm{s}_{\mathrm{i}}-\mu_{\mathrm{i}} \mathrm{Q}_{\mathrm{i}}+\lambda_{\mathrm{i}-1} \mathrm{Q}_{\mathrm{i}-1}
\end{aligned}
$$

where

$\mathrm{Q}_{\mathrm{i}}=$ the number of atoms for the $\mathrm{i}^{\text {th }}$ radio nuclide of the decay chain

$\mathrm{t}=$ operating time $(\mathrm{s})$

$\mathrm{s}_{\mathrm{i}}=$ the source rate at which atoms are being produced by fission for the $\mathrm{i}^{\text {th }}$ radionuclide (atoms/s).

$\mu_{\mathrm{i}}=\lambda_{\mathrm{i}}+\sigma_{\mathrm{ci}} \emptyset$

$$
\begin{aligned}
& \lambda_{\mathrm{i}}=\text { the decay constant for the } \mathrm{i}^{\text {th }} \text { radionuclide }\left(\mathrm{s}^{-1}\right) \\
& \sigma_{\mathrm{ci}}=\text { neutron capture cross section for the } \mathrm{i}^{\text {th }} \text { radionuclide }\left(\mathrm{cm}^{-2}\right) \\
& \emptyset=\text { neutron flux }\left(\mathrm{n} / \mathrm{cm}^{2}-\mathrm{s}\right)
\end{aligned}
$$




$$
\mathrm{S}_{\mathrm{i}}=(C O N V)(\text { POWER })\left(\text { Yield }_{i}\right)
$$

where

$\begin{array}{ll}\text { CONV } & \text { the conversion factor from power to fission (fissions/W-s) } \\ \text { POWER } & \text { the reactor power }(\mathrm{W}) \\ \text { Yield }_{\mathrm{i}}= & \begin{array}{l}\text { the fission yield for the } \mathrm{i}^{\text {th }} \text { radionuclide of the decay chain } \\ \text { (atoms/fission) } .\end{array}\end{array}$

The general solution as formulated by Rubinson (1949) for the contribution to the $\mathrm{n}^{\text {th }}$ radionuclide from the $\mathrm{m}^{\text {th }}$ radionuclide precursor is

$$
Q_{n}(t)=S_{m}\left(\prod_{i=m}^{n-1}\left(\lambda_{i}\right)\right) \sum_{i=m}^{n}\left[\frac{1-e^{-\lambda_{i} t}}{\lambda_{i} \prod_{\substack{j=m \\ j \neq i}}^{n}\left(\mu_{j}-\mu_{i}\right)}\right]
$$

By summing all the precursors of a particular nuclide, the general solution for the total number of atoms for the $\mathrm{k}^{\text {th }}$ radionuclide of the decay chain is obtained:

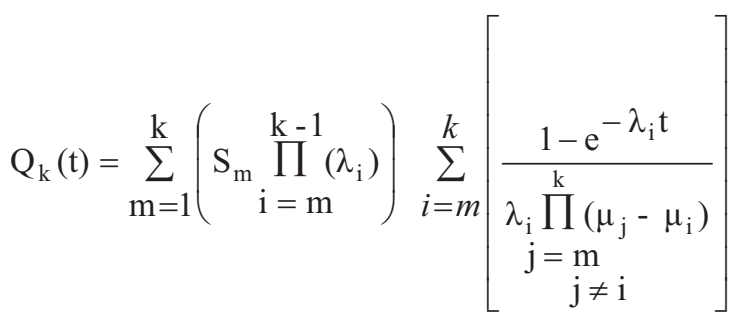

For convenience the linear operator, $\mathrm{E}_{\mathrm{k}}$, is defined as follows:

$$
E_{k}=\sum_{m=1}^{k}\left(S_{m} \prod_{i=m}^{k-1}\left(\lambda_{i}\right)\right) \sum_{i=m}^{k}\left[\frac{1}{\prod_{j \neq i}^{k}\left(\mu_{j}-\mu_{i}\right)}\right]
$$


Therefore, the buildup equation can be written as

$$
\mathrm{Q}_{\mathrm{k}}(\mathrm{t})=\mathrm{E}_{\mathrm{k}}\left(\frac{1-\mathrm{e}^{-\lambda_{\mathrm{i}} \mathrm{t}}}{\lambda_{\mathrm{i}}}\right)
$$

\section{A-1.2 Radionuclide Decay}

The differential equations for the decay rate are similar to those for fission product buildup, except the source rate is considered to be zero. The general solution for the decay equation is

$$
N_{k}(t)=E_{k}\left(e^{-\lambda_{i} t}\right)
$$

where

$$
\mathrm{N}_{\mathrm{k}}(\mathrm{t})=\text { the total number of atoms for the } \mathrm{k}^{\text {th }} \text { radionuclide of the decay chain }
$$

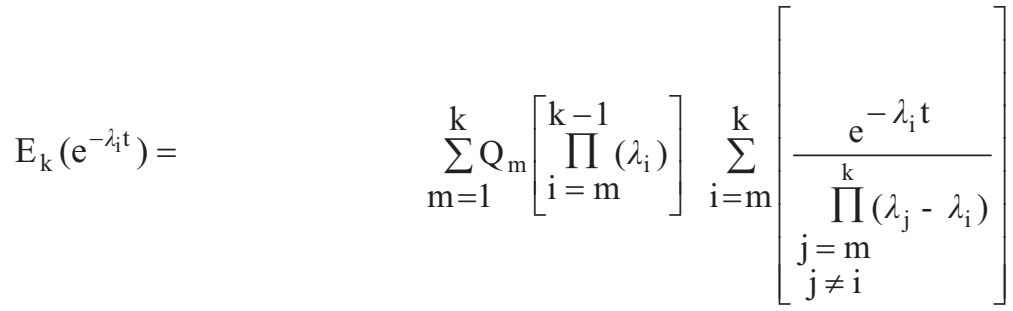

$\mathrm{Q}_{\mathrm{m}}=\quad$ the total number of atoms for the $\mathrm{m}^{\text {th }}$ radionuclide immediately following reactor shutdown as defined above.

$\mathrm{t}=\quad$ the time after reactor shutdown $(\mathrm{s})$.

RSAC-7.2 automatically decays all radioactivity during transport from the point of release to the environment to the downwind receptor location. For simplicity, subsequent equations used in dose calculations do not show the operator $\mathrm{E}_{\mathrm{k}}$. However, RSAC-7.2 programming includes the buildup and decay of all progeny in each of the decay chains. 


\section{A-2. CONCENTRATION FUNCTION}

\section{A-2.1 Atmospheric Diffusion}

Atmospheric diffusion at ground level for a continuous point source can be expressed using the timeintegrated form of the universal diffusion equation (Slade $1986^{34}$; Clawson et al. $1989^{10}$ ) as follows:

$$
\frac{\chi}{\mathrm{Q}}(\mathrm{x}, \mathrm{y}, 0)=\frac{1}{\pi \overline{\mathrm{u}} \sigma_{\mathrm{y}} \sigma_{\mathrm{z}}} \exp \left[-\frac{1}{2}\left(\frac{\mathrm{y}^{2}}{\sigma_{\mathrm{y}}^{2}}+\frac{\mathrm{h}^{2}}{\sigma_{\mathrm{z}}^{2}}\right)\right]
$$

where

$$
\begin{array}{ll}
\frac{\chi}{\mathrm{Q}}(\mathrm{x}, \mathrm{y}, 0) & =\text { ground-level atmospheric diffusion relative to the initial point of release }\left(\mathrm{s} / \mathrm{m}^{3}\right) \\
\mathrm{x} & =\text { distance downwind }(\mathrm{m}) \\
\mathrm{y} & =\text { horizontal distance from plume centerline }(\mathrm{m}) \\
\overline{\mathrm{u}} & =\text { average windspeed at the release level }(\mathrm{m} / \mathrm{s}) \\
\sigma_{\mathrm{y}}, \sigma_{\mathrm{z}} & \text { standard deviations of effluent concentration of the plume in the horizontal and } \\
\mathrm{h} & =\text { elevation of the point of release above the ground plane }(\mathrm{m}) .
\end{array}
$$

Airborne material freely diffuses the atmosphere near the ground level in what is known as the mixing depth. A stable layer exists above the mixing depth that restricts vertical diffusion. The depth of the mixed layer is a function of the heat energy exchange between the air and the ground; it is influenced by cloud cover, time of day, and season. Seasonal and annual mixing depths have been estimated for the Idaho National Laboratory (INL) (Clawson et al. $1989^{10}$ ) and are presented in Table A-1.

RSAC-7.2 treats the ground and the height of the mixing depth as plume reflectors. When $\sigma_{\mathrm{z}}$ becomes large compared to the mixing depth, the plume becomes uniformly distributed between the

Table A-1. Estimated seasonal and annual mixing depths $(\mathrm{m})$ for mornings and afternoons at the Idaho National Laboratory (INL).

\begin{tabular}{lcc}
\hline \multicolumn{1}{c}{ Season } & Morning & Afternoon \\
\hline Spring & 480 & 2330 \\
Summer & 260 & 2900 \\
Autumn & 330 & 1550 \\
Winter & 400 & 730 \\
ANNUAL & 370 & 2090 \\
\hline
\end{tabular}


ground and the height of the mixing depth. Atmospheric diffusion is then calculated using Equation (A-12) (Turner 1970, ${ }^{37}$ Yanskey et al. $1966^{42}$ ).

$$
\frac{\chi}{\mathrm{Q}}(\mathrm{x}, \mathrm{y}, 0)=\frac{1}{\sqrt{2 \pi} \sigma_{\mathrm{y}} \mathrm{Hu}}=\exp \left[-\frac{1}{2}\left(\frac{\mathrm{y}^{2}}{\sigma_{\mathrm{y}}^{2}}\right)\right]
$$

where

$\mathrm{H}$

$$
=\quad \text { height of the mixing depth }(\mathrm{m}) .
$$

An option is provided for ground-level releases to adjust the plume standard deviations to correct for an initial mixing of the effluent plume within a building wake (NUREG/CR-6331). An effective $\sigma_{\mathrm{y}}$ and $\sigma_{\mathrm{z}}$ can be used to correct for building turbulence (Ramsdell $1995^{28}$ ) using the following equations:

$$
\begin{aligned}
& \sum_{\mathrm{y}}=\left(\sigma_{\mathrm{y}}^{2}+\Delta \sigma_{\mathrm{y} 1}^{2}+\Delta \sigma_{\mathrm{y} 2}^{2}\right)^{1 / 2} \\
& \sum_{\mathrm{z}}=\left(\sigma_{\mathrm{z}}^{2}+\Delta \sigma_{\mathrm{z} 1}^{2}+\Delta \sigma_{\mathrm{z} 2}^{2}\right)^{1 / 2}
\end{aligned}
$$

where $\sigma_{\mathrm{y}}$ and $\sigma_{\mathrm{z}}$ are the normal diffusion coefficients, $\Delta \sigma_{\mathrm{y} 1}$ and $\Delta \sigma_{\mathrm{z} 1}$ are the low wind speed corrections, and $\Delta \sigma_{\mathrm{y} 2}$ and $\Delta \sigma_{\mathrm{z} 2}$ are the building wake corrections. The values for $\Delta \sigma_{\mathrm{y} 1}, \Delta \sigma_{\mathrm{z} 1}, \Delta \sigma_{\mathrm{y} 2}$ and $\Delta \sigma_{\mathrm{z} 2}$ are calculated as follows:

$$
\begin{aligned}
& \sigma_{\mathrm{y} 1}^{2}=9.13 \times 10^{5}\left[1-\left(1+\frac{\mathrm{x}}{1000 * \overline{\mathrm{u}}}\right) \exp \left(-\frac{\mathrm{x}}{1000 * \overline{\mathrm{u}}}\right)\right] \\
& \sigma_{\mathrm{z} 1}^{2}=6.67 \times 10^{2}\left[1-\left(1+\frac{\mathrm{x}}{100 * \overline{\mathrm{u}}}\right) \exp \left(-\frac{\mathrm{x}}{100 * \overline{\mathrm{u}}}\right)\right]
\end{aligned}
$$

where $\mathrm{x}$ is the distance from the release point to the receptor, in meters, and $\mathrm{U}$ is the wind speed in meters per second. It is appropriate to use the slant range distance for $\mathrm{x}$ because theses corrections are made only when the release is assumed to be at ground level and the receptor is assumed to be on the axis of the plume. The diffusion coefficients corrections that account for enhanced diffusion in the wake have a similar form. These corrections are:

$$
\begin{aligned}
& \sigma_{\mathrm{y} 2}^{2}=5.24 \times 10^{-2}(\overline{\mathrm{u}})^{2} \mathrm{~A}\left[1-\left(1+\frac{\mathrm{x}}{10 * \sqrt{\mathrm{A}}}\right) \exp \left(-\frac{\mathrm{x}}{10 * \sqrt{\mathrm{A}}}\right)\right] \\
& \sigma_{\mathrm{z} 2}^{2}=1.17 \times 10^{-2}(\overline{\mathrm{u}})^{2} \mathrm{~A}\left[1-\left(1+\frac{\mathrm{x}}{10 * \sqrt{\mathrm{A}}}\right) \exp \left(-\frac{\mathrm{x}}{10 * \sqrt{\mathrm{A}}}\right)\right]
\end{aligned}
$$

where $\mathrm{A}$ is the smallest representative cross-sectional area of the building. 


\section{Mathematical Models}

An upper limit is placed on $\Sigma_{\mathrm{y}}$ as a conservative measure. This limit is the standard deviation associated with a concentration uniformly distributed across a sector with width equal to the circumference of a circle with radius equal to the distance between a source and the receptor. This value is:

$$
\sum_{\mathrm{y}_{\max }}=\frac{2 \pi x}{\sqrt{12}}
$$

When the release is from an elevated point during stable meteorological conditions, significant concentrations of the plume often do not reach ground level until the stability change occurs. The most common breakup of stable meteorology (inversion) is through a phenomenon known as fumigation, which can result in increased ground-level concentrations. While fumigation is often ignored in other codes, it is a well documented phenomena (NRC 1982, Slade $1968,{ }^{34}$ Turner $1970,{ }^{37}$ Yanskey et al. $1966^{42}$ ). Fumigation occurs when the nocturnal temperature inversion at the surface is being broken up by surface heating shortly after sunrise. The plume may be transported large downwind distances during the stable meteorology condition before a fumigation breakup occurs. The length of time that a fumigation condition lasts is a function of the release height and the downwind terrain. Fumigations typically last approximately 30 minutes for stacks in the 30 to 50-meter heights and approximately 60 minutes for stacks in the 75 to 100 -meter heights. The inversion breakup creates moderately unstable conditions under an inversion lid, thereby, limiting vertical dispersion to the area between the ground and the base of the inversion (see Figure A-1).

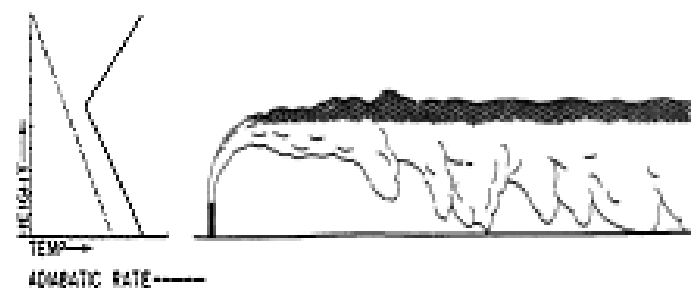

Figure A - 1. Fumigating plume.

Based on the assumption that the concentration is distributed uniformly in the vertical to the inversion base (Yanskey et al. $1966^{42}$ ), diffusion for a fumigating plume can be calculated using Equation (A-12).

Atmospheric dispersion at various heights above the ground level must be calculated to estimate cloud-gamma doses from a finite plume. The form of the time-integrated universal diffusion equation then becomes

$$
\frac{\chi}{Q}(x, y, z)=\frac{1}{2 \pi \bar{u} \sigma_{y} \sigma_{z}} \exp \left[-\frac{1}{2}\left(\frac{y^{2}}{\sigma_{y}^{2}}+\frac{(z-h)^{2}}{\sigma_{z}^{2}}+\frac{(z+h)^{2}}{\sigma_{z}^{2}}\right)\right]
$$

where

$\mathrm{z}=$ vertical distance from the plume centerline $(\mathrm{m})$ 
INTENTIONALLY BLANK

RSAC-7.2

A-8

October 


\section{A-2.2 Plume Deposition}

An estimate of the amount of radioactivity that is deposited on the ground must be made to calculate ground surface, resuspension and ingestion doses.

Dry deposition calculations in RSAC-7.2 are made using a deposition velocity as defined by Chamberlain $(1953)^{8}$ as

$$
\mathrm{V}_{\mathrm{d}}=-\frac{\mathrm{F}}{\chi}
$$

where

$\mathrm{V}_{\mathrm{d}}=$ dry deposition velocity $(\mathrm{m} / \mathrm{s})$
$\mathrm{F}=$ deposition flux $\left(\mathrm{Ci} / \mathrm{m}^{2} \mathrm{~s}\right)$
$\chi=$ airborne concentration $\left(\mathrm{Ci} / \mathrm{m}^{3}\right)$.

The quantity of deposited radioactive material, $\omega$, is then calculated using the following equation:

$$
\omega(\mathrm{x}, 0,0)=\mathrm{Q} \mathrm{V}_{\mathrm{d}} \mathrm{t}
$$

where

$\omega=$ surface contamination $\left(\mathrm{Ci} / \mathrm{m}^{2}\right)$

$\mathrm{V}_{\mathrm{d}}=$ deposition velocity $(\mathrm{m} / \mathrm{s})$

$\mathrm{t}=$ time that the ground is exposed to the plume (s).

Dry deposition velocities are a function of particle size and chemical species. Values recommended for use in RSAC-7.2 are published by Sehmel (1980). ${ }^{33}$

Wet deposition in RSAC-7.2 is based on the modeling summarized by Hanna et al. (1982). The modeling assumes the plume concentration (C) decreases exponentially with time: 


$$
C(t)=C(0) \exp [-\Lambda t]
$$

where

$\Lambda=$ scavenging coefficient $\left(\mathrm{s}^{-1}\right)$
$\mathrm{t}=$ time since precipitation began $(\mathrm{s})$.

\section{A-2.3 Plume Depletion}

RSAC-7.2 has options for modeling plumes depletion by both dry and wet deposition. Plume depletion by dry deposition is based on a modified version of the Chamberlain $(1953)^{8}$ model. The Chamberlain model expressed in Pasquill notation is:

$$
\mathrm{F}_{\text {dry }}^{\mathrm{C}}=\exp \left\{\sqrt{\frac{2}{\pi}} \frac{\mathrm{V}_{\mathrm{d}}}{\overline{\mathrm{u}}} \int_{0}^{\mathrm{x}} \frac{1}{\sigma_{\mathrm{z}}} \exp \left[-\frac{1}{2}\left(\frac{\mathrm{h}^{2}}{\sigma_{\mathrm{z}}^{2}}\right)\right] \mathrm{dx}\right\}
$$

where

$\mathrm{F}_{\text {dry }}^{\mathrm{C}} \quad=$ fraction of plume depleted by dry deposition.

Because the Chamberlain model is known to indicate over depletion of the plume under stable meteorological conditions, an empirical modification has been made based upon plume depletion measurements made of releases of activity as evaluated at the INL (Markee 1967). ${ }^{23}$ The modified Chamberlain equation is as follows:

$$
\mathrm{F}_{\mathrm{dry}}=\mathrm{F}_{\mathrm{dry}}^{\mathrm{C}} \exp \left[-\ln \left(\mathrm{x} \mathrm{C}_{\mathrm{WC}}\right)\right]
$$

Values for the constant $\mathrm{C}_{\mathrm{WC}}$ are presented in Table A-2. 
Table A-2. Values for the constant $\mathrm{C}_{\mathrm{WC}}$

\begin{tabular}{ll}
\hline $\begin{array}{c}\text { Weather } \\
\text { Class }\end{array}$ & $\mathrm{C}_{\mathrm{WC}}$ \\
\hline A & 0. \\
B & 0. \\
C & 0. \\
D & 0. \\
E & 0.0999 \\
F & 0.198 \\
G & 0.198 \\
\hline
\end{tabular}

When it is assumed that the rain falls completely through the plume, the fraction of the plume depleted $\left(\mathrm{F}_{\text {wet }}\right)$ is given by

$$
\mathrm{F}_{\text {wet }}=\frac{\Lambda}{\sqrt{2 \pi} \sigma_{\mathrm{y}} \overline{\mathrm{u}}} \exp \left[-\frac{1}{2}\left(\frac{\mathrm{y}^{2}}{\sigma_{\mathrm{y}}^{2}}\right)\right]
$$

The total plume depletion is:

$$
\mathrm{F}_{\text {total }}=\mathrm{F}_{\mathrm{dry}}^{\mathrm{C}} \mathrm{F}_{\mathrm{wet}}
$$

\section{A-2.4 Leakage Rate Function}

RSAC-7.2 can correct the radionuclide inventory for decay during holdup before leaking from a building, stack, or containment vessel to the atmosphere. Leakage is expressed in the form of a series of exponential approximations of the following form: 


$$
\mathrm{L}(\mathrm{t}-\mathrm{x} / \overline{\mathrm{u}})=\sum_{\mathrm{j}=1}^{\mathrm{n}} \mathrm{K} 1_{\mathrm{j}} \exp \left[-\mathrm{K} 2_{\mathrm{j}}(\mathrm{t}-\mathrm{x} / \overline{\mathrm{u}})\right]
$$

where

$$
\begin{aligned}
& \mathrm{L}(\mathrm{t}-\mathrm{x} / \overline{\mathrm{u}}) \quad=\text { leakage rate function }\left(\mathrm{s}^{-1}\right) \\
& \mathrm{t} \quad=\text { time following the initiation of the release }(\mathrm{s}) \\
& \mathrm{x} / \overline{\mathrm{u}} \\
& \mathrm{n} \quad=\text { number of exponential approximations }(1 \leq \mathrm{n} \leq 10) \\
& \mathrm{K}_{\mathrm{j}} \quad=\quad \text { linear constant }\left(\mathrm{s}^{-1}\right) \\
& \mathrm{K} 2_{\mathrm{j}} \quad=\text { exponential constant }\left(\mathrm{s}^{-1}\right) .
\end{aligned}
$$

Values of $\mathrm{K} 1_{\mathrm{j}}$ and $\mathrm{K} 2_{\mathrm{j}}$ can be either positive or negative. If a constant leakage rate is desired, set $\mathrm{K} 2_{\mathrm{j}}=0$. and $\mathrm{K} 1_{1}=$ the reciprocal of the time that it takes for the activity to be released to the atmosphere. The use of one set of leakage constants is normally sufficient for most calculations.

It is important not to decay the radionuclide inventory twice before its release to the atmosphere. This can inadvertently occur when the total activity of each radionuclide to be released to the atmosphere over an extended period of time is entered directly into RSAC-7.2 rather than using RSAC-7.2 to calculate the radionuclide inventory. When this is the case, no additional decay of the activity before release is desired even though the total activity entered may represent a release over an extended period of time. When the total activity to be released to the atmosphere is entered directly into RSAC-7.2, the user should set $\mathrm{K} 1_{1}=1$., $\mathrm{K} 2_{1}=0$, and the time over which the activity is released to the atmosphere to 1 second.

Proper selection of the leakage constants $\mathrm{K} 1_{\mathrm{j}}$ and $\mathrm{K} 2_{\mathrm{j}}$ can be evaluated by integrating each of the leakage terms over the period of release. The sum of the integrated terms should equal the total release fraction before correction for radioactive decay. Additional information on the use of the RSAC-7.2 leakage function is presented in Section 4.1, Leakage Decay Constants Lines (5201+). 


\section{A-2.5 Plume Rise}

Plume rise in RSAC-7.2 is calculated for either jet or buoyant plumes using the methodology developed by Briggs (1969). ${ }^{7}$ For jet plumes in neutral, windy, or lapse conditions, the jet centerline plume rise is given by

$$
\Delta \mathrm{h}=3 \frac{\omega_{\mathrm{o}}}{\overline{\mathrm{u}} \mathrm{D}}
$$

where

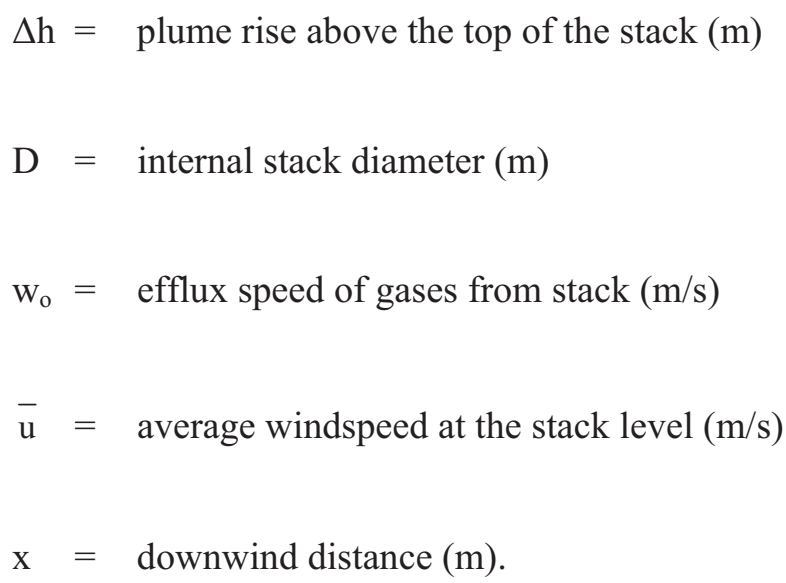

Equation (A-29) is used up to the point that

$$
\frac{\Delta \mathrm{h}}{\mathrm{D}}=1.44\left(\frac{\omega_{\mathrm{o}}}{\overline{\mathrm{u}}}\right)^{2 / 3}\left(\frac{\mathrm{x}}{\mathrm{D}}\right)^{1 / 3}
$$

as long as $\omega_{\mathrm{o}} / \overline{\mathrm{u}} \geq 4$.

When stable meteorological conditions exist, plume rise is calculated using

$$
\Delta \mathrm{h}=1.5\left(\frac{\mathrm{F}_{\mathrm{m}}}{\overline{\mathrm{u}}}\right)^{1 / 3} \mathrm{~s}^{-1 / 6}
$$

where 


$$
\mathrm{F}_{\mathrm{m}}=\omega_{\mathrm{o}}^{2}\left(\frac{\mathrm{D}}{2}\right)^{2}
$$

$\mathrm{S}=$ restoring acceleration per unit vertical displacement $\left(\mathrm{s}^{-2}\right)$.

RSAC-7.2 default values for S are 8.7E-04 $\left(\mathrm{s}^{-2}\right)$ for a weak inversion and $1.75 \mathrm{E}-03\left(\mathrm{~s}^{-2}\right)$ for a strong inversion.

Plume rise for a buoyant plume is calculated using

$$
\Delta \mathrm{h}=\frac{1.6}{\overline{\mathrm{u}}} \mathrm{F}^{\frac{1}{3}} \mathrm{x}^{\frac{2}{3}}
$$

where

$\mathrm{F}=3.7 \times 10^{-5} \mathrm{Q}_{\mathrm{H}}$

$\mathrm{Q}_{\mathrm{H}}=$ stack gasses heat emission (cal/s).

Equation (A-33) is used up to a distance $\mathrm{x}_{\mathrm{e}} / \mathrm{x}_{\mathrm{e}}^{*}=1$, where

$\mathrm{x}_{\mathrm{e}}=$ downwind distance $(\mathrm{ft})$

$$
\mathrm{x}_{\mathrm{e}}^{*}=0.52 \mathrm{~F}_{\mathrm{e}}^{\frac{2}{5}} \mathrm{~h}_{\mathrm{e}}^{\frac{3}{5}}
$$

$\mathrm{F}_{\mathrm{e}}=4.3 \times 10^{-3} \mathrm{Q}_{\mathrm{H}}$

$\mathrm{h}_{\mathrm{e}}=$ elevation of the point of release above the ground plane (ft)

$\Delta \mathrm{h}=0.3048 \Delta \mathrm{h}_{\mathrm{e}}(\mathrm{m})$

Beyond this distance, plume rise is calculated using 


$$
\mathrm{h}_{\mathrm{e}}=1.6 \mathrm{~F}_{\mathrm{e}}^{\frac{1}{3}} \frac{--1}{\mathrm{u}_{\mathrm{e}}} \mathrm{x}_{\mathrm{e}}^{* \frac{2}{3}}\left[\frac{2}{5}+\frac{16}{25} \frac{\mathrm{x}_{\mathrm{e}}}{\mathrm{x}_{\mathrm{e}}^{*}}+\frac{11}{5}\left(\frac{\mathrm{x}_{\mathrm{e}}}{\mathrm{x}_{\mathrm{e}}^{*}}\right)^{2}\right]\left(1+\frac{4}{5} \frac{\mathrm{x}_{\mathrm{e}}}{\mathrm{x}_{\mathrm{e}}^{*}}\right)^{-2}
$$

where

$\overline{\mathrm{u}}_{\mathrm{e}}=$ average windspeed at the elevation of the point of release above the ground plane $(\mathrm{ft} / \mathrm{s})$

and allowing $\mathrm{x}_{\mathrm{e}} / \mathrm{x}_{\mathrm{e}}^{*}$ to increase to a maximum value of 5 .

\section{A-3 DOSE CALCULATIONS}

\section{A-3.1 Inhalation Dose}

RSAC-7.2 calculates inhalation doses using the ICRP $30(1979)^{19}$ model with Federal Guidance Report No. 11 dose conversion factors (DCFs). The committed dose equivalent (CDE) is calculated for individual organs and tissues over a 50-year period after inhalation. The CDE for each organ or tissue is multiplied by the appropriate ICRP $26(1977)^{18}$ weighting factor to calculate what is called the weighted committed dose equivalent (WCDE) in RSAC-7.2. The ICRP 26 weighting factors are presented in Table A-3. The committed effective dose equivalent (CEDE) is then the sum of the WCDEs for the organs and tissues listed in Table A-3.

RSAC-7.2 calculates CEDE for the default $1 \mu \mathrm{m}$ activity median aerodynamic diameter (AMAD). Because of uncertainties in the ICRP 30 modeling, all final doses calculated should be reported to only one significant digit. 
Table A-3. Weighting factors for stochastic risks.

\begin{tabular}{lc}
\hline $\begin{array}{c}\text { Organ or } \\
\text { tissue }\end{array}$ & $\begin{array}{c}\text { Weighting } \\
\text { factor }\end{array}$ \\
\hline Gonads & 0.25 \\
Breast & 0.15 \\
Red bone & 0.12 \\
marrow & 0.12 \\
Lungs & 0.03 \\
Thyroid & 0.03 \\
Bone & \\
surfaces & 0.30 \\
Remainder & \\
a. A weighting factor of 0.06 is applied to each \\
of the five organs or tissues of the remaining \\
organs receiving the greatest dose equivalents.
\end{tabular}

For particle sizes other than the default $1 \mu \mathrm{m}$ AMAD, DCFs are corrected according to deposition in the three regions of the respiratory system; the nasal passage (NP), the trachea and bronchial tree (TB), and the pulmonary parenchyma $(\mathrm{P})$. DCFs are modified according to the following equation:

$$
\frac{\mathrm{DCF}_{(\text {New })}}{\mathrm{DCF}_{(1 \mu \mathrm{m})}}=\mathrm{f}_{\mathrm{NP}} \frac{\mathrm{D}_{\mathrm{NP}_{(\text {New })}}}{\mathrm{D}_{\mathrm{NP}_{(1 \mu \mathrm{m})}}}+\mathrm{f}_{\mathrm{TB}} \frac{\mathrm{D}_{\mathrm{TB}_{(\text {New })}}}{\mathrm{D}_{\mathrm{TB}_{(1 \mu \mathrm{m})}}}+\mathrm{f}_{\mathrm{P}} \frac{\mathrm{D}_{\mathrm{P}_{(\text {New })}}}{\mathrm{D}_{\mathrm{TB}_{(1 \mu \mathrm{m})}}}
$$

where

$$
\begin{aligned}
\mathrm{f}_{\mathrm{NP}}, \mathrm{f}_{\mathrm{TB}} \text {, and } \mathrm{f}_{\mathrm{P}}=\quad \begin{array}{r}
\text { fraction of the CDE in the reference tissue, resulting from } \\
\text { deposition in the N-P, T-B, and P regions, respectively as shown } \\
\text { in Table A-4. }
\end{array} \\
\mathrm{D}_{\mathrm{NP}}, \mathrm{D}_{\mathrm{TB}} \text {, and } \mathrm{D}_{\mathrm{P}}=\quad \begin{array}{l}
\text { deposition probabilities in the respiratory regions as a function of } \\
\text { AMAD as shown in Figure A- } 2 .
\end{array}
\end{aligned}
$$

The model is intended for use with aerosol distributions with AMADs between 0.2 and $10 \mu \mathrm{m}$. Provisional estimates of deposition further extending the size range are given by the dashed lines. The minimum allowable particle size is $0.1 \mu \mathrm{m}$ AMAD. The model assumes complete deposition in the NP region for all AMAD of greater than $20 \mu \mathrm{m}$.

Correction is made for the chemical state of each radionuclide according to the ICRP-30 designated clearance classes of D, W and Y as shown in Table A-4 for the clearance pathways shown in Figure A-3. The allowable clearance classes for each element and the RSAC-7.2 default classes are presented in Appendix D 
Table A-4. ICRP-30 mathematical model used to describe clearance from the respiratory system.

\begin{tabular}{|c|c|c|c|c|c|c|c|}
\hline \multirow[b]{3}{*}{ Region } & \multirow[b]{3}{*}{ Compartment } & \multicolumn{6}{|c|}{ Class $^{\mathrm{a}}$} \\
\hline & & \multicolumn{2}{|c|}{$\mathrm{D}$} & \multicolumn{2}{|c|}{ W } & \multicolumn{2}{|c|}{$\mathrm{Y}$} \\
\hline & & $\mathrm{T}$ day & $\mathrm{F}$ & T day & $\mathrm{F}$ & $\mathrm{T}$ day & $\mathrm{F}$ \\
\hline NP & $\mathrm{a}$ & 0.01 & 0.5 & 0.01 & 0.1 & 0.01 & 0.01 \\
\hline$\left(\mathrm{D}_{\mathrm{NP}}=0.30\right)$ & $\mathrm{b}$ & 0.01 & 0.5 & 0.40 & 0.9 & 0.40 & 0.99 \\
\hline TB & $\mathrm{c}$ & 0.01 & 0.95 & 0.01 & 0.5 & 0.01 & 0.01 \\
\hline \multirow[t]{2}{*}{$\left(\mathrm{D}_{\mathrm{TB}}=0.08\right)$} & $\mathrm{d}$ & 0.2 & 0.05 & 0.2 & 0.4 & 0.2 & 0.99 \\
\hline & $\mathrm{e}$ & 0.5 & 0.8 & 50 & 0.15 & 500 & 0.05 \\
\hline \multirow{3}{*}{$\begin{array}{l}P \\
\left(D_{P}=0.25\right)\end{array}$} & $\mathrm{f}$ & $\mathrm{NA}^{\mathrm{b}}$ & NA & 1.0 & 0.4 & 1.0 & 0.4 \\
\hline & g & NA & NA & 50 & 0.4 & 500 & 0.4 \\
\hline & $\mathrm{h}$ & 0.5 & 0.2 & 50 & 0.05 & 500 & 0.15 \\
\hline \multirow[t]{2}{*}{$\mathrm{L}$} & $\mathrm{i}$ & 0.5 & 1.0 & 50 & 1.0 & 1000 & 0.9 \\
\hline & j & NA & NA & NA & NA & $\infty$ & 0.1 \\
\hline \multicolumn{8}{|c|}{$\begin{array}{l}\text { a. } D, W \text {, and } Y \text { refer to lung retention classes with clearance half-times of } 0.5,50 \text { and } 500 \text { days, } \\
\text { respectively. T refers to the removal half-times, and } F \text { refers to the compartmental fractions. The } \\
\text { values given for } D_{\mathrm{NP}}, \mathrm{D}_{\mathrm{TB}} \text {, and } \mathrm{D}_{\mathrm{P}} \text { (left column) are the regional depositions for an aerosol with an } \\
\text { AMAD of } 1 \mu \mathrm{m} \text {. }\end{array}$} \\
\hline b. $\mathrm{NA}=$ not $\mathrm{a}$ & cable & & & & & & \\
\hline
\end{tabular}




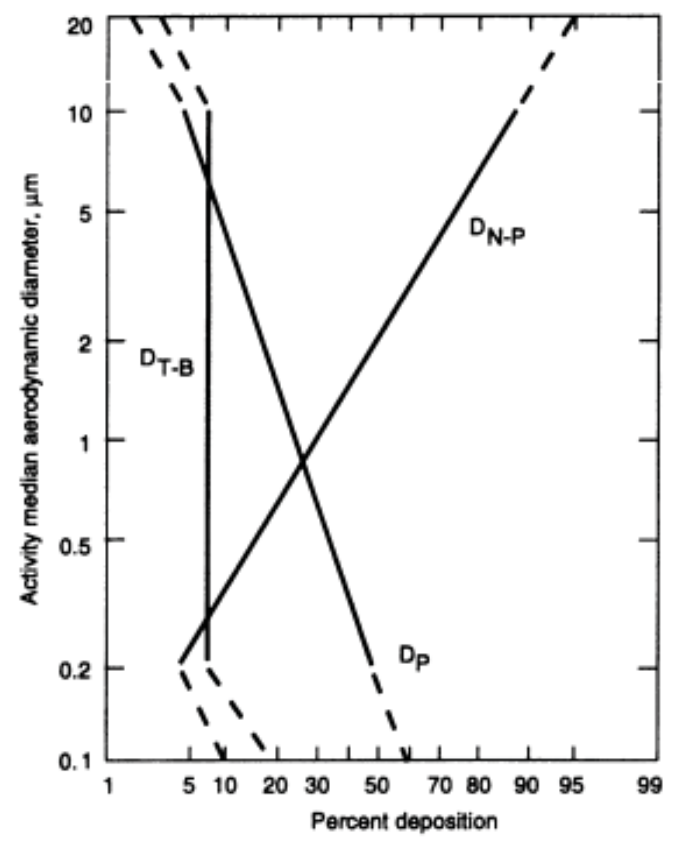

Figure A-2. Deposition of dust in the respiratory system

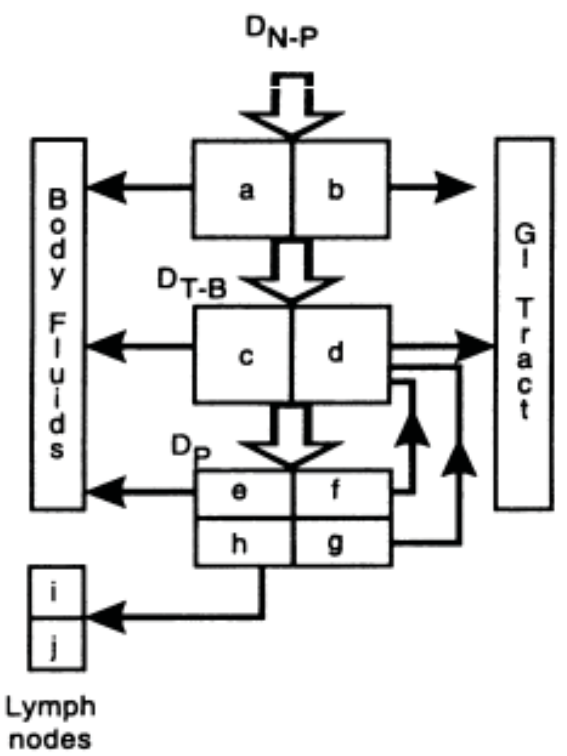

Figure A-3. Clearance pathways for the ICRP-30 model 


\section{A-3.2 Ingestion Dose}

\section{A-3.2.1 Chronic Release}

The calculation of ingestion dose from a chronic release is based on the models and equations from Regulatory Guide 1.109 (NRC 1977a) ${ }^{24}$. Dose pathways from the ingestion of vegetation, meat, and milk have been included for activity deposited on the ground plane. The equation used to calculate the total ingestion dose from the pathways is

$$
\left.D_{i j}=D_{i j} \mid U^{v} f_{g} C_{i}^{v}+U^{m} C_{i}^{m}+U^{F} C_{i}^{F}+U^{L} f_{1} C_{i}^{L}\right\rfloor
$$

where

$\mathrm{D}_{\mathrm{ij}} \quad=$ annual dose equivalent to organ $\mathrm{j}$ from ingestion of food contaminated from the atmospheric release and subsequent deposition of radionuclide $\mathrm{i}$ (rem/yr)

$\mathrm{DFI}_{\mathrm{ij}} \quad=$ ingestion dose factor for radionuclide $\mathrm{i}$ and $\operatorname{organ} \mathrm{j}(\mathrm{rem} / \mathrm{pCi})$

$\mathrm{U}^{\mathrm{v}}, \mathrm{U}^{\mathrm{m}}, \mathrm{U}^{\mathrm{F}}, \mathrm{U}^{\mathrm{L}}=$ usage factors for produce (nonleafy), milk, meat, and leafy vegetables $(\mathrm{kg} / \mathrm{yr}$ and $\mathrm{L} / \mathrm{yr}$ for milk)

$\mathrm{f}_{\mathrm{g}}, \mathrm{f}_{\mathrm{l}} \quad=$ respective fractions of the ingestion rates of produce and leafy vegetables that are produced in the garden of interest

$C_{i}^{\mathrm{v}}, C_{i}^{m}, C_{i}^{F}, C_{i}^{L}=$ concentrations of radionuclide $i$ in produce (nonleafy vegetables), milk, meat and fresh vegetables, respectively $(\mathrm{pCi} / \mathrm{kg})$.

The default dietary ingestion rates for adults $\left(\mathrm{U}^{\mathrm{v}}, \mathrm{U}^{\mathrm{m}}, \mathrm{U}^{\mathrm{F}}\right.$, and $\left.\mathrm{U}^{\mathrm{L}}\right)$ used in RSAC-7.2 are presented in Table A-5.

Table A - 5. Default annual dietary ingestion rates for adults.

\begin{tabular}{lccc}
\multicolumn{1}{c}{ Parameter } & Value & Units & Symbol \\
\hline Leafy vegetables & 64 & $\mathrm{~kg} / \mathrm{yr}$ & $\mathrm{U}^{\mathrm{L}}$ \\
Meat & 110 & $\mathrm{~kg} / \mathrm{yr}$ & $\mathrm{U}^{\mathrm{F}}$ \\
Milk & 310 & $\mathrm{~L} / \mathrm{yr}$ & $\mathrm{U}^{\mathrm{m}}$ \\
Produce & 520 & $\mathrm{~kg} / \mathrm{yr}$ & $\mathrm{U}^{\mathrm{v}}$ \\
\hline
\end{tabular}


The concentration of radionuclide $i$ in and on vegetation is a function of the rate of deposition upon the plant foliage and the rate of uptake from the soil. The equation used to estimate the concentration in and on vegetation from all radioiodines and particulate radionuclides, except tritium and carbon-14 is

$$
C_{i}^{v}=d_{i}\left\{\frac{r F_{T}\left[1-e^{-\lambda_{E i} t_{e}}\right]}{Y_{v} \lambda_{E i}}+\frac{B_{i v}\left[1-e^{-\lambda_{i} t_{b}}\right]}{P \lambda_{i}}\right\} e^{-\lambda_{i} t_{b}}
$$

where

$$
\begin{aligned}
& \mathrm{C}_{\mathrm{i}}^{\mathrm{v}}=\text { concentration of radionuclide } \mathrm{i} \text { in and on vegetation }(\mathrm{pCi} / \mathrm{kg}) \\
& \mathrm{d}_{\mathrm{i}}=\text { deposition rate of radionuclide } \mathrm{i}\left(\mathrm{pCi} / \mathrm{m}^{2}-\mathrm{h}\right) \\
& \mathrm{r}=\text { fraction of deposited activity retained on foliage } \\
& \mathrm{F}_{\mathrm{T}}=\text { fraction of deposited radioactivity translocated from plant surface to edible } \\
& \text { portion of crop } \\
& \lambda_{\mathrm{Ei}}=\text { effective removal rate constant for radionuclide } \mathrm{i} \text { from foliage surfaces }\left(\mathrm{h}^{-1}\right) \text {, } \\
& \lambda_{\mathrm{Ei}}=\lambda_{\mathrm{i}}+\lambda_{\mathrm{w}} \\
& \lambda_{\mathrm{i}}=\text { decay constant for radionuclide } \mathrm{i}\left(\mathrm{s}^{-1}\right) \\
& \lambda_{\mathrm{w}}=\text { rate constant for removal of activity on plant or leaf surfaces by } \\
& \text { weathering }\left(\mathrm{h}^{-1}\right)
\end{aligned}
$$

$\mathrm{t}_{\mathrm{e}}=$ time period that crops are exposed to contamination during the growing season (h)

$\mathrm{Y}_{\mathrm{v}}=$ agricultural productivity (yield) $\left(\mathrm{kg} / \mathrm{m}^{2}\right)$

$\mathrm{B}_{\mathrm{iv}}=$ concentration factor for root uptake of radionuclide $\mathrm{i}$ from soil to edible parts of crops (pCi/kg wet weight per pCi/kg dry soil)

$\mathrm{t}_{\mathrm{b}}=$ period of long-term buildup for activity in soil (h)

$\mathrm{P}=$ effective surface density for soil $\left(\mathrm{kg} / \mathrm{m}^{2}\right.$ dry $)$

$\mathrm{t}_{\mathrm{h}}=$ holdup time between harvest and consumption by either humans or livestock (h).

The units of $t_{b}, t_{e}$ and $t_{h}$ are expressed in hours in Equation (A-38) for convenience; however, user input of $t_{b}$ in Table A-6 and Section 4.1, Dose Calculation Control Line 2 (7001), is in years; and $t_{\mathrm{e}}$ and $\mathrm{t}_{\mathrm{h}}$ in Table A-6 and Section 4.1, Ingestion Constants Line 2 (7052) and Ingestion Constants Line 3 (7053) are in days. 
A summary of element independent default parameters used to calculate the concentration of radioactivity in crops from chronic releases are presented in Table A-6. Element dependent parameters (Baes et al. 1984) are presented in Table A-7.

Table A-6. RSAC-7.2 default radionuclide independent parameters used to calculate concentrations in crops from chronic releases.

\begin{tabular}{|c|c|c|c|}
\hline Parameter & Value & Units & Symbol \\
\hline \multicolumn{4}{|l|}{ Fraction grown in garden } \\
\hline Produce & 0.76 & -- & $f_{g}$ \\
\hline Leafy vegetables & 1.0 & -- & $\mathrm{f}_{1}$ \\
\hline Fallout interception fractions & & & $\mathrm{r}$ \\
\hline Pasture & 0.57 & -- & \\
\hline Vegetables & 0.2 & -- & \\
\hline Iodines on forage & 1.0 & -- & \\
\hline Removal rate constant & 0.0021 & $\mathrm{~h}^{-1}$ & $\lambda_{\mathrm{w}}$ \\
\hline $\begin{array}{l}\text { Period of crop exposure during } \\
\text { growing season }\end{array}$ & & & $t_{e}$ \\
\hline Vegetables & 60. & $\mathrm{~d}$ & \\
\hline Forage & 30. & $d$ & \\
\hline Vegetation yield & & & $Y_{v}$ \\
\hline Vegetables & 2 & $\mathrm{~kg} / \mathrm{m}^{2}$ (dry) & \\
\hline Forage & 0.28 & $\mathrm{~kg} / \mathrm{m}^{2}$ (wet) & \\
\hline $\begin{array}{l}\text { Time of activity buildup } \\
\text { in soil }\end{array}$ & $\begin{array}{l}1.315 \mathrm{E}+5 \\
(15 .)\end{array}$ & $\begin{array}{c}\mathrm{h} \\
(\mathrm{yr})\end{array}$ & $t_{b}$ \\
\hline Soil surface density & 225. & $\mathrm{~kg} / \mathrm{m}^{2}$ & $\mathrm{P}$ \\
\hline Time delays & & & $t_{\mathrm{h}}$ \\
\hline Fresh vegetables & 1. & $d$ & \\
\hline Stored vegetables & 60. & $\mathrm{~d}$ & \\
\hline Feed-milk-person & 2. & $d$ & \\
\hline Slaughter-consumption & 20. & $\mathrm{~d}$ & \\
\hline
\end{tabular}


Table A-7. RSAC-7.2 element-dependent parameters used to calculate concentrations in crops.

\begin{tabular}{|c|c|c|c|c|c|c|}
\hline \multirow{2}{*}{\multicolumn{2}{|c|}{ Element }} & \multicolumn{2}{|c|}{ Root uptake factors } & \multicolumn{2}{|c|}{ Transfer coefficients } & \multirow{2}{*}{$\begin{array}{c}\text { Translocation } \\
\text { factor } \\
\mathrm{F}_{\mathrm{T}} \\
\end{array}$} \\
\hline & & $\begin{array}{c}\text { Forage } \\
\mathrm{B}_{\mathrm{iv} 1} \\
\end{array}$ & $\begin{array}{c}\text { Produce } \\
\mathrm{B}_{\mathrm{iv} 2} \\
\end{array}$ & $\begin{array}{c}\text { Milk } \\
\mathrm{F}_{\mathrm{m}} \\
\end{array}$ & $\begin{array}{c}\text { Meat } \\
\mathrm{F}_{\mathrm{f}} \\
\end{array}$ & \\
\hline 1 & $\mathrm{H}$ & $0.0 \mathrm{E}+00$ & $0.0 \mathrm{E}+00$ & $0.0 \mathrm{E}+00$ & $0.0 \mathrm{E}+00$ & $1.0 \mathrm{E}+00$ \\
\hline 2 & $\mathrm{He}$ & $0.0 \mathrm{E}+00$ & $0.0 \mathrm{E}+00$ & $0.0 \mathrm{E}+00$ & $0.0 \mathrm{E}+00$ & $1.0 \mathrm{E}+00$ \\
\hline 3 & $\mathrm{Li}$ & $2.5 \mathrm{E}-02$ & $1.7 \mathrm{E}-03$ & $2.0 \mathrm{E}-02$ & $1.0 \mathrm{E}-02$ & $1.0 \mathrm{E}+00$ \\
\hline 4 & $\mathrm{Be}$ & $1.0 \mathrm{E}-02$ & $6.4 \mathrm{E}-04$ & $9.0 \mathrm{E}-07$ & $1.0 \mathrm{E}-03$ & $1.0 \mathrm{E}+00$ \\
\hline 5 & B & $4.0 \mathrm{E}+00$ & $8.6 \mathrm{E}-01$ & $1.5 \mathrm{E}-03$ & 8.0E-04 & $1.0 \mathrm{E}+00$ \\
\hline 6 & $\mathrm{C}$ & $0.0 \mathrm{E}+00$ & $0.0 \mathrm{E}+00$ & $0.0 \mathrm{E}+00$ & $0.0 \mathrm{E}+00$ & $1.0 \mathrm{E}+00$ \\
\hline 7 & $\mathrm{~N}$ & $3.0 \mathrm{E}+01$ & $1.3 \mathrm{E}+01$ & $2.5 \mathrm{E}-02$ & $7.5 \mathrm{E}-02$ & $1.0 \mathrm{E}+00$ \\
\hline 8 & $\mathrm{O}$ & $0.0 \mathrm{E}+00$ & $0.0 \mathrm{E}+00$ & $0.0 \mathrm{E}+00$ & $0.0 \mathrm{E}+00$ & $1.0 \mathrm{E}+00$ \\
\hline 9 & $\mathrm{~F}$ & $6.0 \mathrm{E}-02$ & $2.6 \mathrm{E}-03$ & $1.0 \mathrm{E}-03$ & $1.5 \mathrm{E}-01$ & $1.0 \mathrm{E}+00$ \\
\hline 10 & $\mathrm{Ne}$ & $0.0 \mathrm{E}+00$ & $0.0 \mathrm{E}+00$ & $0.0 \mathrm{E}+00$ & $0.0 \mathrm{E}+00$ & $1.0 \mathrm{E}+00$ \\
\hline 11 & $\mathrm{Na}$ & $7.5 \mathrm{E}-02$ & $2.4 \mathrm{E}-02$ & $3.5 \mathrm{E}-02$ & $5.5 \mathrm{E}-02$ & $1.0 \mathrm{E}+00$ \\
\hline 12 & $\mathrm{Mg}$ & $1.0 \mathrm{E}+00$ & $2.4 \mathrm{E}-01$ & $4.0 \mathrm{E}-03$ & $5.0 \mathrm{E}-03$ & $1.0 \mathrm{E}+00$ \\
\hline 13 & $\mathrm{Al}$ & $4.0 \mathrm{E}-03$ & $2.8 \mathrm{E}-04$ & $2.0 \mathrm{E}-04$ & $1.5 \mathrm{E}-03$ & $1.0 \mathrm{E}+00$ \\
\hline 14 & $\mathrm{Si}$ & $3.5 \mathrm{E}-01$ & $3.0 \mathrm{E}-02$ & $2.0 \mathrm{E}-05$ & $4.0 \mathrm{E}-05$ & $1.0 \mathrm{E}+00$ \\
\hline 15 & $\mathrm{P}$ & $3.5 \mathrm{E}+00$ & $1.5 \mathrm{E}+00$ & $1.5 \mathrm{E}-02$ & $5.5 \mathrm{E}-02$ & $1.0 \mathrm{E}+00$ \\
\hline 16 & S & $1.5 \mathrm{E}+00$ & $6.4 \mathrm{E}-01$ & $1.5 \mathrm{E}-02$ & $1.0 \mathrm{E}-01$ & $1.0 \mathrm{E}+00$ \\
\hline 17 & $\mathrm{Cl}$ & $7.0 \mathrm{E}+01$ & $3.0 \mathrm{E}+01$ & $1.5 \mathrm{E}-02$ & $8.0 \mathrm{E}-02$ & $1.0 \mathrm{E}+00$ \\
\hline 18 & $\mathrm{Aa}$ & $0.0 \mathrm{E}+00$ & $0.0 \mathrm{E}+00$ & $0.0 \mathrm{E}+00$ & $0.0 \mathrm{E}+00$ & $1.0 \mathrm{E}+00$ \\
\hline 19 & $\mathrm{~K}$ & $1.0 \mathrm{E}-01$ & $2.4 \mathrm{E}-01$ & 7.0E-03 & $2.0 \mathrm{E}-02$ & $1.0 \mathrm{E}+00$ \\
\hline 20 & $\mathrm{Ca}$ & $3.5 \mathrm{E}+00$ & $1.5 \mathrm{E}-01$ & $1.0 \mathrm{E}-02$ & 7.0E-04 & $1.0 \mathrm{E}+00$ \\
\hline 21 & $\mathrm{Sc}$ & $6.0 \mathrm{E}-03$ & 4.3E-04 & $5.0 \mathrm{E}-06$ & $1.5 \mathrm{E}-02$ & $1.0 \mathrm{E}+00$ \\
\hline 22 & $\mathrm{Ti}$ & $5.5 \mathrm{E}-03$ & $1.3 \mathrm{E}-03$ & $1.0 \mathrm{E}-02$ & $3.0 \mathrm{E}-02$ & $1.0 \mathrm{E}+00$ \\
\hline 23 & $\mathrm{~V}$ & $5.5 \mathrm{E}-03$ & $1.3 \mathrm{E}-03$ & $2.0 \mathrm{E}-05$ & $2.5 \mathrm{E}-03$ & $1.0 \mathrm{E}+00$ \\
\hline 24 & $\mathrm{Cr}$ & 7.5E-03 & $1.9 \mathrm{E}-03$ & $1.5 \mathrm{E}-03$ & $5.5 \mathrm{E}-03$ & $1.0 \mathrm{E}+00$ \\
\hline 25 & $\mathrm{Mn}$ & $2.5 \mathrm{E}-01$ & $2.1 \mathrm{E}-02$ & $3.5 \mathrm{E}-04$ & 4.0E-04 & $1.0 \mathrm{E}+00$ \\
\hline 26 & $\mathrm{Fe}$ & 4.0E-03 & $4.3 \mathrm{E}-04$ & $2.5 \mathrm{E}-04$ & $2.0 \mathrm{E}-02$ & $1.0 \mathrm{E}+00$ \\
\hline 27 & Co & $2.0 \mathrm{E}-02$ & $3.0 \mathrm{E}-03$ & $2.0 \mathrm{E}-03$ & $2.0 \mathrm{E}-02$ & $1.0 \mathrm{E}+00$ \\
\hline 28 & $\mathrm{Ni}$ & $6.0 \mathrm{E}-02$ & $2.6 \mathrm{E}-02$ & $1.0 \mathrm{E}-03$ & $6.0 \mathrm{E}-03$ & $1.0 \mathrm{E}+00$ \\
\hline 29 & $\mathrm{Cu}$ & $4.0 \mathrm{E}-01$ & $1.1 \mathrm{E}-01$ & $1.5 \mathrm{E}-03$ & $1.0 \mathrm{E}-02$ & $1.0 \mathrm{E}+00$ \\
\hline 30 & $\mathrm{Zn}$ & $1.5 \mathrm{E}+00$ & $3.9 \mathrm{E}-01$ & $1.0 \mathrm{E}-02$ & $1.0 \mathrm{E}-01$ & $1.0 \mathrm{E}+00$ \\
\hline 31 & $\mathrm{Ga}$ & $4.0 \mathrm{E}-03$ & 1.7E-04 & $5.0 \mathrm{E}-05$ & $5.0 \mathrm{E}-04$ & $1.0 \mathrm{E}+00$ \\
\hline 32 & $\mathrm{Ge}$ & $4.0 \mathrm{E}-01$ & $3.4 \mathrm{E}-02$ & $7.0 \mathrm{E}-02$ & 7.0E-01 & $1.0 \mathrm{E}+00$ \\
\hline 33 & As & $4.0 \mathrm{E}-02$ & $2.6 \mathrm{E}-03$ & $6.0 \mathrm{E}-05$ & $2.0 \mathrm{E}-03$ & $1.0 \mathrm{E}+00$ \\
\hline 34 & $\mathrm{Se}$ & $2.5 \mathrm{E}-02$ & $1.1 \mathrm{E}-02$ & $4.0 \mathrm{E}-03$ & $1.5 \mathrm{E}-02$ & $1.0 \mathrm{E}+00$ \\
\hline 35 & $\mathrm{Br}$ & $1.5 \mathrm{E}+00$ & $6.4 \mathrm{E}-01$ & $2.0 \mathrm{E}-02$ & $2.5 \mathrm{E}-02$ & $1.0 \mathrm{E}+00$ \\
\hline 36 & $\mathrm{Kr}$ & $0.0 \mathrm{E}+00$ & $0.0 \mathrm{E}+00$ & $0.0 \mathrm{E}+00$ & $0.0 \mathrm{E}+00$ & $1.0 \mathrm{E}+00$ \\
\hline 37 & $\mathrm{Rb}$ & $1.5 \mathrm{E}-01$ & $3.0 \mathrm{E}-02$ & $1.0 \mathrm{E}-02$ & $1.5 \mathrm{E}-02$ & $1.0 \mathrm{E}+00$ \\
\hline 38 & $\mathrm{Sr}$ & $2.5 \mathrm{E}+00$ & $1.1 \mathrm{E}-01$ & $1.5 \mathrm{E}-03$ & $3.0 \mathrm{E}-04$ & $1.0 \mathrm{E}+00$ \\
\hline 39 & $\mathrm{Y}$ & $1.5 \mathrm{E}-02$ & $2.6 \mathrm{E}-03$ & $2.0 \mathrm{E}-05$ & $3.0 \mathrm{E}-04$ & $1.0 \mathrm{E}+00$ \\
\hline 40 & $\mathrm{Zr}$ & $2.0 \mathrm{E}-03$ & $2.1 \mathrm{E}-04$ & $3.0 \mathrm{E}-05$ & $5.5 \mathrm{E}-03$ & $1.0 \mathrm{E}+00$ \\
\hline 41 & $\mathrm{Nb}$ & $2.0 \mathrm{E}-02$ & $2.1 \mathrm{E}-03$ & $2.0 \mathrm{E}-02$ & $2.5 \mathrm{E}-01$ & $1.0 \mathrm{E}+00$ \\
\hline 42 & Mo & $2.5 \mathrm{E}-01$ & $2.6 \mathrm{E}-02$ & $1.5 \mathrm{E}-03$ & $6.0 \mathrm{E}-03$ & $1.0 \mathrm{E}+00$ \\
\hline 43 & $\mathrm{Tc}$ & $9.5 \mathrm{E}+00$ & $6.4 \mathrm{E}-01$ & $1.0 \mathrm{E}-02$ & $8.5 \mathrm{E}-03$ & $1.0 \mathrm{E}+00$ \\
\hline 44 & $\mathrm{Ru}$ & $7.5 \mathrm{E}-02$ & 8.6E-03 & $6.0 \mathrm{E}-07$ & $2.0 \mathrm{E}-03$ & $5.0 \mathrm{E}-02$ \\
\hline 45 & $\mathrm{Rh}$ & $1.5 \mathrm{E}-01$ & $1.7 \mathrm{E}-02$ & $1.0 \mathrm{E}-02$ & $2.0 \mathrm{E}-03$ & $1.0 \mathrm{E}+00$ \\
\hline
\end{tabular}


Table A-7. RSAC-7.2 element-dependent parameters used to calculate concentrations in crops.

\begin{tabular}{|c|c|c|c|c|c|c|}
\hline \multirow{2}{*}{\multicolumn{2}{|c|}{ Element }} & \multicolumn{2}{|c|}{ Root uptake factors } & \multicolumn{2}{|c|}{ Transfer coefficients } & \multirow{2}{*}{$\begin{array}{c}\text { Translocation } \\
\text { factor } \\
\mathrm{F}_{\mathrm{T}} \\
\end{array}$} \\
\hline & & $\begin{array}{c}\text { Forage } \\
\mathrm{B}_{\mathrm{iv} 1} \\
\end{array}$ & $\begin{array}{c}\text { Produce } \\
\mathrm{B}_{\mathrm{iv} 2} \\
\end{array}$ & $\begin{array}{c}\text { Milk } \\
\mathrm{F}_{\mathrm{m}} \\
\end{array}$ & $\begin{array}{c}\text { Meat } \\
\mathrm{F}_{\mathrm{f}} \\
\end{array}$ & \\
\hline 46 & $\mathrm{Pd}$ & $1.5 \mathrm{E}-01$ & $1.7 \mathrm{E}-02$ & $1.0 \mathrm{E}-02$ & $4.0 \mathrm{E}-03$ & $1.0 \mathrm{E}+00$ \\
\hline 48 & $\mathrm{Cd}$ & $5.5 \mathrm{E}-01$ & $6.4 \mathrm{E}-02$ & $1.0 \mathrm{E}-03$ & $5.5 \mathrm{E}-04$ & $1.0 \mathrm{E}+00$ \\
\hline 49 & In & 4.0E-03 & $1.7 \mathrm{E}-04$ & $1.0 \mathrm{E}-04$ & 8.0E-03 & $1.0 \mathrm{E}+00$ \\
\hline 50 & $\mathrm{Sn}$ & $3.0 \mathrm{E}-02$ & $2.6 \mathrm{E}-03$ & $1.0 \mathrm{E}-03$ & 8.0E-02 & $1.0 \mathrm{E}+00$ \\
\hline 51 & $\mathrm{Sb}$ & $2.0 \mathrm{E}-01$ & $1.3 \mathrm{E}-02$ & $1.0 \mathrm{E}-04$ & $1.0 \mathrm{E}-03$ & $1.0 \mathrm{E}+00$ \\
\hline 52 & $\mathrm{Te}$ & $2.5 \mathrm{E}-02$ & $1.7 \mathrm{E}-03$ & $2.0 \mathrm{E}-04$ & $1.5 \mathrm{E}-02$ & $1.0 \mathrm{E}+00$ \\
\hline 53 & I & $1.5 \mathrm{E}-01$ & $2.1 \mathrm{E}-02$ & $1.0 \mathrm{E}-02$ & $7.0 \mathrm{E}-03$ & $1.0 \mathrm{E}-01$ \\
\hline 54 & $\mathrm{Xe}$ & $0.0 \mathrm{E}+00$ & $0.0 \mathrm{E}+00$ & $0.0 \mathrm{E}+00$ & $0.0 \mathrm{E}+00$ & $1.0 \mathrm{E}+00$ \\
\hline 55 & Cs & $8.0 \mathrm{E}-02$ & $1.3 \mathrm{E}-02$ & $7.0 \mathrm{E}-03$ & $2.0 \mathrm{E}-02$ & $5.0 \mathrm{E}-01$ \\
\hline 56 & $\mathrm{Ba}$ & $1.5 \mathrm{E}-01$ & $6.4 \mathrm{E}-03$ & $3.5 \mathrm{E}-04$ & $1.5 \mathrm{E}-04$ & $1.0 \mathrm{E}+00$ \\
\hline 57 & $\mathrm{La}$ & $1.0 \mathrm{E}-02$ & $1.7 \mathrm{E}-03$ & $2.0 \mathrm{E}-05$ & $3.0 \mathrm{E}-04$ & $1.0 \mathrm{E}+00$ \\
\hline 58 & $\mathrm{Ce}$ & $1.0 \mathrm{E}-02$ & $1.7 \mathrm{E}-03$ & $2.0 \mathrm{E}-05$ & $7.5 \mathrm{E}-04$ & $3.0 \mathrm{E}-01$ \\
\hline 59 & $\operatorname{Pr}$ & $1.0 \mathrm{E}-02$ & $1.7 \mathrm{E}-03$ & $2.0 \mathrm{E}-05$ & $3.0 \mathrm{E}-04$ & $1.0 \mathrm{E}+00$ \\
\hline 60 & $\mathrm{Nd}$ & $1.0 \mathrm{E}-02$ & $1.7 \mathrm{E}-03$ & $2.0 \mathrm{E}-05$ & $3.0 \mathrm{E}-04$ & $1.0 \mathrm{E}+00$ \\
\hline 61 & $\mathrm{Pm}$ & $1.0 \mathrm{E}-02$ & $1.7 \mathrm{E}-03$ & $2.0 \mathrm{E}-05$ & $5.0 \mathrm{E}-03$ & $1.0 \mathrm{E}+00$ \\
\hline 62 & $\mathrm{Sm}$ & $1.0 \mathrm{E}-02$ & $1.7 \mathrm{E}-03$ & $2.0 \mathrm{E}-05$ & $5.0 \mathrm{E}-03$ & $1.0 \mathrm{E}+00$ \\
\hline 63 & $\mathrm{Eu}$ & $1.0 \mathrm{E}-02$ & 1.7E-03 & $2.0 \mathrm{E}-05$ & $5.0 \mathrm{E}-03$ & $1.0 \mathrm{E}+00$ \\
\hline 64 & $\mathrm{Gd}$ & $1.0 \mathrm{E}-02$ & $1.7 \mathrm{E}-03$ & $2.0 \mathrm{E}-05$ & $3.5 \mathrm{E}-03$ & $1.0 \mathrm{E}+00$ \\
\hline 65 & $\mathrm{~Tb}$ & $1.0 \mathrm{E}-02$ & $1.7 \mathrm{E}-03$ & $2.0 \mathrm{E}-05$ & $4.5 \mathrm{E}-03$ & $1.0 \mathrm{E}+00$ \\
\hline 66 & Dy & $1.0 \mathrm{E}-02$ & $1.7 \mathrm{E}-03$ & $2.0 \mathrm{E}-05$ & $5.5 \mathrm{E}-03$ & $1.0 \mathrm{E}+00$ \\
\hline 67 & Но & $1.0 \mathrm{E}-02$ & $1.7 \mathrm{E}-03$ & $2.0 \mathrm{E}-05$ & $4.5 \mathrm{E}-03$ & $1.0 \mathrm{E}+00$ \\
\hline 68 & $\mathrm{Er}$ & $1.0 \mathrm{E}-02$ & $1.7 \mathrm{E}-03$ & $2.0 \mathrm{E}-05$ & 4.0E-03 & $1.0 \mathrm{E}+00$ \\
\hline 69 & $\mathrm{Tm}$ & $1.0 \mathrm{E}-02$ & $1.7 \mathrm{E}-03$ & $2.0 \mathrm{E}-05$ & $4.5 \mathrm{E}-03$ & $1.0 \mathrm{E}+00$ \\
\hline 70 & $\mathrm{Yb}$ & $1.0 \mathrm{E}-02$ & $1.7 \mathrm{E}-03$ & $2.0 \mathrm{E}-05$ & $4.0 \mathrm{E}-03$ & $1.0 \mathrm{E}+00$ \\
\hline 71 & $\mathrm{Lu}$ & $1.0 \mathrm{E}-02$ & $1.7 \mathrm{E}-03$ & $2.0 \mathrm{E}-05$ & $4.5 \mathrm{E}-03$ & $1.0 \mathrm{E}+00$ \\
\hline 72 & $\mathrm{Hf}$ & $3.5 \mathrm{E}-03$ & $3.6 \mathrm{E}-04$ & $5.0 \mathrm{E}-06$ & $1.0 \mathrm{E}-03$ & $1.0 \mathrm{E}+00$ \\
\hline 73 & $\mathrm{Ta}$ & $1.0 \mathrm{E}-02$ & $1.1 \mathrm{E}-03$ & $3.0 \mathrm{E}-06$ & $6.0 \mathrm{E}-04$ & $1.0 \mathrm{E}+00$ \\
\hline 74 & W & $4.5 \mathrm{E}-02$ & 4.3E-03 & $3.0 \mathrm{E}-04$ & 4.5E-02 & $1.0 \mathrm{E}+00$ \\
\hline 75 & $\mathrm{Re}$ & $1.5 \mathrm{E}+00$ & $1.5 \mathrm{E}-01$ & $1.5 \mathrm{E}-03$ & $8.0 \mathrm{E}-03$ & $1.0 \mathrm{E}+00$ \\
\hline 76 & Os & $1.5 \mathrm{E}-02$ & $1.5 \mathrm{E}-03$ & $5.0 \mathrm{E}-03$ & 4.0E-01 & $1.0 \mathrm{E}+00$ \\
\hline 77 & $\mathrm{Ir}$ & $5.5 \mathrm{E}-02$ & $6.4 \mathrm{E}-03$ & $2.0 \mathrm{E}-06$ & $1.5 \mathrm{E}-03$ & $1.0 \mathrm{E}+00$ \\
\hline 78 & $\mathrm{Pt}$ & $9.5 \mathrm{E}-02$ & $1.1 \mathrm{E}-02$ & $5.0 \mathrm{E}-03$ & 4.0E-03 & $1.0 \mathrm{E}+00$ \\
\hline 79 & $\mathrm{Au}$ & 4.0E-01 & 4.3E-02 & $5.5 \mathrm{E}-06$ & $8.0 \mathrm{E}-03$ & $1.0 \mathrm{E}+00$ \\
\hline 80 & $\mathrm{Hg}$ & $9.0 \mathrm{E}-01$ & $8.6 \mathrm{E}-02$ & $4.5 \mathrm{E}-04$ & $2.5 \mathrm{E}-01$ & $1.0 \mathrm{E}+00$ \\
\hline 81 & $\mathrm{Tl}$ & 4.0E-03 & $1.7 \mathrm{E}-04$ & $2.0 \mathrm{E}-03$ & 4.0E-02 & $1.0 \mathrm{E}+00$ \\
\hline 82 & $\mathrm{~Pb}$ & $4.5 \mathrm{E}-02$ & $3.9 \mathrm{E}-03$ & $2.5 \mathrm{E}-04$ & $3.0 \mathrm{E}-04$ & $1.0 \mathrm{E}+00$ \\
\hline 83 & $\mathrm{Bi}$ & $3.5 \mathrm{E}-02$ & $2.1 \mathrm{E}-03$ & $5.0 \mathrm{E}-04$ & $4.0 \mathrm{E}-04$ & $1.0 \mathrm{E}+00$ \\
\hline 84 & Po & $2.5 \mathrm{E}-03$ & $1.7 \mathrm{E}-04$ & $3.5 \mathrm{E}-04$ & $9.5 \mathrm{E}-05$ & $1.0 \mathrm{E}+00$ \\
\hline 85 & At & $1.0 \mathrm{E}+00$ & 6.4E-02 & $1.0 \mathrm{E}-02$ & $1.0 \mathrm{E}-02$ & $1.0 \mathrm{E}+00$ \\
\hline 86 & $\mathrm{Rn}$ & $0.0 \mathrm{E}+00$ & $0.0 \mathrm{E}+00$ & $0.0 \mathrm{E}+00$ & $0.0 \mathrm{E}+00$ & $1.0 \mathrm{E}+00$ \\
\hline 87 & $\mathrm{Fr}$ & $3.0 \mathrm{E}-02$ & $3.4 \mathrm{E}-03$ & 2.0E-02 & $2.5 \mathrm{E}-03$ & $1.0 \mathrm{E}+00$ \\
\hline 88 & $\mathrm{Ra}$ & $1.5 \mathrm{E}-02$ & $6.4 \mathrm{E}-04$ & $4.5 \mathrm{E}-04$ & $2.5 \mathrm{E}-04$ & $1.0 \mathrm{E}+00$ \\
\hline 89 & $\mathrm{Ac}$ & $3.5 \mathrm{E}-03$ & $1.5 \mathrm{E}-04$ & $2.0 \mathrm{E}-05$ & $2.5 \mathrm{E}-05$ & $1.0 \mathrm{E}+00$ \\
\hline 90 & Th & 8.5E-04 & $3.6 \mathrm{E}-05$ & $5.0 \mathrm{E}-06$ & $6.0 \mathrm{E}-06$ & $1.0 \mathrm{E}+00$ \\
\hline 91 & $\mathrm{~Pa}$ & $2.5 \mathrm{E}-03$ & 1.1E-04 & $5.0 \mathrm{E}-06$ & $1.0 \mathrm{E}-05$ & $1.0 \mathrm{E}+00$ \\
\hline
\end{tabular}


Table A-7. RSAC-7.2 element-dependent parameters used to calculate concentrations in crops.

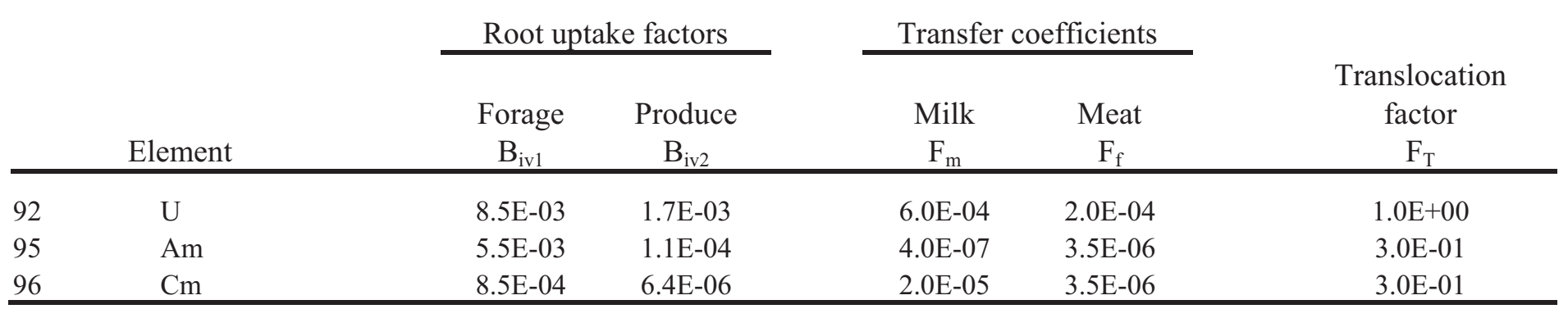

Equation (A-38) is expressed in the same format as presented in Regulatory Guide 1.109 (NRC 1977a). As such, it is expressed for only a single radionuclide. However, when the radionuclide of interest is the progeny of other radionuclides, RSAC-7.2 corrects for decay chain ingrowth.

Equation (A-38) contains a translocation factor, $\mathrm{F}_{\mathrm{T}}$, which is not included in the original formulation of the NRC Regulatory Guide 1.109 model. This parameter corrects for the translocation of activity deposited on plant leaves to the edible portion of the crop. Translocation factors for leafy vegetables and forage are set to 1 . Translocation factors to the edible portions of produce crops are taken from Boone et al. (1981). ${ }^{6}$

The concentration factor for root uptake, $\mathrm{B}_{\mathrm{iv}}$, is element dependent. Root uptake factors have been taken from literature developed to update the NRC Regulatory Guide 1.109 model published by Baes et al. (1984). ${ }^{4}$ The root uptake factors in Table A-7 are dimensionless and express $\mathrm{pCi} / \mathrm{kg}_{\text {plant }}$ per $\mathrm{pCi} / \mathrm{kg}_{\text {soil. }}$. The soil weight is for dry soil. Root uptake factors for forage $\left(\mathrm{B}_{\mathrm{iv1}}\right)$ are for forage measured in dry weight while root uptake factors for produce $\left(B_{\text {iv2 }}\right)$ are for produce measured in wet weight.

Both $\mathrm{C}_{\mathrm{i}}$, the concentration of milk, and $\mathrm{C}_{\mathrm{i}}$, the concentration in meat, depend upon the fraction of the year that the livestock is grazing on pasture as opposed to consuming stored feed. The equation used to calculate the concentration of radionuclide $i$ in the animal's feed is

$$
C_{i}^{f d}=f_{p} f_{s} C_{i}^{p}+\left(1-f_{p}\right) C_{i}^{s}+f_{p}\left(1-f_{s}\right) C_{i}^{s}
$$

where

$$
\begin{aligned}
& \mathrm{C}_{\mathrm{i}}^{\mathrm{fd}}=\text { concentration of radionuclide } \mathrm{i} \text { animals' feed }(\mathrm{pCi} / \mathrm{kg}) \\
& \mathrm{f}_{\mathrm{p}}=\text { fraction of the year that animals graze on pasture } \\
& \mathrm{f}_{\mathrm{s}}=\text { fraction of daily feed that is pasture grass when the animal grazes on pasture } \\
& \mathrm{C}_{\mathrm{i}}^{\mathrm{p}}=\text { concentration of radionuclide } \mathrm{i} \text { on pasture grass }(\mathrm{pCi} / \mathrm{kg}) \\
& \mathrm{C}_{\mathrm{i}}^{\mathrm{s}}=\text { concentration of radionuclide } \mathrm{i} \text { in stored feed }(\mathrm{pCi} / \mathrm{kg}) .
\end{aligned}
$$

Both $\mathrm{C}_{\mathrm{i}}^{\mathrm{p}}$ and $\mathrm{C}_{\mathrm{i}}^{\mathrm{s}}$ are calculated using Equation (A-38) with appropriate constants. 
Mathematical Models

The concentration of radionuclide $\mathrm{i}$ in milk is dependent on the concentration in the feed and the quantity of feed consumed by the animal. The equation used to calculate the concentration in milk is

$$
C_{i}^{m}=F_{m} C_{i}^{f d} Q_{F} e^{-\lambda_{i} t_{f}}
$$

where

$$
\begin{aligned}
& \mathrm{C}_{\mathrm{i}}^{\mathrm{m}}=\text { concentration of radionuclide } \mathrm{i} \text { in milk }(\mathrm{pCi} / \mathrm{L}) \\
& \mathrm{F}_{\mathrm{m}}=\text { average fraction of the animal's daily intake of radionuclide } \mathrm{i} \text { that appears in milk } \\
& (\mathrm{d} / \mathrm{L}) \\
& \mathrm{Q}_{\mathrm{F}}=\text { amount of feed consumed by the animal (normally } 16 \mathrm{~kg} / \mathrm{d} \text { dry weight) } \\
& t_{\mathrm{f}}=\text { average transport time of the activity from the feed into the milk and to the } \\
& \text { receptor }(d) \text {. }
\end{aligned}
$$

The equation used to calculate the concentration in milk is

$$
\mathrm{C}_{\mathrm{i}}^{\mathrm{F}}=\mathrm{F}_{\mathrm{f}} \mathrm{C}_{\mathrm{i}}^{\mathrm{fd}} \mathrm{Q}_{\mathrm{F}} \exp \left(-\lambda_{\mathrm{i}} \mathrm{t}_{\mathrm{e}}\right)
$$

where

$$
\begin{aligned}
& \mathrm{C}_{\mathrm{i}}^{\mathrm{F}}=\text { concentration of radionuclide } \mathrm{i} \text { in meat }(\mathrm{pCi} / \mathrm{kg}) \\
& \mathrm{F}_{\mathrm{f}}=\begin{array}{r}
\text { average fraction of the animal's daily intake of radionuclide } \mathrm{i} \text { that appears in each } \\
\text { kilogram of flesh }(\mathrm{d} / \mathrm{kg})
\end{array} \\
& \mathrm{t}_{\mathrm{c}}=\text { average time between slaughter and consumption }(\mathrm{d}) .
\end{aligned}
$$

The equation used to calculate the concentration of tritium in vegetation from chronic releases is

$$
\mathrm{C}_{\mathrm{T}}^{\mathrm{V}}=3.169 \times 10^{7} \mathrm{Q}_{\mathrm{T}} \frac{\chi}{\mathrm{Q}}\left[\frac{(0.75)(0.5)}{\mathrm{H}}\right]
$$

where

$$
\begin{aligned}
& \mathrm{C}_{\mathrm{T}}^{\mathrm{V}}=\text { concentration of tritium in vegetation }(\mathrm{pCi} / \mathrm{kg}) \\
& \qquad 3.169 \times 10^{7}=\frac{\left(1.0 \times 10^{12} \mathrm{pCi} / \mathrm{Ci}\right)\left(1.0 \times 10^{3} \mathrm{~g} / \mathrm{kg}\right)}{3.156 \times 10^{7} \mathrm{~s} / \mathrm{yr}}
\end{aligned}
$$


Mathematical Models

$\mathrm{Q}_{\mathrm{T}}=$ annual release of tritium $(\mathrm{Ci} / \mathrm{yr})$

$\frac{\chi}{\mathrm{Q}}=$ atmospheric diffusion relative to the initial point of release $\left(\mathrm{s} / \mathrm{m}^{3}\right)$

$0.75=$ fraction of total plant mass that is water

$0.50=$ ratio of tritium concentration in plant water to tritium concentration in atmospheric water

$\mathrm{H}=$ absolute humidity $\left(\mathrm{g} / \mathrm{m}^{3}\right)$.

The equation used to calculate the concentration to carbon-14 in vegetation from chronic releases is

$$
\mathrm{C}_{14}^{\mathrm{v}}=3.169 \times 10^{7} \mathrm{Q}_{14} \frac{\chi}{\mathrm{Q}}\left[\frac{0.11}{0.16}\right]
$$

where

$\mathrm{C}_{14}^{\mathrm{v}}=$ concentration of carbon-14 in vegetation $(\mathrm{pCi} / \mathrm{kg})$

$\mathrm{Q}_{14}=$ annual release of carbon-14 $(\mathrm{Ci} / \mathrm{yr})$

$0.11=$ fraction of total plant mass that is natural carbon

$0.16=$ concentration of natural carbon in the atmosphere $\left(\mathrm{g} / \mathrm{m}^{3}\right)$.

\section{A-3.2.2 Acute Release}

The ingestion equations presented in Regulatory Guide 1.109 (NRC 1977a) ${ }^{24}$ apply to chronic releases. Unfortunately, there is no consensus model for the calculation of ingestion doses from an acute release. Therefore, it was necessary to develop the model used in RSAC-7.2. The model assumes that consumption of contaminated vegetation from an acute release occurs at a constant rate during the acute release period and during the harvest duration time that follows the acute release period. The activity on vegetation $\left(\mathrm{pCi} / \mathrm{m}^{2}\right)$ collected during the acute release period for radionuclide $\mathrm{i}$ can be calculated using the following equation: 


$$
A_{D}=d_{i} \int_{0}^{t_{a}} e^{-\lambda_{E i} t} d t
$$

where

$$
\begin{aligned}
A_{D}= & \text { activity on vegetation collected during the acute release period } \\
d_{i}= & \text { deposition rate of radionuclide } \mathrm{i}\left(\mathrm{pCi} / \mathrm{m}^{2}-\mathrm{h}\right) \\
\mathrm{t}_{\mathrm{a}}= & \text { acute release period }(\mathrm{h}) \\
\lambda_{\mathrm{Ei}}= & \text { effective removal rate constant for radionuclide i from foliage surfaces }\left(\mathrm{h}^{-1}\right), \\
& \lambda_{\mathrm{Ei}}=\lambda_{\mathrm{i}}+\lambda_{\mathrm{w}}
\end{aligned}
$$

Integrating Equation (A-45), the equation for $A_{D}$ becomes

$$
A_{D}=\frac{d_{i}}{\lambda_{E i}}\left[1-e^{-\lambda_{E i} t_{a}}\right]
$$

Assuming that produce collection is constant during the acute release period $\left(\mathrm{t}_{\mathrm{a}}\right)$ and during the harvest duration time period following the acute release $\left(t_{h d}\right)$, the fraction of the uptake that is collected during the acute release period is

$$
\frac{t_{a}}{t_{a}+t_{h d}}
$$

The concentration in produce collected during the acute release period is then

$$
C_{i D}^{v}=\frac{r F_{T} F_{a}}{Y_{v}}\left(\frac{t_{a}}{t_{a}+t_{h d}}\right) A_{D}
$$

where

$\mathrm{r}=$ fraction of deposited activity retained on foliage

$\mathrm{F}_{\mathrm{T}}=$ fraction of deposited radioactivity translocated from plant surface to edible portion of crop

$\mathrm{F}_{\mathrm{a}}=$ fraction of annual crop that is contaminated by the acute release

$\mathrm{Y}_{\mathrm{v}}=$ agricultural productivity (yield) $\left(\mathrm{kg} / \mathrm{m}^{2}\right)$. 
Inserting Equation (A-46) into Equation (A-48), the equation for the concentration in produce collected during the acute release period becomes

$$
\mathrm{C}_{\mathrm{iD}}^{\mathrm{v}}=\frac{d_{i} r F_{T} F_{a} t_{a}}{Y_{v} \lambda_{E i}\left(t_{a}+t_{h d}\right)}\left[1-e^{-\lambda_{E i} t_{a}}\right]
$$

By assuming that the deposition is constant during the acute release period, the equation for calculating the activity on vegetation at the end of the release period is the same as that for the calculation of $A_{D}$. The activity on vegetation at any time following the acute release is

$$
A_{F}=A_{D} e^{-\lambda_{E i} t}
$$

where

$\mathrm{A}_{\mathrm{F}}=$ activity on vegetation at any time following the acute release

$\mathrm{t}_{\mathrm{a}}=$ hours following the end of the acute release period.

The average activity on vegetation $\left(\mathrm{pCi} / \mathrm{m}^{2}\right)$ collected during the harvest period is calculated using the following equation:

$$
A_{F}=\frac{A_{D}}{t_{h d}} \int_{0}^{t_{h d}} e^{-\lambda_{E i} t} d t
$$

Integrating Equation (A-51), the equation for $\mathrm{A}_{\mathrm{F}}$ becomes

$$
A_{F}=\frac{A_{D}}{t_{h d} \lambda_{E i}}\left[1-e^{-\lambda_{E i} t_{h d}}\right]
$$

Multiplying by the appropriate conversion factors and the fraction of the harvest collected during the period following the acute release period, the equation for calculating the activity on produce collected during the harvest period following the acute release is

$$
C_{i F}^{v}=\frac{r F_{T} F_{a}}{Y_{v}}\left(\frac{A_{D}}{t_{h d} \lambda_{E i}}\right)\left(\frac{t_{h d}}{t_{a}+t_{h d}}\right)\left[1-e^{-\lambda_{E i} t_{h d}}\right]
$$


Replacing $A_{D}$ using Equation (A-46) and reorganizing terms, the concentration on produce collected during the harvest period following the acute release is

$$
C_{i F}^{v}=\frac{d_{i} r F_{T} F_{a}\left[1-e^{-\lambda_{E i} t_{a}}\right]}{Y_{v} \lambda_{E i}\left(t_{a}+t_{h d}\right)}\left[\frac{1-e^{-\lambda_{E i} t_{h d}}}{\lambda_{E i}}\right]
$$

The remaining term to be developed is for the concentration of activity in vegetation from the soil uptake pathway. Only slight modifications are required in the equation used for continuous releases. The equation for activity in produce $(\mathrm{pCi} / \mathrm{kg}$ ) for continuous releases for the soil pathway, using the subscript $\mathrm{s}$ to denote the soil pathway, is

$$
C_{i s}^{v}=d_{i} B_{i v} \frac{\left[1-e^{-\lambda_{t} t_{b}}\right]}{P \lambda_{i}}
$$

where

$$
\begin{aligned}
& \mathrm{B}_{\mathrm{iv}}=\begin{array}{c}
\text { concentration factor for root uptake of radionuclide } \mathrm{i} \text { from soil to edible parts of } \\
\text { crops }(\mathrm{pCi} / \mathrm{kg} \text { wet weight per } \mathrm{pCi} / \mathrm{kg} \text { dry soil })
\end{array} \\
& \mathrm{P}=\text { effective surface density for soil }\left(\mathrm{kg} / \mathrm{m}^{2} \text { dry }\right)
\end{aligned}
$$

This equation is changed to the acute release form by changing the soil buildup time $\left(t_{b}\right.$ to $\left.t_{a}\right)$ and adding a term to account for the effect of the acute release on future crops grown on the contaminated soil in subsequent years $\left(\beta_{\mathrm{t}}\right)$. The equation for the concentration of activity in vegetation from the soil uptake pathway from an acute release is then

$$
C_{i s}^{v}=d_{i} B_{i v} \beta_{t} \frac{\left[1-e^{-\lambda_{i} t_{a}}\right]}{P \lambda_{i}}
$$

where $\beta_{\mathrm{t}}$ is defined as

$$
\beta_{t}=F_{a}+\sum_{j=2}^{N_{t b}} e^{-\lambda_{i} j}
$$

and $\mathrm{N}_{\mathrm{tb}}$ is the integer of the number of years that crops are assumed to be grown on the contaminated soil. 
The total concentration in an on produce from an acute release is

$$
C_{i}^{v}=\left[C_{i d}^{v}+c_{i F}^{v}+C_{i s}^{v}\right] e^{-\lambda_{i} t_{h}}
$$

where

$t_{\mathrm{h}}=$ holdup time between harvest and consumption by either humans or livestock (h).

When Equations (A-48), (A-53), and (A-56) are inserted into Equation (A-58), the equation for calculating the concentration of radionuclide $\mathrm{i}$ in and on vegetation following an acute release becomes

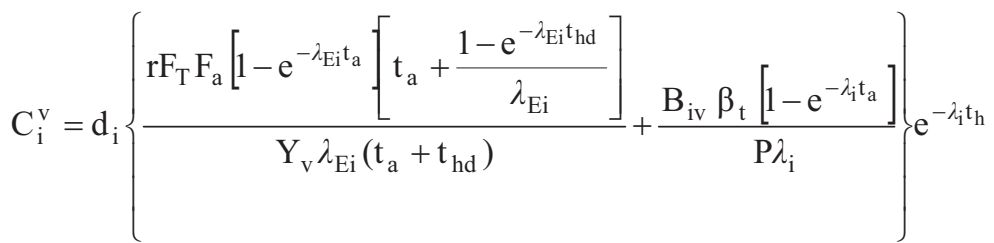

where

$\mathrm{F}_{\mathrm{a}}=$ fraction of annual crop that is contaminated by acute release.

When $t_{\text {hd }}$ is set equal to zero, complete harvest of the produce is assumed to occur immediately following the end of the acute release period. As $t_{h d}$ increases in magnitude, Equation (A-59) models continued consumption from the garden for a period of time following the end of the acute release time. However, limitations are placed on the maximum value for $t_{h d}$ so that the sum of $t_{a}$ and $t_{h d}$ do not exceed the vegetable exposure time to the plume for a chronic release (see $t_{e}$ in Equation [A-38]).

It is assumed that cattle would continue to graze following an acute release of radioactivity. The value for $t_{\text {hd }}$ used to calculate the concentration in and on forage is therefore automatically adjusted by RSAC-7.2 so that the sum of $t_{a}$ and $t_{h d}$ equals the forage exposure time for a chronic release.

Tritium is released from vegetation following an acute release with a nominal 1 day half-time. The acute tritium ingestion model assumes that the harvest occurs at a constant rate beginning when the acute release is initiated. The equation used to calculate the concentration of tritium in vegetation during and following an acute release is

$$
\mathrm{C}_{\mathrm{Ta}}^{\mathrm{v}}=2.778 \times 10^{11} \mathrm{~F}_{\mathrm{a}} \mathrm{Q}_{\mathrm{Ta}} \frac{\chi}{\mathrm{Q}}\left[\frac{(0.75)(0.5)}{\mathrm{H}\left(\mathrm{t}_{\mathrm{a}}+\mathrm{t}_{\mathrm{hd}}\right)}\right]\left[\mathrm{t}_{\mathrm{a}}+\frac{1-\mathrm{e}^{-\lambda_{\mathrm{p}} \mathrm{t}_{\mathrm{hd}}}}{\lambda_{\mathrm{p}}}\right]
$$

where

$$
\begin{aligned}
& \mathrm{C}_{\mathrm{Ta}}^{\mathrm{v}}=\text { concentration of tritium in vegetation following an acute release }(\mathrm{pCi} / \mathrm{kg}) \\
& 2.778 \times 10^{11}=\left(1.0 \times 10^{12} \mathrm{pCi} / \mathrm{Ci}\right)\left(1.0 \times 10^{3} \mathrm{~g} / \mathrm{kg}\right) /\left(3.6 \times 10^{3} \mathrm{~s} / \mathrm{h}\right) \\
& \mathrm{F}_{\mathrm{a}}=\text { fraction of annual crop that is contaminated by acute release } \\
& \mathrm{Q}_{\mathrm{Ta}}=\text { acute release rate of tritium }(\mathrm{Ci} / \mathrm{h})
\end{aligned}
$$


$\lambda_{\mathrm{p}} \quad=$ release rate of tritium in vegetation following termination of release $\left(\mathrm{h}^{-1}\right)$

$\mathrm{t}_{\mathrm{hd}}=$ harvest duration time after acute release $(\mathrm{h})$.

The remaining variables and constants used in Equation (A-60) are as defined in Equation (A-42). The units for $t_{a}$ and $t_{h d}$ are expressed in hours in Equation (A-60) for convenience; however, user input of these variables in Section 4.1, Optional Ingestion Dose Calculation Control Line (7004) is in days. release is

The equation used to calculate concentration of carbon-14 in vegetation following an acute

$$
C_{14 a}^{v}=2.778 \times 10^{11} F_{a} Q_{14 a} \frac{\chi}{Q}\left[\frac{0.11}{0.16}\right]
$$

where

$$
\begin{aligned}
& C_{14 a}^{v}=\text { concentration of } \mathrm{C}-14 \text { in vegetation following an acute release }(\mathrm{pCi} / \mathrm{kg}) \\
& \mathrm{F}_{\mathrm{a}}=\text { fraction of annual crop that is contaminated by acute release } \\
& \mathrm{Q}_{14 \mathrm{a}}=\text { acute release rate of } \mathrm{C}-14(\mathrm{Ci} / \mathrm{h}) .
\end{aligned}
$$

\section{A-3.3 Ground Surface Dose}

The dose from radioactivity deposited on the ground surface is calculated using dose-rate conversion factors (DRCFs) from Federal Guidance Report No. 12 (Eckerman 1993). ${ }^{15}$ This requires integration of the activity on the ground over the exposure period. While this is a very simple integration for a single radionuclide, it can become complex when the radionuclide is the progeny of a long chain of precursors. RSAC-7.2 uses a very subtle relationship that makes this integration simple. When there is only a single radionuclide in a chain, the equation used to calculate the dose to an individual from the activity deposited on the ground is

$$
D_{i}^{G}=D R C F_{i} \frac{\chi}{Q} V_{d} F_{b s} \int_{0}^{t_{b}} A_{i} d t
$$

where

$$
\begin{aligned}
& D_{i}^{G}=\text { dose from radionuclide i deposited on the ground surface (rem) } \\
& \mathrm{DRCF}_{\mathrm{i}}=\text { dose rate conversion factor }\left(\mathrm{rem}-\mathrm{m}^{2} / \mathrm{dis}\right) \\
& \frac{\chi}{Q}=\text { ground-level atmospheric diffusion relative to the initial point of release }\left(\mathrm{s} / \mathrm{m}^{3}\right) \\
& \mathrm{V}_{\mathrm{d}}=\text { dry deposition velocity }(\mathrm{m} / \mathrm{s}) \\
& \mathrm{F}_{\mathrm{bs}}=\text { building shielding factor }
\end{aligned}
$$


$\mathrm{t}_{\mathrm{b}}=$ exposure time to radioactivity deposited on the ground surface (s)

$\mathrm{A}_{\mathrm{i}}=$ activity of radionuclide $\mathrm{i}$ in the plume that reaches the downwind location of the receptor (dis/s).

$A_{i}$ can be replaced using the following equation:

$$
A_{i}=N_{i 0} \lambda_{i} e^{\lambda_{i} t}
$$

where

$$
\begin{aligned}
& \mathrm{N}_{\mathrm{i} 0}=\text { number of atoms of radionuclide } \mathrm{i} \text { released to the atmosphere } \\
& \lambda_{\mathrm{i}}=\text { decay constant for radionuclide } \mathrm{i}\left(\mathrm{s}^{-1}\right) .
\end{aligned}
$$

Substituting Equation (A-63) into Equation (A-62), the equation for the dose becomes

$$
D_{i}^{G}=D R C F_{i} \frac{\chi}{Q} V_{d} F_{b s} N_{i 0} \lambda_{i} \int_{0}^{t_{b}} e^{-\lambda_{i} t} d t
$$

This integrates to

$$
D_{i}^{G}=D R C F_{i} \frac{\chi}{Q} V_{d} F_{b s}\left[N_{i 0}-N_{i 1}\right]
$$

Defining $\mathrm{N}_{\mathrm{i} 1}$ as the number of the original atoms of radionuclide $i$ that were in the plume that reached the downwind location of the receptor and remain undecayed at the end of the exposure, the following relationship exists:

$$
N_{i 1}=N_{i 0} e^{-\lambda_{i} t_{b}}
$$

Substituting Equation (A-66) into Equation (A-65), the equation can be simplified to

$$
D_{i}^{G}=D_{R} C F_{i} \frac{\chi}{Q} V_{d} F_{b s} \sum_{j=1}^{i}\left[N_{j 0}-N_{j 1}\right]
$$

Thus, when the release to the atmosphere is expressed in atoms, the integration of Equation (A-62) reduces to the multiplication of the different conversion factors by the number of atoms of radionuclide $i$ that decay during the exposure period. The generalized equation when radionuclide $i$ is the progeny of a long decay chain is 


$$
D_{i}^{G}=D R C F_{i} \frac{\chi}{Q} V_{d} F_{b s} N_{i 0}\left[1-e^{-\lambda_{i} t_{b}}\right]
$$

where

$$
\begin{aligned}
& \mathrm{N}_{\mathrm{j} 0}=\begin{array}{r}
\text { number of atoms of radionuclide } \mathrm{j} \text { in the plume that reaches the downwind } \\
\text { location of the receptor }
\end{array} \\
& \mathrm{N}_{\mathrm{j} 1}=\text { number of atoms of radionuclide } \mathrm{j} \text { that exist at the end of the exposure period, } \\
& \text { including those that ingrow from precursors in the decay chain. }
\end{aligned}
$$

The ground surface dose calculated by RSAC-7.2 is the dose that a receptor would receive if it is present for the entire exposure period. When a ground surface dose is being calculated for work area, it should be remembered that work normally occurs for only 40 hours during a 168-hour week and appropriate corrections should be made.

The time $t_{b}$ has been expressed in seconds in the above equations for convenience; however, user input of the variable in Section 4.1, Dose Calculation Control Line 2 (7001) is in years.

\section{A-3.4 Air Immersion Dose}

RSAC-7.2 contains an option to calculate air immersion doses using Federal Guidance Report No. 12 (Eckerman $1993^{15}$ ) DRCFs. This model accurately calculates the plume gamma dose when the plume size is large compared to the mean free path of the gamma rays. However, when the plume size is small compared to the mean free path of the gamma rays, this model can overestimate doses by several decades. When the plume has not diffused to the ground level, the model can underestimate doses by several decades. Before this model is used, an evaluation should be using the finite plume cloud gamma model to ensure that the two models have reasonably converged.

The equation used to calculate the air immersion dose is

$$
D_{i}^{A}=A_{i} \frac{\chi}{Q} D R C F_{i}
$$

where

$D_{i}^{A}=$ dose from radionuclide from air immersion (rem)

$\mathrm{A}_{\mathrm{i}}=$ activity of radionuclide $\mathrm{i}$ decayed to the downwind location $(\mathrm{Ci})$

$\frac{\chi}{Q}=$ ground-level atmospheric diffusion relative to the initial point of release $\left(\mathrm{s} / \mathrm{m}^{3}\right)$

$\mathrm{DRCF}_{\mathrm{i}}=$ dose rate conversion factor $\left(\mathrm{rem}-\mathrm{m}^{3} / \mathrm{Ci}-\mathrm{s}\right)$. 


\section{A-3.5 Cloud Gamma Dose}

Two models are provided for calculating cloud gamma doses: a finite plume model and a semi-infinite model (Slade $1968^{34}$ ). The results of both models converge when the plume is relatively large and has diffused to ground level. At relatively short downwind distances the semi- infinite model overestimates the dose for ground-level releases during stable meteorological conditions and underestimates the dose from stack releases. While caution must be used when using the semi-infinite model, it requires little computer time for calculations.

\section{A-3.5.1 Finite Plume Model}

Dose calculations using the finite plume model are made using the equation:

$$
\mathrm{D}_{\mathrm{k}}=\sum_{\mathrm{j}=1}^{\mathrm{n}} \mathrm{K} 1_{\mathrm{j}} \mathrm{f}_{\mathrm{k}} \lambda_{\mathrm{k}} \int_{\mathrm{o}}^{\infty} \mathrm{k}(\mathrm{x}) \mathrm{E}_{\mathrm{k}}\left[\operatorname{GEXP}_{\mathrm{j}}(\mathrm{x})\right]\left[\int_{-\infty}^{\infty} \int_{-\infty}^{\infty} \frac{\chi}{\mathrm{Q}}(\mathrm{x}, \mathrm{y}, \mathrm{z}) \mathrm{G}_{\mathrm{i}}(\mathrm{r}) \mathrm{dz} \mathrm{dy}\right] \mathrm{dx}
$$

where

$\mathrm{D}_{\mathrm{k}}=$ the air entrance dose from the $\mathrm{k}^{\text {th }}$ radionuclide

$\mathrm{n}=$ number of exponential leakage approximations

$\mathrm{Kl}_{\mathrm{j}}=$ linear approximation to leakage rate curve $\left(\mathrm{s}^{-1}\right)$

$\mathrm{f}_{\mathrm{k}}=$ number of photons from the $\mathrm{k}^{\text {th }}$ radionuclide released per disintegration

$\lambda_{\mathrm{k}}=$ decay constant for the $\mathrm{k}^{\text {th }}$ radionuclide $\left(\mathrm{s}^{-1}\right)$

$\mathrm{k}(\mathrm{x})=$ cloud depletion factor

$\mathrm{E}_{\mathrm{k}}=$ decay operator equal to:

$$
\sum_{m=1}^{k} Q_{m}\left(\prod_{j=m}^{k-1} \lambda_{i}\right) \sum_{i=m}^{k}\left[\frac{1}{\prod_{\substack{j=m \\ j \neq i}}^{k}\left(\lambda_{j}-\lambda_{i}\right)}\right]
$$

where

$\mathrm{Q}_{\mathrm{m}}=$ the total number of atoms for the $\mathrm{m}^{\text {th }}$ radionuclide immediately following reactor shut down 


$$
\operatorname{GEXP}_{\mathrm{j}}(\mathrm{x})=\frac{\mathrm{e}^{-\lambda_{\mathrm{i}} \frac{\mathrm{x}}{\mathrm{u}}}}{\lambda_{\mathrm{i}}+\mathrm{K} 2_{\mathrm{j}}}\left[1-\mathrm{e}^{-\left(\lambda_{\mathrm{i}}+\mathrm{K} 2_{\mathrm{j}}\right) \mathrm{T}}\right]
$$

where

$$
\begin{aligned}
& \times=\text { downwind distance }(\mathrm{m}) \\
& \overline{\mathrm{u}}=\text { average wind velocity }(\mathrm{m} / \mathrm{s}) \\
& \mathrm{K} 2_{\mathrm{j}}=\text { leakage rate decay constant }\left(\mathrm{s}^{-1}\right) \\
& \mathrm{T}=\text { period of exposure to cloud }(\mathrm{s}) .
\end{aligned}
$$

$$
\mathrm{G}_{\mathrm{i}}(\mathrm{r})=v_{\mathrm{i}} \mathrm{B}\left(\mathrm{E}_{\mathrm{i}} \mathrm{r}\right) \frac{\mathrm{e}^{-\mu_{\mathrm{i}} \mathrm{r}}}{4 \pi \pi^{2}}
$$

where

$r=$ distance from a source to the receptor

$v=$ flux to dose conversion factor for the $\mathrm{i}^{\text {th }}$ energy group $\left(\mathrm{m}^{-1}\right)$

$\mathrm{B}\left(\mathrm{E}_{\mathrm{i}}, \mathrm{r}\right)=$ dose buildup factor as a function of the $\mathrm{i}^{\text {th }}$ energy group and the distance traveled by the gamma ray.

$\mu_{\mathrm{i}}=$ linear absorption coefficient for air for the $\mathrm{i}^{\text {th }}$ energy group $\left(\mathrm{m}^{-1}\right)$.

Buildup factors for air used in RSAC-7.2 have been developed from those published by Berger et al. (1968). ${ }^{5}$ The Berger buildup factors for air change very rapidly in the 60 to $300 \mathrm{keV}$ energy range when the travel distance exceeds four mean free paths. Traditional equations used to calculate buildup factors for shielding applications do not model buildup factors well in this energy range. The Berger buildup factors for air were therefore approximated in RSAC-7.2 using an equation of the form:

$$
\mathrm{B}(\mathrm{E}, \mu \mathrm{r})=1+\mathrm{a}(\mathrm{E}) \mu \mathrm{r}+\mathrm{b}(\mathrm{E})[\mu \mathrm{r}]^{2}+\mathrm{c}(\mathrm{E})[\mu \mathrm{r}]^{3}
$$

A comparison of buildup factors for air calculated using Equation (A-74) with those published by Berger is presented in Table A-8.

An exact solution to Equation (A-70) does not exist. The equation is solved using numerical integration techniques. An examination of the function being integrated showed that the function can vary rapidly near the receptor. Therefore, integration is accomplished by breaking the integral in the $X$, $\mathrm{Y}$, and $\mathrm{Z}$ directions each into three separate regions, each using the Gaussian quadrature for an arbitrary interval (Abramowitz and Stegum 1964 ${ }^{3}$ ). This allows the regions closest to the receptor or near the plume centerline to be integrated using closely spaced mesh points while the outer regions are integrated using a coarser distribution of mesh points. When the dose is being calculated for an elevated release and at a crosswind distance from the plume centerline, up to 15 integration regions may be used. However, whenever possible, problem symmetry is used to reduce the number of integration regions and thereby the computer running time. 
RSAC-7.2 integrates the activity in the plume using gamma rays distributed the nine energy groups presented in Table A-9. The RSAC-7.2 photon library was developed using photon energies from the Evaluated Nuclear Structure File (ENSDF) as presented in the Lund/LBNL Nuclear Data Search (Chu $\left.1999^{9}\right)$. Photons were energy weighted in each of the nine energy groups.

\section{A-3.5.2 Semi-infinite Model}

This model is very similar to that used to calculate air immersion doses (see Section 4.1, Radionuclide Entry Lines); its use requires caution. The semi-infinite model accurately calculates the plume gamma dose when the plume size is large compared to the mean free path of the gamma rays. As with the air immersion model, the semi-infinite model can overestimate doses by several decades when the plume size is small compared to the mean free path of the gamma rays. When the plume has not diffused to the ground level, the model can underestimate doses by several decades. Before this model is used, an evaluation should be using the finite plume cloud gamma model to ensure that the two models have reasonably converged. 
Table A-8. Comparison of calculated buildup factors for air to Berger's buildup factors.

\begin{tabular}{|c|c|c|c|c|c|c|c|c|c|c|}
\hline \multirow{3}{*}{$\begin{array}{l}\text { Energy } \\
(\mathrm{MeV})\end{array}$} & \multicolumn{10}{|c|}{ Mean free paths } \\
\hline & \multicolumn{2}{|c|}{1} & \multicolumn{2}{|c|}{2} & \multicolumn{2}{|c|}{4} & \multicolumn{2}{|c|}{7} & \multicolumn{2}{|c|}{10} \\
\hline & $\mathrm{C}^{\mathrm{a}}$ & $\mathrm{B}^{\mathrm{b}}$ & $\mathrm{C}^{\mathrm{a}}$ & $\mathrm{B}^{\mathrm{b}}$ & $\mathrm{C}^{\mathrm{a}}$ & $\mathrm{B}^{\mathrm{b}}$ & $\mathrm{C}^{\mathrm{a}}$ & $\mathrm{B}^{\mathrm{b}}$ & $\mathrm{C}^{\mathrm{a}}$ & $\mathrm{B}^{\mathrm{b}}$ \\
\hline 0.015 & 1.17 & 1.17 & 1.28 & 1.25 & 1.37 & 1.36 & 1.43 & 1.46 & 1.52 & 1.54 \\
\hline 0.02 & 1.41 & 1.41 & 1.69 & 1.62 & 1.94 & 1.94 & 2.15 & 2.25 & 2.49 & 2.51 \\
\hline 0.03 & 2.24 & 2.24 & 3.29 & 3.19 & 4.85 & 4.87 & 6.93 & 7.09 & 9.19 & 9.21 \\
\hline 0.04 & 3.33 & 3033 & 5.87 & 5.86 & 11.53 & 11.50 & 21.17 & 21.10 & 32.00 & 32.20 \\
\hline 0.05 & 4.25 & 4.25 & 8.65 & 8.72 & 20.85 & 20.80 & 46.59 & 46.10 & 80.80 & 80.70 \\
\hline 0.06 & 4.75 & 4.75 & 10.69 & 10.80 & 29.22 & 29.40 & 75.55 & 74.60 & 145.00 & 144.00 \\
\hline 0.08 & 4.81 & 4.81 & 12.14 & 12.00 & 37.96 & 38.20 & 117.75 & 115.00 & 253.00 & 252.00 \\
\hline 0.1 & 4.48 & 4.48 & 11.51 & 11.40 & 37.18 & 38.50 & 126.22 & 124.00 & 286.00 & 285.00 \\
\hline 0.15 & 3.72 & 3.72 & 9.47 & 9.20 & 31.03 & 31.70 & 109.44 & 106.00 & 253.00 & 252.00 \\
\hline 0.2 & 3.27 & 3.27 & 7.80 & 7.73 & 24.42 & 25.60 & 85.07 & 83.90 & 196.50 & 196.00 \\
\hline 0.3 & 2.85 & 2.85 & 6.25 & 6.22 & 18.01 & 18.60 & 54.32 & 54.40 & 116.00 & 116.00 \\
\hline 0.4 & 2.60 & 2.60 & 5.39 & 5.37 & 14.66 & 14.90 & 40.38 & 40.30 & 81.50 & 81.50 \\
\hline 0.5 & 2.44 & 2.44 & 4.83 & 4.82 & 12.47 & 12.50 & 31.42 & 31.30 & 59.50 & 59.50 \\
\hline 0.6 & 2.33 & 2.33 & 4.43 & 4.45 & 10.93 & 10.90 & 26.14 & 26.00 & 47.80 & 47.70 \\
\hline 0.8 & 2.18 & 2.18 & 3.90 & 3.94 & 8.91 & 8.86 & 19.53 & 19.30 & 33.50 & 33.40 \\
\hline 1.0 & 2.08 & 2.08 & 3.56 & 3.60 & 7.63 & 7.59 & 15.72 & 15.60 & 25.80 & 25.70 \\
\hline 1.5 & 1.92 & 1.92 & 3.05 & 3.09 & 5.89 & 5.85 & 10.96 & 10.80 & 16.70 & 16.60 \\
\hline 2.0 & 1.81 & 1.81 & 2.74 & 2.78 & 4.94 & 4.92 & 8.66 & 8.53 & 12.70 & 12.50 \\
\hline 3.0 & 1.68 & 1.68 & 2.40 & 2.41 & 3.95 & 3.93 & 6.36 & 6.32 & 8.81 & 8.80 \\
\hline 4.0 & 1.59 & 1.59 & 2.18 & 2.19 & 3.38 & 3.38 & 5.20 & 5.20 & 7.03 & 7.03 \\
\hline 5.0 & 1.52 & 1.52 & 2.03 & 2.03 & 3.03 & 3.03 & 4.51 & 4.51 & 5.97 & 5.97 \\
\hline 6.0 & 1.47 & 1.47 & 1.92 & 1.92 & 2.78 & 2.78 & 4.02 & 4.04 & 5.26 & 5.26 \\
\hline 8.0 & 1.39 & 1.39 & 1.76 & 1.75 & 2.43 & 2.44 & 3.40 & 3.43 & 4.38 & 4.38 \\
\hline 10.0 & 1.33 & 1.33 & 1.64 & 1.64 & 2.21 & 2.21 & 3.01 & 3.01 & 3.78 & 3.79 \\
\hline
\end{tabular}


The equation used to calculate cloud-gamma doses using the semi-infinite model (Slade $1968^{34}$ ) is

$$
D G_{i}^{S}=0.25 \overline{E_{\gamma}} \Psi
$$

where

$$
\begin{aligned}
& D G_{i}^{S}=\text { cloud gamma dose from radionuclide I } \\
& \overline{E_{\gamma}}=\text { average gamma energy }(\mathrm{MeV}) \\
& \Psi=\text { concentration time integral }\left(\mathrm{Ci}-\mathrm{s} / \mathrm{m}^{3}\right) .
\end{aligned}
$$

Table A-9. Photon energy groups and dose conversion factors.

\begin{tabular}{ccccc}
$\begin{array}{c}\text { Energy } \\
\text { group }\end{array}$ & $\begin{array}{c}\text { Energy } \\
(\mathrm{MeV}) / \gamma\end{array}$ & $\begin{array}{c}\text { Energy range } \\
(\mathrm{MeV})\end{array}$ & $\left.\begin{array}{c}\text { Air entrance dose } \\
\text { Conversion } \\
(\text { rem-m }\end{array} / \gamma\right)$ & $\begin{array}{c}\text { Dose ratio } \\
\text { EDE/air entrance }\end{array}$ \\
\hline & & & & \\
1 & $2.5 \mathrm{E}-02$ & 0.02 to 0.03 & $1.080 \mathrm{E}-14$ & 0.1276 \\
2 & $4.0 \mathrm{E}-02$ & 0.03 to 0.05 & $4.800 \mathrm{E}-15$ & 0.3443 \\
3 & $7.5 \mathrm{E}-02$ & 0.05 to 0.10 & $3.360 \mathrm{E}-15$ & 0.6228 \\
4 & $2.0 \mathrm{E}-01$ & 0.10 to 0.30 & $9.280 \mathrm{E}-15$ & 0.6501 \\
5 & $4.0 \mathrm{E}-01$ & 0.30 to 0.50 & $2.048 \mathrm{E}-14$ & 0.6361 \\
6 & $6.5 \mathrm{E}-01$ & 0.50 to 0.80 & $3.328 \mathrm{E}-14$ & 0.6528 \\
7 & $9.0 \mathrm{E}-01$ & 0.80 to 1.00 & $4.392 \mathrm{E}-14$ & 0.6696 \\
8 & $1.5 \mathrm{E}+00$ & 1.00 to 2.00 & $6.480 \mathrm{E}-14$ & 0.6570 \\
9 & $3.7 \mathrm{E}+00$ & 2.00 to 3.70 & $1.243 \mathrm{E}-13$ & 0.7739 \\
\hline
\end{tabular}




\section{Appendix B}

RSAC-7.2 Nuclear Data Library 


\section{Appendix B}

\section{RSAC-7.2 Nuclear Data Library}

This appendix contains a table of constants used to calculate radionuclide inventories and their decay. The radionuclide column contains the radionuclide identification number and radionuclide name. The radionuclide identification number equals the sum of the radionuclide.

$($ atomic number $\times 10,000)+($ mass number $\times 10)+(0$ for ground state or 1 for metastable state $)$.

The half-life column contains the element's half-life. The yield column provides the percent fission yield for the radionuclide. The FRACT column describes the fraction of the radionuclide decayed to the daughter indicated (IDATR). If FRACT $<1.0$ and the daughter indicated is not the next radionuclide in the library, an isomer is assumed. A fraction FRACT is decayed to the daughter indicated and the fraction 1-FRACT is decayed to the next radionuclide in the library.

The IDATR column contains an integer daughter indicator where

$\begin{array}{ll}-1 & =\text { no radioactive daughter } \\ 0 & =\text { daughter is the next radionuclide in the library } \\ \geq 1 & =\text { number of radionuclides in the library that are to be skipped over before the daughter } \\ & \text { is found. }\end{array}$

The NGROUP column contains an integer element group code where

$1=$ solid
$2=$ halogen
$3=$ nobel gas
$4=$ cesium
$5=$ ruthenium.

The ISTART column contains an integer that points to the beginning of the chain. Subtract ISTART from the library position to find the beginning of a chain. The XSECT column contains the average neutron cross section (in barns).

Half-lives are primarily from the Evaluated Nuclear Structure File (ENSDF) as presented in the Lund/LBNL Nuclear Data Search. Pseudo radionuclides used to correct for activation of fission products were suppressed. 
Activation products, actinides, and the daughters of actinides are signified by a cross section value of -1 . Inventories for these radionuclides are not calculated by RSAC-7; however, you may input them directly for dose calculations.

Many short-lived fission products decay to longer-lived daughter products. Often these short-lived fission products do not have available dose conversion factors. Therefore, RSAC-7.2 only uses them to correct fission product inventories calculated by RSAC-7.2 to match those calculated by ORIGEN-2. Many of these short-lived fission products have never been observed experimentally, and their decay-related properties are derived from calculations based on nuclear systematic. These short-lived fission products, which are precursors to longer-lived daughters, are signified by a cross section value of -0.3 . An option is provided in the fission product printout section of RSAC-7.2 to suppress printing these radionuclides. 
RSAC-7.2 Nuclear Data Library

\begin{tabular}{|c|c|c|c|c|c|c|c|c|c|c|}
\hline Nuclide & Half Life & unit & unit & YIELD & $\begin{array}{c}\text { FRAC } \\
\mathrm{T}\end{array}$ & IDATR & NGROUP & ISTART & XSECT & Decay Chain \\
\hline 40070 & $5.32 \mathrm{E}+01$ & 4 & $\mathrm{~d}$ & 0 & 1 & -1 & 1 & 0 & -1 & Be-7 > stable \\
\hline 60110 & $2.04 \mathrm{E}+01$ & 2 & $\mathrm{~m}$ & 0 & 1 & -1 & 1 & 0 & -1 & $\mathrm{C}-11>$ stable \\
\hline 60140 & $5.70 \mathrm{E}+03$ & 5 & $\mathrm{y}$ & $1.30 \mathrm{E}-06$ & 1 & -1 & 1 & 0 & $9.20 \mathrm{E}-08$ & $\mathrm{C}-14>$ stable \\
\hline 110240 & $1.50 \mathrm{E}+01$ & 3 & $\mathrm{~h}$ & 0 & 1 & -1 & 1 & 0 & -1 & $\mathrm{Na}-24>$ stable \\
\hline 120280 & $2.09 \mathrm{E}+01$ & 3 & $\mathrm{~h}$ & 0 & 1 & -1 & 1 & 0 & -1 & Mg-28 > stable \\
\hline 130260 & $7.17 \mathrm{E}+05$ & 5 & $\mathrm{y}$ & 0 & 1 & -1 & 1 & 0 & -1 & Al-26 > stable \\
\hline 140310 & $1.57 \mathrm{E}+02$ & 2 & $\mathrm{~m}$ & 0 & 1 & -1 & 1 & 0 & -1 & Si-31 > stable \\
\hline 140320 & $1.53 \mathrm{E}+02$ & 5 & $\mathrm{y}$ & 0 & 1 & 0 & 1 & 0 & -1 & Si-32 > P-32 1.0 \\
\hline 170380 & $3.72 \mathrm{E}+01$ & 2 & $\mathrm{~m}$ & 0 & 1 & -1 & 2 & 0 & -1 & $\mathrm{Cl}-38>$ stable \\
\hline 170390 & $5.56 \mathrm{E}+01$ & 2 & $\mathrm{~m}$ & 0 & 1 & 0 & 2 & 0 & -1 & Cl-39> Ar-39 1.0 \\
\hline 180390 & $2.69 \mathrm{E}+02$ & 5 & $\mathrm{y}$ & 0 & 1 & -1 & 3 & 1 & -1 & Ar-39 > stable \\
\hline 180410 & $1.10 \mathrm{E}+02$ & 2 & $\mathrm{~m}$ & 0 & 1 & -1 & 3 & 0 & -1 & Ar- $-41>$ stable \\
\hline 190400 & $1.25 \mathrm{E}+09$ & 5 & $\mathrm{y}$ & 0 & 1 & -1 & 1 & 0 & -1 & $\mathrm{~K}-40>$ stable \\
\hline 200410 & $1.02 \mathrm{E}+05$ & 5 & $\mathrm{y}$ & 0 & 1 & -1 & 1 & 0 & -1 & $\mathrm{Ca}-41>$ stable \\
\hline 190420 & $1.24 \mathrm{E}+01$ & 3 & $\mathrm{~h}$ & 0 & 1 & -1 & 1 & 0 & -1 & $\mathrm{~K}-42>$ stable \\
\hline 190430 & $2.23 \mathrm{E}+01$ & 3 & $\mathrm{~h}$ & 0 & 1 & -1 & 1 & 0 & -1 & $\mathrm{~K}-43>$ stable \\
\hline 210430 & $3.89 \mathrm{E}+00$ & 3 & $\mathrm{~h}$ & 0 & 1 & -1 & 1 & 0 & -1 & Sc- $43>$ stable \\
\hline 190440 & $2.21 \mathrm{E}+01$ & 2 & $\mathrm{~m}$ & 0 & 1 & -1 & 1 & 0 & -1 & $\mathrm{~K}-44>$ stable \\
\hline
\end{tabular}


RSAC-7.2 Nuclear Data Library

\begin{tabular}{|c|c|c|c|c|c|c|c|c|c|c|}
\hline 210440 & $3.97 \mathrm{E}+00$ & 3 & $\mathrm{~h}$ & 0 & 1 & -1 & 1 & 2 & -1 & Sc- $44>$ stable \\
\hline 220450 & $1.85 \mathrm{E}+02$ & 2 & $\mathrm{~m}$ & 0 & 1 & -1 & 1 & 0 & -1 & Ti-45 $>$ stable \\
\hline 210460 & $8.38 \mathrm{E}+01$ & 4 & $\mathrm{~d}$ & 0 & 1 & -1 & 1 & 0 & -1 & Sc- $46>$ stable \\
\hline 200470 & $4.54 \mathrm{E}+00$ & 4 & $\mathrm{~d}$ & 0 & 1 & 0 & 1 & 0 & -1 & $\mathrm{Ca}-47>\mathrm{Sc}-471.0$ \\
\hline 210470 & $3.35 \mathrm{E}+00$ & 4 & $\mathrm{~d}$ & 0 & 1 & -1 & 1 & 1 & -1 & Sc- $47>$ stable \\
\hline 230470 & $3.26 \mathrm{E}+01$ & 2 & $\mathrm{~m}$ & 0 & 1 & -1 & 1 & 1 & -1 & V-47 > stable \\
\hline 210480 & $4.37 \mathrm{E}+01$ & 3 & $\mathrm{~h}$ & 0 & 1 & -1 & 1 & 0 & -1 & Sc- $48>$ stable \\
\hline 200490 & $8.72 \mathrm{E}+00$ & 2 & $\mathrm{~m}$ & 0 & 1 & 0 & 1 & 0 & -1 & $\mathrm{Ca}-49>\mathrm{Sc}-491.0$ \\
\hline 210490 & $5.72 \mathrm{E}+01$ & 2 & $\mathrm{~m}$ & 0 & 1 & -1 & 1 & 1 & -1 & Sc- $49>$ stable \\
\hline 240490 & $4.23 \mathrm{E}+01$ & 2 & $\mathrm{~m}$ & 0 & 1 & 0 & 1 & 0 & -1 & Cr-49> V-49 1.0 \\
\hline 230490 & $3.30 \mathrm{E}+02$ & 4 & $\mathrm{~d}$ & 0 & 1 & -1 & 1 & 1 & -1 & V-49 > stable \\
\hline 220510 & $5.76 \mathrm{E}+00$ & 2 & $\mathrm{~m}$ & 0 & 1 & -1 & 1 & 0 & -0.3 & Ti-51> stable \\
\hline 250521 & $2.11 \mathrm{E}+01$ & 2 & $\mathrm{~m}$ & 0 & 0.0175 & 0 & 1 & 1 & -1 & Mn-52m > Mn-52 0.0175 \\
\hline 250520 & $5.59 \mathrm{E}+00$ & 4 & $\mathrm{~d}$ & 0 & 1 & -1 & 1 & 2 & -1 & Mn-52 > stable \\
\hline 250530 & $3.70 \mathrm{E}+06$ & 5 & $\mathrm{y}$ & 0 & 1 & -1 & 1 & 0 & -1 & Mn-53 > stable \\
\hline 250540 & $3.12 \mathrm{E}+02$ & 4 & $\mathrm{~d}$ & 0 & 1 & -1 & 1 & 0 & -1 & Mn-54 > stable \\
\hline 270550 & $1.75 \mathrm{E}+01$ & 3 & $\mathrm{~h}$ & 0 & 1 & 0 & 1 & 0 & -1 & $\mathrm{Co}-55>\mathrm{Fe}-551.0$ \\
\hline 260550 & $2.74 \mathrm{E}+00$ & 5 & $\mathrm{y}$ & 0 & 1 & -1 & 1 & 1 & -1 & Fe-55 > stable \\
\hline 250560 & $2.58 \mathrm{E}+00$ & 3 & $\mathrm{~h}$ & 0 & 1 & -1 & 1 & 0 & -1 & Mn-56 > stable \\
\hline 280560 & $6.08 \mathrm{E}+00$ & 4 & $\mathrm{~d}$ & 0 & 1 & 0 & 1 & 0 & -1 & $\mathrm{Ni}-56>\mathrm{Co}-561.0$ \\
\hline 270560 & $7.72 \mathrm{E}+01$ & 4 & $\mathrm{~d}$ & 0 & 1 & -1 & 1 & 1 & -1 & Co-56 > stable \\
\hline 280570 & $3.56 \mathrm{E}+01$ & 3 & $\mathrm{~h}$ & 0 & 1 & 0 & 1 & 0 & -1 & $\mathrm{Ni}-57>\mathrm{Co}-57 \quad 1.0$ \\
\hline 270570 & $2.72 \mathrm{E}+02$ & 4 & $\mathrm{~d}$ & 0 & 1 & -1 & 1 & 1 & -1 & Co-57 > stable \\
\hline
\end{tabular}


RSAC-7.2 Nuclear Data Library

\begin{tabular}{|c|c|c|c|c|c|c|c|c|c|c|}
\hline 280590 & $7.60 \mathrm{E}+04$ & 5 & $\mathrm{y}$ & 0 & 1 & -1 & 1 & 0 & -1 & Ni-59 > stable \\
\hline 260600 & $1.50 \mathrm{E}+06$ & 5 & $\mathrm{y}$ & 0 & 1 & 0 & 1 & 0 & -1 & Fe-60 > Co- $60 \mathrm{~m} 1.0$ \\
\hline 270601 & $1.05 \mathrm{E}+01$ & 2 & $\mathrm{~m}$ & 0 & 0.9975 & 0 & 1 & 1 & -1 & Co-60m > Co-60 0.9975 \\
\hline 270600 & $5.28 \mathrm{E}+00$ & 5 & $\mathrm{y}$ & 0 & 1 & -1 & 1 & 2 & -1 & Co-60 > stable \\
\hline 290600 & $2.37 \mathrm{E}+01$ & 2 & $\mathrm{~m}$ & 0 & 1 & -1 & 1 & 0 & -1 & $\mathrm{Cu}-60>$ stable \\
\hline 270610 & $1.65 \mathrm{E}+00$ & 3 & $\mathrm{~h}$ & 0 & 1 & -1 & 1 & 0 & -1 & Co-61 > stable \\
\hline 290610 & $3.33 \mathrm{E}+00$ & 3 & $\mathrm{~h}$ & 0 & 1 & -1 & 1 & 0 & -1 & $\mathrm{Cu}-61>$ stable \\
\hline 270621 & $1.39 \mathrm{E}+01$ & 2 & $\mathrm{~m}$ & 0 & 1 & -1 & 1 & 0 & -1 & Co- $62 \mathrm{~m}>$ stable \\
\hline 300620 & $9.26 \mathrm{E}+00$ & 3 & $\mathrm{~h}$ & 0 & 1 & 0 & 1 & 0 & -1 & $\mathrm{Zn}-62>\mathrm{Cu}-62 \quad 1.0$ \\
\hline 290620 & $9.67 \mathrm{E}+00$ & 2 & $\mathrm{~m}$ & 0 & 1 & -1 & 1 & 0 & -1 & $\mathrm{Cu}-62>$ stable \\
\hline 280630 & $1.01 \mathrm{E}+02$ & 5 & $\mathrm{y}$ & 0 & 1 & -1 & 1 & 0 & -1 & Ni-63 > stable \\
\hline 300630 & $3.85 \mathrm{E}+01$ & 2 & $\mathrm{~m}$ & 0 & 1 & -1 & 1 & 0 & -1 & Zn-63 > stable \\
\hline 280650 & $2.52 \mathrm{E}+00$ & 3 & $\mathrm{~h}$ & 0 & 1 & -1 & 1 & 0 & -1 & Ni-65 > stable \\
\hline 290640 & $1.27 \mathrm{E}+01$ & 3 & $\mathrm{~h}$ & 0 & 1 & -1 & 1 & 0 & -1 & Cu-64 > stable \\
\hline 310650 & $1.52 \mathrm{E}+01$ & 2 & $\mathrm{~m}$ & 0 & 1 & 0 & 1 & 0 & -1 & Ga-65 > Zn-65 1.0 \\
\hline 300650 & $2.44 \mathrm{E}+02$ & 4 & $\mathrm{~d}$ & 0 & 1 & -1 & 1 & 1 & -1 & Zn-65 > stable \\
\hline 280660 & $5.46 \mathrm{E}+01$ & 3 & $\mathrm{~h}$ & 0 & 1 & 0 & 1 & 0 & -1 & $\mathrm{Ni}-66>\mathrm{Cu}-66 \quad 1.0$ \\
\hline 290660 & $5.12 \mathrm{E}+00$ & 2 & $\mathrm{~m}$ & 0 & 1 & -1 & 1 & 1 & -0.3 & $\mathrm{Cu}-66>$ stable \\
\hline 320660 & $2.26 \mathrm{E}+00$ & 3 & $\mathrm{~h}$ & 0 & 1 & 0 & 1 & 0 & -1 & Ge-66 > Ga-66 1.0 \\
\hline 310660 & $9.49 \mathrm{E}+00$ & 3 & $\mathrm{~h}$ & 0 & 1 & -1 & 1 & 1 & -1 & Ga-66 > stable \\
\hline 290670 & $6.18 \mathrm{E}+01$ & 3 & $\mathrm{~h}$ & 0 & 1 & -1 & 1 & 0 & -1 & $\mathrm{Cu}-67>$ stable \\
\hline 320670 & $1.89 \mathrm{E}+01$ & 2 & $\mathrm{~m}$ & 0 & 1 & 0 & 1 & 0 & -1 & Ge-67 > Ga-67 1.0 \\
\hline 310670 & $3.26 \mathrm{E}+00$ & 4 & $\mathrm{~d}$ & 0 & 1 & -1 & 1 & 1 & -1 & Ga-67 > stable \\
\hline 320680 & $2.71 \mathrm{E}+02$ & 4 & $\mathrm{~d}$ & 0 & 1 & 0 & 1 & 0 & -1 & Ge-68 > Ga-68 1.0 \\
\hline 310680 & $6.77 \mathrm{E}+01$ & 2 & $\mathrm{~m}$ & 0 & 1 & -1 & 1 & 1 & -1 & Ga-68 > stable \\
\hline 300691 & $1.38 \mathrm{E}+01$ & 3 & $\mathrm{~h}$ & 0 & 1 & 0 & 1 & 0 & -1 & $\mathrm{Zn}-69 \mathrm{~m}>\mathrm{Zn}-69 \quad 1.0$ \\
\hline 300690 & $5.64 \mathrm{E}+01$ & 2 & $\mathrm{~m}$ & 0 & 1 & -1 & 1 & 1 & -1 & Zn-69 > stable \\
\hline 330690 & $1.52 \mathrm{E}+01$ & 2 & $\mathrm{~m}$ & 0 & 1 & 0 & 1 & 0 & -1 & As-69 > Ge-69 1.0 \\
\hline 320690 & $3.91 \mathrm{E}+01$ & 3 & $\mathrm{~h}$ & 0 & 1 & -1 & 1 & 1 & -1 & Ge-69 > stable \\
\hline 310700 & $2.11 \mathrm{E}+01$ & 2 & $\mathrm{~m}$ & 0 & 1 & -1 & 1 & 0 & -1 & Ga-70 > stable \\
\hline 300711 & $3.96 \mathrm{E}+00$ & 3 & $\mathrm{~h}$ & 0 & 1 & -1 & 1 & 0 & -1 & $\mathrm{Zn}-71 \mathrm{~m}>$ stable \\
\hline
\end{tabular}


RSAC-7.2 Nuclear Data Library

\begin{tabular}{|c|c|c|c|c|c|c|c|c|c|c|}
\hline 330710 & $6.53 \mathrm{E}+01$ & 3 & $\mathrm{~h}$ & 0 & 1 & 0 & 1 & 0 & -1 & As-71 > Ge-71 1.0 \\
\hline 320710 & $1.14 \mathrm{E}+01$ & 4 & $\mathrm{~d}$ & 0 & 1 & -1 & 1 & 1 & -1 & Ge-71 > stable \\
\hline 340700 & $4.11 \mathrm{E}+01$ & 2 & $\mathrm{~m}$ & 0 & 1 & 0 & 1 & 0 & -1 & Se-70 > As-70 \\
\hline 330700 & $5.26 \mathrm{E}+01$ & 2 & $\mathrm{~m}$ & 0 & 1 & -1 & 1 & 0 & -1 & As-70 > stable \\
\hline 330720 & $2.60 \mathrm{E}+01$ & 3 & $\mathrm{~h}$ & 0 & 1 & -1 & 1 & 0 & -1 & As-72 $>$ stable \\
\hline 270720 & $9.00 \mathrm{E}-02$ & 1 & $\mathrm{~s}$ & $8.87 \mathrm{E}-07$ & 1 & 0 & 1 & 0 & -0.3 & $\mathrm{Co}-72>\mathrm{Ni}-721.0$ \\
\hline 280720 & $1.57 \mathrm{E}+00$ & 1 & $\mathrm{~s}$ & $2.85 \mathrm{E}-05$ & 1 & 0 & 1 & 1 & -0.3 & $\mathrm{Ni}-72>\mathrm{Cu}-721.0$ \\
\hline 290720 & $6.63 \mathrm{E}+00$ & 1 & $\mathrm{~s}$ & $3.36 \mathrm{E}-05$ & 1 & 0 & 1 & 2 & -0.3 & $\mathrm{Cu}-72>\mathrm{Zn}-721.0$ \\
\hline 300720 & $4.65 \mathrm{E}+01$ & 3 & $\mathrm{~h}$ & $6.76 \mathrm{E}-06$ & 1 & 0 & 1 & 3 & 0 & $\mathrm{Zn}-72>\mathrm{Ga}-721.0$ \\
\hline 310720 & $1.41 \mathrm{E}+01$ & 3 & $\mathrm{~h}$ & 4.22E-08 & 1 & -1 & 1 & 4 & 0 & Ga-72 > stable \\
\hline 270730 & $1.16 \mathrm{E}-01$ & 1 & $\mathrm{~s}$ & $9.07 \mathrm{E}-08$ & 1 & 0 & 1 & 0 & -0.3 & $\mathrm{Co}-73>\mathrm{Ni}-731.0$ \\
\hline 280730 & $8.00 \mathrm{E}-01$ & 1 & $\mathrm{~s}$ & $1.49 \mathrm{E}-05$ & 1 & 0 & 1 & 1 & -0.3 & $\mathrm{Ni}-73>\mathrm{Cu}-731.0$ \\
\hline 290730 & $3.90 \mathrm{E}+00$ & 1 & $\mathrm{~s}$ & $9.86 \mathrm{E}-05$ & 1 & 0 & 1 & 2 & -0.3 & $\mathrm{Cu}-73>\mathrm{Zn}-731.0$ \\
\hline 300730 & $2.35 \mathrm{E}+01$ & 1 & $\mathrm{~s}$ & $1.28 \mathrm{E}-04$ & 1 & 0 & 1 & 3 & -0.3 & $\mathrm{Zn}-73>\mathrm{Ga}-731.0$ \\
\hline 310730 & $4.86 \mathrm{E}+00$ & 3 & $\mathrm{~h}$ & $6.88 \mathrm{E}-06$ & 1 & -1 & 1 & 4 & 0 & Ga-73 > stable \\
\hline 340731 & $3.98 \mathrm{E}+01$ & 2 & $\mathrm{~m}$ & 0 & 0.274 & 1 & 1 & 0 & -1 & $\begin{array}{l}\text { Se-73m Se-73 .726 As-73 } \\
.274\end{array}$ \\
\hline 340730 & $7.15 \mathrm{E}+00$ & 3 & $\mathrm{~h}$ & 0 & 1 & 0 & 1 & 1 & -1 & Se-73 > As-73 1.0 \\
\hline 330730 & $8.03 \mathrm{E}+01$ & 4 & $\mathrm{~d}$ & 0 & 1 & -1 & 1 & 2 & -1 & As-73 > stable \\
\hline 270740 & $1.08 \mathrm{E}-01$ & 1 & $\mathrm{~s}$ & $7.32 \mathrm{E}-08$ & 1 & 0 & 1 & 0 & -0.3 & $\mathrm{Co}-74>\mathrm{Ni}-741.0$ \\
\hline 280740 & $5.00 \mathrm{E}-01$ & 1 & $\mathrm{~s}$ & $2.42 \mathrm{E}-05$ & 1 & 0 & 1 & 1 & -0.3 & $\mathrm{Ni}-74>\mathrm{Cu}-741.0$ \\
\hline 290740 & $1.63 \mathrm{E}+00$ & 1 & $\mathrm{~s}$ & $2.31 \mathrm{E}-04$ & 1 & 0 & 1 & 2 & -0.3 & $\mathrm{Cu}-74>\mathrm{Zn}-741.0$ \\
\hline 300740 & $9.54 \mathrm{E}+01$ & 1 & $\mathrm{~s}$ & $3.62 \mathrm{E}-04$ & 1 & 0 & 1 & 3 & -0.3 & $\mathrm{Zn}-74>\mathrm{Ga}-741.0$ \\
\hline 310740 & $8.12 \mathrm{E}+00$ & 2 & $\mathrm{~m}$ & $2.19 \mathrm{E}-05$ & 1 & -1 & 1 & 4 & 0 & Ga-74 > stable \\
\hline 330740 & $1.78 \mathrm{E}+01$ & 4 & $\mathrm{~d}$ & 0 & 1 & -1 & 1 & 0 & -1 & As-74 > stable \\
\hline 350741 & $4.60 \mathrm{E}+01$ & 2 & $\mathrm{~m}$ & 0 & 1 & -1 & 1 & 0 & -1 & Br-74m $>$ stable \\
\hline 350740 & $2.54 \mathrm{E}+01$ & 2 & $\mathrm{~m}$ & 0 & 1 & -1 & 1 & 0 & -1 & $\mathrm{Br}-74>$ stable \\
\hline 270750 & $8.02 \mathrm{E}-02$ & 1 & $\mathrm{~s}$ & $9.62 \mathrm{E}-09$ & 1 & 0 & 1 & 0 & -0.3 & $\mathrm{Co}-75>\mathrm{Ni}-751.0$ \\
\hline 280750 & $6.00 \mathrm{E}-01$ & 1 & $\mathrm{~s}$ & $9.94 \mathrm{E}-06$ & 1 & 0 & 1 & 1 & -0.3 & $\mathrm{Ni}-75>\mathrm{Cu}-751.0$ \\
\hline 290750 & $1.22 \mathrm{E}+00$ & 1 & $\mathrm{~s}$ & $2.71 \mathrm{E}-04$ & 1 & 0 & 1 & 2 & -0.3 & $\mathrm{Cu}-75>\mathrm{Zn}-75 \quad 1.0$ \\
\hline 300750 & $1.02 \mathrm{E}+01$ & 1 & $\mathrm{~s}$ & $1.09 \mathrm{E}-03$ & 1 & 0 & 1 & 3 & -0.3 & $\mathrm{Zn}-75>\mathrm{Ga}-751.0$ \\
\hline 310750 & $1.26 \mathrm{E}+02$ & 1 & $\mathrm{~s}$ & $1.79 \mathrm{E}-04$ & 1 & 0 & 1 & 4 & -0.3 & $\mathrm{Ga}-75>\mathrm{Ge}-751.0$ \\
\hline
\end{tabular}


RSAC-7.2 Nuclear Data Library

\begin{tabular}{|c|c|c|c|c|c|c|c|c|c|c|}
\hline 320751 & $4.77 \mathrm{E}+01$ & 1 & $\mathrm{~s}$ & $2.06 \mathrm{E}-06$ & 1 & 0 & 1 & 5 & -0.3 & Ge-75m $>$ Ge-75 1.0 \\
\hline 320750 & $8.28 \mathrm{E}+01$ & 2 & $\mathrm{~m}$ & $2.06 \mathrm{E}-06$ & 1 & -1 & 1 & 6 & 4.14E-01 & Ge-75 > stable \\
\hline 350750 & $9.67 \mathrm{E}+01$ & 2 & $\mathrm{~m}$ & 0 & 1 & 0 & 1 & 0 & -1 & Br-75 > Se-75 1.0 \\
\hline 340750 & $1.19 \mathrm{E}+02$ & 4 & $\mathrm{~d}$ & 0 & 1 & -1 & 1 & 1 & -1 & Se-75 > stable \\
\hline 280760 & $4.40 \mathrm{E}-01$ & 1 & $\mathrm{~s}$ & $3.26 \mathrm{E}-06$ & 1 & 0 & 1 & 0 & -0.3 & $\mathrm{Ni}-76>\mathrm{Cu}-761.0$ \\
\hline 290760 & $6.41 \mathrm{E}-01$ & 1 & $\mathrm{~s}$ & $2.70 \mathrm{E}-04$ & 1 & 0 & 1 & 1 & -0.3 & $\mathrm{Cu}-76>\mathrm{Zn}-761.0$ \\
\hline 300760 & $5.70 \mathrm{E}+00$ & 1 & $\mathrm{~s}$ & $2.95 \mathrm{E}-03$ & 1 & 0 & 1 & 2 & -0.3 & $\mathrm{Zn}-76>\mathrm{Ga}-761.0$ \\
\hline 310760 & $3.26 \mathrm{E}+01$ & 1 & $\mathrm{~s}$ & $1.28 \mathrm{E}-03$ & 1 & -1 & 1 & 3 & 0 & Ga-76 > stable \\
\hline 350760 & $1.62 \mathrm{E}+01$ & 3 & $\mathrm{~h}$ & 0 & 1 & -1 & 1 & 0 & -1 & Br-76 > stable \\
\hline 330010 & $8.00 \mathrm{E}+22$ & 5 & $\mathrm{y}$ & $3.40 \mathrm{E}-04$ & 1 & 0 & 1 & 0 & -2 & pseudo \\
\hline 330760 & $1.09 \mathrm{E}+00$ & 4 & $\mathrm{~d}$ & $2.23 \mathrm{E}-07$ & 1 & -1 & 1 & 1 & 0 & As-76 > stable \\
\hline 280770 & $1.03 \mathrm{E}-01$ & 1 & $\mathrm{~s}$ & $4.51 \mathrm{E}-07$ & 1 & 0 & 1 & 0 & -0.3 & $\mathrm{Ni}-77>\mathrm{Cu}-771.0$ \\
\hline 290770 & 4.69E-01 & 1 & $\mathrm{~s}$ & $1.17 \mathrm{E}-04$ & 1 & 0 & 1 & 1 & -0.3 & $\mathrm{Cu}-77>\mathrm{Zn}-771.0$ \\
\hline 300770 & $2.08 \mathrm{E}+00$ & 1 & $\mathrm{~s}$ & $3.62 \mathrm{E}-03$ & 1 & 0 & 1 & 2 & -0.3 & $\mathrm{Zn}-77>\mathrm{Ga}-771.0$ \\
\hline 310770 & $1.32 \mathrm{E}+01$ & 1 & $\mathrm{~s}$ & $5.32 \mathrm{E}-03$ & 1 & 1 & 1 & 3 & 0 & Ga-77 > Ge-77 1.0 \\
\hline 320771 & $5.29 \mathrm{E}+01$ & 1 & $\mathrm{~s}$ & $4.78 \mathrm{E}-04$ & 0.96 & 1 & 1 & 4 & 0 & Ge-77m Ge-77 .04 As-77 .960 \\
\hline 320770 & $1.13 \mathrm{E}+01$ & 3 & $\mathrm{~h}$ & $6.89 \mathrm{E}-04$ & 1 & 0 & 1 & 5 & 0 & Ge-77 > As-77 1.0 \\
\hline 330770 & $3.88 \mathrm{E}+01$ & 3 & $\mathrm{~h}$ & $1.27 \mathrm{E}-05$ & 1 & -1 & 1 & 6 & 0 & As-77 > stable \\
\hline 350770 & $5.70 \mathrm{E}+01$ & 3 & $\mathrm{~h}$ & 0 & 1 & -1 & 1 & 0 & -1 & Br-77 > stable \\
\hline 280780 & $1.38 \mathrm{E}-01$ & 1 & $\mathrm{~s}$ & $5.06 \mathrm{E}-08$ & 1 & 0 & 1 & 0 & -0.3 & $\mathrm{Ni}-78>\mathrm{Cu}-781.0$ \\
\hline 290780 & $3.42 \mathrm{E}-01$ & 1 & $\mathrm{~s}$ & 4.45E-05 & 1 & 0 & 1 & 1 & -0.3 & $\mathrm{Cu}-78>\mathrm{Zn}-781.0$ \\
\hline 300780 & $1.47 \mathrm{E}+00$ & 1 & $\mathrm{~s}$ & $4.25 \mathrm{E}-03$ & 1 & 0 & 1 & 2 & -0.3 & $\mathrm{Zn}-78>\mathrm{Ga}-781.0$ \\
\hline 310780 & $5.09 \mathrm{E}+00$ & 1 & $\mathrm{~s}$ & $1.42 \mathrm{E}-02$ & 1 & 0 & 1 & 3 & -0.3 & Ga-78 > Ge-78 1.0 \\
\hline 320780 & $8.80 \mathrm{E}+01$ & 2 & $\mathrm{~m}$ & $2.00 \mathrm{E}-03$ & 1 & 0 & 1 & 4 & 0 & Ge-78 > As-78 1.0 \\
\hline 330780 & $9.07 \mathrm{E}+01$ & 2 & $\mathrm{~m}$ & $2.18 \mathrm{E}-04$ & 1 & -1 & 1 & 5 & 0 & As-78 > stable \\
\hline 290790 & $1.88 \mathrm{E}-01$ & 1 & $\mathrm{~s}$ & $5.18 \mathrm{E}-06$ & 1 & 0 & 1 & 0 & -0.3 & $\mathrm{Cu}-79>\mathrm{Zn}-79 \quad 1.0$ \\
\hline 300790 & $9.95 \mathrm{E}-01$ & 1 & $\mathrm{~s}$ & $1.65 \mathrm{E}-03$ & 1 & 0 & 1 & 1 & -0.3 & $\mathrm{Zn}-79>\mathrm{Ga}-791.0$ \\
\hline 310790 & $2.85 \mathrm{E}+00$ & 1 & $\mathrm{~s}$ & $1.52 \mathrm{E}-02$ & 1 & 0 & 1 & 2 & -0.3 & Ga-79 > Ge-79 1.0 \\
\hline 320790 & $1.90 \mathrm{E}+01$ & 1 & $\mathrm{~s}$ & $2.66 \mathrm{E}-02$ & 1 & 0 & 1 & 3 & -0.3 & Ge-79 > As-79 1.0 \\
\hline 330790 & $9.01 \mathrm{E}+00$ & 2 & $\mathrm{~m}$ & $9.41 \mathrm{E}-03$ & 1 & 0 & 1 & 4 & 0 & As-79 $>$ Se-79m 1.0 \\
\hline 340791 & $3.92 \mathrm{E}+00$ & 2 & $\mathrm{~m}$ & $8.05 \mathrm{E}-06$ & 1 & 0 & 1 & 5 & 0 & Se-79m $>$ Se-79 1.0 \\
\hline
\end{tabular}


RSAC-7.2 Nuclear Data Library

\begin{tabular}{|c|c|c|c|c|c|c|c|c|c|c|}
\hline 340790 & $2.95 \mathrm{E}+05$ & 5 & $\mathrm{y}$ & $8.03 \mathrm{E}-06$ & 1 & -1 & 1 & 6 & $3.63 \mathrm{E}-01$ & Se-79 > stable \\
\hline 370790 & $2.29 \mathrm{E}+01$ & 2 & $\mathrm{~m}$ & 0 & 1 & 0 & 1 & 0 & -1 & $\mathrm{Rb}-79>\mathrm{Kr}-791.0$ \\
\hline 360790 & $3.50 \mathrm{E}+01$ & 3 & $\mathrm{~h}$ & 0 & 1 & -1 & 3 & 1 & -1 & Kr-79 > stable \\
\hline 290800 & $9.11 \mathrm{E}-02$ & 1 & $\mathrm{~s}$ & $7.03 \mathrm{E}-07$ & 1 & 0 & 1 & 0 & -0.3 & $\mathrm{Cu}-80>\mathrm{Zn}-80 \quad 1.0$ \\
\hline 300800 & $5.40 \mathrm{E}-01$ & 1 & $\mathrm{~s}$ & $7.55 \mathrm{E}-04$ & 1 & 0 & 1 & 1 & -0.3 & $\mathrm{Zn}-80>\mathrm{Ga}-801.0$ \\
\hline 310800 & $1.68 \mathrm{E}+00$ & 1 & $\mathrm{~s}$ & $2.13 \mathrm{E}-02$ & 1 & 0 & 1 & 2 & -0.3 & Ga-80 > Ge-80 1.0 \\
\hline 320800 & $2.95 \mathrm{E}+01$ & 1 & $\mathrm{~s}$ & $8.88 \mathrm{E}-02$ & 1 & 0 & 1 & 3 & -0.3 & Ge-80 > As-80 1.0 \\
\hline 330800 & $1.52 \mathrm{E}+01$ & 1 & $\mathrm{~s}$ & $1.49 \mathrm{E}-02$ & 1 & -1 & 1 & 4 & 0 & As- $80>$ stable \\
\hline 350801 & $4.42 \mathrm{E}+00$ & 3 & $\mathrm{~h}$ & 0 & 1 & 0 & 2 & 0 & -1 & $\mathrm{Br}-80 \mathrm{~m}>\mathrm{Br}-801.0$ \\
\hline 350800 & $1.77 \mathrm{E}+01$ & 2 & $\mathrm{~m}$ & 0 & 1 & -1 & 2 & 1 & -1 & $\mathrm{Br}-80>$ stable \\
\hline 380800 & $1.06 \mathrm{E}+02$ & 2 & $\mathrm{~m}$ & 0 & 1 & 0 & 1 & 0 & -1 & Sr-80 > Rb-80 1.0 \\
\hline 370800 & $3.40 \mathrm{E}+01$ & 1 & $\mathrm{~s}$ & 0 & 1 & -1 & 1 & 1 & -0.3 & $\mathrm{Rb}-80>$ stable \\
\hline 290810 & $7.45 \mathrm{E}-02$ & 1 & $\mathrm{~s}$ & $3.67 \mathrm{E}-08$ & 1 & 0 & 1 & 0 & -0.3 & $\mathrm{Cu}-81>\mathrm{Zn}-811.0$ \\
\hline 300810 & $2.90 \mathrm{E}-01$ & 1 & $\mathrm{~s}$ & $1.32 \mathrm{E}-04$ & 1 & 0 & 1 & 1 & -0.3 & $\mathrm{Zn}-81>\mathrm{Ga}-811.0$ \\
\hline 310810 & $1.22 \mathrm{E}+00$ & 1 & $\mathrm{~s}$ & $1.16 \mathrm{E}-02$ & 1 & 0 & 1 & 2 & -0.3 & Ga-81 > Ge-81 1.0 \\
\hline 320810 & $7.60 \mathrm{E}+00$ & 1 & $\mathrm{~s}$ & $1.33 \mathrm{E}-01$ & 1 & 0 & 1 & 3 & -0.3 & Ge-81 > As-81 1.0 \\
\hline 330810 & $3.33 \mathrm{E}+01$ & 1 & $\mathrm{~s}$ & $5.98 \mathrm{E}-02$ & 1 & 0 & 1 & 4 & 0 & As-81 > Se-81 1.0 \\
\hline 340811 & $5.73 \mathrm{E}+01$ & 2 & $\mathrm{~m}$ & $6.85 \mathrm{E}-03$ & 1 & 0 & 1 & 5 & 0 & Se- $81 \mathrm{~m}>$ Se- 811.0 \\
\hline 340810 & $1.85 \mathrm{E}+01$ & 2 & $\mathrm{~m}$ & $2.19 \mathrm{E}-03$ & 1 & -1 & 1 & 6 & 0 & Se-81 > stable \\
\hline 380810 & $2.23 \mathrm{E}+01$ & 2 & $\mathrm{~m}$ & 0 & 1 & 1 & 1 & 0 & -1 & Sr-81 > Rb-81 1.0 \\
\hline 370811 & $3.05 \mathrm{E}+01$ & 2 & $\mathrm{~m}$ & 0 & 1 & 0 & 1 & 1 & -1 & $\mathrm{Rb}-81 \mathrm{~m}>\mathrm{Rb}-811.0$ \\
\hline 370810 & $4.57 \mathrm{E}+00$ & 3 & $\mathrm{~h}$ & 0 & 1 & 0 & 1 & 2 & -1 & $\mathrm{Rb}-81>\mathrm{Kr}-811.0$ \\
\hline 360810 & $2.29 \mathrm{E}+05$ & 5 & $\mathrm{y}$ & 0 & 1 & -1 & 3 & 3 & -1 & $\mathrm{Kr}-81>$ stable \\
\hline 350010 & $1.00 \mathrm{E}+23$ & 5 & $\mathrm{y}$ & $3.30 \mathrm{E}-02$ & 1 & 3 & 2 & 0 & -2 & pseudo \\
\hline 350020 & $4.00 \mathrm{E}+19$ & 5 & $\mathrm{y}$ & $2.00 \mathrm{E}-04$ & 1 & 2 & 2 & 1 & -2 & pseudo \\
\hline 350030 & $1.00 \mathrm{E}+23$ & 5 & $\mathrm{y}$ & $5.00 \mathrm{E}-02$ & 1 & 2 & 2 & 2 & -2 & pseudo \\
\hline 350040 & $2.00 \mathrm{E}+19$ & 5 & $\mathrm{y}$ & $5.00 \mathrm{E}-05$ & 1 & 1 & 2 & 3 & -2 & pseudo \\
\hline 350821 & $6.13 \mathrm{E}+00$ & 2 & $\mathrm{~m}$ & $8.00 \mathrm{E}-05$ & 0.976 & 0 & 2 & 4 & 0 & $\mathrm{Br}-82 \mathrm{~m}>\mathrm{Br}-82.976$ \\
\hline 350820 & $3.53 \mathrm{E}+01$ & 3 & $\mathrm{~h}$ & $5.92 \mathrm{E}-05$ & 1 & -1 & 2 & 5 & 0 & Br-82 > stable \\
\hline 380820 & $2.54 \mathrm{E}+01$ & 4 & $\mathrm{~d}$ & 0 & 0.99974 & 0 & 1 & 0 & -0.3 & Sr-82 > Rb-82 .99974 \\
\hline 370820 & $1.26 \mathrm{E}+00$ & 2 & $\mathrm{~m}$ & 0 & 1 & -1 & 1 & 1 & -0.3 & $\mathrm{Rb}-82>$ stable \\
\hline
\end{tabular}


RSAC-7.2 Nuclear Data Library

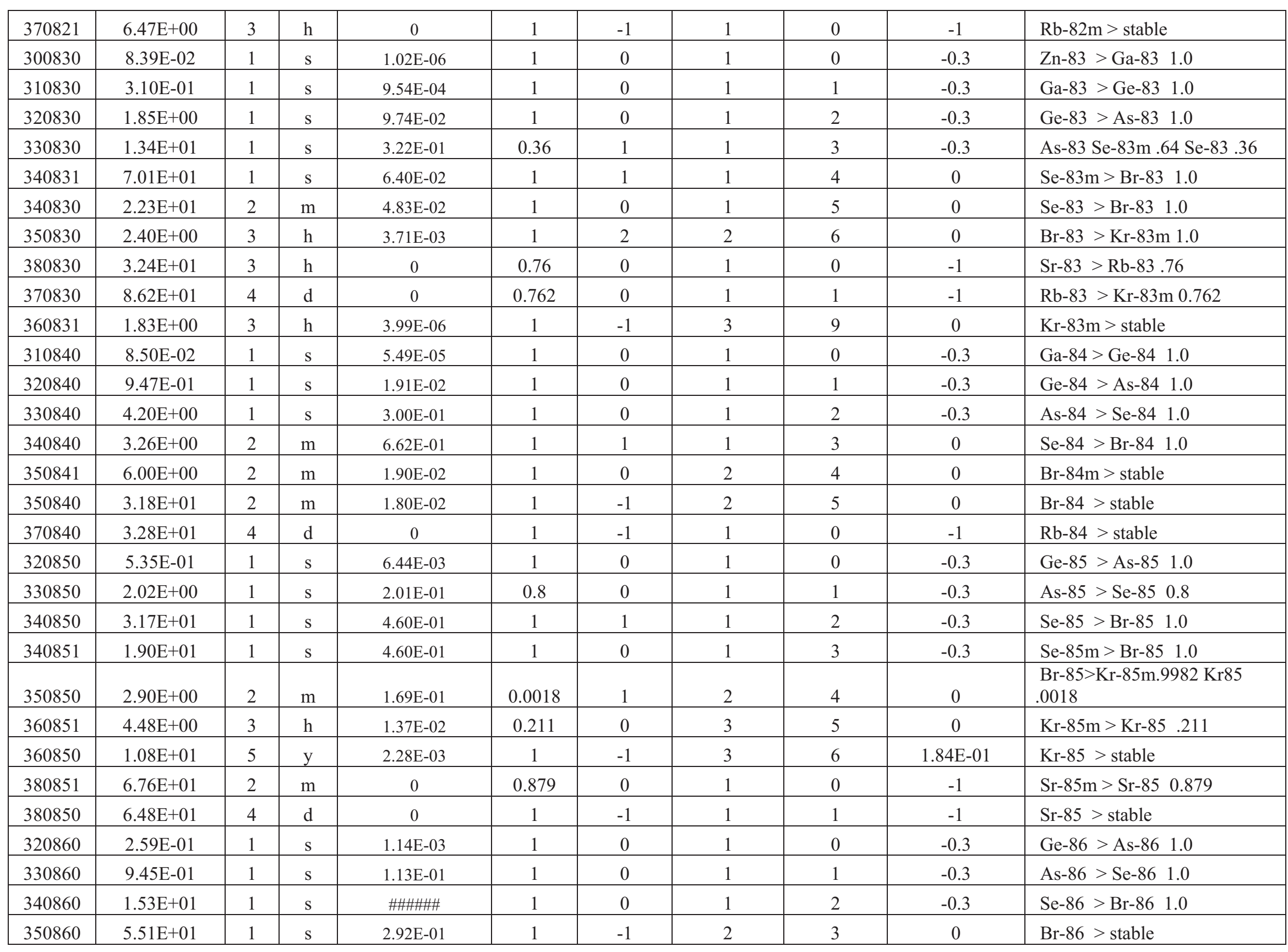


RSAC-7.2 Nuclear Data Library

\begin{tabular}{|c|c|c|c|c|c|c|c|c|c|c|}
\hline 370860 & $1.86 \mathrm{E}+01$ & 4 & $\mathrm{~d}$ & 0 & 1 & -1 & 1 & 0 & -1 & Rb-86 > stable \\
\hline 400860 & $1.65 \mathrm{E}+01$ & 3 & $\mathrm{~h}$ & 0 & 1 & 1 & 1 & 0 & -1 & $\mathrm{Zr}-86>\mathrm{Y}-86 \quad 1.0$ \\
\hline 390861 & $4.80 \mathrm{E}+01$ & 2 & $\mathrm{~m}$ & 0 & 1 & 0 & 1 & 1 & -1 & $\mathrm{Y}-86 \mathrm{~m}>\mathrm{Y}-86 \quad 1.0$ \\
\hline 390860 & $1.47 \mathrm{E}+01$ & 3 & $\mathrm{~h}$ & 0 & 1 & -1 & 1 & 2 & -1 & Y-86 > stable \\
\hline 320870 & $1.26 \mathrm{E}-01$ & 1 & $\mathrm{~s}$ & $1.83 \mathrm{E}-04$ & 1 & 0 & 1 & 0 & -0.3 & Ge-87 > As-87 1.0 \\
\hline 330870 & $5.60 \mathrm{E}-01$ & 1 & $\mathrm{~s}$ & $6.44 \mathrm{E}-02$ & 1 & 0 & 1 & 1 & -0.3 & As- $87>\mathrm{Se}-871.0$ \\
\hline 340870 & $5.50 \mathrm{E}+00$ & 1 & $\mathrm{~s}$ & $9.34 \mathrm{E}-01$ & 1 & 0 & 1 & 2 & -0.3 & Se- $87>$ Br-87 1.0 \\
\hline 350870 & $5.57 \mathrm{E}+01$ & 1 & $\mathrm{~s}$ & 0 & 1 & 0 & 2 & 3 & 0 & $\mathrm{Br}-87>\mathrm{Kr}-871.0$ \\
\hline 360870 & $7.63 \mathrm{E}+01$ & 2 & $\mathrm{~m}$ & $3.42 \mathrm{E}-01$ & 1 & 1 & 3 & 4 & $5.52 \mathrm{E}+01$ & $\mathrm{Kr}-87>\mathrm{Rb}-87 \quad 1.0$ \\
\hline 380871 & $2.82 \mathrm{E}+00$ & 3 & $\mathrm{~h}$ & 0 & 0.003 & 0 & 1 & 0 & -1 & Sr-87m $>$ Rb-87 0.003 \\
\hline 370870 & $4.81 \mathrm{E}+10$ & 5 & $\mathrm{y}$ & $1.00 \mathrm{E}-01$ & 1 & -1 & 1 & 0 & $7.69 \mathrm{E}-02$ & $\mathrm{Rb}-87>$ stable \\
\hline 320880 & $1.43 \mathrm{E}-01$ & 1 & $\mathrm{~s}$ & $2.08 \mathrm{E}-06$ & 1 & 0 & 1 & 0 & -0.3 & Ge-88 > As-88 1.0 \\
\hline 330880 & $1.30 \mathrm{E}-01$ & 1 & $\mathrm{~s}$ & $2.63 \mathrm{E}-03$ & 1 & 0 & 1 & 1 & -0.3 & As- $88>$ Se- 881.0 \\
\hline 340880 & $1.53 \mathrm{E}+00$ & 1 & $\mathrm{~s}$ & $3.55 \mathrm{E}-01$ & 1 & 0 & 1 & 2 & -0.3 & Se- $88>$ Br-88 1.0 \\
\hline 350880 & $1.63 \mathrm{E}+01$ & 1 & $\mathrm{~s}$ & \#\#\#\#\#\# & 1 & 0 & 2 & 3 & 0 & $\mathrm{Br}-88>\mathrm{Kr}-881.0$ \\
\hline 360880 & $2.84 \mathrm{E}+00$ & 3 & $\mathrm{~h}$ & \#\#\#\#\#\# & 1 & 0 & 3 & 4 & 0 & $\mathrm{Kr}-88>\mathrm{Rb}-881.0$ \\
\hline 370880 & $1.78 \mathrm{E}+01$ & 2 & $\mathrm{~m}$ & $3.20 \mathrm{E}-02$ & 1 & -1 & 1 & 5 & $9.20 \mathrm{E}-02$ & Rb-88 > stable \\
\hline 410880 & $1.45 \mathrm{E}+01$ & 2 & $\mathrm{~m}$ & 0 & 1 & 0 & 1 & 0 & -1 & $\mathrm{Nb}-88>\mathrm{Zr}-881.0$ \\
\hline 400880 & $8.34 \mathrm{E}+01$ & 4 & $\mathrm{~d}$ & 0 & 1 & 0 & 1 & 1 & -1 & Zr-88 > Y-88 1.0 \\
\hline 390880 & $1.07 \mathrm{E}+02$ & 4 & $\mathrm{~d}$ & 0 & 1 & -1 & 1 & 2 & -1 & Y-88 > stable \\
\hline 330890 & $1.29 \mathrm{E}-01$ & 1 & $\mathrm{~s}$ & $2.07 \mathrm{E}-04$ & 1 & 0 & 1 & 0 & -0.3 & As-89 > Se-89 1.0 \\
\hline 340890 & $4.10 \mathrm{E}-01$ & 1 & $\mathrm{~s}$ & $9.27 \mathrm{E}-02$ & 1 & 0 & 1 & 1 & -0.3 & Se-89 > Br-89 1.0 \\
\hline 350890 & $4.35 \mathrm{E}+00$ & 1 & $\mathrm{~s}$ & \#\#\#\#\#\# & 1 & 0 & 2 & 2 & -0.3 & Br-89 > Kr-89 1.0 \\
\hline 360890 & $3.15 \mathrm{E}+00$ & 2 & $\mathrm{~m}$ & \#\#\#\#\#\# & 1 & 0 & 3 & 3 & 0 & $\mathrm{Kr}-89>\mathrm{Rb}-891.0$ \\
\hline 370890 & $1.52 \mathrm{E}+01$ & 2 & $\mathrm{~m}$ & $1.70 \mathrm{E}-01$ & 1 & 0 & 1 & 4 & 0 & $\mathrm{Rb}-89>\mathrm{Sr}-891.0$ \\
\hline 380890 & $5.05 \mathrm{E}+01$ & 4 & $\mathrm{~d}$ & $2.58 \mathrm{E}-03$ & 1 & -1 & 1 & 5 & $5.26 \mathrm{E}-02$ & Sr-89 > stable \\
\hline 410891 & $1.18 \mathrm{E}+00$ & 3 & $\mathrm{~h}$ & 0 & 1 & 1 & 1 & 0 & -1 & $\mathrm{Nb}-89 \mathrm{~m}>\mathrm{Zr}-89 \quad 1.0$ \\
\hline 410890 & $1.90 \mathrm{E}+00$ & 3 & $\mathrm{~h}$ & 0 & 1 & 0 & 1 & 0 & -1 & $\mathrm{Nb}-89>\mathrm{Zr}-891.0$ \\
\hline 400890 & $7.84 \mathrm{E}+01$ & 3 & $\mathrm{~h}$ & 0 & 1 & -1 & 1 & 2 & -1 & Zr-89 > stable \\
\hline 340900 & $5.55 \mathrm{E}-01$ & 1 & $\mathrm{~s}$ & $3.22 \mathrm{E}-02$ & 1 & 0 & 1 & 0 & -0.3 & Se-90 > Br-90 1.0 \\
\hline 350900 & $1.91 \mathrm{E}+00$ & 1 & $\mathrm{~s}$ & \#\#\#\#\#\# & 0.88 & 0 & 2 & 1 & -0.3 & Br-90 > Kr-90 .88 \\
\hline
\end{tabular}


RSAC-7.2 Nuclear Data Library

\begin{tabular}{|c|c|c|c|c|c|c|c|c|c|c|}
\hline 360900 & $3.23 \mathrm{E}+01$ & 1 & $\mathrm{~s}$ & \#\#\#\#\#\# & 1 & 1 & 3 & 2 & 0 & Kr-90 > Rb-90 1.0 \\
\hline 370901 & $2.58 \mathrm{E}+02$ & 1 & $\mathrm{~s}$ & $4.28 \mathrm{E}-01$ & 0.974 & 1 & 1 & 3 & 0 & $\begin{array}{l}\text { Rb-90m Sr-90 .026 Rb-90 } \\
.974\end{array}$ \\
\hline 370900 & $1.58 \mathrm{E}+02$ & 1 & $\mathrm{~s}$ & $6.76 \mathrm{E}-01$ & 1 & 0 & 1 & 4 & 0 & Rb-90 > Sr-90 1.0 \\
\hline 380900 & $2.88 \mathrm{E}+01$ & 5 & $\mathrm{y}$ & $2.82 \mathrm{E}-02$ & 1 & 3 & 1 & 5 & 8.74E-02 & Sr-90 > Y-90 1.0 \\
\hline 390010 & $1.00 \mathrm{E}+23$ & 5 & $\mathrm{y}$ & $5.20 \mathrm{E}-05$ & 1 & 1 & 1 & 6 & -2 & pseudo \\
\hline 390020 & $5.00 \mathrm{E}+20$ & 5 & $\mathrm{y}$ & $5.00 \mathrm{E}-07$ & 1 & 0 & 1 & 7 & -2 & pseudo \\
\hline 390901 & $3.19 \mathrm{E}+00$ & 3 & $\mathrm{~h}$ & $1.25 \mathrm{E}-05$ & 1 & 0 & 1 & 8 & 0 & $\mathrm{Y}-90 \mathrm{~m}>\mathrm{Y}-90 \quad 1.0$ \\
\hline 390900 & $6.40 \mathrm{E}+01$ & 3 & $\mathrm{~h}$ & $2.30 \mathrm{E}-04$ & 1 & -1 & 1 & 9 & $5.92 \mathrm{E}-01$ & Y-90 > stable \\
\hline 420900 & $5.56 \mathrm{E}+00$ & 3 & $\mathrm{~h}$ & 0 & 1 & 0 & 1 & 0 & -1 & Mo-90 > Nb-90 1.0 \\
\hline 410900 & $1.46 \mathrm{E}+01$ & 3 & $\mathrm{~h}$ & 0 & 1 & -1 & 1 & 0 & -1 & $\mathrm{Nb}-90>$ stable \\
\hline 340910 & $2.70 \mathrm{E}-01$ & 1 & $\mathrm{~s}$ & $3.22 \mathrm{E}-03$ & 1 & 0 & 1 & 0 & -0.3 & Se-91 > Br-91 1.0 \\
\hline 350910 & $5.41 \mathrm{E}-01$ & 1 & $\mathrm{~s}$ & $3.91 \mathrm{E}-01$ & 1 & 0 & 2 & 1 & -0.3 & Br-91 > Kr-91 1.0 \\
\hline 360910 & $8.57 \mathrm{E}+00$ & 1 & $\mathrm{~s}$ & \#\#\#\#\#\# & 1 & 0 & 3 & 2 & 0 & Kr-91 > Rb-91 1.0 \\
\hline 370910 & $5.84 \mathrm{E}+01$ & 1 & $\mathrm{~s}$ & \#\#\#\#\#\# & 1 & 0 & 1 & 3 & 0 & Rb-91 > Sr-91 1.0 \\
\hline 380910 & $9.63 \mathrm{E}+00$ & 3 & $\mathrm{~h}$ & $2.29 \mathrm{E}-01$ & 1 & 1 & 1 & 4 & 0 & Sr-91 Y-91 1.0 \\
\hline 390911 & $4.97 \mathrm{E}+01$ & 2 & $\mathrm{~m}$ & $2.72 \mathrm{E}-04$ & 1 & 0 & 1 & 5 & 0 & $\mathrm{Y}-91 \mathrm{~m}>\mathrm{Y}-91 \quad 1.0$ \\
\hline 390910 & $5.85 \mathrm{E}+01$ & 4 & $\mathrm{~d}$ & $6.24 \mathrm{E}-04$ & 1 & -1 & 1 & 6 & $1.65 \mathrm{E}-01$ & Y-91 > stable \\
\hline 340920 & $2.48 \mathrm{E}-01$ & 1 & $\mathrm{~s}$ & 4.77E-05 & 1 & 0 & 1 & 0 & -0.3 & Se-92 > Br-92 1.0 \\
\hline 350920 & $3.43 \mathrm{E}-01$ & 1 & $\mathrm{~s}$ & $1.89 \mathrm{E}-02$ & 1 & 0 & 2 & 1 & -0.3 & Br-92 > Kr-92 1.0 \\
\hline 360920 & $1.84 \mathrm{E}+00$ & 1 & $\mathrm{~s}$ & \#\#\#\#\#\# & 1 & 0 & 3 & 2 & 0 & Kr-92 > Rb-92 1.0 \\
\hline 370920 & $4.49 \mathrm{E}+00$ & 1 & $\mathrm{~s}$ & \#\#\#\#\#\# & 1 & 0 & 1 & 3 & 0 & Rb-92 > Sr-92 1.0 \\
\hline 380920 & $2.71 \mathrm{E}+00$ & 3 & $\mathrm{~h}$ & \#\#\#\#\#\# & 1 & 0 & 1 & 4 & 0 & Sr-92 > Y-92 1.0 \\
\hline 390920 & $3.54 \mathrm{E}+00$ & 3 & $\mathrm{~h}$ & $9.81 \mathrm{E}-03$ & 1 & -1 & 1 & 5 & 0 & Y-92> stable \\
\hline 350930 & $1.02 \mathrm{E}-01$ & 1 & $\mathrm{~s}$ & 4.71E-03 & 1 & 0 & 2 & 0 & -0.3 & Br-93 > Kr-93 1.0 \\
\hline 360930 & $1.29 \mathrm{E}+00$ & 1 & $\mathrm{~s}$ & $5.00 \mathrm{E}-01$ & 1 & 0 & 3 & 1 & 0 & Kr-93 > Rb-93 1.0 \\
\hline 370930 & $5.84 \mathrm{E}+00$ & 1 & $\mathrm{~s}$ & \#\#\#\#\#\# & 1 & 0 & 1 & 2 & 0 & Rb-93 > Sr-93 1.0 \\
\hline 380930 & $7.42 \mathrm{E}+00$ & 2 & $\mathrm{~m}$ & \#\#\#\#\#\# & 1 & 0 & 1 & 3 & 0 & Sr-93 > Y-93 1.0 \\
\hline 390930 & $1.02 \mathrm{E}+01$ & 3 & $\mathrm{~h}$ & $9.81 \mathrm{E}-02$ & 1 & 0 & 1 & 4 & 0 & Y-93 > Zr-93 1.0 \\
\hline 400930 & $1.53 \mathrm{E}+06$ & 5 & $\mathrm{y}$ & $2.50 \mathrm{E}-01$ & 1 & 2 & 1 & 5 & 1.029 & $\mathrm{Zr}-93>\mathrm{Nb}-93 \mathrm{~m} 1.0$ \\
\hline 410010 & $2.00 \mathrm{E}+23$ & 5 & $\mathrm{y}$ & $1.20 \mathrm{E}-04$ & 1 & 1 & 1 & 6 & -2 & pseudo \\
\hline 410020 & $2.00 \mathrm{E}+20$ & 5 & $\mathrm{y}$ & 4.00E-06 & 1 & 0 & 1 & 7 & -2 & pseudo \\
\hline
\end{tabular}


RSAC-7.2 Nuclear Data Library

\begin{tabular}{|c|c|c|c|c|c|c|c|c|c|c|}
\hline 410931 & $1.61 \mathrm{E}+01$ & 5 & $\mathrm{y}$ & 9.37E-09 & 1 & -1 & 1 & 8 & 0 & $\mathrm{Nb}-93 \mathrm{~m}>$ stable \\
\hline 420931 & $6.85 \mathrm{E}+00$ & 3 & $\mathrm{~h}$ & 0 & 1 & 2 & 1 & 0 & -1 & Mo-93m > Mo-93 1.0 \\
\hline 430931 & $4.35 \mathrm{E}+01$ & 2 & $\mathrm{~m}$ & 0 & 0.234 & 1 & 1 & 0 & -1 & $\begin{array}{l}\text { Tc-93m Tc-93 .766 Mo-93 } \\
.234\end{array}$ \\
\hline 430930 & $2.75 \mathrm{E}+00$ & 3 & $\mathrm{~h}$ & 0 & 1 & 0 & 1 & 0 & -1 & Tc-93 > Mo-93 1.0 \\
\hline 420930 & $4.00 \mathrm{E}+03$ & 5 & $\mathrm{y}$ & \#\#\#\#\#\# & 1 & -1 & 1 & 3 & -1 & Mo-93 > stable \\
\hline 350940 & $7.00 \mathrm{E}-02$ & 1 & $\mathrm{~S}$ & $3.27 \mathrm{E}-04$ & 1 & 0 & 2 & 0 & -0.3 & Br-94 > Kr-94 1.0 \\
\hline 360940 & $2.00 \mathrm{E}-01$ & 1 & $\mathrm{~s}$ & $2.27 \mathrm{E}-01$ & 1 & 0 & 3 & 1 & -0.3 & Kr-94 > Rb-94 1.0 \\
\hline 370940 & $2.70 \mathrm{E}+00$ & 1 & $\mathrm{~s}$ & \#\#\#\#\#\# & 1 & 0 & 1 & 2 & -0.3 & Rb-94 > Sr-94 1.0 \\
\hline 380940 & $7.53 \mathrm{E}+01$ & 1 & $\mathrm{~S}$ & \#\#\#\#\#\# & 1 & 0 & 1 & 3 & 0 & Sr-94 > Y-94 1.0 \\
\hline 390940 & $1.87 \mathrm{E}+01$ & 2 & $\mathrm{~m}$ & $3.52 \mathrm{E}-01$ & 1 & -1 & 1 & 4 & 0 & Y-94 > Stable 1.0 \\
\hline 410941 & $6.26 \mathrm{E}+00$ & 2 & $\mathrm{~m}$ & $4.38 \mathrm{E}-07$ & 0.9952 & 0 & 1 & 0 & 0 & $\mathrm{Nb}-94 \mathrm{~m}>\mathrm{Nb}-94.9952$ \\
\hline 410940 & $2.03 \mathrm{E}+04$ & 5 & $\mathrm{y}$ & $4.35 \mathrm{E}-07$ & 1 & -1 & 1 & 1 & -1 & $\mathrm{Nb}-94>$ stable \\
\hline 440940 & $5.18 \mathrm{E}+01$ & 2 & $\mathrm{~m}$ & 0 & 1 & 1 & 1 & 0 & -1 & Ru-94 > Tc-94 1.0 \\
\hline 430941 & $5.20 \mathrm{E}+01$ & 2 & $\mathrm{~m}$ & 0 & 1 & -1 & 1 & 1 & -1 & Tc- $94 \mathrm{~m}>$ stable \\
\hline 430940 & $2.93 \mathrm{E}+02$ & 2 & $\mathrm{~m}$ & 0 & 1 & -1 & 1 & 0 & -1 & Tc-94 > stable \\
\hline 350950 & $1.17 \mathrm{E}-01$ & 1 & $\mathrm{~S}$ & $7.33 \mathrm{E}-06$ & 1 & 0 & 2 & 0 & -0.3 & $\mathrm{Br}-95>\mathrm{Kr}-951.0$ \\
\hline 360950 & $7.80 \mathrm{E}-01$ & 1 & $\mathrm{~S}$ & $1.02 \mathrm{E}-02$ & 1 & 0 & 3 & 1 & 0 & $\mathrm{Kr}-95>\mathrm{Rb}-951.0$ \\
\hline 370950 & $3.78 \mathrm{E}-01$ & 1 & $\mathrm{~s}$ & $8.96 \mathrm{E}-01$ & 1 & 0 & 1 & 2 & 0 & Rb-95 > Sr-95 1.0 \\
\hline 380950 & $2.39 \mathrm{E}+01$ & 1 & $\mathrm{~s}$ & \#\#\#\#\#\# & 1 & 0 & 1 & 3 & -0.3 & Sr-95 > Y-95 1.0 \\
\hline 390950 & $1.03 \mathrm{E}+01$ & 2 & $\mathrm{~m}$ & $9.48 \mathrm{E}-01$ & 1 & 0 & 1 & 4 & 0 & $\mathrm{Y}-95>\mathrm{Zr}-951.0$ \\
\hline 400950 & $6.40 \mathrm{E}+01$ & 4 & $\mathrm{~d}$ & $2.95 \mathrm{E}-02$ & 1 & 1 & 1 & 5 & $2.33 \mathrm{E}-01$ & $\mathrm{Zr}-95>\mathrm{Nb}-95 \mathrm{~m} 1.0$ \\
\hline 410030 & $1.40 \mathrm{E}+18$ & 5 & $\mathrm{y}$ & $4.50 \mathrm{E}-02$ & 1 & 0 & 1 & 6 & -2 & pseudo $>$ Nb-95m 1.0 \\
\hline 410951 & $8.66 \mathrm{E}+01$ & 3 & $\mathrm{~h}$ & $1.29 \mathrm{E}-04$ & 0.945 & 0 & 1 & 7 & 0 & $\mathrm{Nb}-95 \mathrm{~m}>\mathrm{Nb}-95.945$ \\
\hline 410950 & $3.50 \mathrm{E}+01$ & 4 & $\mathrm{~d}$ & $4.00 \mathrm{E}-05$ & 1 & -1 & 1 & 8 & $8.51 \mathrm{E}-01$ & $\mathrm{Nb}-95>$ stable \\
\hline 430951 & $6.10 \mathrm{E}+01$ & 4 & $\mathrm{~d}$ & 0 & 0.04 & 0 & 1 & 0 & -1 & Tc-95m > Tc-95 .04 \\
\hline 430950 & $2.00 \mathrm{E}+01$ & 3 & $\mathrm{~h}$ & 0 & 1 & -1 & 1 & 1 & -1 & Tc-95 > stable \\
\hline 410040 & $1.00 \mathrm{E}+23$ & 5 & $\mathrm{y}$ & $8.00 \mathrm{E}-03$ & 1 & 1 & 1 & 0 & -2 & pseudo $>$ Nb-96 1.0 \\
\hline 410050 & $1.00 \mathrm{E}+19$ & 5 & $\mathrm{y}$ & $1.00 \mathrm{E}-03$ & 1 & 0 & 1 & 1 & -2 & pseudo $>$ Nb-96 1.0 \\
\hline 410960 & $2.34 \mathrm{E}+01$ & 3 & $\mathrm{~h}$ & $6.10 \mathrm{E}-04$ & 1 & -1 & 1 & 2 & 0 & $\mathrm{Nb}-96>$ stable \\
\hline 430961 & $5.15 \mathrm{E}+01$ & 2 & $\mathrm{~m}$ & 0 & 0.98 & 0 & 1 & 0 & -1 & Tc-96m > Tc-96 0.98 \\
\hline 430960 & $4.28 \mathrm{E}+00$ & 4 & $\mathrm{~d}$ & 0 & 1 & -1 & 1 & 1 & -1 & Tc-96 > stable \\
\hline
\end{tabular}


RSAC-7.2 Nuclear Data Library

\begin{tabular}{|c|c|c|c|c|c|c|c|c|c|c|}
\hline 360970 & $1.49 \mathrm{E}-01$ & 1 & $\mathrm{~s}$ & 4.06E-05 & 1 & 0 & 3 & 0 & -0.3 & $\mathrm{Kr}-97>\mathrm{Rb}-971.0$ \\
\hline 370970 & $1.70 \mathrm{E}-01$ & 1 & $\mathrm{~s}$ & $3.64 \mathrm{E}-02$ & 1 & 0 & 1 & 1 & -0.3 & Rb-97 > Sr-97 1.0 \\
\hline 380970 & $4.26 \mathrm{E}-01$ & 1 & $\mathrm{~s}$ & \#\#\#\#\# & 1 & 0 & 1 & 2 & 0 & Sr-97 > Y-97 1.0 \\
\hline 390970 & $3.75 \mathrm{E}+00$ & 1 & $\mathrm{~s}$ & \#\#\#\#\#\# & 1 & 0 & 1 & 3 & 0 & $\mathrm{Y}-97>\mathrm{Zr}-97 \quad 1.0$ \\
\hline 400970 & $1.69 \mathrm{E}+01$ & 3 & $\mathrm{~h}$ & $8.74 \mathrm{E}-01$ & 1 & 0 & 1 & 4 & 0 & $\mathrm{Zr}-97>\mathrm{Nb}-97 \mathrm{~m} 1.0$ \\
\hline 410971 & $5.27 \mathrm{E}+01$ & 1 & $\mathrm{~s}$ & $6.86 \mathrm{E}-03$ & 1 & 0 & 1 & 5 & 0 & $\mathrm{Nb}-97 \mathrm{~m}>\mathrm{Nb}-971.0$ \\
\hline 410970 & $7.21 \mathrm{E}+01$ & 2 & $\mathrm{~m}$ & $1.68 \mathrm{E}-02$ & 1 & -1 & 1 & 6 & 0 & $\mathrm{Nb}-97>$ stable \\
\hline 430971 & $9.01 \mathrm{E}+01$ & 4 & $\mathrm{~d}$ & 0 & 1 & 1 & 1 & 0 & -1 & Tc-97m > Tc-97 1.0 \\
\hline 440970 & $2.83 \mathrm{E}+00$ & 4 & $\mathrm{~d}$ & 0 & 0.9992 & 0 & 1 & 0 & -1 & Ru-97 > Tc-97 0.9992 \\
\hline 430970 & $2.60 \mathrm{E}+06$ & 5 & $\mathrm{y}$ & 0 & 1 & -1 & 1 & 2 & -1 & Tc-97> stable \\
\hline 360980 & $2.24 \mathrm{E}-01$ & 1 & $\mathrm{~s}$ & 4.24E-06 & 1 & 0 & 3 & 0 & -0.3 & $\mathrm{Kr}-98>\mathrm{Rb}-981.0$ \\
\hline 370980 & $9.60 \mathrm{E}-02$ & 1 & $\mathrm{~s}$ & $5.26 \mathrm{E}-03$ & 1 & 0 & 1 & 1 & -0.3 & Rb-98 > Sr-98 1.0 \\
\hline 380980 & $6.53 \mathrm{E}-01$ & 1 & $\mathrm{~s}$ & $6.98 \mathrm{E}-01$ & 1 & 0 & 1 & 2 & -0.3 & Sr-98 > Y-98 1.0 \\
\hline 390980 & $2.00 \mathrm{E}+00$ & 1 & $\mathrm{~s}$ & \#\#\#\#\#\# & 1 & 0 & 1 & 3 & -0.3 & Y-98 > Zr-98 1.0 \\
\hline 400980 & $3.07 \mathrm{E}+01$ & 1 & $\mathrm{~s}$ & \#\#\#\#\#\# & 1 & 1 & 1 & 4 & -0.3 & Zr-98 > Nb-98 1.0 \\
\hline 410981 & $5.13 \mathrm{E}+01$ & 2 & $\mathrm{~m}$ & $2.72 \mathrm{E}-02$ & 1 & -1 & 1 & 0 & -0.3 & $\mathrm{Nb}-98 \mathrm{~m}>$ stable \\
\hline 410980 & $5.15 \mathrm{E}+01$ & 2 & $\mathrm{~m}$ & $4.48 \mathrm{E}-02$ & 1 & -1 & 1 & 6 & 0 & $\mathrm{Nb}-98>$ stable \\
\hline 430980 & $4.20 \mathrm{E}+06$ & 5 & $\mathrm{y}$ & 0 & 1 & -1 & 1 & 0 & -1 & Tc-98 > stable \\
\hline 370990 & $5.03 \mathrm{E}-02$ & 1 & $\mathrm{~s}$ & $4.06 \mathrm{E}-04$ & 1 & 0 & 1 & 0 & -0.3 & Rb-99 > Sr-99 1.0 \\
\hline 380990 & $2.69 \mathrm{E}-01$ & 1 & $\mathrm{~s}$ & $1.54 \mathrm{E}-01$ & 1 & 0 & 1 & 1 & -0.3 & Sr-99 > Y-99 1.0 \\
\hline 390990 & $1.47 \mathrm{E}+00$ & 1 & $\mathrm{~s}$ & \#\#\#\#\#\# & 1 & 0 & 1 & 2 & -0.3 & Y-99 > Zr-99 1.0 \\
\hline 400990 & $2.10 \mathrm{E}+00$ & 1 & $\mathrm{~s}$ & \#\#\#\#\#\# & 1 & 0 & 1 & 3 & 0 & Zr-99 > Nb-99m 1.0 \\
\hline 410991 & $2.60 \mathrm{E}+00$ & 2 & $\mathrm{~m}$ & $1.49 \mathrm{E}-01$ & 1 & 1 & 1 & 4 & 0 & Nb-99m > Mo-99 1.0 \\
\hline 410990 & $1.50 \mathrm{E}+01$ & 1 & $\mathrm{~s}$ & $1.37 \mathrm{E}-01$ & 1 & 0 & 1 & 5 & 0 & Nb-99 > Mo-99 1.0 \\
\hline 420990 & $6.59 \mathrm{E}+01$ & 3 & $\mathrm{~h}$ & $2.87 \mathrm{E}-03$ & 1 & 0 & 1 & 6 & 1.013 & Mo-99 > Tc-99m 1.0 \\
\hline 430991 & $6.02 \mathrm{E}+00$ & 3 & $\mathrm{~h}$ & $3.34 \mathrm{E}-07$ & 1 & 0 & 1 & 7 & 0 & Tc-99m > Tc-99 1.0 \\
\hline 430990 & $2.11 \mathrm{E}+05$ & 5 & $\mathrm{y}$ & $7.50 \mathrm{E}-02$ & 1 & -1 & 1 & 8 & 9.136 & Tc-99 > stable \\
\hline 450991 & $4.70 \mathrm{E}+00$ & 3 & $\mathrm{~h}$ & 0 & 1 & -1 & 1 & 0 & -1 & Rh-99m > stable \\
\hline 450990 & $1.61 \mathrm{E}+01$ & 4 & $\mathrm{~d}$ & 0 & 1 & -1 & 1 & 0 & -1 & Rh-99 > stable \\
\hline 371000 & $5.10 \mathrm{E}-02$ & 1 & $\mathrm{~s}$ & $1.70 \mathrm{E}-05$ & 1 & 0 & 1 & 0 & -0.3 & $\mathrm{Rb}-100>\mathrm{Sr}-1001.0$ \\
\hline 381000 & $2.02 \mathrm{E}-01$ & 1 & $\mathrm{~s}$ & $2.38 \mathrm{E}-02$ & 1 & 0 & 1 & 1 & -0.3 & Sr- $100>$ Y -1001.0 \\
\hline
\end{tabular}


RSAC-7.2 Nuclear Data Library

\begin{tabular}{|c|c|c|c|c|c|c|c|c|c|c|}
\hline 391000 & $9.40 \mathrm{E}-01$ & 1 & $\mathrm{~s}$ & 8.57E-01 & 1 & 0 & 1 & 2 & -0.3 & Y-100 > Zr-100 1.0 \\
\hline 401000 & $7.10 \mathrm{E}+00$ & 1 & $\mathrm{~s}$ & \#\#\#\#\#\# & 1 & 1 & 1 & 3 & -0.3 & $\mathrm{Zr}-100>\mathrm{Nb}-100$ \\
\hline 411001 & $2.99 \mathrm{E}+00$ & 1 & $\mathrm{~s}$ & 4.69E-01 & 1 & -1 & 1 & 4 & -0.3 & $\mathrm{Nb}-100 \mathrm{~m}>$ stable \\
\hline 411000 & $1.50 \mathrm{E}+00$ & 1 & $\mathrm{~s}$ & 4.69E-01 & 1 & -1 & 1 & 5 & -0.3 & $\mathrm{Nb}-100>$ stable \\
\hline 461000 & $3.63 \mathrm{E}+00$ & 4 & $\mathrm{~d}$ & 0 & 1 & -1 & 1 & 0 & -1 & Pd-100 > Rh-100 \\
\hline 451000 & $2.08 \mathrm{E}+01$ & 3 & $\mathrm{~h}$ & 0 & 1 & -1 & 1 & 0 & -1 & Rh-100 > stable \\
\hline 381010 & $1.18 \mathrm{E}-01$ & 1 & $\mathrm{~s}$ & $2.96 \mathrm{E}-03$ & 1 & 0 & 1 & 0 & -0.3 & Sr-101 > Y-101 1.0 \\
\hline 391010 & $4.48 \mathrm{E}-01$ & 1 & $\mathrm{~s}$ & $2.69 \mathrm{E}-01$ & 1 & 0 & 1 & 1 & -0.3 & Y-101 > Zr-101 1.0 \\
\hline 401010 & $2.30 \mathrm{E}+00$ & 1 & $\mathrm{~s}$ & \#\#\#\#\#\# & 1 & 0 & 1 & 2 & -0.3 & $\mathrm{Zr}-101>\mathrm{Nb}-1011.0$ \\
\hline 411010 & $7.10 \mathrm{E}+00$ & 1 & $\mathrm{~s}$ & \#\#\#\#\#\# & 1 & 0 & 1 & 3 & 0 & $\mathrm{Nb}-101>\mathrm{Mo}-1011.0$ \\
\hline 421010 & $1.46 \mathrm{E}+01$ & 2 & $\mathrm{~m}$ & $1.12 \mathrm{E}-01$ & 1 & 0 & 1 & 4 & 0 & Mo-101 > Tc-101 1.0 \\
\hline 431010 & $1.42 \mathrm{E}+01$ & 2 & $\mathrm{~m}$ & $2.34 \mathrm{E}-04$ & 1 & -1 & 1 & 5 & 0 & Tc-101 > stable \\
\hline 461010 & $8.47 \mathrm{E}+00$ & 3 & $\mathrm{~h}$ & 0 & 0.997 & 0 & 1 & 0 & -1 & Pd-101 > Rh-101 .997 \\
\hline 451011 & $4.34 \mathrm{E}+00$ & 4 & $\mathrm{~d}$ & 0 & 0.072 & 0 & 1 & 1 & -1 & Rh-101m> Rh-101 0.072 \\
\hline 451010 & $3.30 \mathrm{E}+00$ & 5 & $\mathrm{y}$ & 0 & 1 & -1 & 1 & 2 & -1 & Rh-101 > stable \\
\hline 381020 & $6.90 \mathrm{E}-02$ & 1 & $\mathrm{~s}$ & $1.97 \mathrm{E}-04$ & 1 & 0 & 1 & 0 & -0.3 & Sr-102 > Y-102 1.0 \\
\hline 391020 & $3.60 \mathrm{E}-01$ & 1 & $\mathrm{~s}$ & $5.37 \mathrm{E}-02$ & 1 & 0 & 1 & 1 & -0.3 & $\mathrm{Y}-102>\mathrm{Zr}-1021.0$ \\
\hline 401020 & $2.90 \mathrm{E}+00$ & 1 & $\mathrm{~s}$ & \#\#\#\#\#\# & 1 & 0 & 1 & 2 & -0.3 & $\mathrm{Zr}-102>\mathrm{Nb}-1021.0$ \\
\hline 411020 & $4.30 \mathrm{E}+00$ & 1 & $\mathrm{~s}$ & \#\#\#\#\#\# & 1 & 0 & 1 & 3 & -0.3 & $\mathrm{Nb}-102>\mathrm{Mo}-1021.0$ \\
\hline 421020 & $1.13 \mathrm{E}+01$ & 2 & $\mathrm{~m}$ & 4.14E-01 & 1 & 1 & 1 & 4 & -0.3 & Mo-102 > Tc-102 1.0 \\
\hline 431021 & $4.35 \mathrm{E}+00$ & 2 & $\mathrm{~m}$ & $1.29 \mathrm{E}-03$ & 0.5 & 0 & 1 & 5 & 0 & Tc- $102 \mathrm{~m}>$ Tc- 102.5 \\
\hline 431020 & $5.28 \mathrm{E}+00$ & 1 & $\mathrm{~s}$ & $1.29 \mathrm{E}-03$ & 1 & -1 & 1 & 6 & 0 & Tc-102 > stable \\
\hline 471020 & $7.70 \mathrm{E}+00$ & 2 & $\mathrm{~m}$ & 0 & 1 & -1 & 1 & 0 & -1 & Ag-102 > stable \\
\hline 451021 & $3.74 \mathrm{E}+00$ & 5 & $\mathrm{y}$ & 0 & 0.05 & 0 & 1 & 0 & -1 & Rh-102m> Rh-102 0.05 \\
\hline 451020 & $2.07 \mathrm{E}+02$ & 4 & $\mathrm{~d}$ & 0 & 1 & -1 & 1 & 1 & -1 & Rh-102 > stable \\
\hline 381030 & $1.39 \mathrm{E}-01$ & 1 & $\mathrm{~s}$ & $4.80 \mathrm{E}-06$ & 1 & 0 & 1 & 0 & -0.3 & Sr-103 > Y-103 1.0 \\
\hline 391030 & $2.30 \mathrm{E}-01$ & 1 & $\mathrm{~s}$ & $5.34 \mathrm{E}-03$ & 1 & 0 & 1 & 1 & -0.3 & Y-103 > Zr-103 1.0 \\
\hline 401030 & $1.30 \mathrm{E}+00$ & 1 & $\mathrm{~s}$ & $5.26 \mathrm{E}-01$ & 1 & 0 & 1 & 2 & -0.3 & Zr-103 > Nb-103 1.0 \\
\hline 411030 & $1.50 \mathrm{E}+00$ & 1 & $\mathrm{~s}$ & \#\#\#\#\#\# & 1 & 0 & 1 & 3 & -0.3 & $\mathrm{Nb}-103>\mathrm{Mo}-1031.0$ \\
\hline 421030 & $6.75 \mathrm{E}+01$ & 1 & $\mathrm{~s}$ & $9.23 \mathrm{E}-01$ & 1 & 0 & 1 & 4 & -0.3 & Mo-103 > Tc-103 1.0 \\
\hline 431030 & $5.42 \mathrm{E}+01$ & 1 & $\mathrm{~s}$ & $1.80 \mathrm{E}-02$ & 1 & 2 & 1 & 5 & -0.3 & Tc-103 > Ru-103 1.0 \\
\hline
\end{tabular}


RSAC-7.2 Nuclear Data Library

\begin{tabular}{|c|c|c|c|c|c|c|c|c|c|c|}
\hline 471030 & $6.57 \mathrm{E}+01$ & 2 & $\mathrm{~m}$ & 0 & 1 & 0 & 1 & 0 & -1 & Ag-103 > Pd-103 \\
\hline 461030 & $1.70 \mathrm{E}+01$ & 4 & $\mathrm{~d}$ & 0 & 1 & -1 & 1 & 1 & -1 & Pd-103 > Stable \\
\hline 441030 & $3.92 \mathrm{E}+01$ & 4 & $\mathrm{~d}$ & 4.00E-05 & 0.9006 & 0 & 5 & 8 & 2.666 & $\mathrm{Ru}-103>\mathrm{Rh}-103 \mathrm{~m} .9006$ \\
\hline 451031 & $5.61 \mathrm{E}+01$ & 2 & $\mathrm{~m}$ & $1.05 \mathrm{E}-09$ & 1 & -1 & 1 & 9 & 0 & Rh-103m $>$ stable \\
\hline 471060 & $2.40 \mathrm{E}+01$ & 2 & $\mathrm{~m}$ & 0 & 1 & -1 & 1 & 0 & -1 & Ag-106 > stable \\
\hline 471061 & $8.28 \mathrm{E}+00$ & 4 & $\mathrm{~d}$ & 0 & 1 & -1 & 1 & 0 & -1 & Ag-106m $>$ stable \\
\hline 381040 & $1.93 \mathrm{E}-01$ & 1 & $\mathrm{~s}$ & $8.23 \mathrm{E}-08$ & 1 & 0 & 1 & 0 & -0.3 & Sr-104 > Y-104 1.0 \\
\hline 391040 & $1.44 \mathrm{E}-01$ & 1 & $\mathrm{~s}$ & $2.54 \mathrm{E}-04$ & 1 & 0 & 1 & 1 & -0.3 & Y-104 > Zr-104 1.0 \\
\hline 401040 & $1.20 \mathrm{E}+00$ & 1 & $\mathrm{~s}$ & $8.01 \mathrm{E}-02$ & 1 & 0 & 1 & 2 & -0.3 & $\mathrm{Zr}-104>\mathrm{Nb}-1041.0$ \\
\hline 411040 & $4.80 \mathrm{E}+00$ & 1 & $\mathrm{~s}$ & 7.32E-01 & 1 & 0 & 1 & 3 & -0.3 & $\mathrm{Nb}-104>\mathrm{Mo}-1041.0$ \\
\hline 421040 & $6.00 \mathrm{E}+01$ & 1 & $\mathrm{~s}$ & \#\#\#\#\#\# & 1 & 0 & 1 & 4 & -0.3 & Mo-104 > Tc-104 1.0 \\
\hline 431040 & $1.83 \mathrm{E}+01$ & 2 & $\mathrm{~m}$ & $5.75 \mathrm{E}-02$ & 1 & -1 & 1 & 5 & 0 & Tc-104 > stable \\
\hline 481040 & $5.77 \mathrm{E}+01$ & 2 & $\mathrm{~m}$ & 0 & 1 & 1 & 1 & 0 & -1 & Cd-104 > Ag-104 1.0 \\
\hline 471041 & $3.35 \mathrm{E}+01$ & 2 & $\mathrm{~m}$ & 0 & 0.33 & 0 & 1 & 0 & -1 & Ag-104m>Ag-104 .33 \\
\hline 471040 & $6.92 \mathrm{E}+01$ & 2 & $\mathrm{~m}$ & 0 & 1 & -1 & 1 & 2 & -1 & Ag-104 > stable \\
\hline 391050 & $1.74 \mathrm{E}-01$ & 1 & $\mathrm{~s}$ & $2.25 \mathrm{E}-05$ & 1 & 0 & 1 & 0 & -0.3 & Y-105 > Zr-105 1.0 \\
\hline 401050 & $6.00 \mathrm{E}-01$ & 1 & $\mathrm{~s}$ & $1.03 \mathrm{E}-02$ & 1 & 0 & 1 & 1 & -0.3 & $\mathrm{Zr}-105>\mathrm{Nb}-1051.0$ \\
\hline 411050 & $2.95 \mathrm{E}+00$ & 1 & $\mathrm{~s}$ & $2.03 \mathrm{E}-01$ & 1 & 0 & 1 & 2 & -0.3 & Nb-105 > Mo-105 1.0 \\
\hline 421050 & $3.56 \mathrm{E}+01$ & 1 & $\mathrm{~s}$ & $7.21 \mathrm{E}-01$ & 1 & 0 & 1 & 3 & -0.3 & Mo-105 > Tc-105 1.0 \\
\hline 431050 & $7.60 \mathrm{E}+00$ & 2 & $\mathrm{~m}$ & $9.69 \mathrm{E}-02$ & 1 & 0 & 1 & 4 & -0.3 & Tc-105 > Ru-105 1.0 \\
\hline 441050 & $4.44 \mathrm{E}+00$ & 3 & $\mathrm{~h}$ & $2.34 \mathrm{E}-03$ & 1 & 1 & 5 & 5 & $2.91 \mathrm{E}-01$ & Ru-105 > Rh-105 1.0 \\
\hline 451051 & $4.00 \mathrm{E}+01$ & 1 & $\mathrm{~s}$ & $7.30 \mathrm{E}-07$ & 0.8 & 0 & 1 & 6 & 0 & Rh-105m $>$ Rh-105.800 \\
\hline 451050 & $3.54 \mathrm{E}+01$ & 3 & $\mathrm{~h}$ & $5.20 \mathrm{E}-03$ & 1 & -1 & 1 & 7 & $2.80 \mathrm{E}-01$ & Rh-105 > stable \\
\hline 471050 & $4.13 \mathrm{E}+01$ & 4 & $\mathrm{~d}$ & 0 & 1 & -1 & 1 & 0 & -1 & Ag-105 > stable \\
\hline 401060 & $9.80 \mathrm{E}-01$ & 1 & $\mathrm{~s}$ & $2.48 \mathrm{E}-03$ & 1 & 0 & 1 & 0 & -0.3 & $\mathrm{Zr}-106>\mathrm{Nb}-1061.0$ \\
\hline 411060 & $1.02 \mathrm{E}+00$ & 1 & $\mathrm{~s}$ & $7.00 \mathrm{E}-02$ & 1 & 0 & 1 & 1 & -0.3 & $\mathrm{Nb}-106>\mathrm{Mo}-1061.0$ \\
\hline 421060 & $8.40 \mathrm{E}+00$ & 1 & $\mathrm{~s}$ & $2.94 \mathrm{E}-01$ & 1 & 0 & 1 & 2 & -0.3 & Mo-106 > Tc-106 1.0 \\
\hline 431060 & $3.56 \mathrm{E}+01$ & 1 & $\mathrm{~s}$ & $4.98 \mathrm{E}-02$ & 1 & 0 & 1 & 3 & -0.3 & Tc-106 > Ru-106 1.0 \\
\hline 441060 & $3.72 \mathrm{E}+02$ & 4 & $\mathrm{~d}$ & $1.20 \mathrm{E}-03$ & 1 & 3 & 5 & 4 & $7.71 \mathrm{E}-01$ & Ru-106 > Rh-106 1.0 \\
\hline 450010 & $1.00 \mathrm{E}+23$ & 5 & $\mathrm{y}$ & $2.70 \mathrm{E}-02$ & 1 & 0 & 1 & 5 & -2 & pseudo \\
\hline 450020 & $8.80 \mathrm{E}+16$ & 5 & $\mathrm{y}$ & $9.00 \mathrm{E}-04$ & 1 & 0 & 1 & 6 & -2 & pseudo \\
\hline
\end{tabular}


RSAC-7.2 Nuclear Data Library

\begin{tabular}{|c|c|c|c|c|c|c|c|c|c|c|}
\hline 451061 & $1.31 \mathrm{E}+02$ & 2 & $\mathrm{~m}$ & $3.40 \mathrm{E}-03$ & 1 & -1 & 1 & 7 & 0 & Rh- $106 \mathrm{~m}>$ stable 1.0 \\
\hline 451060 & $3.01 \mathrm{E}+01$ & 1 & $\mathrm{~s}$ & $8.30 \mathrm{E}-03$ & 0.7519 & -1 & 1 & 8 & 0 & Rh-106 > stable \\
\hline 391070 & $1.05 \mathrm{E}-01$ & 1 & $\mathrm{~s}$ & 3.74E-08 & 1 & 0 & 1 & 0 & -0.3 & Y-107 > Zr-107 1.0 \\
\hline 401070 & $2.49 \mathrm{E}-01$ & 1 & $\mathrm{~s}$ & $1.19 \mathrm{E}-04$ & 1 & 0 & 1 & 1 & -0.3 & $\mathrm{Zr}-107>\mathrm{Nb}-1071.0$ \\
\hline 411070 & $3.30 \mathrm{E}-01$ & 1 & $\mathrm{~s}$ & $1.14 \mathrm{E}-02$ & 1 & 0 & 1 & 2 & -0.3 & $\mathrm{Nb}-107>\mathrm{Mo}-1071.0$ \\
\hline 421070 & $3.50 \mathrm{E}+00$ & 1 & $\mathrm{~s}$ & $1.24 \mathrm{E}-01$ & 1 & 0 & 1 & 3 & -0.3 & Mo-107 > Tc-107 1.0 \\
\hline 431070 & $2.12 \mathrm{E}+01$ & 1 & $\mathrm{~s}$ & $5.38 \mathrm{E}-02$ & 1 & 0 & 1 & 4 & -0.3 & Tc-107 > Ru-107 1.0 \\
\hline 441070 & $3.75 \mathrm{E}+00$ & 2 & $\mathrm{~m}$ & 4.94E-06 & 1 & 0 & 1 & 5 & -0.3 & Ru-107 > Rh-107 1.0 \\
\hline 451070 & $2.17 \mathrm{E}+01$ & 2 & $\mathrm{~m}$ & $7.24 \mathrm{E}-06$ & 1 & 2 & 1 & 6 & 0 & Rh-107 > Pd-107 1.0 \\
\hline 460010 & $1.10 \mathrm{E}+21$ & 5 & $\mathrm{y}$ & $2.10 \mathrm{E}-05$ & 1 & 0 & 1 & 7 & -2 & pseudo \\
\hline 461071 & $2.13 \mathrm{E}+01$ & 1 & $\mathrm{~s}$ & $7.64 \mathrm{E}-10$ & 1 & 0 & 1 & 8 & 0 & Pd-107m $>$ Pd-107 1.0 \\
\hline 461070 & $6.50 \mathrm{E}+06$ & 5 & $\mathrm{y}$ & $7.40 \mathrm{E}-10$ & 1 & -1 & 1 & 9 & 2.816 & Pd-107 > stable \\
\hline 481070 & $6.50 \mathrm{E}+00$ & 3 & $\mathrm{~h}$ & 0 & 1 & -1 & 1 & 0 & -1 & Cd-107 > stable \\
\hline 401080 & $4.08 \mathrm{E}-01$ & 1 & $\mathrm{~s}$ & $2.64 \mathrm{E}-06$ & 1 & 0 & 1 & 0 & -0.3 & $\mathrm{Zr}-108>\mathrm{Nb}-1081.0$ \\
\hline 411080 & $1.93 \mathrm{E}-01$ & 1 & $\mathrm{~s}$ & 8.49E-04 & 1 & 0 & 1 & 1 & -0.3 & Nb-108> Mo-108 1.0 \\
\hline 421080 & $1.09 \mathrm{E}+00$ & 1 & $\mathrm{~s}$ & $3.27 \mathrm{E}-02$ & 1 & 0 & 1 & 2 & -0.3 & Mo-108 > Tc-108 1.0 \\
\hline 431080 & $5.17 \mathrm{E}+00$ & 1 & $\mathrm{~s}$ & 4.64E-02 & 1 & 0 & 1 & 3 & -0.3 & Tc-108 > Ru-108 1.0 \\
\hline 441080 & $4.55 \mathrm{E}+00$ & 2 & $\mathrm{~m}$ & $1.15 \mathrm{E}-02$ & 1 & 2 & 5 & 4 & 0 & Ru-108 > Rh-108 1.0 \\
\hline 450030 & $1.00 \mathrm{E}+19$ & 5 & $\mathrm{y}$ & $2.00 \mathrm{E}-05$ & 1 & 0 & 1 & 0 & -2 & pseudo \\
\hline 451081 & $6.00 \mathrm{E}+00$ & 2 & $\mathrm{~m}$ & $4.58 \mathrm{E}-05$ & 1 & -1 & 1 & 1 & 0 & Rh- $108 \mathrm{~m}>$ stable \\
\hline 451080 & $1.68 \mathrm{E}+01$ & 1 & $\mathrm{~s}$ & $4.58 \mathrm{E}-05$ & 1 & -1 & 1 & 0 & 0 & Rh-108> stable \\
\hline 471081 & $4.38 \mathrm{E}+02$ & 5 & $\mathrm{y}$ & 0 & 0.0869 & 0 & 1 & 0 & -1 & Ag-108m> Ag-108 0.089 \\
\hline 471080 & $2.38 \mathrm{E}+00$ & 2 & $\mathrm{~m}$ & 0 & 1 & -1 & 1 & 1 & -1 & Ag-108 > stable \\
\hline 401090 & $1.39 \mathrm{E}-01$ & 1 & $\mathrm{~s}$ & $1.75 \mathrm{E}-08$ & 1 & 0 & 1 & 0 & -0.3 & Zr-109> Nb-109 1.0 \\
\hline 411090 & $1.90 \mathrm{E}-01$ & 1 & $\mathrm{~s}$ & $2.62 \mathrm{E}-05$ & 1 & 0 & 1 & 1 & -0.3 & Nb-109> Mo-109 1.0 \\
\hline 421090 & $5.30 \mathrm{E}-01$ & 1 & $\mathrm{~s}$ & 4.05E-03 & 1 & 0 & 1 & 2 & -0.3 & Mo-109 > Tc-109 1.0 \\
\hline 431090 & $8.70 \mathrm{E}-01$ & 1 & $\mathrm{~s}$ & $2.10 \mathrm{E}-02$ & 1 & 0 & 1 & 3 & -0.3 & Tc-109 > Ru-109 1.0 \\
\hline 441090 & $3.45 \mathrm{E}+01$ & 1 & $\mathrm{~s}$ & $1.89 \mathrm{E}-02$ & 1 & 1 & 5 & 4 & -0.3 & Ru-109 > Rh-109 1.0 \\
\hline 451091 & $5.00 \mathrm{E}+01$ & 1 & $\mathrm{~s}$ & $3.17 \mathrm{E}-04$ & 1 & 0 & 1 & 5 & -0.3 & Rh-109m> Rh-109 1.0 \\
\hline 451090 & $8.00 \mathrm{E}+01$ & 1 & $\mathrm{~s}$ & $3.17 \mathrm{E}-04$ & 1 & 2 & 1 & 6 & -0.3 & Rh-109 > Pd-109 1.0 \\
\hline 461091 & 4.69E +00 & 2 & $\mathrm{~m}$ & $1.30 \mathrm{E}-06$ & 1 & 1 & 1 & 7 & 0 & Pd-109m> Pd-109 1.0 \\
\hline
\end{tabular}




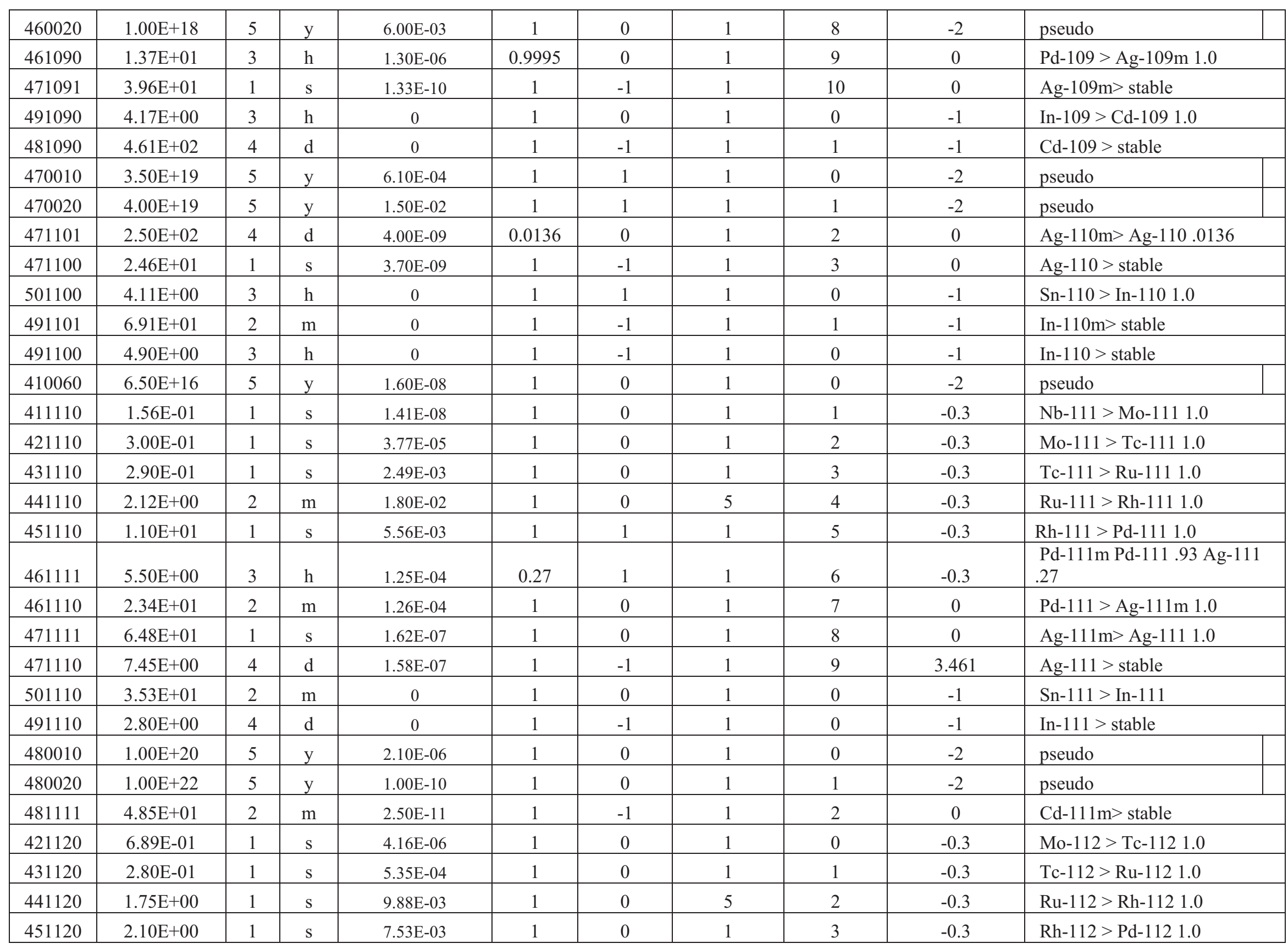




\begin{tabular}{|c|c|c|c|c|c|c|c|c|c|c|}
\hline 461120 & $2.10 \mathrm{E}+01$ & 3 & $\mathrm{~h}$ & $8.99 \mathrm{E}-04$ & 1 & 0 & 1 & 4 & 0 & Pd-112 > Ag-112 1.0 \\
\hline 471120 & $3.13 \mathrm{E}+00$ & 3 & $\mathrm{~h}$ & $1.70 \mathrm{E}-04$ & 1 & -1 & 1 & 5 & 0 & Ag-112 > stable \\
\hline 491120 & $1.50 \mathrm{E}+01$ & 2 & $\mathrm{~m}$ & 0 & 1 & -1 & 1 & 0 & 0 & In-112 > stable \\
\hline 501130 & $1.15 \mathrm{E}+02$ & 4 & $\mathrm{~d}$ & 0 & 1 & -1 & 1 & 0 & -1 & Sn-113 > Stable \\
\hline 491131 & $1.66 \mathrm{E}+00$ & 3 & $\mathrm{~h}$ & 0 & 1 & -1 & 1 & 1 & -1 & In- $113 \mathrm{~m}>$ stable \\
\hline 421130 & $1.97 \mathrm{E}-01$ & 1 & $\mathrm{~s}$ & $2.70 \mathrm{E}-07$ & 1 & 0 & 1 & 0 & -0.3 & Mo-113 > Tc-113 1.0 \\
\hline 431130 & $1.30 \mathrm{E}-01$ & 1 & $\mathrm{~s}$ & $1.13 \mathrm{E}-04$ & 1 & 0 & 1 & 1 & -0.3 & Tc-113 > Ru-113 1.0 \\
\hline 441130 & $8.00 \mathrm{E}-01$ & 1 & $\mathrm{~s}$ & $5.50 \mathrm{E}-03$ & 1 & 0 & 5 & 2 & -0.3 & Ru-113 > Rh-113 1.0 \\
\hline 451130 & $2.80 \mathrm{E}+00$ & 1 & $\mathrm{~s}$ & $9.75 \mathrm{E}-03$ & 1 & 0 & 1 & 3 & -0.3 & Rh-113> Pd-113 1.0 \\
\hline 461130 & $9.30 \mathrm{E}+01$ & 1 & $\mathrm{~s}$ & $3.02 \mathrm{E}-03$ & 0.9 & 1 & 1 & 4 & -0.3 & Pd-113 Ag-113m .1 Ag-113.9 \\
\hline 471131 & $6.87 \mathrm{E}+01$ & 1 & $\mathrm{~s}$ & $1.52 \mathrm{E}-05$ & 1 & 0 & 1 & 5 & -0.3 & Ag-113m $>$ stable \\
\hline 471130 & $5.37 \mathrm{E}+00$ & 3 & $\mathrm{~h}$ & $1.52 \mathrm{E}-05$ & 0.13 & 0 & 1 & 6 & -0.3 & Ag-113 > stable \\
\hline 481131 & $1.41 \mathrm{E}+01$ & 5 & $\mathrm{y}$ & 0 & 1 & -1 & 1 & 7 & -1 & Cd-113m $>$ stable \\
\hline 481130 & $7.70 \mathrm{E}+15$ & 5 & $\mathrm{y}$ & 0 & 1 & -1 & 1 & 0 & -1 & Cd-113 > stable \\
\hline 421140 & $3.22 \mathrm{E}-01$ & 1 & $\mathrm{~s}$ & $1.73 \mathrm{E}-08$ & 1 & 0 & 1 & 0 & -0.3 & Mo-114 > Tc-114 1.0 \\
\hline 431140 & $1.73 \mathrm{E}-01$ & 1 & $\mathrm{~s}$ & $1.63 \mathrm{E}-05$ & 1 & 0 & 1 & 1 & -0.3 & Tc-114 > Ru-114 1.0 \\
\hline 441140 & $5.30 \mathrm{E}-01$ & 1 & $\mathrm{~s}$ & $2.04 \mathrm{E}-03$ & 1 & 0 & 5 & 2 & -0.3 & Ru-114 > Rh-114 1.0 \\
\hline 451140 & $1.85 \mathrm{E}+00$ & 1 & $\mathrm{~s}$ & $8.64 \mathrm{E}-03$ & 1 & 0 & 1 & 3 & -0.3 & Rh-114 > Pd-114 1.0 \\
\hline 461140 & $2.42 \mathrm{E}+00$ & 2 & $\mathrm{~m}$ & $6.39 \mathrm{E}-03$ & 1 & 0 & 1 & 4 & -0.3 & Pd-114 > Ag-114 1.0 \\
\hline 471140 & $4.60 \mathrm{E}+00$ & 1 & $\mathrm{~s}$ & $1.67 \mathrm{E}-04$ & 1 & -1 & 1 & 5 & 0 & Ag-114 > stable \\
\hline 491141 & $4.95 \mathrm{E}+01$ & 4 & $\mathrm{~d}$ & 0 & 0.957 & 0 & 1 & 0 & -1 & In-114m $>$ In-114 0.957 \\
\hline 491140 & $7.19 \mathrm{E}+01$ & 1 & $\mathrm{~s}$ & 0 & 1 & -1 & 1 & 1 & -1 & In-114 > stable \\
\hline 461150 & $5.00 \mathrm{E}+01$ & 1 & $\mathrm{~s}$ & $1.51 \mathrm{E}-02$ & 0.73 & 0 & 1 & 0 & -0.3 & Pd-115 > Ag-115 .73 \\
\hline 471150 & $2.00 \mathrm{E}+01$ & 2 & $\mathrm{~m}$ & $4.67 \mathrm{E}-04$ & 0.0001 & 0 & 1 & 1 & 0 & Ag-115 > Cd-115m .0001 \\
\hline 481151 & $4.46 \mathrm{E}+01$ & 4 & $\mathrm{~d}$ & $1.46 \mathrm{E}-03$ & 1 & 3 & 1 & 2 & 8.225 & Cd-115m $>$ stable \\
\hline 491150 & $4.41 \mathrm{E}+14$ & 5 & $\mathrm{y}$ & 0 & 1 & -1 & 1 & 0 & -1 & In-115 > stable \\
\hline 511150 & $3.21 \mathrm{E}+01$ & 2 & $\mathrm{~m}$ & 0 & 1 & -1 & 1 & 0 & -1 & Sb-115 > stable \\
\hline 481150 & $5.35 \mathrm{E}+01$ & 3 & $\mathrm{~h}$ & $1.46 \mathrm{E}-02$ & 1 & 0 & 1 & 0 & 0 & Cd-115 > In-115m \\
\hline 491151 & $4.49 \mathrm{E}+00$ & 3 & $\mathrm{~h}$ & $4.05 \mathrm{E}-05$ & 1 & -1 & 1 & 1 & 0 & In- $115 \mathrm{~m}>$ stable \\
\hline 491161 & $5.43 \mathrm{E}+01$ & 2 & $\mathrm{~m}$ & 0 & 1 & -1 & 1 & 0 & -1 & In-116m $>$ stable \\
\hline 521160 & $2.49 \mathrm{E}+00$ & 3 & $\mathrm{~h}$ & 0 & 1 & 1 & 1 & 0 & -1 & Te-116 > Sb-116 1.0 \\
\hline
\end{tabular}




\begin{tabular}{|c|c|c|c|c|c|c|c|c|c|c|}
\hline 511161 & $6.03 \mathrm{E}+01$ & 2 & $\mathrm{~m}$ & 0 & 1 & -1 & 1 & 0 & -1 & Sb-116m> stable \\
\hline 511160 & $1.58 \mathrm{E}+01$ & 2 & $\mathrm{~m}$ & 0 & 1 & -1 & 1 & 0 & -1 & Sb-116 > stable \\
\hline 481171 & $3.36 \mathrm{E}+00$ & 3 & $\mathrm{~h}$ & $4.55 \mathrm{E}-03$ & 1 & 2 & 1 & 0 & 0 & $\mathrm{Cd}-117 \mathrm{~m}>\mathrm{Cd}-117$ \\
\hline 500010 & $1.00 \mathrm{E}+18$ & 5 & $\mathrm{y}$ & $2.20 \mathrm{E}-03$ & 1 & 0 & 1 & 0 & -2 & pseudo $>$ pseudo \\
\hline 500020 & $1.00 \mathrm{E}+24$ & 5 & $\mathrm{y}$ & $3.00 \mathrm{E}-04$ & 1 & 4 & 1 & 1 & -2 & pseudo $>$ Sb-117 \\
\hline 481170 & $2.49 \mathrm{E}+00$ & 3 & $\mathrm{~h}$ & $2.56 \mathrm{E}-03$ & 0.1 & 1 & 1 & 3 & 0 & Cd-117 In-117m .1 In-117.9 \\
\hline 491171 & $1.16 \mathrm{E}+02$ & 2 & $\mathrm{~m}$ & $1.00 \mathrm{E}-02$ & 0.47 & 0 & 1 & 4 & $9.20 \mathrm{E}-01$ & In-117m $>$ In-117 .47 \\
\hline 491170 & $4.32 \mathrm{E}+01$ & 2 & $\mathrm{~m}$ & $6.33 \mathrm{E}-10$ & 1 & 0 & 1 & 5 & $9.20 \mathrm{E}-01$ & In-117 > Sn-117m \\
\hline 501171 & $1.36 \mathrm{E}+01$ & 4 & $\mathrm{~d}$ & \#\#\#\#\#\# & 1 & -1 & 1 & 6 & 0 & Sn- $117 m>$ stable \\
\hline 511170 & $2.80 \mathrm{E}+00$ & 3 & $\mathrm{~h}$ & 0 & 1 & -1 & 1 & 0 & -1 & Sb-117> stable \\
\hline 440010 & $7.50 \mathrm{E}+16$ & 5 & $\mathrm{y}$ & $3.90 \mathrm{E}-06$ & 1 & 0 & 5 & 0 & -2 & pseudo $>$ Ru-118 \\
\hline 441180 & $6.16 \mathrm{E}-01$ & 1 & $\mathrm{~s}$ & $8.44 \mathrm{E}-07$ & 1 & 0 & 5 & 1 & -0.3 & Ru-118 > Rh-118 1.0 \\
\hline 451180 & $2.95 \mathrm{E}-01$ & 1 & $\mathrm{~s}$ & $2.32 \mathrm{E}-04$ & 1 & 0 & 1 & 2 & -0.3 & $\mathrm{Rh}-118>\mathrm{Pd}-118$ \\
\hline 461180 & $1.90 \mathrm{E}+00$ & 1 & $\mathrm{~S}$ & $6.38 \mathrm{E}-03$ & 1 & 0 & 1 & 3 & -0.3 & Pd-118> Ag-118m 1.0 \\
\hline 471181 & $2.00 \mathrm{E}+00$ & 1 & $\mathrm{~s}$ & $3.58 \mathrm{E}-03$ & 0.59 & 1 & 1 & 4 & -0.3 & $\begin{array}{l}\text { Ag-118m Ag-118.41 Cd-118 } \\
.59\end{array}$ \\
\hline 471180 & $3.76 \mathrm{E}+00$ & 1 & $\mathrm{~s}$ & $6.57 \mathrm{E}-03$ & 1 & 0 & 1 & 5 & -0.3 & Ag-118 > Cd-118.59 \\
\hline 481180 & $5.03 \mathrm{E}+01$ & 2 & $\mathrm{~m}$ & $1.38 \mathrm{E}-03$ & 1 & 1 & 1 & 6 & -0.3 & Cd-118 In-118 1.0 \\
\hline 491181 & $4.45 \mathrm{E}+00$ & 2 & $\mathrm{~m}$ & 4.15E-06 & 1 & -1 & 1 & 7 & 0 & In- $118 \mathrm{~m}>$ stable 1.0 \\
\hline 491180 & $5.00 \mathrm{E}+00$ & 1 & $\mathrm{~S}$ & 4.15E-06 & 1 & -1 & 1 & 8 & 0 & In-118 > stable \\
\hline 511181 & $5.00 \mathrm{E}+00$ & 3 & $\mathrm{~h}$ & 0 & 1 & -1 & 1 & 0 & 0 & Sb-118m $>$ stable \\
\hline 451190 & $4.48 \mathrm{E}-01$ & 1 & $\mathrm{~s}$ & 4.17E-05 & 1 & 0 & 1 & 0 & -0.3 & Rh-119> Pd-119 1.0 \\
\hline 461190 & $9.20 \mathrm{E}-01$ & 1 & $\mathrm{~s}$ & $3.39 \mathrm{E}-03$ & 1 & 0 & 1 & 1 & -0.3 & Pd-119 > Ag-119 1.0 \\
\hline 471190 & $2.10 \mathrm{E}+00$ & 1 & $\mathrm{~S}$ & $9.26 \mathrm{E}-03$ & 1 & 0 & 1 & 2 & -0.3 & Ag-119> Cd-119 1.0 \\
\hline 481190 & $2.69 \mathrm{E}+00$ & 2 & $\mathrm{~m}$ & $2.23 \mathrm{E}-03$ & 0.1 & 1 & 1 & 3 & -0.3 & Cd-119 > In-119m 1.0 \\
\hline 491191 & $1.80 \mathrm{E}+01$ & 2 & $\mathrm{~m}$ & $1.59 \mathrm{E}-05$ & 0.025 & 0 & 1 & 4 & -0.3 & In-119m $>$ stable \\
\hline 491190 & $2.40 \mathrm{E}+00$ & 2 & $\mathrm{~m}$ & 4.72E-04 & 1 & -1 & 1 & 5 & -0.3 & In-119 > stable \\
\hline 501191 & $2.93 \mathrm{E}+02$ & 4 & $\mathrm{~d}$ & $2.65 \mathrm{E}-04$ & 1 & -1 & 1 & 0 & 0 & Sn-119m $>$ stable \\
\hline 511190 & $3.82 \mathrm{E}+01$ & 3 & $\mathrm{~h}$ & 0 & 1 & -1 & 1 & 0 & -1 & Sb-119 > stable \\
\hline 441200 & $2.93 \mathrm{E}-01$ & 1 & $\mathrm{~s}$ & 3.07E-09 & 1 & 0 & 5 & 0 & -0.3 & Ru-120> Rh-120 1.0 \\
\hline 451200 & $1.62 \mathrm{E}-01$ & 1 & $\mathrm{~S}$ & $5.48 \mathrm{E}-06$ & 1 & 0 & 1 & 1 & -0.3 & Rh-120 > Pd-120 1.0 \\
\hline 461200 & $5.00 \mathrm{E}-01$ & 1 & $\mathrm{~s}$ & $1.14 \mathrm{E}-03$ & 1 & 0 & 1 & 2 & -0.3 & Pd-120 > Ag-120 1.0 \\
\hline
\end{tabular}


RSAC-7.2 Nuclear Data Library

\begin{tabular}{|c|c|c|c|c|c|c|c|c|c|c|}
\hline 471200 & $3.20 \mathrm{E}-01$ & 1 & $\mathrm{~s}$ & $7.65 \mathrm{E}-03$ & 1 & 0 & 1 & 3 & -0.3 & Ag-120 > Cd-120 1.0 \\
\hline 481200 & $5.08 \mathrm{E}+01$ & 1 & $\mathrm{~s}$ & $8.71 \mathrm{E}-03$ & 1 & 1 & 1 & 4 & -0.3 & Cd-120> In-120 1.0 \\
\hline 491201 & $4.62 \mathrm{E}+01$ & 1 & $\mathrm{~s}$ & $1.85 \mathrm{E}-04$ & 1 & -1 & 1 & 5 & $1.48 \mathrm{E}-03$ & In-120m $>$ stable \\
\hline 491200 & $3.08 \mathrm{E}+00$ & 1 & $\mathrm{~s}$ & $1.85 \mathrm{E}-04$ & 1 & -1 & 1 & 6 & $1.48 \mathrm{E}-03$ & In-120 > stable \\
\hline 511203 & $5.76 \mathrm{E}+00$ & 4 & $\mathrm{~d}$ & 0 & 1 & -1 & 1 & 0 & -1 & Sb- $120 b>$ stable \\
\hline 531201 & $5.30 \mathrm{E}+01$ & 2 & $\mathrm{~m}$ & 0 & 1 & -1 & 1 & 0 & -1 & $\mathrm{I}-120 \mathrm{~m}>$ stable \\
\hline 511200 & $1.59 \mathrm{E}+01$ & 2 & $\mathrm{~m}$ & 0 & 1 & -1 & 1 & 0 & -1 & Sb-120 > stable \\
\hline 531200 & $8.16 \mathrm{E}+01$ & 2 & $\mathrm{~m}$ & 0 & 1 & -1 & 1 & 0 & -1 & I-120 $>$ stable \\
\hline 451210 & $2.21 \mathrm{E}-01$ & 1 & $\mathrm{~s}$ & $5.34 \mathrm{E}-07$ & 1 & 0 & 1 & 0 & -0.3 & Rh-121> Pd-121 1.0 \\
\hline 461210 & $6.22 \mathrm{E}-01$ & 1 & $\mathrm{~s}$ & $2.92 \mathrm{E}-04$ & 1 & 0 & 1 & 1 & -0.3 & Pd-121 > Ag-121 1.0 \\
\hline 471210 & $7.80 \mathrm{E}-01$ & 1 & $\mathrm{~s}$ & $4.80 \mathrm{E}-03$ & 1 & 0 & 1 & 2 & -0.3 & Ag-121>Cd-121 1.0 \\
\hline 481210 & $1.35 \mathrm{E}+01$ & 1 & $\mathrm{~s}$ & $1.21 \mathrm{E}-02$ & 1 & 0 & 1 & 3 & -0.3 & Cd-121 > In-121m 1.0 \\
\hline 491211 & $3.88 \mathrm{E}+00$ & 2 & $\mathrm{~m}$ & $9.58 \mathrm{E}-04$ & 1 & 2 & 1 & 4 & -0.3 & In-121m>Sn-121 1.0 \\
\hline 491210 & $2.31 \mathrm{E}+01$ & 1 & $\mathrm{~s}$ & $6.28 \mathrm{E}-04$ & 1 & 1 & 1 & 5 & -0.3 & In-121 > Sn-121 1.0 \\
\hline 501211 & $5.50 \mathrm{E}+01$ & 5 & $\mathrm{y}$ & $8.78 \mathrm{E}-06$ & 1 & -1 & 1 & 6 & 0 & Sn-121m $>$ stable \\
\hline 501210 & $2.70 \mathrm{E}+01$ & 3 & $\mathrm{~h}$ & $8.75 \mathrm{E}-06$ & 1 & -1 & 1 & 7 & 0 & Sn-121 > stable \\
\hline 531210 & $2.12 \mathrm{E}+00$ & 3 & $\mathrm{~h}$ & 0 & 1 & 1 & 1 & 0 & -1 & $\mathrm{I}-121>\mathrm{Te}-121$ \\
\hline 521211 & $1.54 \mathrm{E}+02$ & 4 & $\mathrm{~d}$ & 0 & 0.886 & 0 & 1 & 0 & -1 & Te-121m $>$ Te-121 0.886 \\
\hline 521210 & $1.92 \mathrm{E}+01$ & 4 & $\mathrm{~d}$ & 0 & 1 & -1 & 1 & 2 & -1 & Te-121 > stable \\
\hline 511220 & $2.72 \mathrm{E}+00$ & 4 & $\mathrm{~d}$ & 0 & 1 & -1 & 1 & 0 & -1 & Sb-122 > stable \\
\hline 541220 & $2.01 \mathrm{E}+01$ & 3 & $\mathrm{~h}$ & 0 & 1 & 0 & 3 & 0 & -1 & $\mathrm{Xe}-122>\mathrm{I}-122 \quad 1.0$ \\
\hline 531220 & $3.63 \mathrm{E}+00$ & 2 & $\mathrm{~m}$ & 0 & 1 & -1 & 2 & 1 & -1 & I-122 > stable \\
\hline 451230 & $1.34 \mathrm{E}-01$ & 1 & $\mathrm{~s}$ & $5.12 \mathrm{E}-09$ & 1 & 0 & 1 & 0 & -0.3 & Rh-123 > Pd-123 1.0 \\
\hline 461230 & $3.10 \mathrm{E}-01$ & 1 & $\mathrm{~s}$ & $1.54 \mathrm{E}-05$ & 1 & 0 & 1 & 1 & -0.3 & Pd-123 > Ag-123 1.0 \\
\hline 471230 & $3.00 \mathrm{E}-01$ & 1 & $\mathrm{~s}$ & $1.28 \mathrm{E}-03$ & 1 & 0 & 1 & 2 & -0.3 & Ag-123 > Cd-123 1.0 \\
\hline 481230 & $2.10 \mathrm{E}+00$ & 1 & $\mathrm{~s}$ & $1.39 \mathrm{E}-02$ & 1 & 2 & 1 & 3 & -0.3 & Cd-123 > In-123 1.0 \\
\hline 491231 & $4.78 \mathrm{E}+01$ & 1 & $\mathrm{~s}$ & $3.13 \mathrm{E}-03$ & 1 & 2 & 1 & 0 & -0.3 & In- $123 \mathrm{~m}>\mathrm{Sn}-123 \mathrm{~m} 1.0$ \\
\hline 501230 & $1.29 \mathrm{E}+02$ & 4 & $\mathrm{~d}$ & $1.62 \mathrm{E}-03$ & 1 & -1 & 1 & 1 & 0 & Sn-123 > stable \\
\hline 491230 & $6.17 \mathrm{E}+00$ & 1 & $\mathrm{~s}$ & $3.21 \mathrm{E}-03$ & 1 & 0 & 1 & 6 & 0 & In-123 > Sn123m 1.0 \\
\hline 501231 & $4.01 \mathrm{E}+01$ & 2 & $\mathrm{~m}$ & $2.94 \mathrm{E}-04$ & 1 & -1 & 1 & 7 & 0 & Sn- $123 m>$ stable \\
\hline 541230 & $2.08 \mathrm{E}+00$ & 3 & $\mathrm{~h}$ & 0 & 1 & 0 & 3 & 0 & -1 & $\mathrm{Xe}-123>\mathrm{I}-123 \quad 1.0$ \\
\hline
\end{tabular}




\begin{tabular}{|c|c|c|c|c|c|c|c|c|c|c|}
\hline 531230 & $1.32 \mathrm{E}+01$ & 3 & $\mathrm{~h}$ & 0 & 1 & 1 & 2 & 1 & -1 & $\mathrm{I}-123>$ Te-123 1.0 \\
\hline 521231 & $1.19 \mathrm{E}+02$ & 4 & $\mathrm{~d}$ & 0 & 1 & 0 & 1 & 2 & -1 & Te-123m> Te-123 1.0 \\
\hline 521230 & $9.20 \mathrm{E}+16$ & 5 & $\mathrm{y}$ & 0 & 1 & -1 & 1 & 3 & -1 & Te-123 $>$ stable \\
\hline 511240 & $6.02 \mathrm{E}+01$ & 4 & $\mathrm{~d}$ & 0 & 1 & -1 & 1 & 0 & -1 & $\mathrm{Sb}-124>$ stable \\
\hline 531240 & $4.18 \mathrm{E}+00$ & 4 & $\mathrm{~d}$ & 0 & 1 & -1 & 2 & 0 & -1 & I-124 > stable \\
\hline 461240 & $5.60 \mathrm{E}-01$ & 1 & $\mathrm{~s}$ & $3.03 \mathrm{E}-06$ & 1 & 0 & 1 & 0 & -0.3 & Pd-124 > Ag-124 1.0 \\
\hline 471240 & $1.72 \mathrm{E}-01$ & 1 & $\mathrm{~s}$ & $5.85 \mathrm{E}-04$ & 1 & 0 & 1 & 1 & -0.3 & Ag-124 > Cd-124 1.0 \\
\hline 481240 & $1.25 \mathrm{E}+00$ & 1 & $\mathrm{~s}$ & $1.41 \mathrm{E}-02$ & 1 & 0 & 1 & 2 & -0.3 & Cd-124 > In-124 1.0 \\
\hline 491240 & $3.12 \mathrm{E}+00$ & 1 & $\mathrm{~s}$ & $1.35 \mathrm{E}-02$ & 1 & -1 & 1 & 3 & -0.3 & In-124 > stable \\
\hline 511241 & $9.30 \mathrm{E}+01$ & 1 & $\mathrm{~s}$ & 0 & 1 & -1 & 1 & 0 & -1 & Sb- $124 \mathrm{~m}>$ stable \\
\hline 471250 & $1.66 \mathrm{E}-01$ & 1 & $\mathrm{~s}$ & $1.39 \mathrm{E}-04$ & 1 & 0 & 1 & 0 & -0.3 & Ag-125 > Cd-125 1.0 \\
\hline 481250 & $6.50 \mathrm{E}-01$ & 1 & $\mathrm{~s}$ & $7.78 \mathrm{E}-03$ & 1 & 1 & 1 & 1 & -0.3 & Cd-125 > In-125 1.0 \\
\hline 491251 & $1.22 \mathrm{E}+01$ & 1 & $\mathrm{~s}$ & $7.96 \mathrm{E}-03$ & 1 & 1 & 1 & 2 & -0.3 & In- $125 \mathrm{~m}>$ Sn- $125 \mathrm{~m} 1.0$ \\
\hline 491250 & $2.36 \mathrm{E}+00$ & 1 & $\mathrm{~s}$ & $1.35 \mathrm{E}-02$ & 1 & 0 & 1 & 3 & -0.3 & In-125 > Sn-125m 1.0 \\
\hline 501251 & $9.52 \mathrm{E}+00$ & 2 & $\mathrm{~m}$ & $5.00 \mathrm{E}-03$ & 1 & 1 & 1 & 4 & 0 & $\mathrm{Sn}-125 \mathrm{~m}>\mathrm{Sb}-1251.0$ \\
\hline 501250 & $9.64 \mathrm{E}+00$ & 4 & $\mathrm{~d}$ & $1.00 \mathrm{E}-02$ & 1 & 0 & 1 & 5 & $5.44 \mathrm{E}-01$ & Sn-125 > Sb-125 1.0 \\
\hline 511250 & $2.76 \mathrm{E}+00$ & 5 & $\mathrm{y}$ & $1.20 \mathrm{E}-04$ & 1 & 0 & 1 & 6 & $7.62 \mathrm{E}-01$ & $\mathrm{Sb}-125>\mathrm{Te}-125 \mathrm{~m}$ \\
\hline 521251 & $5.74 \mathrm{E}+01$ & 4 & $\mathrm{~d}$ & $1.38 \mathrm{E}-07$ & 1 & -1 & 1 & 0 & 0 & Te- $125 \mathrm{~m}>$ stable \\
\hline 551250 & $4.67 \mathrm{E}+01$ & 2 & $\mathrm{~m}$ & 0 & 1 & 0 & 4 & 0 & -1 & Cs-125> Xe-125 1.0 \\
\hline 541250 & $1.69 \mathrm{E}+01$ & 3 & $\mathrm{~h}$ & 0 & 1 & 0 & 3 & 1 & -1 & $\mathrm{Xe}-125>\mathrm{I}-1251.0$ \\
\hline 531250 & $5.94 \mathrm{E}+01$ & 4 & $\mathrm{~d}$ & 0 & 1 & -1 & 2 & 2 & -1 & I-125 > stable \\
\hline 461260 & $2.87 \mathrm{E}-01$ & 1 & $\mathrm{~s}$ & $3.78 \mathrm{E}-08$ & 1 & 0 & 1 & 0 & -0.3 & Pd-126 > Ag-126 1.0 \\
\hline 471260 & $1.07 \mathrm{E}-01$ & 1 & $\mathrm{~s}$ & $5.32 \mathrm{E}-05$ & 1 & 0 & 1 & 1 & -0.3 & $\mathrm{Ag}-126>\mathrm{Cd}-1261.0$ \\
\hline 481260 & $5.06 \mathrm{E}-01$ & 1 & $\mathrm{~s}$ & $8.16 \mathrm{E}-03$ & 1 & 0 & 1 & 2 & -0.3 & Cd-126> In-126 1.0 \\
\hline 491260 & $1.64 \mathrm{E}+00$ & 1 & $\mathrm{~s}$ & $4.12 \mathrm{E}-02$ & 1 & 0 & 1 & 3 & -0.3 & In-126> Sn-126 1.0 \\
\hline 501260 & $2.30 \mathrm{E}+05$ & 5 & $\mathrm{y}$ & $2.50 \mathrm{E}-02$ & 1 & 1 & 1 & 4 & 4.44E-02 & Sn-126 > Sb-126m 1.0 \\
\hline 510010 & $1.00 \mathrm{E}+20$ & 5 & $\mathrm{y}$ & $1.40 \mathrm{E}-04$ & 1 & 1 & 1 & 5 & -2 & pseudo > Sb-126 \\
\hline 511261 & $1.92 \mathrm{E}+01$ & 2 & $\mathrm{~m}$ & $5.02 \mathrm{E}-04$ & 0.14 & 0 & 1 & 6 & 0 & $\mathrm{Sb}-126 \mathrm{~m}>\mathrm{Sb}-126.14$ \\
\hline 511260 & $1.24 \mathrm{E}+01$ & 4 & $\mathrm{~d}$ & $9.74 \mathrm{E}-04$ & 1 & -1 & 1 & 7 & 1.871 & $\mathrm{Sb}-126>$ stable \\
\hline 531260 & $1.29 \mathrm{E}+01$ & 4 & $\mathrm{~d}$ & 0 & 1 & -1 & 2 & 0 & -1 & I-126 > stable \\
\hline 561260 & $1.00 \mathrm{E}+02$ & 2 & $\mathrm{~m}$ & 0 & 1 & 0 & 1 & 0 & -1 & Ba-126 > Cs-126 1.0 \\
\hline
\end{tabular}




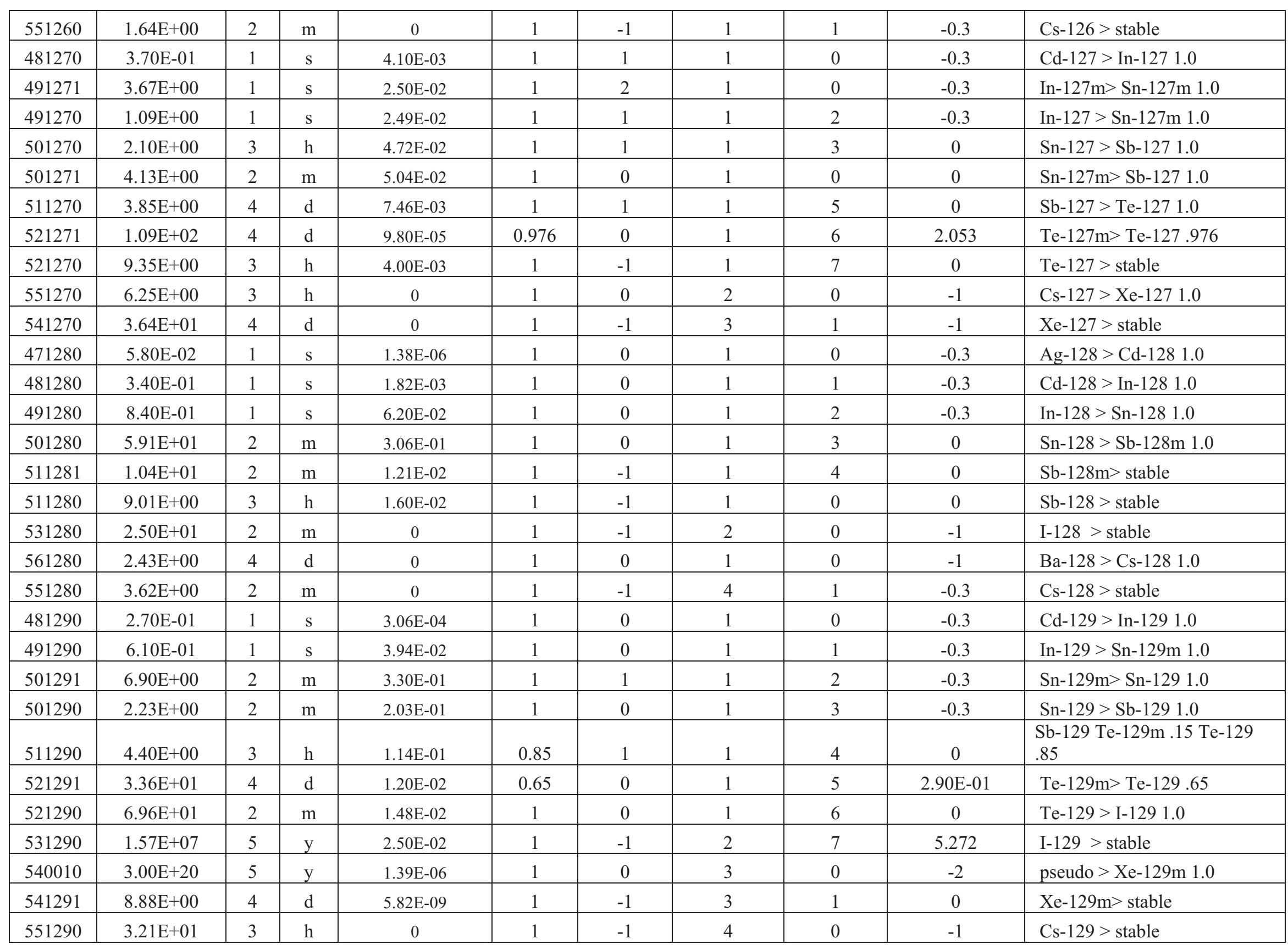


RSAC-7.2 Nuclear Data Library

\begin{tabular}{|c|c|c|c|c|c|c|c|c|c|c|}
\hline 481300 & $2.00 \mathrm{E}-01$ & 1 & $\mathrm{~s}$ & $8.10 \mathrm{E}-04$ & 1 & 0 & 1 & 0 & -0.3 & Cd-130 > In-130 1.0 \\
\hline 491300 & $2.90 \mathrm{E}-01$ & 1 & $\mathrm{~S}$ & 7.34E-02 & 0.7 & 0 & 1 & 1 & -0.3 & In-130 > In-130m 1.0 \\
\hline 491301 & $1.70 \mathrm{E}+00$ & 2 & $\mathrm{~m}$ & 0 & 1 & 2 & 1 & 2 & 0 & In-130m > Sb-130 \\
\hline 501300 & $3.72 \mathrm{E}+00$ & 2 & $\mathrm{~m}$ & $8.72 \mathrm{E}-01$ & 1 & 0 & 1 & 3 & 0 & Sn-130 > Sb-130m 1.0 \\
\hline 511301 & $6.30 \mathrm{E}+00$ & 2 & $\mathrm{~m}$ & $3.02 \mathrm{E}-01$ & 1 & -1 & 1 & 4 & 0 & Sb-130m $>$ stable \\
\hline 511300 & $3.95 \mathrm{E}+01$ & 2 & $\mathrm{~m}$ & $2.18 \mathrm{E}-01$ & 1 & -1 & 1 & 5 & 0 & Sb-130 > stable \\
\hline 530010 & $1.00 \mathrm{E}+24$ & 5 & $\mathrm{y}$ & \#\#\#\#\#\# & 1 & 0 & 2 & 0 & -2 & pseudo \\
\hline 530020 & $4.00 \mathrm{E}+19$ & 5 & $\mathrm{y}$ & $1.50 \mathrm{E}-03$ & 1 & 2 & 2 & 1 & -2 & pseudo \\
\hline 530030 & $1.00 \mathrm{E}+24$ & 5 & $\mathrm{y}$ & \#\#\#\#\#\# & 1 & 0 & 2 & 2 & -2 & pseudo \\
\hline 530040 & $3.50 \mathrm{E}+19$ & 5 & $\mathrm{y}$ & $4.00 \mathrm{E}-03$ & 1 & 1 & 2 & 3 & -2 & pseudo > I-130 1.0 \\
\hline 531301 & $8.84 \mathrm{E}+00$ & 2 & $\mathrm{~m}$ & $1.05 \mathrm{E}-04$ & 0.83 & 0 & 2 & 4 & 0 & $\mathrm{I}-130 \mathrm{~m}>\mathrm{I}-130.83$ \\
\hline 531300 & $1.24 \mathrm{E}+01$ & 3 & $\mathrm{~h}$ & $1.97 \mathrm{E}-04$ & 1 & -1 & 2 & 5 & 0 & I-130 > stable \\
\hline 551300 & $2.92 \mathrm{E}+01$ & 2 & $\mathrm{~m}$ & 0 & 1 & -1 & 4 & 0 & -1 & Cs-130 > stable \\
\hline 481310 & $1.19 \mathrm{E}-01$ & 1 & $\mathrm{~s}$ & $7.70 \mathrm{E}-05$ & 1 & 0 & 1 & 0 & -0.3 & Cd-131 > In-131 1.0 \\
\hline 491310 & $2.80 \mathrm{E}-01$ & 1 & $\mathrm{~s}$ & $2.44 \mathrm{E}-02$ & 1 & 0 & 1 & 1 & -0.3 & In-131 > Sn-131 1.0 \\
\hline 501310 & $5.60 \mathrm{E}+01$ & 1 & $\mathrm{~s}$ & $9.59 \mathrm{E}-01$ & 1 & 0 & 1 & 2 & -0.3 & Sn-131> Sb-131 1.0 \\
\hline 511310 & $2.30 \mathrm{E}+01$ & 2 & $\mathrm{~m}$ & \#\#\#\#\# & 0.932 & 1 & 1 & 3 & 0 & $\mathrm{Sb}-131>\mathrm{Te}-1311.0$ \\
\hline 521311 & $3.33 \mathrm{E}+01$ & 3 & $\mathrm{~h}$ & $1.90 \mathrm{E}-01$ & 0.778 & 1 & 1 & 4 & 0 & $\begin{array}{l}\text { Te-131m Te-131 .222 I-131 } \\
.778\end{array}$ \\
\hline 521310 & $2.50 \mathrm{E}+01$ & 2 & $\mathrm{~m}$ & $1.19 \mathrm{E}-01$ & 1 & 0 & 1 & 5 & 0 & Te-131 > I-131 1.0 \\
\hline 531310 & $8.03 \mathrm{E}+00$ & 4 & $\mathrm{~d}$ & 4.15E-03 & 0.01086 & 0 & 2 & 6 & $3.23 \mathrm{E}-01$ & $\mathrm{I}-131>\mathrm{Xe}-131.01086$ \\
\hline 541311 & $1.18 \mathrm{E}+01$ & 4 & $\mathrm{~d}$ & $1.04 \mathrm{E}-06$ & 1 & -1 & 3 & 7 & 0 & $\mathrm{Xe}-131 \mathrm{~m}>\mathrm{Ba}-131>1.0$ \\
\hline 561311 & $1.46 \mathrm{E}+01$ & 2 & $\mathrm{~m}$ & 0 & 1 & 1 & 1 & 0 & -1 & $\mathrm{Ba}-131 \mathrm{~m}>\mathrm{Ba}-1311.0$ \\
\hline 571310 & $5.90 \mathrm{E}+01$ & 2 & $\mathrm{~m}$ & 0 & 1 & 0 & 1 & 0 & -1 & La-131 > Ba-131 1.0 \\
\hline 561310 & $1.15 \mathrm{E}+01$ & 4 & $\mathrm{~d}$ & 0 & 1 & 0 & 1 & 2 & -1 & Ba-131 > Cs-131 1.0 \\
\hline 551310 & $9.69 \mathrm{E}+00$ & 4 & $\mathrm{~d}$ & 0 & 1 & -1 & 4 & 3 & -1 & Cs-131 > stable \\
\hline 481320 & $1.45 \mathrm{E}-01$ & 1 & $\mathrm{~s}$ & $6.14 \mathrm{E}-06$ & 1 & 0 & 1 & 0 & -0.3 & Cd-132 > In-132 1.0 \\
\hline 491320 & $2.07 \mathrm{E}-01$ & 1 & $\mathrm{~S}$ & $6.62 \mathrm{E}-03$ & 1 & 0 & 1 & 1 & -0.3 & In-132 > Sn-132 1.0 \\
\hline 501320 & $3.97 \mathrm{E}+01$ & 1 & $\mathrm{~s}$ & $5.86 \mathrm{E}-01$ & 1 & 1 & 1 & 2 & 0 & Sn-132 > Sb-132 1.0 \\
\hline 511321 & $4.10 \mathrm{E}+00$ & 2 & $\mathrm{~m}$ & \#\#\#\#\#\# & 1 & 1 & 1 & 3 & 0 & Sb-132m> Te-132 1 \\
\hline 511320 & $2.79 \mathrm{E}+00$ & 2 & $\mathrm{~m}$ & \#\#\#\#\#\# & 1 & 0 & 1 & 4 & 0 & Sb-132 > Te-132 \\
\hline 521320 & $3.20 \mathrm{E}+00$ & 4 & $\mathrm{~d}$ & \#\#\#\#\#\# & 1 & 1 & 1 & 5 & 4.89E-04 & Te-132 > I-132 1.0 \\
\hline
\end{tabular}




\begin{tabular}{|c|c|c|c|c|c|c|c|c|c|c|}
\hline 531321 & $1.39 \mathrm{E}+00$ & 3 & $\mathrm{~h}$ & 0 & 0.86 & 0 & 2 & 0 & -1 & $\mathrm{I}-132 \mathrm{~m}>\mathrm{I}-132.86$ \\
\hline 531320 & $2.30 \mathrm{E}+00$ & 3 & $\mathrm{~h}$ & $2.06 \mathrm{E}-02$ & 1 & -1 & 2 & 7 & 0 & I-132 > stable \\
\hline 551320 & $6.48 \mathrm{E}+00$ & 4 & $\mathrm{~d}$ & 0 & 1 & -1 & 4 & 0 & -1 & Cs- $132>$ stable \\
\hline 571320 & $4.80 \mathrm{E}+00$ & 3 & $\mathrm{~h}$ & 0 & 1 & -1 & 1 & 0 & -1 & La-132 > stable \\
\hline 491330 & $1.80 \mathrm{E}-01$ & 1 & $\mathrm{~s}$ & $3.95 \mathrm{E}-04$ & 1 & 0 & 1 & 0 & -0.3 & In-133 > Sn-133 1.0 \\
\hline 501330 & $1.45 \mathrm{E}+00$ & 1 & $\mathrm{~s}$ & $1.69 \mathrm{E}-01$ & 1 & 0 & 1 & 1 & -0.3 & Sn-133 > Sb-133 1.0 \\
\hline 511330 & $2.50 \mathrm{E}+00$ & 2 & $\mathrm{~m}$ & \#\#\#\#\# & 0.978 & 1 & 1 & 2 & 0 & $\begin{array}{l}\text { Sb-133 Te-133m .022 Te-133 } \\
.978\end{array}$ \\
\hline 521331 & $5.54 \mathrm{E}+01$ & 2 & $\mathrm{~m}$ & \#\#\#\#\#\# & 0.13 & 0 & 1 & 3 & 0 & Te- $133 \mathrm{~m}>$ Te-133.13 \\
\hline 521330 & $1.25 \mathrm{E}+01$ & 2 & $\mathrm{~m}$ & \#\#\#\#\#\# & 1 & 1 & 2 & 4 & 0 & Te-133 > I-133 1.0 \\
\hline 531331 & $9.00 \mathrm{E}+00$ & 1 & $\mathrm{~s}$ & $1.29 \mathrm{E}-01$ & 1 & 0 & 2 & 5 & 0 & $\mathrm{I}-133 \mathrm{~m}>\mathrm{Xe}-1331.0$ \\
\hline 531330 & $2.08 \mathrm{E}+01$ & 3 & $\mathrm{~h}$ & \#\#\#\#\# & 0.9712 & 1 & 2 & 6 & 0 & $\begin{array}{l}\text { I-133 .0288 Xe-133m Xe-133 } \\
.9712\end{array}$ \\
\hline 541331 & $2.19 \mathrm{E}+00$ & 4 & $\mathrm{~d}$ & 2.67E-03 & 1 & 0 & 3 & 7 & 0 & Xe-133m $>$ Xe-133 1.0 \\
\hline 541330 & $5.24 \mathrm{E}+00$ & 4 & $\mathrm{~d}$ & 8.79E-04 & 1 & -1 & 3 & 8 & $2.44 \mathrm{E}+01$ & Xe-133 > stable \\
\hline 561331 & $3.89 \mathrm{E}+01$ & 3 & $\mathrm{~h}$ & 0 & 1 & 0 & 1 & 0 & -1 & Ba-133m $>$ Ba-133 1.0 \\
\hline 561330 & $1.05 \mathrm{E}+01$ & 5 & $\mathrm{y}$ & 0 & 1 & -1 & 1 & 1 & -1 & Ba-133 > stable \\
\hline 491340 & $1.38 \mathrm{E}-01$ & 1 & $\mathrm{~s}$ & $6.96 \mathrm{E}-06$ & 1 & 0 & 1 & 0 & -0.3 & In-134 > Sn-134 1.0 \\
\hline 501340 & $1.12 \mathrm{E}+00$ & 1 & $\mathrm{~s}$ & $1.19 \mathrm{E}-02$ & 1 & 1 & 1 & 1 & -0.3 & Sn-134 > Sb-134 1.0 \\
\hline 511341 & $1.01 \mathrm{E}+01$ & 1 & $\mathrm{~s}$ & $2.58 \mathrm{E}-01$ & 1 & 1 & 1 & 2 & -0.3 & Sb-134m> Te-134 1.0 \\
\hline 511340 & $7.80 \mathrm{E}-01$ & 1 & $\mathrm{~s}$ & $2.58 \mathrm{E}-01$ & 1 & 0 & 1 & 3 & 0 & Sb-134 > Te-134 1.0 \\
\hline 521340 & $4.18 \mathrm{E}+01$ & 2 & $\mathrm{~m}$ & \#\#\#\#\#\# & 1 & 0 & 1 & 4 & $9.20 \mathrm{E}-03$ & Te-134 > I-134m 1.0 \\
\hline 531341 & $3.52 \mathrm{E}+00$ & 2 & $\mathrm{~m}$ & $4.52 \mathrm{E}-01$ & 0.98 & 0 & 2 & 5 & 0 & $\mathrm{I}-134 \mathrm{~m}>\mathrm{I}-134.98$ \\
\hline 531340 & $5.25 \mathrm{E}+01$ & 2 & $\mathrm{~m}$ & 4.57E-01 & 1 & -1 & 2 & 6 & 0 & I-134 > stable \\
\hline 541341 & $2.90 \mathrm{E}-01$ & 1 & $\mathrm{~s}$ & $2.38 \mathrm{E}-02$ & 1 & -1 & 3 & 0 & -0.3 & $\mathrm{Xe}-134 \mathrm{~m}>$ stable \\
\hline 550010 & $1.00 \mathrm{E}+23$ & 5 & $\mathrm{y}$ & $8.00 \mathrm{E}-01$ & 1 & 1 & 4 & 0 & -2 & pseudo \\
\hline 550020 & $1.90 \mathrm{E}+20$ & 5 & $\mathrm{y}$ & $5.00 \mathrm{E}-03$ & 1 & 0 & 4 & 1 & -2 & pseudo $>$ Cs- $134 \mathrm{~m} 1.0$ \\
\hline 551341 & $2.91 \mathrm{E}+00$ & 3 & $\mathrm{~h}$ & $5.30 \mathrm{E}-05$ & 1 & 2 & 4 & 2 & 0 & Cs-134m> Cs-134 1.0 \\
\hline 550030 & $3.00 \mathrm{E}+18$ & 5 & $\mathrm{y}$ & $3.80 \mathrm{E}-01$ & 1 & 0 & 4 & 0 & -2 & pseudo \\
\hline 550040 & $1.00 \mathrm{E}+19$ & 5 & $\mathrm{y}$ & $1.00 \mathrm{E}-03$ & 1 & 0 & 4 & 1 & -2 & pseudo > Cs-134 1.0 \\
\hline 551340 & $2.07 \mathrm{E}+00$ & 5 & $\mathrm{y}$ & $1.38 \mathrm{E}-05$ & 1 & -1 & 4 & 5 & $2.30 \mathrm{E}+01$ & Cs-134 > stable \\
\hline 581340 & $3.16 \mathrm{E}+00$ & 4 & $\mathrm{~d}$ & 0 & 1 & 0 & 1 & 6 & -1 & Ce-134 > La-134 \\
\hline
\end{tabular}




\begin{tabular}{|c|c|c|c|c|c|c|c|c|c|c|}
\hline 571340 & $6.45 \mathrm{E}+00$ & 2 & $\mathrm{~m}$ & 0 & 1 & -1 & 1 & 7 & -0.3 & La-134 > stable \\
\hline 501350 & $2.91 \mathrm{E}-01$ & 1 & $\mathrm{~s}$ & $1.24 \mathrm{E}-03$ & 1 & 0 & 1 & 0 & -0.3 & Sn-135 > Sb-135 1.0 \\
\hline 511350 & $1.71 \mathrm{E}+00$ & 1 & $\mathrm{~s}$ & $1.96 \mathrm{E}-01$ & 1 & 0 & 1 & 1 & -0.3 & $\mathrm{Sb}-135>$ Te-135 1.0 \\
\hline 521350 & $1.90 \mathrm{E}+01$ & 1 & $\mathrm{~s}$ & \#\#\#\#\#\# & 1 & 0 & 1 & 2 & 0 & Te-135 > I-135 1.0 \\
\hline 531350 & $6.58 \mathrm{E}+00$ & 3 & $\mathrm{~h}$ & \#\#\#\#\#\# & 0.835 & 2 & 2 & 3 & $2.12 \mathrm{E}-03$ & $\mathrm{I}-135>\mathrm{Xe}-1351.0$ \\
\hline 541351 & $1.53 \mathrm{E}+01$ & 2 & $\mathrm{~m}$ & $1.52 \mathrm{E}-01$ & 1 & 1 & 3 & 4 & 0 & $\mathrm{Xe}-135 \mathrm{~m}>\mathrm{Xe}-1351.0$ \\
\hline 540020 & $9.00 \mathrm{E}+16$ & 5 & $\mathrm{y}$ & $3.20 \mathrm{E}-01$ & 1 & 0 & 3 & 5 & -2 & pseudo $>$ Xe-135 1.0 \\
\hline 541350 & $9.14 \mathrm{E}+00$ & 3 & $\mathrm{~h}$ & $9.78 \mathrm{E}-02$ & 1 & 4 & 3 & 6 & $2.09 \mathrm{E}+05$ & $\mathrm{Xe}-135>\mathrm{I}-1351.0$ \\
\hline 550050 & $6.50 \mathrm{E}+22$ & 5 & $\mathrm{y}$ & \#\#\#\#\#\# & 1 & 0 & 4 & 7 & -2 & pseudo \\
\hline 550060 & $1.00 \mathrm{E}+24$ & 5 & $\mathrm{y}$ & \#\#\#\#\#\# & 1 & 0 & 4 & 8 & -2 & pseudo > I-135m 1.0 \\
\hline 551351 & $5.30 \mathrm{E}+01$ & 2 & $\mathrm{~m}$ & $6.25 \mathrm{E}-04$ & 1 & 1 & 4 & 9 & 0 & Cs-135m> Cs-135 1.0 \\
\hline 550070 & $8.80 \mathrm{E}+16$ & 5 & $\mathrm{y}$ & \#\#\#\#\#\# & 1 & 0 & 4 & 10 & -2 & pseudo $>$ I-135 1.0 \\
\hline 551350 & $2.30 \mathrm{E}+06$ & 5 & $\mathrm{y}$ & $9.01 \mathrm{E}-04$ & 1 & -1 & 4 & 11 & 2.391 & Cs-135 > stable \\
\hline 561351 & $2.87 \mathrm{E}+01$ & 3 & $\mathrm{~h}$ & 0 & 1 & -1 & 1 & 0 & -1 & Ba- $135 \mathrm{~m}>$ stable \\
\hline 581350 & $1.77 \mathrm{E}+01$ & 3 & $\mathrm{~h}$ & 0 & 1 & 0 & 1 & 0 & -1 & Ce-135 > La-135 1.0 \\
\hline 571350 & $1.95 \mathrm{E}+01$ & 3 & $\mathrm{~h}$ & 0 & 1 & -1 & 1 & 1 & -1 & La-135 > stable \\
\hline 501360 & 4.13E-01 & 1 & $\mathrm{~s}$ & $5.43 \mathrm{E}-05$ & 1 & 0 & 1 & 0 & -0.3 & Sn-136 > Sb-136 1.0 \\
\hline 511360 & $8.20 \mathrm{E}-01$ & 1 & $\mathrm{~s}$ & $2.99 \mathrm{E}-02$ & 1 & 0 & 1 & 1 & -0.3 & Sb-136 > Te-136 1.0 \\
\hline 521360 & $1.75 \mathrm{E}+01$ & 1 & $\mathrm{~s}$ & \#\#\#\#\#\# & 1 & 1 & 1 & 2 & -0.3 & Te-136 > I-136 1.0 \\
\hline 531361 & $4.69 \mathrm{E}+01$ & 1 & $\mathrm{~s}$ & \#\#\#\#\#\# & 1 & -1 & 2 & 0 & -0.3 & $\mathrm{I}-136 \mathrm{~m}>$ stable \\
\hline 531360 & $8.34 \mathrm{E}+01$ & 1 & $\mathrm{~s}$ & \#\#\#\#\#\# & 1 & -1 & 2 & 4 & 0 & I-136 > stable \\
\hline 560010 & $5.00 \mathrm{E}+22$ & 5 & $\mathrm{y}$ & $6.10 \mathrm{E}-01$ & 1 & 0 & 1 & 0 & -2 & pseudo > Cs-136 1.0 \\
\hline 551360 & $1.32 \mathrm{E}+01$ & 4 & $\mathrm{~d}$ & $7.51 \mathrm{E}-03$ & 1 & -1 & 4 & 1 & 0 & Cs-136 > stable \\
\hline 601360 & $5.07 \mathrm{E}+01$ & 2 & $\mathrm{~m}$ & 0 & 1 & 0 & 1 & 0 & -1 & Nd-136 > Pr-136 1.0 \\
\hline 591360 & $1.31 \mathrm{E}+01$ & 2 & $\mathrm{~m}$ & 0 & 1 & -1 & 1 & 1 & -1 & $\operatorname{Pr}-136>$ stable \\
\hline 511370 & $2.84 \mathrm{E}-01$ & 1 & $\mathrm{~s}$ & $2.13 \mathrm{E}-03$ & 1 & 0 & 1 & 0 & -0.3 & Sb-137 > Te-137 1.0 \\
\hline 521370 & $2.49 \mathrm{E}+00$ & 1 & $\mathrm{~s}$ & 4.20E-01 & 1 & 0 & 1 & 1 & -0.3 & Te-137 > I-137 1.0 \\
\hline 531370 & $2.45 \mathrm{E}+01$ & 1 & $\mathrm{~s}$ & \#\#\#\#\#\# & 1 & 0 & 2 & 2 & -0.3 & $\mathrm{I}-137>\mathrm{Xe}-1371.0$ \\
\hline 541370 & $3.82 \mathrm{E}+00$ & 2 & $\mathrm{~m}$ & \#\#\#\#\#\# & 1 & 0 & 3 & 3 & 0 & Xe-137 > Cs-137 1.0 \\
\hline 551370 & $3.01 \mathrm{E}+01$ & 5 & $\mathrm{y}$ & $1.25 \mathrm{E}-01$ & 0.946 & 0 & 4 & 4 & $2.56 \mathrm{E}-02$ & Cs-137> Ba-137m .946 \\
\hline 561371 & $2.55 \mathrm{E}+00$ & 2 & $\mathrm{~m}$ & $2.58 \mathrm{E}-04$ & 1 & -1 & 1 & 5 & 0 & Ba- $137 \mathrm{~m}>$ stable \\
\hline
\end{tabular}




\begin{tabular}{|c|c|c|c|c|c|c|c|c|c|c|}
\hline 591370 & $1.28 \mathrm{E}+00$ & 3 & $\mathrm{~h}$ & 0 & 1 & 1 & 1 & 0 & -1 & $\operatorname{Pr}-137>\mathrm{Ce}-1371.0$ \\
\hline 581371 & $3.44 \mathrm{E}+01$ & 3 & $\mathrm{~h}$ & 0 & 0.9941 & 1 & 1 & 1 & -1 & $\begin{array}{l}\text { Ce-137m La-137 .9941 } \\
\text { Ce-137 .0059 }\end{array}$ \\
\hline 581370 & $9.00 \mathrm{E}+00$ & 3 & $\mathrm{~h}$ & 0 & 1 & 0 & 2 & 2 & -1 & Ce-137 > La-137 1.0 \\
\hline 571370 & $6.00 \mathrm{E}+04$ & 5 & $\mathrm{y}$ & 0 & 1 & -1 & 3 & 3 & -1 & La-137 > stable \\
\hline 511380 & $1.30 \mathrm{E}-01$ & 1 & $\mathrm{~s}$ & $1.32 \mathrm{E}-04$ & 1 & 0 & 1 & 0 & -0.3 & $\mathrm{Sb}-138>\mathrm{Te}-1381.0$ \\
\hline 521380 & $1.40 \mathrm{E}+00$ & 1 & $\mathrm{~s}$ & $8.72 \mathrm{E}-02$ & 1 & 0 & 1 & 1 & -0.3 & Te-138> I-138 1.0 \\
\hline 531380 & $6.23 \mathrm{E}+00$ & 1 & $\mathrm{~s}$ & \#\#\#\#\#\# & 1 & 0 & 2 & 2 & 0 & $\mathrm{I}-138>\mathrm{Xe}-1381.0$ \\
\hline 541380 & $1.41 \mathrm{E}+01$ & 2 & $\mathrm{~m}$ & \#\#\#\#\#\# & 1 & 1 & 3 & 3 & 0 & Xe-138 > Cs-138 1.o \\
\hline 551381 & $2.91 \mathrm{E}+00$ & 2 & $\mathrm{~m}$ & $2.48 \mathrm{E}-01$ & 0.75 & 0 & 4 & 0 & 0 & Cs- $138 m>$ Cs- 138.75 \\
\hline 551380 & $3.34 \mathrm{E}+01$ & 2 & $\mathrm{~m}$ & $3.01 \mathrm{E}-01$ & 1 & -1 & 4 & 5 & 0 & Cs-138> stable \\
\hline 571380 & $1.02 \mathrm{E}+11$ & 5 & $\mathrm{y}$ & 0 & 1 & -1 & 1 & 0 & -1 & La-138 > stable \\
\hline 591381 & $2.12 \mathrm{E}+00$ & 3 & $\mathrm{~h}$ & 0 & 1 & -1 & 1 & 0 & 0 & Pr- $138 \mathrm{~m}>$ stable \\
\hline 601380 & $5.04 \mathrm{E}+00$ & 3 & $\mathrm{~h}$ & 0 & 1 & 0 & 1 & 0 & -1 & Nd-138 > Pr-138 1.0 \\
\hline 591380 & $1.45 \mathrm{E}+00$ & 2 & $\mathrm{~m}$ & 0 & 1 & -1 & 1 & 1 & -0.3 & Pr-138 > Stable \\
\hline 511390 & $1.72 \mathrm{E}-01$ & 1 & $\mathrm{~s}$ & $5.87 \mathrm{E}-06$ & 1 & 0 & 1 & 0 & -0.3 & Sb-139> Te-139 1.0 \\
\hline 521390 & $4.24 \mathrm{E}-01$ & 1 & $\mathrm{~s}$ & $1.30 \mathrm{E}-02$ & 1 & 0 & 1 & 1 & -0.3 & Te-139> I-139 1.0 \\
\hline 531390 & $2.29 \mathrm{E}+00$ & 1 & $\mathrm{~s}$ & $7.23 \mathrm{E}-01$ & 1 & 0 & 2 & 2 & 0 & $\mathrm{I}-139>\mathrm{Xe}-1391.0$ \\
\hline 541390 & $3.97 \mathrm{E}+01$ & 1 & $\mathrm{~s}$ & \#\#\#\#\#\# & 1 & 0 & 3 & 3 & 0 & Xe-139> Cs-139 1.0 \\
\hline 551390 & $9.27 \mathrm{E}+00$ & 2 & $\mathrm{~m}$ & \#\#\#\#\# & 1 & 0 & 4 & 4 & 0 & Cs-139> Ba-139 1.0 \\
\hline 561390 & $8.31 \mathrm{E}+01$ & 2 & $\mathrm{~m}$ & $6.71 \mathrm{E}-02$ & 1 & -1 & 1 & 5 & $5.52 \mathrm{E}-01$ & Ba-139 > stable \\
\hline 601391 & $5.50 \mathrm{E}+00$ & 3 & $\mathrm{~h}$ & 0 & 0.882 & 1 & 1 & 0 & -1 & $\begin{array}{l}\text { Nd-139m Nd-139 .118 Pr-139 } \\
.882\end{array}$ \\
\hline 601390 & $2.97 \mathrm{E}+01$ & 2 & $\mathrm{~m}$ & 0 & 1 & 0 & 1 & 1 & -1 & Nd-139 > Pr-139 1.0 \\
\hline 591390 & $4.41 \mathrm{E}+00$ & 3 & $\mathrm{~h}$ & 0 & 1 & 0 & 1 & 2 & -1 & Pr-139> Ce-139 1.0 \\
\hline 581390 & $1.38 \mathrm{E}+02$ & 4 & $\mathrm{~d}$ & 0 & 1 & -1 & 1 & 3 & -1 & Ce-139 > stable \\
\hline 521400 & $7.52 \mathrm{E}-01$ & 1 & $\mathrm{~s}$ & $1.21 \mathrm{E}-03$ & 1 & 0 & 1 & 0 & -0.3 & Te-140 > I-140 1.0 \\
\hline 531400 & $8.60 \mathrm{E}-01$ & 1 & $\mathrm{~s}$ & $2.15 \mathrm{E}-01$ & 1 & 0 & 2 & 1 & 0 & $\mathrm{I}-140>\mathrm{Xe}-1401.0$ \\
\hline 541400 & $1.36 \mathrm{E}+01$ & 1 & $\mathrm{~s}$ & \#\#\#\#\#\# & 1 & 0 & 3 & 2 & 0 & Xe-140 > Cs-140 1.0 \\
\hline 551400 & $6.37 \mathrm{E}+01$ & 1 & $\mathrm{~s}$ & \#\#\#\#\#\# & 1 & 0 & 4 & 3 & 0 & Cs-140 > Ba-140 1.0 \\
\hline 561400 & $1.28 \mathrm{E}+01$ & 4 & $\mathrm{~d}$ & 4.29E-01 & 1 & 0 & 1 & 4 & $5.29 \mathrm{E}-01$ & Ba-140 > La-140 1.0 \\
\hline 571400 & $1.68 \mathrm{E}+00$ & 4 & $\mathrm{~d}$ & $6.04 \mathrm{E}-03$ & 1 & -1 & 1 & 5 & 2.21 & La-140 > stable \\
\hline
\end{tabular}




\begin{tabular}{|c|c|c|c|c|c|c|c|c|c|c|}
\hline 521410 & $2.36 \mathrm{E}-01$ & 1 & $\mathrm{~s}$ & 4.19E-05 & 1 & 0 & 1 & 0 & -0.3 & Te-141 > I-141 1.0 \\
\hline 531410 & $4.30 \mathrm{E}-01$ & 1 & $\mathrm{~s}$ & $3.08 \mathrm{E}-02$ & 1 & 0 & 2 & 1 & 0 & $\mathrm{I}-141>\mathrm{Xe}-1411.0$ \\
\hline 541410 & $1.73 \mathrm{E}+00$ & 1 & $\mathrm{~s}$ & \#\#\#\#\#\# & 1 & 0 & 3 & 2 & 0 & Xe-141 > Cs-141 1.0 \\
\hline 551410 & $2.48 \mathrm{E}+01$ & 1 & $\mathrm{~s}$ & \#\#\#\#\#\# & 1 & 0 & 4 & 3 & $1.52 \mathrm{E}-03$ & Cs-141 > Ba-141 1.0 \\
\hline 561410 & $1.83 \mathrm{E}+01$ & 2 & $\mathrm{~m}$ & \#\#\#\#\#\# & 1 & 0 & 1 & 4 & 0 & Ba-141 > La-141 1.0 \\
\hline 571410 & $3.92 \mathrm{E}+00$ & 3 & $\mathrm{~h}$ & $1.94 \mathrm{E}-02$ & 1 & 0 & 1 & 5 & 0 & La-141 > Ce-141 1.0 \\
\hline 581410 & $3.25 \mathrm{E}+01$ & 4 & $\mathrm{~d}$ & $2.43 \mathrm{E}-05$ & 1 & -1 & 1 & 6 & 2.971 & Ce-141 > stable \\
\hline 621411 & $2.26 \mathrm{E}+01$ & 2 & $\mathrm{~m}$ & 0 & 0.9969 & 0 & 1 & 0 & -1 & Sm-141m > Pm-141 1.0 \\
\hline 621410 & $1.02 \mathrm{E}+01$ & 2 & $\mathrm{~m}$ & 0 & 1 & 0 & 1 & 1 & -1 & Sm-141 > Pm-141 1.0 \\
\hline 611410 & $2.09 \mathrm{E}+01$ & 2 & $\mathrm{~m}$ & 0 & 0.999 & 0 & 1 & 2 & -1 & Pm-141 > Nd-141 .999 \\
\hline 601410 & $2.49 \mathrm{E}+00$ & 3 & $\mathrm{~h}$ & 0 & 1 & -1 & 1 & 3 & -1 & Nd-141 > stable \\
\hline 521420 & $4.91 \mathrm{E}-01$ & 1 & $\mathrm{~s}$ & $8.03 \mathrm{E}-07$ & 1 & 0 & 1 & 0 & -0.3 & Te-142> I-142 1.0 \\
\hline 531420 & $1.96 \mathrm{E}-01$ & 1 & $\mathrm{~s}$ & $2.23 \mathrm{E}-03$ & 1 & 0 & 2 & 1 & 0 & $\mathrm{I}-142>\mathrm{Xe}-1421.0$ \\
\hline 541420 & $1.22 \mathrm{E}+00$ & 1 & $\mathrm{~s}$ & $3.80 \mathrm{E}-01$ & 1 & 0 & 3 & 2 & 0 & $\mathrm{Xe}-142>$ Cs-142 1.0 \\
\hline 551420 & $1.68 \mathrm{E}+00$ & 1 & $\mathrm{~s}$ & \#\#\#\#\#\# & 1 & 0 & 4 & 3 & -0.3 & Cs-142 > Ba-142 1.0 \\
\hline 561420 & $1.06 \mathrm{E}+01$ & 2 & $\mathrm{~m}$ & \#\#\#\#\#\# & 1 & 0 & 1 & 4 & 0 & Ba-142 > La-142 1.0 \\
\hline 571420 & $9.11 \mathrm{E}+01$ & 2 & $\mathrm{~m}$ & $1.00 \mathrm{E}-01$ & 1 & -1 & 1 & 0 & 0 & La-142 > stable \\
\hline 581420 & $5.00 \mathrm{E}+16$ & 5 & $\mathrm{y}$ & 0 & 1 & -1 & 1 & 5 & -1 & Ce-142 > stable \\
\hline 591421 & $1.46 \mathrm{E}+01$ & 3 & $\mathrm{~h}$ & 0 & 0.0164 & 0 & 1 & 0 & -1 & Pr- $142 \mathrm{~m}>$ Pr-142 1.0 \\
\hline 591420 & $1.91 \mathrm{E}+01$ & 3 & $\mathrm{~h}$ & 0 & 1 & -1 & 1 & 1 & -1 & Pr-142 > stable \\
\hline 621420 & $7.25 \mathrm{E}+01$ & 2 & $\mathrm{~m}$ & 0 & 1 & 0 & 1 & 0 & -1 & Sm-142 > Pm-142 1.0 \\
\hline 611420 & $4.05 \mathrm{E}+01$ & 1 & $\mathrm{~s}$ & 0 & 1 & -1 & 1 & 1 & -0.3 & Pm-142 > stable \\
\hline 531430 & $3.28 \mathrm{E}-01$ & 1 & $\mathrm{~s}$ & $9.08 \mathrm{E}-05$ & 1 & 0 & 2 & 0 & 0 & $\mathrm{I}-143>\mathrm{Xe}-1431.0$ \\
\hline 541430 & $3.00 \mathrm{E}-01$ & 1 & $\mathrm{~s}$ & $5.20 \mathrm{E}-02$ & 1 & 0 & 3 & 1 & 0 & Xe-143>Cs-143 1.0 \\
\hline 551430 & $1.78 \mathrm{E}+00$ & 1 & $\mathrm{~s}$ & \#\#\#\#\#\# & 1 & 0 & 4 & 2 & -0.3 & Cs-143 > Ba-143 1.0 \\
\hline 561430 & $1.45 \mathrm{E}+01$ & 1 & $\mathrm{~s}$ & \#\#\#\#\#\# & 1 & 0 & 1 & 3 & -0.3 & Ba-143 > La-143 1.0 \\
\hline 571430 & $1.42 \mathrm{E}+01$ & 2 & $\mathrm{~m}$ & $6.01 \mathrm{E}-01$ & 1 & 0 & 1 & 4 & 0 & La-143> Ce-143 1.0 \\
\hline 581430 & $3.30 \mathrm{E}+01$ & 3 & $\mathrm{~h}$ & $2.85 \mathrm{E}-02$ & 1 & 0 & 1 & 5 & 1.755 & Ce-143 > Pr-143 1.0 \\
\hline 591430 & $1.36 \mathrm{E}+01$ & 4 & $\mathrm{~d}$ & $2.95 \mathrm{E}-06$ & 1 & -1 & 1 & 6 & $1.21 \mathrm{E}+01$ & Pr-143 > stable \\
\hline 611430 & $2.65 \mathrm{E}+02$ & 4 & $\mathrm{~d}$ & 0 & 1 & -1 & 1 & 0 & -1 & Pm-143 > stable \\
\hline 531440 & $1.33 \mathrm{E}-01$ & 1 & $\mathrm{~s}$ & $3.42 \mathrm{E}-06$ & 1 & 0 & 2 & 0 & 0 & $\mathrm{I}-144>\mathrm{Xe}-1441.0$ \\
\hline
\end{tabular}




\begin{tabular}{|c|c|c|c|c|c|c|c|c|c|c|}
\hline 541440 & $1.15 \mathrm{E}+00$ & 1 & $\mathrm{~s}$ & $6.57 \mathrm{E}-03$ & 1 & 0 & 3 & 1 & 0 & Xe-144 > Cs-144 1.0 \\
\hline 551440 & $1.01 \mathrm{E}+00$ & 1 & $\mathrm{~s}$ & $3.11 \mathrm{E}-01$ & 1 & 0 & 4 & 2 & 0 & Cs-144 > Ba-144 1.0 \\
\hline 561440 & $1.15 \mathrm{E}+01$ & 1 & $\mathrm{~s}$ & \#\#\#\#\# & 1 & 0 & 1 & 3 & 0 & Ba-144 > La-144 1.0 \\
\hline 571440 & $4.08 \mathrm{E}+01$ & 1 & $\mathrm{~s}$ & \#\#\#\#\#\# & 1 & 0 & 1 & 4 & 0 & La-144 > Ce-144 1.0 \\
\hline 581440 & $2.85 \mathrm{E}+02$ & 4 & $\mathrm{~d}$ & $6.09 \mathrm{E}-02$ & 1 & 1 & 1 & 5 & $1.49 \mathrm{E}-01$ & $\mathrm{Ce}-144>\operatorname{Pr}-1441.0$ \\
\hline 591441 & $7.20 \mathrm{E}+00$ & 2 & $\mathrm{~m}$ & $6.68 \mathrm{E}-05$ & 0.9993 & 0 & 1 & 6 & 0 & Pr- $144 m>\operatorname{Pr}-144.994$ \\
\hline 591440 & $1.73 \mathrm{E}+01$ & 2 & $\mathrm{~m}$ & $8.25 \mathrm{E}-05$ & 1 & -1 & 1 & 7 & 0 & $\operatorname{Pr}-144>$ stable \\
\hline 611440 & $3.63 \mathrm{E}+02$ & 4 & $\mathrm{~d}$ & 0 & 1 & 0 & 1 & 0 & -1 & Pm-144 > stable \\
\hline 601440 & $2.29 \mathrm{E}+15$ & 5 & $\mathrm{y}$ & 0 & 1 & -1 & 1 & 0 & -1 & Nd-144 > stable \\
\hline 541450 & $9.00 \mathrm{E}-01$ & 1 & $\mathrm{~s}$ & $1.48 \mathrm{E}-04$ & 1 & 0 & 3 & 0 & 0 & Xe-145 > Cs-145 1.0 \\
\hline 551450 & $5.94 \mathrm{E}-01$ & 1 & $\mathrm{~s}$ & $7.18 \mathrm{E}-02$ & 1 & 0 & 4 & 1 & -0.3 & Cs-145 > Ba-145 1.0 \\
\hline 561450 & $4.31 \mathrm{E}+00$ & 1 & $\mathrm{~s}$ & \#\#\#\#\#\# & 1 & 0 & 1 & 2 & -0.3 & Ba-145 > La-145 1.0 \\
\hline 571450 & $2.48 \mathrm{E}+01$ & 1 & $\mathrm{~S}$ & \#\#\#\#\#\# & 1 & 0 & 1 & 3 & -0.3 & La-145>Ce-145 1.0 \\
\hline 581450 & $3.01 \mathrm{E}+00$ & 2 & $\mathrm{~m}$ & $2.30 \mathrm{E}-01$ & 1 & 0 & 1 & 4 & 0 & $\mathrm{Ce}-145>\operatorname{Pr}-145$ \\
\hline 591450 & $5.98 \mathrm{E}+00$ & 3 & $\mathrm{~h}$ & $9.32 \mathrm{E}-04$ & 1 & -1 & 1 & 5 & 0 & Pr-145 > stable \\
\hline 651490 & $4.12 \mathrm{E}+00$ & 3 & $\mathrm{~h}$ & 0 & 0.0167 & 3 & 1 & 0 & -1 & $\begin{array}{l}\text { Tb-149 Gd-149 .833 Eu-145 } \\
.167\end{array}$ \\
\hline 641490 & $9.28 \mathrm{E}+00$ & 4 & $\mathrm{~d}$ & 0 & 1 & 0 & 1 & 1 & -1 & Gd-149 > Eu-149 \\
\hline 631490 & $9.31 \mathrm{E}+01$ & 4 & $\mathrm{~d}$ & 0 & 1 & -1 & 1 & 2 & -1 & Eu-149 > stable \\
\hline 641450 & $2.30 \mathrm{E}+01$ & 2 & $\mathrm{~m}$ & 0 & 1 & 0 & 1 & 0 & -1 & Gd-145 > Eu-145 1.0 \\
\hline 631450 & $5.93 \mathrm{E}+00$ & 4 & $\mathrm{~d}$ & 0 & 1 & 0 & 1 & 4 & -1 & Eu-145 > Sm-145 1.0 \\
\hline 621450 & $3.40 \mathrm{E}+02$ & 4 & $\mathrm{~d}$ & 0 & 1 & 0 & 1 & 5 & -1 & Sm-145 > Pm-145 1.0 \\
\hline 611450 & $1.77 \mathrm{E}+01$ & 5 & $\mathrm{y}$ & 0 & 1 & -1 & 1 & 6 & -1 & Pm-145 > stable \\
\hline 541460 & $9.37 \mathrm{E}-01$ & 1 & $\mathrm{~s}$ & $1.38 \mathrm{E}-05$ & 1 & 0 & 3 & 0 & -0.3 & Xe-146>Cs-146 1.0 \\
\hline 551460 & $3.21 \mathrm{E}-01$ & 1 & $\mathrm{~s}$ & $8.10 \mathrm{E}-03$ & 1 & 0 & 4 & 1 & -0.3 & Cs-146 > Ba-146 1.0 \\
\hline 561460 & $2.22 \mathrm{E}+00$ & 1 & $\mathrm{~S}$ & $6.68 \mathrm{E}-01$ & 1 & 0 & 1 & 2 & -0.3 & $\mathrm{Ba}-146>\mathrm{La}-1461.0$ \\
\hline 571460 & $6.27 \mathrm{E}+00$ & 1 & $\mathrm{~s}$ & \#\#\#\#\#\# & 1 & 0 & 1 & 3 & -0.3 & La-146 > Ce-146 1.0 \\
\hline 581460 & $1.35 \mathrm{E}+01$ & 2 & $\mathrm{~m}$ & $6.73 \mathrm{E}-01$ & 1 & 0 & 1 & 4 & 0 & Ce-146 > Pr-146 1.0 \\
\hline 591460 & $2.42 \mathrm{E}+01$ & 2 & $\mathrm{~m}$ & $8.54 \mathrm{E}-03$ & 1 & -1 & 1 & 5 & 0 & Pr-146 > stable \\
\hline 641460 & $4.83 \mathrm{E}+01$ & 4 & $\mathrm{~d}$ & 0 & 1 & 0 & 1 & 0 & -1 & Gd-146> Eu-146 1.0 \\
\hline 631460 & $4.59 \mathrm{E}+00$ & 4 & $\mathrm{~d}$ & 0 & 1 & 1 & 1 & 1 & -1 & Eu-146 > Sm-146 1.0 \\
\hline 611460 & $5.53 \mathrm{E}+00$ & 5 & $\mathrm{y}$ & 0 & 0.359 & 0 & 1 & 0 & -1 & Pm-146 > Sm-146 0.359 \\
\hline
\end{tabular}




\begin{tabular}{|c|c|c|c|c|c|c|c|c|c|c|}
\hline 621460 & $1.03 \mathrm{E}+08$ & 5 & $\mathrm{y}$ & 0 & 1 & -1 & 1 & 3 & -1 & Sm-146> stable \\
\hline 541470 & $2.64 \mathrm{E}-01$ & 1 & $\mathrm{~s}$ & $2.39 \mathrm{E}-07$ & 1 & 0 & 1 & 0 & -0.3 & Xe-147> Cs-147 1.0 \\
\hline 551470 & $2.25 \mathrm{E}-01$ & 1 & $\mathrm{~s}$ & $5.90 \mathrm{E}-04$ & 1 & 0 & 4 & 1 & -0.3 & Cs-147> Ba-147 1.0 \\
\hline 561470 & 8.94E-01 & 1 & $\mathrm{~s}$ & $1.30 \mathrm{E}-01$ & 1 & 0 & 1 & 2 & -0.3 & Ba-147 > La-147 1.0 \\
\hline 571470 & $4.06 \mathrm{E}+00$ & 1 & $\mathrm{~s}$ & 9.37E-01 & 1 & 0 & 1 & 3 & -0.3 & La-147> Ce-147 1.0 \\
\hline 581470 & $5.64 \mathrm{E}+01$ & 1 & $\mathrm{~s}$ & \#\#\#\#\#\# & 1 & 0 & 1 & 4 & -0.3 & $\mathrm{Ce}-147>$ Pr-147 1.0 \\
\hline 591470 & $1.34 \mathrm{E}+01$ & 2 & $\mathrm{~m}$ & $5.38 \mathrm{E}-02$ & 1 & 0 & 1 & 5 & 0 & $\operatorname{Pr}-147>\mathrm{Nd}-1471.0$ \\
\hline 601470 & $1.10 \mathrm{E}+01$ & 4 & $\mathrm{~d}$ & $2.96 \mathrm{E}-04$ & 1 & 2 & 1 & 6 & $2.01 \mathrm{E}+01$ & Nd-147> Pm-147 1.0 \\
\hline 610010 & $1.00 \mathrm{E}+17$ & 5 & $\mathrm{y}$ & \#\#\#\#\#\# & 1 & 0 & 1 & 7 & -2 & pseudo $>$ pseudo 1.0 \\
\hline 610020 & $1.00 \mathrm{E}+19$ & 5 & $\mathrm{y}$ & $1.00 \mathrm{E}-01$ & 1 & 0 & 1 & 8 & -2 & pseudo > Pm-147 1.0 \\
\hline 611470 & $2.62 \mathrm{E}+00$ & 5 & $\mathrm{y}$ & \#\#\#\#\#\# & 1 & 6 & 1 & 9 & $6.19 \mathrm{E}+02$ & Pm-147 > Sm-147 1.0 \\
\hline 620010 & $7.00 \mathrm{E}+19$ & 5 & $\mathrm{y}$ & $7.00 \mathrm{E}-01$ & 1 & 5 & 1 & 0 & -2 & pseudo $>$ Sm-147 1.0 \\
\hline 651470 & $1.64 \mathrm{E}+00$ & 3 & $\mathrm{~h}$ & 0 & 1 & 0 & 1 & 0 & 0 & Tb-147> Gd-147 1.0 \\
\hline 641470 & $3.81 \mathrm{E}+01$ & 3 & $\mathrm{~h}$ & 0 & 1 & 2 & 1 & 1 & 0 & Gd-147> Eu-147 1.0 \\
\hline 651510 & $1.76 \mathrm{E}+01$ & 3 & $\mathrm{~h}$ & 0 & 1 & 0 & 1 & 0 & 0 & Tb-151 Gd-151 1.0 \\
\hline 641510 & $1.24 \mathrm{E}+02$ & 4 & $\mathrm{~d}$ & 0 & 1 & -1 & 1 & 1 & -1 & Gd-151 > Stable \\
\hline 631470 & $2.41 \mathrm{E}+01$ & 4 & $\mathrm{~d}$ & 0 & 1 & 0 & 1 & 2 & 0 & Eu-147 > Sm-147 1.0 \\
\hline 621470 & $1.06 \mathrm{E}+11$ & 5 & $\mathrm{y}$ & $1.01 \mathrm{E}-06$ & 1 & -1 & 1 & 16 & 0 & Sm-147> stable \\
\hline 551480 & $1.58 \mathrm{E}-01$ & 1 & $\mathrm{~s}$ & $1.81 \mathrm{E}-05$ & 1 & 0 & 4 & 0 & -0.3 & $\mathrm{Cs}-148>\mathrm{Ba}-1481.0$ \\
\hline 561480 & $6.07 \mathrm{E}-01$ & 1 & $\mathrm{~s}$ & $1.52 \mathrm{E}-02$ & 1 & 0 & 1 & 1 & -0.3 & Ba-148 > La-148 1.0 \\
\hline 571480 & $1.26 \mathrm{E}+00$ & 1 & $\mathrm{~s}$ & $3.42 \mathrm{E}-01$ & 1 & 0 & 1 & 2 & -0.3 & La-148> Ce-148 1.0 \\
\hline 581480 & $5.60 \mathrm{E}+01$ & 1 & $\mathrm{~s}$ & \#\#\#\#\#\# & 1 & 0 & 1 & 3 & -0.3 & $\mathrm{Ce}-148>$ Pr-148 1.0 \\
\hline 591480 & $2.29 \mathrm{E}+00$ & 2 & $\mathrm{~m}$ & $1.61 \mathrm{E}-01$ & 1 & -1 & 1 & 4 & 0 & Pr-148 > stable \\
\hline 610030 & $8.00 \mathrm{E}+19$ & 5 & $\mathrm{y}$ & $1.50 \mathrm{E}-01$ & 1 & 0 & 1 & 0 & -2 & pseudo > Pm-148m 1.0 \\
\hline 611481 & $4.13 \mathrm{E}+01$ & 4 & $\mathrm{~d}$ & $7.42 \mathrm{E}-07$ & 0.042 & 1 & 1 & 1 & 0 & $\begin{array}{l}\text { Pm-148m pseudo .958 Pm-148 } \\
.042\end{array}$ \\
\hline 610040 & $1.12 \mathrm{E}+20$ & 5 & $\mathrm{y}$ & 4.20E-01 & 1 & 0 & 1 & 2 & -2 & pseudo > Pm-148 1.0 \\
\hline 611480 & $5.37 \mathrm{E}+00$ & 4 & $\mathrm{~d}$ & $5.10 \mathrm{E}-06$ & 1 & 2 & 1 & 3 & 0 & Pm-148 > Sm-148 \\
\hline 641480 & $7.46 \mathrm{E}+01$ & 5 & $\mathrm{y}$ & 0 & 1 & -1 & 1 & 0 & -1 & Gd-148 > stable \\
\hline 631480 & $5.45 \mathrm{E}+01$ & 4 & $\mathrm{~d}$ & 0 & 1 & 0 & 1 & 0 & -1 & Eu-148 > Sm-148 \\
\hline 621480 & $7.00 \mathrm{E}+15$ & 5 & $\mathrm{y}$ & 0 & 1 & -1 & 1 & 1 & -1 & Sm-148> stable \\
\hline 561490 & $3.44 \mathrm{E}-01$ & 1 & $\mathrm{~s}$ & $9.27 \mathrm{E}-04$ & 1 & 0 & 1 & 0 & -0.3 & Ba-149 > La-149 1.0 \\
\hline
\end{tabular}


RSAC-7.2 Nuclear Data Library

\begin{tabular}{|c|c|c|c|c|c|c|c|c|c|c|}
\hline 571490 & $1.05 \mathrm{E}+00$ & 1 & $\mathrm{~s}$ & 7.02E-02 & 1 & 0 & 1 & 1 & -0.3 & La-149> Ce-149 1.0 \\
\hline 581490 & $5.30 \mathrm{E}+00$ & 1 & $\mathrm{~s}$ & $7.10 \mathrm{E}-01$ & 1 & 0 & 1 & 2 & -0.3 & Ce-149 > Pr-149 1.0 \\
\hline 591490 & $2.26 \mathrm{E}+00$ & 2 & $\mathrm{~m}$ & 2.89E-01 & 1 & 0 & 1 & 3 & 0 & Pr-149> Nd-149 1.0 \\
\hline 601490 & $1.73 \mathrm{E}+00$ & 3 & $\mathrm{~h}$ & $1.81 \mathrm{E}-02$ & 1 & 1 & 1 & 4 & 0 & Nd-149 > Pm-149 1.0 \\
\hline 610050 & $1.00 \mathrm{E}+18$ & 5 & $\mathrm{y}$ & $1.70 \mathrm{E}-01$ & 1 & 0 & 1 & 5 & -2 & pseudo > Pm-149 1.0 \\
\hline 611490 & $5.31 \mathrm{E}+01$ & 3 & $\mathrm{~h}$ & $3.12 \mathrm{E}-05$ & 1 & -1 & 1 & 6 & $1.32 \mathrm{E}+02$ & Pm-149 > stable \\
\hline 621490 & $2.00 \mathrm{E}+15$ & 5 & $\mathrm{y}$ & 0 & 1 & -1 & 1 & 0 & -1 & Sm-149 > stable \\
\hline 610060 & $1.00 \mathrm{E}+17$ & 5 & $\mathrm{y}$ & $3.73 \mathrm{E}-03$ & 1 & 0 & 1 & 0 & -2 & pseudo > Pm-115 1.0 \\
\hline 611500 & $2.68 \mathrm{E}+00$ & 3 & $\mathrm{~h}$ & $2.82 \mathrm{E}-07$ & 1 & -1 & 1 & 1 & 0 & Pm-150 > stable \\
\hline 631500 & $3.69 \mathrm{E}+01$ & 5 & $\mathrm{y}$ & 0 & 1 & -1 & 1 & 0 & -1 & Eu-150 > stable \\
\hline 631503 & $1.28 \mathrm{E}+01$ & 3 & $\mathrm{~h}$ & 0 & 1 & -1 & 1 & 0 & -1 & Eu-150b $>$ stable \\
\hline 651500 & $3.48 \mathrm{E}+00$ & 3 & $\mathrm{~h}$ & 0 & 1 & -1 & 1 & 0 & -1 & Tb-150 > stable \\
\hline 571510 & $9.54 \mathrm{E}-01$ & 1 & $\mathrm{~s}$ & $8.95 \mathrm{E}-04$ & 1 & 0 & 1 & 0 & -0.3 & La-151>Ce-151 1.0 \\
\hline 581510 & $1.02 \mathrm{E}+00$ & 1 & $\mathrm{~s}$ & $7.58 \mathrm{E}-02$ & 1 & 0 & 1 & 1 & -0.3 & $\mathrm{Ce}-151>\operatorname{Pr}-1511.0$ \\
\hline 591510 & $1.89 \mathrm{E}+01$ & 1 & $\mathrm{~s}$ & $2.24 \mathrm{E}-01$ & 1 & 0 & 1 & 2 & -0.3 & Pr- $151>$ Nd-151 1.0 \\
\hline 601510 & $1.24 \mathrm{E}+01$ & 2 & $\mathrm{~m}$ & $1.19 \mathrm{E}-01$ & 1 & 0 & 1 & 3 & 0 & Nd-151 > Pm-151 1.0 \\
\hline 611510 & $2.84 \mathrm{E}+01$ & 3 & $\mathrm{~h}$ & $1.77 \mathrm{E}-03$ & 1 & 0 & 1 & 4 & $1.03 \mathrm{E}+02$ & Pm-151 > Sm-151 1.0 \\
\hline 621510 & $9.00 \mathrm{E}+01$ & 5 & $\mathrm{y}$ & $3.80 \mathrm{E}-06$ & 1 & -1 & 1 & 5 & $7.26 \mathrm{E}+02$ & Sm-151 > stable \\
\hline 561520 & $7.55 \mathrm{E}-01$ & 1 & $\mathrm{~s}$ & $1.96 \mathrm{E}-08$ & 1 & 0 & 1 & 0 & -0.3 & Ba-152> La-152 1.0 \\
\hline 571520 & $3.09 \mathrm{E}-01$ & 1 & $\mathrm{~s}$ & $4.98 \mathrm{E}-05$ & 1 & 0 & 1 & 1 & -0.3 & La-152 > Ce-152 1.0 \\
\hline 581520 & $1.40 \mathrm{E}+00$ & 1 & $\mathrm{~s}$ & $1.36 \mathrm{E}-02$ & 1 & 0 & 1 & 2 & -0.3 & $\mathrm{Ce}-152>\operatorname{Pr}-1521.0$ \\
\hline 591520 & $3.63 \mathrm{E}+00$ & 1 & $\mathrm{~s}$ & $1.08 \mathrm{E}-01$ & 1 & 0 & 1 & 3 & -0.3 & Pr-152 > Nd-152 1.0 \\
\hline 601520 & $1.14 \mathrm{E}+01$ & 2 & $\mathrm{~m}$ & $1.45 \mathrm{E}-01$ & 1 & 1 & 1 & 4 & -0.3 & Nd-152 > Pm-152 1.0 \\
\hline 611521 & $7.52 \mathrm{E}+00$ & 2 & $\mathrm{~m}$ & $3.67 \mathrm{E}-03$ & 1 & 0 & 1 & 5 & -0.3 & Pm-152m> Pm-152 1.0 \\
\hline 611520 & $4.12 \mathrm{E}+00$ & 2 & $\mathrm{~m}$ & $3.67 \mathrm{E}-03$ & 1 & -1 & 1 & 6 & 0 & Pm-152 > stable \\
\hline 630010 & $9.00 \mathrm{E}+19$ & 5 & $\mathrm{y}$ & $1.59 \mathrm{E}-04$ & 1 & 0 & 1 & 0 & -2 & pseudo $>$ pseudo \\
\hline 630020 & $1.00 \mathrm{E}+19$ & 5 & $\mathrm{y}$ & $9.70 \mathrm{E}-05$ & 1 & 0 & 1 & 1 & -2 & pseudo $>$ Eu-152 1.0 \\
\hline 631520 & $1.35 \mathrm{E}+01$ & 5 & $\mathrm{y}$ & \#\#\#\#\#\# & 1 & -1 & 1 & 2 & $1.91 \mathrm{E}+02$ & Eu-152 > stable \\
\hline 631521 & $9.31 \mathrm{E}+00$ & 3 & $\mathrm{~h}$ & 0 & 0.72 & 0 & 1 & 0 & -1 & Eu-152m > Gd-152 0.72 \\
\hline 641520 & $1.08 \mathrm{E}+14$ & 5 & $\mathrm{y}$ & 0 & 1 & -1 & 1 & 1 & -1 & Gd-152 > stable \\
\hline 571530 & 4.37E-01 & 1 & $\mathrm{~s}$ & $1.46 \mathrm{E}-06$ & 1 & 0 & 1 & 0 & -0.3 & La-153 > Ce-153 1.0 \\
\hline
\end{tabular}




\begin{tabular}{|c|c|c|c|c|c|c|c|c|c|c|}
\hline 581530 & $1.73 \mathrm{E}+00$ & 1 & $\mathrm{~s}$ & $1.31 \mathrm{E}-03$ & 1 & 0 & 1 & 1 & -0.3 & Ce-153 > Pr-153 1.0 \\
\hline 591530 & $4.30 \mathrm{E}+00$ & 1 & $\mathrm{~s}$ & $3.13 \mathrm{E}-02$ & 1 & 0 & 1 & 2 & -0.3 & Pr- $153>$ Nd-153 1.0 \\
\hline 601530 & $3.16 \mathrm{E}+01$ & 1 & $\mathrm{~s}$ & $1.17 \mathrm{E}-01$ & 1 & 0 & 1 & 3 & -0.3 & Nd-153 > Pm-153 \\
\hline 611530 & $5.25 \mathrm{E}+00$ & 2 & $\mathrm{~m}$ & $1.65 \mathrm{E}-02$ & 1 & 2 & 1 & 4 & -0.3 & Pm-153 > Sm-153 \\
\hline 651530 & $2.34 \mathrm{E}+00$ & 4 & $\mathrm{~d}$ & 0 & 1 & 4 & 1 & 0 & -1 & Tb-153 > Gd-153 1.0 \\
\hline 620020 & $2.00 \mathrm{E}+19$ & 5 & $\mathrm{y}$ & $4.50 \mathrm{E}-01$ & 1 & 0 & 1 & 0 & -2 & pseudo > Sm-153 1.0 \\
\hline 621530 & $4.65 \mathrm{E}+01$ & 3 & $\mathrm{~h}$ & $3.34 \mathrm{E}-04$ & 1 & -1 & 1 & 7 & $8.98 \mathrm{E}+01$ & Sm-153 > stable \\
\hline 640010 & $5.10 \mathrm{E}-02$ & $\begin{array}{c}5 \\
.68 \\
E+1 \\
8 \\
\end{array}$ & $\begin{array}{c}\# \# \# \\
\# \\
\end{array}$ & 1 & 0 & 1 & 0 & -2 & $\begin{array}{l}\text { pseudo }> \\
\text { pseudo }\end{array}$ & \\
\hline 640020 & $1.00 \mathrm{E}+24$ & 5 & $\mathrm{y}$ & $1.00 \mathrm{E}-03$ & 1 & 0 & 1 & 1 & -2 & pseudo > Gd-153 1.0 \\
\hline 641530 & $2.41 \mathrm{E}+02$ & 4 & $\mathrm{~d}$ & $9.70 \mathrm{E}-12$ & 1 & -1 & 1 & 10 & 0 & Gd-153 > stable \\
\hline 571540 & $1.75 \mathrm{E}-01$ & 1 & $\mathrm{~s}$ & $3.14 \mathrm{E}-08$ & 1 & 0 & 1 & 0 & -0.3 & La-154 > Ce-154 1.0 \\
\hline 581540 & $3.59 \mathrm{E}-01$ & 1 & $\mathrm{~s}$ & 8.09E-05 & 1 & 0 & 1 & 1 & -0.3 & $\mathrm{Ce}-154>\operatorname{Pr}-1541.0$ \\
\hline 591540 & $2.30 \mathrm{E}+00$ & 1 & $\mathrm{~s}$ & $5.53 \mathrm{E}-03$ & 1 & 0 & 1 & 2 & -0.3 & Pr-154 > Nd-154 1.0 \\
\hline 601540 & $2.59 \mathrm{E}+01$ & 1 & $\mathrm{~s}$ & $5.10 \mathrm{E}-02$ & 1 & 1 & 1 & 3 & -0.3 & Nd-154 > Pm-154 1.0 \\
\hline 611541 & $2.68 \mathrm{E}+00$ & 2 & $\mathrm{~m}$ & $9.40 \mathrm{E}-03$ & 1 & 0 & 1 & 4 & -0.3 & Pm-154m> Pm-154.10 \\
\hline 611540 & $1.73 \mathrm{E}+00$ & 2 & $\mathrm{~m}$ & $9.40 \mathrm{E}-03$ & 1 & -1 & 1 & 5 & -0.3 & Pm-154 > stable \\
\hline 630030 & $1.75 \mathrm{E}+17$ & 5 & $\mathrm{y}$ & $5.20 \mathrm{E}-02$ & 1 & 0 & 1 & 0 & -2 & pseudo $>$ pseudo \\
\hline 630040 & $1.00 \mathrm{E}+19$ & 5 & $\mathrm{y}$ & $1.00 \mathrm{E}-03$ & 1 & 0 & 1 & 1 & -2 & pseudo $>$ Eu-154 1.0 \\
\hline 631540 & $8.60 \mathrm{E}+00$ & 5 & $\mathrm{y}$ & $1.73 \mathrm{E}-06$ & 1 & -1 & 1 & 2 & $1.29 \mathrm{E}+02$ & Eu-154 > stable \\
\hline 651540 & $2.15 \mathrm{E}+01$ & 3 & $\mathrm{~h}$ & 0 & 1 & -1 & 1 & 0 & -1 & Tb-154 > stable \\
\hline 581550 & $7.13 \mathrm{E}-01$ & 1 & s & $3.31 \mathrm{E}-06$ & 1 & 0 & 1 & 0 & -0.3 & Ce-155 > Pr-155 1.0 \\
\hline 591550 & $1.89 \mathrm{E}+00$ & 1 & $\mathrm{~s}$ & $6.84 \mathrm{E}-04$ & 1 & 0 & 1 & 1 & -0.3 & Pr- $155>$ Nd-155 1.0 \\
\hline 601550 & $8.90 \mathrm{E}+00$ & 1 & $\mathrm{~s}$ & $1.72 \mathrm{E}-02$ & 1 & 0 & 1 & 2 & -0.3 & Nd-155 > Pm-155 1.0 \\
\hline 611550 & $4.15 \mathrm{E}+01$ & 1 & $\mathrm{~S}$ & $1.57 \mathrm{E}-02$ & 1 & 0 & 1 & 3 & -0.3 & Pm-155 > Sm-155 1.0 \\
\hline 621550 & $2.23 \mathrm{E}+01$ & 2 & $\mathrm{~m}$ & $2.59 \mathrm{E}-03$ & 1 & 1 & 1 & 4 & 0 & Sm-155 > Eu-155 1.0 \\
\hline 630050 & $1.00 \mathrm{E}+18$ & 5 & $\mathrm{y}$ & \#\#\#\#\#\# & 1 & 0 & 1 & 0 & -2 & pseudo $>$ Eu-155 1.0 \\
\hline 631550 & $4.75 \mathrm{E}+00$ & 5 & $\mathrm{y}$ & $2.00 \mathrm{E}-08$ & 1 & -1 & 1 & 6 & $3.66 \mathrm{E}+02$ & Eu-155 > stable \\
\hline 671550 & $4.80 \mathrm{E}+01$ & 2 & $\mathrm{~m}$ & 0 & 1 & 0 & 1 & 0 & -1 & Ho-155 > Dy-155 1.0 \\
\hline 661550 & $9.90 \mathrm{E}+00$ & 3 & $\mathrm{~h}$ & 0 & 1 & 0 & 1 & 1 & -1 & Dy-155 > Tb-155 1.0 \\
\hline
\end{tabular}




\begin{tabular}{|c|c|c|c|c|c|c|c|c|c|c|}
\hline 651550 & $5.32 \mathrm{E}+00$ & 4 & $\mathrm{~d}$ & 0 & 1 & -1 & 1 & 2 & -1 & Tb-155> stable \\
\hline 581560 & $1.16 \mathrm{E}+00$ & 1 & $\mathrm{~s}$ & $9.13 \mathrm{E}-08$ & 1 & 0 & 1 & 0 & -0.3 & $\mathrm{Ce}-156>\operatorname{Pr}-1561.0$ \\
\hline 591560 & $5.10 \mathrm{E}-01$ & 1 & $\mathrm{~s}$ & $5.08 \mathrm{E}-05$ & 1 & 0 & 1 & 1 & -0.3 & Pr-156 > Nd-156 1.0 \\
\hline 601560 & $5.47 \mathrm{E}+00$ & 1 & $\mathrm{~s}$ & $3.50 \mathrm{E}-03$ & 1 & 0 & 1 & 2 & -0.3 & Nd-156 > Pm-156 1.0 \\
\hline 611560 & $2.67 \mathrm{E}+01$ & 1 & $\mathrm{~s}$ & $8.04 \mathrm{E}-03$ & 1 & 1 & 1 & 3 & -0.3 & Pm-156 > Sm-156 1.0 \\
\hline 630070 & $2.30 \mathrm{E}+17$ & 5 & $\mathrm{y}$ & $7.70 \mathrm{E}-02$ & 1 & 0 & 1 & 0 & -2 & pseudo > Sm-156 1.0 \\
\hline 621560 & $9.40 \mathrm{E}+00$ & 3 & $\mathrm{~h}$ & $3.34 \mathrm{E}-03$ & 0.001 & 0 & 1 & 5 & 0 & Sm-156 > Eu-156 1.0 \\
\hline 631560 & $1.52 \mathrm{E}+01$ & 4 & $\mathrm{~d}$ & 4.54E-05 & 1 & -1 & 1 & 6 & $7.38 \mathrm{E}+02$ & Eu-156 > stable \\
\hline 651561 & $5.00 \mathrm{E}+00$ & 3 & $\mathrm{~h}$ & 0 & 1 & 0 & 1 & 0 & -1 & Tb- $156 \mathrm{~m}>\mathrm{Tb}-1561.0$ \\
\hline 651560 & $5.35 \mathrm{E}+00$ & 4 & $\mathrm{~d}$ & 0 & 1 & -1 & 1 & 1 & -1 & Tb-156 > stable \\
\hline 581570 & $3.62 \mathrm{E}-01$ & 1 & $\mathrm{~s}$ & $2.45 \mathrm{E}-09$ & 1 & 0 & 1 & 0 & -0.3 & $\mathrm{Ce}-157>\operatorname{Pr}-1571.0$ \\
\hline 591570 & $6.78 \mathrm{E}-01$ & 1 & $\mathrm{~s}$ & $3.10 \mathrm{E}-06$ & 1 & 0 & 1 & 1 & -0.3 & Pr- $157>$ Nd-157 1.0 \\
\hline 601570 & $4.15 \mathrm{E}+00$ & 1 & $\mathrm{~s}$ & 5.94E-04 & 1 & 0 & 1 & 2 & -0.3 & Nd-157> Pm-157 1.0 \\
\hline 611570 & $1.06 \mathrm{E}+01$ & 1 & $\mathrm{~s}$ & $3.47 \mathrm{E}-03$ & 1 & 0 & 1 & 3 & -0.3 & Pm-157 > Sm-157 1.0 \\
\hline 621570 & $4.82 \mathrm{E}+02$ & 1 & $\mathrm{~s}$ & $3.53 \mathrm{E}-03$ & 0.001 & 0 & 1 & 4 & -0.3 & Sm-157 > Eu-157.001 \\
\hline 631570 & $1.52 \mathrm{E}+01$ & 3 & $\mathrm{~h}$ & $8.12 \mathrm{E}-03$ & 1 & -1 & 1 & 5 & $4.61 \mathrm{E}+02$ & Eu-157> stable \\
\hline 671570 & $1.26 \mathrm{E}+01$ & 2 & $\mathrm{~m}$ & 0 & 1 & 0 & 1 & 0 & -1 & Ho-157 > Dy-157 1.0 \\
\hline 661570 & $8.14 \mathrm{E}+00$ & 3 & $\mathrm{~h}$ & 0 & 1 & 0 & 1 & 1 & -1 & Dy-157 > Tb-157 1.0 \\
\hline 651570 & $7.10 \mathrm{E}+01$ & 5 & $\mathrm{y}$ & 0 & 1 & -1 & 1 & 2 & -1 & Tb-157> stable \\
\hline 591580 & $2.63 \mathrm{E}-01$ & 1 & $\mathrm{~s}$ & $1.28 \mathrm{E}-07$ & 1 & 0 & 1 & 0 & -0.3 & Pr- $158>$ Nd-158 1.0 \\
\hline 601580 & $7.89 \mathrm{E}+00$ & 1 & $\mathrm{~s}$ & $6.66 \mathrm{E}-05$ & 1 & 0 & 1 & 1 & -0.3 & Nd-158 > Pm-158 1.0 \\
\hline 611580 & $4.80 \mathrm{E}+00$ & 1 & $\mathrm{~s}$ & $1.04 \mathrm{E}-03$ & 1 & 0 & 1 & 2 & -0.3 & Pm-158 > Sm-158 1.0 \\
\hline 621580 & $5.30 \mathrm{E}+00$ & 2 & $\mathrm{~m}$ & $2.58 \mathrm{E}-03$ & 1 & 0 & 1 & 3 & -0.3 & Sm-158 > Eu-158 1.0 \\
\hline 631580 & $4.59 \mathrm{E}+01$ & 2 & $\mathrm{~m}$ & $2.58 \mathrm{E}-04$ & 1 & -1 & 1 & 4 & 0 & Eu-158 > stable \\
\hline 651580 & $1.80 \mathrm{E}+02$ & 5 & $\mathrm{y}$ & 0 & 1 & -1 & 1 & 0 & -1 & Tb-158 > stable \\
\hline 591590 & $3.14 \mathrm{E}-01$ & 1 & $\mathrm{~s}$ & $2.10 \mathrm{E}-09$ & 1 & 0 & 1 & 0 & -0.3 & Pr-159> Nd-159 1.0 \\
\hline 601590 & $1.41 \mathrm{E}+00$ & 1 & $\mathrm{~s}$ & $3.08 \mathrm{E}-06$ & 1 & 0 & 1 & 1 & -0.3 & Nd-159 > Pm-159 1.0 \\
\hline 611590 & $4.23 \mathrm{E}+00$ & 1 & $\mathrm{~s}$ & $1.43 \mathrm{E}-04$ & 1 & 0 & 1 & 2 & -0.3 & Pm-159 > Sm-159 1.0 \\
\hline 621590 & $1.14 \mathrm{E}+01$ & 1 & $\mathrm{~s}$ & $9.04 \mathrm{E}-04$ & 1 & 0 & 1 & 3 & -0.3 & Sm-159 > Eu-159 1.0 \\
\hline 631590 & $1.81 \mathrm{E}+01$ & 2 & $\mathrm{~m}$ & $2.62 \mathrm{E}-04$ & 1 & 1 & 1 & 4 & 0 & Eu-159> Gd-159 1.0 \\
\hline 640030 & $5.00 \mathrm{E}+18$ & 5 & $\mathrm{y}$ & $2.20 \mathrm{E}-04$ & 1 & 0 & 1 & 0 & -2 & pseudo > Gd-159 1.0 \\
\hline
\end{tabular}


RSAC-7.2 Nuclear Data Library

\begin{tabular}{|c|c|c|c|c|c|c|c|c|c|c|}
\hline 641590 & $1.85 \mathrm{E}+01$ & 3 & $\mathrm{~h}$ & $1.22 \mathrm{E}-05$ & 1 & -1 & 1 & 6 & 0 & Gd-159> stable \\
\hline 671590 & $3.31 \mathrm{E}+01$ & 2 & $\mathrm{~m}$ & 0 & 1 & 0 & 1 & 0 & -1 & Ho-159 > Dy-159 1.0 \\
\hline 661590 & $1.44 \mathrm{E}+02$ & 4 & $\mathrm{~d}$ & 0 & 1 & -1 & 1 & 1 & -1 & Dy-159> stable \\
\hline 651600 & $7.23 \mathrm{E}+01$ & 4 & $\mathrm{~d}$ & 0 & 1 & -1 & 1 & 0 & -1 & Tb- $160>$ stable \\
\hline 651610 & $6.91 \mathrm{E}+00$ & 4 & $\mathrm{~d}$ & 0 & 1 & -1 & 1 & 0 & -1 & Tb-161 > stable \\
\hline 681610 & $3.21 \mathrm{E}+00$ & 3 & $\mathrm{~h}$ & 0 & 1 & 0 & 1 & 0 & -1 & Er-161 > Ho-161 1.0 \\
\hline 671610 & $2.48 \mathrm{E}+00$ & 3 & $\mathrm{~h}$ & 0 & 1 & -1 & 1 & 1 & -1 & Ho- $161>$ stable \\
\hline 701620 & $1.89 \mathrm{E}+01$ & 2 & $\mathrm{~m}$ & 0 & 1 & 0 & 1 & 0 & -1 & Yb-162 > Tm-162 1.0 \\
\hline 691620 & $2.43 \mathrm{E}+01$ & 1 & $\mathrm{~s}$ & 0 & 1 & -1 & 1 & 1 & -1 & Tm-162> stable \\
\hline 671641 & $3.75 \mathrm{E}+01$ & 2 & $\mathrm{~m}$ & 0 & 1 & 0 & 1 & 0 & -1 & Ho- $164 \mathrm{~m}>$ Ho-164 1.0 \\
\hline 671640 & $2.90 \mathrm{E}+01$ & 2 & $\mathrm{~m}$ & 0 & 1 & -1 & 1 & 1 & -1 & Ho- $164>$ stable \\
\hline 661650 & $2.33 \mathrm{E}+00$ & 3 & $\mathrm{~h}$ & 0 & 1 & -1 & 1 & 0 & -1 & Dy-165 > stable \\
\hline 671661 & $1.20 \mathrm{E}+03$ & 5 & $\mathrm{y}$ & 0 & 1 & -1 & 1 & 0 & -1 & Ho- $166 \mathrm{~m}>$ stable \\
\hline 701660 & $5.67 \mathrm{E}+01$ & 3 & $\mathrm{~h}$ & 0 & 1 & 0 & 1 & 0 & -1 & Yb-166 > Tm-166 1.0 \\
\hline 691660 & $7.70 \mathrm{E}+00$ & 3 & $\mathrm{~h}$ & 0 & 1 & -1 & 1 & 1 & -1 & Tm-166 > stable \\
\hline 671670 & $3.10 \mathrm{E}+00$ & 3 & $\mathrm{~h}$ & 0 & 1 & -1 & 1 & 0 & -1 & Ho- $167>$ stable \\
\hline 701670 & $1.75 \mathrm{E}+01$ & 2 & $\mathrm{~m}$ & 0 & 1 & 0 & 1 & 0 & -1 & Yb-167> Tm-167 1.0 \\
\hline 691670 & $9.25 \mathrm{E}+00$ & 4 & $\mathrm{~d}$ & 0 & 1 & -1 & 1 & 1 & -1 & Tm-167 > stable \\
\hline 681690 & $9.39 \mathrm{E}+00$ & 4 & $\mathrm{~d}$ & 0 & 1 & -1 & 1 & 0 & -1 & Er-169> stable \\
\hline 711690 & $3.41 \mathrm{E}+01$ & 3 & $\mathrm{~h}$ & 0 & 1 & 0 & 1 & 0 & -1 & Lu-169 > Yb-169 1.0 \\
\hline 701690 & $3.20 \mathrm{E}+01$ & 4 & $\mathrm{~d}$ & 0 & 1 & -1 & 1 & 1 & -1 & Yb-169> stable \\
\hline 691700 & $1.29 \mathrm{E}+02$ & 4 & $\mathrm{~d}$ & 0 & 1 & -1 & 1 & 0 & -1 & Tm-170 > stable \\
\hline 721700 & $1.60 \mathrm{E}+01$ & 3 & $\mathrm{~h}$ & 0 & 1 & 0 & 1 & 0 & -1 & Hf-170 > Lu-170 1.0 \\
\hline
\end{tabular}




\begin{tabular}{|c|c|c|c|c|c|c|c|c|c|c|}
\hline 711710 & $8.24 \mathrm{E}+00$ & 4 & $\mathrm{~d}$ & 0 & 1 & -1 & 1 & 0 & -1 & Lu-171 > stable \\
\hline 681720 & $4.93 \mathrm{E}+01$ & 3 & $\mathrm{~h}$ & 0 & 1 & 0 & 1 & 0 & -1 & Er-172> Tm-172 1.0 \\
\hline 691720 & $6.36 \mathrm{E}+01$ & 3 & $\mathrm{~h}$ & 0 & 1 & -1 & 1 & 1 & -1 & Tm-172> stable \\
\hline 731720 & $3.67 \mathrm{E}+01$ & 2 & $\mathrm{~m}$ & 0 & 1 & 0 & 1 & 0 & -1 & Ta-172> Hf-172 1.0 \\
\hline 721720 & $1.87 \mathrm{E}+00$ & 5 & $\mathrm{y}$ & 0 & 1 & 0 & 1 & 1 & -1 & Hf-172 > Lu-172 1.0 \\
\hline 711720 & $6.70 \mathrm{E}+00$ & 4 & $\mathrm{~d}$ & 0 & 1 & -1 & 1 & 2 & -1 & Lu-172 $>$ stable \\
\hline 691730 & $8.24 \mathrm{E}+00$ & 3 & $\mathrm{~h}$ & 0 & 1 & -1 & 1 & 0 & -1 & Tm-173 > stable \\
\hline 711730 & $1.37 \mathrm{E}+00$ & 5 & $\mathrm{y}$ & 0 & 1 & -1 & 1 & 2 & -1 & Lu-173 $>$ stable \\
\hline 711741 & $1.42 \mathrm{E}+02$ & 4 & $\mathrm{~d}$ & 0 & 0.993 & 0 & 1 & 0 & -1 & Lu-174m> Lu-174 0.993 \\
\hline 711740 & $3.31 \mathrm{E}+00$ & 5 & $\mathrm{y}$ & 0 & 1 & -1 & 1 & 1 & -1 & Lu-174 > stable \\
\hline 731740 & $1.14 \mathrm{E}+00$ & 3 & $\mathrm{~h}$ & 0 & 1 & -1 & 1 & 1 & -1 & Ta-174 > stable \\
\hline 691750 & $1.52 \mathrm{E}+01$ & 2 & $\mathrm{~m}$ & 0 & 1 & 0 & 1 & 0 & -1 & Tm-175 > Yb-175 1.0 \\
\hline 711761 & $3.64 \mathrm{E}+00$ & 3 & $\mathrm{~h}$ & 0 & 1 & -1 & 1 & 0 & -1 & Lu-176m $>$ stable \\
\hline 711760 & $3.76 \mathrm{E}+10$ & 5 & $\mathrm{y}$ & 0 & 1 & -1 & 1 & 0 & -1 & Lu-176 > stable \\
\hline 741760 & $2.50 \mathrm{E}+00$ & 3 & $\mathrm{~h}$ & 0 & 1 & 0 & 1 & 0 & -1 & $\mathrm{~W}-176>$ Ta-176 1.0 \\
\hline 731760 & $8.09 \mathrm{E}+00$ & 3 & $\mathrm{~h}$ & 0 & 1 & -1 & 1 & 1 & -1 & Ta-176> stable \\
\hline 701770 & $1.91 \mathrm{E}+00$ & 3 & $\mathrm{~h}$ & 0 & 1 & 1 & 1 & 0 & -1 & Yb-177> Lu-177 1.0 \\
\hline 711771 & $1.60 \mathrm{E}+02$ & 4 & $\mathrm{~d}$ & 0 & 0.22 & 0 & 1 & 1 & -1 & Lu-177m > Lu-177 0.22 \\
\hline 711770 & $6.65 \mathrm{E}+00$ & 4 & $\mathrm{~d}$ & 0 & 1 & -1 & 1 & 2 & -1 & Lu-177 > stable \\
\hline 721771 & $5.14 \mathrm{E}+01$ & 2 & $\mathrm{~m}$ & 0 & 1 & -1 & 1 & 0 & -1 & Hf- $177 \mathrm{~m}>\mathrm{Hf}-1771.0$ \\
\hline 751770 & $1.40 \mathrm{E}+01$ & 2 & $\mathrm{~m}$ & 0 & 1 & 0 & 1 & 0 & -1 & Re-177> W-177 1.0 \\
\hline 741770 & $1.32 \mathrm{E}+02$ & 2 & $\mathrm{~m}$ & 0 & 1 & 0 & 1 & 1 & -1 & W-177> Ta-177 1.0 \\
\hline 731770 & $5.66 \mathrm{E}+01$ & 3 & $\mathrm{~h}$ & 0 & 1 & -1 & 1 & 2 & -1 & Ta-177> stable \\
\hline
\end{tabular}


RSAC-7.2 Nuclear Data Library

\begin{tabular}{|c|c|c|c|c|c|c|c|c|c|c|}
\hline 721781 & $3.10 \mathrm{E}+01$ & 5 & $\mathrm{y}$ & 0 & 1 & -1 & 1 & 0 & -1 & Hf- $178 m>$ stable \\
\hline 731781 & $2.36 \mathrm{E}+00$ & 3 & $\mathrm{~h}$ & 0 & 1 & -1 & 1 & 0 & -1 & Ta- $178 \mathrm{~m}>$ stable \\
\hline 751780 & $1.32 \mathrm{E}+01$ & 2 & $\mathrm{~m}$ & 0 & 1 & 0 & 1 & 0 & -1 & Re-178 $>$ W-178 1.0 \\
\hline 741780 & $2.16 \mathrm{E}+01$ & 4 & $\mathrm{~d}$ & 0 & 1 & 0 & 1 & 1 & -1 & W-178 > Ta-178 1.0 \\
\hline 731780 & $9.31 \mathrm{E}+00$ & 2 & $\mathrm{~m}$ & 0 & 1 & -1 & 1 & 2 & -0.3 & Ta-178 $>$ stable \\
\hline 711790 & $4.59 \mathrm{E}+00$ & 3 & $\mathrm{~h}$ & 0 & 1 & -1 & 1 & 0 & -1 & Lu-179 > stable \\
\hline 721791 & $2.51 \mathrm{E}+01$ & 4 & $\mathrm{~d}$ & 0 & 1 & -1 & 1 & 0 & -1 & Hf- $179 \mathrm{~m}>$ stable 1.0 \\
\hline 721801 & $5.50 \mathrm{E}+00$ & 3 & $\mathrm{~h}$ & 0 & 1 & -1 & 1 & 0 & -1 & Hf- $180 \mathrm{~m}>$ stable \\
\hline 731801 & $1.20 \mathrm{E}+15$ & 5 & $\mathrm{y}$ & 0 & 1 & -1 & 1 & 0 & -1 & Ta- $180 \mathrm{~m}>$ stable \\
\hline 731800 & $8.15 \mathrm{E}+00$ & 3 & $\mathrm{~h}$ & 0 & 1 & -1 & 1 & 0 & -1 & Ta- $180>$ stable \\
\hline 761800 & $2.15 \mathrm{E}+01$ & 2 & $\mathrm{~m}$ & 0 & 1 & 0 & 1 & 0 & -1 & Os-180 > Re-180 1.0 \\
\hline 751800 & $2.44 \mathrm{E}+00$ & 2 & $\mathrm{~m}$ & 0 & 1 & -1 & 1 & 1 & -0.3 & Re- $180>$ stable \\
\hline 741810 & $1.21 \mathrm{E}+02$ & 4 & $\mathrm{~d}$ & 0 & 1 & -1 & 1 & 2 & -1 & $\mathrm{~W}-181>$ stable \\
\hline 721821 & $6.15 \mathrm{E}+01$ & 2 & $\mathrm{~m}$ & 0 & 0.54 & 2 & 1 & 0 & -1 & $\begin{array}{l}\text { Hf-182m Hf-182 .46 Ta-182 } \\
.54\end{array}$ \\
\hline 721820 & $9.00 \mathrm{E}+06$ & 5 & $\mathrm{y}$ & 0 & 1 & 1 & 1 & 1 & -1 & Hf-182 > Ta-182 1.0 \\
\hline 731821 & $2.64 \mathrm{E}-01$ & 3 & $\mathrm{~h}$ & 0 & 1 & 0 & 1 & 0 & -1 & Ta- $182 \mathrm{~m}>\mathrm{Ta}-1821.0$ \\
\hline 731820 & $1.15 \mathrm{E}+02$ & 4 & $\mathrm{~d}$ & 0 & 1 & -1 & 1 & 3 & -1 & Ta- $182>$ stable \\
\hline 771820 & $1.20 \mathrm{E}+01$ & 2 & $\mathrm{~m}$ & 0 & 1 & 1 & 1 & 0 & -1 & Ir-182> Os-182 1.0 \\
\hline 751823 & $6.40 \mathrm{E}+01$ & 3 & $\mathrm{~h}$ & 0 & 1 & -1 & 1 & 0 & -1 & Re- $182 b>$ stable \\
\hline 761820 & $2.21 \mathrm{E}+01$ & 3 & $\mathrm{~h}$ & 0 & 1 & 0 & 1 & 1 & -1 & Os-182 > Re-182a 1.0 \\
\hline 751822 & $6.40 \mathrm{E}+01$ & 3 & $\mathrm{~h}$ & 0 & 1 & -1 & 1 & 0 & -1 & Re-182a $>$ stable \\
\hline 721830 & $1.07 \mathrm{E}+00$ & 3 & $\mathrm{~h}$ & 0 & 1 & 0 & 1 & 0 & -1 & Hf-183 > Ta-183 1.0 \\
\hline
\end{tabular}




\begin{tabular}{|c|c|c|c|c|c|c|c|c|c|c|}
\hline 751840 & $3.54 \mathrm{E}+01$ & 4 & $\mathrm{~d}$ & 0 & 1 & -1 & 1 & 1 & -1 & Re-184 > stable \\
\hline 771840 & $3.09 \mathrm{E}+00$ & 3 & $\mathrm{~h}$ & 0 & 1 & -1 & 1 & 1 & -1 & Ir-184 > stable \\
\hline 731850 & $4.94 \mathrm{E}+01$ & 2 & $\mathrm{~m}$ & 0 & 1 & 0 & 1 & 0 & -1 & Ta-185> W-185 1.0 \\
\hline 741850 & $7.51 \mathrm{E}+01$ & 4 & $\mathrm{~d}$ & 0 & 1 & -1 & 1 & 1 & -1 & $\mathrm{~W}-185>$ stable \\
\hline 771850 & $1.44 \mathrm{E}+01$ & 3 & $\mathrm{~h}$ & 0 & 1 & 0 & 1 & 0 & -1 & Ir-185 > Os-185 1.0 \\
\hline 761850 & $9.36 \mathrm{E}+01$ & 4 & $\mathrm{~d}$ & 0 & 1 & -1 & 1 & 1 & -1 & Os- $185>$ stable \\
\hline 731860 & $1.05 \mathrm{E}+01$ & 2 & $\mathrm{~m}$ & 0 & 1 & -1 & 1 & 0 & -1 & Ta-186> stable \\
\hline 771861 & $1.90 \mathrm{E}+00$ & 3 & $\mathrm{~h}$ & 0 & 1 & -1 & 1 & 0 & -1 & Ir- $186 \mathrm{~m}>$ stable \\
\hline 781860 & $2.20 \mathrm{E}+00$ & 3 & $\mathrm{~h}$ & 0 & 1 & 0 & 1 & 0 & -1 & Pt-186 > Ir-186 1.0 \\
\hline 771860 & $1.66 \mathrm{E}+01$ & 3 & $\mathrm{~h}$ & 0 & 1 & -1 & 1 & 1 & -1 & Ir-186> stable \\
\hline 741870 & $2.40 \mathrm{E}+01$ & 3 & $\mathrm{~h}$ & 0 & 1 & 0 & 1 & 0 & -1 & W-187 > Re-187 1.0 \\
\hline 751870 & $4.33 \mathrm{E}+10$ & 5 & $\mathrm{y}$ & 0 & 1 & -1 & 1 & 1 & -1 & Re- $187>$ stable \\
\hline 751880 & $1.70 \mathrm{E}+01$ & 3 & $\mathrm{~h}$ & 0 & 1 & -1 & 1 & 2 & -1 & Re- $188>$ stable \\
\hline 781880 & $1.01 \mathrm{E}+01$ & 4 & $\mathrm{~d}$ & 0 & 1 & 0 & 1 & 0 & -1 & Pt-188 > Ir-188 1.0 \\
\hline 771880 & $4.15 \mathrm{E}+01$ & 3 & $\mathrm{~h}$ & 0 & 1 & -1 & 1 & 1 & -1 & Ir-188 > stable \\
\hline 781890 & $1.08 \mathrm{E}+01$ & 3 & $\mathrm{~h}$ & 0 & 1 & 0 & 1 & 0 & -1 & Pt-189 > Ir-189 1.0 \\
\hline 771890 & $1.32 \mathrm{E}+01$ & 4 & $\mathrm{~d}$ & 0 & 1 & 1 & 1 & 1 & -0.3 & Ir-189> Ir-189m 1.0 \\
\hline 751890 & $2.43 \mathrm{E}+01$ & 3 & $\mathrm{~h}$ & 0 & 0.241 & 0 & 1 & 0 & -1 & Re-189 > Ir-189m 0.241 \\
\hline 771891 & $1.33 \mathrm{E}-02$ & 1 & $\mathrm{~s}$ & 0 & 1 & -1 & 1 & 3 & -1 & Ir- $189 m>$ stable \\
\hline 761901 & $9.90 \mathrm{E}+00$ & 2 & $\mathrm{~m}$ & 0 & 1 & -1 & 1 & 4 & -1 & Os-190m>stable \\
\hline 771904 & $3.25 \mathrm{E}+00$ & 3 & $\mathrm{~h}$ & 0 & 0.05 & 0 & 1 & 0 & -1 & Ir-190n Ir-190m0.05 \\
\hline 771901 & $1.12 \mathrm{E}+00$ & 3 & $\mathrm{~h}$ & 0 & 1 & 0 & 1 & 1 & -1 & Ir-190m> Ir-190 1.0 \\
\hline 771900 & $1.18 \mathrm{E}+01$ & 4 & $\mathrm{~d}$ & 0 & 1 & -1 & 1 & 2 & -1 & Ir-190 > stable \\
\hline
\end{tabular}


RSAC-7.2 Nuclear Data Library

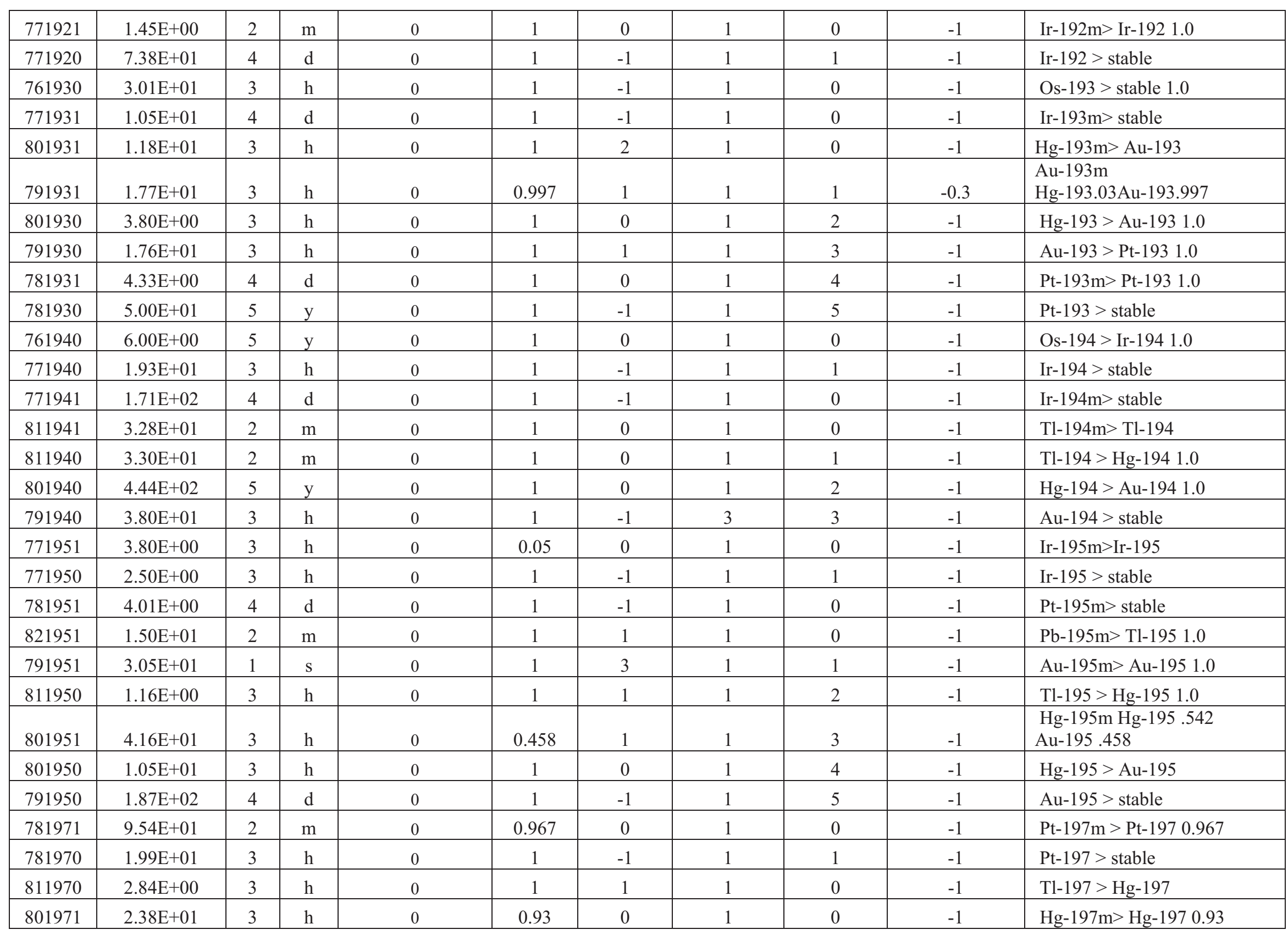


RSAC-7.2 Nuclear Data Library

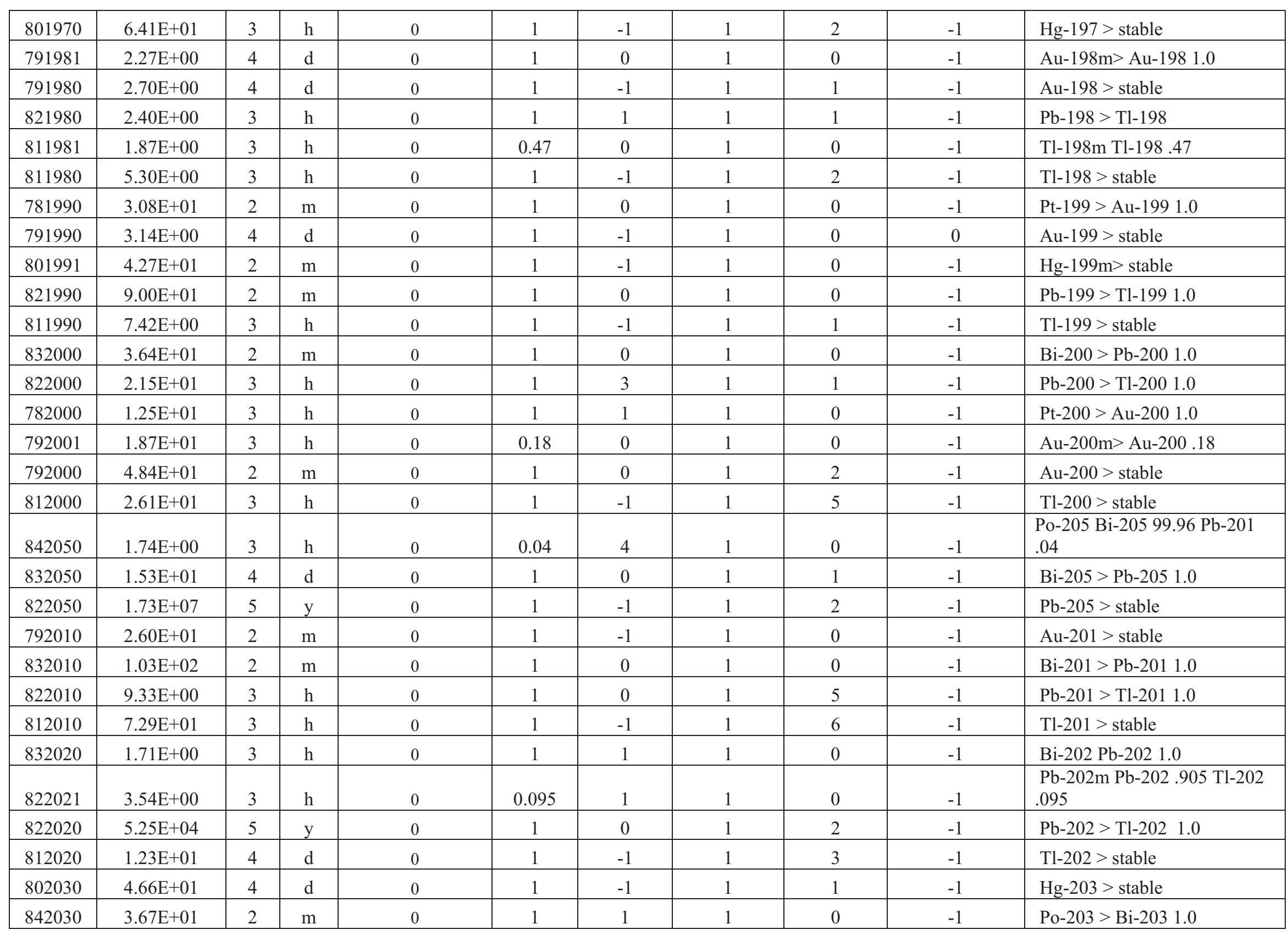


RSAC-7.2 Nuclear Data Library

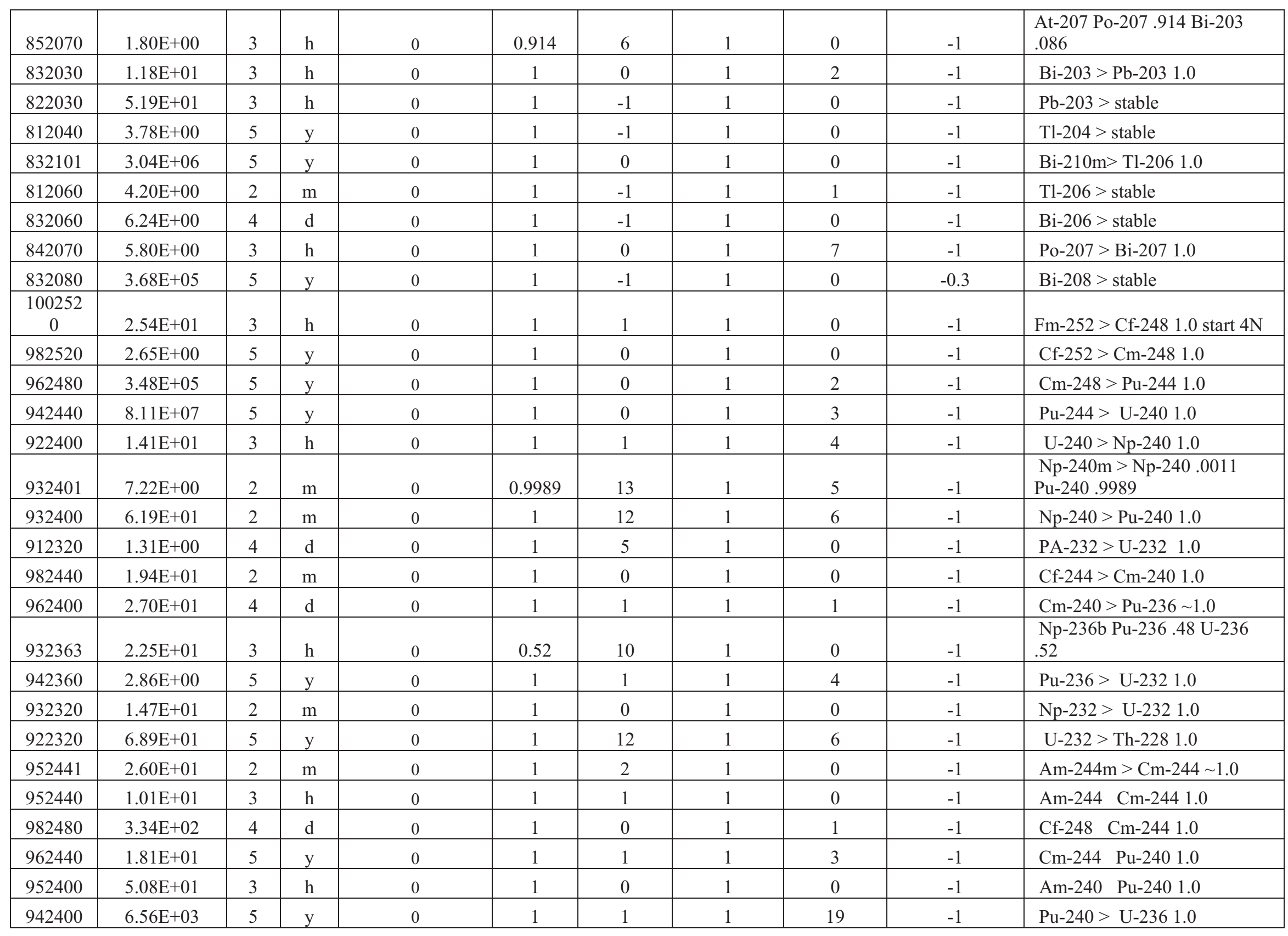




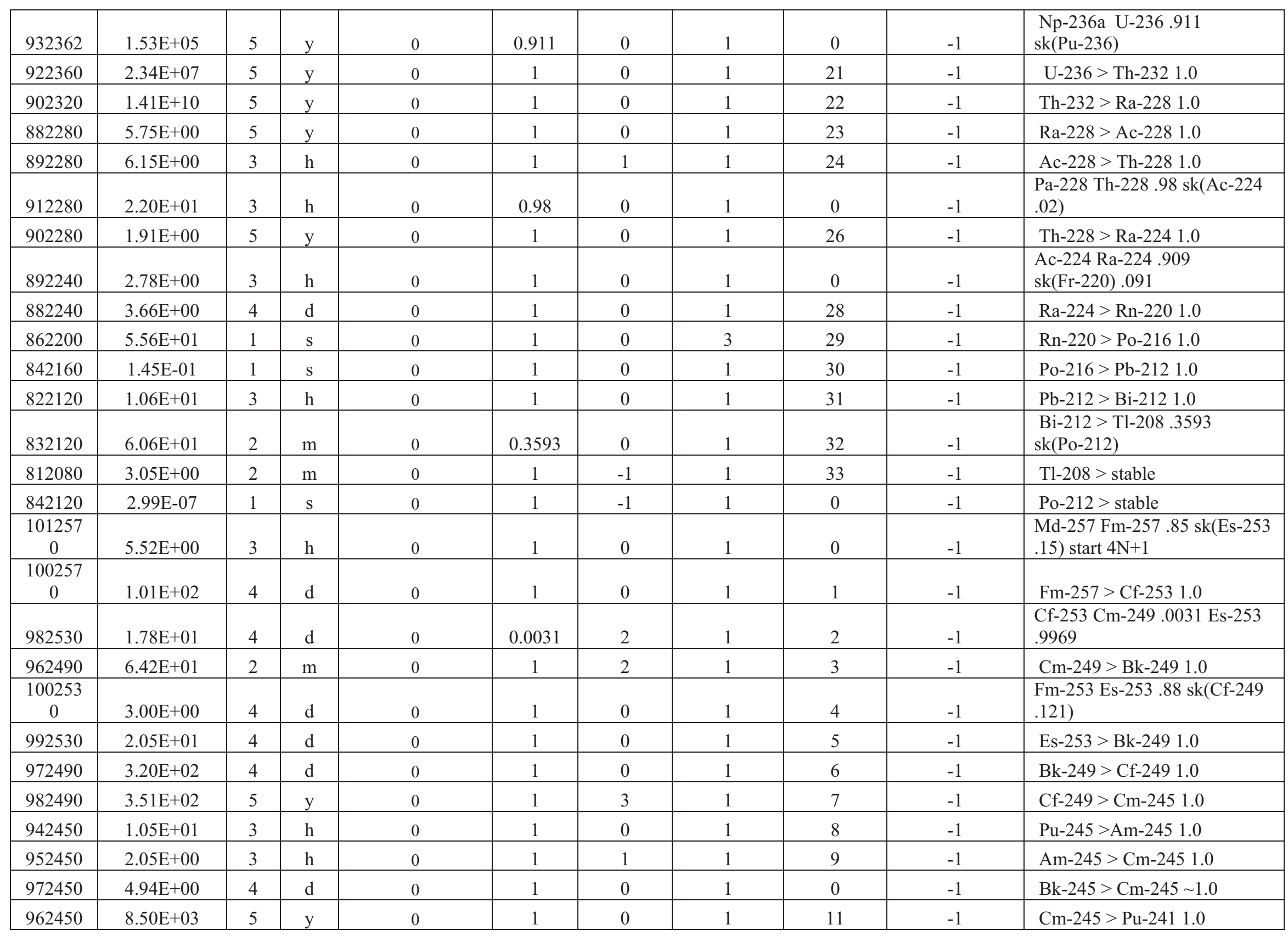


RSAC-7.2 Nuclear Data Library

\begin{tabular}{|c|c|c|c|c|c|c|c|c|c|c|}
\hline 942410 & $1.43 \mathrm{E}+01$ & 5 & $\mathrm{y}$ & 0 & 1 & 1 & 1 & 12 & -1 & $\mathrm{Pu}-241>\mathrm{Am}-2411.0$ \\
\hline 962410 & $3.28 \mathrm{E}+01$ & 4 & $\mathrm{~d}$ & 0 & 0.99 & 0 & 1 & 0 & -1 & $\begin{array}{l}\text { Cm-241 Am-241 .99 } \\
\text { sk(Pu-237 .01) }\end{array}$ \\
\hline 952410 & $4.33 \mathrm{E}+02$ & 5 & $\mathrm{y}$ & 0 & 1 & 3 & 1 & 14 & -1 & Am-241 > Np-237 1.0 \\
\hline 952370 & $7.30 \mathrm{E}+01$ & 2 & $\mathrm{~m}$ & 0 & 1 & 0 & 1 & 0 & -1 & $\mathrm{Am}-237>\mathrm{Pu}-237 \sim 1.0$ \\
\hline 942370 & $4.52 \mathrm{E}+01$ & 4 & $\mathrm{~d}$ & 0 & 1 & 0 & 1 & 0 & -1 & $\mathrm{Pu}-237$ sk(U-233) Np-237 1.0 \\
\hline 932370 & $2.14 \mathrm{E}+06$ & 5 & $\mathrm{y}$ & 0 & 1 & 0 & 1 & 18 & -1 & Np-237 > Pa-233 1.0 \\
\hline 932330 & $3.62 \mathrm{E}+01$ & 2 & $\mathrm{~m}$ & 0 & 1 & 0 & 1 & 0 & -1 & Np-233 > U-233 1.0 \\
\hline 922330 & $1.59 \mathrm{E}+05$ & 5 & $\mathrm{y}$ & 0 & 1 & 0 & 1 & 21 & -1 & U-233 > Th-229 1.0 \\
\hline 902290 & $7.34 \mathrm{E}+03$ & 5 & $\mathrm{y}$ & 0 & 1 & 1 & 1 & 22 & -1 & Th-229 > Ra-225 1.0 \\
\hline 872250 & $4.00 \mathrm{E}+00$ & 2 & $\mathrm{~m}$ & 0 & 1 & 0 & 1 & 0 & -0.3 & Fr-225 > Ra-225 1.0 \\
\hline 882250 & $1.49 \mathrm{E}+01$ & 4 & $\mathrm{~d}$ & 0 & 1 & 0 & 1 & 24 & -1 & Ra-225 > Ac-225 1.0 \\
\hline 842130 & $4.20 \mathrm{E}-06$ & 1 & $\mathrm{~s}$ & 0 & 1 & 1 & 1 & 29 & -1 & Po-213 > Pb-209 1.0 \\
\hline 812090 & $2.20 \mathrm{E}+00$ & 2 & $\mathrm{~m}$ & 0 & 1 & 0 & 1 & 30 & -1 & Tl-209 > Pb-209 1.0 \\
\hline 822090 & $3.25 \mathrm{E}+00$ & 3 & $\mathrm{~h}$ & 0 & 1 & -1 & 1 & 31 & -1 & $\mathrm{~Pb}-209>$ stable \\
\hline $\begin{array}{c}101258 \\
0 \\
\end{array}$ & $5.15 \mathrm{E}+01$ & 4 & $\mathrm{~d}$ & 0 & 1 & 4 & 1 & 0 & -1 & $\begin{array}{l}\text { Md-258 > Es-254 } 1.0 \text { start } \\
2 \mathrm{~N}+2\end{array}$ \\
\hline 982460 & $3.57 \mathrm{E}+01$ & 3 & $\mathrm{~h}$ & 0 & 1 & 2 & 1 & 0 & -1 & $\mathrm{Cf}-246>\mathrm{Cm}-2421.0$ \\
\hline 952421 & $1.41 \mathrm{E}+02$ & 5 & $\mathrm{y}$ & 0 & 0.9952 & 0 & 1 & 0 & -1 & $\begin{array}{l}\text { Am-242m sk(Np-238) Am-242 } \\
.9952\end{array}$ \\
\hline 952420 & $1.60 \mathrm{E}+01$ & 3 & $\mathrm{~h}$ & 0 & 0.173 & 14 & 1 & 1 & -1 & $\begin{array}{l}\mathrm{Am}-242 \mathrm{Cm}-242.827 \mathrm{Pu}-242 \\
.173\end{array}$ \\
\hline 962420 & $1.63 \mathrm{E}+02$ & 4 & $\mathrm{~d}$ & 0 & 1 & 17 & 1 & 2 & -1 & $\mathrm{Cm}-242>\mathrm{Pu}-2381.0$ \\
\hline
\end{tabular}


RSAC-7.2 Nuclear Data Library

\begin{tabular}{|c|c|c|c|c|c|c|c|c|c|c|}
\hline 982540 & $6.05 \mathrm{E}+01$ & 4 & $\mathrm{~d}$ & 0 & 0.0031 & 0 & 1 & 0 & -1 & Cf-254 > Cm-250 .0031 \\
\hline 962500 & $9.00 \mathrm{E}+03$ & 5 & $\mathrm{y}$ & 0 & 0.11 & 3 & 1 & 1 & -1 & $\begin{array}{l}\mathrm{Cm}-250 \mathrm{Pu}-246.11 \mathrm{Bk}-250 \\
.14\end{array}$ \\
\hline 972500 & $3.21 \mathrm{E}+00$ & 3 & $\mathrm{~h}$ & 0 & 1 & 1 & 1 & 10 & -1 & $\mathrm{Bk}-250>\mathrm{Cf}-2501.0$ \\
\hline 992500 & $8.60 \mathrm{E}+00$ & 3 & $\mathrm{~h}$ & 0 & 1 & 0 & 1 & 0 & -1 & Es-250>Cf-250 1.0 \\
\hline 982500 & $1.31 \mathrm{E}+01$ & 5 & $\mathrm{y}$ & 0 & 1 & 4 & 1 & 12 & -1 & Cf-250 $>$ Cm-246 1.0 \\
\hline 942460 & $1.08 \mathrm{E}+01$ & 4 & $\mathrm{~d}$ & 0 & 1 & 1 & 1 & 8 & -1 & Pu-246 > Am-246 1.0 \\
\hline 952461 & $2.50 \mathrm{E}+01$ & 2 & $\mathrm{~m}$ & 0 & 1 & 2 & 1 & 0 & -1 & Am-246m > Cm-246 1.0 \\
\hline 952460 & $3.90 \mathrm{E}+01$ & 2 & $\mathrm{~m}$ & 0 & 1 & 1 & 1 & 10 & -1 & Am-246 > Cm-246 1.0 \\
\hline 972460 & $1.80 \mathrm{E}+00$ & 4 & $\mathrm{~d}$ & 0 & 1 & 0 & 1 & 0 & -1 & Bk-246>Cm-246 1.0 \\
\hline 962460 & $4.76 \mathrm{E}+03$ & 5 & $\mathrm{y}$ & 0 & 0.9997 & 0 & 1 & 12 & -1 & $\mathrm{Cm}-246>\mathrm{Pu}-242=1.0$ \\
\hline 942420 & $3.74 \mathrm{E}+05$ & 5 & $\mathrm{y}$ & 0 & 1 & 4 & 1 & 13 & -1 & $\mathrm{Pu}-242>\mathrm{U}-2381.0$ \\
\hline 932380 & $2.12 \mathrm{E}+00$ & 4 & $\mathrm{~d}$ & 0 & 1 & 2 & 1 & 0 & -1 & $\mathrm{~Np}-238>\mathrm{Pu}-2381.0$ \\
\hline 962380 & $2.40 \mathrm{E}+00$ & 3 & $\mathrm{~h}$ & 0 & 0.9116 & 0 & 1 & 0 & -1 & $\begin{array}{l}\text { Cm-238 Am-238 .9616 } \\
\text { sk(Pu-234) }\end{array}$ \\
\hline 952380 & $9.80 \mathrm{E}+01$ & 2 & $\mathrm{~m}$ & 0 & 1 & 0 & 1 & 0 & -1 & Am-238 $>$ Pu-238 $\sim 1.0$ \\
\hline 942380 & $8.77 \mathrm{E}+01$ & 5 & $\mathrm{y}$ & 0 & 1 & 6 & 1 & 22 & -1 & $\mathrm{Pu}-238>\mathrm{U}-2341.0$ \\
\hline 922380 & $4.47 \mathrm{E}+09$ & 5 & $\mathrm{y}$ & 0 & 1 & 3 & 1 & 23 & -1 & U-238 $>$ Th-234 1.0 \\
\hline 912340 & $6.70 \mathrm{E}+00$ & 3 & $\mathrm{~h}$ & 0 & 1 & 3 & 1 & 24 & -1 & $\mathrm{~Pa}-234>\mathrm{U}-2341.0$ \\
\hline 942340 & $8.80 \mathrm{E}+00$ & 3 & $\mathrm{~h}$ & 0 & 1 & 0 & 1 & 0 & -1 & Pu-234 Np-234 .94 sk(U-230) \\
\hline 932340 & $4.40 \mathrm{E}+00$ & 4 & $\mathrm{~d}$ & 0 & 1 & 2 & 1 & 0 & -1 & $\mathrm{~Np}-234>\mathrm{U}-2341.0$ \\
\hline 902340 & $2.41 \mathrm{E}+01$ & 4 & $\mathrm{~d}$ & 0 & 0.998 & 0 & 1 & 27 & -1 & $\begin{array}{l}\text { Th-234 > Pa-234m .998 } \\
\text { sk(Pa-234) }\end{array}$ \\
\hline 912341 & $1.16 \mathrm{E}+00$ & 2 & $\mathrm{~m}$ & 0 & 0.9987 & 0 & 1 & 28 & -0.3 & $\begin{array}{l}\mathrm{Pa}-234 \mathrm{~m}>\mathrm{U}-234.9987 \\
\mathrm{sk}(\mathrm{Pa}-234)\end{array}$ \\
\hline 922340 & $2.46 \mathrm{E}+05$ & 5 & $\mathrm{y}$ & 0 & 1 & 4 & 1 & 29 & -1 & U-234 > Th-230 1.0 \\
\hline 912300 & $1.74 \mathrm{E}+01$ & 4 & $\mathrm{~d}$ & 0 & 0.095 & 0 & 1 & 30 & -1 & $\begin{array}{l}\text { Pa-230 U-230 } 0.095 \\
\text { sk(Th-230) }\end{array}$ \\
\hline 922300 & $2.08 \mathrm{E}+01$ & 4 & $\mathrm{~d}$ & 0 & 1 & 1 & 1 & 31 & -1 & $\mathrm{U}-230>$ Th-226 1.0 \\
\hline 892260 & $2.94 \mathrm{E}+01$ & 3 & $\mathrm{~h}$ & 0 & 0.83 & 0 & 1 & 0 & -1 & $\begin{array}{l}\text { Ac-226 Th-226.88 } \\
\text { sk(Ra-226) }\end{array}$ \\
\hline 902260 & $3.06 \mathrm{E}+01$ & 2 & $\mathrm{~m}$ & 0 & 1 & 1 & 1 & 33 & -1 & Th-226 > Ra-222 1.0 \\
\hline 902300 & $7.54 \mathrm{E}+04$ & 5 & $\mathrm{y}$ & 0 & 1 & 0 & 1 & 34 & -1 & Th-230 > Ra-226 1.0 \\
\hline 882260 & $1.60 \mathrm{E}+03$ & 5 & $\mathrm{y}$ & 0 & 1 & 1 & 1 & 35 & -1 & $\mathrm{Ra}-226>\mathrm{Rn}-2221.0$ \\
\hline
\end{tabular}


RSAC-7.2 Nuclear Data Library

\begin{tabular}{|c|c|c|c|c|c|c|c|c|c|c|}
\hline 872220 & $1.42 \mathrm{E}+01$ & 2 & $\mathrm{~m}$ & 0 & 1 & 1 & 1 & 0 & -1 & Fr-222 > Ra-222 1.0 \\
\hline 862220 & $3.82 \mathrm{E}+00$ & 4 & $\mathrm{~d}$ & 0 & 1 & 1 & 3 & 37 & -1 & Rn-222 > Po-218 \\
\hline 882220 & $3.62 \mathrm{E}+01$ & 1 & $\mathrm{~s}$ & 0 & 1 & 2 & 1 & 38 & -1 & $\begin{array}{l}\text { Ra-222 sk(Rn-218) } \\
1.0>\text { Po-214 } 1.0\end{array}$ \\
\hline 842180 & $3.98 \mathrm{E}+00$ & 2 & $\mathrm{~m}$ & 0 & 1 & 0 & 1 & 39 & -1 & $\begin{array}{l}\text { Po-218 > Pb-214 .9998 } \\
\text { sk(Ac-218) }\end{array}$ \\
\hline 822140 & $2.68 \mathrm{E}+01$ & 2 & $\mathrm{~m}$ & 0 & 1 & 1 & 1 & 40 & -1 & $\mathrm{~Pb}-214>\mathrm{Bi}-2141.0$ \\
\hline 862180 & $3.50 \mathrm{E}-02$ & 1 & $\mathrm{~s}$ & 0 & 1 & 1 & 1 & 41 & -1 & Rn-218 > Po-214 1.0 \\
\hline 832140 & $1.99 \mathrm{E}+01$ & 2 & $\mathrm{~m}$ & 0 & 0.9998 & 0 & 1 & 42 & -1 & $\begin{array}{l}\text { Bi-214>.9998 Po-214 } \\
\text { sk(Po-214) }\end{array}$ \\
\hline 842140 & $1.64 \mathrm{E}-04$ & 1 & $\mathrm{~S}$ & 0 & 1 & 1 & 1 & 43 & -1 & Po-214 > Pb-210 1.0 \\
\hline 812100 & $1.30 \mathrm{E}+00$ & 2 & $\mathrm{~m}$ & 0 & 1 & 0 & 1 & 0 & -1 & $\mathrm{Tl}-210>\mathrm{Pb}-2101.0$ \\
\hline 822100 & $2.22 \mathrm{E}+01$ & 5 & $\mathrm{y}$ & 0 & 1 & 0 & 1 & 45 & -1 & $\mathrm{~Pb}-210>\mathrm{Bi}-2101.0$ \\
\hline 832100 & $5.01 \mathrm{E}+00$ & 4 & $\mathrm{~d}$ & 0 & 1 & 0 & 1 & 46 & -1 & Bi-210 > Po-210 1.0 \\
\hline 842100 & $1.38 \mathrm{E}+02$ & 4 & $\mathrm{~d}$ & 0 & 1 & -1 & 1 & 47 & -1 & Po-210 > stable \\
\hline 992550 & $3.98 \mathrm{E}+01$ & 4 & $\mathrm{~d}$ & 0 & 1 & 0 & 1 & 0 & -0.3 & $\begin{array}{l}\text { Es-255 Fm-255 .92 sk(Bk-251) } \\
\text { start } 4 \mathrm{~N}+3\end{array}$ \\
\hline $\begin{array}{c}100255 \\
0 \\
\end{array}$ & $2.01 \mathrm{E}+01$ & 3 & $\mathrm{~h}$ & 0 & 1 & 1 & 1 & 0 & -1 & Fm-255 > Cf-251 1.0 \\
\hline 992510 & $3.30 \mathrm{E}+01$ & 3 & $\mathrm{~h}$ & 0 & 1 & 0 & 1 & 0 & -1 & Es-251 > Cf-251 1.0 \\
\hline 982510 & $8.98 \mathrm{E}+02$ & 5 & $\mathrm{y}$ & 0 & 1 & 0 & 1 & 3 & -1 & Cf-251 > Cm-247 1.0 \\
\hline 962470 & $1.56 \mathrm{E}+07$ & 5 & $\mathrm{y}$ & 0 & 1 & 0 & 1 & 4 & -1 & $\mathrm{Cm}-247>\mathrm{Pu}-2431.0$ \\
\hline 942430 & $4.96 \mathrm{E}+00$ & 3 & $\mathrm{~h}$ & 0 & 1 & 1 & 1 & 5 & -1 & $\mathrm{Pu}-243>\mathrm{Am}-2431.0$ \\
\hline 972470 & $1.38 \mathrm{E}+03$ & 5 & $\mathrm{y}$ & 0 & 1 & 0 & 1 & 0 & -1 & Bk-247 > Am-243 1.0 \\
\hline 952430 & $7.37 \mathrm{E}+03$ & 5 & $\mathrm{y}$ & 0 & 1 & 1 & 1 & 7 & -1 & Am-243 > Np-239 1.0 \\
\hline 922390 & $2.35 \mathrm{E}+01$ & 2 & $\mathrm{~m}$ & 0 & 1 & 0 & 1 & 0 & -1 & U-239 > Np-239 1.0 \\
\hline 932390 & $2.36 \mathrm{E}+00$ & 4 & $\mathrm{~d}$ & 0 & 1 & 2 & 1 & 1 & -1 & Np-239 > Pu-239 1.0 \\
\hline 952390 & $1.19 \mathrm{E}+01$ & 3 & $\mathrm{~h}$ & 0 & 1 & 1 & 1 & 1 & -1 & Am-239 $>$ Pu-239 $\sim 1.0$ \\
\hline 962430 & $2.91 \mathrm{E}+01$ & 5 & $\mathrm{y}$ & 0 & 0.998 & 0 & 1 & 2 & -1 & $\begin{array}{l}\mathrm{Cm}-243 \mathrm{Pu}-239.998 \\
\text { sk(Am-243) }\end{array}$ \\
\hline 942390 & $2.41 \mathrm{E}+04$ & 5 & $\mathrm{y}$ & 0 & 1 & 2 & 1 & 12 & -1 & $\mathrm{Pu}-239>\mathrm{U}-2351.0$ \\
\hline 942350 & $2.53 \mathrm{E}+01$ & 2 & $\mathrm{~m}$ & 0 & 1 & 0 & 1 & 0 & -1 & $\mathrm{Pu}-235>\mathrm{Np}-235 \sim 1.0$ \\
\hline 932350 & $3.96 \mathrm{E}+02$ & 4 & $\mathrm{~d}$ & 0 & 0.9999 & 0 & 1 & 0 & -1 & Np-235 > U-235 0.9999 \\
\hline 922350 & $7.04 \mathrm{E}+08$ & 5 & $\mathrm{y}$ & 0 & 1 & 0 & 1 & 15 & -1 & U-235 > Th-231 1.0 \\
\hline
\end{tabular}


RSAC-7.2 Nuclear Data Library

\begin{tabular}{|c|c|c|c|c|c|c|c|c|c|c|}
\hline 902310 & $2.55 \mathrm{E}+01$ & 3 & $\mathrm{~h}$ & 0 & 1 & 1 & 1 & 16 & -1 & Th-231> Pa-231 1.0 \\
\hline 922310 & $4.20 \mathrm{E}+00$ & 4 & $\mathrm{~d}$ & 0 & 1 & 0 & 1 & 17 & -1 & $\mathrm{U}-231>\mathrm{Pa}-2311.0$ \\
\hline 912310 & $3.28 \mathrm{E}+04$ & 5 & $\mathrm{y}$ & 0 & 1 & 5 & 1 & 18 & -1 & $\mathrm{~Pa}-231>\mathrm{Ac}-2271.0$ \\
\hline 882270 & $4.22 \mathrm{E}+01$ & 2 & $\mathrm{~m}$ & 0 & 1 & 4 & 1 & 0 & -1 & $\mathrm{Ra}-227>$ Ac-227 1.0 \\
\hline 912270 & $3.83 \mathrm{E}+01$ & 2 & $\mathrm{~m}$ & 0 & 0.15 & 4 & 1 & 0 & -1 & Pa-227 Th-227 .15 Ac-223 .85 \\
\hline 892230 & $2.10 \mathrm{E}+00$ & 2 & $\mathrm{~m}$ & 0 & 1 & 0 & 1 & 1 & -0.3 & Ac-223 > Fr-219 1.0 \\
\hline 852150 & $1.00 \mathrm{E}-04$ & 1 & $\mathrm{~s}$ & 0 & 1 & 10 & 1 & 3 & -0.3 & At-215 > Bi-211 1.0 \\
\hline 892270 & $2.18 \mathrm{E}+01$ & 5 & $\mathrm{y}$ & 0 & 0.9862 & 0 & 1 & 24 & -1 & $\begin{array}{l}\text { Ac-227 > Th-227 .9862 } \\
\text { sk(Fr-223) }\end{array}$ \\
\hline 902270 & $1.87 \mathrm{E}+01$ & 4 & $\mathrm{~d}$ & 0 & 1 & 1 & 1 & 25 & -1 & Th-227 > Ra-223 1.0 \\
\hline 872230 & $2.18 \mathrm{E}+01$ & 2 & $\mathrm{~m}$ & 0 & 0.9999 & 0 & 1 & 0 & -1 & Fr-223 > Ra-223 .9999 \\
\hline 882230 & $1.14 \mathrm{E}+01$ & 4 & $\mathrm{~d}$ & 0 & 1 & 0 & 1 & 27 & -1 & Ra-223 > Rn-219 1.0 \\
\hline 862190 & $3.96 \mathrm{E}+00$ & 1 & $\mathrm{~s}$ & 0 & 1 & 0 & 3 & 28 & -1 & Rn-219 > Po-215 1.0 \\
\hline 842150 & $1.78 \mathrm{E}-03$ & 1 & $\mathrm{~s}$ & 0 & 1 & 0 & 1 & 29 & -1 & Po-215 > Pb-211 1.0 \\
\hline 822110 & $3.61 \mathrm{E}+01$ & 2 & $\mathrm{~m}$ & 0 & 1 & 3 & 1 & 30 & -1 & $\mathrm{~Pb}-211>\mathrm{Bi}-2111.0$ \\
\hline 852110 & $7.21 \mathrm{E}+00$ & 3 & $\mathrm{~h}$ & 0 & 0.582 & 1 & 2 & 0 & -1 & $\begin{array}{l}\text { At-211 Bi-207 0.417 Po-211 } \\
.583\end{array}$ \\
\hline 832070 & $3.29 \mathrm{E}+01$ & 5 & $\mathrm{y}$ & 0 & 1 & -1 & 1 & 32 & -1 & Bi-207 > stable \\
\hline 842110 & $5.16 \mathrm{E}-01$ & 1 & $\mathrm{~s}$ & 0 & 1 & 1 & 1 & 33 & -1 & Po-211 > Tl-207 \\
\hline 832110 & $2.14 \mathrm{E}+00$ & 2 & $\mathrm{~m}$ & 0 & 0.99724 & 0 & 1 & 13 & -1 & $\begin{array}{l}\text { Bi-211> Tl-207 .99727 } \\
\text { sk(Po-211) }\end{array}$ \\
\hline 812070 & $4.77 \mathrm{E}+00$ & 2 & $\mathrm{~m}$ & 0 & 1 & -1 & 1 & 35 & -1 & Tl-207> stable \\
\hline
\end{tabular}




\section{Appendix C \\ Meteorological Diffusion Parameters}




\section{Appendix C}

\section{Meteorological Diffusion Parameters}

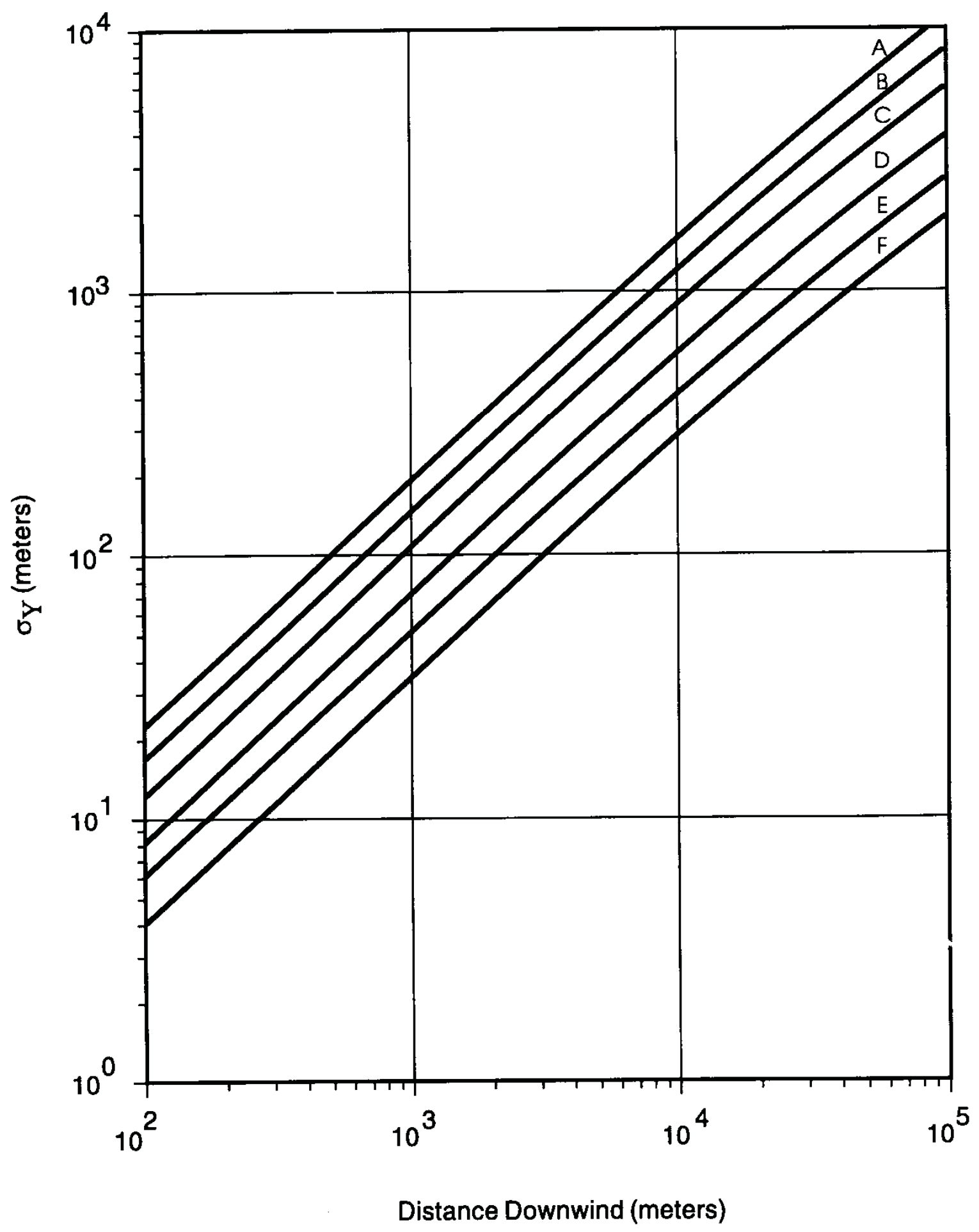

Figure C-1. $\sigma_{\mathrm{y}}$ versus distance downwind by stability class (Hilsmeier-Gifford). 


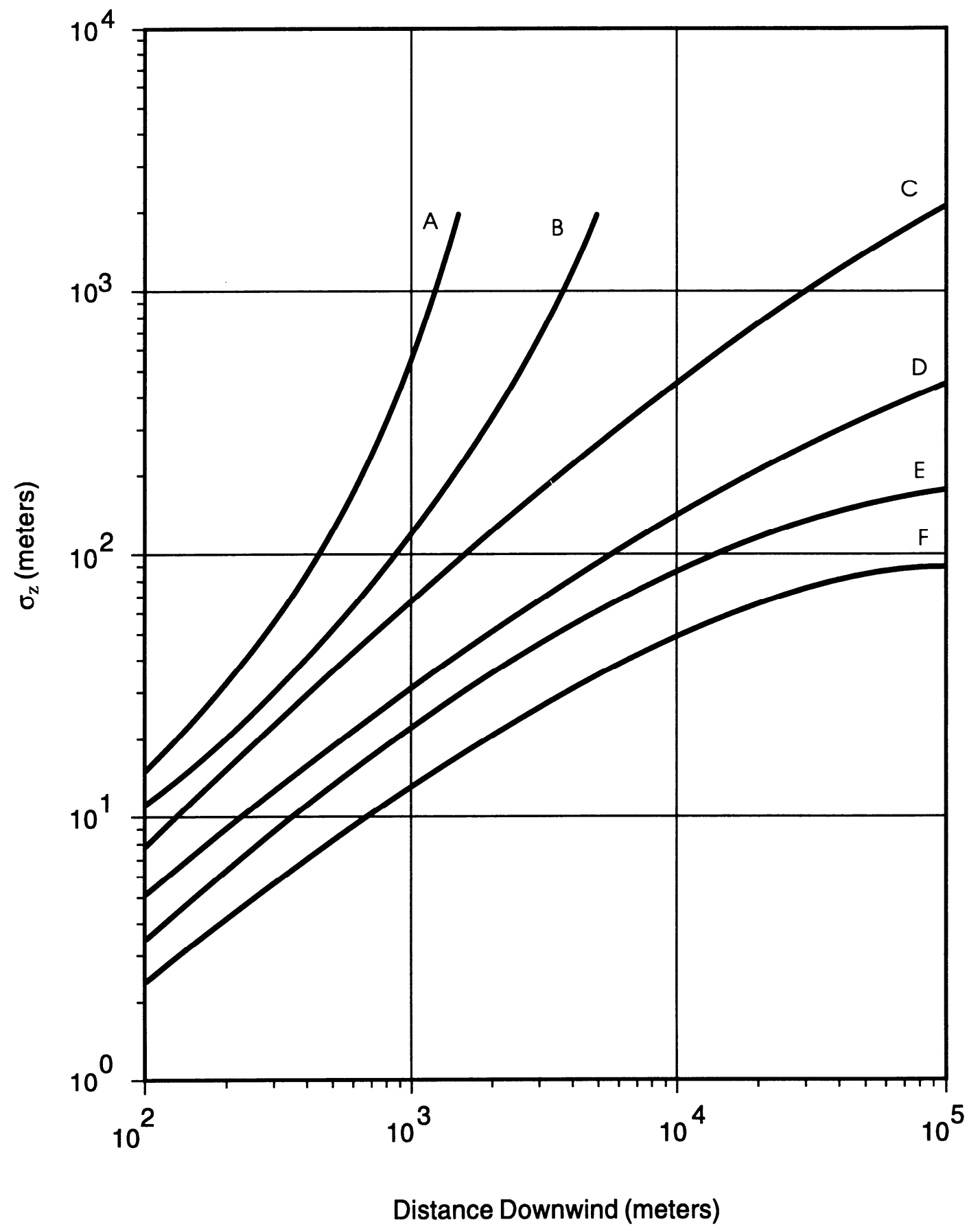

Figure C-2. $\sigma_{z}$ versus distance downwind by stability class (Hilsmeier-Gifford). 


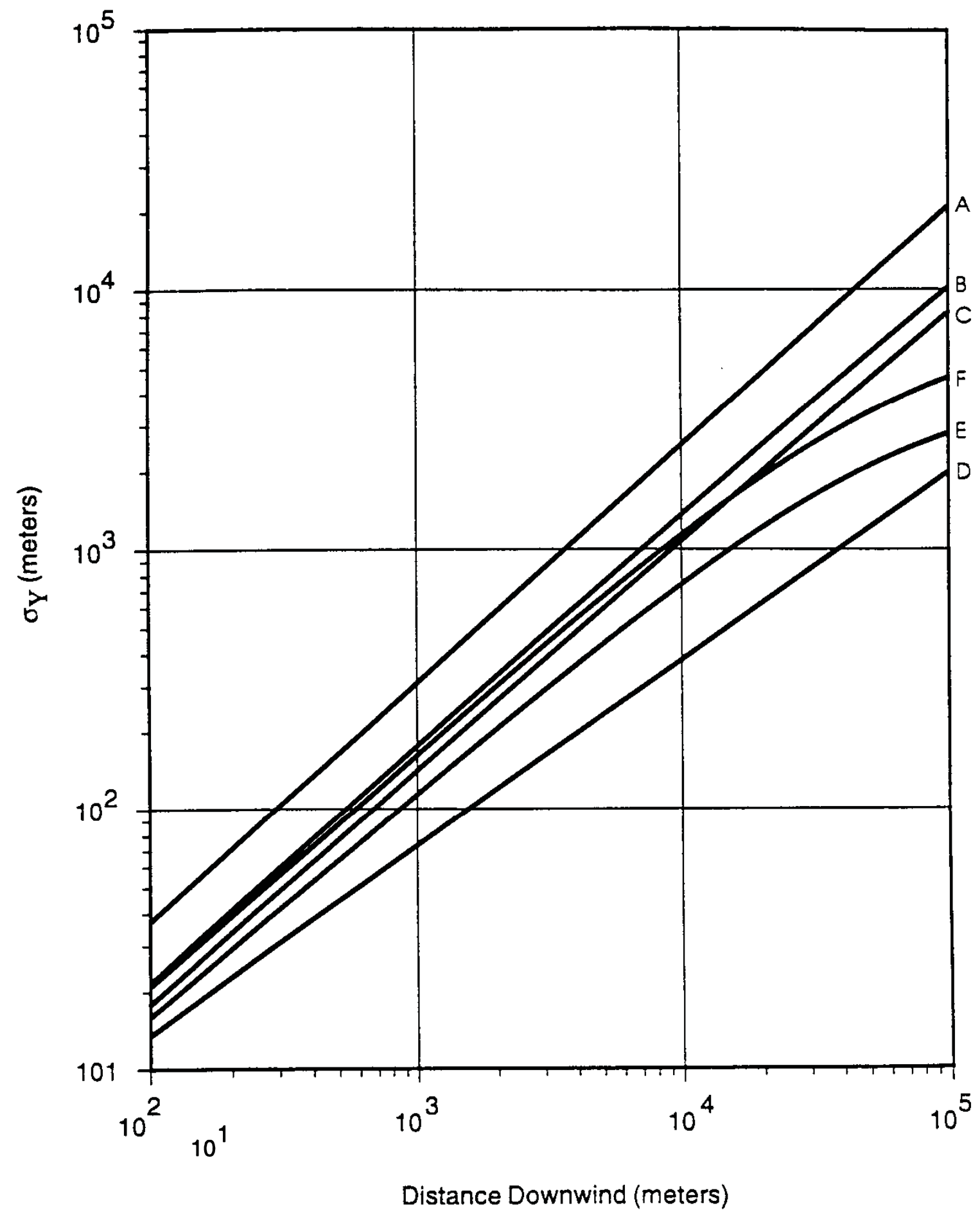

Figure C-3. $\sigma_{\mathrm{y}}$ versus distance downwind by stability class (Markee). 


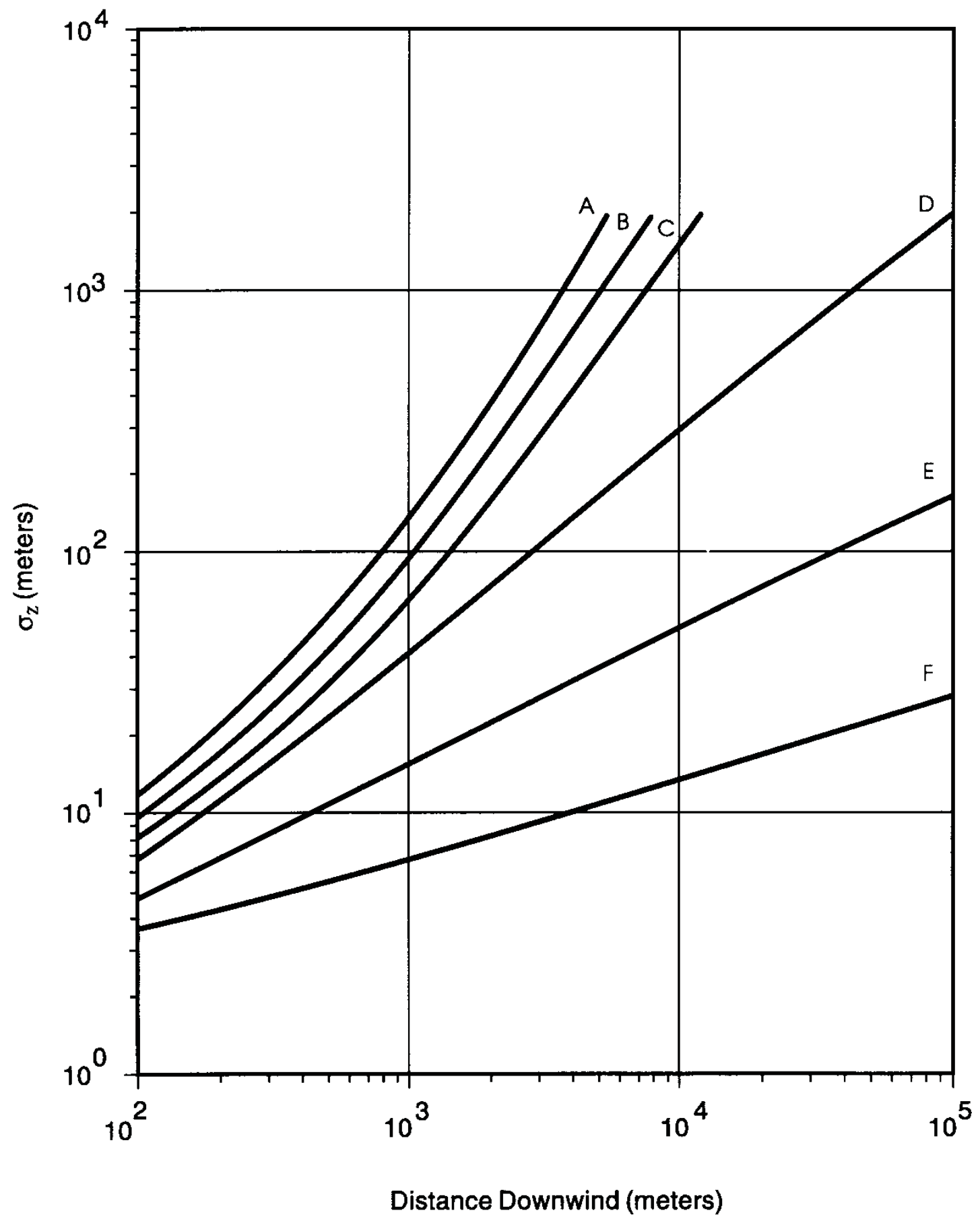

Figure C-4. $\sigma_{z}$ versus distance downwind by stability class (Markee). 


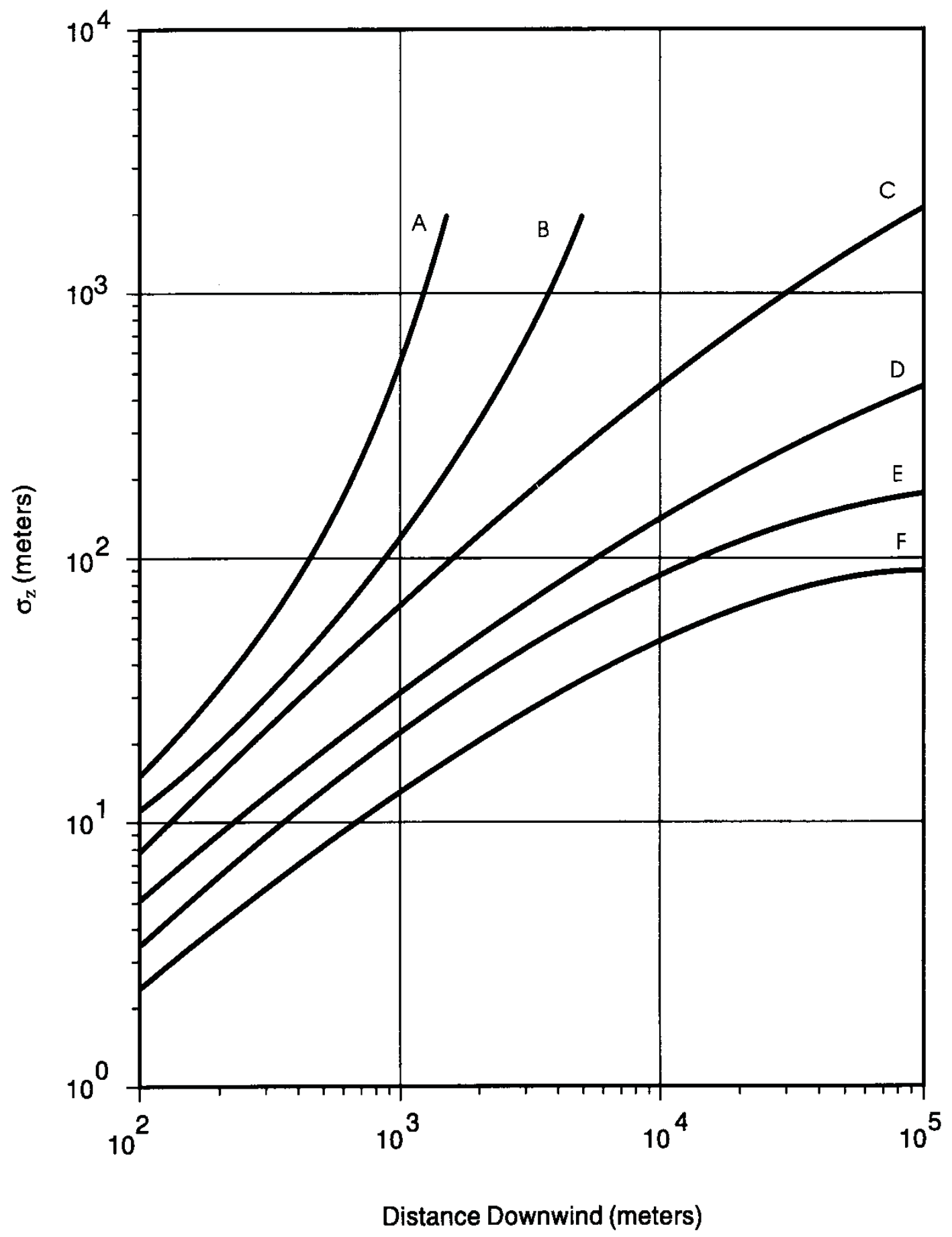

Figure C-5. $\sigma_{\mathrm{y}}$ versus distance downwind by stability class (Pasquill-Gifford). 


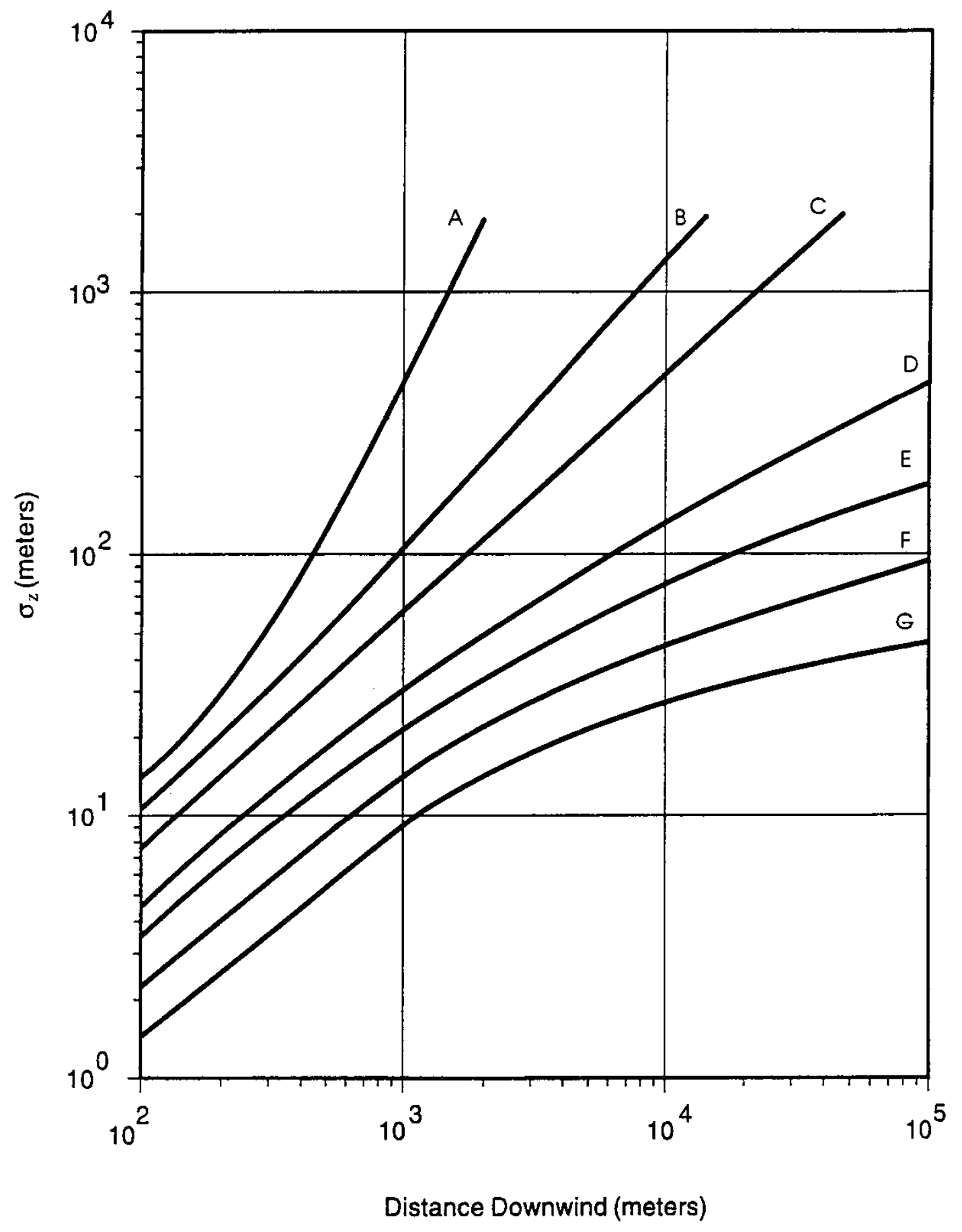

Figure C-6. $\sigma_{z}$ versus distance downwind by stability class (Pasquill-Gifford). 


\section{CLASSIFICATION OF ATMOSPHERIC STABILITY}

(Till and Meyer, 1983)

BY VERTICAL TEMPERATURE DIFFERENCE

\begin{tabular}{|c|c|c|}
\hline $\begin{array}{l}\text { Stability } \\
\text { classification }\end{array}$ & $\begin{array}{l}\text { Pasquill } \\
\text { categories }\end{array}$ & $\begin{array}{c}\text { Temperature change } \\
\text { with height } \\
\left({ }^{\circ} \mathrm{C} / 100 \mathrm{~m}\right)\end{array}$ \\
\hline Extremely unstable & $A$ & $\Delta T / \Delta z \leqslant-1$ \\
\hline Moderately unstable & $B$ & $-1.9<\Delta T / \Delta z \leqslant-1$ \\
\hline Slightly unstable & $C$ & $-1.7<\Delta T / \Delta z \leqslant-1$ \\
\hline Neutral & $D$ & $-1.5<\Delta T / \Delta z \leqslant-0$ \\
\hline Slightly stable & $E$ & $-0.5<\Delta T / \Delta z \leqslant 1$ \\
\hline Moderately stable & $F$ & $1.5<\Delta T / \Delta z \leqslant 4$ \\
\hline Extremely stable & $G$ & $4.0<\Delta T / \Delta z$ \\
\hline \multicolumn{3}{|c|}{$\begin{array}{l}\text { BY STANDARD DEVIATION OF } \\
\text { HORIZONTAL WIND DLRECTIO }\end{array}$} \\
\hline $\begin{array}{l}\text { Stability } \\
\text { classification }\end{array}$ & $\begin{array}{l}\text { Pasquill } \\
\text { categories }\end{array}$ & $\begin{array}{c}\sigma_{\theta}^{f} \\
(\mathrm{deg})\end{array}$ \\
\hline Extremely unstable & $A$ & $\sigma_{\theta} \geqslant 22.5$ \\
\hline Moderately unstable & $B$ & $22.5>\sigma_{\theta} \geqslant 17.5$ \\
\hline Slightly unstable & $C$ & $17.5>\sigma_{\theta} \geqslant 12.5$ \\
\hline Neutral & $D$ & $12.5>\sigma_{\theta} \geqslant 7.5$ \\
\hline Slightly stable & $E$ & $7.5>\sigma_{\theta} \geqslant 3.8$ \\
\hline Moderately stable & $F$ & $3.8>\sigma_{\theta} \geqslant 2.1$ \\
\hline Extremely stable & $G$ & $2.1>\sigma_{\theta}$ \\
\hline
\end{tabular}

"Determined for a 15-min to 1-h period for horizontal diffusion. 


\section{Appendix D \\ Lung Clearance Classes}




\section{Appendix D}

\section{ICRP 30 / FGR 11}

\section{Lung Clearance Classes ${ }^{a}$ for Oxides or Hydroxides}

\begin{tabular}{|c|c|c|c|c|c|c|c|c|c|}
\hline \multirow{2}{*}{$\begin{array}{l}\mathrm{Z} \\
1\end{array}$} & \multirow{2}{*}{$\begin{array}{c}\text { Element } \\
\mathrm{H}^{\mathrm{b}}\end{array}$} & \multicolumn{3}{|c|}{$\begin{array}{c}\text { Allowable Clearance } \\
\text { Classes }\end{array}$} & \multirow{2}{*}{$\frac{Z}{41}$} & \multirow{2}{*}{$\begin{array}{c}\text { Element } \\
\mathrm{Nb}\end{array}$} & \multicolumn{3}{|c|}{$\begin{array}{c}\text { Allowable Clearance } \\
\text { Classes } \\
\end{array}$} \\
\hline & & $\underline{\mathrm{HTO}}$ & & & & & & $\mathrm{W}$ & $\underline{Y}$ \\
\hline 4 & $\mathrm{Be}$ & & & $\underline{Y}$ & 42 & Mo & $\mathrm{D}$ & & $\underline{Y}$ \\
\hline 6 & $C^{b}$ & $\mathrm{CO}$ & $\underline{\mathrm{ORG}}$ & $\mathrm{CO}_{2}$ & 43 & $\mathrm{Tc}$ & $\mathrm{D}$ & $\underline{\mathrm{W}}$ & \\
\hline 9 & F & $\underline{\mathrm{D}}$ & W & $\mathrm{Y}$ & 44 & $\mathrm{Ru}$ & $\mathrm{D}$ & W & $\underline{Y}$ \\
\hline 11 & $\mathrm{Na}$ & $\underline{\mathrm{D}}$ & & & 45 & $\mathrm{Rh}$ & $\mathrm{D}$ & W & $\underline{Y}$ \\
\hline 12 & $\mathrm{Mg}$ & $\mathrm{D}$ & $\underline{\mathrm{W}}$ & & 46 & $\mathrm{Pd}$ & $\mathrm{D}$ & W & $\underline{Y}$ \\
\hline 13 & $\mathrm{Al}$ & $\mathrm{D}$ & $\underline{\mathrm{W}}$ & & 47 & $\mathrm{Ag}$ & $\mathrm{D}$ & W & $\underline{Y}$ \\
\hline 14 & $\mathrm{Si}$ & $\mathrm{D}$ & $\underline{\mathrm{W}}$ & $\mathrm{Y}$ & 48 & $\mathrm{Cd}$ & $\mathrm{D}$ & W & $\underline{Y}$ \\
\hline 15 & $\mathrm{P}$ & $\mathrm{D}$ & $\underline{\mathrm{W}}$ & & 49 & In & $\mathrm{D}$ & $\underline{\mathrm{W}}$ & \\
\hline 16 & $\mathrm{~S}$ & $\mathrm{D}$ & $\underline{\mathrm{W}}$ & $\mathrm{V}^{\mathrm{c}}$ & 50 & $\mathrm{Sn}$ & $\mathrm{D}$ & $\underline{\mathrm{W}}$ & \\
\hline 17 & $\mathrm{Cl}$ & $\underline{D}$ & W & $\mathrm{Y}$ & 51 & $\mathrm{Sb}$ & $\underline{\mathrm{D}}$ & W & \\
\hline 19 & $\mathrm{~K}$ & $\underline{\mathrm{D}}$ & & & 52 & $\mathrm{Te}$ & $\mathrm{D}$ & $\underline{\mathrm{W}}$ & \\
\hline 20 & $\mathrm{Ca}$ & & $\underline{\mathrm{W}}$ & & 53 & I & $\underline{\mathrm{D}}$ & & \\
\hline 21 & $\mathrm{Sc}$ & & & $\underline{Y}$ & 55 & Cs & $\underline{\mathrm{D}}$ & & \\
\hline 22 & $\mathrm{Ti}$ & $\mathrm{D}$ & $\underline{\mathrm{W}}$ & $\mathrm{Y}$ & 56 & $\mathrm{Ba}$ & $\mathrm{D}$ & & \\
\hline 23 & $\mathrm{~V}$ & $\mathrm{D}$ & $\underline{\mathrm{W}}$ & & 57 & $\mathrm{La}$ & $\mathrm{D}$ & $\underline{\mathrm{W}}$ & \\
\hline 24 & $\mathrm{Cr}$ & $\mathrm{D}$ & W & $\underline{Y}$ & 58 & $\mathrm{Ce}$ & & W & $\underline{Y}$ \\
\hline 25 & $\mathrm{Mn}$ & $\mathrm{D}$ & $\underline{\mathrm{W}}$ & & 59 & $\operatorname{Pr}$ & & W & $\underline{Y}$ \\
\hline 26 & $\mathrm{Fe}$ & $\mathrm{D}$ & $\underline{\mathrm{W}}$ & & 60 & $\mathrm{Nd}$ & & W & $\underline{Y}$ \\
\hline 27 & $\mathrm{Co}$ & & W & $\underline{Y}$ & 61 & $\mathrm{Pm}$ & & W & $\underline{Y}$ \\
\hline 28 & $\mathrm{Ni}$ & $\mathrm{D}$ & $\underline{\mathrm{W}}$ & $\mathrm{V}$ & 62 & $\mathrm{Sm}$ & & $\underline{\mathrm{W}}$ & \\
\hline 29 & $\mathrm{Cu}$ & $\mathrm{D}$ & W & $\underline{Y}$ & 63 & $\mathrm{Eu}$ & & $\underline{\mathrm{W}}$ & \\
\hline 30 & $\mathrm{Zn}$ & & & $\underline{Y}$ & 64 & $\mathrm{Gd}$ & $\mathrm{D}$ & $\underline{\mathrm{W}}$ & \\
\hline 31 & $\mathrm{Ga}$ & $\underline{\mathrm{D}}$ & & & 65 & $\mathrm{~Tb}$ & & $\underline{\mathrm{W}}$ & \\
\hline 32 & $\mathrm{Ge}$ & $\mathrm{D}$ & $\underline{\mathrm{W}}$ & & 66 & Dy & & $\underline{\mathrm{W}}$ & \\
\hline 33 & As & & $\underline{\mathrm{W}}$ & & 67 & Ho & & $\underline{\mathrm{W}}$ & \\
\hline 34 & $\mathrm{Se}$ & $\mathrm{D}$ & $\underline{\mathrm{W}}$ & & 68 & Er & & $\underline{\mathrm{W}}$ & \\
\hline 35 & $\mathrm{Br}$ & $\underline{\mathrm{D}}$ & W & & 69 & $\mathrm{Tm}$ & & $\underline{\mathrm{W}}$ & \\
\hline 37 & $\mathrm{Rb}$ & $\underline{\mathrm{D}}$ & & & 70 & $\mathrm{Yb}$ & & W & $\underline{Y}$ \\
\hline 38 & $\mathrm{Sr}$ & $\underline{\mathrm{D}}$ & & $\mathrm{Y}$ & 71 & $\mathrm{Lu}$ & & W & $\underline{Y}$ \\
\hline 39 & $\mathrm{Y}$ & & W & $\underline{Y}$ & 72 & $\mathrm{Hf}$ & $\mathrm{D}$ & $\underline{\mathrm{W}}$ & \\
\hline 40 & $\mathrm{Zr}$ & D & $\underline{\mathrm{W}}$ & $\mathrm{Y}$ & 73 & $\mathrm{Ta}$ & & W & $\underline{Y}$ \\
\hline
\end{tabular}




\section{ICRP 30 / FGR 11 \\ Lung Clearance Classes for Oxides or Hydroxides}

\begin{tabular}{|c|c|c|c|c|c|c|c|c|c|}
\hline Z & Element & All & $\begin{array}{l}\text { le } \\
\text { lass }\end{array}$ & nce & Z & Element & \multicolumn{3}{|c|}{$\begin{array}{c}\text { Allowable Clearance } \\
\text { Classes }\end{array}$} \\
\hline 74 & W & $\underline{\mathrm{D}}$ & & & 88 & $\mathrm{Ra}$ & & $\underline{\mathrm{W}}$ & \\
\hline 75 & $\operatorname{Re}$ & $\mathrm{D}$ & $\underline{\mathrm{W}}$ & & 89 & Ac & $\mathrm{D}$ & $\mathrm{W}$ & $\underline{Y}$ \\
\hline 76 & Os & $\mathrm{D}$ & W & $\underline{Y}$ & 90 & Th & & W & $\underline{Y}$ \\
\hline 77 & Ir & $\mathrm{D}$ & W & $\underline{Y}$ & 91 & $\mathrm{~Pa}$ & & W & $\underline{Y}$ \\
\hline 78 & $\mathrm{Pt}$ & $\underline{\mathrm{D}}$ & & & 92 & $\mathrm{U}$ & $\mathrm{D}$ & W & $\underline{Y}$ \\
\hline 79 & $\mathrm{Au}$ & $\mathrm{D}$ & W & $\underline{Y}$ & 93 & $\mathrm{~Np}$ & & $\underline{\mathrm{W}}$ & \\
\hline 80 & $\mathrm{Hg}$ & $\mathrm{D}$ & $\underline{\mathrm{W}}$ & $\mathrm{V}$ & 94 & $\mathrm{Pu}$ & & W & $\underline{Y}$ \\
\hline 81 & $\mathrm{Tl}$ & $\underline{\mathrm{D}}$ & & & 95 & $\mathrm{Am}$ & & $\underline{\mathrm{W}}$ & \\
\hline 82 & $\mathrm{~Pb}$ & $\underline{\mathrm{D}}$ & & & 96 & $\mathrm{Cm}$ & & $\underline{\mathrm{W}}$ & \\
\hline 83 & $\mathrm{Bi}$ & $\mathrm{D}$ & $\underline{\mathrm{W}}$ & & 97 & $\mathrm{Bk}$ & & $\underline{\mathrm{W}}$ & \\
\hline 84 & Po & $\mathrm{D}$ & $\underline{\mathrm{W}}$ & & 98 & $\mathrm{Cf}$ & & W & $\underline{Y}$ \\
\hline 85 & At & $\underline{\mathrm{D}}$ & W & & 99 & Es & & $\underline{\mathrm{W}}$ & \\
\hline 87 & Fr & $\underline{\mathrm{D}}$ & & & 100 & $\mathrm{Fm}$ & & $\underline{\mathrm{W}}$ & \\
\hline
\end{tabular}

a. Default lung clearance classes are underlined. $\mathrm{D}=$ day class, $\mathrm{W}=$ week class, and $\mathrm{Y}=$ year class.

b. Chemical species rather than clearance classes are indicated for hydrogen and carbon.

c. $\mathrm{V}=$ vapor. 


\section{ICRP 30 / FGR 11}

\section{Lung Clearance Classes for Maximum Element Dose}

\begin{tabular}{|c|c|c|c|c|c|c|c|c|c|}
\hline \multirow{2}{*}{$\begin{array}{l}\mathrm{Z} \\
1\end{array}$} & \multirow{2}{*}{$\begin{array}{c}\text { Element } \\
\mathrm{H}\end{array}$} & \multicolumn{3}{|c|}{$\begin{array}{c}\text { Allowable Clearance } \\
\text { Classes }\end{array}$} & \multirow{2}{*}{$\begin{array}{r}\mathrm{Z} \\
41\end{array}$} & \multirow{2}{*}{$\begin{array}{c}\text { Element } \\
\mathrm{Nb}\end{array}$} & \multicolumn{3}{|c|}{$\begin{array}{c}\text { Allowable Clearance } \\
\text { Classes }\end{array}$} \\
\hline & & $\underline{\mathrm{HTO}}$ & & & & & & W & $\underline{Y}$ \\
\hline 4 & $\mathrm{Be}$ & & & $\underline{Y}$ & 42 & Mo & $\mathrm{D}$ & & $\underline{Y}$ \\
\hline 6 & $\mathrm{C}$ & $\mathrm{CO}$ & $\underline{\mathrm{ORG}}$ & $\mathrm{CO}_{2}$ & 43 & $\mathrm{Tc}$ & $\mathrm{D}$ & $\underline{\mathrm{W}}$ & \\
\hline 9 & $\mathrm{~F}$ & $\underline{\mathrm{D}}$ & W & Y & 44 & $\mathrm{Ru}$ & $\mathrm{D}$ & W & $\underline{Y}$ \\
\hline 11 & $\mathrm{Na}$ & $\underline{D}$ & & & 45 & $\mathrm{Rh}$ & $\mathrm{D}$ & W & $\underline{Y}$ \\
\hline 12 & $\mathrm{Mg}$ & $\mathrm{D}$ & $\underline{\mathrm{W}}$ & & 46 & $\mathrm{Pd}$ & $\mathrm{D}$ & W & $\underline{Y}$ \\
\hline 13 & $\mathrm{Al}$ & $\underline{\mathrm{D}}$ & W & & 47 & $\mathrm{Ag}$ & $\mathrm{D}$ & W & $\underline{Y}$ \\
\hline 14 & $\mathrm{Si}$ & $\mathrm{D}$ & W & $\underline{Y}$ & 48 & $\mathrm{Cd}$ & $\underline{\mathrm{D}}$ & W & $\mathrm{Y}$ \\
\hline 15 & $\mathrm{P}$ & $\mathrm{D}$ & $\underline{\mathrm{W}}$ & & 49 & In & $\underline{\mathrm{D}}$ & W & \\
\hline 16 & S & $\mathrm{D}$ & $\underline{\mathrm{W}}$ & $\mathrm{V}^{\mathrm{c}}$ & 50 & $\mathrm{Sn}$ & $\mathrm{D}$ & $\underline{\mathrm{W}}$ & \\
\hline 17 & $\mathrm{Cl}$ & $\underline{\mathrm{D}}$ & W & $\mathrm{Y}$ & 51 & $\mathrm{Sb}$ & $\mathrm{D}$ & $\underline{\mathrm{W}}$ & \\
\hline 19 & $\mathrm{~K}$ & $\underline{\mathrm{D}}$ & & & 52 & $\mathrm{Te}$ & $\mathrm{D}$ & $\underline{\mathrm{W}}$ & \\
\hline 20 & $\mathrm{Ca}$ & & $\underline{\mathrm{W}}$ & & 53 & I & $\underline{\mathrm{D}}$ & & \\
\hline 21 & $\mathrm{Sc}$ & & & $\underline{Y}$ & 55 & $\mathrm{Cs}$ & $\underline{\mathrm{D}}$ & & \\
\hline 22 & $\mathrm{Ti}$ & $\mathrm{D}$ & W & $\underline{Y}$ & 56 & $\mathrm{Ba}$ & $\underline{\mathrm{D}}$ & & \\
\hline 23 & $\mathrm{~V}$ & D & $\underline{\mathrm{W}}$ & & 57 & $\mathrm{La}$ & $\mathrm{D}$ & $\underline{\mathrm{W}}$ & \\
\hline 24 & $\mathrm{Cr}$ & D & W & $\underline{Y}$ & 58 & $\mathrm{Ce}$ & & W & $\underline{Y}$ \\
\hline 25 & $\mathrm{Mn}$ & $\mathrm{D}$ & $\underline{\mathrm{W}}$ & & 59 & $\operatorname{Pr}$ & & W & $\underline{Y}$ \\
\hline 26 & $\mathrm{Fe}$ & $\underline{\mathrm{D}}$ & W & & 60 & $\mathrm{Nd}$ & & W & $\underline{Y}$ \\
\hline 27 & $\mathrm{Co}$ & & W & $\underline{Y}$ & 61 & $\mathrm{Pm}$ & & W & $\underline{Y}$ \\
\hline 28 & $\mathrm{Ni}$ & $\mathrm{D}$ & $\underline{\mathrm{W}}$ & $\mathrm{V}$ & 62 & $\mathrm{Sm}$ & & $\underline{\mathrm{W}}$ & \\
\hline 29 & $\mathrm{Cu}$ & $\mathrm{D}$ & W & $\underline{Y}$ & 63 & $\mathrm{Eu}$ & & $\underline{\mathrm{W}}$ & \\
\hline 30 & $\mathrm{Zn}$ & & & $\underline{Y}$ & 64 & $\mathrm{Gd}$ & $\underline{\mathrm{D}}$ & W & \\
\hline 31 & $\mathrm{Ga}$ & $\mathrm{D}$ & $\underline{\mathrm{W}}$ & & 65 & $\mathrm{~Tb}$ & & $\underline{\mathrm{W}}$ & \\
\hline 32 & $\mathrm{Ge}$ & $\underline{D}$ & W & & 66 & Dy & & $\underline{\mathrm{W}}$ & \\
\hline 33 & As & & $\underline{\mathrm{W}}$ & & 67 & Но & & $\underline{\mathrm{W}}$ & \\
\hline 34 & $\mathrm{Se}$ & D & $\underline{\mathrm{W}}$ & & 68 & $\mathrm{Er}$ & & $\underline{\mathrm{W}}$ & \\
\hline 35 & $\mathrm{Br}$ & $\mathrm{D}$ & $\underline{\mathrm{W}}$ & & 69 & $\mathrm{Tm}$ & & $\underline{\mathrm{W}}$ & \\
\hline 37 & $\mathrm{Rb}$ & $\underline{\mathrm{D}}$ & & & 70 & $\mathrm{Yb}$ & & W & $\underline{Y}$ \\
\hline 38 & $\mathrm{Sr}$ & D & & $\underline{Y}$ & 71 & $\mathrm{Lu}$ & & W & $\underline{Y}$ \\
\hline 39 & $\mathrm{Y}$ & & W & $\underline{Y}$ & 72 & Hf & $\underline{\mathrm{D}}$ & W & \\
\hline 40 & $\mathrm{Zr}$ & $\underline{D}$ & W & $\mathrm{Y}$ & 73 & $\mathrm{Ta}$ & & W & $\underline{Y}$ \\
\hline
\end{tabular}




\section{ICRP 30 / FGR 11}

\section{Lung Clearance Classes for Maximum Element Dose}

\begin{tabular}{|c|c|c|c|c|c|c|c|c|c|}
\hline \multirow{2}{*}{$\frac{Z}{74}$} & \multirow{2}{*}{$\frac{\text { Element }}{\mathrm{W}}$} & \multicolumn{3}{|c|}{$\begin{array}{c}\text { Allowable Clearance } \\
\text { Classes }\end{array}$} & \multirow{2}{*}{$\frac{Z}{88}$} & \multirow{2}{*}{$\frac{\text { Element }}{\mathrm{Ra}}$} & \multicolumn{3}{|c|}{$\begin{array}{c}\text { Allowable Clearance } \\
\text { Classes } \\
\end{array}$} \\
\hline & & $\underline{\mathrm{D}}$ & & & & & & $\underline{\mathrm{W}}$ & \\
\hline 75 & $\mathrm{Re}$ & $\mathrm{D}$ & $\underline{\mathrm{W}}$ & & 89 & $\mathrm{Ac}$ & $\underline{\mathrm{D}}$ & W & $\mathrm{Y}$ \\
\hline 76 & Os & $\mathrm{D}$ & W & $\underline{Y}$ & 90 & $\mathrm{Th}$ & & $\underline{\mathrm{W}}$ & $\mathrm{Y}$ \\
\hline 77 & $\mathrm{Ir}$ & $\mathrm{D}$ & W & $\underline{Y}$ & 91 & $\mathrm{~Pa}$ & & W & $\underline{Y}$ \\
\hline 78 & $\mathrm{Pt}$ & $\underline{\mathrm{D}}$ & & & 92 & $\mathrm{U}$ & $\mathrm{D}$ & W & $\underline{Y}$ \\
\hline 79 & $\mathrm{Au}$ & $\underline{\mathrm{D}}$ & W & $\mathrm{Y}$ & 93 & $\mathrm{~Np}$ & & $\underline{\mathrm{W}}$ & \\
\hline 80 & $\mathrm{Hg}$ & $\mathrm{D}$ & $\underline{\mathrm{W}}$ & $\mathrm{V}$ & 94 & $\mathrm{Pu}$ & & $\underline{\mathrm{W}}$ & $\mathrm{Y}$ \\
\hline 81 & $\mathrm{Tl}$ & $\underline{\mathrm{D}}$ & & & 95 & $\mathrm{Am}$ & & $\underline{\mathrm{W}}$ & \\
\hline 82 & $\mathrm{~Pb}$ & $\underline{\mathrm{D}}$ & & & 96 & $\mathrm{Cm}$ & & $\underline{\mathrm{W}}$ & \\
\hline 83 & $\mathrm{Bi}$ & $\mathrm{D}$ & $\underline{\mathrm{W}}$ & & 97 & $\mathrm{Bk}$ & & $\underline{\mathrm{W}}$ & \\
\hline 84 & Po & $\underline{\mathrm{D}}$ & W & & 98 & $\mathrm{Cf}$ & & W & $\underline{Y}$ \\
\hline 85 & At & $\mathrm{D}$ & $\underline{\mathrm{W}}$ & & 99 & Es & & $\underline{\mathrm{W}}$ & \\
\hline 87 & $\mathrm{Fr}$ & $\underline{\mathrm{D}}$ & & & 100 & $\mathrm{Fm}$ & & $\underline{\mathrm{W}}$ & \\
\hline
\end{tabular}




\begin{tabular}{|c|c|c|c|c|c|c|c|c|c|}
\hline \multirow{2}{*}{$\begin{array}{l}\mathrm{Z} \\
1\end{array}$} & \multirow{2}{*}{$\begin{array}{c}\text { Element } \\
\mathrm{H}^{\mathrm{b}}\end{array}$} & \multicolumn{3}{|c|}{$\begin{array}{c}\text { Allowable Clearance } \\
\text { Classes }\end{array}$} & \multirow{2}{*}{$\begin{array}{r}Z \\
41\end{array}$} & \multirow{2}{*}{$\begin{array}{c}\text { Element } \\
\mathrm{Nb}\end{array}$} & \multicolumn{3}{|c|}{$\begin{array}{c}\text { Allowable Clearance } \\
\text { Classes }\end{array}$} \\
\hline & & $\underline{\mathrm{HTO}}$ & & OBT & & & & $\underline{\mathrm{M}}$ & $\mathrm{S}$ \\
\hline 4 & $\mathrm{Be}$ & & $\mathrm{M}$ & $\underline{\mathrm{S}}$ & 42 & Mo & $\mathrm{F}$ & & $\underline{\mathrm{S}}$ \\
\hline 6 & $\mathrm{C}^{\mathrm{b}}$ & $\mathrm{CO}$ & $\underline{\mathrm{ORG}}$ & $\mathrm{CO}_{2}$ & 43 & $\mathrm{Tc}$ & $\mathrm{F}$ & $\underline{\mathrm{M}}$ & \\
\hline 9 & $\mathrm{~F}$ & $\underline{F}$ & $\mathrm{M}$ & $\mathrm{S}$ & 44 & $\mathrm{Ru}$ & $\mathrm{F}$ & $\underline{\mathrm{M}}$ & $\mathrm{S}$ \\
\hline 11 & $\mathrm{Na}$ & $\underline{F}$ & & & 45 & $\mathrm{Rh}$ & $\mathrm{F}$ & $\underline{\mathrm{M}}$ & $\mathrm{S}$ \\
\hline 12 & $\mathrm{Mg}$ & $\mathrm{F}$ & $\underline{\mathrm{M}}$ & & 46 & $\mathrm{Pd}$ & $\mathrm{F}$ & $\mathrm{M}$ & $\underline{\mathrm{S}}$ \\
\hline 13 & $\mathrm{Al}$ & $\mathrm{F}$ & $\underline{\mathrm{M}}$ & & 47 & $\mathrm{Ag}$ & $\mathrm{F}$ & $\underline{\mathrm{M}}$ & $\mathrm{S}$ \\
\hline 14 & $\mathrm{Si}$ & $\mathrm{F}$ & $\underline{\mathrm{M}}$ & $\mathrm{S}$ & 48 & $\mathrm{Cd}$ & $\mathrm{F}$ & $\mathrm{M}$ & $\underline{\mathrm{S}}$ \\
\hline 15 & $\mathrm{P}$ & $\mathrm{F}$ & $\underline{\mathrm{M}}$ & & 49 & In & $\mathrm{F}$ & $\underline{\mathrm{M}}$ & \\
\hline 16 & $\mathrm{~S}$ & $\mathrm{~F}$ & $\underline{\mathrm{M}}$ & $\mathrm{V}^{\mathrm{c}}$ & 50 & $\mathrm{Sn}$ & $\mathrm{F}$ & $\underline{\mathrm{M}}$ & \\
\hline 17 & $\mathrm{Cl}$ & $\underline{F}$ & $\mathrm{M}$ & & 51 & $\mathrm{Sb}$ & $\mathrm{F}$ & $\underline{\mathrm{M}}$ & \\
\hline 19 & $\mathrm{~K}$ & $\underline{F}$ & & & 52 & $\mathrm{Te}$ & $\mathrm{F}$ & $\underline{\mathrm{M}}$ & \\
\hline 20 & $\mathrm{Ca}$ & & $\underline{\mathrm{M}}$ & & 53 & I & $\underline{F}$ & & \\
\hline 21 & $\mathrm{Sc}$ & & & $\underline{S}$ & 55 & $\mathrm{Cs}$ & $\underline{F}$ & & \\
\hline 22 & $\mathrm{Ti}$ & $\mathrm{F}$ & $\underline{\mathrm{M}}$ & $\mathrm{S}$ & 56 & $\mathrm{Ba}$ & $\underline{F}$ & & \\
\hline 23 & $\mathrm{~V}$ & $\mathrm{~F}$ & $\underline{\mathrm{M}}$ & & 57 & $\mathrm{La}$ & $\mathrm{F}$ & $\underline{\mathrm{M}}$ & \\
\hline 24 & $\mathrm{Cr}$ & $\mathrm{F}$ & $\mathrm{M}$ & $\underline{S}$ & 58 & $\mathrm{Ce}$ & & $\underline{\mathrm{M}}$ & $\mathrm{S}$ \\
\hline 25 & $\mathrm{Mn}$ & $\mathrm{F}$ & $\underline{\mathrm{M}}$ & & 59 & $\operatorname{Pr}$ & & $\mathrm{M}$ & $\underline{S}$ \\
\hline 26 & $\mathrm{Fe}$ & $\mathrm{F}$ & $\underline{\mathrm{M}}$ & & 60 & $\mathrm{Nd}$ & & $\mathrm{M}$ & $\underline{S}$ \\
\hline 27 & $\mathrm{Co}$ & & $\underline{\mathrm{M}}$ & S & 61 & $\mathrm{Pm}$ & & $\mathrm{M}$ & $\underline{S}$ \\
\hline 28 & $\mathrm{Ni}$ & $\mathrm{F}$ & $\underline{\mathrm{M}}$ & & 62 & $\mathrm{Sm}$ & & $\underline{\mathrm{M}}$ & \\
\hline 29 & $\mathrm{Cu}$ & $\mathrm{F}$ & $\mathrm{M}$ & $\underline{S}$ & 63 & $\mathrm{Eu}$ & & $\underline{\mathrm{M}}$ & \\
\hline 30 & $\mathrm{Zn}$ & & & $\underline{S}$ & 64 & $\mathrm{Gd}$ & $\mathrm{F}$ & $\underline{\mathrm{M}}$ & \\
\hline 31 & $\mathrm{Ga}$ & $\underline{F}$ & $\mathrm{M}$ & & 65 & $\mathrm{~Tb}$ & & $\underline{\mathrm{M}}$ & \\
\hline 32 & $\mathrm{Ge}$ & $\mathrm{F}$ & $\underline{\mathrm{M}}$ & & 66 & Dy & & $\underline{\mathrm{M}}$ & \\
\hline 33 & As & & $\underline{\mathrm{M}}$ & & 67 & Но & & $\underline{\mathrm{M}}$ & \\
\hline 34 & $\mathrm{Se}$ & $\underline{F}$ & $\mathrm{M}$ & & 68 & $\mathrm{Er}$ & & $\underline{\mathrm{M}}$ & \\
\hline 35 & $\mathrm{Br}$ & $\underline{\mathrm{F}}$ & $\mathrm{M}$ & & 69 & $\mathrm{Tm}$ & & $\underline{\mathrm{M}}$ & \\
\hline 37 & $\mathrm{Rb}$ & $\underline{F}$ & & & 70 & $\mathrm{Yb}$ & & $\mathrm{M}$ & $\underline{S}$ \\
\hline 38 & $\mathrm{Sr}$ & $\underline{F}$ & & $\mathrm{~S}$ & 71 & $\mathrm{Lu}$ & & $\mathrm{M}$ & $\underline{S}$ \\
\hline 39 & $\mathrm{Y}$ & & $\underline{\mathrm{M}}$ & $\mathrm{S}$ & 72 & $\mathrm{Hf}$ & $\mathrm{F}$ & $\underline{\mathrm{M}}$ & \\
\hline 40 & $\mathrm{Zr}$ & $\mathrm{F}$ & $\underline{\mathrm{M}}$ & $\mathrm{S}$ & 73 & $\mathrm{Ta}$ & & $\mathrm{M}$ & $\underline{S}$ \\
\hline
\end{tabular}




\section{ICRP 68 \\ Recommended Lung Clearance Classes}

\begin{tabular}{|c|c|c|c|c|c|c|c|c|c|}
\hline \multirow{2}{*}{$\frac{Z}{74}$} & \multirow{2}{*}{$\frac{\text { Element }}{\mathrm{W}}$} & \multicolumn{3}{|c|}{$\begin{array}{c}\text { Allowable Clearance } \\
\text { Classes }\end{array}$} & \multirow{2}{*}{$\frac{Z}{88}$} & \multirow{2}{*}{$\frac{\text { Element }}{\mathrm{Ra}}$} & \multicolumn{3}{|c|}{$\begin{array}{c}\text { Allowable Clearance } \\
\text { Classes }\end{array}$} \\
\hline & & $\underline{F}$ & & & & & & $\underline{\mathrm{M}}$ & \\
\hline 75 & $\mathrm{Re}$ & $\mathrm{F}$ & $\underline{\mathrm{M}}$ & & 89 & $\mathrm{Ac}$ & $\mathrm{F}$ & $\mathrm{M}$ & $\underline{S}$ \\
\hline 76 & Os & $\mathrm{F}$ & $\mathrm{M}$ & $\underline{S}$ & 90 & Th & & $\mathrm{M}$ & $\underline{S}$ \\
\hline 77 & Ir & $\mathrm{F}$ & $\mathrm{M}$ & $\underline{S}$ & 91 & $\mathrm{~Pa}$ & & $\mathrm{M}$ & $\underline{S}$ \\
\hline 78 & $\mathrm{Pt}$ & $\underline{F}$ & & & 92 & $\mathrm{U}$ & $\mathrm{F}$ & $\underline{\mathrm{M}}$ & $\mathrm{S}$ \\
\hline 79 & $\mathrm{Au}$ & $\mathrm{F}$ & $\mathrm{M}$ & $\underline{S}$ & 93 & $\mathrm{~Np}$ & & $\underline{\mathrm{M}}$ & \\
\hline 80 & $\mathrm{Hg}$ & $\mathrm{F}$ & $\underline{\mathrm{M}}$ & $\mathrm{V}$ & 94 & $\mathrm{Pu}$ & & $\underline{\mathrm{M}}$ & $\mathrm{S}$ \\
\hline 81 & $\mathrm{Tl}$ & $\underline{F}$ & & & 95 & $\mathrm{Am}$ & & $\underline{\mathrm{M}}$ & \\
\hline 82 & $\mathrm{~Pb}$ & $\underline{F}$ & & & 96 & $\mathrm{Cm}$ & & $\underline{\mathrm{M}}$ & \\
\hline 83 & $\mathrm{Bi}$ & $\mathrm{F}$ & $\underline{\mathrm{M}}$ & & 97 & $\mathrm{Bk}$ & & $\underline{\mathrm{M}}$ & \\
\hline 84 & Po & $\mathrm{F}$ & $\underline{\mathrm{M}}$ & & 98 & $\mathrm{Cf}$ & & $\mathrm{M}$ & \\
\hline 85 & At & $\underline{F}$ & $\mathrm{M}$ & & 99 & Es & & $\underline{\mathrm{M}}$ & \\
\hline 87 & $\mathrm{Fr}$ & $\underline{F}$ & & & 100 & $\mathrm{Fm}$ & & $\underline{\mathrm{M}}$ & \\
\hline
\end{tabular}

a. Default lung clearance classes are underlined. $\mathrm{F}=\mathrm{Fast}, \mathrm{M}=$ Medium class, and $\mathrm{S}=\mathrm{Slow}$

b. Chemical species rather than clearance classes are indicated for hydrogen and carbon.

c. $\mathrm{V}=$ vapor. 


\section{ICRP 68 Lung Clearance Classes for Maximum Element Dose}

\begin{tabular}{|c|c|c|c|c|c|c|c|c|c|}
\hline \multirow{2}{*}{$\begin{array}{l}\mathrm{Z} \\
1\end{array}$} & \multirow{2}{*}{$\begin{array}{c}\text { Element } \\
\mathrm{H}^{\mathrm{b}}\end{array}$} & \multicolumn{3}{|c|}{$\begin{array}{c}\text { Allowable Clearance } \\
\text { Classes }\end{array}$} & \multirow{2}{*}{$\begin{array}{r}\mathrm{Z} \\
41\end{array}$} & \multirow{2}{*}{$\begin{array}{c}\text { Element } \\
\mathrm{Nb}\end{array}$} & \multicolumn{3}{|c|}{$\begin{array}{c}\text { Allowable Clearance } \\
\text { Classes }\end{array}$} \\
\hline & & & $\underline{\mathrm{HTO}}$ & OBT & & & & $\mathrm{M}$ & $\underline{S}$ \\
\hline 4 & $\mathrm{Be}$ & & $\mathrm{M}$ & $\underline{S}$ & 42 & Mo & $\mathrm{F}$ & & $\underline{\mathrm{S}}$ \\
\hline 6 & $\mathrm{C}^{\mathrm{b}}$ & $\mathrm{CO}$ & $\mathrm{CO}_{2}$ & $\underline{\text { ORG }}$ & 43 & $\mathrm{Tc}$ & $\mathrm{F}$ & $\underline{\mathrm{M}}$ & \\
\hline 9 & $\mathrm{~F}$ & $\mathrm{~F}$ & $\mathrm{M}$ & $\underline{\mathrm{S}}$ & 44 & $\mathrm{Ru}$ & $\mathrm{F}$ & $\mathrm{M}$ & $\underline{\mathrm{S}}$ \\
\hline 11 & $\mathrm{Na}$ & $\underline{F}$ & & & 45 & $\mathrm{Rh}$ & $\mathrm{F}$ & $\mathrm{M}$ & $\underline{\mathrm{S}}$ \\
\hline 12 & $\mathrm{Mg}$ & $\mathrm{F}$ & $\underline{\mathrm{M}}$ & & 46 & $\mathrm{Pd}$ & $\mathrm{F}$ & $\mathrm{M}$ & $\underline{\mathrm{S}}$ \\
\hline 13 & $\mathrm{Al}$ & $\underline{F}$ & M & & 47 & $\mathrm{Ag}$ & $\mathrm{F}$ & $\mathrm{M}$ & $\underline{\mathrm{S}}$ \\
\hline 14 & $\mathrm{Si}$ & $\mathrm{F}$ & M & $\underline{S}$ & 48 & $\mathrm{Cd}$ & $\underline{F}$ & M & $\mathrm{S}$ \\
\hline 15 & $\mathrm{P}$ & F & $\underline{\mathrm{M}}$ & & 49 & In & $\mathrm{F}$ & $\underline{\mathrm{M}}$ & \\
\hline 16 & $\mathrm{~S}$ & F & $\underline{\mathrm{M}}$ & $\mathrm{V}^{\mathrm{c}}$ & 50 & $\mathrm{Sn}$ & $\mathrm{F}$ & $\underline{\mathrm{M}}$ & \\
\hline 17 & $\mathrm{Cl}$ & $\mathrm{F}$ & $\underline{\mathrm{M}}$ & & 51 & $\mathrm{Sb}$ & $\mathrm{F}$ & $\underline{\mathrm{M}}$ & \\
\hline 19 & $\mathrm{~K}$ & $\underline{F}$ & & & 52 & $\mathrm{Te}$ & $\mathrm{F}$ & $\underline{\mathrm{M}}$ & \\
\hline 20 & $\mathrm{Ca}$ & & $\underline{\mathrm{M}}$ & & 53 & I & $\underline{F}$ & & \\
\hline 21 & $\mathrm{Sc}$ & & & $\underline{S}$ & 55 & Cs & $\underline{F}$ & & \\
\hline 22 & $\mathrm{Ti}$ & $\underline{F}$ & M & $\mathrm{S}$ & 56 & $\mathrm{Ba}$ & $\underline{F}$ & & \\
\hline 23 & V & $\mathrm{F}$ & $\underline{\mathrm{M}}$ & & 57 & $\mathrm{La}$ & $\mathrm{F}$ & $\underline{\mathrm{M}}$ & \\
\hline 24 & $\mathrm{Cr}$ & $\mathrm{F}$ & M & $\underline{S}$ & 58 & $\mathrm{Ce}$ & & $\mathrm{M}$ & $\underline{\mathrm{S}}$ \\
\hline 25 & $\mathrm{Mn}$ & $\mathrm{F}$ & $\underline{\mathrm{M}}$ & & 59 & $\operatorname{Pr}$ & & M & $\underline{\mathrm{S}}$ \\
\hline 26 & $\mathrm{Fe}$ & $\mathrm{F}$ & $\underline{\mathrm{M}}$ & & 60 & $\mathrm{Nd}$ & & M & $\underline{\mathrm{S}}$ \\
\hline 27 & $\mathrm{Co}$ & & M & $\underline{\mathrm{S}}$ & 61 & $\mathrm{Pm}$ & & $\mathrm{M}$ & $\underline{\mathrm{S}}$ \\
\hline 28 & $\mathrm{Ni}$ & $\mathrm{F}$ & $\underline{\mathrm{M}}$ & & 62 & $\mathrm{Sm}$ & & $\underline{\mathrm{M}}$ & \\
\hline 29 & $\mathrm{Cu}$ & $\mathrm{F}$ & $\mathrm{M}$ & $\underline{S}$ & 63 & $\mathrm{Eu}$ & & $\underline{\mathrm{M}}$ & \\
\hline 30 & $\mathrm{Zn}$ & & & $\underline{\mathrm{S}}$ & 64 & $\mathrm{Gd}$ & $\mathrm{F}$ & $\underline{\mathrm{M}}$ & \\
\hline 31 & $\mathrm{Ga}$ & $\mathrm{F}$ & $\underline{\mathrm{M}}$ & & 65 & $\mathrm{~Tb}$ & & $\overline{\mathrm{M}}$ & \\
\hline 32 & $\mathrm{Ge}$ & $\mathrm{F}$ & $\underline{\mathrm{M}}$ & & 66 & Dy & & $\overline{\mathrm{M}}$ & \\
\hline 33 & As & & $\underline{\mathrm{M}}$ & & 67 & Ho & & $\overline{\mathrm{M}}$ & \\
\hline 34 & $\mathrm{Se}$ & $\mathrm{F}$ & $\underline{\mathrm{M}}$ & & 68 & Er & & $\overline{\mathrm{M}}$ & \\
\hline 35 & $\mathrm{Br}$ & $\mathrm{F}$ & $\underline{\mathrm{M}}$ & & 69 & $\mathrm{Tm}$ & & $\overline{\mathrm{M}}$ & \\
\hline 37 & $\mathrm{Rb}$ & $\underline{F}$ & & & 70 & $\mathrm{Yb}$ & & $\bar{M}$ & $\underline{S}$ \\
\hline 38 & $\mathrm{Sr}$ & $\mathrm{F}$ & & $\underline{S}$ & 71 & $\mathrm{Lu}$ & & $\mathrm{M}$ & $\underline{\mathrm{S}}$ \\
\hline 39 & $\mathrm{Y}$ & & M & $\underline{S}$ & 72 & $\mathrm{Hf}$ & $\mathrm{F}$ & $\underline{\mathrm{M}}$ & \\
\hline 40 & $\mathrm{Zr}$ & $\underline{F}$ & M & $\bar{S}$ & 73 & $\mathrm{Ta}$ & & $\mathrm{M}$ & $\underline{S}$ \\
\hline
\end{tabular}




\section{ICRP 68 Lung Clearance Classes for Maximum Element Dose}

\begin{tabular}{|c|c|c|c|c|c|c|c|c|c|}
\hline Z & Element & Allo & $\begin{array}{l}\text { le } C \\
\text { lass }\end{array}$ & nce & Z & Element & \multicolumn{3}{|c|}{$\begin{array}{c}\text { Allowable Clearance } \\
\text { Classes }\end{array}$} \\
\hline 74 & W & $\underline{F}$ & & & 88 & $\mathrm{Ra}$ & & $\underline{\mathrm{M}}$ & \\
\hline 75 & $\mathrm{Re}$ & $\mathrm{F}$ & $\underline{\mathrm{M}}$ & & 89 & Ac & $\mathrm{F}$ & M & $\underline{\mathrm{S}}$ \\
\hline 76 & Os & $\mathrm{F}$ & M & $\underline{S}$ & 90 & Th & & M & $\underline{\mathrm{S}}$ \\
\hline 77 & $\mathrm{Ir}$ & $\mathrm{F}$ & M & $\underline{S}$ & 91 & $\mathrm{~Pa}$ & & M & $\underline{S}$ \\
\hline 78 & $\mathrm{Pt}$ & $\underline{F}$ & & & 92 & $\mathrm{U}$ & $\mathrm{F}$ & M & $\underline{S}$ \\
\hline 79 & $\mathrm{Au}$ & $\mathrm{F}$ & M & $\underline{S}$ & 93 & $\mathrm{~Np}$ & & $\underline{\mathrm{M}}$ & \\
\hline 80 & $\mathrm{Hg}$ & $\mathrm{F}$ & $\underline{\mathrm{M}}$ & $\mathrm{V}$ & 94 & $\mathrm{Pu}$ & & $\underline{\mathrm{M}}$ & $\mathrm{S}$ \\
\hline 81 & $\mathrm{Tl}$ & $\underline{F}$ & & & 95 & $\mathrm{Am}$ & & $\underline{\mathrm{M}}$ & \\
\hline 82 & $\mathrm{~Pb}$ & $\underline{F}$ & & & 96 & $\mathrm{Cm}$ & & $\underline{\mathrm{M}}$ & \\
\hline 83 & $\mathrm{Bi}$ & $\mathrm{F}$ & $\underline{\mathrm{M}}$ & & 97 & $\mathrm{Bk}$ & & $\underline{\mathrm{M}}$ & \\
\hline 84 & Po & $\mathrm{F}$ & $\underline{\mathrm{M}}$ & & 98 & $\mathrm{Cf}$ & & $\underline{\mathrm{M}}$ & \\
\hline 85 & At & $\mathrm{F}$ & $\underline{\mathrm{M}}$ & & 99 & Es & & $\underline{\mathrm{M}}$ & \\
\hline 87 & $\mathrm{Fr}$ & $\underline{F}$ & & & 100 & $\mathrm{Fm}$ & & $\underline{\mathrm{M}}$ & \\
\hline
\end{tabular}

a. Default lung clearance classes are underlined. $\mathrm{F}=\mathrm{Fast}, \mathrm{M}=$ Medium class, and $\mathrm{S}=\mathrm{Slow}$

b. Chemical species rather than clearance classes are indicated for hydrogen and carbon.

c. $\mathrm{V}=$ vapor. 


\section{ICRP 72}

Recommended Lung Clearance Classes ${ }^{a}$

\begin{tabular}{|c|c|c|c|c|c|c|c|c|c|}
\hline \multirow[t]{2}{*}{$\mathrm{Z}$} & \multirow[t]{2}{*}{ Element } & \multicolumn{3}{|c|}{$\begin{array}{c}\text { Allowable Clearance } \\
\text { Classes }\end{array}$} & \multirow[t]{2}{*}{ Z } & \multirow[t]{2}{*}{ Element } & \multicolumn{3}{|c|}{$\begin{array}{c}\text { Allowable Clearance } \\
\text { Classes }\end{array}$} \\
\hline & & & & & & & $\mathrm{F}$ & & \\
\hline 1 & $\mathrm{H}^{\mathrm{b}}$ & & $\underline{\mathrm{HTO}}$ & OBT & 41 & $\mathrm{Nb}$ & & $\underline{\mathrm{M}}$ & $\mathrm{S}$ \\
\hline 4 & $\mathrm{Be}$ & & M & $\underline{S}$ & 42 & Mo & $\mathrm{F}$ & $\underline{\mathrm{M}}$ & $\mathrm{S}$ \\
\hline 6 & $\mathrm{C}^{\mathrm{b}}$ & $\mathrm{CO}$ & $\underline{\mathrm{CO}}_{2}$ & ORG & 43 & $\mathrm{Tc}$ & $\mathrm{F}$ & $\underline{\mathrm{M}}$ & $\mathrm{S}$ \\
\hline 9 & $\mathrm{~F}$ & $\underline{F}$ & M & $\mathrm{S}$ & 44 & $\mathrm{Ru}$ & $\mathrm{F}$ & $\underline{\mathrm{M}}$ & $\mathrm{S}$ \\
\hline 11 & $\mathrm{Na}$ & $\underline{F}$ & & & 45 & $\mathrm{Rh}$ & $\mathrm{F}$ & $\underline{\mathrm{M}}$ & $\mathrm{S}$ \\
\hline 12 & $\mathrm{Mg}$ & F & $\underline{\mathrm{M}}$ & & 46 & $\mathrm{Pd}$ & $\mathrm{F}$ & $\mathrm{M}$ & $\underline{S}$ \\
\hline 13 & $\mathrm{Al}$ & F & $\underline{\mathrm{M}}$ & & 47 & $\mathrm{Ag}$ & $\mathrm{F}$ & $\underline{\mathrm{M}}$ & $\mathrm{S}$ \\
\hline 14 & $\mathrm{Si}$ & F & $\underline{\mathrm{M}}$ & $\mathrm{S}$ & 48 & $\mathrm{Cd}$ & $\mathrm{F}$ & $\mathrm{M}$ & $\underline{S}$ \\
\hline 15 & $\mathrm{P}$ & F & $\underline{\mathrm{M}}$ & & 49 & In & $\mathrm{F}$ & $\underline{\mathrm{M}}$ & \\
\hline 16 & S & F & $\underline{\mathrm{M}}$ & $\mathrm{V}^{\mathrm{c}}$ & 50 & Sn & $\mathrm{F}$ & $\underline{\mathrm{M}}$ & \\
\hline 17 & $\mathrm{Cl}$ & $\underline{F}$ & M & & 51 & $\mathrm{Sb}$ & $\mathrm{F}$ & $\underline{\mathrm{M}}$ & $\mathrm{S}$ \\
\hline 19 & K & $\underline{F}$ & & & 52 & $\mathrm{Te}$ & $\mathrm{F}$ & $\underline{\mathrm{M}}$ & $\mathrm{S}$ \\
\hline 20 & $\mathrm{Ca}$ & $\mathrm{F}$ & $\underline{\mathrm{M}}$ & $\mathrm{S}$ & 53 & I & $\underline{F}$ & $\mathrm{M}$ & $\mathrm{S}$ \\
\hline 21 & $\mathrm{Sc}$ & & & $\underline{S}$ & 55 & Cs & $\underline{F}$ & $\mathrm{M}$ & $\mathrm{S}$ \\
\hline 22 & $\mathrm{Ti}$ & $\mathrm{F}$ & $\underline{\mathrm{M}}$ & $\mathrm{S}$ & 56 & $\mathrm{Ba}$ & $\mathrm{F}$ & $\underline{\mathrm{M}}$ & $\mathrm{S}$ \\
\hline 23 & V & $\mathrm{F}$ & $\underline{\mathrm{M}}$ & & 57 & $\mathrm{La}$ & $\mathrm{F}$ & $\underline{\mathrm{M}}$ & \\
\hline 24 & $\mathrm{Cr}$ & $\mathrm{F}$ & M & $\underline{S}$ & 58 & $\mathrm{Ce}$ & $\mathrm{F}$ & $\underline{\mathrm{M}}$ & $\mathrm{S}$ \\
\hline 25 & $\mathrm{Mn}$ & F & $\underline{\mathrm{M}}$ & & 59 & $\operatorname{Pr}$ & & $\mathrm{M}$ & $\underline{\mathrm{S}}$ \\
\hline 26 & $\mathrm{Fe}$ & $\mathrm{F}$ & $\underline{\mathrm{M}}$ & $\mathrm{S}$ & 60 & $\mathrm{Nd}$ & & $\mathrm{M}$ & $\underline{S}$ \\
\hline 27 & $\mathrm{Co}$ & $\mathrm{F}$ & $\underline{\mathrm{M}}$ & $\mathrm{S}$ & 61 & $\mathrm{Pm}$ & & $\mathrm{M}$ & $\underline{S}$ \\
\hline 28 & $\mathrm{Ni}$ & F & $\underline{\mathrm{M}}$ & $\mathrm{S}$ & 62 & $\mathrm{Sm}$ & & $\underline{\mathrm{M}}$ & \\
\hline 29 & $\mathrm{Cu}$ & F & $\mathrm{M}$ & $\underline{S}$ & 63 & $\mathrm{Eu}$ & & $\underline{\mathrm{M}}$ & \\
\hline 30 & $\mathrm{Zn}$ & $\mathrm{F}$ & $\underline{\mathrm{M}}$ & $\mathrm{S}$ & 64 & $\mathrm{Gd}$ & $\mathrm{F}$ & $\underline{\mathrm{M}}$ & \\
\hline 31 & $\mathrm{Ga}$ & $\underline{F}$ & $\mathrm{M}$ & & 65 & $\mathrm{~Tb}$ & & $\underline{\mathrm{M}}$ & \\
\hline 32 & $\mathrm{Ge}$ & $\mathrm{F}$ & $\underline{\mathrm{M}}$ & & 66 & Dy & & $\underline{\mathrm{M}}$ & \\
\hline 33 & As & & $\underline{\mathrm{M}}$ & & 67 & Но & & $\underline{\mathrm{M}}$ & \\
\hline 34 & $\mathrm{Se}$ & $\underline{F}$ & $\mathrm{M}$ & $\mathrm{S}$ & 68 & $\mathrm{Er}$ & & $\underline{\mathrm{M}}$ & \\
\hline 35 & $\mathrm{Br}$ & $\underline{F}$ & $\mathrm{M}$ & & 69 & $\mathrm{Tm}$ & & $\underline{\mathrm{M}}$ & \\
\hline 37 & $\mathrm{Rb}$ & $\underline{\mathrm{F}}$ & & & 70 & $\mathrm{Yb}$ & & $\mathrm{M}$ & $\underline{S}$ \\
\hline 38 & $\mathrm{Sr}$ & $\mathrm{F}$ & $\underline{\mathrm{M}}$ & $\mathrm{S}$ & 71 & $\mathrm{Lu}$ & & $\mathrm{M}$ & $\underline{\mathrm{S}}$ \\
\hline 39 & $\mathrm{Y}$ & & $\mathrm{M}$ & $\underline{S}$ & 72 & Hf & $\mathrm{F}$ & $\underline{\mathrm{M}}$ & \\
\hline 40 & $\mathrm{Zr}$ & $\mathrm{F}$ & $\underline{\mathrm{M}}$ & $\mathrm{S}$ & 73 & $\mathrm{Ta}$ & & $\mathrm{M}$ & $\underline{\mathrm{S}}$ \\
\hline
\end{tabular}




\section{ICRP 72 \\ Recommended Lung Clearance Classes}

\begin{tabular}{lllllllll}
\hline Z & Element & \multicolumn{2}{c}{$\begin{array}{c}\text { Allowable Clearance } \\
\text { Classes }\end{array}$} & \multicolumn{2}{c}{ Z } & Element & \multicolumn{3}{c}{ Allowable Clearance } \\
Classes
\end{tabular}

a. Default lung clearance classes are underlined. $\mathrm{F}=$ Fast, $\mathrm{M}=$ Medium class, and $\mathrm{S}=$ Slow.

Highlighted classes are taken from ICRP 72 Table 2, recommended default absorption Type for particulate aerosol, when no specific information is available.

b. Chemical species rather than clearance classes are indicated for hydrogen and carbon.

c. $\mathrm{V}=$ vapor. 


\section{ICRP 72}

Maximum Lung Clearance Classes ${ }^{a}$

\begin{tabular}{|c|c|c|c|c|c|c|c|c|c|}
\hline \multirow{3}{*}{$\begin{array}{l}\mathrm{Z} \\
1\end{array}$} & \multirow{3}{*}{$\begin{array}{c}\text { Element } \\
\mathrm{H}^{\mathrm{b}}\end{array}$} & \multicolumn{3}{|c|}{$\begin{array}{c}\text { Allowable Clearance } \\
\text { Classes }\end{array}$} & \multirow{3}{*}{$\begin{array}{r}\mathrm{Z} \\
41\end{array}$} & \multirow{3}{*}{$\begin{array}{c}\text { Element } \\
\mathrm{Nb}\end{array}$} & \multicolumn{3}{|c|}{$\begin{array}{c}\text { Allowable Clearance } \\
\text { Classes }\end{array}$} \\
\hline & & & & & & & $\mathrm{F}$ & & \\
\hline & & $\mathrm{F}$ & $\mathrm{M}$ & $\underline{\mathrm{S}}$ & & & & $\mathrm{M}$ & $\underline{\mathrm{S}}$ \\
\hline 4 & $\mathrm{Be}$ & & $\mathrm{M}$ & $\underline{S}$ & 42 & Mo & $\mathrm{F}$ & $\mathrm{M}$ & $\underline{\mathrm{S}}$ \\
\hline 6 & $\mathrm{C}^{\mathrm{b}}$ & $\mathrm{CO}$ & $\mathrm{CO}_{2}$ & $\underline{\mathrm{ORG}}$ & 43 & $\mathrm{Tc}$ & $\mathrm{F}$ & $\mathrm{M}$ & $\underline{S}$ \\
\hline 9 & $\mathrm{~F}$ & $\mathrm{~F}$ & M & $\underline{\mathrm{S}}$ & 44 & $\mathrm{Ru}$ & $\mathrm{F}$ & M & $\underline{\mathrm{S}}$ \\
\hline 11 & $\mathrm{Na}$ & $\underline{F}$ & & & 45 & $\mathrm{Rh}$ & $\mathrm{F}$ & $\mathrm{M}$ & $\underline{\mathrm{S}}$ \\
\hline 12 & $\mathrm{Mg}$ & $\mathrm{F}$ & $\underline{\mathrm{M}}$ & & 46 & $\mathrm{Pd}$ & $\mathrm{F}$ & $\mathrm{M}$ & $\underline{\mathrm{S}}$ \\
\hline 13 & $\mathrm{Al}$ & $\mathrm{F}$ & $\underline{\mathrm{M}}$ & & 47 & $\mathrm{Ag}$ & $\mathrm{F}$ & $\mathrm{M}$ & $\underline{\mathrm{S}}$ \\
\hline 14 & $\mathrm{Si}$ & $\mathrm{F}$ & $\mathrm{M}$ & $\underline{\mathrm{S}}$ & 48 & $\mathrm{Cd}$ & $\underline{F}$ & $\mathrm{M}$ & $\mathrm{S}$ \\
\hline 15 & $\mathrm{P}$ & $\mathrm{F}$ & $\underline{\mathrm{M}}$ & & 49 & In & $\mathrm{F}$ & $\underline{\mathrm{M}}$ & \\
\hline 16 & $\mathrm{~S}$ & $\mathrm{~F}$ & $\mathrm{M}$ & $\underline{\mathrm{V}^{\mathrm{c}}}$ & 50 & $\mathrm{Sn}$ & $\mathrm{F}$ & $\underline{\mathrm{M}}$ & \\
\hline 17 & $\mathrm{Cl}$ & $\mathrm{F}$ & $\underline{\mathrm{M}}$ & & 51 & $\mathrm{Sb}$ & $\mathrm{F}$ & $\mathrm{M}$ & $\underline{\mathrm{S}}$ \\
\hline 19 & $\mathrm{~K}$ & $\underline{F}$ & & & 52 & $\mathrm{Te}$ & $\mathrm{F}$ & $\mathrm{M}$ & $\underline{\mathrm{S}}$ \\
\hline 20 & $\mathrm{Ca}$ & $\mathrm{F}$ & $\mathrm{M}$ & $\underline{\mathrm{S}}$ & 53 & I & $\underline{F}$ & $\mathrm{M}$ & $\mathrm{S}$ \\
\hline 21 & $\mathrm{Sc}$ & & & $\underline{\mathrm{S}}$ & 55 & $\mathrm{Cs}$ & $\mathrm{F}$ & $\mathrm{M}$ & $\underline{\mathrm{S}}$ \\
\hline 22 & $\mathrm{Ti}$ & $\mathrm{F}$ & $\mathrm{M}$ & $\underline{\mathrm{S}}$ & 56 & $\mathrm{Ba}$ & $\mathrm{F}$ & $\mathrm{M}$ & $\underline{\mathrm{S}}$ \\
\hline 23 & $\mathrm{~V}$ & $\mathrm{~F}$ & $\underline{\mathrm{M}}$ & & 57 & $\mathrm{La}$ & $\mathrm{F}$ & $\underline{\mathrm{M}}$ & \\
\hline 24 & $\mathrm{Cr}$ & $\mathrm{F}$ & $\mathrm{M}$ & $\underline{S}$ & 58 & $\mathrm{Ce}$ & $\mathrm{F}$ & $\mathrm{M}$ & $\underline{\mathrm{S}}$ \\
\hline 25 & $\mathrm{Mn}$ & $\mathrm{F}$ & $\underline{\mathrm{M}}$ & & 59 & $\operatorname{Pr}$ & & $\mathrm{M}$ & $\underline{\mathrm{S}}$ \\
\hline 26 & $\mathrm{Fe}$ & $\mathrm{F}$ & $\mathrm{M}$ & $\underline{S}$ & 60 & $\mathrm{Nd}$ & & $\mathrm{M}$ & $\underline{\mathrm{S}}$ \\
\hline 27 & Co & $\mathrm{F}$ & $\mathrm{M}$ & $\underline{S}$ & 61 & $\mathrm{Pm}$ & & $\mathrm{M}$ & $\underline{S}$ \\
\hline 28 & $\mathrm{Ni}$ & $\mathrm{F}$ & $\mathrm{M}$ & $\underline{S}$ & 62 & $\mathrm{Sm}$ & & $\underline{\mathrm{M}}$ & \\
\hline 29 & $\mathrm{Cu}$ & $\mathrm{F}$ & $\mathrm{M}$ & $\underline{S}$ & 63 & $\mathrm{Eu}$ & & $\underline{\mathrm{M}}$ & \\
\hline 30 & $\mathrm{Zn}$ & $\mathrm{F}$ & $\mathrm{M}$ & $\underline{S}$ & 64 & $\mathrm{Gd}$ & $\mathrm{F}$ & $\underline{\mathrm{M}}$ & \\
\hline 31 & $\mathrm{Ga}$ & $\mathrm{F}$ & $\underline{\mathrm{M}}$ & & 65 & $\mathrm{~Tb}$ & & $\underline{\mathrm{M}}$ & \\
\hline 32 & $\mathrm{Ge}$ & $\mathrm{F}$ & $\underline{\mathrm{M}}$ & & 66 & Dy & & $\underline{\mathrm{M}}$ & \\
\hline 33 & As & & $\underline{\mathrm{M}}$ & & 67 & Но & & $\underline{\mathrm{M}}$ & \\
\hline 34 & $\mathrm{Se}$ & $\mathrm{F}$ & $\mathrm{M}$ & $\underline{S}$ & 68 & $\mathrm{Er}$ & & $\underline{\mathrm{M}}$ & \\
\hline 35 & $\mathrm{Br}$ & $\underline{F}$ & $\mathrm{M}$ & & 69 & $\mathrm{Tm}$ & & $\underline{\mathrm{M}}$ & \\
\hline 37 & $\mathrm{Rb}$ & $\underline{F}$ & & & 70 & $\mathrm{Yb}$ & & M & $\underline{S}$ \\
\hline 38 & $\mathrm{Sr}$ & $\mathrm{F}$ & $\mathrm{M}$ & $\underline{S}$ & 71 & $\mathrm{Lu}$ & & $\mathrm{M}$ & $\underline{S}$ \\
\hline 39 & $\mathrm{Y}$ & & $\mathrm{M}$ & $\underline{S}$ & 72 & Hf & $\mathrm{F}$ & $\underline{\mathrm{M}}$ & \\
\hline 40 & $\mathrm{Zr}$ & $\mathrm{F}$ & $\mathrm{M}$ & $\underline{S}$ & 73 & $\mathrm{Ta}$ & & $\mathrm{M}$ & $\underline{S}$ \\
\hline
\end{tabular}




\section{ICRP 72 \\ Maximum Dose Lung Clearance Classes}

\begin{tabular}{ccccccccc}
\hline Z & Element & \multicolumn{2}{c}{$\begin{array}{c}\text { Allowable Clearance } \\
\text { Classes }\end{array}$} & \multicolumn{2}{c}{ Z } & Element & \multicolumn{3}{c}{ Allowable Clearance } \\
Classes
\end{tabular}

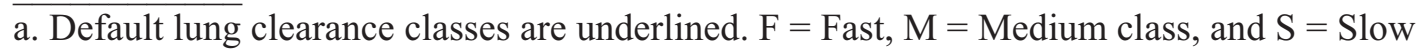

b. Chemical species rather than clearance classes are indicated for hydrogen and carbon.

c. $\mathrm{V}=$ vapor. 